\title{
Anais do Congresso Acervo+ 2022 | Eixo Saúde
}

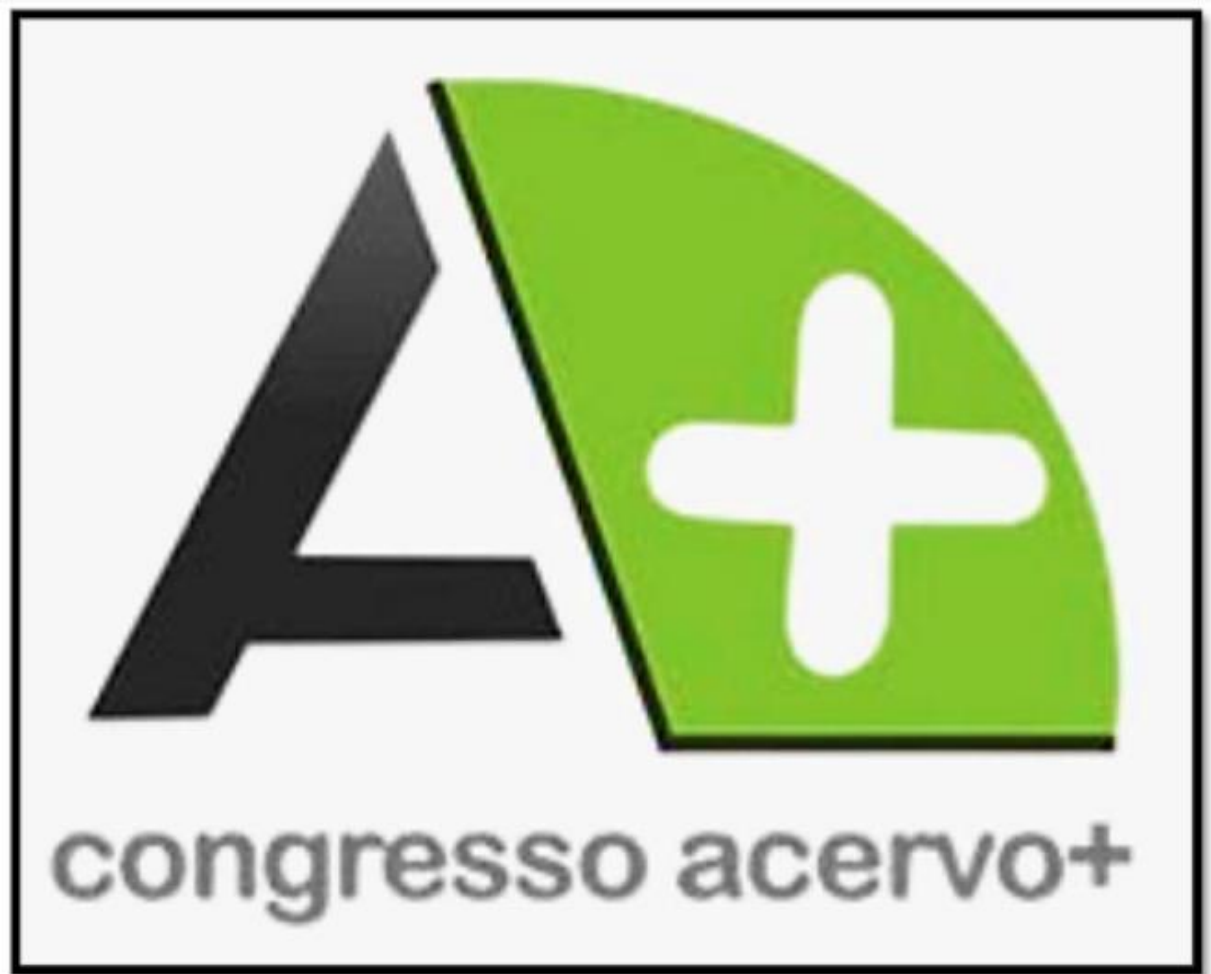

Apoio:

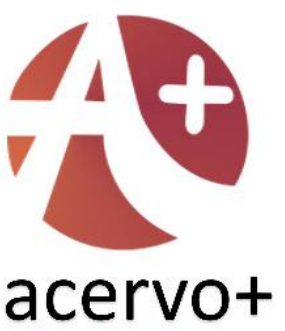

Eventos

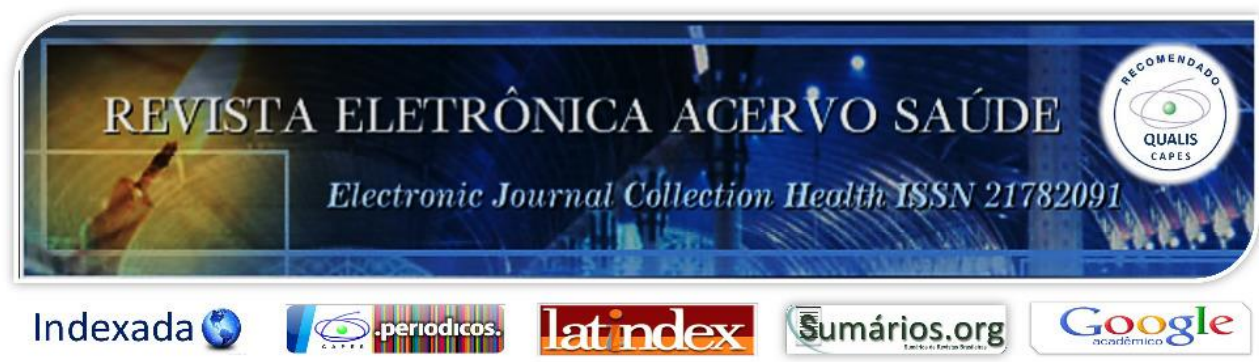




\section{SUMÁRIO}

SOBRE O EVENTO 20

Organizadores do Evento 21

Comissão Científica 21

Programação. 22

Apresentação dos resumos 23

RESUMOS SIMPLES 25

| ESTUDOS ORIGINAIS 26

A PRÁtICA dA AUTOMEDICAÇÃo EM PACIENTES COM DOR AGUDA DE ORIGEM ODONTOGÊNICA. 26

PERFIL DO TIPO DE VIOLÊNCIA NOTIFICADO EM UM MUNICÍPIO DO ESTADO DE GOIÁS, BRASIL. 28

CONDIÇÕES SOCIOECONÔMICAS, AMBIENTAIS E DE SAÚDE EM COMUNIDADES VULNERÁVEIS NA PANDEMIA DA COVID- 19 30

ASSOCIAÇÃO DA SÍNDROME RESPIRATÓRIA AGUDA GRAVE E COMORBIDADES EM CRIANÇAS DE $O$ A 14 ANOS

INCIDÊNCIA DA SÍNDROME RESPIRATÓRIA AGUDA GRAVE EM CRIANÇAS E ADOLESCENTES DE 0 A 14 ANOS: UMA COMPARAÇÃO ANTES E DURANTE A PANDEMIA

PERFIL DA SINTOMATOLOGIA DA SÍNDROME RESPIRATÓRIA AGUDA GRAVE EM CRIANÇAS DE 0 A 14 ANOS

HIV/AIDS NAS CINCO MACRORREGIÕES BRASILEIRAS: UMA ANÁLISE DA INFLUÊNCIA DAS PROFILAXIAS PRÉ E PÓS-EXPOSIÇÃO NO NÚMERO DE CASOS NOTIFICADOS .... 38 EVOLUÇÃO DA SÍFILIS NO SEMIÁRIDO NORDESTE II: UMA ANÁLISE DOS DADOS EPIDEMIOLÓGICOS DO SINAN

MORTALIDADE DE ADULTOS JOVENS POR ACIDENTES DE TRANSPORTE OCORRIDOS NO BRASIL NO PERÍODO DE 2015 A 2019.

CASOS NOTIFICADOS E ÓBITOS POR TUBERCULOSE NOS ÚLTIMOS CINCO ANOS NO ESTADO DO AMAPÁ 
CASOS NOTIFICADOS DE VIOLÊNCIA INTERPESSOAL/AUTOPROVOCADA NO ESTADO

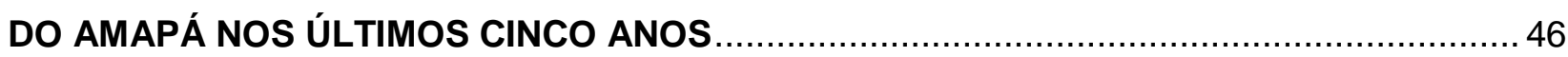

ACIDENTES POR SERPENTES ENTRE OS ANOS 2009 A 2019 NO BRASIL

ANÁLISE EPIDEMIOLÓGICA DOS CASOS DE LEPTOSPIROSE NO BRASIL ENTRE 2015 E 2019

PERCEPÇÃO SOBRE O CONHECIMENTO E CONSUMO DE ALIMENTOS LIGHT E DIET .. 52 A INFLUÊNCIA DO ESTADO EMOCIONAL NO CONSUMO ALIMENTAR ..........................54 COBERTURA VACINAL DE MENINGITE NO DISTRITO FEDERAL DE 2018 A 2019 ............56 ANÁLISE EPIDEMIOLÓGICA DOS CASOS DE COINFECÇÃO TUBERCULOSE/HIV NO ESTADO DO PARÁ - 2018 A 2020. 58

INFUSÃo dE FENILEFRINA PARA PREVENÇÃO DE HIPOTENSÃo ARTERIAL EM GESTANTES OBESAS SUBMETIDAS À CESARIANA ELETIVA: RESULTADOS PRELIMINARES

PERFIL EPIDEMIOLÓGICO DA SÍFILIS EM GESTANTES NA REGIÃO NORTE NO PERÍODO DE 2014 A 2018

O TRABALHO INTERPROFISSIONAL EM SAÚDE MENTAL: A COMPREENSÃO DOS PROFISSIONAIS DE UM CAPS

INTOXICAÇÃO POR AGROTÓXICOS POR EXPOSIÇÃO OCUPACIONAL NOS ESTADOS DA REGIÃO SUL DO BRASIL DE 2010 A 2019 66

UTILIZAÇÃO DE DISPOSITIVOS ELETRÔNICOS POR ESTUDANTES UNIVERSITÁRIOS DURANTE A PANDEMIA DE COVID-19

PERFIL EPIDEMIOLÓGICO DAS ALTERAÇÕES DE EXAMES DE COLO DE ÚTERO DE MULHERES JOVENS DO DISTRITO FEDERAL 70

PREVALÊNCIA DE ÓBITOS MATERNOS DURANTE O PUERPÉRIO NO BRASIL: O RETRATO DE UMA DÉCADA. 72

O AUTOCUIDADO DE MULHERES COM DIAGNÓSTICO DE DIABETES GESTACIONAL... 74 QUALIDADE DE VIDA DOS INDIVÍDUOS COM DPOC APÓS INTERVENÇÃO FISIOTERAPÊUTICA AQUÁTICA. 
COMPARAÇÃO DOS NÍVEIS DE FRAGILIDADE COM AS FERRAMENTAS CARDIOVASCULAR HEALTH STUDY E TILBURG FRAILTY INDICATOR EM INDIVÍDUOS COM DOENÇA CARDIOVASCULAR CRÔNICA

DIAGNÓSTICOS TARDIOS DE INFECÇÃO POR HIV EM RESIDENTES DO ESTADO DO AMAPÁ: CASOS NOTIFICADOS NO PERÍODO DE 2014 A 2020

TRATAMENTO FARMACOLÓGICO DOS PACIENTES COM HANSENÍASE NA REGIÃO NORDESTE: ESTUDO EPIDEMIOLÓGICO

ANÁLISE DO PERFIL CLÍNICO-EPIDEMIOLÓGICO DOS PACIENTES ACOMETIDOS POR INTOXICAÇÃO OCASIONADA POR MEDICAMENTOS NA REGIÃO NORDESTE

INTOXICAÇÃO MEDICAMENTOSA ACIDENTAL EM CRIANÇAS NA CIDADE DE CAMPINA GRANDE-PB

PERFIL EPIDEMIOLÓgICO DE ACOMETIDOS POR INTOXICAÇÃO PELO USO DE COSMÉTICOS NO ESTADO DA PARAÍBA

TUBERCULOSE NA CIDADE DE SOUSA-PB, ENTRE 2015 E 2020 90

Música COMO ESTRATÉGIA de PROMOÇÃo EM SAÚde: PERSPECTIVAS DE FAMILIARES QUE AGUARDAM NOTÍCIAS NA SALA DE ESPERA DE UM HOSPITAL ........92 ESTUDO EPIDEMIOLÓGICO DE SÍFILIS GESTACIONAL NO MUNICÍPIO DE ABAETETUBAPARÁ

ANÁLISE EPIDEMIOLÓGICA E O PAPEL DO ENFERMEIRO NAS OCORRÊNCIAS DE ESCORPIONISMO NO MUNICÍPIO DE BELÉM-PA.

PERFIL EPIDEMIOLÓGICO DA MORTALIDADE MATERNA POR SÍNDROME HIPERTENSIVA NA GESTAÇÃO NO BRASIL

PANORAMA DAS INTERNAÇÕES E ÓBITOS POR DENGUE NO TERRITÓRIO BRASILEIRO 100

ÓBITOS POR AMEBÍASE NO BRASIL: UM ESTUDO DESCRITIVO 102

AVALIAÇÃO DA ATIVIDADE DE COMPONENTES HIDROFíLICOS DO EXTRATO DE FOLHAS DE L. SIBIRICUS NA RESOLUÇÃO DE FERIDAS CUTÂNEAS EXPERIMENTAIS EM RATOS WISTAR. 104

REPERCUSSÕES CLÍNICAS E LABORATORIAIS DA INTERVENÇÃO COM SOLUÇÃO DE BICARBONATO DE SÓDIO EM PACIENTES PEDIÁTRICOS ACOMETIDOS PELA COVID-19 
INFLUÊNCIA DA UTILIZAÇÃO EMPÍRICA DE EXTRATOS AQUOSOS DE LEONURUS SIBIRICUS NO PROCESSO DE CICATRIZAÇÃO DE FERIDAS CUTÂNEAS EXPERIMENTAIS

INTERNAÇÕES POR AUTO-INTOXICAÇÃO COM ÁLCOOL EM ADOLESCENTES E ADULTOS DE TODO O BRASIL, NO PERÍODO DE 2018 A 2020: UM ESTUDO EPIDEMIOLÓGICO

ANÁLISE DA DISPENSAÇÃO DE MEDICAMENTOS PSICOTRÓPICOS EM UMA DROGARIA DA REDE PRIVADA NA CIDADE DE BELO HORIZONTE/MG

CARACTERIZAÇÃO DO PERFIL EPIDEMIOLÓGICO DO REGISTRO DE INDIVÍDUOS COM EXCESSO DE PESO NO CONTEXTO DA PANDEMIA DE SARS-COV-2

PERFIL DE MORBIDADE ENTRE OS ADOLESCENTES EM MUNICÍPIOS DA REGIÃO EXTREMO-SUL DA BAHIA

ANÁLISE DA PERCEPÇÃO DOS PACIENTES DE FISIOTERAPIA AQUÁTICA QUANTO A SUA QUALIDADE DE VIDA DURANTE A PANDEMIA DA COVID-19

DOENÇAS DE CHAGAS: PERFIL EPIDEMIOLÓGICO POR TRANSMISSÃO ORAL PELO CONSUMO DO AÇAI NO ESTADO DO PARÁ

O PERFIL EPIDEMIOLÓGICO DOS PACIENTES COM HIV/AIDS NO BRASIL DE 2010 A 2020

EDUCAÇÃo EM SAÚDE NA CAMPANHA do SETEMBRO AMARELO: UM RELATO DE EXPERIÊNCIA

O PERFIL EPIDEMIOLÓGICO DA HEPATITE A NO TERRITÓRIO BRASILEIRO ENTRE 2010 E 2018

INIBIÇÃO DA VIA DE SINALIZAÇÃO DE MTOR CINASE COMO ESTRATÉGIA DE REDUÇÃO DA PATOGENICIDADE DO SARS COV-2 EM CÉLULAS INFECTADAS: UMA ANÁLISE IN SILICO

| REVISÕES BIBLIOGRÁFICAS

ENXAGUATÓRIOS OXIDATIVOS E MÁSCARAS NA ODONTOLOGIA: USO BIOSSEGURO E PREVENTIVO NA ATUALIDADE

CUIDADOS DE ENFERMAGEM FRENTE AOS SINTOMAS DE PACIENTES COM SÍFILIS 132 BENEFíCIOS DAS PRÁTICAS INTEGRATIVAS E COMPLEMENTARES EM CRIANÇAS ONCOLÓGICAS 
ATIVIDADE GASTROPROTETORA DA MAYTENUS ROBUSTA (CELASTRACEAE) 136

FISIOTERAPIA NO CUIDADO PALIATIVO PEDIÁTRICO: UMA REVISÃO NARRATIVA .... 138 ASSISTÊNCIA HUMANIZADA A MULHERES NO PERÍODO GESTACIONAL E PUERPERAL NO AMBIENTE AMBULATORIAL

O PAPEL DO ENFERMEIRO NA ATENÇÃO DOMICILIAR 142

QUEDAS EM IDOSOS E FATORES DE RISCO: ASSISTÊNCIA NA ATENÇÃO PRIMÁRIA À SAÚDE

FATORES QUE CONTRIBUEM PARA A PROMOÇÃO DO ALEITAMENTO MATERNO EXCLUSIVO

DELEÇÃO COMPLETA DOS GENES GSTM1 E GSTT1 E A SUSCETIBILIDADE PARA CÂNCER COLORRETAL: REVISÃO SISTEMÁTICA COM META-ANÁLISE. 148 SUPLEMENTAÇÃO DE L-ARGININA E O DESEMPENHO DE EXERCícIOS AERÓBIOS E ANAERÓBIOS

KLEBSIELLA PNEUMONIAE: MECANISMOS DE VIRULÊNCIA E RELAÇÃo COM RESISTÊNCIA ANTIMICROBIANA 152

O CUIDADO MULTIPROFISSIONAL À CRIANÇA ONCOLÓGICA: UMA REVISÃO INTEGRATIVA 154

IMPACTOS DA POLIFARMÁCIA NA SAÚDE DO IDOSO 156 SUPLEMENTAÇÃO DE ÁCIDO FÓLICO NA GESTAÇÃO: UMA REVISÃO INTEGRATIVA 158 FISIOTERAPIA NO MANEJO DA DOR NEONATAL 160

A IMPORTÂNCIA DA VIGILÂNCIA EPIDEMIOLÓGICA NO COMBATE À DOENÇA DE CHAGAS: REVISÃO INTEGRATIVA.. 162 EDUCAÇÃo EM SAÚdE: UMA ESTRATÉGIA NA IMPLEMENTAÇÃO DO NÚCLEO DE SEGURANÇA DO PACIENTE 164

ESTRATÉGIAS EDUCATIVAS PARA PREVENÇÃO DA COVID-19 166

A CONCENTRAÇÃo DE IL-6 NO SANGUE PERIFÉRICO E O TRATAMENTO COM TOCILIZUMABE 168

ATUAÇÃO FARMACÊUTICA NO COMBATE DO USO INDISCRIMINADO DE MEDICAMENTOS NA PANDEMIA DE COVID-19. 170 
A RELEVÂNCIA DA SUPLEMENTAÇÃO DA VITAMINA B12 EM DIETAS VEGETARIANAS

RISCOS ASSOCIADOS AO USO DE POLIFÁRMACOS E O IMPACTO NA QUALIDADE DE VIDA DO IDOSO

O USO DA TOXINA BOTULÍNICA NO TRATAMENTO DA ESPASTICIDADE DECORRENTE DE LESÕES NEUROLÓGICAS: REVISÃO BIBLIOGRÁFICA.

CÂNCER COLORRETAL: FATORES DE RISCOS, DIAGNÓSTICO E TRATAMENTO 178

EFEITO DA ACUPUNTURA NA REDUÇÃO DA DOR EM MULHERES JOVENS COM DISMENORREIA PRIMARIA: REVISÃO DE LITERATURA.

EFEITOS DA ACUPUNTURA SOBRE A DOR EM MULHERES COM FIBROMIALGIA: UMA REVISÃO DE LITERATURA. 182

SÍNDROME DE LI-FRAUMENI NA POPULAÇÃO BRASILEIRA: UM REVISÃO INTEGRATIVA

POSSIBILIDADES E UTILIZAÇÕES DA TÉCNICA CRISPR-CAS9 NA SAÚDE PÚBLICA... 186 OBESIDADE, SOBREPESO E GORDURA CORPORAL: RISCO CARDIOVASCULAR PARA CRIANÇAS E ADOLESCENTES

A INFLUÊNCIA DA HELICOBACTER PYLORI NAS PATOLOGIAS GÁSTRICAS E EXTRAGÁSTRICAS.

COMPLICAÇÕES DA SÍNDROME HIPERTENSIVA ESPECÍFICA DA GESTAÇÃO. 192

O POTENCIAL INFECCIOSO DO PIERCING 194

SUSCETIBILIDADE GENÉTICA NA DOENÇA CELÍACA 196

RELAÇÃO ENTRE MICROBIOTA INTESTINAL E A CANDIDÍASE DE REPETIÇÃO NAS MULHERES

PREVALÊNCIA DA AUTOMEDICAÇÃO EM IDOSOS 200

ALIMENTOS FUNCIONAIS: A CÚRCUMA E O CÂNCER 202

SAÚDE MENTAL DOS PROFISSIONAIS DE ENFERMAGEM NA PANDEMIA COVID-19 ... 204 ATUAÇÃO DA ENFERMAGEM NOS CUIDADOS DE ALTA COMPLEXIDADE E A SÍNDROME DE BURNOUT, UMA REVISÃO NARRATIVA. 206

A IMPORTÂNCIA DO PROGRAMA FARMÁCIA POPULAR DO BRASIL (PFPB) 208 CUIDADOS FARMACÊUTICOS AO PACIENTE COM DOENÇAS RENAIS 210 
A IMPORTÂNCIA DO APOIO DAS ESCOLAS NA PROMOÇÃO DOS PROGRAMAS DE SAÚDE BUCAL: UMA REVISÃO DA LITERATURA.

TRATAMENTO FISIOTERAPEUTICO EM MULHERES PORTADORAS DE VAGINISMO ....214 HUMANIZAÇÃO NA ASSISTÊNCIA DA ENFERMAGEM AO PARTO NORMAL: REVISÃO INTEGRATIVA.

BENEFÍCIOS DAS PRÁTICAS INTEGRATIVAS E COMPLEMENTARES NO TRABALHO DE PARTO 218

EFEITOS DO CONSUMO DE ALIMENTOS FUNCIONAIS EM IDOSOS. 220 IMPACTO NA SAÚDE MENTAL DOS (AS) ENFERMEIROS (AS) EM TEMPO DE PANDEMIA DA COVID-19 222

IMPACTOS DO MOVIMENTO ANTIVACINA E A COBERTURA VACINAL DO SARAMPO NO BRASIL. 224

INTER-RELAÇÃo ENTRE PERIOdONTITE E DIABETES MELLITUS: UMA REVISÃO INTEGRATIVA 226

TRATAMENTO PARA A CEFALEIA PÓS-PUNÇÃO DURAL: UMA REVISÃO SISTEMÁTICA 228

IMPORTÂNCIA DOS CUIDADOS PALIATIVOS ODONTOLÓGICOS EM PACIENTES TERMINAIS: UMA REVISÃO INTEGRATIVA 230

REFLEXOS DA PANDEMIA NO DESENVOLVIMENTO DAS CRIANÇAS AUTISTAS, UMA REVISÃO INTEGRATIVA 232

DESCONEXÃo do TRABALHO NA ÁREA DE ENFERMAGEM E SUAS IMPLICAÇÕES PSICOLÓGICAS

A ATUAÇÃo dA EQUiPE dE ENFERMAGEM EM CUIDAdOS PALIATIVOS NA UTI NEONATAL E PEDIÁTRICA 236

MEDIDAS NÃO FARMACOLÓGICAS PARA O CONTROLE E MANEJO DA DOR EM RECÉMNASCIDOS INTERNADOS NA UTI NEONATAL: REVISÃO INTEGRATIVA.

IMPACTO DA PANDEMIA DA COVID-19 NOS ATENDIMENTOS ODONTOLÓGICOS NO SISTEMA DE SAÚDE PÚBLICA: UMA REVISÃO INTEGRATIVA 240 INFLUÊNCIA DA SAÚDE BUCAL NA PERFORMANCE DOS ATLETAS 242 
USO DE CURATIVOS HIDROCOLÓIDES NA PREVENÇÃO DE LESÃO POR PRESSÃO DECORRENTES DO USO DE EQUIPAMENTOS DE PROTEÇÃO INDIVIDUAL POR PROFISSIONAIS DE SAÚDE

HIDROTERAPIA COMO MÉTODO NÃO FARMACOLÓGICO NO ALÍVIO DA DOR DURANTE O TRABALHO DE PARTO

A UTILIZAÇÃO DA MICROCORRENTES COMO RECURSO FISIOTERAPÊUTICO NA

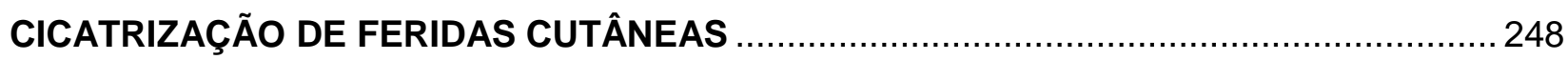

MANUTENÇÃO DE LENTES DE CONTATO DENTÁRIA - REVISÃO INTEGRATIVA …........250 MUCORMICOSE ORBITAL EM PACIENTES COM COVID-19 GRAVE..............................252 ABORDAGENS E TRATAMENTOS DAS INFECÇÕES ODONTOGÊNICAS SEVERAS: REVISÃO DE LITERATURA.

EFEITOS DA COVID-19, NA SAÚDE MENTAL DOS PROFISSIONAIS QUE ATUAM NA LINHA DE FRENTE

IMPACTO DA ATIVIDADE FÍSICA REGULAR NA EVOLUÇÃO CLíNICA DA INFECÇÃO POR SARS-CoV-2.

ANSIEDADE E ESTRESSE NA EQUIPE DE ENFERMAGEM DIANTE AO ENFRENTAMENTO DA COVID-19: UMA REVISÃO INTEGRATIVA DA LITERATURA

UTILIZAÇÃO DO LAVADO PERITONEAL DIAGNÓSTICO NO TRAUMA ABDOMINAL FECHADO EM SERVIÇOS DE SAÚDE SEM RECURSOS AVANÇADOS DE IMAGEM ........262 CANDIDA AURIS E SEU MECANISMO DE RESISTÊNCIA: UM RISCO PARA A SOCIEDADE

PRINCIPAIS SEQUELAS PÓS-COVID-19: UMA REVISÃO DE LITERATURA 266

DIFERENÇA DE CARGA VIRAL DA COVID-19 ENTRE FLUIDOS SALIVARES E NASOFARÍNGEOS: REVISÃO NARRATIVA

EXPANSÃO DA CHIKUNGUNYA: NOVAS ESPÉCIES DE CULICÍDEOS INFECTADOS NO BRASIL.

O PAPEL DO ENFERMEIRO NA EDUCAÇÃo EM SAÚdE SOBRE INFECÇÕES SEXUALMENTE TRANSMISSÍVEIS

RASTREAMENTO MAMOGRÁFICO COMO ESTRATÉGIA DA ATENÇÃO PRIMÁRIA NA REDUÇÃO DA MORTALIDADE 
A RELAÇÃO ENTRE A FISIOPATOLOGIA DA HEMORRAGIA SUBARACNÓIDEA NÃO TRAUMÁTICA E SEU QUADRO CLÍNICO

POTENCIALIDADE DO USO DA FOLHA DA ESTÉVIA NO DESENVOLVIMENTO DE PRODUTOS PARA CONTROLE DE DOENÇAS CRÔNICAS NÃO TRANSMISSÍVEIS: UMA REVISÃo

O REFLEXO DAS MÍDIAS SOCIAIS NOS TRANSTORNOS DE IMAGEM CORPORAL EM MULHERES

AVALIAÇÃO DOS EFEITOS DA APLICAÇÃO DO LASER DE BAIXA FREQUÊNCIA EM PACIENTES PORTADORES DE PÉ DIABÉTICO

O USO DA ACUPUNTURA NA DIMINUIÇÃO DA DOR EM IDOSOS COM ARTRITE REUMATOIDE: REVISÃO INTEGRATIVA

ASSISTÊNCIA E CUIDADOS DE ENFERMAGEM AO RECÉM-NASCIDO PREMATURO E A SUA FAMÍLIA

AS ESTRATÉGIAS DE HUMANIZAÇÃO DA ASSISTÊNCIA AO PARTO UTILIZADAS POR ENFERMEIROS

A ABORDAGEM DE PACIENTES COM TRANSTORNO OBSESSIVO-COMPULSIVO (TOC): UMA REVISÃO NARRATIVA

USO DA FITOTERAPIA NA ATENÇÃO BÁSICA: PAPEL DO PROFISSIONAL DE SAÚDE 292 APLICAÇÃO DA DIETA CETOGÊNICA NO TRATAMENTO DE CRIANÇAS COM EPILEPSIA: UMA REVISÃO DA LITERATURA

ANSIEDADE NA GRAVIDEZ: PREVALÊNCIA E FATORES ASSOCIADOS: REVISÃo INTEGRATIVA

BOAS PRÁTICAS NA ASSISTÊNCIA DE ENFERMAGEM AOS RECÉM-NASCIDOS SAUDÁVEIS: REVISÃO INTEGRATIVA

A INCIDÊNCIA DE INTERNAÇÕES EM DECORRÊNCIA DE QUEDAS EM IDOSOS BRASILEIROS

INIQUIDADES SOCIAIS DE GÊNERO DURANTE A PANDEMIA DA COVID-19 NO BRASIL

BOAS PRÁTICAS NA ADMINISTRAÇÃO DE MEDICAMENTOS ENDOVENOSOS 304 OS EFEITOS DO USO DA PÍLULA ANTICONCEPCIONAL NA SAÚDE DA MULHER 306 
LESÃO RENAL AGUDA EM PACIENTES COM COVID-19. 308

DESENVOLVIMENTO MOTOR DE CRIANÇAS COM A SÍNDROME CONGÊNITA DO ZIKA VÍRUS: UMA REVISÃO SISTEMÁTICA

CARACTERÍSTICAS DE CRIANÇAS E ADOLESCENTES INTERNADOS EM UNIDADE DE TERAPIA INTENSIVA ACOMETIDOS PELA A COVID-19.

A RELEVÂNCIA dO ATENDIMENTO ESTOMATOLÓGICO PARA O DIAGNÓSTICO DE DESORDENS COM POTENCIAL DE TRANSFORMAÇÃO MALIGNA

AÇÃO DAS PROTEÍNAS SALIVARES NO DESENVOLVIMENTO DO BIOFILME DE CANDIDA ALBICANS EM PESSOAS COM DOENÇA DE PARKINSON

O EFEITO DA TERAPIA CIRÚRGICA POR MEIO DA IMPLANTOPLASTIA NA RESOLUÇÃO DA DOENÇA PERI- IMPLANTAR: REVISÃO INTEGRATIVA

A ENFERMAGEM EM CASOS RAROS DE CÂNCER DE MAMA MASCULINO: UMA REVISÃO INTEGRATIVA DA LITERATURA

O USO DA QUITOSANA NO TRATAMENTO DA PERIODONTITE: UMA REVISÃo INTEGRATIVA DA LITERATURA

AGENTES OXIGENANTES EM ANTISSÉPTICOS ORAIS COMO ALTERNATIVA NO TRATAMENTO DA MUCOSITE E PERI-IMPLANTITE.

MANEJO ODONTOLÓGICO EM PACIENTES SOB USO DE ANTICOAGULANTES SUBMETIDOS A EXODONTIA - REVISÃO NARRATIVA

ANESTESIA CONTROLADA ELETRONICAMENTE EM ODONTOLOGIA - REVISÃO NARRATIVA

CORONECTOMIA DE TERCEIROS MOLARES: UMA ALTERNATIVA DE TRATAMENTO QUANTO A PROXIMIDADE DO NERVO ALVEOLAR INFERIOR

DIFICULDADE NO DIAGNÓSTICO E TRATAMENTO DA DOR FACIAL ATíPICA: REVISÃO NARRATIVA

A IMPORTÂNCIA DO ISOLAMENTO ABSOLUTO PARA A ODONTOLOGIA RESTAURADORA

CONSEQUÊNCIAS DA PERDA PRECOCE DE MOLARES DECÍDUOS EM ODONTOPEDIATRIA . 336 BENEFÍCIOS DA CASTANHA DO BRASIL COMO FONTE DE SELÊNIO NA ALIMENTAÇÃO DE IDOSOS 
FATORES ASSOCIADOS AO REGANHO DE PESO APÓS O OPERATÓRIO DE CIRURGIA BARIÁTRICA. 340

CÂNCER DE CÓLON: TRATAMENTOS E NOVAS PERSPECTIVAS 342 CONDUTAS DE ENFERMAGEM NOS CUIDADOS AO PACIENTE COM O PÉ DIABÉTICO344 SUPLEMENTAÇÃO DE VITAMINA D NO TRATAMENTO DE MULHERES COM LÚPUS: REVISÃO SISTEMÁTICA. 346

BENEFÍCIOS DO USO DA AROMATERAPIA NO TRABALHO DE PARTO 348 O IMPACTO DO EXERCícIO FÍSICO NA SÍNDROME METABÓLICA: UMA REVISÃO DA LITERATURA 350

ANEMIA NO PACIENTE ONCOLÓGICO: UMA REVISÃO SOBRE ESSA ENTIDADE CLÍNICA 352

O CONHECIMENTO E A ASSISTÊNCIA DE ENFERMAGEM FRENTE AO SERVIÇO DE HEMOTERAPIA: UMA REVISÃO INTEGRATIVA. 354

ADMISSÃO DE PACIENTE AO CENTRO CIRÚRGICO EM TEMPOS DE PANDEMIA 356 QUALIDADE DE VIDA DE PORTADORES DE ESCLEROSE MÚLTIPLA E FATORES ASSOCIADOS: UMA REVISÃO INTEGRATIVA 358

REALIZAÇÃO DO TESTE RÁPIDO ORAL DE DETECÇÃO DO HIV NA ODONTOLOGIA ... 360 O PAPEL DO ENFERMEIRO NOS CUIDADOS PALIATIVOS EM ONCOLOGIA PEDIÁTRICA: UMA REVISÃO INTEGRATIVA 362

AS IMPLICAÇÕES DA LIDERANÇA DE ENFERMAGEM EM TEMPOS DE COVID-19 ........ 364 TRANSTORNO DE ANSIEDADE GENERALIZADA COMO FATOR DESENCADEANTE DE AUTOMEDICAÇÃO NO CONTEXTO DA PANDEMIA DE COVID-19 366

DISFUNÇÃO TEMPOROMANDIBULAR E IMPACTO NA QUALIDADE DE VIDA: UMA REVISÃO NARRATIVA.

PROTOTIPAGEM NA RADIOLOGIA ODONTOLÓGICA E O SISTEMA CAD/CAM: UMA REVISÃO NARRATIVA.

PANORAMA DE ATUAÇÃO DE ENFERMEIROS FRENTE A TERAPIA NUTRICIONAL POR VIA ENTERAL E PARENTERAL NAS DOENÇAS INFLAMATÓRIAS DO TRATO GASTROINTESTINAL. 
RECOMENDAÇÕES PARA A ASSISTÊNCIA À PUÉRPERA NO CONTEXTO DA PANDEMIA DE COVID-19: UMA REVISÃO INTEGRATIVA.

AÇÕES DE SAÚDE PARA PREVENIR A OCORRÊNCIA DA GRAVIDEZ NA ADOLESCÊNCIA

FALTA DE ORIENTAÇÃO NO MANUSEIO DOS INSUMOS DE INSULINOTERAPIA 378 ASSISTÊNCIA DE ENFERMAGEM NA MANUTENÇÃO DO POTENCIAL DOADOR DE ÓRGÃOS EM MORTE ENCEFÁLICA: UMA REVISÃO INTEGRATIVA 380 TRANSMISSÃO, PREVENÇÃo E CONTROLE dA hANSENÍASE: UMA REVISÃo INTEGRATIVA 382

TREINAMENTO DE FORÇA E QUALIDADE DO SONO EM IDOSOS: UMA REVISÃO NARRATIVA 384

A SOLIDÃO EM IDOSOS NO CONTEXTO DA PANDEMIA DE COVID-19: UMA REVISÃO INTEGRATIVA 386

CEFALEIA EM SALVAS: MECANISMOS NEURAIS E FISIOPATOGÊNICOS 388 TREINAMENTO DOS MÚSCULOS DO ASSOALHO PÉLVICO COMO TRATAMENTO DA INCONTINÊNCIA URINÁRIA EM MULHERES

UTILIZAÇÃO DO PLASMA RICO EM PLAQUETAS (PRP) PARA O TRATAMENTO DE LESÕES MUSCULOESQUELÉTICAS

O POTENCIAL TERAPÊUTICO DO CANABIDIOL NO TRATAMENTO DE CRIANÇAS COM TRANSTORNO DO ESPECTRO AUTISTA

O PROTAGONISMO DO ENFERMEIRO NO AMBIENTE ESCOLAR: A EDUCAÇÃO PODE SALVAR VIDAS

FATORES DESENCADEANTES DA SÍNDROME DE BURNOUT EM MÉDICOS RESIDENTES: CUIDAR DE QUEM CUIDA.

ASSISTÊNCIA DE ENFERMAGEM NO PRÉ-NATAL DE ALTO RISCO: UMA REVISÃO INTEGRATIVA 400

TRATAMENTO NUTRICIONAL DO DIABETES MELLITUS NA ATENÇÃO PRIMÁRIA 402 ATUAÇÃO DA ENFERMAGEM NA PREVENÇÃO DE LESÃO POR PRESSÃO EM TERAPIA INTENSIVA 
INFECÇÃO POR MICROORGANISMO MULTIRRESISTENTE EM RECÉM-NASCIDOS NA UNIDADE DE CUIDADOS INTERMEDIÁRIOS NEONATAIS . 406

ATUAÇÃO DA EQUIPE DE ENFERMAGEM NO PROCESSO DE ENVELHECIMENTO SAUDÁVEL: REVISÃO DE LITERATURA 408

DIREITOS SEXUAIS E REPRODUTIVOS PARA MULHERES COM TRANSTORNOS MENTAIS: REVISÃO INTEGRATIVA DA LITERATURA.

MANEJO DA ENFERMAGEM NA LESÃO POR PRESSÃO DE PACIENTES IDOSOS EM CUIDADOS PALIATIVOS: REVISÃO INTEGRATIVA

QUALIDADE E SEGURANÇA NO USO DA INSULINOTERAPIA PELA POPULAÇÃO IDOSA

CARDIOMIOPATIA HIPERTRÓFICA E RISCO PARA ATLETAS

NEAR MISS NA ATENÇÃO PRIMÁRIA À SAÚDE E A SEGURANÇA DO PACIENTE 418

PREDITORES DE VIA AÉREA DIFÍCIL (VAD) 420

DORES E LESÕES MUSCULOESQUELÉTICAS EM ATLETAS RELACIONADAS A PRÁTICA DE E-SPORTS: UMA REVISÃO NARRATIVA DA LITERATURA.

MANIFESTAÇÕES ORAIS E COVID-19: REVISÃO DE LITERATURA 424

MANIFESTAÇÕES OROFACIAIS DECORRENTES DA COVID-19: UMA REVISÃO LITERÁRIA 426

POLUIÇÃO LUMINOSA: UMA REVISÃO SISTEMÁTICA SOBRE OS IMPACTOS DO AUMENTO DA EXPOSIÇÃO Á LUZ ARTIFICIAL NA SAÚDE HUMANA. 428 ANOMALIAS DENTÁRIAS DE TAMANHO 430

FATORES QUE VIABILIZAM O SURGIMENTO DE DIABULIMIA E SUAS CONSEQUÊNCIAS NO CORPO DA POPULAÇÃO COM DIABETES TIPO 1

ASPECTOS DIETÉtICOS ASSOCIADOS AO CÂNCER GÁSTRICO: REVISÃO BIBLIOGRÁFICA NARRATIVA 434

ALEITAMENTO MATERNO E PRÁTICAS DE INTRODUÇÃO AO GLÚTEN COMO FATORES RELACIONADOS À INCIDÊNCIA DE DOENÇA CELÍACA 436

OS EFEITOS DO USO DE ALIMENTOS ULTRAPROCESSADOS COMO ESTRATÉGIA DE RECOMPENSA ALIMENTAR NO COMPORTAMENTO ALIMENTAR INFANTIL 438 
BENEFÍ́CIOS DA VITAMINA D NO SISTEMA IMUNOLOGICO DE PESSOAS COM COVID-19: UMA REVISÃO DA LITERATURA 440

MANIFESTAÇÕES ORAIS, DIAGNÓSTICO E TRATAMENTO PARA HANSENÍASE 442

PAPEL DO ZINCO NA IMUNIDADE DO ORGANISMO EM TEMPOS DE COVID-19: UMA REVISÃO DA LITERATURA

ASSISTÊNCIA E MANEJO ODONTOLÓGICO PARA PACIENTES COM SÍNDROME DE DOWN

ATENDIMENTO ODONTOLÓGICO PARA PACIENTES AUTISTAS: UMA JORNADA ADAPTATIVA

A NECESSIDADE DO ACOMPANHAMENTO ODONTOLÓGICO PARA PACIENTES ONCOLÓGICOS.

O REFLEXO DA OBESIDADE EM PACIENTES COM COVID-19: UMA REVISÃO DA LITERATURA .

A RELEVÂNCIA DA ODONTOLOGIA NA AMAMENTAÇÃO DE RECÉM-NASCIDOS. 454

A OBESIDADE COMO DESFECHO DO DISTANCIAMENTO SOCIAL NA PANDEMIA DO SARS-CoV-2.

ASSISTÊNCIA DE ENFERMAGEM A PACIENTES COM COMPORTAMENTO SUICIDA: UMA REVISÃO INTEGRATIVA 458

CUIDADOS DE ENFERMAGEM AO PACIENTE COM DERIVAÇÃO VENTRICULAR EXTERNA

TEORIA TRANSCULTURAL DE LEININGER ASSOCIADA AO CUIDADO DE ENFERMAGEM: UMA REVISÃO INTEGRATIVA DA LITERATURA

A INTERRUPÇÃo PRECOCE do ALEITAMENTO MATERNO ASSOCIADA A MAIOR INCIDÊNCIA DE OBESIDADE INFANTIL 464

DISTÚRBIO DO SONO EM PROFISSIONAIS DA SAÚDE EM TEMPOS DE PANDEMIA: UMA

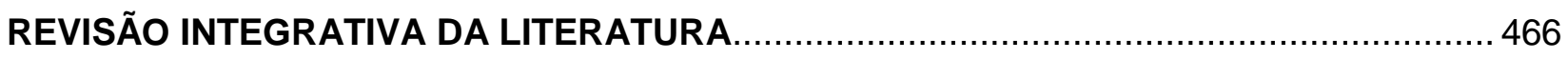

O PROTAGONISMO DO ENFERMEIRO NA ASSISTÊNCIA AO PRÉ-NATAL....................... 468

MANIFESTAÇÕES ORAIS DECORRENTES DA SÍNDROME DE SJÖGREN ........................ 470

ATUALIZAÇÃO DA NR 32 MEDIANTE O CENÁRIO PANDÊMICO DE COVID-19 NO CONTEXTO DA HIGIENIZAÇÃO DAS MÃOS 
O USO DAS TÉCNICAS DE JATEAMENTO E MICRO-OXIDAÇÃO PARA PROMOÇÃO DE UMA MELHOR OSSEOINTEGRAÇÃO EM IMPLANTES DE TITÂNIO …………………..... 474

O USO DA INTELIGENCIA ARTIFICIAL NA ODONTOLOGIA …...................................... 476

IMPLICAÇÕES DO TABAGISMO NA DOENÇA PERIODONTAL …….............................. 478

BACTÉRIAS DO GÊNERO BIFIDOBACTERIUM SP.: UMA POSSÍVEL CORRELAÇÃO BENÉFICA NA ATENUAÇÃO DE HEPATITE AUTOIMUNE............................................... 480

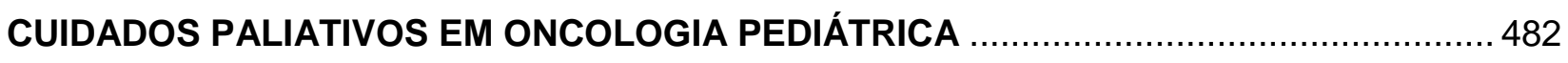

ALEITAMENTO MATERNO DURANTE A PANDEMIA POR COVID-19 (SARS-COV-2):

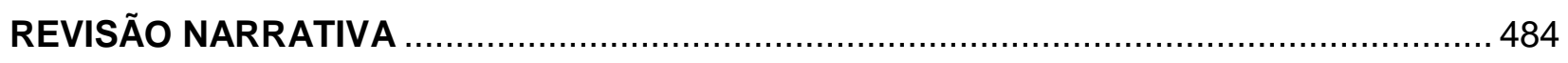

OS BENEFícIOS DAS PRÁTICAS INTEGRATIVAS E COMPLEMENTARES NO PERÍODO

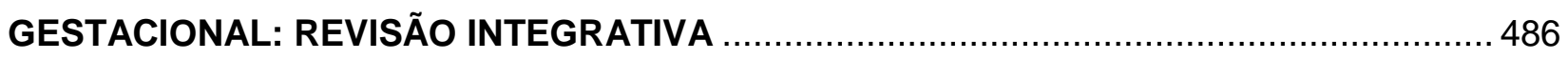

ATENÇÃO FARMACÊUTICA NO MANEJO DA DOR ONCOLÓGICA ..................................48

IMPACTO NA SAÚDE BUCAL DE PACIENTES COM SOROPOSITIVIDADE PARA HIV ..... 490 CONSEQUÊNCIAS DO DÉFICIT DE VITAMINA B12 EM PESSOAS COM ESTILO DE VIDA VEGETARIANO

ATUAÇÃO DA EQUIPE DE ENFERMAGEM NO CONTROLE DA SÍFILIS GESTACIONAL NA

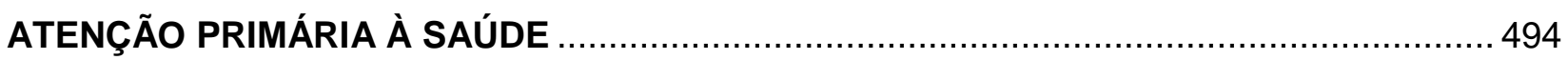

RELAÇÃO ENTRE A PERIODONTITE E O LÚPUS ERITEMATOSO SISTÊMICO (LES) ..... 496 FATORES DE RISCO E FATORES PROTETORES PARA AUTO-ESTIMA NA GESTAÇÃO498 ATRIBUIÇÕES DA EQUIPE DE ENFERMAGEM NO TRANSPORTE DE PACIENTES NO

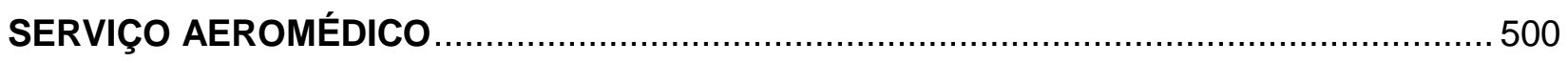

COMPLICAÇÕES NEUROLÓGICAS POR SHIGELOSE NA PRIMEIRA INFÂNCIA ..............502 VIOLÊNCIAS OBSTÉTRICAS: ANÁLISE DO RECONHECIMENTO E SUA ABORDAGEM . 504 ADERÊNCIA DOS BUNDLES COMO ESTRATÉGIA DE PREVENÇÃO DE PNEUMONIA

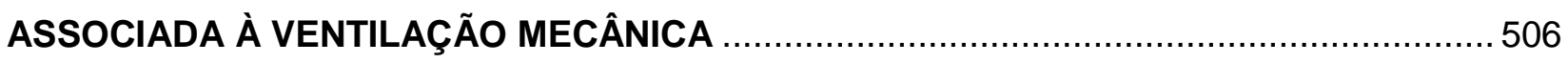

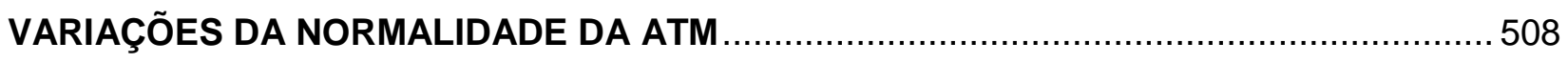

ESTUDO DA ATM POR MEIO DA RESSONÂNCIA MAGNÉTICA ……..............................510

ATUAÇÃO DA EQUIPE MULTIPROFISSIONAL NO ATENDIMENTO A MULHERES VÍTIMAS

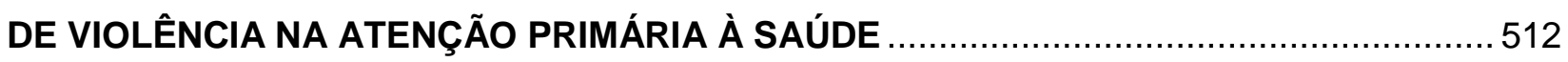




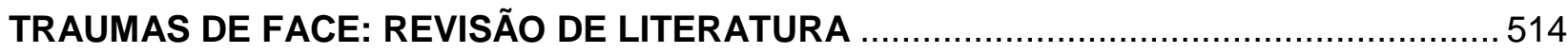

IMPACTOS DA SUPLEMENTAÇÃO DE CREATINA PARA A POPULAÇÃO IDOSA ...........516 PAPEL DO ENFERMEIRO NO ACOLHIMENTO DE ADOLESCENTES COM IDEAÇÕES SUICIDAS.

PROTOCOLOS DO CONVERSOR RADIOELÉTRICO ASSIMÉTRICO (REAC) EM ÍNDICES DE SONOLÊNCIA EXCESSIVA

ABORDAGEM TERAPÊUTICA PARA QUALIDADE DO SONO PELA TECNOLOGIA REAC COM OS PROTOCOLOS DE NEUROMODULAÇÃO.

OTIMIZAÇÃO NEURO POSTURAL E OTIMIZAÇÃO NEUROPSICOFÍSICA REAC NO ÍNDICE DE GRAVIDADE DE INSÔNIA (IGI): ESTUDO DE CASO

AUTOPERCEPÇÃO ACERCA DA QUALIDADE DO SONO FRENTE AOS PROTOCOLOS DE NEUROMODULAÇÃO PELA TECNOLOGIA REAC

A LIGA ACADÊMICA E O PROTAGONISMO DO ACADÊMICO: UM RELATO DE EXPERIÊNCIA 528

IMPORTÂNCIA DAS ATIVIDADES DE MONITORIA NA DISCIPLINA DE ANATOMIA HUMANA EM MEIO À PANDEMIA

VIVÊNCIA ACADÊMICA DURANTE A MONITORIA NA DISCIPLINA DE PSICOLOGIA DA SAÚDE: UM RELATO DE EXPERIÊNCIA

VIVÊNCIA DE MONITORIA NA DISCIPLINA DE ASSISTÊNCIA DE ENFERMAGEM EM PACIENTES EM ESTADO GRAVE

ALEITAMENTO MATERNO: EXPERIÊNCIA VIRTUAL EDUCATIVA EM SAÚDE 536

EXPERIÊNCIA DE ESTUDANTES NA CAMPANHA DE VACINAÇÃO CONTRA A COVID-19

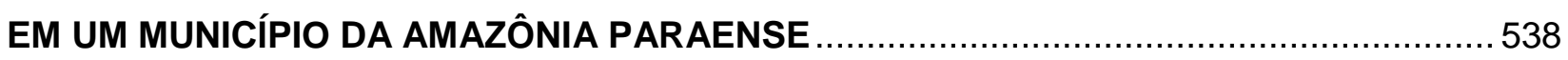

EDUCAÇÃO EM SAÚDE EM UM HOSPITAL PÚBLICO DE MANAUS 540 ATUAÇÃO DE ENFERMEIRAS NOS CUIDAdOS DE PACIENTES SUSPEITOS E CONFIRMADOS DA COVID-19

ABORDAGEM EDUCACIONAL PARA PROMOÇÃO DE SAÚDE EM ADOLESCENTES: UM RELATO DE EXPERIÊNCIA. 
SEGURANÇA DO PACIENTE: PREVENÇÃO DE QUEDAS EM IDOSOS HOSPITALIZADOS

A RELEVÂNCIA dOS PROJETOS DE EXTENSÃo PARA ACADÊMICOS DA ÁREA DA SAÚDE: RELATO DE EXPERIÊNCIA 548

IMPLICAÇÕES NUTRICIONAIS EM ADULTOS JOVENS E IDOSOS TABAGISTAS 550

DIFICULDADES E FACILIDADES DOS AGENTES COMUNITÁRIOS DE SAÚDE NA REALIZAÇÃO DAS VISITAS DOMICILIARES

COVID-19: AS BARREIRAS ENCONTRADAS PARA A VACINAÇÃO NA ZONA RURAL DO MARANHÃO 554

PERCEPÇÃO DA ENFERMAGEM DOS IMPACTOS CAUSADOS AO PACIENTE PEDIÁTRICO E FAMILIARES NA SUSPENSÃO DE VISITAS E TROCA DE ACOMPANHANTES NA PANDEMIA DA COVID-19. 556

ATUAÇÃO DA LIGA ACADÊMICA EM SAÚDE DA CRIANÇA DURANTE A PANDEMIA: UM RELATO DE EXPERIÊNCIA. 558

RESSIGNIFICANDO O VALOR DA EQUIPE DE ENFERMAGEM DO AMBULATÓRIO DE UM HOSPITAL DE ALTA COMPLEXIDADE EM TEMPOS DE PANDEMIA 560

DESAFIOS DO ENSINO REMOTO NA GRADUAÇÃO DE ENFERMAGEM: UM RELATO DE EXPERIÊNCIA

BIOSSEGURANÇA DURANTE A PANDEMIA DA COVID-19, A IMPORTÂNCIA DA PARAMENTAÇÃO E DESPARAMENTAÇÃO. 564

SETEMBRO AMARELO: A COMUNICAÇÃO EM SAÚDE COMO ESTRATÉGIA PARA VALORIZAÇÃO DA VIDA. 566

AÇÃO DE ACESSO AOS EXAMES DE MAMOGRAFIA E PCCU À MULHERES DE UM DISTRITO RURAL: UM RELATO DE EXPERIÊNCIA 568

REESTRUTURAÇÃO DE UMA UNIDADE DE INTERNAÇÃO ORTOPÉDICA: RELATO DE EXPERIÊNCIA DA GESTÃO DE ENFERMAGEM NO CONTEXTO DA PANDEMIA 570 IMPLEMENTAÇÃO DA ROTINA DE BANHO DE SOL COMO ESTRATÉGIA DE HUMANIZAÇÃO DO CUIDADO DE ENFERMAGEM 572 IMPLEMENTAÇÃO DA ROTINA DE LANCHE ESPECIAL COMO ESTRATÉGIA DE HUMANIZAÇÃO DO CUIDADO INTERDISCIPLINAR 574 
CONTRIBUIÇÃO DO PROGRAMA DE RESIDÊNCIA MULTIPROFISSIONAL NO SERVIÇO PÚBLICO DE SAÚDE ATRAVÉS DA CONSULTORIA ESPECIALIZADA. 576

PRIMEIRO CONTATO DO DISCENTE DE ODONTOLOGIA COM O SERVIÇO DE CIRURGIA BUCO-MAXILO FACIAL: RELATO DE EXPERIÊNCIA 578

GESTÃO DO ENFERMEIRO NA CONSTRUÇÃO DE ROTINAS DE INTERFACE DE UM INSTITUTO ESPECIALIZADO EM TRAUMATOLOGIA E ORTOPEDIA: RELATO DE EXPERIÊNCIA 580

CAPACITAÇÃO DOS AGENTES COMUNITÁRIOS DE SAÚDE DA ZONA RIBEIRINHA SOBRE PRIMEIROS SOCORROS: RELATO DE EXPERIÊNCIA 582

EDUCAÇÃO EM SAÚDE E ELABORAÇÃO DO PLANO DE PARTO COM GESTANTES EM UMA ESTRATÉGIA SAÚDE DA FAMÍLIA EM BELÉM-PA: RELATO DE EXPERIÊNCIA ....584 VIVÊNCIA DA COMUNIDADE FEMININA DO MUNICÍPIO DE TUCURUÍ SOBRE ALTERAÇÕES FISIOLÓGICAS NATURAIS: CLIMATÉRIO E MENOPAUSA. 586 AGRADECIMENTOS 588 


\section{SOBRE O EVENTO}

O Congresso Acervo+ mantém o seu propósito de contribuir para a disseminação da ciência. Através dos cadernos de anais publicados na Revista Eletrônica Acervo Saúde (REAS) e na Revista Eletrônica Acervo Científico (REAC), a sociedade é agraciada com um rico material científico de diversas áreas do conhecimento.

A organização enfrentou novos desafios para realizar mais uma edição de sucesso do evento, que contasse com uma programação robusta e proveitosa aos participantes, além da publicação de um caderno de anais de qualidade. A partir da inovação, um dos pilares da Acervo+, os desafios foram superados.

Antes mesmo do anúncio oficial da data do evento, os autores contaram com a assistência de uma masterclass com sete aulas, esclarecendo todos os pontos a respeito da construção de um resumo científico. Além disso, o processo de submissão foi reestruturado e se tornou intuitivo e didático aos autores, visando garantir que erros comuns fossem evitados nos resumos.

As apresentações orais, por meio do evento ao vivo no YouTube, e dos episódios de podcast, garantem acessibilidade e inovação na disseminação da ciência. Em mais um evento, a Acervo+ possibilita que pessoas de todo o Brasil e do mundo fortaleçam a pesquisa e iniciem sua trajetória científica.

Para garantir uma programação de excelência, a organização estruturou palestra, mesa-redonda, relato de experiência e aula-aberta divididos entre os quatro dias de Congresso. Além disso, a Oficina do Artigo foi uma novidade da edição de 2022, um convite para que os autores avancem na pesquisa e atinjam novos objetivos e metas, como a publicação de um artigo em periódico.

Acervo+ conectando você ao universo científico!

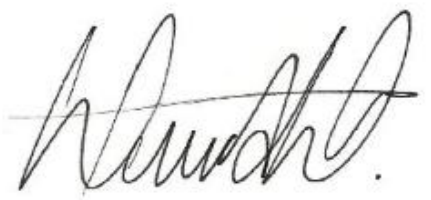

Dr. Andreazzi Duarte editor-líder 


\section{Organizadores do Evento}

- Equipe Editorial de Anais de Eventos Acervo+

- Equipe de Comunicação Acervo+

- Equipe Administrativa Acervo+

\section{Comissão Científica}

- Equipe Editorial de Anais de Eventos Acervo+

- Equipe Editorial de Artigos Acervo+ 


\section{Programação}

\begin{tabular}{|c|c|c|}
\hline \multicolumn{3}{|c|}{ 1ㅇ DIA - 24/01/2022 } \\
\hline Horário & Evento & Local \\
\hline $19 \mathrm{~h} 00$ & Cerimônia de abertura & \multirow{4}{*}{ YouTube } \\
\hline $19 \mathrm{~h} 10$ & Aula: Publicação científica na graduação, é possível? & \\
\hline $20 \mathrm{~h} 00$ & Premiação Impactos A+ de 2021 & \\
\hline $21 \mathrm{~h} 00$ & Encerramento do $1^{\circ}$ dia & \\
\hline \multicolumn{3}{|c|}{ 20 DIA - 25/01/2022 } \\
\hline Horário & Evento & Local \\
\hline $19 \mathrm{~h} 00$ & Início do $2^{\circ}$ dia & \multirow{6}{*}{ YouTube } \\
\hline 19h05 & Palestra: Gestão e liderança hospitalar & \\
\hline $20 \mathrm{~h} 00$ & Introdução à Oficina do Artigo (1 ${ }^{a}$ parte) & \\
\hline $20 \mathrm{~h} 40$ & Intervalo & \\
\hline $20 h 45$ & Apresentação de 10 trabalhos & \\
\hline $22 \mathrm{~h} 00$ & Encerramento do $2^{\circ}$ dia & \\
\hline \multicolumn{3}{|c|}{ 3 DIA - 26/01/2022 } \\
\hline Horário & Evento & Local \\
\hline $19 \mathrm{~h} 00$ & Início do 3ํ dia & \multirow{6}{*}{ YouTube } \\
\hline 19h05 & Mesa-redonda: Saúde mental e a Logoterapia na pós-pandemia & \\
\hline $20 \mathrm{~h} 00$ & Introdução à Oficina do Artigo (2ª parte) & \\
\hline $20 \mathrm{~h} 40$ & Intervalo & \\
\hline $20 \mathrm{~h} 45$ & Apresentação de 10 trabalhos & \\
\hline $22 \mathrm{~h} 00$ & Encerramento do $3^{\circ}$ dia & \\
\hline \multicolumn{3}{|c|}{ 4 DIA - 27/01/2022 } \\
\hline Horário & Evento & Local \\
\hline $19 \mathrm{~h} 00$ & Início do $4^{\circ}$ dia & \multirow{6}{*}{ YouTube } \\
\hline $19 h 10$ & Relato de experiência: Empreendedorismo em saúde & \\
\hline $20 \mathrm{~h} 00$ & Intervalo & \\
\hline $20 \mathrm{~h} 05$ & Apresentação de 10 trabalhos & \\
\hline $21 \mathrm{~h} 30$ & Premiação & \\
\hline $21 \mathrm{~h} 40$ & Cerimônia de encerramento & \\
\hline
\end{tabular}




\section{Apresentação dos resumos}

Mais de 400 resumos foram enviados por autores de todo o Brasil e exterior para o Congresso Acervo+. A submissão, nesta edição do evento, foi feita por meio de uma nova plataforma, didática e intuitiva, que orientava os autores a respeito de elementos que não estivessem de acordo com a diretriz da revista.

Cada processo foi avaliado individualmente pela equipe editorial da Revista Eletrônica Acervo Saúde (REAS) e da Revista Eletrônica Acervo Científico (REAC), que emitia o parecer favorável ou não à publicação. Todos os resumos que não atendiam às normas dos periódicos receberam oportunidade de correção e reenvio.

Dentre os critérios utilizados para a avaliação dos resumos estão:

1. Concisão e fidedignidade textual;

2. Impacto, atualidade e originalidade;

3. Dados preliminares por fontes confiáveis;

4. Acessibilidade e clareza;

5. Delineamento adequado da pesquisa;

6. Ética em pesquisa;

7. Definição clara dos objetivos, resultados e variáveis do estudo;

8. Narrativa com fluidez e linguagem adequada;

9. Didática e coerência de raciocínio e percurso;

10. Aplicação, informação e/ou conhecimento no âmbito científico.

Após a avaliação, 290 resumos foram considerados aptos à publicação. Destes, 281 dispõem de temáticas da área da saúde, sendo direcionados para publicação na REAS. O caderno é composto de 52 estudos originais, 195 revisões bibliográficas, quatro estudos de caso e 30 relatos de experiência. Outros nove resumos do eixo multidisciplinar foram direcionados para publicação na REAC, sendo sete revisões bibliográficas e dois relatos de experiência.

A avaliação feita pela equipe editorial também solicitou e verificou a documentação pertinente de cada resumo, incluindo os Termos de Consentimento Livre e Esclarecido (TCLEs) dos estudos de caso e os pareceres do Comitê de Ética em Pesquisa (CEP) para 

Anais de Evento do Congresso Acervo+ 2022 | Eixo Saúde

os estudos originais. Quando necessário, outros documentos também foram solicitados durante a auditoria de cada processo. 


\section{RESUMOS SIMPLES}

Estudo Original: 52 resumos

Revisão Bibliográfica: 195 resumos

Estudo de Caso: 04 resumos

Relato de Experiência: 30 resumos 


\title{
| ESTUDOS ORIGINAIS
}

RESUMO SIMPLES: Estudo Original

\section{A PRÁTICA DA AUTOMEDICAÇÃO EM PACIENTES COM DOR AGUDA DE ORIGEM ODONTOGÊNICA}

\author{
Felipe de Souza Duarte ${ }^{1}$ \\ Leonardo Oliveira de Freitas ${ }^{2}$ \\ Silvio Rocha Corrêa da Silva ${ }^{3}$
}

1. Universidade de Ribeirão Preto (UNAERP), Ribeirão Preto - SP.

2. Universidade Federal de Alfenas (UNIFAL), Alfenas - MG.

3. Universidade de São Paulo (USP), Ribeirão Preto - SP.

Palavras-chave: Automedicação, Dor aguda, Dor odontogênica.

\section{INTRODUÇÃO}

A automedicação é muito praticada em nosso país, principalmente pelo fácil acesso da população a medicamentos sem necessidade de prescrição profissional (SCHMID B, et al., 2019). Esse cenário é ainda mais agravante em quadros de dor aguda, como a maior parte das odontalgias, e uma das principais razões para a automedicação nesses casos é o fato de que os brasileiros não possuem o hábito de frequentar o cirurgião-dentista frequentemente, postergando a visita através do uso de medicamentos (ALVES WA, et al., 2018). As razões para esse adiamento variam desde situações de medo e ansiedade até razões financeiras (OLIVEIRA JVL, et al., 2021).

\section{OBJETIVO}

Avaliar o perfil, as características e as motivações associadas a prática da automedicação em pacientes que apresentaram quadros de dor aguda de origem odontogênica, bem como os principais medicamentos utilizados, intervalos e doses empregadas.

\section{MÉTODO}

Estudo do tipo descritivo e transversal realizado por meio da aplicação de um questionário digital na plataforma "Google Forms" com 11 questões, em um processo de amostragem aleatória. Convites para o seu preenchimento foram disponibilizados em mídias sociais. Todos os participantes eram maiores de 18 anos de idade e concordaram com o Termo de Consentimento Livre e Esclarecido. Aprovado no Comitê de Ética da Universidade de Ribeirão Preto, CAAE: 14358419.3.0000.5498. 


\section{RESULTADOS}

Participaram do estudo 111 pessoas, com idade média de 36,9 anos $( \pm 13,7)$. A maioria dos participantes (82,9\%) era do gênero feminino. Com relação a escolaridade, 58,6\% tinham o ensino superior, 36,9\% o ensino médio e $4,5 \%$ o ensino fundamental. Questionados se procuraram um dentista por causa da dor, $88,3 \%$ responderam que sim.

A queixa principal foi a dor de origem endodôntica (45,1\%). Do total de participantes, 78 (70,3\%) relataram a ingestão de algum medicamento por conta própria o que corresponde a prevalência da automedicação. Entre as pessoas que se automedicaram, apenas 30,6\% leram a bula do medicamento escolhido antes de sua ingestão.

\section{CONSIDERAÇÕES FINAIS}

Com base nos achados do presente estudo, infere-se que a automedicação tem sido uma prática crescente, facilitada pela maior difusão do conhecimento e do acesso à informação. A automedicação deve ser desencorajada por todos os profissionais da saúde através da disseminação de informações que ressaltem os riscos e malefícios dessa prática, buscando o desenvolvimento de uma consciência social a respeito do tema. Novos estudos sobre o tema devem ser realizados.

\section{REFERÊNCIAS}

1. ALVES WA, et al. Automedicação frente à odontalgia: revisão de literatura. Revista Saúde Ciência (Online), 2018; 7(3): 77-89.

2. OLIVEIRA JVL, et al. A automedicação no período de pandemia de COVID-19: Revisão integrativa. Research, Society and development, 2021; 10(3): 1-11.

3. SCHMID B, et al. Automedicação em adultos de baixa renda no município de São Paulo. Revista Saúde Pública, 2019; 44(6): 1039-1045. 


\title{
PERFIL DO TIPO DE VIOLÊNCIA NOTIFICADO EM UM MUNICÍPIO DO ESTADO DE GOIÁS, BRASIL
}

\author{
Regina Ribeiro de Castro Lima ${ }^{1}$ \\ Alexandre Lopes de Bastos ${ }^{1}$ \\ Amanda de Brito Vigiano ${ }^{1}$ \\ Flávia Silva Arruda ${ }^{1}$
}

1. Universidade Evangélica de Goiás (UniEVANGÉLICA), Anápolis - GO.

Palavras-chave: Atenção à saúde, Saúde pública, Violência.

\section{INTRODUÇÃO}

Casos de violência constituem agravantes sociais que afetam diretamente as vítimas e indiretamente seus familiares e toda a sociedade. Violência em seu sentido, trata de uma ação ou sua ausência, provocando sofrimento e dano à pessoa violentada, apresentando diversas modalidades (BRASIL, 2018).

Para registro e investigação das situações ligadas à violência, utiliza-se a notificação compulsória. A notificação compulsória é um instrumento legal que oferece possibilidades de medidas protetivas às vítimas, podendo subsidiar a vigilância, o acompanhamento e a criação de políticas de atenção direcionada a população vulnerável (BRASIL, 2016). Nessa temática, percebe-se como relevante estar atento sobre as situações de violência no país.

\section{OBJETIVO}

Destacar os tipos de violências prevalentes nas notificações compulsórias, registradas em um serviço de saúde de um município do Estado de Goiás, descritos conforme faixa etária menor e acima de 19 anos de idade.

\section{MÉTODO}

Pesquisa quantitativa com abordagem descritiva de dados secundários de uma amostragem não probalística, referentes a notificação dos casos de violência, arquivados no Sistema de Informação de Agravos Notificados- Sinan net Anápolis, no Núcleo de Vigilância Epidemiológica de 2013 a 2018 (LAKATOS EM e MARCONI AM, 2012). Esses foram coletados após a aprovação do Comitê de Ética em Pesquisa Envolvendo Seres Humanos da UniEVANGÉLICA (CAEE: 20286419.2.0000.5076), seguindo as orientações da Resolução 466/2012.

\section{RESULTADOS}


A análise estatística dos dados foi realizada com os cálculos de frequência absoluta e relativa. $\mathrm{Na}$ distribuição dos dados na faixa etária de 0 a menor de 19 anos por tipo de violência e ano em Anápolis, Goiás, 2013 a 2018, obteve-se um total de 1.947 notificações, com a prevalência das violências sexual e estupro com $55,3 \%$, seguidas pelas violências psicológica e moral $17 \%$ e pôr fim a negligência $14,9 \%$. Na faixa etária de 19 anos acima, no mesmo período, totalizou-se 1.416 registros. Tem-se assim, a prevalência da violência física com $65 \%$ das notificações, em sequência surgem a violência psicológica e moral $16,2 \%$, sexual e estupro com $11,9 \%$.

\section{CONSIDERAÇÕES FINAIS}

Nessa análise de dados, as violências sexuais e o estupro estiveram presentes em mais de $50 \%$ dos casos de violência contra os menores de 19 anos. Para a população acima dos 19 anos, torna-se motivo de preocupação ações de prevenção de violência física. Em ambas as faixas etárias, as violências sexual, estupro e psicológica/moral merecem ser investigadas e acompanhadas pela vigilância em saúde.

\section{REFERÊNCIAS}

1. BRASIL. Portaria no 204. Define a Lista Nacional de Notificação Compulsória de Doença. 2016. Disponível em: http://bvsms.saude.gov.br/bvs/saudelegis/gm/2016/prt0204_17_02_2016.html. Acesso em: 03 de outubro de 2020.

2. BRASIL. Combate à Violência Contra a Mulher. 2018. Disponível em: http://www.serpro.gov.br/menu/noticias/noticias-

2018/cartilha_combate_violencia_contra_mulher_serpro_2018.pdf. Acesso em: 03 de outubro de 2020.

3. LAKATOS EM, MARCONI MA. Metodologia do trabalho científico: procedimentos básicos, pesquisa bibliográfica, projeto e relatório, publicações e trabalhos científicos. 7nd ed. São Paulo: Atlas, 2012. 


\title{
CONDIÇÕES SOCIOECONÔMICAS, AMBIENTAIS E DE SAÚDE EM COMUNIDADES VULNERÁVEIS NA PANDEMIA DA COVID- 19
}

\author{
Simone Figueiredo Freitas de Campos ${ }^{1}$ \\ Cristiane Costa da Cunha Oliveira ${ }^{1}$ \\ Cláudia Moura de Melo ${ }^{1}$
}

1. Universidade Tiradentes (UNIT) - Aracaju - SE.

Palavras-chave: COVID-19, Populações vulneráveis, População negra.

\section{INTRODUÇÃO}

No final do ano de 2019 surgiu na China a COVID-19, doença de rápida disseminação (HERMES FS, et al., 2021). Sabe-se que o acometimento desta doença não está relacionado a um grupo populacional específico. Todavia, existe uma maior atenção na dinâmica do adoecimento associada aos determinantes sociais desfavoráveis, já que estes podem potencializar a vulnerabilidade a exposição a COVID-19, especialmente em populações negras, como os quilombolas (SANTOS VC, et al., 2021; MAGALHÃES FJC e PAULO PL, 2017). Os quilombolas são passíveis a maior exposição ao adoecimento, à medida que residem em moradias precárias, acesso deficiente aos serviços básicos de saneamento, água potável e de saúde (GOES EF, et al., 2020).

\section{OBJETIVO}

Analisar a vulnerabilidade socioeconômica, ambiental e as condições de saúde em comunidades quilombolas, no nordeste brasileiro, durante a pandemia da COVID-19 e a exposição a doença nestes grupos sociais fragilizados.

\section{MÉTODO}

Trata-se de um estudo seccional de abordagem quantitativa, com análise da percepção dos quilombolas sobre a COVID-19, condições de saúde, socioeconômicas e ambientais que foram embasadas nas entrevistas consentidas realizadas por meio de questionário online, no período de março de 2021 a agosto de 2021 nas comunidades quilombolas de Alagamar, Aningas, Terra Dura Coqueiral e Pirangi localizadas no estado de Sergipe - Nordeste, Brasil. A pesquisa foi aprovada sob CAAE 37888620.7.0000.5371.

\section{RESULTADOS}

Dentre os entrevistados $(n=248)$, predominou indivíduos do sexo feminino $(82,3 \%)$, com idade entre 18 a 89 anos, solteiro(a), cor autodeclarada parda e desempregados no âmbito formal. A maioria declarou ter ensino fundamental incompleto e não saber ler e escrever. A maior parte dos indivíduos moram em ruas 
asfaltadas, possuem casas de tijolos, utilizam água de beber da rede geral de distribuição e não realizam nenhum tipo de tratamento na água. O escoamento é através de fossa rudimentar e o lixo queimado na propriedade. Majoritariamente, os entrevistados informaram que a reclusão em casa, durante o período do isolamento social na pandemia da COVID -19, influenciou diretamente na redução da renda familiar.

\section{CONSIDERAÇÕES FINAIS}

A pandemia da COVID-19 revela as desigualdades socioeconômicas, ambientais existentes na população, especialmente àquelas que se encontram à margem da sociedade, como os quilombolas. Os aspectos socioeconômicos e ambientais devem ser considerados nas estratégias de promoção e prevenção de agravos à saúde direcionadas aos grupos vulneráveis. Devido à carência de estudos relacionados a temática, é importante que outras pesquisas possam abordar os aspectos relacionados à saúde dos quilombolas.

\section{REFERÊNCIAS}

1. GOES EF, et al. Desigualdades raciais em saúde e a pandemia da Covid-19. Trabalho, Educação e Saúde, 2020; 18(3): 1-7.

2. HERMES FS, et al. Análise de tratamentos profilático para a COVID-19: uma revisão integrativa. Revista Eletrônica Acervo Saúde, 2021; 13(5): e7167.

3. MAGALHÃES FJC, PAULO PL. Abastecimento de água, esgotamento doméstico e aspectos de saúde em comunidades Quilombolas no Estado de Mato Grosso do Sul. Ministério da Saúde. Interações (Campo Grande), 2017, 18(2): 103-116.

4. SANTOS VC, et al. Saúde da população negra no contexto da pandemia da covid-19: uma revisão narrativa. Brazilian Journal of Development, 2021, 7(1): 2306-2320. 


\title{
ASSOCIAÇÃO DA SÍNDROME RESPIRATÓRIA AGUDA GRAVE E COMORBIDADES EM CRIANÇAS DE $O$ A 14 ANOS
}

\author{
José Arthur Silva e Sousa ${ }^{1}$ \\ Géssica Silva Cazagrande ${ }^{2}$ \\ Ana Carolina Fratane Siqueira ${ }^{3}$ \\ Thiemmy Almeida Silva Guedes ${ }^{2}$ \\ Lucas Cândido Gonçalves ${ }^{4}$
}

1. Instituto Monte Pascoal (IMP), Goiânia - GO.

2. Universidade de Vassouras (UV), Rio de Janeiro - RJ.

3. Faculdade Venda Nova do Imigrante (FAVENI), Campina Grande - PB.

4. Universidade Federal de Goiás (UFG), Goiânia - GO.

Palavras-chave: Comorbidades, Imunodeprimidos, Doenças pulmonares.

\section{INTRODUÇÃO}

Entende-se por comorbidade doenças que podem ser associadas a outra doença. Ou seja, uma enfermidade que se relaciona a outra, podendo predispor o desenvolvimento de diversos males (KHAN M, et al., 2020). A Síndrome Respiratória Aguda Grave (SRAG), acomete principalmente crianças e adolescente e é causada pela infecção por microrganismos como os vírus (WIERSINGA WJ, et al., 2020).

Há, então, uma preocupação maior em relação aos pacientes com SRAG e que possuem comorbidades, principalmente pulmonares; pois não se tem à disposição tratamento específico para SRAG (ALMEIDA KC, et al., 2020). A presença de comorbidades afeta o prognóstico e o tratamento do paciente, aumentando a morbimortalidade da doença.

\section{OBJETIVO}

Analisar se a presença de comorbidades pulmonares ou pacientes imunodeprimidos estão associadas ou não a SRAG em crianças e adolescentes de 0 a 14 anos, agrupadas por faixa etária, no Brasil.

\section{MÉTODO}

Realizou-se regressão logística binária para associação das comorbidades com SRAG, por faixa etária. Para referencial teórico utilizou-se estudos publicados no PubMed e Acervo Mais index base. Foram utilizados dados do Sistema de informação da Vigilância Epidemiológica da Gripe (SIVEP-gripe), do Ministério da Saúde do Brasil (BRASIL, 2021). O software STATA 16.0 foi utilizado e adotou-se intervalo de confiança de 95\% (IC95\%), e p-valor de 0.05 (CORNFIELD J, 1951). 


\section{RESULTADOS}

Doenças pulmonares apresentam associação com SRAG para grupos de 1 a 14 anos. Porém, para menores de um ano não houve associação OR=0.36; IC95\% entre 0.35 e 0.38 ; ou seja, a estimativa pontual e o intervalo de confiança foi menor que 01 , significância $p<0.0001$. Indivíduos imunodeprimidos estão associados a SRAG para idades entre 3 e 14 anos, com aumento progressivo da associação OR=1.57; IC95\% entre 1.43 e 1.72; significância p<0.0001, para 3 e 4 anos, e, OR=3.37; IC95\% entre 3.07 e 3.72; significância $\mathrm{p}<0.0001$, para 11 a 14 anos. Para menores de um ano e 1 e 2 anos há uma associação quando não se tem a presença da imunodepressão.

\section{CONSIDERAÇÕES FINAIS}

A presença de comorbidades pulmonares e pacientes imunodeprimidos estão, de acordo com estes resultados, intimamente associados a SRAG. A associação se deu com maior força para adolescentes de 11 a 14 anos com quadro de imunodepressão. Dessa forma, é necessário a vigilância e maior atenção aos cuidados em pacientes que apresentam tais comorbidades, a fim de prevenir a SRAG. Uma vez que a doença é potencialmente grave.

\section{REFERÊNCIAS}

1. ALMEIDA KC, et al. Prevalência e correlação das comorbidades por idade e sexo dos óbitos por COVID19 no estado de Sergipe - Brasil: Parte I. Revista Eletrônica Acervo Saúde, 2020; 12(11): e4806.

2. BRASIL. SRAG 2020 - Banco de Dados de Síndrome Respiratória Aguda Grave - incluindo dados da COVID-19. [2021]. Disponível em: https://opendatasus.saude.gov.br/dataset/bd-srag-2020. Acessado em: 02 de setembro de 2021.

3. CORNFIELD J. A method of estimating comparative rates from clinical data. Aplications to cancer of the lung, beast and cervic. Journal National Cancer Institute, 1951; 11(1):.268-75.

4. KHAN M, et al. Epidemiological and clinical characteristics of coronavirus disease (COVID-19) cases at a screening clinic during the early outbreak period: a single-centre study. Journal Medical Microbiology, 2020; 69(8): 1114-23.

5. WIERSINGA WJ, et al. Pathophysiology, Transmission, Diagnosis, and Treatment of Coronavirus Disease 2019 (COVID-19): A Review. JAMA, 2020; 324(8): 782-793. 


\title{
INCIDÊNCIA DA SÍNDROME RESPIRATÓRIA AGUDA GRAVE EM CRIANÇAS E ADOLESCENTES DE 0 A 14 ANOS: UMA COMPARAÇÃO ANTES E DURANTE A PANDEMIA
}

\author{
José Arthur Silva e Sousa ${ }^{1}$ \\ Géssica Silva Cazagrande ${ }^{2}$ \\ Ana Carolina Fratane Siqueira ${ }^{3}$ \\ Thiemmy Almeida Silva Guedes ${ }^{2}$ \\ Lucas Cândido Gonçalves ${ }^{4}$
}

1. Instituto Monte Pascoal (IMP), Goiânia - GO.

2. Universidade de Vassouras (UV), Rio de Janeiro - RJ.

3. Faculdade Venda Nova do Imigrante (FAVENI), Campina Grande - PB.

4. Universidade Federal de Goiás (UFG), Goiânia - GO.

Palavras-chave: Idade, incidência, Infecção respiratória.

\section{INTRODUÇÃO}

A Síndrome Respiratória Aguda Grave (SRAG), é definida como um conjunto de sinais e sintomas graves gerados a partir de inúmeras causas (KHAN M, et al., 2020). A infecção viral é a maior causa dos casos, principalmente em crianças e adolescentes (WIERSINGA WJ, et al., 2020). A incidência de SRAG, considerando a idade, obedece a um padrão desde 2013 a 2019 (BRASIL, 2021). No entanto, com a pandemia do SARS-Cov2 percebe-se que tal padrão foi descontinuado (SANTOS GRAC, et al., 2020). Desde modo, conhecer o perfil atual de incidência de SRAG nos anos pandêmicos, é de grande valia para adequação de políticas de prevenção à SRAG.

\section{OBJETIVO}

Analisar e comparar o perfil de incidência de SRAG em crianças e adolescentes de 0 a 14 anos, no Brasil, entre os anos de 2013 a 2019 e no período pandêmico, 2020 e 2021.

\section{MÉTODO}

Pesquisa nas bases de dados PubMed e Acervo Mais index base, para referencial teórico. Os dados utilizados na análise quantitativa foram retirados do Sistema de Informação da Vigilância Epidemiológica da Gripe (SIVEP-gripe) do Ministério da Saúde do Brasil (BRASIL, 2021). Analisou-se todos os casos de SRAG de pacientes de 0 a 14 anos notificados de 2013 a 31 de agosto de 2021 .

\section{RESULTADOS}


A idade com a maior taxa de incidência de SRAG foi em crianças menores de um ano, sendo $30 \%$ em média para homens e $20 \%$ para mulheres, considerando o período de 2013 a 2019 . Ainda, neste período, verifica-se que a doença incide em menores proporções com o aumento da idade.

No ano de 2020 e 2021 há uma mudança com relação a incidência da SRAG, passando acarretar em maiores proporções crianças e adolescentes mais velhos. Ademais, a faixa etária em que mais incide é de um ano de idade para homens e mulheres, sendo bastante semelhante à taxa em menores de um ano; decrescendo para as idades maiores.

\section{CONSIDERAÇÕES FINAIS}

Verificou-se que entre 2013 e 2019 a idade com maior incidência foi em <01 ano. Já entre 2020 e 2021 , foi para 01 ano de idade. Porém, analisa-se que a incidência para 01 ano de idade não foi alterada em relação entre 2013 e 2019, sendo 10\% para ambos períodos. Nota-se, entre 2020 e 2021, diminuição acentuada da incidência em $<01$ ano, valores estes, distribuídos nas demais faixas etárias.

\section{REFERÊNCIAS}

1. BRASIL. SRAG 2020 - Banco de Dados de Síndrome Respiratória Aguda Grave - incluindo dados da COVID-19. 2021. Disponível em: https://opendatasus.saude.gov.br/dataset/bd-srag-2020. Acessado em: 02 de setembro de 2021.

2. KHAN M, et al. Epidemiological and clinical characteristics of coronavirus disease (COVID-19) cases at a screening clinic during the early outbreak period: a single-centre study. Journal Medical Microbiology, 2020; 69(8): 1114-23.

3. SANTOS GRAC, et al. Perfil epidemiológico dos casos e óbitos por COVID-19 nos estados da região nordeste. Revista Eletrônica Acervo Saúde, 2020; 12(2): e4251

4. WIERSINGA WJ, et al. Pathophysiology, Transmission, Diagnosis, and Treatment of Coronavirus Disease 2019 (COVID-19): A Review. JAMA, 2020; 324(8): 782-793. 


\title{
PERFIL DA SINTOMATOLOGIA DA SÍNDROME RESPIRATÓRIA AGUDA GRAVE EM CRIANÇAS DE 0 A 14 ANOS
}

\author{
José Arthur Silva e Sousa ${ }^{1}$ \\ Géssica Silva Cazagrande² \\ Ana Carolina Fratane Siqueira ${ }^{3}$ \\ Thiemmy Almeida Silva Guedes ${ }^{2}$ \\ Lucas Cândido Gonçalves ${ }^{4}$
}

1. Instituto Monte Pascoal (IMP), Goiânia - GO.

2. Universidade de Vassouras (UV), Rio de Janeiro - RJ.

3. Faculdade Venda Nova do Imigrante (FAVENI), Campina Grande - PB.

4. Universidade Federal de Goiás (UFG), Goiânia - GO.

Palavras-chave: Sintomas, prevalência, febre.

\section{INTRODUÇÃO}

A Síndrome Respiratória Aguda Grave (SRAG), é causada principalmente em razão da infecção por microrganismos, como os vírus (KHAN M, et al., 2020). A SRAG é diagnosticada a partir da identificação dos sinais e sintomas (SILVEIRA RBC, et al., 2021). A capacidade de testagem para identificação do microrganismo do sistema público é limitada, então, devido à capacidade restrita de teste, a triagem baseada em sintomas pode priorizar o teste e aumentar a precisão do diagnóstico (WIERSINGA WJ, et al., 2020). Ademais, a realização de uma triagem correta a partir de avaliação das caracteriscticas semiológicas, permite um melhor prognóstico por ser mais agil e totalmente clínica.

\section{OBJETIVO}

Analisar e apresentar com abordagem quantitativa o perfil dos sintomas mais prevalentes de SRAG em crianças e adolescentes de 0 a 14 anos, no Brasil, entre os anos de 2013 a 2021.

\section{MÉTODO}

Foi feito pesquisa nas bases de dados PubMed e Acervo Mais index base, para referencial teórico. Os dados foram retirados do Sistema de Informação da Vigilância Epidemiológica da Gripe (SIVEP-gripe) do Ministério da Saúde do Brasil (BRASIL, 2021). Analisou-se a variável sintomas de todos os casos de SRAG de pacientes de 0 a 14 anos notificados de 2013 a 31 de agosto de 2021.

\section{RESULTADOS}


O sintoma mais prevalente em todo o período foi tosse seguida de febre, autorreferida ou não, dispneia, mialgia e dor de garganta. Nota-se que vômito somente apareceu como sintoma em 2019, 2020 e 2021. Fadiga surgiu como sintomatologia da SRAG nos anos afetados pela pandemia do novo coronavírus, em 2020 e 2021.

Dor abdominal somente foi relatada em 2021 por uma pequena parcela dos doentes. Observa-se que febre, tosse e dispneia durante os anos de 2020 e 2021, apesar de serem os mais prevalentes, apresentam uma queda quando comparado com os anos de 2013 a 2019.

\section{CONSIDERAÇÕES FINAIS}

A análise demostrou que os sintomas mais prevalentes foram tosse e febre e que, a partir de 2020, fadiga foi notificada como sintoma de SRAG. Sugere-se que partir da avaliação dos sintomas e uma correta investigação clínica o profissional pode realizar intervenções e encaminhar o paciente para testagem e identificação do patógeno causador da SRAG de modo precoce, a fim de proporcionar melhor prognóstico e tratamento adequado.

\section{REFERÊNCIAS}

1. BRASIL. SRAG 2020 - Banco de Dados de Síndrome Respiratória Aguda Grave - incluindo dados da COVID-19. 2021. Disponível em: https://opendatasus.saude.gov.br/dataset/bd-srag-2020. Acessado em: 02 de setembro de 2021.

2. KHAN M, et al. Epidemiological and clinical characteristics of coronavirus disease (COVID-19) cases at a screening clinic during the early outbreak period: a single-centre study. Journal Medical Microbiology, 2020; 69(8): 1114-23.

3. SILVEIRA RBC, et al. Atualização em COVID-19: manifestações do coronavírus e suas implicações oftalmológicas Revista Eletrônica Acervo Científico, 2021; 31: e8197

4. WIERSINGA WJ, et al. Pathophysiology, Transmission, Diagnosis, and Treatment of Coronavirus Disease 2019 (COVID-19): A Review. JAMA, 2020; 324(8): 782-793. 


\title{
HIV/AIDS NAS CINCO MACRORREGIÕES BRASILEIRAS: UMA ANÁLISE DA INFLUÊNCIA DAS PROFILAXIAS PRÉ E PÓS-EXPOSIÇÃO NO NÚMERO DE CASOS NOTIFICADOS
}

\author{
Gabriel Gonçalves Batista dos Reis ${ }^{1}$ \\ Tatiana Cibelle de Souza Silva ${ }^{1}$ \\ Everton da Silva Batista ${ }^{1}$
}

1. Centro Universitário FTC (UNIFTC), Salvador - BA.

Palavras-chave: Síndrome de Imunodeficiência Adquirida, Profilaxia pré-exposição, Profilaxia pós-exposição.

\section{INTRODUÇÃO}

O enfrentamento à epidemia gerada pelo Vírus da Imunodeficiência Humana (HIV), agente causador da Síndrome da Imunodeficiência Adquirida (AIDS), é um dos objetivos globais do desenvolvimento sustentável (FRANCISCO MTR, et al., 2021). No Brasil, estudos têm alertado para a possibilidade de haver um aumento na incidência de HIV/AIDS decorrente do retrocesso das ações brasileiras contra o vírus (SANTOS BRD, et al., 2021).

Atualmente, o Ministério da Saúde preconiza que sejam adotadas estratégias de prevenção combinada do HIV capazes de abranger diversos focos e determinantes em saúde (BRASIL, 2017). Para isso, ações preventivas baseadas em antirretrovirais têm sido gradualmente incorporadas ao Sistema Único de Saúde (SUS) (ZUCCI EM, et al., 2018).

\section{OBJETIVO}

Verificar se houve alteração no número de notificações de casos diagnosticados de HIV/AIDS através da análise dos anos anteriores e posteriores à implantação das medidas profiláticas pré- exposição (PrEP) e pós-exposição (PEP).

\section{MÉTODO}

Estudo epidemiológico, observacional, transversal e retrospectivo de caráter descritivo, que estuda todos os casos confirmados de HIV/AIDS nas cinco macrorregiões brasileiras, entre janeiro de 2005 e dezembro de 2020, que foram notificados através do Sistema de Informação de Agravos de Notificação (SINAN), composto por dados de domínio público, sem possibilidade de identificação individual, isentando este estudo de apreciação pelo Comitê de Ética em Pesquisa (CEP).

\section{RESULTADOS}

No período estudado, foram identificados 614.715 casos de AIDS no Brasil, distribuídos entre Sudeste (42,69\%), Sul (21,07\%), Nordeste (20,20\%), Norte $(9,19 \%)$ e Centro-Oeste $(6,82 \%)$. Nos 5 anos anteriores à 
implementação da PEP, em 2010, o número de diagnósticos anuais apresentou média de crescimento aproximada de 1,92\%, superando os 40.000 casos em 2008 e 2009.

Entre 2010 e 2016, mesmo mantendo valores diagnósticos elevados, a média do período mostrou uma redução de 0,51\%. Em dezembro de 2017 foi instituída a PrEP e a tendência de redução manteve-se perceptível nos 3 anos seguintes, com queda para 11.880 casos de AIDS identificados em 2020 e média de $23,77 \%$ de redução no período.

\section{CONSIDERAÇÕES FINAIS}

Apesar do cenário de queda após a implementação das profilaxias, devemos considerar que a situação epidemiológica atual do Brasil ainda não é favorável ao controle da infecção por HIV. Além disso, o resultado com alto percentual de queda apresentado em 2020 pode ter sido fortemente influenciado pelo estado pandêmico, gerando interferência significativa no rastreio e diagnóstico adequado neste ano.

\section{REFERÊNCIAS}

1. BRASIL. Prevenção Combinada do HIV. 2017. Disponível em: https://apsredes.org/wpcontent/uploads/2021/01/prevencao_combinada_-_bases_conceituais_web.pdf. Acessado em: 30 de novembro de 2020.

2. FRANCISCO MTR, et al. Testagem para o HIV e profilaxia pós-exposição entre homens que fazem/não fazem sexo com homens. Escola Anna Nery, 2021; 25(3): 1-8.

3. SANTOS BRD, et al. HIV/AIDS, a justiça e a busca por direitos. Revista Eletrônica Acervo Saúde, 2021; 13(2): e6477.

4. ZUCCHI EM, et al. From evidence to action: Challenges for the Brazilian unified national health system in offering pre-exposure prophylaxis (prep) for hiv to persons with the greatest vulnerability. Cadernos de Saúde Pública, 2018: 34(7): 1-16. 


\section{EVOLUÇÃO DA SÍFILIS NO SEMIÁRIDO NORDESTE II: UMA ANÁLISE DOS DADOS EPIDEMIOLÓGICOS DO SINAN}

Fabio Luiz Oliveira de Carvalho ${ }^{1}$ Kaique Maximo de Oliveira Carvalho ${ }^{1}$

Pollyana dos Santos Gois²

Marcos Carvalho da Silva ${ }^{1}$

Bruno Oliveira Santos ${ }^{1}$

1. Centro Universitário AGES (UNIAGES), Paripiranga - BA.

2. Faculdade Dom Luiz de Orleans e Bragança (FDLOB), Ribeira do Pombal - BA.

Palavras-chave: Sífilis, Epidemiologia, Infecção sexualmente transmissível.

\section{INTRODUÇÃO}

A sífilis causada pela bactéria Treponema pallidum vem aumentando a cada ano em todo o território brasileiro (ALMEIDA KT, et al., 2019), se tornando uma patologia cada vez mais preocupante inclusive para a região do Semiárido Nordeste II, a qual 18 municípios são integrantes. As formas de transmissão são a adquirida (através da relação sexual desprotegida), a congênita (onde a gestante infectada transmite para o feto via transplacentária), por lesão com perfurocortantes e por transfusão sanguínea contaminada (SOUZA GKO, et al., 2021). No Brasil, essa IST (Infecção Sexualmente Transmissível) está em constante aumento no número de casos, sendo necessário que exista um controle (BRASIL, 2020).

\section{OBJETIVO}

Discutir os dados epidemiológicos dos casos de sífilis na população da Região do Semiárido Nordeste II do Estado da Bahia, notificados durante o período de 2010 a 2020 no Sistema de Informação de Agravos e Notificações (SINAN).

\section{MÉTODO}

Trata-se de um estudo ecológico, descritivo e retrospectivo onde foram coletados e analisados dados de sífilis adquirida, em gestantes e congênita no período de 2010 a 2020 nos 18 municípios integrantes da região do Semiárido II, através do Sistema de Informação de Agravos de Notificação (SINAN). Não foi necessário submeter ao CEP (Comitê de Ética e Pesquisa), pois os dados são de domínio público

\section{RESULTADOS}


A partir da análise dos dados colhidos, foi revelado que na região, o número de casos de sífilis adquirida teve uma elevação de $1500 \%$; em gestantes o número cresceu mais de $1000 \%$; e a congênita o aumento foi de $970 \%$, quando comparado aos anos anteriores a 2010. O total de casos notificados de sífilis foi de 645 , sendo 58 em Jeremoabo, 68 em Euclides da Cunha, 62 em Cícero Dantas, 112 em Ribeira do Pombal e 99 em Nova Soure, somando $61,86 \%$ no total. Salienta-se que as mulheres, as pessoas pretas e pardas, de baixa escolaridade, entre 20 a 29 anos e aquelas de classe econômica inferior estão mais vulneráveis.

\section{CONSIDERAÇÕES FINAIS}

O crescimento do número de casos pode estar relacionado a pouca efetividade das políticas públicas e no rastreamento de novos casos, principalmente no público masculino, pois os dados apresentam que o maior número de infectados são mulheres. É de suma importância os serviços de saúde do Semiárido Nordeste II, desenvolverem ações e implementá-las para o controle dessa IST, por se tratar de um problema real em saúde coletiva.

\section{REFERÊNCIAS}

1. ALMEIDA KT, et al. Perfil epidemiológico da sífilis congênita em microrregião no interior do Estado da Bahia (2007- 2017). Enfermería Global, 2019; 18(56): 198-208.

2. BRASIL. Boletim epidemiológico. 2020. Disponível em: http://www.aids.gov.br/pt-br/pub/2020/boletimsifilis-2020. Acesso em: 05 de outubro de 2021.

3. SOUZA GKO, et al. Perfil epidemiológico dos casos de gestantes com sífilis no estado da Bahia: 2014 a 2019. Revista Eletrônica Acervo Saúde, 2021; 13(2): e6454. 


\title{
MORTALIDADE DE ADULTOS JOVENS POR ACIDENTES DE TRANSPORTE OCORRIDOS NO BRASIL NO PERÍODO DE 2015 A 2019
}

\author{
Ester Suane Lima Monteiro ${ }^{1}$ \\ Emilly Dhara dos Santos Ferreira ${ }^{1}$ \\ Pedro Guilherme Castilho Costa ${ }^{1}$ \\ Victória Neves dos Passos ${ }^{1}$ \\ Camila Rodrigues Barbosa Nemer ${ }^{1}$
}

1. Universidade Federal do Amapá (UNIFAP), Macapá - AP.

Palavras-chave: Mortalidade, Índice, Faixa etária.

\section{INTRODUÇÃO}

As mortes por Causas Externas (CE) constituem um problema de saúde pública. Dentre as principais mortes por $\mathrm{CE}$, encontram-se as causadas pelo trânsito, lesões não intencionais, suicídio, homicídio e quedas (ZHOU M, et al., 2019). No período de 2015 a 2019 a faixa etária de 20 a 39 anos foi a que mais apresentou internações hospitalares por CE e maior mortalidade por Acidentes de Transporte (AT) (CELINO SDM, et al., 2021). As CE apresentam uma urgente necessidade de estudo para prevenção, demonstradas pelas crescentes taxas de incidência, prevalência e mortalidade (JUNIOR WOR, et al., 2020).

\section{OBJETIVO}

Analisar os índices de mortalidade por CE, AT na classificação do grande grupo CID- 10 (Classificação Internacional de Doenças e Problemas Relacionados à Saúde), ocorridos no Brasil, segundo unidade federativa, faixa etária e sexo no período de 2015 a 2019.

\section{MÉTODO}

O levantamento de dados foi realizado na plataforma de Informações de Saúde (TABNET), reunidos através da base de dados do Departamento de Análise e Tabulação de Dados do Sistema Único de Saúde (DATASUS), considerando as variáveis: Unidade Federativa, ano do óbito ocorrido, faixa etária e sexo dentro do grande grupo CID10: AT (V01-V99).

\section{RESULTADOS}

No período de 2015 a 2019, houve um total de 77.271 óbitos por AT, onde 66.249 (86\%) corresponderam ao sexo masculino e 11.022 (14\%) ao sexo feminino. A porcentagem de óbitos notificados apresentou um decréscimo de 2015 a 2019 de $22 \%$ e 16\%, correspondentes ao sexo masculino e feminino, respectivamente. 
O ano de 2015 apresentou maior número de óbitos notificados, com o total de 14.908 óbitos do sexo masculino e 2.355 óbitos do sexo feminino. O estado com maior número de óbitos em ambos os sexos foi o Estado de São Paulo, em contrapartida o Estado do Amapá apresentou menor número de óbitos.

\section{CONSIDERAÇÕES FINAIS}

Observa-se uma diminuição no número de óbitos por AT em ambos os sexos no período adotado, porém no sexo masculino há uma diferença significativa nos óbitos em comparação ao sexo feminino. Evidenciando mais mortes por AT no sexo masculino. Face ao exposto, a análise epidemiológica é de suma importância para o planejamento de intervenções que possam mitigar os altos índices de mortes por AT.

\section{REFERÊNCIAS}

1. CELINO SDM, et al. Morbimortalidade por causas externas no brasil entre 2015 e 2019: estudo ecológico. Revista Ciência Plural, 2021; 7(3):180-201.

2. JUNIOR WOR, et al. Análise epidemiológica da mortalidade por causas externas em Sobral, Ceará, no período de 2013 a 2017. Revista Eletrônica Acervo Saúde, 2020; 12(9): e3893.

3. ZHOU M, et al. Mortalidade, morbidade e fatores de risco na China e suas províncias, 1990-2017: uma análise sistemática para o Global Burden of Disease Study 2017. The Lancet, 2019; 394(10204): 11451158. 


\title{
CASOS NOTIFICADOS E ÓBITOS POR TUBERCULOSE NOS ÚLTIMOS CINCO ANOS NO ESTADO DO AMAPÁ
}

\author{
Emilly Dhara dos Santos Ferreira ${ }^{1}$ \\ Ester Suane Lima Monteiro ${ }^{1}$ \\ Carollyne Prata dos Santos ${ }^{1}$ \\ Pedro Guilherme Castilho Costa ${ }^{1}$ \\ Camila Rodrigues Barbosa Nemer ${ }^{1}$
}

1. Universidade Federal do Amapá (UNIFAP), Macapá - AP

Palavras-chave: Tuberculose, Epidemiologia, Casos notificados.

\section{INTRODUÇÃO}

A Tuberculose (TB), considerada uma doença milenar, continua sendo uma das dez principais causas de morte por doença infecciosa no mundo, afetando aproximadamente 10 milhões de pessoas por ano (GERMANO SNF, et al., 2021). No país, em 2020, no contexto pandêmico, observou-se uma queda acentuada da incidência de TB em comparação aos anos anteriores (BRASIL, 2021).

Em contrapartida, o norte do país apresenta uma alta incidência de casos, o que infere a realidade da região, uma população privada de serviços básicos (JÚNIOR AMF, et al., 2021). Portanto, a análise epidemiológica oferece subsídios para criação de novas estratégias de prevenção e controle da disseminação da tuberculose (SANTOS BA, et al., 2020).

\section{OBJETIVO}

Realizar uma análise epidemiológica do índice de casos confirmados de tuberculose e o índice de casos confirmados por óbito por tuberculose, ocorrido no Estado do Amapá, segundo município de notificação, ocorridos no período de 2016 a 2020.

\section{MÉTODO}

A busca foi realizada na plataforma de Informações de Saúde (TABNET), reunida através dos dados do Departamento de Análise e Tabulação de Dados do Sistema Único de Saúde (DATASUS), vinculado ao Sistema de Informação de Agravo de Notificação (SINAN). Considerando as variáveis, ano de notificação, sexo, municipio e óbito. O estudo não foi apresentado ao Comitê de Ética em Pesquisa (CEP), pois a pesquisa foi realizada com dados públicos.

\section{RESULTADOS}


Entre os anos de 2016 a 2020, houve um total de 1.448 casos, onde 495 (34,18\%) e $953(65,81 \%)$ corresponderam, respectivamente, aos sexos feminino e masculino, a incidência do número de casos notificados do sexo feminino apresentou um decréscimo de $3,03 \%$ nos últimos anos, em contrapartida 0 número de casos no sexo masculino, apresentou um crescimento de $33,12 \%$. Só houve casos confirmados por situação encerrada por óbito por tuberculose nas cidades de Macapá (11), Santana (2) e Tartarugalzinho (1), as demais cidades do Estado não apresentaram dados informados.

\section{CONSIDERAÇÕES FINAIS}

Observa-se maior incidência de casos por tuberculose em pessoas do sexo masculino. Bem como, um aumento progressivo do número de casos notificados, acompanhando um percentual de crescimento anual de mais $19 \%$. Os dados obtidos evidenciam a importância da vigilância epidemiológica para desenvolver ações públicas que garantam e estimulem o acesso à prevenção, cuidado, controle e assistência da tuberculose. Ademais, observou-se a limitação de dados notificados nos últimos 5 anos.

\section{REFERÊNCIAS}

1. BRASIL. Ministério da Saúde. Boletim Epidemiológico de Tuberculose 2021. 2021. Disponível em: https://www.gov.br/saude/pt-br/media/pdf/2021/marco/24/boletim-tuberculose-2021_24.03. Acessado em: 28 de setembro de 2021.

2. GERMANO SNF, et al. Tuberculose drogarresistente, orientações e acompanhamento pela atenção primária à saúde: revisão integrativa. Revista Eletrônica Acervo Saúde, 2021; 13(1): e5867.

3. JÚNIOR AMF, et al. Análise da incidência de tuberculose nos estados da região norte do Brasil. Revista Eletrônica Acervo Científico, 2021; 24: e7041.

4. SANTOS BA, et al. Tuberculose em crianças e adolescentes: uma análise epidemiológica e espacial no estado de Sergipe, Brasil, 2001-2017. Ciência \& Saúde Coletiva, 2020; 25: 2939-2948. 


\title{
CASOS NOTIFICADOS DE VIOLÊNCIA INTERPESSOAL/AUTOPROVOCADA NO ESTADO DO AMAPÁ NOS ÚLTIMOS CINCO ANOS
}

\author{
Pedro Guilherme Castilho Costa ${ }^{1}$ \\ Emilly Dhara dos Santos Ferreira ${ }^{1}$ \\ Ester Suane Lima Monteiro ${ }^{1}$ \\ Victória Neves dos Passos ${ }^{1}$ \\ Camila Rodrigues Barbosa Nemer ${ }^{1}$
}

1. Universidade Federal do Amapá (UNIFAP), Macapá - AP.

Palavras-chave: Epidemiologia, Violência, Autoprovocada.

\section{INTRODUÇÃO}

É definido como lesão autoprovocada a violência infligida a si próprio e pode ser classificada como comportamento suicida ou autoagressão (BAHIA CA, et al., 2020). A violência autoprovocada é um sério, crescente e desafiador problema de saúde a ser enfrentado pela vítima, familiares e serviços de saúde (CASTRO RR, et al., 2020).

O Ministério da Saúde (MS) através da Portaria de № 1.271, definiu a notificação compulsória de lesões decorrentes de violências interpessoais/autoprovocadas (BRASIL, 2014). Dito isto, as notificações adequadas desses casos são imprescindíveis para identificar essa população e traçar possíveis estratégias de prevenção e manejo (PAIXÃO BTA, et al., 2021).

\section{OBJETIVO}

Realizar uma análise epidemiológica do índice de casos notificados de violência interpessoal ou autoprovocada no Estado do Amapá, segundo faixa etária e município de notificação, no período de 2015 a 2019.

\section{MÉTODO}

A busca foi realizada na plataforma de Informações de Saúde (TABNET), reunida através dos dados do Departamento de Análise e Tabulação de Dados do Sistema Único de Saúde (DATASUS), vinculado ao Sistema de Informação de Agravo de Notificação (SINAN). Considerando as variáveis, ano de notificação, sexo, município e faixa etária. O estudo não foi apresentado ao Comitê de Ética em Pesquisa (CEP), pois a pesquisa foi realizada com dados públicos.

\section{RESULTADOS}


Entre os anos de 2015 e 2019 houve um total de 2.075 casos notificados, onde 1.543 (74,36\%) representam o sexo feminino e $532(25,64 \%)$ o sexo masculino, onde verificou-se sua maior incidência nos municipios de Macapá, com média de 165 casos ao ano, e Laranjal do Jari, com média de 64,4 casos ao ano.

Houve também um crescimento de, aproximadamente, $22,1 \%$ de casos notificados quando comparados o ano de 2015 (227 casos) ao de 2019 (616 casos) no estado Amapá. Os municípios de Itaubal, Serra do Navio, Pedra Branca do Amapari e Mazagão apresentaram, juntos, média de 3,6 casos ao ano.

\section{CONSIDERAÇÕES FINAIS}

Identifica-se maior incidência de casos notificados em pessoas do sexo feminino, bem como um aumento progressivo no número de casos notificados, seguido por um percentual de $24,2 \%$ de crescimento anual. Os dados obtidos evidenciam a importância da vigilância epidemiológica para desenvolver ações públicas que garantam e estimulem a prevenção e a redução de casos de automutilação, bem como o que se deve fazer e evitar diante de sua identificação.

\section{REFERÊNCIAS}

1. BAHIA CA, et al. Notificações e internações por lesão autoprovocada em adolescentes no Brasil, 20072016. Epidemiologia e Serviços de Saúde, 2020; 29: e2019060.

2. CASTRO RR, et al. Situação Epidemiológica dos Casos de Violência Notificados em um Município do Estado de Goiás, Brasil. Artigos.com, 2020; 23: e5474.

3. BRASIL. Ministério da Saúde. PORTARIA MS № 1.271. 2014. Disponível em: http://www.pncq.org.br/uploads/2014/qualinews/portaria_1271_6jun2014.pdf. Acessado em: 28 de set de 2021.

4. PAIXÃO BTA, et al. Suicídio e lesões autoprovocadas: análise do perfil epidemiológico e prevalência dos casos no Brasil entre 1996 e 2019. Revista Eletrônica Acervo Saúde, 2021; 13(8): e8583. 


\section{ACIDENTES POR SERPENTES ENTRE OS ANOS 2009 A 2019 NO BRASIL}

\section{Paola Rotili ${ }^{1}$}

Camila Santana Silva²

Marianne Aguiar e Silva ${ }^{3}$

Emmanuel Henrique Pires de Freitas ${ }^{4}$

André Abrantes Rosique ${ }^{5}$

1. Universidad Politécnica y Artística del Paraguay (UPAP), Encarnación - Paraguai.

2. Faculdades Santo Agostinho de Vitória da Conquista (FASAVIC), Vitória da Conquista - BA.

3. Centro Universitário de Goiatuba (UNICERRADO), Goiatuba - GO.

4. Universidade de Rio Verde (UniRV), Aparecida de Goiânia - GO.

5. Universidade de Franca (UNIFRAN), Franca - SP.

Palavras-chave: Cobra, Acidente, Óbitos.

\section{INTRODUÇÃO}

Um animal peçonhento é aquele que possui um meio (presas, ferrões, cerdas ou espinhos) de inocular sua peçonha em predadores ou presas (BRASIL, 2001). A peçonha ou também chamada veneno, são secreções com poder de causar consequências tanto locais como sistêmicas e levar a sequelas incapacitantes na vítima acometida (CRUZ K de O, et al., 2021).

Estes acidentes remetem a 3 gêneros de cobras de grande importância no meio médico: Bothrops, Crotalus e Micrurus. No ano de 2016 houve 26.000 casos notificados no Brasil, sendo aproximadamente $90 \%$ por serpentes do gênero Bothrops (SANTANA CR e OLIVEIRA MG, 2020).

\section{OBJETIVO}

Analisar a prevalência de acidentes ofídicos, o tempo de atendimento e destacar os óbitos provocados por esses animais peçonhentos com enfoque em serpentes entre os anos de 2009 a 2019 no território brasileiro.

\section{MÉTODO}

Estudo epidemiológico, transversal descritivo, sobre acidentes envolvendo serpentes, por meio do Ministério da Saúde usando o Departamento de Informações do Sistema Único de Saúde (DATASUS) Informações de Saúde (TABNET), sendo este um banco de domínio público. Foi colocado em análise epidemiológicas e morbidades onde analisamos o ano de prevalência, a espécie da serpente, o tempo de atendimento e o sexo das vítimas. 


\section{RESULTADOS}

Observou-se 312.941 casos de acidentes por serpente de 2009 a 2019 no Brasil, sendo que desses, 1.252 casos foram à óbito. $O$ ano de maior mortalidade foi 2019 com 147 casos (12\%) e o de menor foi 2014 com 95 casos (7\%). Quanto ao sexo das vítimas, $76 \%$ eram homens e $24 \%$ eram mulheres. A espécie Bothrops lidera com 824 casos, seguido pela Crotalus com 224 e por último a Micrurus com 5 casos. Quanto ao atendimento após a picada, 23\% são atendidos em 1 a 3 horas, seguido de 0 a 1 hora com 19\% e o último de 12 a 24 horas com $9 \%$.

\section{CONSIDERAÇÕES FINAIS}

Em suma, analisando a ocorrência de acidentes e óbitos provocados por serpentes no Brasil, observouse que 2019 teve a maior prevalência de casos e que a maioria deles são causados pelo gênero Bothrops (com frequência relativa de 65,8\% em relação aos outros gêneros). Percebe-se também que a maioria recebe atendimento de 1 a 3 horas após a picada e que há uma maior suscetibilidade ao sexo masculino.

\section{REFERÊNCIAS}

1. BRASIL. Manual de Diagnóstico e Tratamento de Acidentes por Animais Peçonhentos. 2001. Disponível em: https://www.icict.fiocruz.br/sites/www.icict.fiocruz.br/files/Manual-de-Diagnostico-e-Tratamento-deAcidentes-por- Animais-Pe--onhentos.pdf Acessado em: 06 de novembro de 2020.

2. BRASIL, Ministério da Saúde. Banco de dados do Sistema Único de Saúde - DATASUS. Epidemiologia e morbidade, Doenças e Agravos de Notificação - 2007 em diante (SINAN), Acidentes com Animais Peçonhentos. Disponível em http://tabnet.datasus.gov.br/cgi/deftohtm.exe?sinannet/cnv/animaisbr.def Acessado em 07 de novembro de 2020.

3. $\mathrm{CRUZ} \mathrm{K}$ de $\mathrm{O}$, et al. Injúria renal e hemorragia em paciente vítima de acidente botrópico: relato de caso. Revista Eletrônica Acervo Saúde, 2021; 13(2): e6204.

4. SANTANA CR, OLIVEIRA MG. Avaliação do uso de soros antivenenos na emergência de um hospital público regional de Vitória da Conquista (BA), Brasil. Revista Ciência \& Saúde Coletiva, 2020; 25(3): 869878. 
RESUMO SIMPLES: Estudo Original

\title{
ANÁLISE EPIDEMIOLÓGICA DOS CASOS DE LEPTOSPIROSE NO BRASIL ENTRE 2015 E 2019
}

\author{
Laíne Carvalho França Menezes ${ }^{1}$ \\ Giovana Perez de Souza ${ }^{1}$ \\ Lídia Nathielly Cavalcante Alves ${ }^{1}$ \\ Letícia Felício Lopes ${ }^{1}$ \\ Mariana Kely Diniz Gomes de Lima ${ }^{1}$
}

1. Centro Universitário UNIFACIMED, Cacoal - RO.

Palavras-chave: Brasil, Infecção, Leptospirose.

\section{INTRODUÇÃO}

A leptospirose é uma das zoonoses de maior preocupação em todo o mundo. Ela é causada pela bactéria espiroqueta do gênero Leptospira.Os sintomas introdutórios da doença podem surgir no dia do contato com a bactéria ou após 30 dias (AGEVISA, 2021), sendo os principais: febre, dor muscular (mais comumente na panturrilha), náuseas e vômito, cefaleia e icterícia. A doença negligenciada tem caráter sazonal e é transmitida ao homem pela exposição direta ou indireta da urina de animais infectados (LACERDA FB, 2021). O diagnóstico é feito por meio da avaliação clínica e laboratorial através de testes sorológicos, moleculares e, também, pela cultura para isolamento da Leptospira (BRASIL, 2019).

\section{OBJETIVO}

Apresentar os dados dos casos de leptospirose no Brasil entre os anos de 2015 a 2019, a fim de fornecer subsídios para o planejamento e avaliação das ações de saúde.

\section{MÉTODO}

Trata-se de um estudo observacional, descritivo, de abordagem quantitativa, com dados obtidos no Sistema de Informação de Agravos de Notificações (SINAN) na página do Departamento de Informática do Sistema Único de Saúde do Brasil (DATASUS) na categoria de Epidemiológicas e Morbidade. É uma pesquisa que utiliza informações de acesso público, nos termos da Lei n 12.527, de 18 de novembro de 2011, sendo dispensado a autorização do comitê de ética.

\section{RESULTADOS}

Foram identificados 16.824 casos de leptospirose no Brasil, sendo o ano de maior notificação 2015 com 4.340 casos (25,79\%). No variável sexo 13.810 (82,09\%) eram masculinos e 3.014 (17,91\%) femininos. Em relação a idade, o intervalo de maior prevalência foi entre 15 a 59 anos, com 13.736 casos $(81,65 \%)$. Dos 
casos notificados $14.195(84,37 \%)$ foram confirmados por critério clínico-laboratorial e a área urbana se sobressai com maior número,8.766 $(52,10 \%)$ casos. Tendo em consideração a evolução, 13.955 casos $(82,95 \%)$ foram curados, $1.440(8,56 \%)$ vieram a óbito por leptospirose, $139(0,83 \%)$ vieram a óbito por outra causa e $1.289(7,66 \%)$ ignorados/em branco.

\section{CONSIDERAÇÕES FINAIS}

O presente estudo possibilitou o conhecimento do perfil epidemiológico da leptospirose no Brasil de 2015 a 2019. Assim, conhecer os indicadores epidemiológicos da leptospirose é essencial para o planejamento de ações que visem a prevenção e o tratamento da doença.

\section{REFERÊNCIAS}

1. AGEVISA. Agência Estadual de Vigilância em Saúde de Rondônia. Leptospirose. Governo do Estado de Rondônia. Disponível em: http://www.rondonia.ro.gov.br/agevisa/institucional/vigilanciaambiental/controle-de-zoonoses-e- animais-peconhentos/leptospirose/. Acesso em: 26 de setembro de 2021.

2. BRASIL. Ministério da Saúde. Guia de Vigilância em Saúde. 4. ed. Brasília 2019. Disponível em:https://bvsms.saude.gov.br/bvs/publicacoes/guia_vigilancia_saude_4ed.pdf. Acesso em: 26 de setembro de 2021.

3. BRASIL. Ministério da Saúde. Leptospirose. Brasília, 2020. Disponível em:https://www.gov.br/saude/ptbr/assuntos/saude-de-a-a-z///leptospirose. Acesso em 26 de setembro de 2021.

4. LACERDA FB, et al. Fatores determinantes na caracterização da leptospirose como doença negligenciada: revisão integrativa. Revista Eletrônica Acervo Científico, 2021; 9: e6256. 


\title{
PERCEPÇÃO SOBRE O CONHECIMENTO E CONSUMO DE ALIMENTOS LIGHT E DIET
}

\author{
Larissa Cristiane Murta Faria ${ }^{1}$ \\ Anne Christine Carvalho² \\ Camila Lima Soares ${ }^{2}$ \\ Fernanda Kellen Vieira² \\ Kássia Héllen Vieira ${ }^{2}$
}

1. Faculdades Unidas do Norte de Minas (FUNORTE), Montes Claros - MG.

2. Faculdade de Saúde e Humanidades Ibituruna (FASI), Montes Claros - MG.

Palavras-chave: Alimentos, Informação nutricional, Rotulagem nutricional.

\section{INTRODUÇÃO}

Devido à rotina acelerada, diversas adaptações foram realizadas ao longo dos anos para atender a necessidade de praticidade que as pessoas prezam no cotidiano (BARBOSA MAG, et al., 2021). Consequentemente, o consumo de alimentos processados aumentou e, a longo prazo, potencializa 0 surgimento de doenças como a obesidade (SANTOS IKSS e CONDE WL, 2020).

Por outro lado, existem pessoas que procuram alimentos que possam minimizar estes efeitos negativos como os light, que possuem redução de, no mínimo, 25\% de algum ingrediente da sua versão original, e diet, destinados para fins especiais, como para dietas que tenham restrição de alguns nutrientes (LOHN SK, et al., 2017).

\section{OBJETIVO}

Avaliar se o consumidor possui o hábito de consumir os alimentos light e diet e a percepção sobre o conhecimento sobre o que são e quais as diferenças desses alimentos.

\section{MÉTODO}

Estudo de caráter descritivo, corte transversal e análise qualitativa, realizado com 50 adultos em fevereiro de 2021. Para a coleta de dados utilizou-se um questionário semiestruturado com questões relacionadas a esses alimentos, aplicado via GoogleForms, através das redes socias. A análise dos dados ocorreu através do software SPSS. O estudo foi aprovado pelo Comitê de Ética em Pesquisa (CEP), CAAE de no 40825320.3.0000.5141, parecer $n^{\circ} 4.494 .292$.

\section{RESULTADOS}


Dos 50 participantes, 68\% eram do sexo feminino. A idade média foi de $36,20 \pm 12,31$ anos. Quanto a escolaridade, a maioria possui ensino superior completo (42\%). Quanto a renda, mais da metade recebiam entre 1 e 5 salários mínimos (54\%). 86\% não possuim nenhuma doença crônica. Quanto ao consumo de produtos light e diet, $74 \%$ dos participantes não tinham o hábito de consumir alimentos light e $78 \%$ não possuiam o costume de ingerir produtos diet. Quanto ao conhecimento sobre o que são os produtos light e diet, $76 \%$ e $74 \%$ afirmam que sabem o que são, respectivamente. Cerca de $68 \%$ dos participantes afirmaram entender a diferença entre esses alimentos.

\section{CONSIDERAÇÕES FINAIS}

Observou-se que, após a análise de dados, a maioria das pessoas entrevistadas conhece o que são alimentos light e diet e sabe sobre suas diferenças, porém grande parte não possui o hábito de consumir esses alimentos que recebem esta rotulagem, preferindo os alimentos em sua forma original.

\section{REFERÊNCIAS}

1. BARBOSA MAG, et al. Hábitos alimentares e aconselhamento sobre alimentação saudável na atenção primária à saúde. Revista Eletrônica Acervo Saúde, 2021; 13(2): 1-12.

2. LOHN SK, et al. avaliação do conhecimento sobre produtos diet e light por funcionários e universitários de instituição de ensino superior. Higiene Alimentar, 2017; 31(245): 30-37

3. SANTOS IKSS e CONDE WL. Tendência de padrões alimentares entre adultos das capitais brasileiras. Revista Brasileira de Epidemiologia, 2020; 23(1): E200035. 


\title{
A INFLUÊNCIA DO ESTADO EMOCIONAL NO CONSUMO ALIMENTAR
}

\author{
Nelciane Silva Andrade ${ }^{1}$ \\ Tatiane Fernandes ${ }^{1}$ \\ Fernanda Kellen Vieira ${ }^{1}$ \\ Kássia Héllen Vieira ${ }^{1}$
}

1. Faculdade de Saúde e Humanidades Ibituruna (FASI), Montes Claros - MG

Palavras-chave: Saúde mental, Ansiedade, Isolamento social.

\section{INTRODUÇÃO}

Com o surgimento da pandemia da COVID-19, no ano de 2020, e devido a alta virulência do vírus causador da COVID-19, o SARS-CoV-2, o isolamento social se fez necessário para conter a disseminação do mesmo (LIMA RC, 2020). No entanto, essa medida promoveu alterações drásticas na rotina dos indivíduos e alguns pontos negativos estão sendo observados, como a potencialização do sentimento de solidão, que pode gerar depressão, ansiedade e estresse (REIS MAOM, et al., 2021). Esses sentimentos e emoções desfavoráveis, podem impactar no comportamento relacionado à alimentação, podendo influenciar diretamente no aumento do consumo alimentar e potencializar o comer emocional (MATOS SMR e FERREIRA JCS, 2021).

\section{OBJETIVO}

Avaliar se o estado emocional tem influenciado no comportamento alimentar de pessoas adultas, em tempos de isolamento social imposto pela pandemia da COVID-19 e se pode contribuir para aumentar a ingestão alimentar e, consequentemente, promover o ganho de peso.

\section{MÉTODO}

Estudo transversal, descritivo, qualitativo, realizado com 40 adultos em fevereiro de 2021. Coletou-se os dados através do envio do Questionário Holandês de Comportamento Alimentar, com modificações, via Google Forms, nas redes socias. O estudo foi aprovado pelo Comitê de Ética em Pesquisa (CEP), CAAE: 40768420.7.0000.5141, parecer $n^{\circ}$ 4.488.285. Analisou-se os dados através do programa SPSS, realizando estatísticas descritivas.

\section{RESULTADOS}

Participaram do estudo 40 pessoas, com idades entre 18 e 56 anos, sendo que $80 \%$ da amostra era do sexo feminino. Com relação ao Índice de Massa Corporal (IMC), 42,5\% dos indivíduos estava com sobrepeso, $37,5 \%$, eutróficos, $12,5 \%$, abaixo do peso, $5 \%$ e 2,5\% estavam com Obesidade Grau I e Obesidade Grau II, 
respectivamente. $67,5 \%$ dos entrevistados informaram que sentem desejo de comer quando não tem nada para fazer.

Quando perguntados se tinham desejo de comer quando se sentiam ansiosos, preocupados ou tensos, $42,5 \%$ afirmaram que sim. 35\% e $45 \%$ dos indivíduos afirmaram que sentiam desejo de comer quando estavam deprimidos ou desanimados e quando se sentiam sozinhos, respectivamente.

\section{CONSIDERAÇÕES FINAIS}

Diante dos resultados apresentados, observa-se que o estado emocional interfere no comportamento alimentar, principalmente quando as pessoas estão ociosas, sem companhia, tensas, preocupadas e ansiosas. Sugere-se que a situação de isolamento social, vivenciada atualmente, pode ter contribuído para potencializar esses sentimentos citados e, consequentemente, sendo gatilho para o desenvolvimento do comer emocional e culminando no ganho de peso, visto que a maioria se encontrava acima do peso, segundo o IMC.

\section{REFERÊNCIAS}

1. LIMA RC. Distanciamento e isolamento sociais pela Covid-19 no Brasil: impactos na saúde mental. Physis: Revista de Saúde Coletiva, 2020; 30(2): 1-10.

2. MATOS SMR e FERREIRA JCS. Estresse e comportamento alimentar. Research, Society and Development, 2021; 10(7): e26210716726.

3. REIS MAOM, et al. Impactos na saúde mental por distanciamento e isolamento sociais pela COVID-19: uma perspectiva brasileira e mundial. Revista Eletrônica Acervo Saúde, 2021; 13(2): e6535. 


\title{
COBERTURA VACINAL DE MENINGITE NO DISTRITO FEDERAL DE 2018 A 2019
}

\author{
Thaís da Silva Rodrigues ${ }^{1}$ \\ Ágatha Cristina Moraes Campos ${ }^{1}$ \\ Amanda Dantas Temoteo ${ }^{1}$ \\ Sarah Emily Borges Pereira ${ }^{1}$ \\ Thais Ranielle Souza de Oliveira ${ }^{1}$
}

1. Centro Universitário Euro Americano (UNIEURO), Brasília - DF.

Palavras-chave: Meningite, Cobertura vacinal, Casos confirmados.

\section{INTRODUÇÃO}

A meningite é caracterizada por ser uma doença inflamatória que atinge as membranas que envolvem o sistema nervoso central (SNC). É considerada uma doença de importância epidemiológica devido sua gravidade e ao grande potencial de produzir surtos, sendo de maior relevância á saúde pública as meningites bacterianas (FONTES FLL, et al., 2019).

A transmissão ocorre de pessoa para pessoa, sendo disseminada através de gotículas e secreções nasais e da garganta. Essa propagação também pode ocorrer por via fecal-oral, pela ingestão de alimento ou água contaminada e pelo contato direto com fezes. As vacinas: Meningocócica C (Conjugada), Pneumocócica 10valente (conjugada) e Pentavalente, são consideradas as principais formas de prevenção (BRASIL, 2020).

\section{OBJETIVO}

Analisar a cobertura vacinal da meningite e quantificar os casos confirmados da doença por idade no Distrito Federal (DF) nos anos de 2018 e 2019, através dos dados do Departamento de Informática do Sistema Único de Saúde do Brasil (DATASUS).

\section{MÉTODO}

Estudo epidemiológico transversal retrospectivo, baseado em informações encontradas no banco de dados DATASUS do Ministério da Saúde. Analisado os casos de meningite e a taxa de cobertura vacinal no DF, nos anos de 2018 e 2019 direcionado á crianças de 0 a 1 ano e adultos de 20 a 39 anos. Considerando a resolução 466/12 do CONEP, para dados de domínio público dispensa análise do Comitê de Ética e Pesquisa.

\section{RESULTADOS}


Ao realizar a análise epidemiológica os resultados obtidos evidenciam um aumento significativo no total de números casos confirmados por notificação compulsória no DF. Em 2018 ocorreu 100 casos confirmados e no ano de 2019 chegou a 149 confirmações. Em contrapartida no mesmo período a taxa de cobertura vacinal, reduziu de $82,22 \%$ em 2018 para $79,12 \%$ em 2019. Quanto aos casos confirmados e notificados no banco de dados DATASUS/Ministério da Saúde por faixa etária, as idades mais acometidas com essa infecção foram adultos entre 20 a 39 anos e crianças menores de 1 ano de idade.

\section{CONSIDERAÇÕES FINAIS}

Pelo exposto, percebe-se a necessidade de melhorar a divulgação acerca das vacinas de meningite para o público, para aumentar a cobertura vacinal e como consequência alcançar a redução no número de casos na população do DF. Pois a vacinação é o meio mais eficaz para prevenir a doença, já que a meningite pode acometer qualquer pessoa, pincipalmente crianças menores de 1 ano e jovens adultos de 20 a 39 anos.

\section{REFERÊNCIAS}

1. BRASIL. Manual do Ministério de Saúde. Guia de vigilância em saúde. 2017. Disponível em: https://bvsms.saude.gov.br/bvs/publicacoes/guia_vigilancia_saude_volume_1.pdf. Acessado em: 18 de junho de 2021.

1. BRASIL, Ministério da Saúde. Banco de dados do Sistema Único de Saúde-DATASUS. Disponível em: http://www.datasus.gov.br. Acessado em 18 de junho de 2021.

2. FONTES FLL, et al. Meningite em um estado do Nordeste brasileiro: descrição das características epidemiológicas em um período de 11 anos. Revista Eletrônica Acervo Saúde, 2019; 25: e628. 


\title{
ANÁLISE EPIDEMIOLÓGICA DOS CASOS DE COINFECÇÃO TUBERCULOSE/HIV NO ESTADO DO PARÁ - 2018 A 2020
}

\author{
Taynara da Costa Silva ${ }^{1}$ \\ Cássia Vitoria Passos dos Santos ${ }^{1}$ \\ Thayana de Almeida Vieira ${ }^{1}$ \\ Matheus de Oliveira Queiroz ${ }^{1}$ \\ Karytta Sousa Naka ${ }^{2}$
}

1. Faculdade Estácio de Castanhal, Castanhal - PA.

2. Instituto Evandro Chagas (IEC/SVS/MS), Belém - PA.

Palavras-chave: Epidemiologia, Tuberculose, Saúde.

\section{INTRODUÇÃO}

Em 2018 a Tuberculose (TB) acarretou o adoecimento de 10 milhões de pessoas e 1,4 milhão de mortes, representando um grande desafio à saúde pública global. A epidemia da Síndrome da Imunodeficiência Adquirida (AIDS/HIV) impactou fortemente o perfil epidemiológico e o controle da TB e esta associação TB/HIV impacta negativamente na redução destas infecções (CAVALIN RFC, et al., 2020; DIAS WB, et al., 2020). Dessa forma, existe uma maior preocupação em relação as pessoas que não reconhecem o risco da doença, e assim, adiam a procura de atendimento para evitar receber o devido diagnóstico (MAGNO L, et al., 2017; SILVA JDP, et al., 2020).

\section{OBJETIVO}

Analisar os casos de coinfecção Tuberculose/HIV no estado do Pará entre o período 2018 a 2020, enfatizando as características do perfil epidemiológico dos indivíduos e situações clinicas da coinfecção no estado.

\section{MÉTODO}

Estudo ecológico, retrospectivo e descritivo, com abordagem quantitativa, realizado a partir da coleta de informações no banco de dados do Sistema de Informações de Agravos de Notificação (SINAN), utilizando casos confirmados de coinfecção tuberculose/HIV no estado do Pará no período de 2017 a 2020 . As variáveis coletadas foram: ano diagnóstico, sexo, faixa etária, forma clínica e evolução dos casos.

\section{RESULTADOS}


Verificou-se, no período estudado, 15.107 casos de TB/HIV no Pará. O maior número de casos ocorreu no ano de 2019 (36,5\%, $n=5.519)$, contudo, percebeu-se um declínio de 32,5\% ao decorrer dos anos, apresentando em 2020 uma redução considerável. Foram observados os maiores acometimentos da coinfecção no sexo masculino $(67,4 \%, n=10.188)$ e na faixa etária entre 20 a 39 anos $(48,1 \%, n=7.278)$. Dentre as formas clínicas, a pulmonar ocorreu em $88,9 \%$ dos casos $(n=13.429)$ e, em relação ao desfecho, a cura foi obtida em $22 \%$ ( $n=3.330$ ) e abandono em 10,5\% ( $n=1.594)$.

\section{CONSIDERAÇÕES FINAIS}

Foram observados altos casos de coinfecção entre TB/HIV entre indivíduos do sexo masculino, pessoas adultas e com evolução para a cura. Porém, apesar do declínio observado ao longo dos anos estudados, torna-se fundamental realizar ações de promoção e prevenção à saúde, visando a redução contínua dos casos no estado.

\section{REFERÊNCIAS}

1. CAVALIN RFC, et al. Coinfecção TB-HIV: distribuição espacial e temporal na maior metrópole brasileira. Revista de Saúde Pública, 2020; 54(112): 1-13.

2. DIAS WB, et al. O perfil psicossocial de pessoas vivendo com HIV/AIDS em uma unidade de acompanhamento em Belém-PA: Relato de Experiência. Revista Eletrônica Acervo Saúde, 2020; 12(1): e1429.

3. MAGNO L, et al. Factors associated with self-reported discrimination against men who have sex with men in Brazil. Revista de Saúde Pública, 2017; 51(102): 1-11.

4. SILVA JDP, et al. Tendência temporal da incidencia da coinfecção TB/HIV e testarem de HIV da população idosa brasileira de 2008 a 2018. Revista Brasileira Geriatria Gerontologia, 2020; 23(3): 200215. 


\title{
INFUSÃO DE FENILEFRINA PARA PREVENÇÃO DE HIPOTENSÃO ARTERIAL EM GESTANTES OBESAS SUBMETIDAS À CESARIANA ELETIVA: RESULTADOS PRELIMINARES
}

\author{
Samara Campos Carneiro Maia ${ }^{1}$ \\ Márcio Luiz Benevides ${ }^{1}$ \\ Yan Mamede Untar Zardette 1 \\ Marília Marquioreto Benevides² \\ Cristhiano Camargo Prados ${ }^{1}$
}

1. Hospital Universitário Júlio Muller, Cuiabá - MT.

2. Universidade de Cuiabá (UNIC), Cuiabá - MT.

Palavras-chave: Obesidade, Cesariana, Hipotensão arterial.

\section{INTRODUÇÃO}

No Brasil, entre 2014 a 2017, foram realizados 6.580 .432 cesarianas. Bloqueio de neuroeixo é a técnica mais empregada nas gestantes, particularmente em obesas. Dentre as técnicas de bloqueio de neuroeixo, destaca-se a raquianestesia (TAYLOR CR, et al., 2019). Porém, um dos eventos indesejáveis mais frequentes desta técnica é a hipotensão arterial (HA), que pode ocorrer em até $90 \%$ das pacientes, podendo causar náusea e vômito (NV) com risco de broncoaspiração de conteúdo gástrico, colapso cardiovascular, perda da consciência materna, bem como redução do fluxo útero placentário e consequente acidose fetal (MASSOUTH C, et al., 2020). O emprego de fenilefrina (vasopressor) é recomendado para prevenção e tratamento deste evento.

\section{OBJETIVO}

Avaliar o efeito da utilização de fenilefrina em infusão contínua para prevenção de HA durante cesariana de gestantes obesas e seus efeitos no Recém-Nascido (RN).

\section{MÉTODO}

Estudo placebo-controlado, aleatório e duplamente encoberto. Foram incluídas 72 pacientes $>18$ anos submetidas a cesariana eletiva para receberem fenilefrina $50 \mu \mathrm{g} / \mathrm{min}, 100 \mu \mathrm{g} / \mathrm{min}$ ou solução salina. Excluídos prematuridade, gemelaridade e hipertensão arterial. Foram avaliadas incidências de HA (desfecho principal), hipertensão arterial, bradicardia e NV; quantidade de fenilefrina para tratamento de HA; índice de Apgar $<7$ no quinto minuto; pH e base excess da artéria umbilical do RN. CAAE 89114418.2.0000.5541.

\section{RESULTADOS}


A incidência de HA foi maior no Grupo C comparado com o Grupo F50 (92 versus 33,3 \%, $p<0,0001$ ) e com o grupo $\mathrm{F} 100$ (92 versus 17,4\%), $\mathrm{p}<0,0001$ ). A quantidade de fenilefrina para tratamento de $\mathrm{HA}$ foi maior no Grupo C (368,1 mg comparado com o Grupo F50 (54,1 mg), p < 0,000 e com o Grupo F100 (17,3 mg, p < 0,000 . Houve maior número de episódios de hipertensão reativa no Grupo F100 comparado com o Grupo C $(52,1$ versus $8 \%, p<0,001)$. Outros desfechos materno e neonatal foram similares nos três grupos.

\section{CONSIDERAÇÕES FINAIS}

Os resultados deste estudo sugerem que a fenilefrina, quando administrada em infusão contínua profilática, reduz significativamente a incidência de HA, assim como a quantidade deste fármaco para tratamento deste evento em gestantes obesas submetidas a cesarianas sob raquianestesia. Porém, pode aumentar a incidência de hipertensão reativa e bradicardia materna na dose de $100 \mu \mathrm{g} . \mathrm{min}-1$. Além disso, demonstrou-se que a fenilefrina pode ser segura para o RN.

\section{REFERÊNCIAS}

1. MASSOUTH C, et al. Hypotension after spinal anesthesia for cesarean section: how to approach the iatrogenic sympathectomy. Current Opinion Anaesthesiology, 2020; 33(3): 291-298.

2. RULEY EL, et al. Cesarean section rates in Brazil: trend analysis using the Robson classification system. Medicine, 2020; 99: 17(e19880).

3. TAYLOR CR, et al. Obesity And Obstetric Anesthesia: Current Insights. Local Regional Anesthesia, 2019; 12: $111-124$. 


\title{
PERFIL EPIDEMIOLÓGICO DA SÍFILIS EM GESTANTES NA REGIÃO NORTE NO PERÍODO DE 2014 A
} 2018

\author{
Karytta Sousa Naka ${ }^{1}$ \\ Cássia Vitória Passos dos Santos ${ }^{2}$ \\ Taynara da Costa Silva² \\ Maria Beatriz Caetano de Souza ${ }^{2}$
}

1. Instituto Evandro Chagas, Belém - PA.

2. Estácio, Castanhal - PA.

Palavras-chave: Sífilis, Gestantes, SINAN.

\section{INTRODUÇÃO}

A Sífilis é uma infecção sexualmente transmissível cujo agente etiológico é o Treponema pallidum, bactéria com forma espiral do grupo das espiroquetas que, quando o tratamento não é realizado corretamente, pode evoluir. Em casos de gestantes que adquirem a doença e não realizam o tratamento, $40 \%$ dos casos podem evoluir para aborto espontâneo, natimorto e óbito perinatal. Desta forma, a bactéria pode atravessar a barreira placentária, infectando o feto e causando a chamada sífilis congênita (ALMEIDA AS, et al., 2020; MACÊDO VC, et al., 2020; REIS MPL, et al., 2020).

\section{OBJETIVO}

Analisar o perfil epidemiológico da Sífilis na gestação na região Norte do Brasil no período de 2014 a 2020, enfatizando a sífilis nas mulheres gestantes caracterizando o perfil sociodemográfico e clínico.

\section{MÉTODO}

Trata-se de um estudo retrospectivo, quantitativo e epidemiológico baseado em informações coletadas do banco de dados do Sistema de Informações de Agravos de Notificação (SINAN) e do Departamento de Doenças de condições Crônicas e infecções Sexualmente Transmissíveis (DCCl), Dados estes disponíveis para consulta, sem exigir aprovação prévia do comitê de ética de pesquisa (CEP). Foram coletados dados dos casos confirmados de sífilis em gestantes entre os anos de 2014 e 2018.

\section{RESULTADOS}

Observou-se, no período estudado, 20.055 casos de sífilis em gestantes na região Norte. Em 2014, 12\% (n- 2.478) das gestantes foram acometidas, de 2014 a 2018 houve um acréscimo de 28,8\% (n- 5.675) dos casos. Em relação à faixa etária, cerca de $28,8 \%$ das gestantes tinham entre 20 e 29 anos. Sobre a 
escolaridade notou-se que as gestantes com o ensino superior completo possuem $39,5 \%$ dos casos, enquanto que, $32,4 \%$ não possuem o ensino superior. De acordo com a classificação clínica, $44,1 \%$ das gestantes só descobriram a doença no período latente.

\section{CONSIDERAÇÕES FINAIS}

Com base nos aspectos observados, torna-se imprescindível enfatizar a realização do rastreamento da Sífilis no início da gestação, com o intuito de prevenir os efeitos acarretados pela infecção, bem como o uso dos testes rápidos para sífilis, disponível nos serviços de saúde pública, sendo prático e de fácil execução. Diante do exposto, nota-se que o acompanhamento das gestantes e seu parceiro é imprescindível no controle da sífilis.

\section{REFERÊNCIAS}

1. ALMEIDA AS, et al. Syphilis in pregnancy, factors associated with congenital syphilis and newborn conditions at birth. Texto e contexto-Enfermagem, 2020; e20200423.

2. MACÊDO VC, et al. Sífilis na gestação: barreiras na assistência pré-natal para o controle da transmissão vertical. Caderno Saúde Coletiva, 2020; 518- 528.

3. BARBOSA DFR, et al. Perfil Epidemiológico da Sífilis Congênita em gestantes no município de Maceió. Revista Eletrônica Acervo Saúde, 2020; 12(11): e4881.

4. REIS MPL, et al. Sífilis na gestação e sua influência nas complicações materno-fetais. Braz. J. Hea, 2020; 19748-19758. 


\title{
O TRABALHO INTERPROFISSIONAL EM SAÚDE MENTAL: A COMPREENSÃO DOS PROFISSIONAIS DE UM CAPS
}

\author{
Mirelly Thaina de Oliveira Cebalho ${ }^{1}$ \\ Larissa de Almeida Rézio ${ }^{1}$ \\ Ana Karolina Lobo da Silva ${ }^{1}$
}

1. Universidade Federal de Mato Grosso (UFMT), Cuiabá - MT.

Palavras-chave: Saúde mental, Trabalho interprofissional, Profissionais da saúde.

\section{INTRODUÇÃO}

A interprofissionalidade é uma prática que possibilita o trabalho colaborativo entre grupos profissionais, proporciona o compartilhamento de conhecimentos, o reconhecimento entre as profissões e a oferta de uma assistência centrada nas necessidades das pessoas em sofrimento mental, potencializando a assistência e a corresponsabilização do cuidado (REUTER CLO, et al., 2018; CECCIM RB, 2018; VATN e DAHL, 2021).

Porém, evidencia-se fragilidade na formação interprofissional e atenção psicossocial, materializando um cuidado a partir de práticas biomédicas, contrárias ao modelo de atenção psicossocial. Portanto, a introdução da interprofissionalidade na formação e nos serviços mostra-se necessária para a transfromação do cuidado em saúde mental (CERVO EB, et al., 2020; SOUZA MA, et al., 2021).

\section{OBJETIVO}

Identificar a compreensão dos profissionais da saúde de um Centro de Atenção Psicossocial (CAPS) sobre o trabalho interprofissional em sofrimento mental e como a interprofissionalidade se manifesta no cotidiano do exercício profissional.

\section{MÉTODO}

Trata-se de um estudo qualitativo do tipo exploratório descritivo, realizado com profissionais de um CAPS da capital de Mato Grosso. A coleta/produção de dados foi realizada presencialmente por meio da utilização da observação participante, anotações em diário de pesquisa e entrevista semiestruturada, com questões norteadoras referentes ao cotidiano de trabalho e a compreensão dos profissionais quanto ao sofrimento mental. Foi aprovado sob Parecer oㅜ 4.199.950 e CAAE n² 29310620.1.0000.8124.

\section{RESULTADOS}

A maioria dos profissionais da saúde relatam dúvidas ou apresentam compreensão frágil referente ao termo interprofissionalidade e relacionam o trabalho ideal ao exercício de funções específicas por cada membro da equipe. Esse modo de trabalho instituído é pautado em práticas fragmentadas, com ausência ou 
pouco espaço de trabalho/ discussão em equipe. Entretanto, alguns profissionais manifestam uma compreensão que se direciona ao trabalho colaborativo ao apontarem o estudo de caso e a reunião de equipe como espaços potentes para discussões, integração e colaboração de ações e agentes, apontando para um movimento de transformação das relações de trabalho e do cuidado.

\section{CONSIDERAÇÕES FINAIS}

A fragilidade na compreensão acerca do trabalho interprofissional pode resultar em cuidado fragmentado e repetitivo, o que precariza a assistência em saúde mental pautada na atenção psicossocial. $O$ trabalho apresentado pode contribuir para a elaboração de ações mais direcionadas para garantir a efetivação do trabalho interprofissional e, assim, proporcionar cuidado integral, preparando a enfermagem desde a sua formação.

\section{REFERÊNCIAS}

1. CECCIM RB. Connections and boundaries of interprofessionality: form and formation. Interface (Botucatu), 2018; 22(Suppl 2): 1739-1749.

2. CERVO EB, et al. Interprofissionalidade e saúde mental: uma revisão integrativa. Psicol. Saúde em Debate, 2020; 6(2): 260-272.

3. REUTER CLO, et al. The exercise of interprofessionality and intersetoriality as an art of caring: innovations and challenges. Escola Anna Nery, 2018; 22(4): e20170441.

4. SOUZA MA, et al. Atuação interprofissional vivenciada no Programa de Educação pelo Trabalho pela Saúde: um relato de experiência. Revista Eletrônica Acervo Saúde, 2021; 13(6): e6945.

5. VATN L, DAHL BM. Interprofessional collaboration between nurses and doctors for treating patients in surgical wards. Journal of interprofissional Care, 2021: 1-9. 


\title{
INTOXICAÇÃO POR AGROTÓXICOS POR EXPOSIÇÃO OCUPACIONAL NOS ESTADOS DA REGIÃO SUL DO BRASIL DE 2010 A 2019
}

\author{
Rodrigo Dalke Meucci ${ }^{1}$ \\ Bianca Correa Milano ${ }^{1}$ \\ Isadora da Silveira ${ }^{1}$ \\ Julia Barcelos Braglia ${ }^{1}$
}

1. Universidade Federal do Rio Grande (FURG), Rio Grande - RS.

Palavras-chave: Intoxicação exógena, Epidemiologia, Sistemas de informação na saúde.

\section{INTRODUÇÃO}

O termo intoxicação exógena refere-se aos sinais e sintomas resultantes da interação prejudicial entre organismo e agentes tóxicos, sendo essa relação responsável por provocar um desequilíbrio de ordem sistêmica ao indivíduo exposto (MAIA SS, et al., 2019). O Brasil é um dos países que mais utiliza uma classe de produtos tóxicos que interfere em processos biológicos naturais, os agrotóxicos, sendo que, em 2019, a região sul ocupava o segundo lugar do ranking nacional de utilização desses produtos químicos, chegando, nesse ano, a um total de cerca de 150 toneladas vendidas (IBAMA, 2019).

\section{OBJETIVO}

Descrever o perfil epidemiológico da intoxicação por agrotóxicos agrícolas devido à exposição ocupacional a esses produtos químicos na região sul do Brasil no período compreendido entre os anos de 2010 e 2019.

\section{MÉTODO}

Estudo ecológico, quantitativo, baseado em dados do Sistema de Informação de Agravos de Notificação (SINAN). Delimitou-se a amostra a casos ocorridos por exposição ocupacional a agrotóxicos agrícolas, na região sul brasileira, de 2010-2019. Variáveis: emissão de Comunicação de Acidente de Trabalho (CAT), circunstância, evolução, faixa etária, raça e sexo. Desconsiderou-se dados ignorados ou em branco. Por serem dados públicos, não foi necessário submeter ao Comitê de Ética em Pesquisa (CEP).

\section{RESULTADOS}

No período analisado, foram notificados 5.950 casos de intoxicação exógena por agrotóxico agrícola por exposição ocupacional na região sul, passando de 469 em 2010 para 976 em 2019. Destes, em 3.857 (64,8\%) casos não houve emissão de CAT. As circunstâncias de exposição mais frequentes foram: acidental (51\%), uso habitual $(33,98 \%)$, ambiental $(8,7 \%)$ e erro de administração $(1,2 \%)$. A maioria dos expostos era do sexo 
masculino (83,2\%), de cor branca (80,7\%), com idade entre $20-39$ anos (47,2\%). Além disso, 173 (2,9\%) casos evoluíram para cura com sequelas, perda de seguimento ou óbito por intoxicação exógena.

\section{CONSIDERAÇÕES FINAIS}

Em geral, as intoxicações ocorreram predominantemente em homens, de cor branca, entre 20-39 anos, de maneira acidental, culminando em cura sem sequelas, sem emissão de CAT. Esses dados reforçam a subnotificação desse tipo de intoxicação, expondo a necessidade de incentivar a adesão dos profissionais da saúde ao correto preenchimento da notificação e da CAT, a fim de diminuir a subnotificação e tornar os dados do SINAN mais fidedignos à realidade.

\section{REFERÊNCIAS}

1. BRASIL. Instituto Brasileiro do Meio Ambiente e dos Recursos Naturais Renováveis. Boletim Anual de Produção, Importação, Exportação e Vendas de Agrotóxicos no Brasil. 2019. Disponível em: https://www.gov.br/ibama/pt-br. Acessado em: 29 de setembro de 2021.

2. BRASIL. Sistema de Informação de Agravos de Notificação. Departamento de Informática a Serviço do SUS, Ministério da Saúde. Disponível em: https://datasus.saude.gov.br. Acessado em: 29 de setembro de 2021.

3. MAIA SS, et al. Anos potenciais de vida perdidos por intoxicação exógena no Brasil no período de 2007 a 2017. Revista Enfermagem Contemporânea, 2019; 8(2):135-142. 


\title{
UTILIZAÇÃO DE DISPOSITIVOS ELETRÔNICOS POR ESTUDANTES UNIVERSITÁRIOS DURANTE A PANDEMIA DE COVID-19
}

\author{
Keilla Barbosa de Souza ${ }^{1}$ \\ Marina Campos Nogueira da Silva ${ }^{1}$ \\ Andréia Guedes Oliva Fernandes ${ }^{1}$
}

1. Centro Universitário Euro Americano (UNIEURO), Brasília - DF.

Palavras-chave: Dispositivos eletrônicos, Universitários, COVID-19.

\section{INTRODUÇÃO}

A doença denominada COVID-19 é causada pelo vírus SARS-CoV-2 cuja transmissão acontece através de gotículas e contato com superfícies contaminadas. As pessoas diagnosticadas com esta doença podem apresentar sintomas gripais e em casos mais graves ocorre pneumonia e óbito (BRASIL, 2020).

Devido à gravidade da COVID-19, em março de 2020 foi caracterizada como uma pandemia, o que gerou impactos a nível mundial e nacional. Desta forma, sucedeu o isolamento social que ocasionou alterações nos hábitos de vida dos indivíduos, a exemplo os universitários, que passaram a utilizar do ensino remoto, o que implicou no aumento do uso de dispositivos eletrônicos (SILVA MD, et al., 2021; SADEEH H, et al., 2021).

\section{OBJETIVO}

Identificar o uso de dispositivos eletrônicos e o tempo de televisão entre estudantes universitários de uma Instituição de Ensino Superior (IES) devido ao isolamento social durante a pandemia de COVID-19.

\section{MÉTODO}

Trata-se de uma pesquisa descritiva, transversal com abordagem quantitativa realizada no segundo semestre de 2020. A coleta de dados foi realizada de forma remota através do recrutamento dos universitários por convite via Microsoft Teams, para envio do questionário eletrônico. Foram incluídos no estudo os estudantes matriculados na IES nos cursos das diferentes áreas do conhecimento. $O$ estudo foi aprovado pelo Comitê de Ética em Pesquisa, sob o CAAE no 29338819.1.0000.5056.

\section{RESULTADOS}

Participaram da pesquisa 87 estudantes universitários no qual $65,5 \%$ eram do sexo feminino, destes $51,7 \%$ se autodeclaram pardos e $77 \%$ afirmaram ser solteiros. Observou-se que a maioria dos universitários estavam nos últimos semestres da graduação e foi predominante os cursos da área da saúde. No que concerne o uso de dispositivos eletrônicos no tempo livre evidenciou que $92 \%$ dos estudantes informaram fazer uso e 49,3\% relataram que a duração do uso ultrapassa três horas diárias. Quanto ao tempo de televisão, 54\% dos 
discentes afirmaram que possuem o hábito de assistir televisão com duração de igual ou inferior a duas horas diárias.

\section{CONSIDERAÇÕES FINAIS}

Observou-se que o uso dos dispositivos eletrônicos e o tempo de televisão foram frequentes entre os estudantes universitários. Infere-se que a crescente utilização de dispositivos eletrônicos foi desencadeada pelo ensino remoto e a dependência do uso da internet para o convívio social e o acesso às aulas. Como limitação desta pesquisa ressalta-se o possível viés dos dados autorreferidos. Ademais, espera-se que a partir deste haja novas pesquisas acerca do tema.

\section{REFERÊNCIAS}

1. BRASIL. Ministério da saúde. Recomendações de proteção aos trabalhadores dos serviços de saúde no atendimento de COVID-19 e outras síndromes gripais. 2020. Disponível em: https://www.saude.go.gov.br/files/banner_coronavirus/GuiaMS-

Recomendacoesdeprotecaotrabalhadores-COVID- 19.pdf. Acessado em: 28 de setembro de 2021.

2. SAADEH H, et al. Smartphone use among university students during Covid-19 quarantine: an ethical trigger. Frontiers in Public Health, 2021; 9: 1-11.

3. SILVA MD, et. al. Coronavírus: consequências da pandemia no ensino superior. Revista Eletrônica Acervo Saúde, 2021; 13(5): e7120. 


\section{PERFIL EPIDEMIOLÓGICO DAS ALTERAÇÕES DE EXAMES DE COLO DE ÚTERO DE MULHERES JOVENS DO DISTRITO FEDERAL}

Thaís da Silva Rodrigues ${ }^{1}$

Karyne Santana Marques de Queiroz ${ }^{1}$

Márcio Sousa Jerônimo ${ }^{1}$

1. Centro Universitário Euro Americano (UNIEURO), Brasília - DF.

Palavras-chave: Câncer de colo de útero, Infecção, Papilomavírus Humano.

\section{INTRODUÇÃO}

O câncer de colo uterino é um problema de saúde pública responsável por elevadas taxas de mortalidade entre mulheres em todo o Brasil, sendo um dos fatores relacionado ao grande número de pacientes que não realizam os exames preventivos periodicamente. Existem várias etiologias, destacando-se a infecção por alguns tipos de Papilomavírus Humano (HPV), transmitido através da relação sexual desprotegida que provocam alterações nas células uterinas, tem evolução lenta, progressiva e inicialmente assintomática (RODRIGUES LG, et al., 2021). Portanto, se torna importante realizar a detecção precoce através do exame preventivo Papanicolaou contra HPV, a fim de diminuir agravos pela doença (SÁ KCC e SILVA RL, 2019).

\section{OBJETIVO}

Determinar a prevalência do câncer de colo de útero em mulheres jovens entre 15 e 19 anos no Distrito Federal entre 2020 e 2021, através de dados obtidos no Sistema de Informações de Câncer (SISCAN).

\section{MÉTODO}

Foi realizada uma pesquisa descritiva, quantitativa, temporal dos casos de câncer de colo de útero e/ou alterações citopatológicas em mulheres entre 15 e 19 anos no Distrito Federal no período de 2020 e 2021. Os dados foram coletados da plataforma SISCAN, do Ministério da Saúde e analisados estatisticamente no programa Prism GraphPad 6.0. Por serem dados abertos de domínio público, não foi necessária a apresentação ao Comitê de Ética em Pesquisa (CEP).

\section{RESULTADOS}

No período de 15 de setembro de 2020 a 15 de setembro de 2021 foram realizados 2.568 exames de colo de útero em mulheres entre 15 e 19 anos no Distrito Federal, um número consideravelmente baixo quando comparado com outras faixas etárias no mesmo período. A maioria significativa dos exames deu resultado negativo para alterações neoplásicas. 
Os exames citopatológicos que apresentaram alterações mais significativas mostraram presença de células escamosas atípicas (5,76\% dos exames) e lesão intraepitelial (2,95\% dos exames) na sua maioria. As alterações intraepiteliais de baixo grau e células escamosas atípicas indeterminadas foram encontradas em quantidade maior nos exames analisados.

\section{CONSIDERAÇÕES FINAIS}

A menor quantidade de exames de colo de útero realizada na faixa etária da população analisada pode mascarar alterações importantes como a presença de células escamosas atípicas ou lesão intraepiteliais. Orientações preventivas e continuidade do acompanhamento das pacientes com essas alterações são fundamentais para saúde da mulher jovem com essas alterações.

\section{REFERÊNCIAS}

1. BRASIL, Ministério da Saúde. Banco de dados do Sistema Único de Saúde-DATASUS. Disponível em: https://datasus.saude.gov.br/acesso-a-informacao/sistema-de-informacao-do-cancer-siscan-colo-doutero-e-mama/. Acessado em: 28 de Setembro 2021.

2. RODRIGUES LG, et al. Câncer de colo uterino e a infecção pelo HPV: consequências da não adesão aos métodos de prevenção. Revista Eletrônica Acervo Saúde, 2021; 13(4): e7211.

3. SÁ KCC, SILVA RL. Exame papanicolaou na prevenção do câncer no colo uterino: Uma revisão integrativa. Revista Eletrônica da Faculdade Evangélica de Ceres, 2019; 8(1): 8-8. 


\title{
PREVALÊNCIA DE ÓBITOS MATERNOS DURANTE O PUERPÉRIO NO BRASIL: O RETRATO DE UMA DÉCADA
}

\author{
Francisco Lucas Leandro de Sousa ${ }^{1}$ \\ Angelica Ribeiro do Nascimento Oliveira ${ }^{1}$ \\ Danilo da Silva Alves ${ }^{1}$
}

1. Centro Universitário Maurício de Nassau (UNINASSAU), Fortaleza - CE.

Palavras-chave: Mortalidade materna, Registros de mortalidade, Saúde da mulher.

\section{INTRODUÇÃO}

Mortalidade materna é definida como o óbito da mulher durante a gestação, no momento do parto ou até 42 dias do puerpério, decorrente de causas obstétricas diretas ou indiretas (LIMA MRG, et al., 2017). Países desenvolvidos possuem alta prevalência de óbitos maternos resultante da associação de fatores econômicos, biológicos, culturais e sociais, na qual evidencia deficiências no sistema de saúde (RUAS CAM, et al., 2020). Dentre as principais causas de óbito materno estão a hipertensão, hemorragia, infecção puerperal e aborto, tornando um problema de saúde pública em decorrência dos altos índices de mortalidade associado à saúde da mulher (MARTINS ASC e SILVA LS, 2018).

\section{OBJETIVO}

Analisar o levantamento do perfil epidemiológico do número de mortes maternas com destaque nas regiões brasileiras associadas ao tempo do puerpério de até 42 dias referentes ao período de 2009 e 2018 .

\section{MÉTODO}

Pesquisa epidemiológica, descritiva de cunho quantitativo e retrospectivo com destaque no número de mortes maternas durante o puerpério de 42 dias, entre 2009 a 2018. Os dados foram colhidos mediante busca eletrônica nos registros do Sistema de Informação sobre Mortalidade (SIM). As variáveis utilizadas foram: número de óbitos, faixa etária, região e cor/raça. Os dados apresentados são de domínio público não necessitando a submissão aop comitê de ética e pesquisa.

\section{RESULTADOS}

Dentre os achados, em 10 anos no Brasil foram encontrados um total de 8.836 óbitos maternos durante o puerpério, sendo que desse valor, 3.547 são da faixa etária de 20-29 anos e 3.492 da faixa etária 30-39 anos, remetendo um maior número em mães jovens. Quanto a distribuição regional, observou-que a maior taxa de morte durante o puerpério concentrava-se no Sudeste (3.410 óbitos), seguidos de Nordeste (2.613 óbitos), Norte (1.103 óbitos), Sul (954 óbitos) e Centro-Oeste (756 óbitos). Em 2017 houve o maior número de 
registros de óbitos, sendo 991 puérperas. Em relação a raça, os maiores índices ocorreram entre mulheres pardas (513 óbitos) e brancas (347 óbitos).

\section{CONSIDERAÇÕES FINAIS}

É possível identificar que a prevalência de mortes maternas, concentra-se na faixa etária entre 20-29 anos, população jovem, sendo um problema que merece enfoque da saúde pública. Nesse viés, é de suma importância o aumento de ações voltadas para prevenção da saúde e incentivo a participação nas consultas de pré-natal, evitando futuras complicações obstétricas.

\section{REFERÊNCIAS}

1. LIMA MRG, et al. Alterações maternas e desfecho gravídico-puerperal na ocorrência de óbito materno. Caderno de Saúde Coletiva, 2017; 25: 324-331.

2. MARTINS ACS, SILVA LS. Perfil epidemiológico de mortalidade materna. Revista Brasileira de Enfermagem, 2018; 71: 725-731.

3. RUAS CAM, et al. Perfil e distribuição especial da mortalidade materna. Revista Brasileira de Saúde Materna e Infantil, 2020; 20: 397-409. 
RESUMO SIMPLES: Estudo Original

\title{
O AUTOCUIDADO DE MULHERES COM DIAGNÓSTICO DE DIABETES GESTACIONAL
}

\author{
Ágatha Cristina Moraes Campos ${ }^{1}$ \\ Beatriz de Sousa Campos ${ }^{1}$ \\ Victória Ellenn Bomfim Golbi ${ }^{1}$ \\ Ana Paula Franco Pacheco ${ }^{1}$
}

1. Centro Universitário Euro Americano (Unieuro), Brasília - DF.

Palavras-chave: Diabetes gestacional, Autocuidado, Vínculo.

\section{INTRODUÇÃO}

Diabetes Mellitus Gestacional é uma alteração metabólica caracterizada pelo aumento dos hormônios contrários a ação da insulina e o pâncreas então, não consegue produzir maior quantidade de insulina. Sendo assim, os níveis de glicemia ficam aumentados (REIS MGV, et al., 2019). O diagnóstico é realizado através do exame conhecido como TOTG, que deve ser realizado entre a $24^{\mathrm{a}}$ e $28^{\mathrm{a}}$ semana (FERNANDES CN e BEZERRA MMM, 2020). Após o diagnóstico é importante o profissional de saúde conscientizar a gestante quanto ao tratamento, associação da alimentação saudável e prática de exercícios físicos para preparar seu corpo para o bom desenvolvimento do feto (ZUCCOLOTTO DCC, et al., 2019).

\section{OBJETIVO}

Analisar os fatores condicionantes que interferem no autocuidado de mulheres com DMG, sendo eles: o conhecimento sobre a doença e o vínculo da gestante com a equipe multidisciplinar de saúde.

\section{MÉTODO}

Trata-se de um estudo de campo, descritivo e exploratório, realizado no período de junho a setembro de 2021. Realizou-se uma coleta de dados, através de um formulário do aplicativo Google Forms. Foram enviados às mulheres que já tiveram o diagnóstico de DMG ou estavam com essa condição clínica no momento da pesquisa. Esse estudo foi aceito pelo Comitê de Ética em Pesquisa (CEP) com seres humanos $n^{\circ} 45401421.6 .0000 .5056$.

\section{RESULTADOS}

Participaram do estudo 113 mulheres (100\%), dentre essas 38 (33,6\%) já tinham diagnóstico prévio de Diabetes Mellitus Tipo 1 (DM1) ou Tipo 2 (DM2) e por esse motivo foram excluídas as respostas, permanecendo um total de 75 respostas (66,4\%). A partir disso, identificou-se que $49,6 \%$ das mulheres não sabiam reconhecer os sinais e sintomas do DMG. 
Em relação à amamentação após o parto, 60,2\% não sabiam informar se tinha alguma restrição. No que concerne às orientações da equipe multiprofissional, $49,6 \%$ disseram que foi eficaz. Quanto ao acolhimento, $88,5 \%$ sentiram-se acolhidas pela equipe pela qual foram atendidas e $91,2 \%$ relataram que esse acolhimento favoreceu no autocuidado durante a gestação.

\section{CONSIDERAÇÕES FINAIS}

Diante do exposto, faz-se necessário promover um vínculo entre os profissionais de saúde e as gestantes, pois é uma forma de promoção da singularidade e integralidade do cuidado; realizar uma escuta ativa, compreender sua realidade e estabelecer uma relação de confiança, colaborando assim, com uma educação em saúde de qualidade, agindo como um facilitador do processo de tratamento e controle do DMG.

\section{REFERÊNCIAS}

1. FERNANDES CN, BEZERRA MMM. O Diabetes Mellitus Gestacional: Causa e Tratamento. Revista Multidisciplinar e de Psicologia, 2020; 14: 127-139.

2. REIS MG, et al. Diabetes Mellitus Gestacional: Aspectos Fisiopatológicos Materno-Fetais. Revista Terra e Cultura, 2019; 35: 69.

3. ZUCCOLOTTO DCC, et al. Padrões alimentares de gestantes, excesso de peso materno e diabetes gestacional. Revista de Saúde Pública, 2019; 53: 52. 


\title{
QUALIDADE DE VIDA DOS INDIVÍDUOS COM DPOC APÓS INTERVENÇÃO FISIOTERAPÊUTICA AQUÁTICA
}

\author{
Ana Carolina Moraes de Oliveira ${ }^{1}$ \\ Daniele Oliveira Sousa da Silva Marra ${ }^{1}$ \\ Maryanna Freitas Alves ${ }^{1}$ \\ Renato Canevari Dutra da Silva ${ }^{1}$
}

1. Universidade de Rio Verde (UniRV), Rio Verde - GO.

Palavras-chave: Qualidade de vida, DPOC, Intervenção fisioterapêutica aquática.

\section{INTRODUÇÃO}

A Doença Pulmonar Obstrutiva Crônica (DPOC) é a terceira causa de morte entre as doenças crônicas não transmissíveis no Brasil. As manifestações clínicas decorrem de lesões do parênquima pulmonar, o que agrava o estado de saúde e reduz a qualidade de vida do indivíduo (WUS V, et al., 2021). Sintomas como dispneia, tosse, sibilos, aperto torácico e fadiga prejudicam a realização de atividades básicas de vida, com repercussões nas esferas física, socioemocional, mental, econômica, familiar e bem-estar (ACHURYBELTRAN LF e GARCIA- PENUELA P, 2019). A fisioterapia aquática entra como recurso para minimizar os efeitos danosos gerados pelas condições que afetam o idoso (PIANNA B, et al., 2019).

\section{OBJETIVO}

Avaliar e comparar, de modo efetivo, a qualidade de vida de pacientes com DPOC antes e após a intervenção fisioterapêutica aquática por meio do questionário específico (SOLDQ), com o intuito de observar se há diferença estatisticamente significativa entre as médias.

\section{MÉTODO}

Estudo intervencionista não experimental realizado com indivíduos com DPOC, cuja idade média é de 76 anos. Foram inclusos voluntários clinicamente estáveis e excluídos participantes com outras doenças pulmonares ou doenças não pulmonares agudas e crônicas. Os participantes passaram por avaliação física e avaliação da qualidade de vida (QV) por meio do questionário, intervenção fisioterapêutica aquática, seguida de reavaliação. Foi aprovado sob parecer: 1.592.432. CAAE: 56397516.0.0000.5077.

\section{RESULTADOS}

A população estudada foi composta inicialmente por 40 indivíduos, porém 14 foram incapazes de participar do grupo, resultando em uma amostra de 26 indivíduos com DPOC, que apresentavam tosse crônica, produção crônica de secreção, dispneia progressiva e persistente e história de exposição a fatores de riscos. 
No questionário específico (SOLDQ), viu-se diferença estaticamente significativa no domínio de função física $(p=0,030)$ e função emocional $(p=0,009)$ antes e após intervenção fisioterapêutica aquática. Quanto à relação dos domínios do SOLDQ com o número de sessões de fisioterapia aquática, observa- se diferença em relação aos domínios função emocional $(p=0,019)$, habilidade de cooping $(p=0,049)$, satisfação com tratamento $(p=0,053)$.

\section{CONSIDERAÇÕES FINAIS}

A fisioterapia aquática é crucial no tratamento dos pacientes com DPOC para reduzir os danos. Observase o aumento significativo no domínio Função Física do questionário SOLDQ - diminuindo as limitações físicas dos sujeitos. Os escores do SOLDQ estão relacionadas as sessões de fisioterapia. Logo, quanto maior a quantidade de sessões maior o valor obtido nos escores dos domínios Função Emocional, Habilidade de Cooping e Satisfação com o Tratamento.

\section{REFERÊNCIAS}

1. ACHURY-BELTRAN LF, GARCIA-PENUELA P. Efecto de una actividad grupal educativa en la calidad de vida de la persona con EPOC. Enferm. univ, Ciudad de México, 2019; 16(2): 171-184.

2. PIANNA B, et al. Fisioterapia aquática no aumento da força muscular em idosas com doenças crônicas não transmissíveis: estudo piloto. Fisioterapia Brasil, 2019; 20(3): 348-356.

3. WUS V, et al. Marcadores de estresse oxidativo e dano muscular em pacientes com DPOC submetidos a um programa de reabilitação pulmonar. Revista Eletrônica Acervo Saúde, 2021; 13(5): e6940. 


\title{
COMPARAÇÃO DOS NÍVEIS DE FRAGILIDADE COM AS FERRAMENTAS CARDIOVASCULAR HEALTH STUDY E TILBURG FRAILTY INDICATOR EM INDIVÍDUOS COM DOENÇA CARDIOVASCULAR CRÔNICA
}

\author{
George Santos Simões ${ }^{1}$ \\ Luana Pereira de Freitas ${ }^{1}$ \\ Daiana Aparecida Rech ${ }^{1}$
}

1. Universidade do Vale do Itajaí (UNIVALI), Itajaí - SC.

Palavras-chave: Fragilidade, Síndrome da fragilidade, Doença cardiovascular.

\section{INTRODUÇÃO}

A Síndrome da Fragilidade é caracterizada por diminuição das reservas biológicas (KLEIPOOL EEF, et al., 2018). Atualmente existem diversas ferramentas para avaliar a fragilidade, sendo a ferramenta Cardiovascular Health Study (CHS) proposta por Linda Fried, a mais utilizada. O fenótipo da fragilidade da ferramenta CHS avalia os critérios de perda de peso não intencional, exaustão, fraqueza, baixa velocidade de marcha e baixo nível de atividade física (ZHANG XMPH, et al., 2020). Entretanto, ferramenta Tilburg Frailty Indicator (TFI) construída e validada pelo grupo Gobbens é constituída por duas partes através de 15 questões objetivas, autorreferidas, que avaliam aspectos físico, psicológicos e sociais do indivíduo (VROTSOU K, et al., 2018).

\section{OBJETIVO}

Comparar os níveis de fragilidade avaliado pelas ferramentas CHS e TFI em indivíduos com Doença Cardiovascular Crônica (DCV), atendidos nas disciplinas de Cardiovascular I e II em uma Universidade no Norte de Santa Catarina.

\section{MÉTODO}

Trata-se de estudo transversal, quantitativo descritivo, aprovado pelo Comitê de Ética em Pesquisa (CAAE: 16197319.8.0000.0120). A pesquisa foi realizada com indivíduos que atenderam aos critérios de inclusão. Estes indivíduos foram submetidos à avaliação da fragilidade, utilizando as ferramentas CHS e TFI. Os resultados foram agrupados e classificados com as escalas. Os dados coletados foram registrados e analisados por meio de estatística descritiva e teste qui-quadrado, no programa SPSS $\AA_{20.0}$.

\section{RESULTADOS}

Foram avaliados 14 indivíduos com idade média (DP) de $63,7( \pm 6,6)$ anos sendo a maioria composta pelo sexo masculino $(57,1 \%)$. Através da ferramenta TFI o indivíduo é classificado como muito frágil, frágil ou robusto e foi possível verificar que cinco indivíduos eram considerados frágeis. Já na ferramenta CHS que 
classifica o indivíduo como robusto, pré frágil ou frágil foi possível verificar que oito indivíduos possuíam algum nível de fragilidade, sendo que $25 \%$ eram considerados frágeis e $75 \%$ eram considerados pré-frágeis. Ao compararmos as ferramentas pela frequência de indivíduos frágeis e robustos, não observamos diferença estatística significativa $(p>0,05)$.

\section{CONSIDERAÇÕES FINAIS}

Por possuírem a mesma finalidade, porém com abordagens metodológicas distintas, as ferramentas se assemelharam na detecção do nível da fragilidade dos indivíduos com doenças cardiovasculares avaliados. No entanto, é necessário ampliar a amostra a fim de verificar a significância de ambas as ferramentas.

\section{REFERÊNCIAS}

1. KLEIPOOL EEF, et al. Frailty in Older Adults with Cardiovascular Disease: Cause, Effect or Both?. Aging and disease, 2018; 9(3): 489-497.

2. VROTSOU K, et al. Psychometric properties of the Tilburg Frailty Indicator in older Spanish people. Archives of Gerontology and Geriatrics, 2018; (12): 28.

3. ZHANG XMPH, et al. Reliability and Validity of the Tilburg Frailty Indicator in 5 European Countries. Journal of the American Medical Directors Association, 2020; 6(22): 773. 


\title{
DIAGNÓSTICOS TARDIOS DE INFECÇÃO POR HIV EM RESIDENTES DO ESTADO DO AMAPÁ: CASOS NOTIFICADOS NO PERÍODO DE 2014 A 2020
}

\author{
João Douglas Quaresma de Oliveira ${ }^{1}$ \\ Lucas dos Santos Silva ${ }^{1}$ \\ Ester Suane Lima Monteiro ${ }^{1}$ \\ Camila Rodrigues Barbosa Nemer ${ }^{1}$
}

1. Universidade Federal do Amapá (UNIFAP), Macapá - AP.

Palavras-chave: Epidemiologia, Diagnóstico tardio, HIV.

\section{INTRODUÇÃO}

O Vírus da Imunodeficiência Humana (HIV), dos tipos HIV-1 e HIV-2, pode levar à Síndrome da Imunodeficiência Adquirida (AIDS), modificando linfócitos T CD4+ circulantes, levando à supressão imunológica (MELO BO, et al., 2018). Atualmente, a Terapia Antirretroviral (TARV) prolonga e proporciona maior qualidade de vida das pessoas que convivem com HIV, o diagnóstico em tempo oportuno é fundamental para que medidas terapêuticas também iniciem em tempo hábil e agravamentos futuros sejam evitados (MELLO CJFA, et al., 2020). O diagnóstico tardio (DT) é definido pela contagem de linfócitos T CD4+ abaixo de 200 células/ $\mathrm{ml}$ no primeiro exame de CD4 e representa atualmente um entrave no enfrentamento ao HIV (BRASIL, 2018).

\section{OBJETIVO}

Analisar dados secundários de casos de diagnósticos tardios por HIV em residentes do Estado do Amapá notificados no período adotado de 2014 a 2020, considerando as variáveis sexo e faixa etária.

\section{MÉTODO}

Estudo transversal, epidemiológico, descritivo, quantitativo, com análise de dados obtidos na Plataforma de Indicadores e Dados Básicos de Monitoramento Clínico de HIV. Foram selecionados indivíduos com primeiro CD4 abaixo de 200 células $/ \mathrm{mL}$, no período de 2014 a 2020. As variáveis foram: sexo e faixa etária. Foram excluídos dados divergentes de diagnóstico tardio. O estudo não foi apresentado ao Comitê de Ética em Pesquisa (CEP), pois foram utilizados dados públicos.

\section{RESULTADOS}

Evidencia-se um total de 1.007 homens e 619 mulheres que realizaram o primeiro CD4, por meio de uma média aritmética simples das porcentagens, 32,42\% (326) destes homens e 24,14\% (149) das mulheres foram diagnosticados tardiamente. Em relação à faixa etária, dos 475 totais com diagnóstico tardio, 15\% (70) 
estavam na faixa etária de 18 a 24 anos; $15 \%$ (69) dos 25 a 29 anos; 55\% (261) pessoas dos 30 aos 49 anos e $13 \%$ (64) na idade 50 anos ou mais. O grupo etário de 50 ou mais apresentou maior porcentagem de diagnósticos tardios por HIV.

\section{CONSIDERAÇÕES FINAIS}

Observou-se que no período estudado de 2014 a 2020 o percentual de DT de HIV mostrou-se mais elevado no sexo masculino. E com relação à faixa etária, o Amapá acompanha a tendência nacional de quanto maior a idade maior é a porcentagem de DT, sendo predominante na faixa dos 50 anos ou mais. A autopercepção da invulnerabilidade à contaminação pode ser o motivo do diagnóstico tardio de HIV.

\section{REFERÊNCIAS}

1. BRASIL. Ministério da Saúde. Relatório de Monitoramento Clínico do HIV. 2018. Disponível em: http://indicadoresclinicos.aids.gov.br/. Acessado em: 29 de setembro de 2021.

2. MELLO CJFA, et al. Terapia Antirretroviral: principais causas de abandono no estado do Amapá. Revista Eletrônica Acervo Saúde, 2018; 12(8): e3423.

3. MELO BO, et. al. Epidemiologia e aspectos imunopatológicos do vírus da imunodeficiência humana (HIV): revisão de literatura. Revista Ceuma Perspectiva, 2018; 31(1): 86-100. 


\title{
TRATAMENTO FARMACOLÓGICO DOS PACIENTES COM HANSENÍASE NA REGIÃO NORDESTE: ESTUDO EPIDEMIOLÓGICO
}

\author{
Bruno Morais Kos ${ }^{1}$ \\ Grazielly Lima Queiroz ${ }^{1}$ \\ João Manoel de Sousa Silva² \\ Romário Garcia Silva Teles ${ }^{3}$
}

Alessandra Camillo da Silveira Castello Branco ${ }^{1}$

1. Centro Universitário Santo Agostinho (UNIFSA), Teresina - PI.

2. Pontifícia Universidade Católica de Goiás (PUC Goiás), Goiânia - GO.

3. Universidade Federal de Campina Grande (UFCG), Campina Grande - PB.

Palavras-chave: Hanseníase, Paciente, Tratamento.

\section{INTRODUÇÃO}

Hanseníase é uma doença infectocontagiosa causada pela Mycobacterium leprae (LOPES FC, et al., 2021). Sua transmissão é pelo contato próximo e prolongado com pessoas infectadas através das gotículas no ar (QUARESMA MSM, et al., 2019). No Brasil, a doença afeta cerca de 28 mil pessoas, sendo registrados 13.807 casos em 2020 (MACEDO GMM, et al., 2019).

O diagnóstico é realizado através do exame dermatoneurológico, para a observação de possíveis regiões da pele que estão com sensibilidades alteradas e também exame laboratorial de baciloscopia (QUARESMA MSM, et al., 2019). Por ser um tratamento longo, muitos pacientes abandonam o mesmo, dificultando a cura da doença (LOPES FC, et al., 2021).

\section{OBJETIVO}

Determinar o perfil epidemiológico relacionado ao tratamento farmacológico através do esquema terapêutico dos pacientes acometidos pela hanseníase notificados entre os estados da região nordeste durante a última década no Brasil.

\section{MÉTODO}

Trata-se de um estudo transversal, descritivo e qualitativo das notificações de paciente com hanseníase na região nordeste, com delimitação temporal entre 2010 a 2020. Os dados foram obtidos pelo Departamento de Informática do Sistema Única do SUS - Ministério da Saúde (DATASUS-MS). Para tabulação, foi utilizado o Microsoft Excel 2016®. Dispensou-se apreciação pelo Comitê de Ética em Pesquisa (CEP) por terem sido utilizados dados públicos, sem identificação dos participantes. 


\section{RESULTADOS}

Foram registradas 166.964 notificações decorrentes de hanseníase. Houve um declínio de infecções entre o ano de 2012 (16.907; 10,13\%) até 2020 (8.859; 5,31\%), estabelecendo uma média anual de 15.179 notificações. A unidade federativa com maior quantitativo de casos foi o Maranhão $(46.933 ; 28,11 \%)$ e 0 estado do Rio Grande do Norte (3.164; 1,90\%) com o menor número de notificações.

Em relação ao esquema terapêutico, houve maior número de pacientes que realizaram tratamento com poliquimioterapia (PQT) multibacilar (110.093; 65,94\%). O número de doses em casos multibacilar (75.793; $45,40 \%)$ foi menor que 12 doses durante o tratamento, enquanto para casos paubacilar $(39.675 ; 46,73 \%)$ foi um quantitativo de 6 doses.

\section{CONSIDERAÇÕES FINAIS}

Foi observado que o número de casos relacionados a infecção por hanseníase apresentou ocorrência recorrente no estado do Maranhão. Paciente em tratamento com poliquimioterapia para quadros multibacilar foram recorrentes. Esses dados reiteram a necessidade de reforçar a importância da continuidade do tratamento, visto que o esquema terapêutico longo desmotiva o paciente a continuar, diminuído a eficácia e resultado de cura esperado.

\section{REFERÊNCIAS}

1. LOPES FC, et al. Análise espaço-temporal da hanseníase em município do Nordeste brasileiro prioritário para o controle da doença. Revista Brasileira de Enfermagem, 2021; 74(3): e20201101.

2. MACEDO GMM, et al. Distribuição espacial e evolução temporal da hanseníase em uma área de antiga colônia no estado do Pará. Revista Eletrônica Acervo Saúde, 2019; 11(12): e582.

3. QUARESMA MSM, et al. Perfil clínico e epidemiológico dos pacientes portadores de hanseníase em uma unidade de referência no estado do Pará. Revista Eletrônica Acervo Saúde, 2019; (18): e269. 


\title{
ANÁLISE DO PERFIL CLÍNICO-EPIDEMIOLÓGICO DOS PACIENTES ACOMETIDOS POR INTOXICAÇÃO OCASIONADA POR MEDICAMENTOS NA REGIÃO NORDESTE
}

\author{
Bruno Morais Kos ${ }^{1}$
}

Grazielly Lima Queiroz ${ }^{1}$

Alessandra Camillo da Silveira Castello Branco ${ }^{1}$

1. Centro Universitário Santo Agostinho (UNIFSA), Teresina - PI.

Palavras-chave: Medicamento, Paciente, Tratamento.

\section{INTRODUÇÃO}

Intoxicação é caracterizada como uma manifestação clínica de um agente invasor ao organismo do ser humano (XAVIER LA, et al., 2018). Dentre os principais agentes causadores, destaca-se a utilização de substâncias químicas, medicamentos e plantas toxicas, causando efeitos nocivos à saúde (SILVA VT, et al., 2021).

O ambiente que ocorre este agravo está relacionado com peculiaridades sociais, econômicas e culturais, que determinam perfis diferentes entre as regiões geográficas de um mesmo país (MORAES DQ, et al., 2021). Por ser considerado um problema de saúde pública, entende-se que há necessidade de investigação e geração de informações para projetar intervenções conforme a localidade (XAVIER LA, et al., 2018).

\section{OBJETIVO}

Determinar o perfil clínico-epidemiológico através das notificações dos pacientes decorrente de intoxicação exógena relacionada a utilização de medicamentos entre os estados da região nordeste durante a última década no Brasil.

\section{MÉTODO}

Trata-se de um estudo transversal, descritivo e qualitativo das notificações de intoxicação por medicamentos na região nordeste, com delimitação temporal entre 2010 a 2020. Os dados foram obtidos pelo Departamento de Informática do Sistema Única do SUS - Ministério da Saúde (DATASUS-MS). Para tabulação, foi utilizado o Microsoft Excel 2016®. Dispensou-se apreciação pelo Comitê de Ética em Pesquisa (CEP) por terem sido utilizados dados públicos, sem identificação dos participantes.

\section{RESULTADOS}

Foram identificadas 166.964 notificações decorrentes de intoxicação por medicamentos. Observou-se um aumento entre o ano de 2010 (1.274; 13,87\%) até 2019 (5.116; 15,55\%), reduzindo em 2020 (1.228; 3,73\%), estabelecendo uma média anual de 2.992 notificações. A unidade federativa com maior quantitativo foi 
Pernambuco $(12.663 ; 38,48 \%)$ e o estado de Sergipe $(4.168 ; 12,67 \%)$ com o menor. A exposição agudaúnica apresentou maior ocorrência (25.050; 76,12\%). Em relação à circunstância, a utilização acidental $(13.231 ; 40,20 \%)$ foi a mais recorrente, seguida do uso terapêutico habitual $(9.521 ; 28,93 \%)$ e automedicação (6.835; $20,77 \%)$. Na evolução clínica, a maior parte apresentou cura sem sequelas $(27.732 ; 84,27 \%)$, com poucos casos de óbito $(81 ; 0,25 \%)$.

\section{CONSIDERAÇÕES FINAIS}

Foi observado que o número de notificações relacionadas a intoxicação por medicamentos apresentou ocorrência recorrente no estado de Pernambuco. Paciente que realizam tratamento terapêutico habitual de forma aguda-única mostram serem os mais expostos. Esses dados reiteram a necessidade de reforçar a importância do atendimento em unidade de urgência e emergência, para evitar a complicação do quadro clínico do paciente, reduzindo as chances de sequelas e até o óbito.

\section{REFERÊNCIAS}

1. MORAES DQ, et al. Intoxicação por medicamentos em crianças no ambiente doméstico: Revisão sistemática. Brazilian Applied Science Review, 2021; 5(3): 1384-1398.

2. SILVA VT, et al. Intoxicação por medicamentos: uma revisão de literatura com abordagem no tratamento. Revista Eletrônica Acervo Científico, 2021; 23: 6781-6781.

3. XAVIER LA, et al. Intoxicações exógenas por agentes tóxicos em crianças em município do norte de Minas Gerais. Revista Eletrônica Acervo Saúde, 2018; (5): 481-485. 


\title{
INTOXICAÇÃO MEDICAMENTOSA ACIDENTAL EM CRIANÇAS NA CIDADE DE CAMPINA GRANDE-PB
}

\author{
Wagner Bernardo da Silva ${ }^{1}$ \\ Beatriz Maria da Conceição Murilo ${ }^{1}$ \\ Cassiano Augusto Oliveira da Silva²
}

1. Universidade Federal de Campina Grande (UFCG), Cuité - PB.

2. Universidade Federal da Paraíba (UFPB), João Pessoa - PB.

Palavras-chave: Envenenamento, Saúde infantil, Epidemiologia.

\section{INTRODUÇÃO}

O uso indiscriminado de medicamentos pode causar diferentes danos como a intoxicação, que é um resultado de várias manifestações clinicas ou laboratoriais que apontam um desequilibro orgânico, causado por uma ou diversas substâncias tóxicas com sistema biológico (XAVIER A, et al., 2018). As crianças estão entre os grupos com mais frequência desse agravo, pois muitos medicamentos contem embalagens e líquidos coloridos, que são atrativos para essa faixa etária, além do armazenamento inadequado que facilita o consumo e assim podendo levar ao quadro de intoxicação (MAIOR MCLS, et al., 2017; SILVA WB, et al., 2021).

\section{OBJETIVO}

Tendo em vista a problemática, objetivou-se determinar o perfil epidemiológico de crianças acometidas por intoxicação medicamentosa de forma acidental, na cidade de Campina Grande-PB, no período compreendido entre os anos de 2015 a 2019.

\section{MÉTODO}

Trata-se de um estudo epidemiológico, retrospectivo, analítico, documental e do tipo quantitativo. Os dados foram coletados através do Departamento de Informática do Sistema Único de Saúde (DATASUS) (SILVA WB, et al., 2021; BRASIL, 2021). Analisou-se as variáveis como ano, sexo, faixa etária, raça, zona de residência e evolução dos casos. Este estudo é feito com dados secundários públicos e assim dispensa a autorização do Comitê de Ética em Pesquisa (CEP).

\section{RESULTADOS}

Foram registrados 142 casos, entre 2015 e 2019. 2017 teve maior percentual (26,8\%), seguido de 2019 (23,9\%), 2018 (23,2\%), $2016(13,4 \%)$ e 2015 (12,7\%). No tocante ao sexo, 52,8\% foram meninas e 47,2\% meninos. A faixa etária de 1 a 4 anos foi mais prevalente (72,5\%), seguido de 5 a 9 anos (18,3\%), menores 
de 1 ano $(4,9 \%)$ e 10 a 14 anos (4,2\%). A raça mais acometida foi parda $(53,8 \%)$, branca $(32,4 \%)$, preta (2,8\%), outros $0,7 \%$ e $10,6 \%$ ignorados. A zona urbana teve mais casos $(94,4 \%)$, a zona rural $2,1 \%$ e $3,5 \%$ ignorados. Com relação a evolução dos casos, $90,1 \%$ curados, $7,7 \%$ tiveram perda de seguimento e $2,1 \%$ ignorados.

\section{CONSIDERAÇÕES FINAIS}

Os resultados obtidos podem ser utilizados para nortear política públicas voltadas para ações em educação em saúde, feita por profissionais na distribuição dos medicamentos para que orientem aos pais sobre o perigo de deixar medicamentos expostos para as crianças e a forma correta de armazená-los.

\section{REFERÊNCIAS}

1. BRASIL. Departamento de Informática do SUS (DATASUS). 2020. Informações Epidemiológicas e Morbilidade: banco de dados. Disponível em: https://datasus.saude.gov.br/informacoes-de-saude-tabnet/. Acessado em: 1 de Outubro de 2021

2. MAIOR MCLS, et al. Internações por intoxicações medicamentosas em crianças menores de cinco anos no Brasil, 2003-2012. Epidemiologia e Serviços de Saúde, 2017; 26: 771-782.

3. SILVA WB, et al. Epidemiological study of elderly people affected by drug intoxication in the state of Paraíba: a portrait of a decade. Research, Society and Development, 2021; 10(10): e176101018563.

4. XAVIER LA, et al. Intoxicações exógenas por agentes tóxicos em crianças em município do norte de Minas Gerais. Revista Eletrônica Acervo Saúde, 2018; (5): S481-S485. 


\title{
PERFIL EPIDEMIOLÓGICO DE ACOMETIDOS POR INTOXICAÇÃO PELO USO DE COSMÉTICOS NO ESTADO DA PARAÍBA
}

\author{
Wagner Bernardo da Silva ${ }^{1}$ \\ Beatriz Maria da Conceição Murilo ${ }^{1}$ \\ Cassiano Augusto Oliveira da Silva ${ }^{2}$
}

1. Universidade Federal de Campina Grande (UFCG), Cuité - PB.

2. Universidade Federal da Paraíba (UFPB), João Pessoa - PB.

Palavras-chave: Cosmetovigilância, Reações adversas, Epidemiologia.

\section{INTRODUÇÃO}

A intoxicação exógena é a união de sinais e sintomas devido a uma resposta fisiológica posterior ao contato com um agente tóxico, que podem ser alimentos, medicamentos, produtos domissanitários, medicamentos e cosméticos (SILVA ESF, et al., 2020). De certa maneira, os cosméticos comumente não são relacionados a danos sérios a saúde, no entanto isso não quer dizer que são 100\% seguros (SOUSA FDA, et al., 2021). Dessa forma, uma caracterização das pessoas envolvidas com acidentes com cosméticos pode ajudar os profissionais entendam como evitar esse tipo de caso (MIRANDA CCS, et al., 2021).

\section{OBJETIVO}

Identificar e descrever o perfil epidemiológico de pessoas acometidas por intoxicação por cosméticos no estado da Paraíba, em ambos os sexos, faixas etárias, raças e locais de residência, durante o período de 2010 a 2020.

\section{MÉTODO}

Trata-se de um estudo epidemiológico, retrospectivo, analítico, quantitativo e documental, os dados foram coletados no Departamento de Informática do Sistema Único de Saúde (DATASUS) (SILVA WB, et al., 2021; BRASIL, 2021). Foram analisadas variáveis como ano, sexo, faixa etária, raça, zona de residência, circunstâncias da intoxicação e evolução dos casos. Este estudo é feito com dados secundários públicos e assim dispensa a autorização do Comitê de Ética em Pesquisa (CEP).

\section{RESULTADOS}

Foram confirmados 200 casos, entre 2010 e 2019. 2019 teve mais casos (20\%), 2015 (12,5\%), 2018, 2016 e 2015 (12\%), 2014 (7,5\%), 2016 (7\%), 2020 (4\%), 2010 (1\%) e 2010 (2\%). As mulheres tiverem 75,5\% e os homens $24,5 \%$. A faixa etária de 20 a 59 anos foi prevalente (45,5\%), seguido de 0 a $9(41 \%), 10$ a 19 (8\%) e 60 ou $+(5,5 \%)$. A raça parda teve $49 \%$, branca $25,5 \%$, preta $2,5 \%$ e $23 \%$ ignorados. A zona urbana teve 
$89 \%$ e rural $7,5 \%$ e 3,5\% ignorados. Segundo a circunstância, $46,5 \%$ acidental, $31,5 \%$ habitual, $17,5 \%$ outros e $4,5 \%$ tentativa de suicídio. $85,5 \%$ foram curados e $14,5 \%$ ignorados.

\section{CONSIDERAÇÕES FINAIS}

Os cosméticos podem vir a causar danos à saúde e devem ser usados com precauções e cuidado. Dessa forma espera-se que os dados obtidos nessa pesquisa possam servir como base para criar políticas públicas voltadas ao uso racional de cosméticos para a população mais vulnerável.

\section{REFERÊNCIAS}

1. BRASIL, Departamento de Informática do SUS (DATASUS). 2020. Informações Epidemiológicas e Morbilidade: banco de dados. Disponível em: https://datasus.saude.gov.br/informacoes-de-saude-tabnet/. Acessado em: 1 de Outubro 2021.

2. MIRANDA CCS, et al. Intoxicação por cosméticos: uma caracterização epidemiológica. Revista de Casos e Consultoria, 2021; 1: e25400.

3. SILVA ESF, et al. Perfil epidemiológico das intoxicações exógenas no Piauí nos anos de 2013 a 2017. Revista Eletrônica Acervo Saúde, 2020; 44: e998.

4. SILVA WB, et al. Epidemiological study of elderly people affected by drug intoxication in the state of Paraíba: a portrait of a decade. Research, Society and Development, 2021; 10(10): e176101018563.

5. SOUSA FDA. et al. Toxicologia dos cosméticos: avaliação dos riscos que os produtos capilares trazem à saúde. Visão Acadêmica, 2020; 20: 78-93. 


\title{
TUBERCULOSE NA CIDADE DE SOUSA-PB, ENTRE 2015 E 2020
}

\author{
Wagner Bernardo da Silva ${ }^{1}$ \\ Beatriz Maria da Conceição Murilo ${ }^{1}$ \\ Cassiano Augusto Oliveira da Silva ${ }^{2}$
}

1. Universidade Federal de Campina Grande (UFCG), Cuité - PB.

2. Universidade Federal da Paraíba (UFPB), João Pessoa - PB.

Palavras-chave: Epidemiologia, Mycobacterium tubercolosis, Saúde Pública.

\section{INTRODUÇÃO}

A tuberculose (TB) é uma doença infectocontagiosa causada pela bactéria Mycobacterium tuberculosis e estima-se que no Brasil, a cada ano 70 mil pessoas são infectadas e 4,5 mil veem a óbito (BRASIL, 2021). A TB é caracterizada por lesões granulomatosas, principalmente, nos pulmões, apesar de acontecer em outros órgãos (formas extrapulmonares), e se não tratada pode levar a morte do indivíduo (SILVA WB e ANDRADE JUNIOR FP, 2020). Apesar de ser uma doença tratável e de fácil diagnóstico a tuberculose ainda é um problema de saúde pública mundial e nacional, visto que em 2019 no Brasil foram diagnosticados 73.846 novos casos (BRASIL, 2020; SOUZA AC, et al., 2019).

\section{OBJETIVO}

Delinear o perfil epidemiológico de pessoas acometidas por tuberculose na cidade de Sousa-PB, durante o período de 2015 a 2020. Visto que, há uma ausência de estudos epidemiológicos realizados em diversos municípios do nordeste brasileiro.

\section{MÉTODO}

Trata-se de um estudo epidemiológico, ecológico, retrospectivo, analítico, quantitativo e documental, os dados foram coletados no Departamento de Informática do Sistema Único de Saúde (DATASUS) (SILVA WB, et al., 2021; BRASIL, 2021). Analisaram-se variáveis como ano, sexo, faixa etária, raça, zona de residência e evolução dos casos. Devido o estudo ser feito com dados secundários públicos dispensa-se a autorização do Comitê de Ética em Pesquisa (CEP).

\section{RESULTADOS}

Foram registrados 123 casos de tuberculose, entre 2015 a 2020. 2015 teve mais casos (22,8\%), 2020 e 2019 (16,3\%), 2018 (15,4\%), 2017 e 2016 (14,6\%). Os homens foram mais acometidos (78,9\%) em relação as mulheres $(21,1 \%)$. A faixa etária de 20 a 59 anos foi prevalente $(75,6 \%)$, seguido de 60 ou $+(21,9 \%), 15$ a 19 anos (1,6\%) e 1 a 4 anos (0,8\%). A raça parda teve $51,2 \%$, seguida da branca $34,1 \%$, preta $13,8 \%$ e 
amarela $0,8 \%$ ignorados. A zona urbana teve $95,9 \%$ dos casos e a zona rural $4,1 \%$. No tocante a evolução dos casos $57,7 \%$ foram curados, $4,8 \%$ tiveram óbito por TB e outras destinos $37,5 \%$.

\section{CONSIDERAÇÕES FINAIS}

Os dados obtidos no presente estudo, podem servir para guiar o desenvolvimento de políticas públicas direcionada a população mais susceptível e assim contribuir com a diminuição dos casos, além de permitir uma maior promoção e proteção da saúde frente a tuberculose no município de Sousa-PB.

\section{REFERÊNCIAS}

1. BRASIL. Departamento de Informática do SUS (DATASUS). 2020. Informações Epidemiológicas e Morbilidade: banco de dados. Disponível em: https://datasus.saude.gov.br/informacoes-de-saude-tabnet/. Acessado em: 9 de outubro de 2021.

2. BRASIL. Ministério da Saúde. Tuberculose: o que é, causas, sintomas, tratamento, diagnóstico e prevenção. 2021. Disponível em: http://antigo.saude.gov.br/saude-de-a-z/tuberculose. Acessado em: 10 de outubro de 2021.

3. BRASIL, Ministério da Saúde. Secretaria de Vigilância em Saúde. Boletim Epidemiológico Especial. 2020. Disponível em: https://www.saude.gov.br/images/pdf/2020/marco/24/Boletim-tuberculose-2020-marcas-1-.pdf. Acessado em: 10 de outubro de 2021.

4. SILVA WB, ANDRADE JÚNIOR FP. Perfil epidemiológico de acometidos por tuberculose em Catolé do Rocha-PB, durante os anos de 2008 a 2018. Journal of Medicine and Health Promotion, 2020; 5(3): 9099.

5. SILVA WB, et al. Epidemiological study of elderly people affected by drug intoxication in the state of Paraíba: a portrait of a decade. Research, Society and Development, 2021; 10(10): e176101018563.

6. SOUZA AC, et al. Cenário epidemiológico da tuberculose no município de Sobral (CE) entre os anos de 2013 e 2017. Revista Eletrônica Acervo Saúde, 2019; (23): e445. 


\title{
MÚSICA COMO ESTRATÉGIA DE PROMOÇÃO EM SAÚDE: PERSPECTIVAS DE FAMILIARES QUE AGUARDAM NOTÍCIAS NA SALA DE ESPERA DE UM HOSPITAL
}

\author{
Richard Augusto Thomann Beckert ${ }^{1}$ \\ Jeane Barros de Souza ${ }^{1}$ \\ Andreina Carla de Almeida ${ }^{1}$ \\ Ricardo Demeneck Reinaldo ${ }^{1}$ \\ Débora Ceccatto ${ }^{1}$
}

1. Universidade Federal da Fronteira Sul (UFFS), Chapecó - SC.

Palavras-chave: Promoção da saúde, Música, Enfermagem.

\section{INTRODUÇÃO}

O conceito ampliado de saúde e os determinantes que a afetam são pontos essenciais para a produção do cuidado e estratégias de promoção da saúde podem contemplar tais conceitos (FAGUNDES AS e WÜNSCH DS, 2021). Nesta perspectiva, emergiu o programa de extensão Musicagem, do Curso de Enfermagem de uma Universidade Federal de Santa Catarina, o qual realiza intervenções musicais em dois hospitais públicos, tendo a música como tecnologia para promover a saúde de pessoas hospitalizadas, seus familiares e equipe profissional. Cabe salientar que o processo de hospitalização é desgastante devido ao clima de tensão e medo, além de ser uma mudança drástica de rotina (SILVA GH e PIOVESAN JC, 2019).

\section{OBJETIVO}

Compartilhar as perspectivas dos familiares que aguardam notícias de seus entes queridos, sobre o uso da música como intervenção de promoção da saúde na sala de espera de um hospital.

\section{MÉTODO}

Estudo descritivo, exploratório, de abordagem qualitativa. Contou com a participação de 15 familiares que estavam na sala de espera de um hospital público da região Oeste de Santa Catarina. Realizou-se a intervenção musical e, posteriormente, iniciou-se as entrevistas semiestruturadas, que foram gravadas, transcritas e analisadas segundo análise de conteúdo temática. Aprovação do Comitê de Ética em Pesquisa (CEP), sob número CAAE: 50504521.4.0000.5564.

\section{RESULTADOS}

Os entrevistados revelaram sentimentos negativos de angústia, ansiedade, preocupação, além de prejuízos na vida afetiva e profissional devido à espera no hospital. Também, foi apontado que a música é 
capaz de despertar sentimentos como a alegria, a melhora do humor, a paz, a tranquilidade, a emoção, além de distrair um pouco acerca da realidade desgastante do ambiente hospitalar, trazendo alívio da tensão e do estresse e sensação de segurança. Por conseguinte, a música contribui para amenizar os desafios da hospitalização, propiciando sentimentos positivos e quebrando a monotonia da sala de espera (SOUZA JB, et al., 2020).

\section{CONSIDERAÇÕES FINAIS}

É premente o desenvolvimento de ações promotoras da saúde no hospital, como o programa Musicagem realiza, pois além de contribuírem para uma formação mais holística e humanizada dos acadêmicos de enfermagem envolvidos, também propiciam bem-estar às pessoas hospitalizadas, bem como aos seus familiares, sobretudo para aqueles que aguardam exaustivamente por notícias em uma sala de espera.

\section{REFERÊNCIAS}

1. FAGUNDES AS, WÜNSCH DS. Processos de trabalho coletivo em saúde e o trabalho do/a assistente social: os fios (in)visíveis que materializam o conceito ampliado de saúde. Serviço Social e Saúde, 2021; 19.

2. SILVA GH, PIOVESAN JC. Música e Alegria: uma prática humanizada para crianças hospitalizadas. Revista Vivências, 2019; 16(30): 127-144.

3. SOUZA JB, et al. Atuação na oncologia pediátrica e a música como promotora de saúde: significados para os profissionais. Revista de Enfermagem do Centro-Oeste Mineiro, 2020; 10: 1-9. 


\title{
ESTUDO EPIDEMIOLÓGICO DE SÍFILIS GESTACIONAL NO MUNICÍPIO DE ABAETETUBA-PARÁ
}

\author{
Nathália Lorena Pinheiro Veras ${ }^{1}$ \\ Patricia da Silva Ferreira ${ }^{1}$ \\ Ana Beatriz Mendes Furtado ${ }^{1}$ \\ Letícia Gomes de Oliveira²
}

1. Universidade da Amazônia (UNAMA), Belém - PA.

2. Faculdade Paraense de Ensino (FAPEN), Belém - PA.

Palavras-chave: Epidemiologia, Sífilis, Gestantes.

\section{INTRODUÇÃO}

Sífilis é uma doença infectocontagiosa sistêmica, de transmissão predominantemente por via sexual e vertical, causada por uma bactéria chamada Treponema pallidum (OLIVEIRA KTA, et al., 2019). Trata-se de uma infecção sexualmente transmissível (IST) e representa um grande problema de saúde pública que possui um aumento significativo e preocupante, e está associada a complicações perinatais como a sífilis congênita, transmitindo durante a gestação, parto ou amamentação (PADOVANI C, et al., 2018). A sífilis é uma doença que possui fácil diagnóstico e um tratamento de baixo custo, logo, é necessária intervenção imediata para reduzir as possibilidades de complicações gestacionais e da transmissão para o feto (CAMPOS CO e CAMPOS CO, 2020).

\section{OBJETIVO}

Analisar o perfil epidemiológico de gestantes com sífilis no município de Abaetetuba no estado do Pará notificados no período de 2016 a 2020, de acordo com as variáveis: idade gestacional, faixa etária e escolaridade.

\section{MÉTODO}

Trata-se de um estudo epidemiológico, do tipo transversal, de caráter descritivo, onde analisou-se o perfil de gestantes portadoras de sífilis no período de 2016 a 2020 através dos dados do Sistema Nacional de Agravos de Notificação (SINAN), disponíveis no Departamento em Informática do SUS (DATASUS). O acesso a esses dados não precisa de aprovação do comitê de ética, pois trata-se de dados secundários com informações de acesso público.

\section{RESULTADOS}


Foram registrados 62 casos de sífilis em gestantes no período de 2016 a 2020, sendo o maior número de casos em 2019. De acordo com o período gestacional 38,7\% das mulheres encontrou-se com a doença no terceiro trimestre da gestação, sendo um período de maior risco. A faixa etária de 20 a 29 anos foi a mais frequente ao acometimento pela enfermidade, com um total de 32 casos. Com relação a escolaridade, encontrou-se um total de zero mulheres com nível superior, sendo o maior nível escolar encontrado de $5^{\underline{a}}$ a $8^{\mathrm{a}}$ séries do ensino fundamental, podendo analisar que tal variável implica na importância do ensino na prevenção a IST.

\section{CONSIDERAÇÕES FINAIS}

Portanto, é importante pesquisar sífilis no pré-natal pois, diagnóstico e tratamento precoce, apresentam diminuição das complicações e dos riscos de transmissão vertical. A baixa escolaridade observada nas gestantes, é um dado relevante nas políticas públicas de saúde para o controle da doença. Campanhas educacionais de saúde para prevenção, triagem no pré-natal e a realização de testes para detectar a IST são medidas importantes para redução da incidência de sífilis.

\section{REFERÊNCIAS}

1. CAMPOS CO, CAMPOS CO. Abordagem diagnóstica e terapêutica da sífilis gestacional e congênita: revisão narrativa. Revista Eletrônica Acervo Saúde, 2020; (53): e3786.

2. OLIVEIRA KTA, et al. Caracterização da sífilis em gestantes no município de Codó - Maranhão no período de 2012 a 2017. Revista Eletrônica Acervo Saúde, 2019; (19): e236.

3. PADOVANI C, et al. Syphilis in during pregnancy: association of maternal and perinatal characteristics in a region of southern Brazil. Revista Latino-Americana de Enfermagem, 2018; (26): e3019. 


\title{
ANÁLISE EPIDEMIOLÓGICA E O PAPEL DO ENFERMEIRO NAS OCORRÊNCIAS DE ESCORPIONISMO NO MUNICÍPIO DE BELÉM-PA
}

\author{
Amanda Monteiro Veloso ${ }^{1}$ \\ Isabelle Cristine Cardoso do Rosário ${ }^{1}$ \\ Leonardo de Paula Vieira Martinez ${ }^{1}$ \\ Andréa do Socorro Campos de Araújo Sousa ${ }^{1}$
}

1. Universidade Federal do Pará (UFPA), Belém - PA.

Palavras-chave: Escorpionismo, Enfermeiro, Belém.

\section{INTRODUÇÃO}

Caracteriza-se escorpionismo como a intoxicação decorrente da inoculação da peçonha do escorpião no organismo humano (CARVALHO DR e FRANCO-ASSIS GA, 2017). No Brasil, foram descritas 131 espécies de escorpiões, das quais o Tityus obscurus, T. silvetris e T. metuendus se destacam por elevada importância médica na região Norte (ARAÚJO KAM, et al., 2017).

Assim, faz-se indispensável pleitear acerca desse agravo em saúde no município de Belém do Pará, dada a incidência dos casos anualmente. Portanto, a assistência requer que os enfermeiros estejam aptos a prestarem auxílio às vítimas e capacitados a realizarem atividades educacionais em saúde que potencializem o cuidado (COSTA DA, et al., 2020; SILVA EXS, et al., 2020).

\section{OBJETIVO}

Avaliar a epidemiologia dos acidentes escorpiônicos no município de Belém do Pará, e correlacionar com a importância da atuação do enfermeiro na assistência e educação em saúde referentes à problemática abordada.

\section{MÉTODO}

Estudo quanti-qualitativo acerca da epidemiologia do escorpionismo em Belém, entre os anos de 2016 a 2020. Os dados foram obtidos dos relatórios do Centro de Informações Toxicológicas (CIT) Belém em agosto de 2021 e de produções com enfoque no proceder do enfermeiro diante dessa problemática em saúde, consultadas e extraídas das bases LILACS e MEDLINE, sem apreciação do Comitê de Ética em Pesquisa, pois as informações são de domínio público.

\section{RESULTADOS}


No recorte temporal, foram notificadas 145 ocorrências de escorpionismo em Belém. Sincronicamente, a distribuição dos casos entre as zonas de acontecimentos dos acidentes evidencia disparidade, haja vista que cerca de $74 \%$ se sucederam na área urbana, decorrente da assolação do habitat dos escorpiões, crescimento desordenado das cidades e de moradias insalubres.

Portanto, entende-se como imprescindível a habilitação dos enfermeiros, já que eles devem ser capazes de oferecerem atendimentos ágeis e excelentes às vítimas, em consonância ao manual do Ministério da Saúde, assim como, de maneira cortês, desmistificar os saberes do senso comum, pois ações não recomendadas têm elevado potencial de agravar o quadro dos acidentados.

\section{CONSIDERAÇÕES FINAIS}

Em vista disso, infere-se que o escorpionismo é um dilema de saúde pública pungente no município de Belém do Pará, principalmente nas áreas urbanas da capital, as quais, por diversos fatores, propiciam a proliferação de escorpiões nessas localidades. Continuadamente, os enfermeiros necessitam ser profissionais capacitados para prestarem assistência e terapêutica de qualidade às vítimas, além de atuarem com propriedade em ações de promoção e prevenção aos acidentes envolvendo escorpiões.

\section{REFERÊNCIAS}

1. ARAÚJO KAM, et al. Epidemiological study of scorpions stings in the Rio Grande do Norte State, Northeastern Brazil. Revista do Instituto de Medicina Tropical de São Paulo, 2017; 59: e58.

2. BRASIL. Relatório Anual de Notificações. 2020. Disponível em: https://www.gov.br/ebserh/pt-br/hospitaisuniversitarios/regiao-norte/chu-ufpa/saude/centro-de-informacoes-toxicologicas-cit. Acessado em: 26 de agosto de 2020.

3. CARVALHO DR, FRANCO-ASSIS GA. Acidente com escorpiões no município de Barreiras, Bahia, Brasil. Revista Baiana de Saúde Pública, 2017; 40(3): 729-740.

4. COSTA DA, et al. Enfermagem e a educação em saúde. Revista Científica da Escola Estadual de Saúde Pública do Goiás "Cândido Santiago". 2020; 6(3): e6000012.

5. SILVA EXS, et al. Cuidados de enfermagem no atendimento às vítimas de picadas escorpiônicas na atenção primária à saúde. Revista Cogitare Enfermagem, 2020; 25: e67322. 


\title{
PERFIL EPIDEMIOLÓGICO DA MORTALIDADE MATERNA POR SÍNDROME HIPERTENSIVA NA GESTAÇÃO NO BRASIL
}

\author{
Geice Silva Ribeiro ${ }^{1}$ \\ Ivana Pereira de Oliveira ${ }^{1}$ \\ Deuziane de Jesus Sousa Luz ${ }^{1}$ \\ Thamiris Soares Feitosa ${ }^{1}$ \\ Laiane de Paula Aquino Oliveira Carvalho ${ }^{1}$
}

1. Universidade do Estado do Pará (UEPA), Conceição do Araguaia - PA.

Palavras-chave: Mortalidade materna, Hipertensão, Enfermagem.

\section{INTRODUÇÃO}

A Síndrome Hipertensiva da Gestação (SHG) ocorre em cerca de 2 a $8 \%$ de todas as gestações (ACOG, 2020). É uma patologia que merece grande atenção dos profissionais de saúde, pois segundo a Organização Mundial de Saúde (OMS) está relacionada a uma das principais causas de mortalidade materna e fetal no Brasil e no mundo (COSTA ES, et al., 2021). Ela surge após a $20^{a}$ semana de gestação, sendo mais frequente no terceiro trimestre, podendo se prolongar até o puerpério. Sua apresentação clínica é sob a forma de: préeclâmpsia, eclâmpsia, hipertensão gestacional e pré-eclâmpsia sobreposta à hipertensão crônica (ABRAHÃO ACM, et al., 2020).

\section{OBJETIVO}

Avaliar e apresentar os dados epidemiológicos sobre a mortalidade materna no Brasil ocasionada por SHG na gravidez, no parto e puerpério. Entre os períodos de 2009 a 2019, por meio do Departamento de Informática do Sistema Único de Saúde (DATASUS).

\section{MÉTODO}

Trata-se de um estudo descritivo de caráter quantitativo. As informações foram extraídas pelo DATASUS. Posteriormente, os dados foram organizados em planilhas e analisados, considerando as seguintes variáveis: número de óbitos maternos, faixa etária, estado civil, raça, escolaridade e causa básica do óbito. $\mathrm{O}$ acesso a esses dados não necessita de aprovação do comitê de ética, uma vez que são de domínio público, fundamentada na Lei no 12.527 de 2011.

\section{RESULTADOS}


No intervalo estudado, o Brasil registrou cerca de 18.569 casos de óbitos maternos, sendo que 3.920 (21\%) desses óbitos estão relacionados a SHG. Verificou-se que $92 \%$ dessas mortes foram ocasionadas por causa obstétrica direta. A faixa etária mais acometida foi de 30 a 39 anos $(39,6 \%)$, seguida pela faixa de 20 a 29 anos (37,6\%). Quanto à raça, $(53,6 \%)$ dos registros são de pessoas pardas. O nível de escolaridade mais prevalente foi em mulheres com 8 a 11 anos de estudo concluídos. Sobre estado civil dessas mulheres $(45,7 \%)$ eram solteiras. As principais causas de óbito materno foram por eclâmpsia (44,5\%) seguida por préeclâmpsia correspondendo a $(33,1 \%)$ dos óbitos.

\section{CONSIDERAÇÕES FINAIS}

Os altos índices de óbitos maternos relacionados as síndromes hipertensivas na gestação é um importante problema de saúde pública, sendo necessário que seja realizados estudos e ações que promovam a diminuição dessas mortes. Uma assistência de saúde qualificada principalmente durante o pré-natal é a base de uma gestação saudável e minimização de possíveis complicações relacionadas ao ciclo gravídico.

\section{REFERÊNCIAS}

1. ABRAHÃO ACM, et al. Atuação do enfermeiro a pacientes portadoras de Síndrome Hipertensiva Específica da Gestação. Revista Cientifica da Escola Estadual Saúde Pública Goiás "Candido Santiago". 2020; 06(01): 51-63.

2. ACOG. Gestational Hypertension and Preeclampsia: ACOG Practice Bulletin, Number 222. Obstet Gynecol. 2020; 135(6): e237-e260.

3. BRASIL. Ministério da Saúde. Bancos de dados do Sistema Único de Saúde - DATASUS. 2021. Disponível em: https://datasus.saude.gov.br/informacoes-de-saude-tabnet/ Acesso em 20 de setembro de 2021.

4. COSTA ES, et al. As principais causas de morte maternas entre mulheres no Brasil. Revista Eletrônica Acervo Saúde, 2021; 13(1): e5826. 
RESUMO SIMPLES: Estudo Original

\title{
PANORAMA DAS INTERNAÇÕES E ÓBITOS POR DENGUE NO TERRITÓRIO BRASILEIRO
}

\author{
Gabriel Gonçalves Batista dos Reis ${ }^{1}$ \\ Júlia Gonçalves Batista dos Reis ${ }^{1}$ \\ Tatiana Cibelle de Souza Silva ${ }^{1}$ \\ Marconi José Soares Chaves ${ }^{1}$ \\ Everton da Silva Batista ${ }^{1}$
}

1. Centro Universitário FTC (UNIFTC), Salvador - BA.

Palavras-chave: Dengue, Internação hospitalar, Mortalidade.

\section{INTRODUÇÃO}

A Dengue é a doença transmitida por artrópodes mais prevalente no mundo, representando um enorme desafio para a saúde pública, principalmente no território brasileiro (RAMOS ALBM, et al., 2021). Atualmente, - Brasil é o país das Américas com maior prevalência de casos de dengue, sendo responsável, aproximadamente, por $70 \%$ das notificações (BARROSO ILD, et al., 2020).

Infecções por dengue podem evoluir com gravidade, ocasionando complicações hemorrágicas e óbito, principalmente quando acometem pacientes com comorbidades prévias (OSSA DPS, et al., 2019). Dessa forma, estudos epidemiológicos, voltados aos casos de dengue, são importantes por fornecerem documentação atual para fomentar o desenvolvimento de políticas públicas eficazes.

\section{OBJETIVO}

Avaliar o número de internações e óbitos decorrentes da infecção causada pelo vírus da dengue, notificados no Brasil e nas cinco regiões brasileiras, descrevendo as diferenças regionais, entre janeiro de 2016 e dezembro de 2020.

\section{MÉTODO}

Estudo epidemiológico, retrospectivo, de caráter descritivo, sobre internações e óbitos por dengue no Brasil e regiões, realizado com base nos casos notificados no Sistema de Informações Hospitalares (SIH/DATASUS), entre janeiro de 2016 e dezembro de 2020. O presente estudo dispensa apreciação pelo Comitê de Ética em Pesquisa (CEP), pois utiliza dados gratuitos e de domínio público, sem possibilidade de identificação individual.

\section{RESULTADOS}


No período analisado foram notificadas 57.300.247 internações e 2.608.144 óbitos por dengue no Brasil, representando uma taxa de mortalidade hospitalar de 4,55. Avaliando as regiões, destacam-se Sudeste, Nordeste e Sul, tanto nas internações $(39,35 \%, 26,68 \%, 17,71 \%$, respectivamente) quanto nos óbitos (46,78\%, 23,33\% e 17,89\%, na devida ordem).

A soma das internações e óbitos das regiões Norte e Centro-Oeste, representa apenas 16,25\% e 11,98\% do total, respectivamente. O cálculo da taxa de mortalidade hospitalar entre as regiões é de $5,41 \%$ (Sudeste), 4,59\% (Sul), 3,98\% (Nordeste), 3,75\% (Centro-Oeste) e 2,99\% (Norte). Percebe-se que a taxa de mortalidade hospitalar obtida no Sudeste e Sul do país, superam a porcentagem a nível nacional.

\section{CONSIDERAÇÕES FINAIS}

O elevado número de internamentos sustenta a importância do desenvolvimento de ações voltadas para prevenção de fatores de risco para a multiplicação do principal vetor da dengue, o Aedes aegypti, além da capacitação dos Agentes comunitários de saúde (ACS) e conscientização da população. O fato de algumas regiões possuírem taxa de mortalidade maior que a nacional, enfatiza a importância da detecção e tratamento precoce para prevenção do desenvolvimento de complicações.

\section{REFERÊNCIAS}

1. BARROSO ILD, et al. Um estudo sobre a prevalência da dengue no Brasil: Análise da literatura. Brazilian Journal of Development, 2020; 6(8): 61878-61883.

2. OSSA DPS, et al. Arbovírus circulantes no Brasil: fatores associados com a disseminação e estratégias terapêuticas. Revista Eletrônica Acervo Saúde, 2019; 33: e1067

3. RAMOS ALBM, et al. A eficiência das ações de combate à dengue na atenção primária à saúde no Brasil. Brazilian Journal of Health Review, 2021; 4(3): 10575-10595. 


\section{ÓBITOS POR AMEBÍASE NO BRASIL: UM ESTUDO DESCRITIVO}

Analice Barbosa Santos de Oliveira ${ }^{1}$

1. Centro Universitário FIEO, São Paulo - SP.

Palavras-chave: Amebíase, Óbito, Saneamento básico.

\section{INTRODUÇÃO}

A Amebíase é causada pelo protozoário parasita Entamoeba histolytica (EH). Ele secreta proteinases que dissolvem os tecidos, mata as células e invade a mucosa intestinal (STANLEY SL, 2003). Os trofozoítos do EH de forma desconhecida, se tornam virulentos e invasivos, causando disenteria amebiana e danos hepatocelulares (NAGARAJA S, ANKRI S, 2019). Há síndromes clínicas, que vão desde a disenteria clássica até a amebíase hepática. Existe dor abdominal, sensibilidade e diarreia das fezes aquosas, às vezes com sangue, são os sintomas predominantes da colite amebiana (SALLES JM, et al., 2007). A presença de enteroparasitas em alimentos consumidos aponta que as condições higiênico-sanitárias são insatisfatórias (SILVA J, et al., 2019).

\section{OBJETIVO}

Quantificar o número de óbitos ocorridos em todas as unidades federativas do Brasil decorrentes de amebíase de janeiro de 2008 a agosto de 2021 a partir de dados do Departamento de Informática do Sistema Único de Saúde (DATASUS).

\section{MÉTODO}

Trata-se de um estudo observacional descritivo de abordagem quantitativa e qualitativa, com coleta de informações através da Base de Dados do Sistema de Informações Hospitalares, do DATASUS, no período de janeiro de 2008 a agosto de 2021. Conforme Conselho Nacional de Saúde, os dados do DATASUS são considerados de domínio público, logo a avaliação do Comitê de Ética em Pesquisa não é necessária (Resolução CHS 03/07 /15).

\section{RESULTADOS}

Região norte (Acre $=1$, Amazonas $=3$, Pará $=1$, Tocantins $=3$ ). Na região nordeste (Maranhão $=13$, Piauí $=1$, Ceará $=6$, Paraíba $=58$, Pernambuco $=5$, Alagoas $=1$, Sergipe $=1$, Bahia $=18$ ), na região sudeste (Minas Gerais $=38$, Rio de janeiro $=6$, São Paulo $=14)$, na região sul (Paraná $=9$, Santa Catarina $=9$ e Rio Grande do Sul $=13$ ) e região Centro-Oeste (Mato Grosso $=2$, Goiás $=12$ e Distrito Federal $=1$. A Paraíba apresentou 58 casos, em segundo lugar, em Minas Gerais com 38 casos. Foram 215 casos de óbito em decorrência da amebíase no Brasil. 


\section{CONSIDERAÇÕES FINAIS}

O Rio Grande do Norte, Amapá, Rondônia, Roraima, Mato Grosso do Sul e Espírito Santo não apresentaram nenhum caso de óbito pela amebíase. A Paraíba com 58 casos, exige atenção ao estado. Conhecer os dados the permite a melhor tomada de decisão. A prevenção da doença está relacionada a condições adequadas de higiene. Sugere-se lavar as mãos após uso do banheiro e cozer alimentos e utilizar água de procedência.

\section{REFERÊNCIAS}

1. NAGARAJA S, ANKRI S. Target identification and intervention strategies against amebiasis. Drug Resist Updat. 2019; 44: 1-14.

2. SALLES JM et al. Invasive amebiasis: an update on diagnosis and management. Expert Rev Anti Infect Ther. 2007; 5(5): 893-901

3. STANLEY SL Jr. Amoebiasis. Lancet. 2003; 361(9362): 1025-34.

4. SILVA J, et al. Ocorrência de enteroparasitas em alface crespa (Lactuca sativa) de cultivo convencional comercializadas em supermercados e hortas comunitárias de Teresina, Piauí. Revista Eletrônica Acervo Saúde. 2019, 11(17): e1728. 


\title{
AVALIAÇÃO DA ATIVIDADE DE COMPONENTES HIDROFÍLICOS DO EXTRATO DE FOLHAS DE L. SIBIRICUS NA RESOLUÇÃO DE FERIDAS CUTÂNEAS EXPERIMENTAIS EM RATOS WISTAR
}

\author{
Ghabriel Luiz Bellotto ${ }^{1}$ \\ Ériky Fernandes Guimarães Silva ${ }^{1}$ \\ Marcelo de Oliveira Machado ${ }^{1}$ \\ Matheus Bertolini Coutinho ${ }^{1}$ \\ Rafael Messias Luiz ${ }^{1}$ \\ Kádima Nayara Teixeira ${ }^{1}$
}

1. Universidade Federal do Paraná (UFPR), Toledo - PR.

Palavras-chave: Cicatrização, Ferimentos, Fitoterapia.

\section{INTRODUÇÃO}

Plantas medicinais e seus extratos são utilizados na cicatrização de feridas pela humanidade desde a antiguidade, sendo um importante método terapêutico de regeneração tecidual (RAMALHO MP, et al., 2018). O processo de cicatrização é dividido em três etapas: fase inflamatória, proliferativa e remodelação, que, na prática, se sobrepõem (LIMA JUNIOR EM et al., 2018).

No Brasil, ao menos 3\% da população apresenta algum tipo de perda da integridade da pele, ocasionando, além de danos físicos, prejuízos psicológicos (OLIVEIRA LSB, et al., 2020). Assim, este estudo pretende analisar o extrato aquoso da planta Leonurus sibiricus (rubim), que segundo a sabedoria popular possui atividades cicatrizantes e anti-inflamatórias, podendo agir como opção terapêutica na resolução de feridas.

\section{OBJETIVO}

Avaliar e mensurar a possível atividade adjuvante, in vivo, de componentes do extrato aquoso das folhas (EAF) do rubim (L. sibiricus) no processo de cicatrização e resolução de feridas cutâneas abertas confeccionadas em modelo experimental murino.

\section{MÉTODO}

Utilizaram-se 48 Ratos Wistar divididos em 3 grupos. Os animais foram anestesiados e realizou-se ferida cutânea dorsal (2x2cm) (CEUA/UFPR - Protocolo no 34/2020). Foram tratados diariamente com Alginato de sódio (AS) $5 \%$ (controle negativo), EAF 10\% + AS 5\% ou Dexpantenol $42 \mathrm{mg} / \mathrm{g}$ (controle positivo). Nos dias 3 , 7, 14 e 21 as feridas foram medidas (paquímetro, programa Image $(\mathbb{R})$ e avaliadas quanto às bordas, edema e necrose. $O$ experimento foi feito em duplicata. 


\section{RESULTADOS}

Em termos de área média, foram encontrados nos grupos Controle negativo, EAF e Controle positivo, respectivamente, os valores (cm2): Dia 3: 5,641; 5,679; 7,645; Dia 7: 3,105; 3,927; 5,401; Dia 14: 0,250; 0,318; 0,870; Dia 21: 0,013; 0,066; 0,050, observou-se redução total média da área da ferida de 99,76\%, $98,83 \%$ e $99,34 \%$ respectivamente.

A avaliação macroscópica das feridas nos grupos experimentais indicou melhor aspecto em relação à delimitação de bordas, necrose e edema nos animais tratados com o EAF. As feridas do controle negativo, apesar de resolvidas, apresentaram aspecto "repuxado", indicando pouca uniformidade tecidual.

\section{CONSIDERAÇÕES FINAIS}

Os componentes do extrato aquoso das folhas do rubim, apesar de não se mostrarem significativamente mais eficientes na redução da área média de feridas cutâneas experimentais, quando comparados com controles positivo e negativo, se mostraram eficaz na melhora do aspecto macroscópico dessas feridas ao longo do processo cicatricial.

\section{REFERÊNCIAS}

1. LIMA JÚNIOR, EM, et al. Elaboration, development, and installation of the first animal skin bank in Brazil for the treatment of burns and wounds. Revista Brasileira de Cirurgia Plástica (RBCP) - Brazilian Journal of Plastic Sugery, 2019; 34: 349-354.

2. OLIVEIRA, LSB, et al. Os efeitos da capacitação da equipe de enfermagem sobre avaliação e cuidado de pacientes com feridas. Brazilian Journal of Development, 2020; 6: 29707-29725.

3. RAMALHO MP, et al. Plantas Medicinais No Processo De Cicatrização De Feridas: Revisão De Literatura. Revista Expressão Católica Saúde, 2018; 3: 64. 


\section{REPERCUSSÕES CLÍNICAS E LABORATORIAIS DA INTERVENÇÃO COM SOLUÇÃO DE BICARBONATO DE SÓDIO EM PACIENTES PEDIÁTRICOS ACOMETIDOS PELA COVID-19}

Helen Gadelha ${ }^{1}$

Ana Karolina Santana dos Santos ${ }^{1}$

Carolina Pontes Soares ${ }^{1}$

1. Universidade Federal do Acre (UFAC), Rio Branco - AC.

Palavras-chave: COVID-19, Pediátricos, Bicarbonato de sódio.

\section{INTRODUÇÃO}

Em 2019 um novo vírus da família coronaviridae surgiu na China (MALIK YA, 2020). Causador da COVID19, os sintomas mais prevalentes são a febre, tosse e taquipnéia. Esse patógeno apresenta amplo espectro, acometendo desde crianças até idosos (LOTFI M, et al., 2020). Quanto às medidas terapêuticas, lacunas ainda existem (NAJA M, et al., 2020).

Partindo da relação entre o $\mathrm{pH}$ e a patogenia do vírus, destaca-se a necessidade de um meio ácido para que ocorra a fusão à membrana do hospedeiro (MIR MA, et al., 2020). Assim, essa pesquisa buscou avaliar a interação da alcalinização das vias áreas com a otimização do tratamento em pacientes pediátricos, diagnosticados com a COVID-19.

\section{OBJETIVO}

Avaliar o papel da intervenção com solução de bicarbonato de sódio, em uma concentração de 2 a $9 \%$, na modalidade tópica, como medida terapêutica em pacientes com até dezoito anos, acometidos pela COVID19.

\section{MÉTODO}

Trata-se de um ensaio clínico não randomizado. Foram realizadas intervenções com solução de bicarbonato de sódio em pacientes pediátricos, com diagnóstico fechado, na modalidade de nebulização. $O$ procedimento se estendia por uma semana, cerca de três vezes ao dia. Outrossim, os valores de saturação eram coletados antes e após as intervenções, para posterior análise. O estudo apresenta aprovação no Comitê de Ética em Pesquisa (CEP), sob o CAEE 35002720.3.1001.5010.

\section{RESULTADOS}

Foram incluídos no estudo dois adolescentes, com idade de 13 a 17 anos, e duas crianças na faixa etária de 2 a 5 anos. Os quatro pacientes eram do sexo masculino. Foi realizado o tratamento com a solução de bicarbonato de sódio, mediante a confirmação por teste para a COVID-19. Após a nebulização, os pacientes 
apresentaram melhora nos valores de saturação em relação aos pacientes que não receberam o protocolo de tratamento. $O$ desfecho dos indivíduos, que receberam a intervenção, foi a alta domiciliar, cerca de $24 \mathrm{~h}$ após o tratamento, enquanto os que não fizeram uso da solução foi a necessidade de transferência para o hospital de campanha.

\section{CONSIDERAÇÕES FINAIS}

O estudo almejou expandir as possíveis terapêuticas inalatórias para a COVID-19, em pacientes pediátricos. Espera-se, com estes resultados, ampliar o estudo para um número maior de participantes, em diferentes condições clínicas com ou sem comorbidades, para que seja analisado o papel da solução de bicarbonato de sódio, nas concentrações de 2 a 9\%, como uma das terapêuticas aplicadas no curso da COVID-19.

\section{REFERÊNCIAS}

1. LOTFI M, et al. COVID-19: Transmission, prevention, and potential therapeutic opportunities. Clinica chimica acta, 2020; 508: 254-266.

2. MALIK YA. Properties of coronavirus and SARS-CoV-2. The Malaysian journal of pathology, 2020; 42(1): 3-11.

3. MIR M. A, et al. Lysosomotropic properties of sodium bicarbonate and covid-19. Farmacia, 2020; 68(5): e771.

4. NAJA M, et al. COVID-19 infection in children and adolescents. British Journal of Hospital Medicine, 2020; 81(8): $1-10$. 


\title{
INFLUÊNCIA DA UTILIZAÇÃO EMPÍRICA DE EXTRATOS AQUOSOS DE LEONURUS SIBIRICUS NO PROCESSO DE CICATRIZAÇÃO DE FERIDAS CUTÂNEAS EXPERIMENTAIS
}

\author{
Rafaela Viana Vieira ${ }^{1}$ \\ Queren Hapuque Oliveira Alencar ${ }^{1}$ \\ Luana Pacheco de Souza ${ }^{2}$ \\ Gabrielle Caroline Peiter ${ }^{1}$ \\ Kádima Nayara Teixeira ${ }^{1}$
}

1. Universidade Federal do Paraná (UFPR), Toledo - PR.

2. Universidade Federal do Paraná (UFPR), Palotina - PR.

Palavras-chave: Cicatrização, Plantas medicinais, Rubim.

\section{INTRODUÇÃO}

A cicatrização é um processo complexo, envolve atividade celular, mediadores químicos e respostas vasculares. O mecanismo fisiológico de reparação passa por três fases básicas: inflamatória, proliferativa e remodelação (MACEDO JL, et al., 2017). Pesquisas recentes têm priorizado o desenvolvimento de materiais naturais e sintéticos que aumentem as taxas de cicatrização de feridas ou eliminem as possíveis complicações do processo, e essas ações têm sido comprovadas em inúmeras plantas, sendo relacionadas a diferentes compostos bioativos. No entanto, o uso de grande parte dessas plantas ainda permanece empírico, sem que suas hipóteses terapêuticas sejam comprovadas cientificamente, resultando em efeitos adversos ao paciente (RUDMAN MD, et al., 2018; SOUZA DR, et al., 2016).

\section{OBJETIVO}

Avaliar a interferência de componentes do extrato aquoso das raízes (EAR) e das flores (EAF) de Leonurus sibiricus (rubim) no processo macroscópico de cicatrização de feridas cutâneas abertas experimentais em modelo animal.

\section{MÉTODO}

Ratos Wistar foram submetidos à confecção de feridas 2x2cm (dorso) (CEUA/UFPR- protocolo n`34/2020), e tratados diariamente com Alginato de sódio (AS) 5\% (controle negativo), EAR 10\%+AS 5\% ou EAF 10\%+AS $5 \%$. Nos dias 3, 7, 14 e 21 as feridas foram medidas (paquímetro, fotodocumentação e ImageJ $\mathbb{R}$ ) e avaliadas quanto às bordas, edema, hemorragia e crosta. $O$ experimento foi feito em duplicata e as médias foram analisadas estatisticamente. 


\section{RESULTADOS}

Nos 21 dias de experimento, os grupos tratados com AS 5\%, EAR 10\% + AS 5\% e EAF $10 \%+$ AS 5\% apresentaram redução da área $\left(\mathrm{cm}^{2}\right)$ de ferida de, respectivamente, 100\%; 99,98\%; e 99,99\%. O aspecto da lesão, até a segunda eutanásia, para o controle negativo era de exulceração evidente, contração da ferida e bordas irregulares, com melhora da aparência apenas ao final do experimento. Os animais tratados com EAF $10 \%+$ AS $5 \%$ apresentaram feridas com bordas irregulares e maior processo de necrose, enquanto os animais tratados com EAR 10\% + AS 5\%, já a partir do 7을 dia, apresentavam feridas com bordas regulares e pouca necrose.

\section{CONSIDERAÇÕES FINAIS}

A avaliação do processo de cicatrização experimental não indicou atividade significativa dos componentes hidrofílicos das raízes e flores do rubim na redução da área das feridas. Entretanto, a avaliação macroscópica apontou maior uniformidade da área reparada nos animais tratados com EAR; enquanto o EAF parece ter aumentado a necrose e a formação de crosta, piorando a cicatrização. Uma possível explicação, seria a grande quantidade de mucilagem nas flores da planta.

\section{REFERÊNCIAS}

1. MACEDO JL, et al. Phytotherapy Effectiveness in the Process of Healing of Patients With Diabetes Mellitus Tissue Diagnosis. Revista e Ciência e Saberes - UniFacema, 2017; 3(1): 396-400.

2. RUDMAN MD, et al. Bromodomain and extraterminal domain-containing protein inhibition attenuates acute inflammation after spinal cord injury. Revista Experimental Neurology, 2018; 309: 181-192.

3. SOUZA DR, et al. Plantas medicinais: indicação de raizeiros para o tratamento de feridas. Revista Brasileira de Promoção à Saúde, 2016; 29(2): 197-203. 


\title{
INTERNAÇÕES POR AUTO-INTOXICAÇÃO COM ÁLCOOL EM ADOLESCENTES E ADULTOS DE TODO O BRASIL, NO PERÍODO DE 2018 A 2020: UM ESTUDO EPIDEMIOLÓGICO
}

\author{
Bárbara Ferraz Barbosa ${ }^{1}$ \\ Camila Bordignon Barbosa ${ }^{1}$ \\ Edmy Soza Figueroa ${ }^{2}$
}

1. Universidad de Aquino Bolivia (UDABOL), Santa Cruz de la Sierra - Bolívia.

2. Universidad Católica Boliviana "San Pablo" (UCB), Santa Cruz de La Sierra - Bolívia.

Palavras-chave: Intoxicação alcoólica, Intoxicação exógena, Estudo epidemiológico.

\section{INTRODUÇÃO}

O álcool é a principal substancia psicoativa de uso abusivo, acarretando danos, tanto morais quanto físicos, especialmente por sua acessibilidade (RAIZER PB, et al., 2020). A ingesta em quantidades suficientemente altas está associada a quadros de intoxicações, que provocam sintomas variáveis associados a alterações comportamentais como euforia, irritabilidade, melancolia e ideação suicida (LOUREIRO MC e ARAUJO LMB, 2018).

Determinantes sociais como idade e gênero mostram grande influência, visto que os adolescentes tendem a se expor mais aos riscos; embora seja proibida a venda de bebidas alcoólicas para menores de 18 anos, nos últimos anos houve um aumento de episódios de consumo excessivos na população jovem. (GABIRA FG, et al., 2019).

\section{OBJETIVO}

Verificar a prevalência de internações referentes à intoxicação voluntária com álcool em adolescentes e adultos de todo o Brasil, no período de 2018 a 2020, analisando variáveis relacionadas à faixa etária, sexo e óbitos.

\section{MÉTODO}

Estudo epidemiológico, transversal, descritivo, com dados do Sistema de Informações Hospitalares do SUS (SIH/SUS) do Departamento de Informação em Saúde (DATASUS), referentes a internações por autointoxicação com álcool em adolescentes e adultos no Brasil, entre os anos de 2018 a 2020. Critérios de inclusão: faixa etária (15 a 49 anos), sexo (masculino e feminino). Critérios de exclusão: faixa etária (<15 e/ou $>49$ anos). Variáveis utilizadas: número de óbitos.

\section{RESULTADOS}


Houve 1.354 internações por intoxicação voluntária com álcool em adolescentes e adultos de todo o Brasil, no período de 2018 a 2020. Ao analisar o país por regiões, observou-se que a região Norte apresentou o menor número de internações com 96 casos; o ano de maior incidência em todo o Brasil foi 2018, com 511 notificações. Dos pacientes internados, $79 \%$ eram do sexo masculino, sendo a população de 30 a 49 anos, maiormente acometida, com $72,6 \%$ dos casos; do total de pacientes internados por intoxicação, 34 pessoas evoluíram a óbito, $53 \%$ das vítimas com idades de 40 a 49 anos.

\section{CONSIDERAÇÕES FINAIS}

Verificou-se uma diminuição no número de casos ao longo dos anos, podendo refletir uma maior conscientização da população de risco (homens de 30 a 49 anos), maior resistência por tempo de uso, ou ao uso de outras substancias ilícitas associadas que potencializariam a ação neurossensorial do álcool, aumentando a subnotificação e/ou gerando uma dificuldade nas interpretações de resultados por consumo de drogas associadas.

\section{REFERÊNCIAS}

1. GABIRA FG, et al. Determinantes sociais do consumo de bebidas alcoólicas por adolescentes. Rev. Bras. Pesq. Saúde, 2019; 21(1): 156-178.

2. LOUREIRO MC, ARAUJO LMB. Alcool e comportamento suicida. Revista Brasileira de Neurologia e Psiquiatria, 2018; 22(1): 73-85.

3. RAIZER PB, et al. Políticas públicas sobre álcool no brasil e sua integração com o sus. Revista Internacional De Debates Da Administração \&Amp; Públicas - RIDAP, 2020; 5(1): 19-39. 


\section{ANÁLISE DA DISPENSAÇÃO DE MEDICAMENTOS PSICOTRÓPICOS EM UMA DROGARIA DA REDE PRIVADA NA CIDADE DE BELO HORIZONTE/MG}

Mariana Dias Lula ${ }^{1}$

Luiz Claudio Oliveira Alves de Souza ${ }^{1}$

1. Universidade Federal de Minas Gerais (UFMG), Belo Horizonte - MG.

Palavras-chave: Dispensação, Psicotrópicos, Drogaria.

\section{INTRODUÇÃO}

Os medicamentos psicotrópicos são substâncias capazes de modificar o comportamento, a percepção, os pensamentos e as emoções através de ações no sistema nervoso central (WHO, 2021). No Brasil, a dispensação desses medicamentos é regulamentada pela Portaria ํo344/98 SVS/MS, que estabelece os parâmetros para aquisição, venda, dispensação e prescrição dos medicamentos contidos em suas listas anexas. Um dos parâmetros exigidos pela Portaria no344/98 SVS/MS é o de que a prescrição dos medicamentos esteja de acordo com a Denominação Comum Brasileira (DCB) ou Denominação Comum Internacional (DCl) (BRASIL, 1998). O uso de medicamentos é essencial para o tratamento de diversas patologias e a prescrição adequada favorece a dispensação correta, maior segurança ao usuário e maior sucesso terapêutico (CAZAROTTI MLB, et al., 2019).

\section{OBJETIVO}

Avaliar as prescrições de medicamentos psicotrópicos dispensados em uma drogaria da rede privada situada na cidade de Belo Horizonte/MG, aviadas por profissionais qualificados e que estivessem listados nas listas B1 e C1 da Portaria nํ344/98 SVS/MS.

\section{MÉTODO}

Trata-se de um estudo quantitativo, com abordagem descritiva e documental. Avaliou-se todas as prescrições de medicamentos psicotrópicos contidos nas listas B1 e C1 da Portaria nํㅜ44/98, dispensados no mês de setembro de 2021, em uma drogaria da rede privada, na cidade de Belo Horizonte/MG. Os dados obtidos a partir das prescrições foram tabulados em uma planilha do programa Microsoft Excel 2013 para realização de análise estatística. Para análise, foram observados os parâmetros mínimos preconizados na Portaria, como: identificação do prescritor, nome completo e endereço do paciente, prescrição pela DCB ou $\mathrm{DCl}$, concentração, forma farmacêutica, quantidade e posologia.

\section{RESULTADOS}

Das 76 prescrições avaliadas, $69(90,8 \%)$ eram da lista C1 e sete $(9,2 \%)$ eram da lista B1. Todas as prescrições analisadas apresentavam a identificação do prescritor e o nome completo do paciente, sendo que 
2,6\% não apresentavam o endereço do paciente. Todas as prescrições apresentavam a concentração do medicamento e posologia, 34,3\% não continham a forma farmacêutica, 19,8\% não referiam a quantidade de medicamento a ser utilizado e $2,63 \%$ dos medicamentos prescritos não estavam de acordo com a DCB ou DCl. O medicamento mais prescrito da lista B1 foi o clonazepam $(57,1 \%)$ e da lista C1 foi o zolpidem (10,29\%).

\section{CONSIDERAÇÕES FINAIS}

O estudo evidencia a necessidade de adequação das prescrições de medicamentos psicotrópicos de acordo com os parâmetros estabelecidos na Portaria nำ344/98, visando a dispensação correta desses medicamentos em drogarias da rede privada, contribuindo para o uso racional dos medicamentos pela população.

\section{REFERÊNCIAS}

1. BRASIL. Ministério da Saúde/Secretaria de Vigilância em Saúde. Portaria no344/98 de 12 de maio de 1998. 1998. https://bvsms.saude.gov.br/bvs/saudelegis/svs/1998/prt0344_12_05_1998_rep.html. Acessado em: 17 de outubro de 2021.

2. CAZAROTTI MLB, et al. Psicotrópicos: Prescrições Médicas Dispensados em uma Drogaria no Município de Santa Inês - MA. Revista Eletrônica Acervo Científico, 2019; 2: e326.

3. WORLD HEALTH ORGANIZATION (WHO). Drugs (psychoactive). 2021. Disponível em: https://www.who.int/health-topics/drugs-psychoactive\#tab=tab_1. Acessado em: 06 de dezembro de 2021. 


\title{
CARACTERIZAÇÃO DO PERFIL EPIDEMIOLÓGICO DO REGISTRO DE INDIVÍDUOS COM EXCESSO DE PESO NO CONTEXTO DA PANDEMIA DE SARS-COV-2
}

\author{
Leonardo Gonçalves Guimarães de Castro ${ }^{1}$ \\ Anne Josiele de Lima Vital ${ }^{1}$ \\ Ingrid Werneck Linhares ${ }^{2}$ \\ Nathália Domingues Costa da Silva ${ }^{1}$
}

1. Pontifícia Universidade Católica de Minas Gerais (PUC Minas), Betim - MG.

2. Universidade Federal de Minas Gerais (UFMG), Belo Horizonte - MG.

Palavras-chave: Epidemiologia, Sars-Cov-2, Vigilância nutricional.

\section{INTRODUÇÃO}

A vigilância alimentar e nutricional tem importância no contexto da promoção à saúde em diferentes esferas de governo, com o intuito de apoiar o desenvolvimento de um país. A partir dela é possível coletar, monitorar e avaliar informações, como uma forma de se obter parâmetros mais fidedignos para apoiar a tomada de decisão e intervenções em Alimentação e Nutrição (BRASIL, 2015). Contudo, ao longo do ano de 2020, do período pandêmico de COVID-19, diante das novas recomendações que compreendem as dificuldades do cenário em questão, as ações em vigilância nutricional se mostram dificultadas (MENEZES RSM, et al., 2021).

\section{OBJETIVO}

Caracterizar os registros antropométricos no SISVAN (Sistema de Vigilância Alimentar e Nutricional), assim como dos diagnósticos nutricionais em município de médio porte da Região Metropolitana de Belo Horizonte em 2019 (pré-pandemia) e 2020 (período pandêmico Covid-19).

\section{MÉTODO}

Foram emitidos relatórios disponíveis no site do SISVAN para o município de Betim (BRASIL, 2021). Os dados foram comparados por diagnóstico nutricional, faixa etária, utilizando como referência as médias entre anos de 2019 e 2020. A análise estatística foi através do teste t de Student, com intervalo de confiança de $95 \%$ e $p<0,05$. Por serem dados secundários não foi necessária submissão ao Comitê de Ética em Pesquisa (CEP).

\section{RESULTADOS}

As medidas de distanciamento adotadas que tiveram como intuito o controle da Pandemia no ano de 2020 impactaram no acesso dos usuários ao serviço de saúde de vigilância alimentar e consequentemente no 
registro dos dados antropométricos do estado nutricional (peso corporal e medidas). Assim, houve redução no registro de acompanhamento de crianças, adolescentes e adultos com excesso de peso ( $p$ para registro de criança $=0,0 ; p$ para registro de adolescente $=0,00 ; p$ para registro de adulto $=0,00)$, exceto para idosos $(p$ para registro de idoso $=0,20$ ) do que houve redução no índice de excesso de peso durante período pandêmico da COVID-19.

\section{CONSIDERAÇÕES FINAIS}

Assim, nota-se que o impacto dos usuários ao serviço de saúde está atrelado ao período pandêmico, neste contexto, compreende-se que a implementação de ações mais específicas se faz necessário diante do cenário exposto, visto sua importância no acompanhamento e registro desses usuários.

\section{REFERÊNCIAS}

1. BRASIL. Ministério da Saúde. Marco de referência da vigilância alimentar e nutricional na atenção básica, 2015. https://bvsms.saude.gov.br/bvs/publicacoes/marco_referencia_vigilancia_alimentar.pdf. Acessado em: 25 de novembro de 2021.

2. BRASIL. Ministério da Saúde. Relatório de Acesso Público do Sistema de Vigilância Alimentar e Nutricional, 2021. Disponível em: https://sisaps.saude.gov.br/sisvan/relatoriopublico/index. Acessado em: 25 de novembro de 2021.

3. MENEZES SM, et al. Enfrentamento e operacionalização do trabalho na Atenção Primária à Saúde frente à pandemia de COVID 19. Revista Eletrônica Acervo Saúde, 2021, 13(9): e8750. 


\title{
PERFIL DE MORBIDADE ENTRE OS ADOLESCENTES EM MUNICÍPIOS DA REGIÃO EXTREMO-SUL DA BAHIA
}

\author{
João Gabriel de Moraes Pinheiro ${ }^{1}$ \\ Emanuella Gomes Maia ${ }^{1}$
}

1. Universidade Estadual de Santa Cruz (UESC), Ilhéus - BA.

Palavras-chave: Adolescente, Sistema de informação, Morbidade.

\section{INTRODUÇÃO}

A adolescência é uma fase da vida caracterizada por mudanças biológicas, psicológicas e sociais (FONSECA et al, 2013) que compreende, segundo a Organização Mundial de Saúde, a faixa etária 10 a 19 anos (BRASIL, 2017). Essas mudanças podem influenciar na adoção de comportamentos de riscos relacionados à saúde não só do indivíduo adolescente, mas também de toda sua rede de apoio, envolvendo familiares, amigos e sociedade (PEREIRA FNA e QUEIROZ BL, 2016). Nesse sentido, a assistência integral à saúde dos adolescentes demanda um planejamento estratégico e uma gestão de qualidade na rede de assistência, desde ações de promoção da saúde e prevenção de doenças, até tratamentos, reabilitações e hospitalizações (OPAS, 2018).

\section{OBJETIVO}

Analisar o perfil de morbidade entre os adolescentes das regiões de saúde de Porto Seguro (8 municípios) e Teixeira de Freitas (13 municípios), no Extremo-Sul da Bahia, entre 2010 e 2020.

\section{MÉTODO}

Trata-se de um estudo observacional, por meio da coleta de dados secundários no Sistema de Informações Hospitalares $(\mathrm{SIH})$ do Ministério da Saúde, sem a necessidade de apresentação no Comitê de Ética e Pesquisa. Os dados foram tabulados e analisados por meio da frequência absoluta e do coeficiente geral de morbidade (por 1.000 adolescentes). As variáveis de interesse foram: sexo, faixa etária, ano de notificação e a Classificação Estatística Internacional de Doenças.

\section{RESULTADOS}

No período analisado, observou-se uma redução dos coeficientes de morbidade (independente da causa) em ambas as regiões de saúde: Porto Seguro (de 43,2/1.000 em 2010 para 28,8/1000 em 2020) e Teixeira de Freitas (de 40,0/1000 em 2010 para 33,2/1000 em 2020). As principais causas de internações hospitalares entre os adolescentes dessas regiões duas regiões foram gravidez, parto e puerpério, lesões, envenenamentos e causas externas e algumas doenças infecciosas e parasitárias. Adolescentes mais velhos (15 - 19 anos) e do sexo feminino foram as principais vítimas de hospitalizações de ambas as regiões. 


\section{CONSIDERAÇÕES FINAIS}

Observa-se que as notificações de internação têm reduzido ao longo dos anos. Entretanto, milhares de adolescentes ainda são vítimas de diferentes causas de morbidade, principalmente adolescentes mais velhos e do sexo feminino, sendo a principal causa deste último a gravidez, parto e puerpério. Os dados levantados poderão subsidiar outras pesquisas sobre a saúde do adolescente nessas regiões, bem como a criação de políticas específicas voltadas ao público adolescente.

\section{REFERÊNCIAS}

1. BRASIL. Ministério da Saúde. Secretaria de Atenção à Saúde. Departamento de Ações Programáticas e Estratégicas. Proteger e cuidar da saúde de adolescentes na Atenção Básica. Brasília, 2017. Disponível em:

https://bvsms.saude.gov.br/bvs/publicacoes/diretrizes_nacionais_atencao_saude_adolescentes_jovens_ promocao_s aude.pdf. Acessado em: 16 de outubro de 2021.

2. OPAS. Organização Pan-Americana Da Saúde. Plano de Ação para a Saúde da Mulher, da Criança e do Adolescente: $2018 \quad-2030.2018 .2$ Disponível em: https://iris.paho.org/bitstream/handle/10665.2/49609/CD56-8-pt.pdf?sequence=16\&isAllowed=y.

Acessado em: 16 de outubro de 2021.

3. PEREIRA FNA, QUEIROZ BL. Diferenciais de mortalidade jovem no Brasil: a importância dos fatores socioeconômicos dos domicílios e das condições de vida nos municípios e estados brasileiros. Cadernos de Saúde Pública. 2016; 32: 1-12.

4. FONSECA FF, et al. As vulnerabilidades na infância e adolescência e as políticas públicas brasileiras de intervenção. Revista Paulista de Pediatria, 2013; 31: 258-264. 


\title{
ANÁLISE DA PERCEPÇÃO DOS PACIENTES DE FISIOTERAPIA AQUÁTICA QUANTO A SUA QUALIDADE DE VIDA DURANTE A PANDEMIA DA COVID-19
}

\author{
Laercio Brehner Gemaque do Couto ${ }^{1}$ \\ Monize de Melo e Sousa ${ }^{1}$ \\ Naurilene das Chagas Nascimento ${ }^{1}$ \\ Bárbara Fernanda Lima Silva Maia ${ }^{1}$ \\ Iranete Corpes Oliveira França ${ }^{1}$
}

1. Universidade da Amazônia (UNAMA), Belém - PA.

Palavras-chave: COVID-19, Qualidade de vida, Hidroterapia

\section{INTRODUÇÃO}

Desde o final de 2019, o mundo tem enfrentado uma grande crise sanitária devido ao surgimento do novo corona-vírus, e para promover sua contenção e reduzir a transmissão, muitos países implementaram diversas medidas protetivas, incluindo o isolamento social (MAHASE E, 2020). Logo, houve o fechamento das escolas, do comércio e das clínicas de saúde, que obtiveram restrições quanto aos atendimentos, afetando consideravelmente os pacientes, especialmente aqueles que faziam uso da fisioterapia aquática (WILDERSMITH A e FREEDMAN DO, 2020).

Ademais, dado o isolamento social e a incerteza a respeito do futuro, manifestaram-se problemas de saúde, como depressão e crises de ansiedade, que contribuem para o desenvolvimento de uma desfavorável qualidade de vida (MAGALHÃES RA e GARCIA JMM, 2021).

\section{OBJETIVO}

Analisar a percepção dos pacientes, os quais receberam tratamento de fisioterapia aquática em uma Clínica Escola da Região Norte do Brasil, quanto a sua auto-avaliação da qualidade de vida durante a pandemia da COVID-19.

\section{MÉTODO}

Apresenta o número do Certificado de Apresentação para Apreciação Ética 46308821.4.0000.5173. A amostra contém 12 pacientes de ambos os sexos, sendo maiores de 18 anos e que tenham feito, ao menos, 10 sessões de fisioterapia aquática e excluídos aqueles que apresentem déficits cognitivos, paralisia cerebral e acidente vascular encefálico. Os resultados foram obtidos mediante os dados coletados através do questionário WHOQOL-BREF, conforme a estatística descritiva conferida pelo Excel. 


\section{RESULTADOS}

A qualidade de vida significa não apenas a ausência de doença, mas a experiência de um estado de bemestar físico, social e mental, sendo, portanto, um conceito multidimensional e que reflete a avaliação subjetiva da satisfação pessoal (AZEVEDO WF e MATHIAS LADST, 2017). Sendo assim, a partir da amostra, obtevese como resultado uma qualidade de vida com uma porcentagem de 76,04\%. No entanto, é importante atentar para alguns fatores que se afastaram da média, como sentimentos negativos, com uma porcentagem de $70,83 \%$; dependência a medicamentos ou a tratamentos, com $58,33 \%$ e a presença de dor e desconforto, com $72,92 \%$.

\section{CONSIDERAÇÕES FINAIS}

Conforme as informações coletadas, conclui-se que a qualidade de vida da amostra é satisfatória, contudo, é válido observar alguns fatores os quais se distanciaram da média, como pensamentos negativos, a dependência de medicamentos e tratamentos, além da presença de quadros álgicos e desconfortos, visto que essas condições contribuem para o desenvolvimento de uma desfavorável qualidade de vida, afetando, consideravelmente o bem-estar e a saúde.

\section{REFERÊNCIAS}

1 AZEVEDO WF, MATHIAS LADST. Work addiction and quality of life: a study with physicians. Einstein (São Paulo), 2017; 15(2): 130-135.

2 MAGALHÃES RA, GARCIA JMM. Efeitos Psicológicos do Isolamento Social no Brasil durante a pandemia de COVID-19. Revista Científica Multidisciplinar Núcleo do Conhecimento, 2021; 1(1): 18-33.

3 MAHASE E. Coronavirus covid-19 haskilled more peoplethan SARS and MERS combined, despitelower case fatality rate. BMJ 2020; 368: m641.

4 WILDER-SMITH A, FREEDMAN DO. Isolation, quarantine, social distancingandcommunitycontainment: pivotal role for old-stylepublichealthmeasures in the novel coronavirus (2019-nCoV) outbreak. JTravelMed 2020; 27: 2. 
RESUMO SIMPLES: Estudo Original

\title{
DOENÇAS DE CHAGAS: PERFIL EPIDEMIOLÓGICO POR TRANSMISSÃO ORAL PELO CONSUMO DO AÇAI NO ESTADO DO PARÁ
}

\author{
Patricia da Silva Ferreira ${ }^{1}$ \\ Nathália Lorena Pinheiro Veras ${ }^{1}$ \\ Camila de Paula Sousa da Rocha ${ }^{1}$ \\ Ana Beatriz Mendes Furtado ${ }^{1}$ \\ Fabiane Diniz Machado Vilhena²
}

1. Universidade da Amazônia (UNAMA), Belém - PA.

2. Universidade Federal do Pará (UFPA), Belém - PA.

Palavras-chave: Epidemiologia, Doença de Chagas, Transmissão Oral.

\section{INTRODUÇÃO}

A Doença de Chagas também chamada de tripanossomíase americana, causada pelo protozoário Trypanosoma cruzi, e pode ser transmitido vetorialmente ou oralmente no consumo de alimentos com insetos triatomíneos (PACHECO LV, et al., 2021). Atualmente a transmissão por via oral envolvendo alimentos infectados caracteriza a principal via de contaminação humana (PARENTE MF, et al., 2020).

Grande parte dos casos no Brasil ocorre em regiões do estado do Pará, por concentrar grande extração do açaí, que simboliza um dos principais frutos que faz parte da cultura alimentar da região, quando não feita a higienização correta pode ocorrer a contaminação durante seu processamento para ingestão do alimento (SOUZA DSM e POVOA RMS, 2016).

\section{OBJETIVO}

Apresentar o perfil epidemiológico dos casos de Doença de Chagas no Estado do Pará, notificados no período de 2017 a 2020, de acordo com variáveis: número total de casos, modo provável da infecção, sexo, faixa etária e evolução da doença.

\section{MÉTODO}

Estudo descritivo, transversal e quantitativo, onde analisou-se o perfil dos casos da Doença de Chagas no período de 2017 a 2020, as informações extraídas do Sistema de Informação de Agravos de Notificação (SINAN), disponibilizado na plataforma Departamento de Informática do Sistema Único de Saúde (DATASUS). Por se tratar de dados secundários de domínio público, não se fez necessário a submissão ao Comitê de Ética e Pesquisa (CEP). 


\section{RESULTADOS}

No período estudado o Pará registrou 694 casos de doença de Chagas, sendo o maior número de casos no ano de 2018 com total de 295 casos. O modo provável de infecção mais registrado foi o de transmissão oral com total de 611 casos (88\%) comprovando que a maior forma de contágio é por meio de alimentos contaminados. Quanto ao sexo a predominância foi no sexo masculino com 390 casos (56.1\%). A faixa etária mais acometida foi de 20 a 39 anos (34.7\%) com total de 241 casos. Houve total de 11 óbitos pelo agravo notificado.

\section{CONSIDERAÇÕES FINAIS}

Os dados epidemiológicos constataram altos casos de Doença de Chagas na região Norte no Estado do Pará, a principal via de transmissão, atualmente, é a oral devido um hábito comum de consumir açaí na região, o que reforça a precisão de planejamentos de vigilância para redução de agravo, onde se consiga intervir com orientações de higiene e produção de medidas preventivas para reduzir a incidência da doença.

\section{REFERÊNCIAS}

1. PACHECO LV, et al. Oral transmission of Chagas disease: A literature review. Research, Society and Development, 2021; 10(2): e31910212636.

2. PARENTE MF, et al. Cenário epidemiológico da Doença de Chagas no Estado do Pará, Brasil. Brazilian Journal of Health Review, 2020; 3(1): 1223-1234.

3. SOUZA DSM, POVOA RMS. Aspectos epidemiológicos e clínicos da doença de chagas aguda no Brasil e na América Latina. Rev. Soc. Cardiologia do Estado de São Paulo, 2016; 26(4): 222-229. 
RESUMO SIMPLES: Estudo Original

\title{
O PERFIL EPIDEMIOLÓGICO DOS PACIENTES COM HIV/AIDS NO BRASIL DE 2010 A 2020
}

\author{
Géssica Silva Cazagrande ${ }^{1}$ \\ Ana Carolina Fratane Siqueira ${ }^{1}$ \\ José Arthur Silva e Sousa ${ }^{2}$ \\ Thiemmy de Souza Almeida Guedes ${ }^{3}$ \\ Célio Pereira de Sousa Júnior ${ }^{4}$
}

1. Universidade Federal Fluminense (UFF), Niterói - RJ.

2. Faculdade Venda Nova do Imigrante (FAVENI), Venda Nova do Imigrante - ES.

3. Universidade Paulista (UNIP), São Paulo - SP.

4. Universidade Federal do Pará (UFPA), Belém - PA.

Palavras-chave: Perfil epidemiológico, AIDS, Brasil.

\section{INTRODUÇÃO}

A Síndrome da Imunodeficiência Adquirida (AIDS), surgiu na década de 80 e nos dias atuais continua sendo um importante problema de saúde mundial, com mais de 33 milhões de mortes, destas, 690 mil em 2020 (OPAS, 2021). A partir da evolução do tratamento, através da implementação das medicações antirretrovirais (ARV), os portadores do vírus do HIV passaram a viver com uma doença crônica (SANTOS ACF, et.al., 2020).

A administração dos antirretrovirais não promove a cura, porém auxilia na promoção de uma maior e melhor sobrevida do paciente. Todavia, a diminuição do risco de mortes, induziu ao aumento do desconhecimento quanto à prevenção e a crescente contaminação (FILHO O de JLD, et al., 2021).

\section{OBJETIVO}

Identificar o perfil epidemiológico dos pacientes portadores de HIV/AIDS no Brasil. Os objetivos específicos são descrever o perfil epidemiológico identificado na pesquisa; listar as principais características e comorbidades dos pacientes portadores de HIV/AIDS.

\section{MÉTODO}

Trata-se de uma pesquisa com obtenção de dados secundários fornecidos pelo Departamento de Informática do Sistema Único de Saúde (DATASUS), sobre os casos confirmados de HIV/AIDS, no intervalo de 2010 a 2020, considerando a incidência e as variáveis, ano, região, sexo, raça e idade. O DATASUS é uma plataforma online com dados públicos, portanto, não foi necessário a apresentação do estudo ao Comitê de Ética e Pesquisa (CEP). 


\section{RESULTADOS}

Observou-se 417.713 casos de AIDS no Brasil, principalmente nas regiões Sudeste $(40,3 \%)$ e Nordeste (21,7\%), com diferença entre os sexos, sendo 23 casos em homens para 10 mulheres a partir de 2017 (BRASIL, 2020). A maior escolaridade se mantinha entre os homens e principalmente com ensino médio completo. Verificou-se a prevalência em 30 a 39 anos com 126.399 eventos, seguida de 20 a 29 com 97.717 . Foram notificados 120.214 óbitos, destes, $66,1 \%$ homens e $33,9 \%$ mulheres. A via de transmissão principal, em maiores de 13 anos, foi a sexual e o principal grupo de risco os heterossexuais com 149.281 notificações.

\section{CONSIDERAÇÕES FINAIS}

Os casos de pacientes contaminados sofreram uma redução relativa. Apesar dessa redução ainda há uma elevada incidência de casos, ocasionando maiores gastos com uma doença passível de prevenção. Fica evidente a necessidade de investimentos em campanhas preventivas, a deteç̧ão precoce por testagem sorológica periódica, além de campanhas que incentivem a adesão ao tratamento para impedir futuras infecções e óbitos por AIDS.

\section{REFERÊNCIAS}

1. BRASIL. Secretaria de Vigilância em Saúde. Boletim epidemiológico de HIV/AIDS 2020. Disponível em: http://www.aids.gov.br/pt-br/pub/2020/boletim-epidemiologico-hivaids-2020. Acessado em: 21 de setembro de 2021.

2. BRASIL. Ministério da Saúde. Departamento de Informática do Sistema Único de Saúde [DATASUS]. Disponível em: http://www2.datasus.gov.br/DATASUS/index.php?area=02. Acessado em: 20 de setembro de 2021.

3. FILHO O de JLD, et al. Manifestações orais em pacientes imunodeprimidos pelo Vírus da Imunodeficiência Humana (HIV): revisão da literatura. Revista Eletrônica Acervo Saúde, 2021. 13(2): e6034.

4. ORGANIZAÇÃO PAN-AMERICANA DA SAÚDE (OPAS). HIV/aids: Plano de Ação para a prevenção e controle da infecção pelo HIV e infecções sexualmente transmissíveis 2016-2021. 2021. Disponível em: https://www.paho.org/pt/topicos/hivaids. Acessado em: 20 de setembro de 2021.

5. SANTOS ACF, et al. Perfil epidemiológico dos pacientes internados por HIV no Brasil. Revista Eletrônica Acervo Saúde, 2020; 48: e3243. 
RESUMO SIMPLES: Estudo Original

\title{
EDUCAÇÃO EM SAÚDE NA CAMPANHA DO SETEMBRO AMARELO: UM RELATO DE EXPERIÊNCIA
}

\author{
Ana Beatriz Mendes Furtado ${ }^{1}$ \\ Nathália Lorena Pinheiro Veras ${ }^{1}$ \\ Patricia da Silva Ferreira ${ }^{1}$ \\ Fabiane Diniz Machado Vilhena²
}

1. Universidade da Amazônia (UNAMA), Belém - PA.

2. Universidade Federal do Pará (UFPA), Belém - PA.

Palavras-chave: Educação em saúde, Suicídio, Prevenção.

\section{INTRODUÇÃO}

Setembro amarelo é uma campanha voltada para prevenção do suicídio, objetivando conscientizar a população sobre esse problema de saúde pública (de OLIVEIRA ACF, et al., 2021). É realizada neste mês devido ao dia 10 de setembro ser o Dia Mundial de Prevenção ao Suicídio. Criado em 2015, no Brasil, pelo Centro de Valorização da Vida (CVV), Associação Brasileira de Psiquiatria (ABP) e o Conselho Federal de Medicina (CFM) com finalidade de quebrar o tabu existente frente ao suicídio. (FERREIRA GS, et al., 2019). Segundo a Organização Mundial da Saúde (OMS) o suicídio é a segunda causa de morte de jovens entre 15 e 29 anos (RIBEIRO JM e MOREIRA MR, 2018).

\section{OBJETIVO}

Relatar a experiência vivenciada por uma acadêmica de enfermagem, durante uma ação realizada pela Liga Acadêmica Interdisciplinar de Cancerologia (LICAN), em alusão ao setembro amarelo, em uma unidade básica de saúde na cidade de Belém do Pará.

\section{RESULTADOS}

A ação em saúde setembro amarelo, foi realizada em uma UBS, e teve como organizadoras a Psicóloga da unidade e as acadêmicas de enfermagem. Foram desenvolvidas atividades na recepção com cartazes alusivos à temática, na qual cada acadêmica com o apoio da psicóloga abordaram os pontos importantes como o que é o setembro amarelo e o seu objetivo, a importância da saúde mental e da rede de apoio familiar, como identificar quem está precisando de ajuda com risco de suicídio, enfatizando a importância de prevenir e valorizar a vida.

Durante a ação foi possível identificar que muitas pessoas da comunidade não tinham conhecimento sobre o assunto, não sabiam do que se tratava o setembro amarelo, devido a essa falta de informação houve um acolhimento e entusiasmo para compreender melhor sobre a temática. Para finalizar foram entregues brindes, 
laços na qual simboliza o setembro amarelo, cartões com o número 188 para apoio emocional e com frases motivacionais ressaltando que toda vida importa.

\section{CONSIDERAÇÕES FINAIS}

A ação realizada foi de grande importância, pois foi possível levar informações e tirar muitas dúvidas da comunidade que frequenta aquela unidade de saúde, transmitindo conhecimento sobre o assunto. É válido ressaltar, a importância de estratégias como essa para o crescimento das acadêmicas como profissionais da saúde, ampliando a visão sobre a atuação da Enfermagem na Atenção primária e atuação na área preventiva.

\section{REFERÊNCIAS}

1. de OLIVEIRA A, et al. Setembro Amarelo e os enlutados por suicídio: relato de experiências. Brazilian Journal of Health Review, 2021; 4(2): 6518-6524.

2. FERREIRA GS. Possibilidades de abordagem do tema do suicídio na Estratégia Saúde da Família. Physis: Revista de Saúde Coletiva, 2019; 29: e290413.

3. RIBEIRO JM, MOREIRA MR. Uma abordagem sobre o suicídio de adolescentes e jovens no Brasil. Ciência \& Saúde Coletiva, 2018; 23: 2821-2834. 


\title{
O PERFIL EPIDEMIOLÓGICO DA HEPATITE A NO TERRITÓRIO BRASILEIRO ENTRE 2010 E 2018
}

\author{
Ana Carolina Fratane Siqueira ${ }^{1}$ \\ Géssica Silva Cazagrande ${ }^{1}$
}

1. Universidade Federal Fluminense (UFF), Niterói - RJ.

Palavras-chave: Perfil epidemiológico, Hepatite A, Brasil.

\section{INTRODUÇÃO}

A Hepatite A continua sendo um problema de saúde pública nacional. Essa patologia possui transmissão fecal-oral e ocorre por falta de higienização de alimentos, água contaminada e saneamento básico precário (SILVA ACB, et al, 2021). Por possuir uma taxa de contaminação e disseminação elevada há estratégias de mobilização à prevenção, por intermédio da estratégia global de hepatites da OMS (OMS, 2021).

Devido a sua vasta taxa de prevalência e incidência é considerada uma patologia de notificação compulsória. Entende-se por notificação compulsória a obrigatoriedade de comunicação à autoridade de saúde em caso de suspeita e/ou confirmação da doença (BRASIL, 2020).

\section{OBJETIVO}

Identificar o perfil epidemiológico da população brasileira contaminada com o vírus da Hepatite A no período de 2010 a 2018. Tendo como objetivos específicos descrever e listar as principais características e comorbidades do perfil epidemiológico identificado.

\section{MÉTODO}

Trata-se de pesquisa documental, retrospectiva e quantitativa, onde os dados sobre os casos confirmados de Hepatite A foram coletados do Departamento de Informática do Sistema Único de Saúde (DATASUS), aplicando as seguintes variáveis, ano, região, sexo, raça e idade, no intervalo de 2010 a 2018. O DATASUS é uma plataforma online com dados públicos, consequentemente não foi necessário a apresentação do estudo ao Comitê de Ética e Pesquisa (CEP).

\section{RESULTADOS}

Observou-se 39.802 casos confirmados de Hepatite A entre 2010 e 2018. Em 2011 houve 17\% (6.878) de casos, em contrapartida 2016 foi o ano com menos casos, com 2,4\% (974). A região Norte apresentou $36 \%$ dos casos (14.387). O sexo masculino foi o mais afetado com $55 \%$ dos casos (22.037). A faixa etária 05-09 anos apresentou o maior percentual em ambos os sexos e em números totais, apresentando $26 \%$ dos casos (11.765). A raça com maior percentual foi a parda com $56 \%$. O estudo evidencia que o perfil da população 
majoritariamente infectada pela Hepatite $A$ foi: crianças pardas do sexo masculino que residem na Região Norte (BRASIL, 2019; BRASIL, 2020).

\section{CONSIDERAÇÕES FINAIS}

Apesar do avanço que tivemos com a queda do número de casos, principalmente após 2014, a Hepatite A ainda representa um grande problema de saúde pública. Medidas como a melhoria das condições sanitárias, a promoção da educação em saúde e a vacinação universal de crianças devem ser implementadas, pois promovem a diminuição da circulação do vírus, melhorando a qualidade de vida da população.

\section{REFERÊNCIAS}

1. BRASIL. Ministério da Saúde, Departamento de Informática do Sistema Único de Saúde [DATASUS]. Disponível em: http://www2.datasus.gov.br/DATASUS/index.php?area=02. Acessado em: 20 de setembro de 2021.

2. BRASIL. Ministério da Saúde. Boletim Epidemiológico de Hepatites Virais - 2019. Brasília: Ministério da Saúde. $2019.2 \quad$ Disponível em: http://www.aids.gov.br/system/tdf/pub/2016/66453/boletim_hepaties_2019_c_.pdf?file=1\&type=node\&id= $66453 \&$ force $=1$. Acessado em: 19 de setembro de 2021.

3. BRASIL. Portaria no 264, de 17 de fevereiro de 2020. Define a Lista Nacional de Notificação Compulsória de doenças, agravos e eventos de saúde pública nos serviços de saúde públicos e privados em todo o território nacional, nos termos do anexo, e dá outras providências. Diário Oficial da União. 2020. Disponível em: https://bvsms.saude.gov.br/bvs/saudelegis/gm/2020/prt0264_19_02_2020.html. Acessado em: 20 de setembro de 2021.

4. OMS. Organização Mundial da Saúde. Global Health Sector Strategy on Viral Hepatitis, 2016-2021. 2021. Disponível em: https://apps.who.int/iris/handle/10665/246177. Acessado em: 19 de setembro de 2021.

5. SILVA ACB, et al. Perfil Epidemiológico da Hepatite A no Estado do Pará, Amazônia Brasileira, 2017 a 2018. Revista Eletrônica Acervo Saúde, 2021; 13(10). 


\title{
INIBIÇÃO DA VIA DE SINALIZAÇÃO DE MTOR CINASE COMO ESTRATÉGIA DE REDUÇÃO DA PATOGENICIDADE DO SARS COV-2 EM CÉLULAS INFECTADAS: UMA ANÁLISE IN SILICO
}

\author{
Cristiano de Bem Torquato de Souza ${ }^{1}$ \\ Luis Gustavo Pagliarin ${ }^{1}$ \\ Valentina Nunes Fontoura dos Anjos ${ }^{1}$ \\ Lucca Miketen de Oliveira ${ }^{1}$ \\ Gabrielle Caroline Peiter ${ }^{1}$
}

1. Universidade Federal do Paraná (UFPR), Toledo - PR.

Palavras-chave: SARS-CoV-2, Molecular Docking Simulation, mTOR.

\section{INTRODUÇÃO}

A emergência da COVID-19 ao final de 2019 tem sido fator de grande impacto em praticamente todas as atividades sociais. Diversas pesquisas buscam aprofundar o conhecimento acerca dos mecanismos de infecção e da ação do vírus no organismo humano. Dessa forma abordamos o tema sob a perspectiva de uma via de sinalização celular que participa do processo patológico. Como a entrada do vírus é regulada via modulação da mTOR, que regula apoptose (RANADHEERA C, et al., 2018), sobrevivência celular (EHRHARDT C e LUDWIG S, 2009), transcrição e tradução (MIZUTANI T, et al., 2005), torna-se importante a pesquisa deste mecanismo para seu uso no combate à doença.

\section{OBJETIVO}

Analisar o complexo formado entre a enzima mTOR e seu inibidor, C-223 e tentar estabelecer as alterações metabólicas e fisiológicas na transdução de sinais da via, advindas da interação, que envolvem a infecção e a replicação do SARS-CoV-2.

\section{MÉTODO}

A estrutura da proteína mTOR foi adquirida no Protein Data Bank e do inibidor CC-223 no banco de dados Pubchem, sendo seu estado de protonação em pH fisiológico calculado a partir do software MarvinSketch. As interações foram realizadas via docking molecular com o uso do software Autodock acoplado ao software Vina. A análise dos resíduos de aminoácidos envolvidos ocorreu por meio do software PyMol®.

\section{RESULTADOS}

O complexo mTORC1 / CC-223 mais estável apresentou energia de afinidade de -7,7 kcal / mol. Quatro ligações químicas significativas foram observadas entre o receptor e o ligante envolvendo quatro resíduos 
distintos com tamanho de ligação variando de 2,7 a 4,99 Å. Destas, uma é polar (ligação de hidrogênio) e de acordo com seu tamanho, esta é a mais forte $(2,7 \AA$ A $)$; os outros vínculos têm caráter apolar. As quatro ligações significativas no complexo mTORC1 / CC-223 envolvem duas (C e D) das cinco cadeias polipeptídicas (A-E) que formam o domínio FRB (FKBP12-Rapamycin-Binding). Outros 12 resíduos estão envolvidos nas interações de Van der Waals.

\section{CONSIDERAÇÕES FINAIS}

Este estudo sugere a possibilidade de interação da via mTOR com agentes capazes de bloqueá-la, CC223, impedindo mecanismos de patogenicidade viral. Foi identificado que esta interação é, in sílico, capaz de prevenir o desenvolvimento da infecção e, portanto, pode ser classificado como um mecanismo inibitório da entrada celular do SARS-CoV-2. Por conseguinte, uma terapêutica farmacológica com alvos na via de sinalização mTOR pode ajudar pacientes com COVID-19.

\section{REFERÊNCIAS}

1. EHRHARDT C, LUDWIG S. A new player in a deadly game: influenza viruses and the PI3K/Akt signalling pathway. Cell Microbiol, 2009; 11(6): 863-871.

2. MIZUTANI T, et al. JNK and PI3K/Akt signaling pathways are required for establishing persistent SARSCoV infection in Vero E6 cells. Biochimica et biophysica acta, 2005; 1741(1-2): 4-10.

3. RANADHEERA C, et al. Comprehending a Killer: The Akt/mTOR Signaling Pathways Are Temporally HighJacked by the Highly Pathogenic 1918 Influenza Virus. EBioMedicine, 2018; 32: 142-163. 


\section{| REVISÕES BIBLIOGRÁFICAS}

RESUMO SIMPLES: Revisão Integrativa

\section{ENXAGUATÓRIOS OXIDATIVOS E MÁSCARAS NA ODONTOLOGIA: USO BIOSSEGURO E PREVENTIVO NA ATUALIDADE}

Kátia Ferreira dos Santos ${ }^{1}$

Marcelo Barbosa²

Nilton José Fernandes Cavalcante ${ }^{2}$

1. Coordenadoria de Controle de Doenças da Secretaria de Estado da Saúde de São Paulo (CCD-SESSP), São Paulo - SP.

2. Instituto de Infectologia Emílio Ribas (IIER), São Paulo - SP.

Palavras-chave: Antissépticos bucais, Máscaras, Controle de infecções.

\section{INTRODUÇÃO}

Diretrizes biosseguras foram determinadas por órgãos oficiais para evitar propagação da COVID-19, seguido de EPI (equipamento de proteção individual) e higiene das mãos (OLIVEIRA JJM, et al., 2020). Enxaguatórios orais pré-procedimento odontológicos são virucidas, nos estágios assintomáticos da doença (BIDRA AS, et al., 2020).

Máscaras cirúrgicas e peças FFP3 filtram $80 \%$ e 99\%, respectivamente que devem ser utilizadas pelos profissionais em qualquer procedimento (SANTOS KF e CAVALCANTE NJF, 2021). Gargarejos com H2O2, volume 10 a $3 \%$ e iodopovidona $0,2 \%$ têm indicação na cavidade orofaríngea (SANTOS KF e BARBOSA M, 2020).

\section{OBJETIVO}

Revisar a literatura científica para orientar dentistas na indicação de enxaguatórios bucais préprocedimentos e máscaras faciais apropriadas como EPI preventivos à biossegurança com finalidade de evitar disseminação da infecção em pacientes e profissionais durante tratamento odontológico na COVID-19.

\section{MÉTODO}

Revisão integrativa nas bases de dados PubMed/MEDLINE, Scopus e EMBASE. As palavras-chave utilizadas na busca foram: "Mask and Mouthwashes", no período de 23/03/2020 a 23/03/2021. Os critérios de inclusão foram: artigos em inglês, versão completa on-line e gratuita. De exclusão se restringiram a artigos 
sem palavras-chave e repetidos. Foram encontrados 18 artigos, excluídos três restando 15 que reforçaram o uso de enxaguatórios bucais e máscaras como medidas biosseguras.

\section{REVISÃO BIBLIOGRÁFICA}

Uma revisão sistemática avaliou o uso de enxaguatórios bucais com agentes sintéticos e naturais e verificou-se que eles têm efeitos benéficos, auxiliam nas infecções respiratórias mesmo com diferentes propriedades, são seguros e sem efeitos colaterais (AHMAD L, 2021).

Outro estudo de revisão bibliográfica revelou que até o momento não há enxaguatórios contra o SARSCoV-2, mas o uso de substâncias como peróxido de hidrogênio 1\% (H2O2) e iodopovidona 0,2\% (PVP-I) são indicados para pré-procedimentos em odontologia, pois tem baixo custo, são oxidantes, reduzem carga viral e podem contribuir com estudos para confirmar eficácia, além de colaborar com protocolos internacionais de controle de infecção (BRITO LNS, et al., 2020).

\section{CONSIDERAÇÕES FINAIS}

Enxaguatórios bucais e máscaras faciais podem ser considerados complementos biosseguros neste momento da COVID-19, incluindo o uso de peróxido de hidrogênio (H2O2, volume 10 a 3\%), quando não encontrar $\mathrm{H} 2 \mathrm{O} 2$ de 1\%, PVP-I (iodopovidona a 0,2\%) que devem fazer parte de um escopo clínico para evitar disseminação da infecção; contribuir para a não evolução da doença em casos leves e moderados, com possibilidade de novos estudos.

\section{REFERÊNCIAS}

1. AHMAD L. Impact of gargling on respiratory infections. All Life, 2021; 14(1): 147-158.

2. BIDRA AS, et al. Comparison of in vitro inactivation of SARS CoV-2 with hydrogen peroxide and povidoneiodine oral antiseptic rinses. Journal of Prosthodontics, 2020; 29(7): 599-603.

3. BRITO LNS, et al. Uso de enxaguante bucal na prática odontológica durante a pandemia de COVID-19. Archives of Health Investigation, 2020; 9(4): 325-330.

4. OLIVEIRA JJM, et al. O impacto do coronavírus (covid-19) na prática odontológica: desafios e métodos de prevenção. Revista Eletrônica Acervo Saúde, 2020; (46): e3487.

5. SANTOS KF, BARBOSA M. COVID-19 e a Odontologia na prática atual. Revista Eletrônica Acervo Saúde, 2020; 12(11): e5113.

6. SANTOS KF, CAVALCANTE NJF. Aspectos epidemiológicos dos acidentes com material biológico em dentistas. Revista Eletrônica Acervo Saúde, 2021; 13(3): e6602. 
RESUMO SIMPLES: Revisão Integrativa

\title{
CUIDADOS DE ENFERMAGEM FRENTE AOS SINTOMAS DE PACIENTES COM SÍFILIS
}

\author{
Rebeca Ferreira Nery ${ }^{1}$ \\ Cremilson de Paula Silva ${ }^{2}$ \\ Arianny Luiza Barros de Santana ${ }^{3}$ \\ Maria Eduarda Lopes de Macedo Bezerra ${ }^{4}$ \\ Thiemmy de Souza Almeida Guedes 5
}

1. Faculdade São Francisco da Paraíba (FASP), Cajazeiras - PB.

2. Universidade Federal de Alfenas (UNIFAL), Alfenas - MG.

3. Universidade Nove de Julho (UNINOVE), São Paulo - SP.

4. Faculdade Estácio do Rio Grande do Norte (FATERN), Natal - RN.

5. Faculdade Venda Nova do Imigrante (FAVENI), Campina Grande - PB.

Palavras-chave: Cuidados de enfermagem, Tratamento, Sífilis.

\section{INTRODUÇÃO}

Provocada por uma bactéria intitulada de Treponema pallidum, a sífilis é uma infecção sexualmente transmissível que é disseminada por meio de relações sexuais sem o uso de preservativos. Possui três fases: primária, secundária e terciária; e em recém-nascidos ocorre a sífilis congênita, que é adquirida durante a gestação ou no momento do parto. Diante disso, essa patologia pode acarretar várias sequelas tanto na infância quanto na vida adulta. O principal sintoma da sífilis é uma ferida no local de contato com a bactéria, seja ela no pênis, vagina, boca ou ânus, e os sintomas podem eclodir de seis semanas a seis meses após a aparição e cicatrização da ferida inicial (BRASIL, 2021).

\section{OBJETIVO}

Revisar na literatura científica com a finalidade de compreender como são os cuidados de Enfermagem frente aos sintomas de pacientes diagnosticados com sífilis, reforçando a importância da capacitação do enfermeiro nessa área de atuação.

\section{MÉTODO}

Revisão com abordagem integrativa baseada em artigos publicados na Biblioteca Virtual de Saúde (BVS) e no Acervo+. Para a busca, utilizou-se os descritores: "Cuidados de Enfermagem", "Tratamento" e "Sífilis", empregando o operador booleano "AND". Os critérios de exclusão foram artigos que não abordavam o tema, já os de inclusão foram: artigos gratuitos, online, em inglês e português, de 2016 a 2021. Foram encontradas 126 pesquisas, após análise 04 foram selecionadas. 


\section{REVISÃO BIBLIOGRÁFICA}

Apesar das fragilidades existentes quanto às políticas públicas e adesão desses pacientes, vários estudos demonstraram o interesse dos profissionais de saúde em capacitações para ofertar uma melhor assistência a este público específico. Essa assistência vai desde o acolhimento, escuta, tratamento até a ações continuadas de educação em saúde; um apoio que enxerga o paciente como um todo. Além disso, as ações também são voltadas aos parceiros desses pacientes, bem como suas famílias, de modo a sanar dúvidas relacionadas à patologia, exames e aos tratamentos oferecidos pelo sistema público de saúde (NUNES JT, et al., 2017; POLLO D e RENOVATO RD, 2020; TAVARES C, et al., 2021).

\section{CONSIDERAÇÕES FINAIS}

Portanto, evidencia-se que a sífilis ainda é um grande problema para a saúde pública pela transmissibilidade e falta de conhecimento da população. Logo, faz-se necessário implementações e renovações de políticas públicas associadas à quebra da cadeia de transmissão desta infecção por meio da melhoria na qualidade da assistência, ampliando a qualificação de medidas preventivas das Infecções Sexualmente Transmissíveis (IST's), reduzindo o número de casos.

\section{REFERÊNCIAS}

1. FERNANDES R, et al. O manejo da sífilis gestacional no pré-natal. Revista de Enfermagem UFPE online, 2020; 14: e243643.

2. NUNES JT, et al. Sífilis na gestação: perspectivas e condutas do enfermeiro. Revista de Enfermagem UFPE online, 2017; 11(12): 4875-4884.

3. POLLO D, RENOVATO RD. Enfermagem e o tratamento medicamentoso da sífilis sob a ótica da Teoria Sócio-Humanista. Revista Enfermagem UERJ, 2020; 28: e51482.

4. TAVARES C, et al. Sífilis Congênita Na Amazônia: Desvelando A Fragilidade No Tratamento. Revista de Enfermagem UFPE, 2021; 15(1): e245767. 


\section{BENEFÍCIOS DAS PRÁTICAS INTEGRATIVAS E COMPLEMENTARES EM CRIANÇAS ONCOLÓGICAS}

Cremilson de Paula Silva ${ }^{1}$

Arianny Luiza Barros de Santana²

Tamíris Alves Chagas ${ }^{3}$

Lais Nicolly Ribeiro da Silva ${ }^{4}$

Thiemmy de Souza Almeida Guedes ${ }^{5}$

1. Universidade Federal de Alfenas (UNIFAL), Alfenas - MG.

2. Universidade Nove de Julho (UNINOVE), São Paulo - SP.

3. Universidade Federal de Alagoas (UFAL), Maceió - AL.

4. Centro Universitário (UNIFACISA), Campina Grande - PB.

5. Faculdade Venda Nova do Imigrante (FAVENI), Campina Grande - PB.

Palavras-chave: Neoplasia, Saúde da criança, Terapias complementares.

\section{INTRODUÇÃO}

O câncer pediátrico quando descoberto, provoca expectativas nos familiares e nos pacientes, levando a alteração da sua percepção acerca da vida. Por sua vez, o tratamento oncológico, leva a inúmeros efeitos colaterais ao organismo do paciente como: vômitos, náuseas, dor, fadiga e ansiedade (JUNIOR FR, et al., 2018).

No país, as Práticas Integrativas e Complementares (PIC's), são um sistema médico complexo, possuindo grande recursos terapêuticos e abordando mecanismos naturais de recuperação e prevenção à saúde, sendo alternativas comuns entre os pacientes oncológicos (PAES TV, et al., 2021). Ademais, com seu caráter preventivo no tratamento de doenças agressivas, as PIC's oferecem uma maneira mais adequada dos pacientes se relacionarem com sua doença e seu corpo.

\section{OBJETIVO}

Revisar na literatura científica com o intuito de compreender quais são os principais benefícios das terapias alternativas e complementares em prol de crianças sob tratamento oncológico, além de salientar as vantagens da implementação destas práticas como ferramentas do cuidado.

\section{MÉTODO}

Consiste em uma revisão integrativa realizada a partir dos trabalhos científicos disponíveis na BVS, LILACS, SciELO, PUBMED e MEDLINE. Para a busca, utilizou-se os seguintes descritores: "Terapias Complementares", "Saúde da Criança" e "Neoplasias", empregando o operador booleano "AND". Os critérios 
de exclusão foram artigos que não abordavam o tema, já os de inclusão foram: artigos em inglês e português, de 2017 a 2021. Quatro estudos de 1492 foram selecionados.

\section{REVISÃO BIBLIOGRÁFICA}

As Práticas Integrativas e Complementares (PICs) auxiliam no manejo de sintomas e melhora da qualidade de vida de seus usuários (PAES TV, et al., 2021). A massagem terapêutica, musicoterapia e a terapia através de brincadeiras e danças, apresentam uma estreita relação com a população pediátrica, especialmente devido ao uso do aspecto lúdico (LOPES-JÚNIOR LC, et al., 2021; MENUT V, et al., 2019).

Conseguinte, as PICs têm proporcionado inúmeros benefícios ao tratamento oncológico em crianças, dentre eles destaca-se o auxílio no controle da dor, melhora na sensação de cansaço, fadiga, náuseas, vômitos, ganho de peso, melhora no humor, padrões de sono e enfrentamento da patologia (STUB T, et al., 2021).

\section{CONSIDERAÇÕES FINAIS}

Portanto, verificou-se que as PICS são estratégias de impacto positivo no cuidado de crianças portadoras de neoplasias, contribuindo para o alívio dos sintomas existentes durante o trajeto terapêutico, aumentando a qualidade de vida das crianças. Torna-se viável a adesão das terapias complementares, uma vez que as técnicas possuem baixo custo e não são invasivas, auxiliando para redução dos efeitos decorrentes da doença.

\section{REFERÊNCIAS}

1. JUNIOR RF, et al. Refletindo sobre a espiritualidade e a religiosidade relacionadas à prática dos profissionais de saúde na oncologia. Revista Eletrônica Acervo Saúde, 2018; 4: 178 - 185.

2. LOPES-JÚNIOR LC, et al. Efetividade de terapias complementares para o manejo de clusters de sintomas em cuidados paliativos em oncopediatria: revisão sistemática. Revista da Escola de Enfermagem da USP, 2021; 55: e03709.

3. MENUT V, et al. Utilisation des médecines complémentaires et alternatives chez l'enfant et l'adolescent atteint de cancer: une pratique fréquente. Bulletin du Cancer, 2019; 106(3): 189-200.

4. PAES TV, et al. Métodos Não Farmacológicos para o Manejo da Dor em Oncologia Pediátrica: Evidências da Literatura. Revista Brasileira de Cancerologia, 2021; 67(2): e031027.

5. STUB T, et al. Communication and information needs about complementary and alternative medicine: a qualitative study of parents of children with cancer. BMC Complementary Medicine and Therapies, 2021; 21(85): 1-11. 
RESUMO SIMPLES: Revisão Integrativa

\section{ATIVIDADE GASTROPROTETORA DA MAYTENUS ROBUSTA (CELASTRACEAE)}

Samuel Rodrigues do Nascimento Freitas ${ }^{1}$

1. Centro Universitário Maurício de Nassau (UNINASSAU), Recife - PE.

Palavras-chave: Gastroproteção, Medicamento fitoterápico, Planta medicinal.

\section{INTRODUÇÃO}

A úlcera péptica é uma lesão provocada pelo desequilíbrio entre os fatores que protegem a parede digestiva, e os que a danificam (LANAS A e FRANCIS KL, 2017). Atualmente, esta condição é prevalente em cerca de $10 \%$ da população mundial, o que a torna um significativo problema de saúde pública (PETERSON A e CHAN FKL, 2016).

Logo, reforça-se a necessidade de intervenções farmacoterapêuticas que visem a profilaxia e tratamento deste agravo. Neste sentido, a Maytenus robusta (Celastraceae), planta medicinal comumente utilizada no sul do Brasil, mostra-se um objeto de estudo promissor, dada a presença significativa de terpenóides gastroprotetores em sua composição (ZERMIANI T, et al., 2016).

\section{OBJETIVO}

Revisar as evidências científicas descritas na literatura que versam sobre a potencial utilidade clínica dos constituintes químicos da Maytenus robusta (Celastraceae) como entidades farmacologicamente ativas para a proteção da muscosa gástrica.

\section{MÉTODO}

Estudo do tipo revisão integrativa de literatura, dado mediante busca eletrônica nas bases: National Library of Medicine (PubMed); e Centro Latino-Americano de Informação em Ciências da Saúde (BIREME). Considerou-se, por ser o tema pouco comum, artigos publicados entre 2015-2021, no idioma inglês. Como estratégia de busca, utilizou-se as palavras-chave: Phytotherapeutic drugs e Maytenus robusta. Foram identificados um artigo no PubMed e um no BIREME; ambos selecionados para o estudo.

\section{REVISÃO BIBLIOGRÁFICA}

Um estudo realizado em ratos com úlceras induzidas por ácido acético $80 \%$, apontou decrescimo de $53 \%$ nas lesões dos animais tratados com M. robusta, comparado ao grupo que recebeu veículo (SILVA LM, et al., 2015). Isto pode ser explicado pela presença de triterpenos gastroproteores, como 3,15-dioxo-21ahidroxifriedelano, friedelina, B-friedelinol (ZERMIANI T, et al., 2016).

Além de diminuir a área das lesões gástricas, a M. robusta, in vivo, ainda minimiza o seu índice e porcentagem (BENVENUTTI DF, et al., 2016). In vitro, ainda foi capaz de aumentar o conteúdo de mucina 
gástrica, diminuir o estresse oxidativo e os parâmetros da inflamação no local da lesão (SILVA LM, et al., 2015).

\section{CONSIDERAÇÕES FINAIS}

Mytenus robusta é uma planta potencialmente útil, como estratégia terapêutica farmacológica, uma vez que possui atividade cictrizante, antiinflamatória e antioxidante. Cabe, portanto, estudos clínicos multicêntricos que visem averiguar a segurança e se a atividade antiulcerosa, vista in vivo e in vitro, nos testes pré-clínicos, são translacionais.

\section{REFERÊNCIAS}

1. BENVENUTTI DF, et al. Phytochemical Analysis and Gastroprotective Activity of the Root Bark from Maytenus robusta. Nat Prod Commun, 2016; 11(5): 597-9.

2. LANAS A, CHAN FKL. Peptic ulcer disease. The Lancet, 2017; 390(10094): 613-624.

3. PETERSON K, BJORKMAN DJ. Intravenous Proton Pump Inhibitors for Bleeding Peptic Ulcer: What is the Most Cost-Effective Approach?. The American Journal of Gastroenterology, 2016; 111(10): 1399-1401.

4. SILVA LM, et al. Evidence of gastric ulcer healing activity of Maytenus robusta Reissek: in vitro and in vivo studies. Journal of ethnopharmacology, 2015; 175: 75-85.

5. ZERMIANI T, et al. Seasonal variation of gastroprotective terpenoids in Maytenus robusta (Celastraceae) quantified by gas chromatography-flame ionization detection (GC-FID). Z Naturforsch C J Biosci, 2016; 71(11-12): 369-3. 


\section{FISIOTERAPIA NO CUIDADO PALIATIVO PEDIÁTRICO: UMA REVISÃO NARRATIVA}

Jéssica de Carvalho de Morais ${ }^{1}$

1. Faculdade Santa Terezinha (CEST), São Luís - MA.

Palavras-chave: Cuidados paliativos, Fisioterapia, Pediatria.

\section{INTRODUÇÃO}

O cuidado paliativo pediátrico, é o cuidado ativo e integral voltado para crianças que possuem alguma condição limitadora como resultado de doenças graves que afetam diretamente a qualidade de vida. $O$ tratamento objetiva prevenção e alívio de sofrimento, a fim de que o paciente e seus familiares sejam confortados (OLIVEIRA ML, et al., 2021).

Apesar de historicamente a fisioterapia possuir um campo de atuação direcionado a reabilitação, dentro dos cuidados paliativos há a necessidade da expansão deste foco, para assitir demandas em todos os níveis de atenção à saúde, com atividades voltadas para prevenção de complicações e promoção de qualidade de vida (MARQUES CCO, et al., 2020).

\section{OBJETIVO}

Revisar a literatura científica que aborda sobre fisioterapia na assitência ao paciente pediátrico em cuidados paliativos com objetivo de demonstrar formas de atuação e a importância desse profissional durante o período de assistência.

\section{REVISÃO BIBLIOGRÁFICA}

Quando adaptada as necessidades do paciente, objetivando o tratamento dos sintomas e o ganho máximo de função e participação, a fisioterapia auxilia para que paciente ganhe qualidade de vida, e possa viver com conforto o mais ativamente possível (COSTA TD, et al., 2020)

A fisioterapia pode ser incluída de diversas formas dentro do cuidado paliativo, como no manejo da dor, através de técnicas como: cinesioterapia, eletroterapia e massoterapia. Nas complicações respiratórias, utilizando manobras de desobstrução de vias aéreas, manobras de reexpansão pulmonar, oxigenoterapia, ventilação mecânica entre outros procedimentos. Por se tratar de atendimento pediátrico é importante a utilização de uma abordagem que preze pela ludicidade a fim de que o paciente se sinta mais confortável e mais aberto as atividades propostas (BARBOSA JLR e IGLESIAS SOB, 2019).

O profissional fisioterapeuta se mostra como parte relevante nos cuidados paliativos, pois possui habilidades e conhecimento para a utilização de técnicas e recursos que apresentam resultados positivos para o paciente colaborando de forma positiva com a equipe interdisciplinar (BURGOS DBL, 2017). 


\section{CONSIDERAÇÕES FINAIS}

A partir dos dados encontrados na literatura sobre o tema, pode se observar que o fisioterapeuta é parte relevante da equipe interdisciplinar durante $o$ atendimento a pacientes pediátricos em cuidados paliativos, $e$ que existem diversas técnicas que podem ser utilizadas e adequadas de acordo com as metas terapêuticas a serem alcançadas.

\section{REFERÊNCIAS}

1. BARBOSA JLR, IGLESIAS SOB. O que o fisioterapeuta pode fazer pela criança em cuidados paliativos?. Residência Pediátrica. 2019. 9(3); 355-358.

2. BURGOS DBL. Fisioterapia paliativa aplicada ao paciente oncológico terminal. Ensaios e ciência: Ciêncas biológicas, agrárias e da saúde. 2017;21(2);117-122.

3. COSTA TD, et al. Cuidados paliativos ao paciente com esclerose lateral amiotrófica: vivência de fisioterapeutas no âmbito hospitalar. Revista de pesquisa: cuidado é fundamental online. 2020; 12: e9446

4. OLIVEIRA ML, et al. A importância da assistência aos pacientes em cuidados paliativos na atenção primária. Revista Eletrônica Acervo Científico. 2021; 21: e6665.

5. MARQUES CCO, et al. Cuidados paliativos: discurso de fisioterapeutas que atuam em uma unidade de terapia intensiva. Revista de pesquisa: cuidado é fundamental online. 2020; 12: e9446. 
RESUMO SIMPLES: Revisão Integrativa

\title{
ASSISTÊNCIA HUMANIZADA A MULHERES NO PERÍODO GESTACIONAL E PUERPERAL NO AMBIENTE AMBULATORIAL
}

\author{
Thiemmy de Souza Almeida Guedes ${ }^{1}$ \\ Géssica Silva Cazagrande² \\ José Arthur Silva e Sousa ${ }^{3}$ \\ Célio Pereira de Sousa Júnior ${ }^{4}$
}

Angelica Ribeiro do Nascimento Oliveira ${ }^{4}$

1. Faculdade Venda Nova do Imigrante (FAVENI), Campina Grande - PB.

2. Universidade de Vassouras (UV), Rio de Janeiro - RJ.

3. Universidade Federal do Pará (UFPA), Altamira - PA.

4. Instituto Nacional de Cursos (INCURSOS), Goiânia - GO.

Palavras-chave: Parto Humanizado, Políticas Públicas de Saúde, Gravidez.

\section{INTRODUÇÃO}

A gestação é um dos momentos mais marcantes da vida de uma mulher, mas que também é marcado por insegurança e medos sobre as descobertas de um mundo novo. Desde tempos remotos os cuidados a mulheres nos períodos pré e pós gestacional sofreram adaptações (LEAL MS, et al., 2021).

Com a finalidade de promover uma melhor qualidade de vida dessa gestante, a humanização se faz necessária. Entende-se por humanização a valorização da qualidade da assistência, na qual são respeitados os direitos e o paciente de forma integral (DOUDOU HD, et al., 2017).

\section{OBJETIVO}

Verificar, a luz da literatura científica, com o propósito de encontrar resultados suficientes que possam responder qual é a relevância da assistência humanizada para gestantes e puérperas no ambiente ambulatorial.

\section{MÉTODO}

Revisão integrativa, selecionando artigos publicados nas bases de dados LILACS e PUBMED, utilizando os descritores: Humanização da Assistência, Parto Humanizado, Políticas Públicas de Saúde e Gravidez. Com isso, foram selecionados 3 artigos por se enquadrarem nos propósitos dessa revisão. Critérios de Inclusão foram artigos que abordassem a temática em português e inglês, publicados nos últimos 5 anos; e de exclusão, literatura cinzenta e artigos que não abordassem a temática. 


\section{REVISÃO BIBLIOGRÁFICA}

No período gravídico-puerperal, faz-se necessária uma assistência de qualidade para que a qualidade de vida e conforto da gestante sejam mantidos. Portanto, a implantação da humanização nos centros de saúde e, principalmente, em maternidades enfrenta dificuldades e torna-se um verdadeiro desafio; o que implica a necessidade de mudanças que vão desde os profissionais de saúde, com capacitações e sensibilização, até adaptações quanto as estruturas físicas a fim de dar assistência a essas mulheres, bem como sua família. Vale salientar a relevância da educação continuada em saúde para efetivar e preconizar esta assistência humanizada com qualidade (POSSATI AB, et al., 2017; PEREIRA RM, et al., 2018; SILVA LF, et al., 2021).

\section{CONSIDERAÇÕES FINAIS}

Os profissionais de saúde, no papel da equipe multidisciplinar, são os principais responsáveis por ofertar um atendimento de qualidade. Vale salientar que a promoção, ofertada pelos gestores e chefias imediatas, do acesso e divulgação da existência de políticas públicas de saúde que vão proporcionar qualificação a assistência humanizada irá impactar positivamente na assistência e, consequentemente, na qualidade de vida dessas mulheres.

\section{REFERÊNCIAS}

1. DODOU HD, et al. O cuidado à mulher no contexto da maternidade: caminhos e desafios para a humanização, Revista de Pesquisa: Cuidado é fundamental, 2017; 9(1): 222-230.

2. LEAL MS, et al. Práticas de humanização no transcurso parturitivo na ótica de puérperas e enfermeiras obstétricas. Revista Brasileira de Enfermagem, 2021; 74(4): e20190743.

3. POSSATI AB, et al. Humanização do parto: significados e percepções de enfermeiras. Escola Anna Nery, 2017; 21(4): e20160366.

4. PEREIRA RM, et al. Novas práticas de atenção ao parto e os desafios para a humanização da assistência nas regiões sul e sudeste do Brasil. Ciência \& Saúde Coletiva, 2018; 23(1): 3517-3524.

5. SILVA LF, et al. Adesão às boas práticas obstétricas: construção da assistência qualificada em maternidades- escolas. Revista Baiana de Enfermagem, 2021; 35(1): 1-9. 


\section{O PAPEL DO ENFERMEIRO NA ATENÇÃO DOMICILIAR}

Victor Guilherme Pereira da Silva Marques ${ }^{1}$

Mateus Silva Soares ${ }^{2}$

Graciele da Silva Carvalho ${ }^{3}$

Victor Almeida Brito ${ }^{3}$

Bruno Abilio da Silva Machado 4

1. Centro Universitário do Piauí (UNIFAPI), Teresina - PI.

2. Faculdade de Educação São Francisco (FAESF), Pedreiras - MA.

3. Centro Universitário do Piauí (UNIFAPI), Teresina - PI.

4. Universidade Brasil (UNIVBRASIL), Teresina - PI.

Palavras-chave: Cuidados de enfermagem, Saúde da família, Visita domiciliar.

\section{INTRODUÇÃO}

A Atenção Domiciliar $(A D)$ é um instrumento de reorganização do processo de trabalho das equipes, o seu objetivo é a redução da demanda por atendimento hospitalar, favorecendo a humanização da atenção, ações de promoção da saúde e autonomia dos usuários no domicílio (LOPES GVDO, et al., 2017).

Os enfermeiros têm o papel na atenção domiciliar de avaliar as necessidades dos pacientes nos estados de saúde (física, mental, social). Sendo assim, organizam os serviços para buscar a prevenção da alta fragilidade, aumento de problemas de saúde, e dar apoio a integridade familiar por meio da busca ativa desses familiares para investigar a saúde de cada membro (ANDRADE AM, et al., 2017).

\section{OBJETIVO}

Identificar a atuação do enfermeiro no âmbito da atenção domiciliar, visando mostrar suas atribuições conforme descrito nos protocolos que lhes são repassados para assim obter resultados satisfatórios em seu atendimento às famílias.

\section{REVISÃO BIBLIOGRÁFICA}

O papel do enfermeiro é desenvolver e realizar atividades para o cuidado na visita domiciliar, este campo favorece um cuidar, mais do que técnico, mas com envolvimento afetivo, cuidado humanizado, favorecer um vínculo do profissional com o usuário. O enfermeiro realiza demandas e avalia as condições de saúde físicas e psicoemocionais desses usuários (RIBEIRO WA, et al., 2019). O enfermeiro exerce papel essencial na atenção domiciliar, tanto por estar responsável pelo plano de cuidados no domicílio e pelo vínculo que tem com os usuários, familiares e cuidadores (PROCÓPIO LCR, et al., 2019). 
Essa relação com os cuidadores tem grande importância, pois age como um facilitador, para a identificação de problemas e auxílio ao usuário em seus modos de vida. Promovendo incentivos que expressem suas experiências no cuidado ao paciente e buscando conhecer mais detalhadamente os medos existentes nessa família. A visita permite que o enfermeiro e sua equipe tenham uma aproximação à realidade em que vive os indivíduos na família (RIBEIRO WA, et al., 2019).

\section{CONSIDERAÇÕES FINAIS}

Espera-se que, com o presente estudo, que o enfermeiro siga corretamente suas atribuições na atenção domiciliar, para que possa obter resultados positivos e satisfatórios com o indivíduo a ser atendido e seus familiares no ato da visita domiciliar, buscando sempre a bem-estar de toda a comunidade.

\section{REFERÊNCIAS}

1. ANDRADE AM, et al. Atuação do enfermeiro na atenção domiciliar: uma revisão integrativa da literatura. Revista Brasileira Enfermagem, 2017; 70(1): 210-219.

2. LOPES GVDO, et al. Atenção domiciliar na estratégia saúde da família: avaliação do grau de implantação em camaçari (BA). Saúde Debate, 2017; 41(1): 241-254.

3. PROCÓPIO LCR, et al. A atenção domiciliar no âmbito do sistema único de saúde: desafios e potencialidades. Saúde Debate, 2019; 43(121).

4. RIBEIRO WA, et al. Processo de envelhecimento do idoso e protagonização do enfermeiro na visita domiciliar na atenção primária de saúde. Revista Pró-UniverSUS, 2019; 10(2): 53-58. 
RESUMO SIMPLES: Revisão Integrativa

\title{
QUEDAS EM IDOSOS E FATORES DE RISCO: ASSISTÊNCIA NA ATENÇÃO PRIMÁRIA À SAÚDE
}

\author{
Thiemmy de Souza Almeida Guedes ${ }^{1}$ \\ Géssica Silva Cazagrande ${ }^{2}$ \\ José Arthur Silva e Sousa ${ }^{3}$ \\ Célio Pereira de Sousa Júnior ${ }^{4}$
}

Angelica Ribeiro do Nascimento Oliveira ${ }^{4}$

1. Faculdade Venda Nova do Imigrante (FAVENI), Campina Grande - PB.

2. Universidade de Vassouras (UV), Rio de Janeiro - RJ.

3. Universidade Federal do Pará (UFPA), Altamira - PA.

4. Instituto Nacional de Cursos (INCURSOS), Goiânia - GO.

Palavras-chave: Idoso, Acidentes por quedas, Atenção primária à saúde.

\section{INTRODUÇÃO}

Devido ao processo natural de envelhecimento da população brasileira, está cada vez mais comum a assistência a idosas vítimas de quedas na Atenção Primária à Saúde. Com isso, se faz necessário planejamento e execução de ações de prevenção, promoção e reabilitação desse público, fornecendo apoio e suporte da equipe multiprofissional de modo a dar continuidade a essas ações e promover qualidade de vida (MIRANDA DP, et al., 2017). Com isso, ações e medidas voltadas a este público específico estão cada vez mais presente no cotidiano dos profissionais de saúdes atuantes da Atenção Primária à Saúde.

\section{OBJETIVO}

Identificar, com o auxílio da literatura científica, quais são os fatores que podem ocasionar risco de quedas em idosos que são assistidos pela equipe multidisciplinar na Atenção Primária à Saúde.

\section{MÉTODO}

Trata-se de uma revisão de literatura do tipo integrativa, realizada em setembro de 2021 na BVS e Pubmed, com os descritores "Acidentes por Quedas", "Atenção primária à saúde" e "Idoso". Critérios de inclusão foram artigos disponíveis em texto completo nos idiomas espanhol, inglês e português, publicados nos últimos 5 anos. Critérios de exclusão: pesquisas duplicadas, literatura cinzenta. Com isso, selecionou-se 5 artigos para compor esta pesquisa.

\section{REVISÃo BIBLIOGRÁFICA}


Dentre os principais fatores que contribuem para o acontecimento de quedas em idosos estão: ambientes fechados com obstáculos, tapetes, má iluminação, chão molhado e, dentre outros, calçados inadequados. Além disso verificou-se que doenças crônicas, presença de comorbidades, bem como problemas de desnutrição, advindas da má alimentação, contribuem para o aumento das chances de quedas. Questões como polifarmácia e interações advindas destas, além de sequelas de outras doenças (como marcha comprometida advinda de Acidente Vascular Encefálico) são outros fatores que aumentam os riscos de quedas (CRUVINEL FG, et al., 2020; LUZARDO AR, et al., 2018; NOGUEIRA IS, et al., 2019; REIS KMC et al., 2017; VIEIRA RS, et al., 2016).

\section{CONSIDERAÇÕES FINAIS}

Com isso, se faz necessário a promoção de ações de educação continuadas em saúde que sejam ofertadas tanto a este idoso, quanto aos seus familiares e cuidadores com o intuito de prevenção do risco de quedas. Além disso, deve-se promover ações de reabilitação, de conforto e bem-estar aos idosos que já sofreram quedas e estão em recuperação, para que haja uma melhor qualidade de vida deste.

\section{REFERÊNCIAS}

1. CRUVINEL FG, et al. Fatores de riscos para quedas de idosos em domicílio. Brazilian Journal of Heath Review, 2020; 3(1): 477 -90.

2. LUZARDO AR et al. Repercussões da hospitalização por queda de idosos: cuidado e prevenção em saúde. Revista Brasileira de Enfermagem, 2018; 71(2): 763 -769.

3. MIRANDA DP et al. Quedas em idosos em ambiente domiciliar: uma revisão integrativa. Revista Enfermagem Atual, 2017; 1(1): 120-129.

4. NOGUEIRA IS et al. Saberes e práticas dos profissionais da Atenção Primária à Saúde sobre prevenção de quedas em idosos. Revista Kairós Gerontologia, 2019; 22(4): 339 -59.

5. REIS KMC et al. Relação da Polifarmácia e polipatologia com queda em idosos hospitalizados. Texto \& Contexto - Enfermagem, 2017; 26(2): 01 -09.

6. VIEIRA RS et al. Saúde do idoso e execução da política nacional da pessoa idosa nas ações realizadas na atenção básica à saúde. Revista de Direito Sanitário, 2016; 17(1): 14 -37. 
RESUMO SIMPLES: Revisão Integrativa

\title{
FATORES QUE CONTRIBUEM PARA A PROMOÇÃO DO ALEITAMENTO MATERNO EXCLUSIVO
}

\author{
Lais Nicolly Ribeiro da Silva ${ }^{1}$ \\ Cremilson de Paula Silva ${ }^{1}$ \\ Arianny Luiza Barros de Santana ${ }^{2}$ \\ Tamíris Alves Chagas ${ }^{3}$ \\ Thiemmy de Souza Almeida Guedes ${ }^{4}$
}

1. Universidade Federal de Alagoas (UFAL), Alfenas - MG.

2. Centro Universitário UNIFACISA, Campina Grande - PB.

3. Universidade Nove de Julho (UNINOVE), São Paulo - SP.

4. Faculdade Venda Nova do Imigrante (FAVENI), Campina Grande - PB.

Palavras-chave: Aleitamento materno, Promoção da saúde, Fatores contribuintes.

\section{INTRODUÇÃO}

O aleitamento materno é extremamente importante e fornece inúmeros benefícios à saúde do bebê, especialmente nos primeiros 6 meses de vida. Além de contribuir para o amadurecimento do sistema imunológico, a amamentação também favorece a redução da mortalidade infantil. No entanto, apesar dos inúmeros benefícios, os indicadores ainda refletem uma realidade de interrupção precoce da amamentação. Acredita-se que esse indicativo reflete o desconhecimento acerca dos benefícios, a falta de orientação, a maior participação da mulher no mercado de trabalho e as dificuldades relacionadas à técnica incorreta de amamentação. Diante disso, é fundamental a disseminação de informações acerca da promoção do aleitamento materno exclusivo (SOUZA TO, et al., 2020).

\section{OBJETIVO}

Revisar e identificar na literatura científica vigente quais são os fatores e os benefícios que contribuem para a promoção e continuidade do aleitamento materno exclusivo especialmente durante os primeiros meses de vida do bebê.

\section{MÉTODO}

Revisão integrativa da literatura realizada através das bases de dados, SCIELO e MEDLINE, através dos Descritores "Aleitamento materno", "Educação em saúde" e "Promoção em Saúde". Busca realizada em setembro de 2021, os critérios de inclusão foram artigos disponíveis na íntegra, nos idiomas português, inglês e espanhol, já os critérios de exclusão foram publicações duplicadas e que tangenciavam o tema. Foram encontrados 4.432 artigos e foram selecionados 4 para compor a amostra. 


\section{REVISÃO BIBLIOGRÁFICA}

Dentre os fatores contribuintes para a promoção do aleitamento materno exclusivo, destaca-se a orientação durante o pré-natal, participação da gestante em ações de educação em saúde e o incentivo à participação em grupos de apoio (NOBRE R, et al., 2020; SOUZA TO, et al., 2020). Além disso, mulheres que vivem em áreas com maior acesso aos serviços de saúde apresentam uma maior possibilidade de obterem informações durante o pré-natal (FREIRE WB, et al., 2020).

Outrossim, o parto por vaginal, o golden hour (Refere-se a primeira hora de vida do bebê após o nascimento, é importante pois estimula o contato pele a pele com a mãe, bem como a amamentação e o acolhimento com a mãe) e a presença de uma rede de apoio destacam-se como fatores fundamentais para a continuidade da amamentação exclusiva (MARQUES BL, et al., 2020).

\section{CONSIDERAÇÕES FINAIS}

Evidenciou-se que as ações de educação em saúde e a orientação à gestante são fatores que contribuem para a promoção do aleitamento. Compreende-se que a equipe de enfermagem é fundamental para a promoção de saúde na comunidade, favorecendo a adesão das mães ao aleitamento materno exclusivo de maneira humanizadora e transformadora.

\section{REFERÊNCIAS}

1. FREIRE WB, et al. Breastfeeding practices and complementary feeding in Ecuador: implications for localized policy applications and promotion of breastfeeding: a pooled analysis. International Breastfeeding Journal, 2020; 15(1): 75.

2. MARQUES BL, et al. Orientações às gestantes no pré-natal: a importância do cuidado compartilhado na atenção primária em saúde. Escola Anna Nery [online], 2021; 25(1): e20200098.

3. NOBRE RS, et al. Construção e validação de material educativo na promoção do aleitamento materno nas escolas. Revista Brasileira de Enfermagem [online]. 2021; 74(1): e20200511.

4. SOUZA TO, et al. Efeito de uma intervenção educativa na técnica de aleitamento materno sobre a prevalência do aleitamento materno exclusivo. Revista Brasileira de Saúde Materno Infantil [online], 2020; 20(1). 


\title{
DELEÇÃO COMPLETA DOS GENES GSTM1 E GSTT1 E A SUSCETIBILIDADE PARA CÂNCER COLORRETAL: REVISÃO SISTEMÁTICA COM META-ANÁLISE
}

\author{
José Arthur Silva e Sousa ${ }^{1}$ \\ Géssica Silva Cazagrande ${ }^{2}$ \\ Célio Pereira da Silva Júnior ${ }^{3}$ \\ Thiemmy Almeida Silva Guedes ${ }^{4}$ \\ Lucas Cândido Gonçalves 5
}

1. Instituto Monte Pascoal (IMP), Goiânia - GO.

2. Universidade de Vassouras (UV), Rio de Janeiro - RJ.

3. Faculdade Venda Nova do Imigrante (FAVENI), Campina Grande - PB.

4. Universidade Federal do Pará (UFP), Altamira - PA.

5. Universidade Federal de Goiás (UFG), Goiânia - GO.

Palavras-chave: Glutationa-s-transferase, Câncer colorretal, Polimorfismo.

\section{INTRODUÇÃO}

O câncer colorretal (CCR) é uma doença complexa de procedência multifatorial (FELISBERTO SY, et al., 2021). A exposição frequente a compostos mutagênicos e genotóxicos tornam o ambiente celular suscetível ao processo de carcinogênese (O'KEEFE SJD, 2016). Para reparar ou evitar os danos causados no organismo em decorrência da exposição e interação aos compostos deletérios, às células contam com mecanismos de defesa. Neste contexto, destacam-se a enzima Glutationa-S-Transferases M1 e T1 (GSTM1 e GSTT1), respectivamente. Deleções homozigóticas no gene GSTM1 e GSTT1 caracterizam o genótipo nulo de tais genes; portanto, não há expressão das proteínas por eles codificadas (TOMASETTI C, et al., 2017).

\section{OBJETIVO}

Avaliar se o polimorfismo nulo, ou seja, a ausência por completo das duas cópias gênicas dos genes GSTT1 e GSTM1 atuam como fator de suscetibilidade para o desenvolvimento do câncer colorretal.

\section{MÉTODO}

Revisão sistemática com meta-análise. Pesquisa em PubMed, SciELO e Acervo+ index base. Selecionouse artigos casocontrole sobre genes GSTM1 e GSTT1 em pacientes com CCR. Foram selecionados 40 artigos dos 846 achados. Excluiu-se 845 por serem duplicatas ou não se tratarem de CCR. Utilizou-se odds ratio (OR), intervalo de confiança de 95\% (IC95\%). P-valores foram bicaudais e significância $<0,05$. Estatística de $I^{2}$ para heterogeneidade. Software RevMan5.3 foi utilizado (CORNFIELD J, 1951). 


\section{REVISÃO BIBLIOGRÁFICA}

Com um total de 12.698 casos e 19.517 controles. A análise demostrou risco aumentado de CCR para genótipo GSTM1 nulo OR=1,11; ou seja, risco 11\% maior com IC95\% entre 1,03 e 1,19 a significancia foi p $<0,0001$. Em oposição, para GSTT1 e a combinação GSTM1/GSTT1, apesar do risco ser maior que 010 IC95\%, no limite inferior, é menor que 01. Assim, não foi averiguado uma associação aumentada de risco para CCR, sendo: OR=1,09; ou seja, risco 9\% maior e IC95\% entre 0,98 e 1,22 significância de $p<0,00001$ e OR=1,13; ou seja, risco 13\% maior e IC95\% entre 0,89 e 1,43 significância de $p<0,00001$; respectivamente.

\section{CONSIDERAÇÕES FINAIS}

Os resultados sustentam que polimorfismo nulo GSTM1 é tido como fator de suscetibilidade para câncer colorretal, com um risco aumentado de $11 \%$. No entanto, é sabido que a suscetibilidade genética associada a interações ambientais age de modo sinérgico. Assim, pesquisas adicionais correlacionando a interação gene-ambiente para câncer colorretal são assuntos para estudos futuros.

\section{REFERÊNCIAS}

1. CORNFIELD J. A method of estimating comparative rates from clinical data. Aplications to cancer of the lung, beast and cervic. Journal National Cancer Institute, 1951; 11(1): 268-75.

2. FELISBERTO SY, et al. Câncer colorretal: a importância de um rastreio precoce. Revista Eletrônica Acervo Saúde, 2021; 13(4): e7130.

3. O'KEEFE SJD. Diet, microorganisms and their metabolites, and colon cancer. Nature Revision Gastroenterology Hepatology. 2016; 13(12): 691-706.

4. STOJKOVIC-LALOSEVIC ML, et al. Deletion and Single Nucleotide Polymorphisms in Common Glutathione-S Transferases Contribute to Colorectal Cancer Development. Pathology and Oncology Research, 2019; 25(4): 1579- 87.

5. TOMASETTI C, et al. Stem cell divisions, somatic mutations, cancer etiology, and cancer prevention. Word Health Organization chronicle, 2017; 355: 1330-34. 
RESUMO SIMPLES: Revisão Sistemática

\title{
SUPLEMENTAÇÃO DE L-ARGININA E O DESEMPENHO DE EXERCÍCIOS AERÓBIOS E ANAERÓBIOS
}

\author{
José Arthur Silva e Sousa ${ }^{1}$ \\ Géssica Silva Cazagrande ${ }^{2}$ \\ Célio Pereira da Silva Júnior ${ }^{3}$ \\ Thiemmy Almeida Silva Guedes ${ }^{4}$ \\ Lucas Cândido Gonçalves 5
}

1. Instituto Monte Pascoal (IMP), Goiânia - GO.

2. Universidade de Vassouras (UV), Rio de Janeiro - RJ.

3. Faculdade Venda Nova do Imigrante (FAVENI), Campina Grande - PB.

4. Universidade Federal do Pará (UFP), Altamira - PA.

5. Universidade Federal de Goiás (UFG), Goiânia - GO.

Palavras-chave: Arginina, Suplementação, Exercício.

\section{INTRODUÇÃO}

Suplementos dietéticos são bastante utilizados, principalmente no meio atlético, pois acredita-se que que uma dieta enriquecida com esses auxiliares ergogênicos, venham por meio de vários mecanismos fisiológicos e metabólicos melhorar o desempenho esportivo (MAUGHAN RJ, et al., 2018). A L-Arginina (L-Arg), um ergogênico relacionado ao óxido nítrico (ON), tem sido utilizada com a proposta de aumentar a força, a potência e a recuperação muscular, após exercícios aeróbios e anaeróbios (FERREIRA CC, et al., 2019). No entanto, há controversas quanto ao potencial efeito da suplementação de L-Arginina e a melhora da performance aeróbia e anaeróbia.

\section{OBJETIVO}

Revisar a literatura disponível no intuito de avaliar e sintetizar os principais efeitos da suplementação dietética do auxiliar ergogênico, L-Arg, no desempenho de exercícios físicos aeróbios (>VO2máx) e anaeróbios ( $\leq$ VO2máx).

\section{MÉTODO}

Trata-se de uma revisão sistemática de abordagem transversal dos últimos 05 anos. Pesquisa em PubMed, Medline, Scielo e Acervo+ index base. A pesquisa concentrara-se em estudos que avaliaram 0 desempenho de atletas após suplementação de L-Arg. Recuperou-se um total de 15 estudos, excluiu-se aqueles que não fosse de desenho randomizado, duplo-cego, controlado por placebo; restando 05 estudos para revisão. Utilizou-se os descritores: L-arginina, suplementação, exercícios. 


\section{REVISÃO BIBLIOGRÁFICA}

A performance anaeróbia demostrou uma melhora, especialmente, para o teste de força de Wingate e repetições totais de barras fixas. No entanto, boa parte dos estudos relataram $p$-valor $>0,05$; demonstrando que apesar da melhora a significância estatística não é favorável a isto. Em atividade aeróbia foi verificado um aumento significativo do desempenho, destaque o teste de cicloergômetro até a exaustão e Harvad Step Test. As melhoras obtidas nos testes devem-se a priori devido a L-Arg proporcionar o aumento da produção de ON, favorecendo vasodilatação, consequentemente melhorando o fluxo sanguíneo (MAUGHAN RJ, et al., 2018; MEIRELLES CM; MATSUURA C, 2018).

\section{CONSIDERAÇÕES FINAIS}

Apurou-se que há feedback positivo com relação a suplementação de L-Arg e o desempenho de atividades físicas aeróbias e anaeróbias. Havendo melhora na taxa de fadiga, exercício de tronco, pico de energia e tempo de pico de potência. Pesquisas futuras devem concentrar-se na padronização de protocolos de suplementação desses auxiliares ergogênicos, uma vez que os estudos aqui avaliados foram heterogêneos.

\section{REFERÊNCIAS}

1. FERREIRA CC, et al. Suplementação com arginina na terapia nutricional de pacientes com câncer de cabeça e pescoço. Revista Eletrônica Acervo Saúde, 2019; 27: e760.

2. MAUGHAN RJ, et al. IOC consensus statement: Dietary supplements and the high-performance athlete. Brazilian Journal of Sports Medicine, 2018; 52: 439-55.

3. MEIRELLES CM, MATSUURA, C. Acute supplementation of L-arginine affects neither strength performance nor nitric oxide production. Journal Sports Medicine Physical Fitness 2018; 58: 216-20. 
RESUMO SIMPLES: Revisão Integrativa

\title{
KLEBSIELLA PNEUMONIAE: MECANISMOS DE VIRULÊNCIA E RELAÇÃO COM RESISTÊNCIA ANTIMICROBIANA
}

\author{
Hellen Christina de Oliveira Santos ${ }^{1}$ \\ José Arthur Silva e Sousa ${ }^{1}$ \\ Lucas Cândido Gonçalves²
}

1. Instituto Monte Pascoal (IMP), Goiânia - GO.

2. Universidade Federal de Goiás (UFG), Goiânia - GO.

Palavras-chave: Patôgenese, Carbapenemase, Resistência antimicrobiana.

\section{INTRODUÇÃO}

Klebsiella pneumoniae é uma bactéria gram negativa da família Enterobactericeae, faz parte da microbiota gastrointestinal. Este microrganismo degrada antimicrobianos por enzimas, encontra-se em maior número beta- lactamases e carbapenemases (IOVLEVA A e DOI Y, 2018). Essas enzimas foram codificadas, sem a necessidade de cromossomo, com resistência por informação plasmidial (ANTIPOV D, et al., 2016) ou por transposons, elevando patogenicidade e resistência bacteriana no hospedeiro e ambiente. Ela contém fatores de virulência que podem estar relacionados a resistência antimicrobiana como, inativação por enzimas, modificação do alvo do antibiótico, mudanças na permeabilidade de membrana, bombas de efluxo e formação de biofilme (MUNITA JM, et al., 2016; BRITO GB e TREVISAN M, 2021).

\section{OBJETIVO}

Realizar um estudo por meio de revisões e análises da literatura científica sobre as possibilidades de mecanismos de virulência da Klebsiella pneumoniae contribuírem ou não para a resistência aos antimicrobianos.

\section{MÉTODO}

Trata-se de uma revisão integrativa dos últimos 5 anos, no que se refere a patogenicidade e resistência antimicrobiana da K. pneumoniae, exclusos monografias e estudos sobre outras bactérias e incluídos artigos originais recentes que alinhassem a temática. Realizou-se busca em base de dados científicos: LILACS, SCIELO, Acervo+ Index base e NCBI. Utilizando como descritores: K. pneumoniae patôgenese, carbapenemase e Mecanismos de resistência. Foram recuperados 127 resultados, após avaliação selecionaram 6 artigos.

\section{REVISÃO BIBLIOGRÁFICA}


K. pneumoniae se torna resistente a antibióticos por informação de plasmídeos ou transposons e por mecanismos de virulência que podem impedir a eficácia do medicamento. Em um estudo foi demonstrado que as adesinas e os exopolissacarídeos para grudarem em uma superfície e produzir um biofilme parecem empregar vários mecanismos como efluxo ativo e sistema QS e LPS que dificultaria o trabalho do antibiótico (VUOTTO C, et al., 2017).

A urease foi relacionada em um estudo, onde esta enzima causa precipitação de sais que leva à incrustação, principalmente em pacientes com cateteres urinários internos, facilitando formação de biofilmes que podem debilitar o tratamento com antibióticos (CLEGG S e MURPHY CN, 2016).

\section{CONSIDERAÇÕES FINAIS}

O principal fator ligado a virulência e resistência é o biofilme, que por ser uma comunidade de microrganismos com ciclos diferentes torna-se quase que impossível a passagem de antibióticos. O biofilme só é possível se houver boa adesão pelas fimbrias, urease, cápsulas, sideróforos e LPS que é um antígeno contra imunidade humoral. Sugere-se que os fatores de virulência agindo em conjunto podem colaborar para a batalha contra os antibióticos.

\section{REFERÊNCIAS}

1. ANTIPOV D, et al. PlasmidSPAdes: Assembling plasmids from whole genome sequencing data. Bioinformatics. 2016; 32(22): 3380-7.

2. BRITO GB, TREVISAN M. O uso indevido de antibióticos e o eminente risco de resistência bacteriana. Revista Artigos.com, 2021; 30: e7902

3. CLEGG S, MURPHY CN. Epidemiology and Virulence of Klebsiella pneumoniae. Microbiol Spectr. 2016; 4(1): 1-17.

4. IOVLEVA A, DOI Y. Carbapenem-resistant Enterobacteriaceae. HHS Public Access. 2018;37(2):303-15.

5. MUNITA JM, et al. HHS Public Access Mechanisms of Antibiotic Resistance. HHS Public Access. 2016; 4(2): 1-37.

6. VUOTTO $\mathrm{C}$, et al. Biofilm formation and antibiotic resistance in Klebsiella pneumoniae urinary strains. Journal Appl Microbiol. 2017; 123(4): 1003-18. 
RESUMO SIMPLES: Revisão Integrativa

\title{
O CUIDADO MULTIPROFISSIONAL À CRIANÇA ONCOLÓGICA: UMA REVISÃO INTEGRATIVA
}

\author{
Cremilson de Paula Silva ${ }^{1}$ \\ Rebeca Ferreira Nery ${ }^{2}$ \\ Williane Pereira $\mathrm{Cruz}^{3}$
}

Thiemmy de Souza Almeida Guedes ${ }^{2}$

1. Universidade Federal de Alfenas (UNIFAL), Alfenas - MG.

2. Faculdade São Francisco da Paraíba (FASP), Cajazeiras - PB.

3. Faculdade Venda Nova do Imigrante (FAVENI), Campina Grande - PB.

Palavras-chave: Equipe multiprofissional, Oncologia, Pediatria.

\section{INTRODUÇÃO}

O tratamento multifuncional às crianças oncológicas corresponde a um período longo, em que a convivência será contínua com as crianças e com os seus familiares fazendo com que os profissionais vivenciem a expectativa do tratamento e sofram verdadeiramente quando se limitam as possibilidades de cura (GUEDES AKC, et al., 2019).

Porém, há bastantes crianças que se encontram em condições crônicas ameaçadoras da vida que poderiam beneficiar-se deste modelo de cuidados em todo o percurso da doença. Em consideração a isso, a equipe multiprofissional desenvolve um papel fundamental e excelente acerca do cuidado aos pacientes neoplásicos, contribuindo com o melhor manejo acerca da assistência necessária (RODRIGUES BF, et al., 2021).

\section{OBJETIVO}

Identificar pesquisas na literatura científica, em bases de dados, com a finalidade de compreender a atuação da equipe multiprofissional de saúde acerca dos cuidados oferecidos na assistência pediátrica a pacientes oncológicos.

\section{MÉTODO}

Consiste em uma revisão integrativa, baseada em dados da Biblioteca Virtual de Saúde e Google Scholar. Os descritores, "equipe multiprofissional", "oncologia" e "pediatria" foram combinados com o operador booleano AND. Os critérios de inclusão foram: artigos completos, gratuitos, em português e inglês, de 2017 a 2021. Como critérios de exclusão: artigos que não se relacionavam com o tema. Identificou-se 1910 artigos e, após os critérios de inclusão, foram selecionados três. 


\section{REVISÃO BIBLIOGRÁFICA}

A equipe multidisciplinar é fundamental na assistência a crianças em tratamento oncológico, visto que engloba todo o trajeto terapêutico do paciente: desde o físico ao espiritual; além de fornecer orientações e apoio familiar neste momento tão delicado (LORENZZON AM, et al., 2019). Ela atuará conjuntamente para reduzir a ansiedade, incertezas e dores, de forma humanizada e holística com o objetivo de promover melhor qualidade de vida aos pacientes, bem como, estratégias de autocuidado (MARTINS GB e HORA SS, 2019). Revelou-se também a importância do elo entre os profissionais de saúde e a criança hospitalizada, na qual esta irá sentir segurança e conforto durante o tratamento (NEVES LML, et al., 2020).

\section{CONSIDERAÇÕES FINAIS}

Evidenciou-se a importância da equipe multiprofissional no tratamento de tumores infantis, visto que a equipe atuará de forma mútua na linha de frente ao cuidado oncológico, identificando as necessidades do paciente, objetivando a promoção de uma melhor qualidade de vida não somente a criança oncológica, mas também aos seus familiares. Logo, a capacitação dos profissionais é fundamental para promoção de saúde e melhoria da qualidade de vida.

\section{REFERÊNCIAS}

1. GUEDES, AKC, et al. Cuidados paliativos em oncologia pediátrica: perspectivas de profissionais de saúde. Revista da Sociedade Brasileira de Psicologia Hospitalar, 2019; 22(2): 128-148.

2. LORENZZONI AM, et al. Equipe Multiprofissional nos cuidados paliativos em oncologia: uma revisão integrativa. Revista Espaço Ciência e Saúde, 2019; 7(1): 34-48.

3. MARTINS GB, HORA SS. Desafios à Integralidade da Assistência em Cuidados Paliativos na Pediatria Oncológica do Instituto Nacional de Câncer José Alencar Gomes da Silva. Revista Brasileira de Cancerologia, 2019; 63(1): 29- 37.

4. NEVES LML, et al. Cuidados paliativos oncológicos ou cuidados ao fim de vida? O desafio de uma equipe multiprofissional. Saúde em Redes, 2020; 6(3): 25-37.

5. RODRIGUES BF, et al. A comunicação de notícias difíceis por enfermeiros em cuidados paliativos oncológicos pediátricos: uma revisão integrativa. Pesquisa, Sociedade e Desenvolvimento, 2021; 10(10): e335101018788. 


\title{
IMPACTOS DA POLIFARMÁCIA NA SAÚDE DO IDOSO
}

\author{
João Guilherme Sabino da Silva ${ }^{1}$ \\ João Marcos da Silva Costa ${ }^{1}$ \\ Lethícia Maria de Souza Aguiar ${ }^{1}$ \\ Mayara Larissa Melo Ferreira dos Santos ${ }^{1}$ \\ Manuela Carine Cavalcante Erhardt ${ }^{1}$
}

1. Universidade Federal de Pernambuco (UFPE), Recife - PE.

Palavras-chave: Polifarmácia, Idoso, Tratamento farmacológico.

\section{INTRODUÇÃO}

A população idosa vem aumentando nos últimos anos, e isso é um fator preocupante para a saúde pública devido as pessoas com mais de 60 anos apresentarem alta incidência de doenças crônicas. Consequentemente, fazem uso de uma grande quantidade de fármacos, podendo chegar até a situação de polifarmácia, que é o uso concomitante de quatro ou mais medicamentos (SOUZA DM, et al., 2018).

O tratamento farmacológico em pessoas idosas é bastante complexo, devido a comorbidade e às alterações fisiológicas que podem levar a alterações farmacocinéticas, que aumentam a ocorrência de problemas como reações e toxicidade dos medicamentos, sendo necessário atenção e cuidado (ARAUJO BG, et al., 2019).

\section{OBJETIVO}

Revisar a literatura científica acerca da prática de polifarmácia na população idosa, com ênfase nos fatores de risco, principais causadores dos Problemas Relacionados a Medicamentos (PRM), e seus impactos na sobrevida e qualidade de vida desse grupo etário.

\section{REVISÃO BIBLIOGRÁFICA}

Um estudo evidenciou que grande parte da população idosa está em situação de polifarmácia (ROMANOLIEBER NS, et al., 2018). Tais dados são reflexos da alta prevalência de doenças crônicas não transmissíveis em indivíduos desse grupo etário, que requerem a associação de vários medicamentos para o tratamento. Além disso, em alguns casos, a prescrição desses fármacos é feita por diferentes especialistas, o que pode gerar casos de duplicidade terapêutica, interação medicamentosa e PRM (SOUZA DM, et al., 2018).

Os problemas causados pela polifarmácia afetam de forma negativa a saúde do idoso (RAMOS LR, et al., 2016). Os PRM reduzem a adesão à farmacoterapia, enquanto que a duplicidade terapêutica encarece o tratamento e pode aumentar as chances de interação medicamentosa. Além disso, a própria interação medicamentosa pode anular ou potencializar os efeitos de outros fármacos e aumentar as chances de queda, 
reações adversas a medicamentos, causando prejuízo ao quadro clínico do idoso (CARLI FVBO, et al., 2019; de SOUZA DM et al., 2018).

\section{CONSIDERAÇÕES FINAIS}

A partir dos dados existentes na literatura sobre o tema, é possível perceber que a polifarmácia pode causar malefícios à saúde do idoso. Assim, é válido destacar o papel do farmacêutico para minimizar os problemas causados por essa prática. Os serviços de atenção farmacêutica, como o acompanhamento farmacoterapêutico, minimizam os problemas e contribui para o uso racional de medicamentos, otimizando 0 tratamento.

\section{REFERÊNCIAS}

1. ARAUJO BG, et al. Prevalência do uso de medicamentos potencialmente inapropriados ao idoso no Brasil: uma revisão sistemática. Revista Kairós-Gerontologia, 2019; 22(4): 119-139.

2. CARLI FVBO, et al. Ocorrências de quedas em idosos e a polifarmácia. Revista Eletrônica Acervo Saúde, 2019; 37: e1082.

3. de SOUZA, DM et al. Uso inapropriado de medicamentos pelo idoso: Polifarmácia e seus efeitos. Revista Pensar Acadêmico, 2018; 16(2): 166-178

4. RAMOS LR, et al. Polifarmácia e polimorbidade em idosos no Brasil: um desafio em saúde pública. Revista Saúde Pública, 2016; 50(2): 1s-13s.

5. ROMANO-LIEBER NS, et al. Sobrevida de idosos e exposição à polifarmácia no município de São Paulo: Estudo SABE. Revista Brasileira de Epidemiologia, 2018; 21: e180006. 
RESUMO SIMPLES: Revisão Integrativa

\title{
SUPLEMENTAÇÃO DE ÁCIDO FÓLICO NA GESTAÇÃO: UMA REVISÃO INTEGRATIVA
}

\author{
Ana Flávia Conegundes Benício ${ }^{1}$ \\ Letícia Chagas Rocha ${ }^{2}$ \\ Laura Machado Campos ${ }^{1}$
}

1. Universidade Federal de Minas Gerais (UFMG), Belo Horizonte - MG.

2. Universidade de São Paulo (USP), Ribeirão Preto - SP.

Palavras-chave: Suplementação, Ácido fólico, Gestação.

\section{INTRODUÇÃO}

O Ácido Fólico (AF) é uma vitamina hidrossolúvel e pode ser sinteticamente produzido, sendo encontrado tanto em alimentos fortificados quanto em suplementos (BOMFIM VVBS, et al., 2020). A suplementação de AF no período pré-concepção e na gestação previne Defeitos no Tubo Neural (DTNs). Estudos randomizados evidenciam a eficácia da suplementação de ácido fólico para diminuir a ocorrência de DTNs em cerca de $70 \%$, sem efeitos evidentes em relação a outros defeitos congênitos (PARISI F, et al., 2019). Ademais, a suplementação materna de AF no primeiro trimestre relaciona-se a uma menor prevalência de Doenças Cardíacas Congênitas (DCCs) e de fenótipos mais específicos de DCCs no feto (QU Y, et al., 2020).

\section{OBJETIVO}

Revisar, por meio da literatura científica, as descrições acerca dos efeitos da suplementação do ácido fólico na gestação e analisar os benefícios e as doses recomendadas dessa suplementação em gestantes.

\section{MÉTODO}

Trata-se de uma revisão integrativa realizada em setembro de 2021, por meio de pesquisas nas bases de dados PubMed e Acervo+ Index base. Foram utilizados os descritores "suplementação", "ácido fólico" e "gestação", intercalados pelo operador booleano AND. Os critérios de inclusão foram: artigos nos idiomas português e inglês, publicados nos últimos 5 anos. O critério de exclusão foi: artigos que não atendiam a temática. Assim, 3 artigos foram selecionados.

\section{REVISÃO BIBLIOGRÁFICA}

Em uma revisão bibliográfica, verificou-se a indicação de suplementação de ácido fólico antes da concepção até o terceiro mês gestacional, a fim de prevenir Defeitos no Tubo Neural (DTN) do feto (BOMFIM VVBS, et al., 2020). Em outra revisão, verificou-se que uma suplementação diária de ácido fólico $400-800 \mu \mathrm{g}$ é recomendada para mulheres que desejam engravidar. A dose deve ser aumentada $(4-5 \mathrm{mg} / \mathrm{d})$ em pacientes com alto risco de DTN ou com deficiência de folato (PARISI F, et al., 2019). Em um estudo caso-controle, 
evidenciou-se que a suplementação de ácido fólico está associada à menor prevalência de doenças cardíacas congênitas no feto (QU Y, et al., 2020).

\section{CONSIDERAÇÕES FINAIS}

Verifica-se que a suplementação de ácido fólico durante a gestação é importante para prevenir defeitos no tubo neural. A dose recomendada para mulheres saudáveis desse suplemento é de 400 a $800 \mu \mathrm{g}$, sendo que essa concentração deve ser aumentada caso a gestante apresente alto risco de DNT ou deficiência de AF. Outrossim, o AF é relevante para evitar doenças cardíacas congênitas. Novos estudos devem ser realizados para o aprimoramento do tema.

\section{REFERÊNCIAS}

1. BOMFIM VVBS, et al. Repercussões da deficiência de ferro durante a gestação e puerpério para o binômio materno-fetal. Revista Eletrônica Acervo Saúde, 2020; 12(12): e5154.

2. PARISI $F$, et al. Micronutrient supplementation in pregnancy: Who, what and how much? Obstetric Medicine, 2019; 12(1): 5-13.

3. QU Y, et al. First-Trimester Maternal Folic Acid Supplementation Reduced Risks of Severe and Most Congenital Heart Diseases in Offspring: A Large Case-Control Study. Journal of the American Heart Association, 2020; 9(13): e015652. 


\title{
FISIOTERAPIA NO MANEJO DA DOR NEONATAL
}

\author{
Jéssica de Carvalho de Morais ${ }^{1}$ \\ Juliana do Nascimento Cantanhede ${ }^{1}$
}

1. Faculdade Santa Terezinha (CEST), São Luís - MA.

Palavras-chave: Dor, Fisioterapia, Recém-nascido.

\section{INTRODUÇÃO}

O recém-nascido (RN) hospitalizado é submetido a diversos procedimentos clínicos que podem gerar dor, desconforto e estresse. A dor é considerada o quinto sinal vital e por isso deve ser avaliada sempre que houver necessidade. No RN a mensuração desse parâmetro é mais difícil já que não é possível a comunicação verbal, por isso é importante que a equipe responsável pelo atendimento esteja preparada para 0 atendimento adequado desse paciente (PEREIRA LSS, et al., 2019). O fisioterapeuta, como parte da equipe interdisciplinar deve possuir conhecimento adequado de fisiologia, avaliação e do manejo efetivo da dor, sempre priorizando pela sua prevenção (SILVA ACOC, 2018).

\section{OBJETIVO}

Revisar a literatura científica que aborda sobre a fisioterapia no manejo da dor neonatal com a finalidade de apresentar os métodos e técnicas utilizadas durante a assistência no âmbito hospitalar.

\section{REVISÃO BIBLIOGRÁFICA}

A assistência adequada para manejo da dor nos RNs deve incluir uma avaliação adequada e a minimização dos procedimentos realizados, podem ainda ser utilizadas intervenções farmacológicas e nãofarmacológicas, todas essas medidas podem auxiliar no alívio da dor (UEMA RTB, et al., 2021).

Por ser um dos profissionais atuando no ambiente hospitalar o fisioterapeuta deve se preocupar com a prevenção e a redução do desconforto neonatal garantindo a excelência do cuidado. Para a avaliação, são considerados os fatores físicos e comportamentais e são utilizadas diversas escalas para mensuração da dor, estima-se a existência de cerca de 30 escalas validadas, uma das mais conhecidas é a Neonatal Infant Pain Scale (NIPS) (GIMENEZ IL, et al., 2020).

Estratégias não farmacológicas tem se mostrado eficaz no tratamento da dor, pois conseguem a anular em curto prazo, exemplos dessas estratégias são: a contenção e o enrolamento de conforto; criação de ambientes adequados com redução de ruídos, diminuição de luminosidade e horário de sono préestabelecido; e a aplicação do método mãe canguru (SOARES RX, et al., 2019).

\section{CONSIDERAÇÕES FINAIS}


A partir dos dados encontrados na literatura sobre o tema pode se observar que existem diversas estratégias que podem ser utilizadas pela fisioterapia no manejo da dor no RN, e para que essas técnicas possam ser utilizadas de forma adequada uma boa avaliação deve ser realizada, e o profissional deve sempre prezar pela prevenção. Ressalta-se a necessidade de mais estudos voltados para as especificidades da atuação fisioterapêutica na dor neonatal.

\section{REFERÊNCIAS}

1. GIMENEZ IL, et al. Dor neonatal: caracterização da percepção do profissional fisioterapeuta na unidade de terapia intensiva neonatal. Revista Paulista de Pediatria. 2020; 38: e2018178.

2. PEREIRA LSS, et al. Conhecimento dos profissionais de enfermagem na avaliação da dor neonatal em uma unidade de terapia intensiva. Revista Eletrônica Acervo Científico. 2019; 11: e1122.

3. SILVA ACOC. Implementação das escalas de dor em recém-nascidos internados na unidade de terapia intensiva. Revista Eletrônica Atualiza Saúde. 2018; 7(7); 45-52.

4. SOARES RX, et al. Dor em neonatos: avaliações e intervenções farmacológicas e não farmacológicas. Revista de ciências médias e biológicas. 2019; 18(1); 128-134.

5. UEMA RTB, et al. Manejo da dor do recém-nascido internado em unidade de terapia intensiva neonatal. Brasilian Journal of Health Review. 2021; 4(2); 4785-4797. 


\title{
A IMPORTÂNCIA DA VIGILÂNCIA EPIDEMIOLÓGICA NO COMBATE À DOENÇA DE CHAGAS: REVISÃO INTEGRATIVA
}

\author{
Leonardo Fernandes Geres ${ }^{1}$ \\ Larissa Teodoro Rabi ${ }^{1}$ \\ Tais Rondello Bonatti ${ }^{1}$
}

1. Universidade Paulista (UNIP), Campinas - SP.

Palavras-chave: Doença de Chagas, Epidemiologia, Saúde coletiva.

\section{INTRODUÇÃO}

O Trypanosoma cruzi é um protozoário que desenvolve a patogenia no ser humano a partir do seu alojamento em tecidos, causando a Doença de Chagas (DC). A sua transmissão está altamente relacionada com duas vias, a oral e a vetorial. O vetor Triatoma infestans infectado pelo parasito, pode transmitir a doença através da defecação dos protozoários durante o repasto sanguíneo e pela maceração do inseto vetor junto com alimentos. Além de se tratar de uma doença de notificação compulsória, a DC é um problema de grande relevância política e socioeconômica, devido a sua alta incidência em trabalhadores rurais (ACOSTA RODRÍGUEZ EV, et al., 2019; CORREIA JR, et al., 2021).

\section{OBJETIVO}

Revisar trabalhos originais com abrangência nacional de amostragem epidemiológica com o intuito de trazer o perfil epidemiológico da Doença de Chagas pelo país ao longo dos anos, relacionando a epidemiologia com o controle da doença.

\section{MÉTODO}

Trata-se de uma pesquisa de revisão integrativa. Para tal, foram realizadas buscas nas bases de dados Scielo, Pubmed e Lilacs, utilizando como descritores: "Chagas Disease", "Incidence Chagas disease" e "Mortality Chagas disease", procedeu-se à análise de dez artigos e foram selecionados quatro artigos para o presente estudo. Foram incluidos artigos dos últimos 5 anos que atenderam a proposta de amostragem epidemiológica nacional. Foram excluídos artigos de revisão, teses, dissertações e artigos que não tem relação com o tema pesquisado.

\section{REVISÃO BIBLIOGRÁFICA}

Os resultados encontrados mostram que o inseto vetor foi controlado na década de 80 e 90 devido às medidas políticas, principalmente pela primeira análise de inquérito nacional, realizada ente 1975 e 1980 por uma iniciativa de campanhas de saúde pública. Os resultados auxiliaram na melhor estratificação do controle 
ao inseto vetor, mas, por outro lado, a doença de Chagas permaneceu negligenciada, com um fraco sistema de testagem. Atualmente a doença ainda permanece prevalente e a principal fonte de infecção no Brasil é a transmissão oral (SANGENIS LHC, et al., 2016; SANTOS EF, et al., 2020).

\section{CONSIDERAÇÕES FINAIS}

As pesquisas deste artigo de revisão integrativa apontam que a maior parte dos estudos atuais utilizam técnicas analíticas e geoprocessamento a partir de dados secundários como o Sistema de Informação de Agravos e Notificações (SINAN), entre outros. Assim, se expõe a necessidade de trabalhos com amostragem epidemiológica em nível nacional, devido aos poucos trabalhos originais encontrados.

\section{REFERÊNCIAS}

1. ACOSTA RODRÍGUEZ EV, et al. Understanding CD8+ T Cell Immunity to Trypanosoma cruzi and How to Improve It. Trends in Parasitology, 2019; 35(11): 899-917.

2. CORREIA JR, et al. Doença de Chagas: aspectos clínicos, epidemiologicos e fisiopatológicos. Revista Eletrônica Acervo Saúde, 2021; 13(3): 1-7.

3. SANGENIS LHC, et al. Transmissão da doença de Chagas por consumo de carne de caça: Revisão sistemática. Revista Brasileira de Epidemiologia, 2016; 19(4): 803-11

4. SANTOS EF, et al. Acute chagas disease in brazil from 2001 to 2018: A nationwide spatiotemporal analysis. Plos Neglected Tropical Diseases, 2020; 14(8): 1-16. 


\section{EDUCAÇÃO EM SAÚDE: UMA ESTRATÉGIA NA IMPLEMENTAÇÃO DO NÚCLEO DE SEGURANÇA DO PACIENTE}

Jose Luis Silva dos Santos 1

Giselda Bezerra Correia Neves ${ }^{1}$

1. Centro Universitário Brasileiro (UNIBRA), Recife - PE.

Palavras-chave: Segurança do paciente, Educação permanente, Ensino.

\section{INTRODUÇÃO}

O Núcleo de Segurança do Paciente (NSP) faz parte do serviço de saúde, objetiva-se proporcionar a realização de ações que favoreça à segurança do paciente e consequentemente a redução de erros assistenciais (BRASIL, 2016). Os serviços de saúde devem reforça a importância do NSP, considerando que a segurança do paciente condiz à diminuição significativa de riscos à saúde (BRASIL, 2020).

A educação em saúde estimula a diversificação de estratégias para compartilhar conhecimentos e experiências, além, de despertar os profissionais da saúde para uma reflexão sobre as suas práticas e condutas. Essas medidas proporcionam a implementação de programas, tais como o de segurança do paciente (WAGNER W, et al., 2016).

\section{OBJETIVO}

Realizar uma revisão integrativa da literatura científica sobre a educação em saúde como estratégia para a implementação do Núcleo de Segurança do Paciente e suas contribuições para segurança do paciente, por meio da diminuição de erros associado as atividades assistenciais.

\section{REVISÃO BIBLIOGRÁFICA}

O NSP deve ser implementado nos serviços de saúde com o objetivo de propor ações de melhoria da qualidade e da segurança do paciente (BRASIL, 2016). Nesse sentido, os erros ocorridos na área da saúde, não são ao acaso e buscam-se métodos de eliminá-las ou ao menos minimiza-las. É necessário que as instituições hospitalares definam seus processos assistenciais (COSTA OSF, et al., 2019).

As intervenções educativas a respeito da segurança do paciente resultam em melhorias no processo de trabalho, e auxiliam no processo de minimização dos riscos, porque sensibilizam os profissionais de modo a garantir que os mesmos mantenham ações de boas práticas (MARINHO MM, et al., 2018).

\section{CONSIDERAÇÕES FINAIS}

A presente pesquisa evidenciou a importância da educação em saúde como estratégia para a implementação do NSP, tendo em vista que este núcleo favorece a segurança do paciente. Conclui-se que 
ao implementar o NSP nos serviços de saúde é possível identificar a importância para os pacientes, familiares, profissionais de saúde e gestores, além de possibilitar a identificação das necessidades das instituições, assim proporcionando a qualidade e a segurança do paciente.

\section{REFERÊNCIAS}

1. BRASIL. Manual do Ministério de Saúde. Implantação do Núcleo de Segurança do Paciente em Serviços de Saúde -Série Segurança do Paciente e Qualidade em Serviços de Saúde. 2016. Disponível em: https://www.saude.go.gov.br/images/imagens_migradas/upload/arquivos/2017-09/2016-anvisa--caderno6--- implantacao-nucleo-de-seguranca.pdf. Acesso em: 26 set. 2021.

2. BRASIL. Manual do Ministério de Saúde. Núcleo de Segurança do Paciente - NSP. 2020. Disponível em: https://www.gov.br/ebserh/pt-br/hospitais-universitarios/regiao-sudeste/huufj/saude/vigilancia-em-saudee- seguranca-do-paciente/nsp-nucleo-de-seguranca-do-paciente. Acesso em: 26 set. 2021.

3. COSTA OSF, et al. Segurança do paciente: Percepção de profissionais de saúde de uma fundação pública estadual de Belém-PA. Revista Eletrônica Acervo Saúde, 2019; 11(9): e350.

4. MARINHO MM, et al. Intervenções educativas com profissionais de enfermagem e sua relação com a cultura de segurança. Revista Mineira de Enfermagem, 2018; 22: e-1148

5. WAGNER W, et al. Educação para cultura da segurança do paciente: Implicações para a formação profissional. Revista Escola Anna Nery, 2016; 20(3): e20160068. 


\title{
ESTRATÉGIAS EDUCATIVAS PARA PREVENÇÃO DA COVID-19
}

\author{
Patricia Cavalcante Castro do Nascimento ${ }^{1}$ \\ Kadja de Fatima Pinheiro Freitas da Silva² \\ Juliana Gomes Ferreira ${ }^{3}$ \\ Daniele Silva Simões Cavalcanti ${ }^{4}$
}

1. Universidade Federal de Pernambuco (UFPE), Recife - PE.

2. Instituto Aggeu Magalhães/Fundação Oswaldo Cruz (IAM/Fiocruz), Recife - PE.

3. Hospital das Clínicas de Pernambuco (HC/UFPE), Recife - PE.

4. Faculdade de Ciências Humanas de Olinda (FACHO), Olinda - PE.

Palavras-chave: Educação em saúde, Prevenção de doenças, Infecção pelo coronavírus.

\section{INTRODUÇÃO}

Foi identificado em dezembro de 2019 na China um vírus que causava graves problemas respiratórios, alastrando-se rapidamente para outos países. Posteriormente denominado como COVID-19. A Organização Mundial de Saúde (OMS) em 11 de março de 2020 declarou a doença como uma pandemia (NÓBREGA CBM e TEODOSLO SSCS, et al., 2020).

Com o súbito surgimento e sem conhecimento prévio de tratamento ou prevenção a disseminação da doença alcançou rapidamente todas as regiões do Brasil. Uma importante estratégia para prevenir a transmissão da COVID-19 está no foco da educação, que contribui na formação de uma consciência critica estimulando as condutas que corroboram principalmente para o seu controle (SOUZA JS, et al., 2020).

\section{OBJETIVO}

Realizar um levantamento bibliográfico para identificar quais estratégias educativas têm sido utilizadas na sensibilização da população para combater e prevenir o adoecimento pelo vírus da COVID-19 e suas possíveis consequências.

\section{MÉTODO}

Este estudo trata-se de uma Revisão Integrativa da Literatura com busca nas bases de dados Scielo, Medline e Lilacs, no período de setembro de 2021. Critérios de inclusão: estudos publicados nos idiomas português e inglês, nos últimos dois anos. Excluídos: textos da literatura cinzenta. Encontrados 25 artigos, destes foram selecionados quatro artigos enquadrados ao objetivo do estudo, palavras-chave utilizadas: Educação em saúde, Prevenção de doenças, Infecção pelo coronavírus. 


\section{REVISÃO BIBLIOGRÁFICA}

A Organização Mundial de Saúde (OMS) recomenda que é necessário educar plenamente o público em geral sobre a seriedade do COVID-19 e do seu importante papel como disseminador da doença, assim, além das medidas farmacológicas é fundamental a adoção de estratégias de educação em saúde conhecidas como medidas não farmacológicas voltadas para prevenção da doença (NEVES VNS, et al., 2021).

Essas medidas como o distanciamento social, quarentena de indivíduos infectados, etiqueta respiratória e lavagem das mãos são importantes estratégias educativas em saúde voltadas para diminuir a propagação do vírus e apresentam-se como mais uma opção possível no combate a pandemia (CARVALHO KM, et al., 2021).

\section{CONSIDERAÇÕES FINAIS}

Dada a magnitude da pandemia da covid-19, tornou-se imprescendível um projeto de educação em saúde, com informações sanitárias esclarecedoras, com manuais, panfletos e publicações diárias nos meios de comunicação vigentes, afim de abarcar o maior número possível de pesssoas e com isso contribuir para formar uma consciência crítica e coletiva a respeito da COVID-19, alancando dessa forma a prevenção do mesmo.

\section{REFERÊNCIAS}

1. CARVALHO KM, et al. A crença em saúde na adoção de medidas de prevenção e controle da COVID-19. Revista Brasileira de Enfermagem, 2021; 74: e20200576.

2. NEVES VNS, et al. Utilização de lives como ferramenta de educação em saúde durante a pandemia pela Covid-19. Educação e Sociedadde, 2021; 42: e240176.

3. NÓBREGA CBM, TEODOSLOS SCS. Estratégias e ações desenvolvidas no enfrentamento da covid-19. Revista Extensão e Sociedade, 2020; 12: e21786054.

4. SOUZA JS, et al. Ações de educação em saúde para prevenção da Covid-19 por meio da utilização de mídias sociais. Arquivos de Ciências Veterinárias e Zoologia da UNIPAR, 2021; 23: e2306. 


\title{
A CONCENTRAÇÃO DE IL-6 NO SANGUE PERIFÉRICO E O TRATAMENTO COM TOCILIZUMABE
}

\author{
Amanda Miranda da Silva ${ }^{1}$ \\ Leidiana Sousa Sampaio ${ }^{1}$ \\ Lizia Carreiro Tomaz Aguiar ${ }^{1}$ \\ Débora Cavalcante Braz ${ }^{1}$
}

1. Universidade Federal do Piauí (UFPI), Teresina - PI.

Palavras-chave: Artrite reumatoide, Interleucina 6, Tocilizumabe.

\section{INTRODUÇÃO}

A Artrite reumatoide (AR) é uma doença inflamatória crônica de origem desconhecida que causa destruição articular. O Tocilizumabe (TCZ) é um dos imunobiológicos utilizado no tratamento, promove o bloqueio dos receptores de Interleucina 6 (IL-6) e, consequentemente, das vias de sinalização dessa citocina inflamatória (BRASIL, 2019).

Considerando que o mecanismo de ação não está descrito detalhadamente, é importante compreender preditores de resposta. Os pacientes com AR apresentam níveis mais elevados de IL-6 quando comparado aos controles saudáveis. Além disso, a responsividade ao TCZ pode não ser o mesmo (DIAZ-TORNE C, et al., 2017). Assim, é importante compreender a concentração de IL-6 para que possa ser aplicado no monitoramento do paciente.

\section{OBJETIVO}

Avaliar por meio de uma revisão da literatura científica se a melhora clínica de pacientes com AR em tratamento com o TCZ tem relação com a diminuição na concentração de IL-6 no sangue periférico.

\section{MÉTODO}

Nesta revisão integrativa os descritores "Interleukin 6", "IL-6", "Rheumatoid Arthritis", "atlizumab", "actemra", "human" and "serum" foram inseridos nas bases de dados PubMed, Scientific Electronic Library Online e Virtual library in Health, em abril de 2021, no período de 1991 a 2021. Pesquisas prospectivas ou restropectivas realizadas em humanos com AR e que apresentavam a concentração de IL-6 foram selecionadas. Do total de 257 publicações, 11 estudos foram incluídos.

\section{REVISÃO BIBLIOGRÁFICA}

Os artigos avaliaram o total de 1.583 pacientes com AR. Desses, 63,58\% mostraram que os pacientes com AR tratados com TCZ apresentaram melhora clínica, mas a concentração de IL-6 permanecia elevada 
após o tratamento. O tempo de terapia e o quadro clínico do paciente parecem ser parâmetros decisivos para determinar concetração da IL-6 durante o tratamento, considerando que após 4 meses os níveis de IL-6 permaneciam mais elevados (HOFFMAN E, et al., 2019), mas relatou-se uma redução após 6 semanas (SAIKI O e HIROSHI U, 2018). Alguns estudos não descrevem as características clínicas e laboratoriais dos pacientes antes do tratamento, fato que pode influenciar na resposta clínica e na concentração de IL-6 observadas.

\section{CONSIDERAÇÕES FINAIS}

Assim, os dados obtidos nesta revisão indicam que a concentração de IL-6 no sangue periférico, para a maioria dos pacientes com AR, não tem relação direta com a melhora do quadro clínico. No entanto, como existem controvérsias, novas pesquisas devem ser realizadas para definir em quais condições clínicas e laboratoriais é possível observar a redução dos níveis de IL-6 durante o tratamento com TCZ.

\section{REFERÊNCIAS}

1. BRASIL. Ministério da saúde. Secretaria de atenção especializada à saúde. Secretaria de Ciência, Tecnologia e Insumos Estratégicos. Portaria conjunta $N^{\circ} 16$, de 5 de novembro de 2019. Aprova 0 Protocolo clínico e diretrizes terapêuticas da artrite reumatoide. Disponivel em: portalarquivos2.saude.gov.br/imagens/pdf/2019/novembro/08/SITE-Portaria-Conjunta-PCDT-ArtriteReumatoide.pdf. Acessado em: 25 de maio de 2021.

2. CRISTINA GS, CUNHA FBR. Avanços e perspectivas dos estudos da artrite reumatoide. Revista Eletrônica Acervo Saúde, 2017; 6: S386-S391.

3. DIAZ-TORNE C, et al. The combination of IL-6 and its soluble receptor is associated with the response of rheumatoid arthritis patients to tocilizumab. Seminars in Arthritis and Rheumatism, 2017; 47(6): 757-764.

4. HOFFMAN E, et al. Effects of Tocilizumab, an Anti-Interleukin-6 Receptor Antibody, on Serum Lipid and Adipokine Levels in Patients with Rheumatoid Arthritis. International journal of molecular sciences, 2019; 20(18): 4633.

5. SAIKI O, HIROSHI U. Efficacy and safety of extending intravenous tocilizumab intervals from 4 to 6 weeks in rheumatoid arthritis patients with good response to 4-week intervals. Rheumatology international, 2018; 38(12): 2307-2313. 


\title{
ATUAÇÃO FARMACÊUTICA NO COMBATE DO USO INDISCRIMINADO DE MEDICAMENTOS NA PANDEMIA DE COVID-19
}

\author{
Sandra Cristina Ferreira do Rosário ${ }^{1}$ \\ Izadora da Silva Marques ${ }^{1}$ \\ Daniella Paternostro de Araújo ${ }^{1}$
}

1. Universidade da Amazônia (UNAMA), Belém - PA.

Palavras-chave: Medicamentos, Pandemia, Covid-19.

\section{INTRODUÇÃO}

A doença de Covid-19, causada pelo novo coronavírus (SARS-CoV-2), iniciou em dezembro de 2019, em Wuhan na China, com alto poder de transmissão tornou-se uma infecção global, no qual a pessoa pode ser assintomática ou ter sintomas de leves a graves (SOUZA LPM, et al., 2021). À medida que a doença se propagou, atitudes desesperadas com o intuito de prevenir, diminuir a infecção, e os sintomas da doença foram tomadas, como o uso indiscriminado de medicações (HERMES FS, et al., 2021). Diante disso, estudos de possíveis terapias farmacológicas estão sendo produzidos, como estratégia para combater a infecção, pois houve um aumento no consumo de medicamentos (BRAÚNA CC, et al., 2021).

\section{OBJETIVO}

Realizar uma revisão narrativa de literatura com o objetivo de evidenciar a relevância da atuação do profissional farmacêutico no combate do uso indiscriminado de medicamentos como medida de prevenção e tratamento na pandemia de Covid-19.

\section{REVISÃO BIBLIOGRÁFICA}

O atual coronavírus tem um elevado poder de disseminação de pessoa para pessoa, acarretando problemas de baixa complexidade como tosse seca, cansaço, dor de garganta e cefaleia, no entanto em alguns indivíduos apresenta-se quadros mais graves da doença (SOUZA LPM, et al., 2021). Em virtude das supracitadas complicações causadas pela Covid-19 a população recorreu a métodos profiláticos não testados com o propósito de proteção contra os possíveis agravamentos da patologia (HERMES FS, et al., 2021).

Contudo, a Organização Mundial de Saúde (OMS) ratifica que até o momento não existem comprovações científicas que embasem o uso de um tratamento medicamentoso com efetividade e segurança comprovada, com exceção da vacina, para Covid-19 (BRAÚNA CC, et al., 2021). Em vista disso, o farmacêutico tem papel imprescindível na promoção de ações de autocuidado, educação em saúde e na prevenção da automedicação, fazendo um acompanhamento farmacoterapêutico e oferecendo as devidas orientações no ato da dispensação do fármaco (BARROS DSL, et al., 2020). 


\section{CONSIDERAÇÕES FINAIS}

Baseado nos estudos utilizados, presentes na literatura, até o momento não foi comprovado cientificamente um tratamento farmacológico eficaz que combata a Covid-19, consequentemente, o uso inapropriado de medicamentos tem gerado problemas graves à saúde. Por conseguinte, mais estudos precisam ser realizados relacionando à importância do farmacêutico na prevenção da automedicação.

\section{REFERÊNCIAS}

1. BARROS DSL, et al. Serviços farmacêuticos clínicos da atenção primária à saúde do Brasil. Revista Trabalho, Educação e Saúde, 2020; 18(1): e0024071.

2. BRAÚNA CC, et al. Farmacoeconomia aplicada ao tratamento medicamentoso para a COVID-19 em um hospital campanha, Revista Eletrônica Acervo Saúde, 2021; 13(2): e5971.

3. HERMES FS, et al. Análise de tratamentos profiláticos para a COVID-19: uma revisão integrativa, Revista Eletrônica Acervo Saúde, 2021; 13(5): e7167.

4. SOUZA LPM, et al. Terapias medicamentosas propostas no manejo da COVID-19, Revista Eletrônica Acervo Saúde, 2021; 13(4): e6782. 


\title{
A RELEVÂNCIA DA SUPLEMENTAÇÃO DA VITAMINA B12 EM DIETAS VEGETARIANAS
}

\author{
Dhiéssica de Fátima Gonçalves de Souza ${ }^{1}$ \\ Maria Clara Costa Gonçalves ${ }^{1}$ \\ Kássia Héllen Vieira ${ }^{2}$
}

1. Faculdades Integradas do Norte de Minas (FUNORTE), Montes Claros - MG.

2. Faculdade de Saúde e Humanidades Ibituruna (FASI), Montes Claros - MG.

Palavras-chave: Cobalamina, Suplementos nutricionais, Vegetarianismo.

\section{INTRODUÇÃO}

A vitamina B12 ou cobalamina é um micronutriente, envolvido em funções importantes do metabolismo, hematologia e neurologia. Sua síntese é derivada de algumas bactérias. Devido à simbiose e acúmulo nos tecidos, a sua contribuição dietética depende diretamente dos alimentos de origem animal (FILHO OC, et al., 2019).

A deficiência nutricional desta vitamina é um dos efeitos negativos mais comuns em uma dieta vegetariana (KREY IP, et al., 2017). A falta dessa vitamina pode levar à anemia megaloblástica e ao comprometimento do neurodesenvolvimento. No entanto, os vegetarianos que mantêm a ingestão de laticínios e ovos podem manter essa vitamina em níveis normais (CACHIADO EAS, et al., 2021).

\section{OBJETIVO}

Revisar por meio da literatura científica a respeito dos impactos ocasionados pela deficiência de vitamina B12 e a relevância da suplementação desse micronutrientes em indivíduos que seguem uma dieta vegetariana.

\section{MÉTODO}

Trata-se de uma revisão integrativa da literatura realizada nas bases de dados Google Acadêmico e SciELO, de artigos publicados entre os anos de 2017 a 2021, nos idiomas de português e/ou espanhol, empregando os descritores: "Vitamina B12", "Dietas vegetarianas", "Vegetarianismo", "Suplementação", totalizando seis estudos. Incluiu-se artigos que englobaram a temática, respeitando o recorte temporal proposto, sendo selecionados cinco artigos. Excluiu-se estudos que não se encaixavam com o objetivo de estudo.

\section{REVISÃO BIBLIOGRÁFICA}


A maioria dos estudos apontaram alto índice de prevalência da deficiência ou possível deficiência de B12 e é necessário um estudo mais aprofundado do impacto clínico dessa deficiência vitamínica para esclarecer a necessidade de suplementação (PEREIRA ACC, et al., 2020).

Considerando que as pessoas que não consomem produtos de origem animal apresentam menor nível de vitamina B12 sérica, uma análise constatou que os vegetarianos apresentaram níveis baixos e efeitos neurológicos negativos (PEREIRA ACC, et al., 2020). Embora muitas pessoas vegetarianas não consumam a vitamina B12 através da alimentação, a maioria delas se preocupa em manter os níveis séricos normais dessa vitamina por meio da suplementação (BARROS AEL, et al., 2019).

\section{CONSIDERAÇÕES FINAIS}

Os estudos demonstram que indivíduos vegetarianos apresentam maior risco de carência da vitamina B12, devido o não consumo de alimentos de origem animal, que são as fontes alimentares desse micronutriente. Contudo constitui-se de grande relevância a necessidade de um acompanhamento nutricional aos indivíduos que adotam esse estilo alimentar, para avaliação da instalação dessa deficiência nutricional e a necessidade de suplementação.

\section{REFERÊNCIAS}

1. BARROS AEL, et al. Análise e comparação da vitamina B12 sérica em adeptos ao vegetarianismo e indivíduos não vegetarianos. Vita et Sanitas, 2019; 13(2): 181-190.

2. CACHIADO EAS, et al. Os efeitos do veganismo no desenvolvimento infantil. Pesquisa, Sociedade e Desenvolvimento, 2021; 10(11): e227101119732.

3. FILHO OC, et al. Vitaminas hidrossolúveis (B6, B12 e C): uma revisão bibliográfica. Revista Eletrônica Acervo Saúde, 2019; 11(8): e285.

4. KREY IP, et al. Atualidades sobre dieta vegetariana. Nutrição Brasil, 2017; 16(6): 406-413.

5. PEREIRA ACC, et al. Relação entre o uso de metformina e a deficiência de vitamina B12 em pacientes com diabetes mellitus tipo 2. Revista Eletrônica Acervo Saúde, 2020; 12(10): e4469. 


\title{
RISCOS ASSOCIADOS AO USO DE POLIFÁRMACOS E O IMPACTO NA QUALIDADE DE VIDA DO IDOSO
}

\author{
Jhussara Silva Alves ${ }^{1}$ \\ Raiane Araújo Brito ${ }^{1}$ \\ Amélia Carina Messias da Costa ${ }^{1}$ \\ Hernandes Flanklin Carvalho Oliveira ${ }^{1}$ \\ Maria Madalena Gomes Pereira Máximo ${ }^{1}$
}

1. Universidade Estadual do Piauí (UESPI), Floriano - PI.

Palavras-chave: Idoso, Polimedicação, Saúde do Idoso.

\section{INTRODUÇÃO}

O termo polifármacos é caracterizado pelo múltiplo uso de medicamentos. Embora não haja uma concordância quanto ao número, a polifarmácia configura-se pelo uso de cinco ou mais medicamentos pelo mesmo paciente. $\mathrm{O}$ uso da polifarmácia é mais comum entre os idosos. Devido a alterações próprias da idade dos idosos, surge o desenvolvimento de doenças crônicas não transmissíveis, bem como mudanças na capacidade fisiológica, ocasionando a necessidade do uso de medicamentos contínuos (MARQUES GFM, et al., 2017). Vale ressaltar ainda que o corpo dessa população possui fragilidades fisiológicas, o que pode resultar numa farmacocinética diferenciada, isso serve tanto para efeitos medicinais como para efeitos adversos (RODRIGUES MCS e OLIVEIRA SS, 2017).

\section{OBJETIVO}

Revisar e analisar, através de uma revisão integrativa da literatura, os riscos associados ao uso de polifármacos nos idosos e a interferência na sua qualidade de vida, ressaltando seus efeitos.

\section{MÉTODO}

Trata-se de uma revisão integrativa. A pesquisa foi realizada nas bases de dados, MEDLINE, LILACS E BDENF. Para a busca, usaram-se os descritores polimedicação e idoso, combinados através do operador booleano AND. Critérios de inclusão: textos completos, em português, publicados entre 2017 e 2021. Critérios de exclusão: artigos incompletos e que não contemplavam a temática, encontrou-se 54 artigos. Após leitura, restaram cinco artigos, usados na amostra final do estudo.

\section{REVISÃO BIBLIOGRÁFICA}


É perceptível na literatura que a polifarmácia eleva o uso impróprio de drogas, criando assim um obstáculo na aderência ao tratamento ao passo que existe mecanismos medicinais complexos, ocasionando a interação medicamentosa, erros de medicação e uma péssima qualidade de vida, alterando as funções fisiológicas, levando a uma maior sensibilidade, tanto para fins terapêuticos como para reações adversas (SANTANA PPC, et al., 2019).

Além disto, eleva os índices de morbimortalidade e impõe uma alta carga financeira nos idosos (MARQUES GFM, et al., 2021). Estudos revelam que em torno de $80 \%$ dos idosos com mais de 60 anos faz uso de, no mínimo, um medicamento (RODRIGUES MCA de S, et al., 2018).

\section{CONSIDERAÇÕES FINAIS}

O uso de múltiplas medicações está associado a um desenredo nocivo á saúde, como quedas, hospitalizações, efeitos adversos e óbitos. Tal evento tem como protagonista a polifarmácia e surte maior efeito adverso na população idosa, dificultando uma boa qualidade de vida. Realizar o acompanhamento farmacológico do idoso é importante para o uso adequado desses medicamentos. Sendo assim, novos estudos sobre a temática são necessários para entender a real complexidade abordada.

\section{REFERÊNCIAS}

1. MARQUES GFM, et al. Polypharmacy and potentially inappropriate medications for elder people in gerontological nursing. Rev Bras Enferm [Internet]. 2018; 71(5): 2440-6.

2. RODRIGUES MCA de $\mathrm{S}$, et al. Perfi I do consumo de medicamentos por frequentadores de centros de convivências de idosos. Revista Eletrônica Acervo Saúde, 2018; 8(4): 947-957.

3. RODRIGUES MCS, OLIVEIRA C. Drug-drug interactions and adverse drug reactions in polypharmacy among older adults: an integrative review. Rev. Latino-Am. Enfermagem. 2016; 24: e2800.

4. SANTANA PPC et al. Polipharmacy impact In the quality of life in older adults. J Nurs UFPE online, 2019; 13(3): 773-82. 


\title{
O USO DA TOXINA BOTULÍNICA NO TRATAMENTO DA ESPASTICIDADE DECORRENTE DE LESÕES NEUROLÓGICAS: REVISÃO BIBLIOGRÁFICA
}

\author{
Giovanna dos Santos Flora ${ }^{1}$ \\ Mariana Cordeiro Dias ${ }^{1}$ \\ Marcus Vinícius Gomes de Oliveira ${ }^{1}$ \\ Suéllen Nogueira Jardim² \\ Gustavo Henrique de Melo da Silva ${ }^{1}$
}

1. Centro Universitário UNIFACIG, Manhuaçu - MG.

2. Centro Universitário UNIFAA, Valença - RJ.

Palavras-chave: Toxina botulínica, Espasticidade, Lesões neurológicas.

\section{INTRODUÇÃO}

A espasticidade é uma alteração causada pela hiperexcitabilidade muscular devido às lesões das células nervosas responsáveis pelo controle de movimentos voluntários, sendo decorrente da lesão do neurônio motor superior, afetando continuamente a vida diária dos pacientes (ANANDAN C e JANKOVIC J, 2021). Dentre as lesões neurológicas que cursam com espasticidade muscular, as principais são: Acidente Vascular Encefálico (AVE), paralisia cerebral, Esclerose Lateral Amiotrófica (ELA) e lesões medulares. Nesse contexto, a toxina botulínica tem se tornado nos últimos anos uma abordagem terapêutica capaz de emitir bons resultados neurológicos e redução do uso crônico de antiespasmódicos orais (FRANCISCO GE, et al., 2021).

\section{OBJETIVO}

Revisar na literatura científica sobre a utilidade e efeitos da toxina botulínica no tratamento da espasticidade por lesões neurológicas, bem como as particularidades e abordagens que apresentam maiores sucessos na prática médica.

\section{MÉTODO}

Trata-se de uma revisão sistemática com base em dados no PubMed, Medline e Scielo. Os critérios de inclusão foram os artigos publicados entre 2020 a 2021 com os descritores: toxina botulínica, espasticidade, lesões neurológicas. Os critérios de exclusão foram os artigos que não se baseavam no tema e possuíam ano de publicação prévios a 2020. Foram encontrados 45 artigos, sendo 4 artigos científicos selecionados por conter os objetivos determinados.

\section{REVISÃO BIBLIOGRÁFICA}


Os estudos científicos na análise sistemática, evidenciam que a toxina botulínica do tipo A é uma opção terapêutica para as condições neurológicas por serem drogas locais que paralisam a hiperatividade muscular (GHROUBI S, et al., 2020). Avaliou-se que a toxina botulínica tornou-se um método seguro e benéfico para o alívio da espasticidade, por apresentar uma melhora das habilidades funcionais temporariamente, tendo melhores resultados nas contrações espásticas focais e sem relações quanto a abordagem precoce ou tardia. Verificou-se que exibe poucos efeitos colaterais, maior facilidade de ajuste de doses com a resposta prévia neurológica e fácil aplicação (CHIU SY, et al., 2021).

\section{CONSIDERAÇÕES FINAIS}

O uso da toxina botulínica na espasticidade ainda está em estudos e necessitando de mais pesquisas sobre o tema. A toxina botulínica trata-se uma estratégia em avanço nos dias atuais, evidenciando benefícios do uso tanto como uma abordagem individualizada ou terapia adjuvante, bem como na facilidade na manipulação do procedimento e segurança quando comparado com outras condutas.

\section{REFERÊNCIAS}

1. ANANDAN C, JANKOVIC J. Botulinum toxin in movement disorders: an update. Toxins, $2021 ; 13(1): 42$.

2. CHIU SY, et al. An Update on Botulinum Toxin in Neurology. Neurologic Clinics, 2021; 39(1): 209-229.

3. FRANCISCO GE, et al. A practical guide to optimizing the benefits of post-stroke spasticity interventions with botulinum toxin A: An international group consensus. Journal of Rehabilitation Medicine, 2021; 53: 16501977-2753.

4. GHROUBI S, et al. Efficacy of botulinum toxin $A$ for the treatment of hemiparesis in adults with chronic upper limb spasticity. The Pan African Medical Journal, 2020; 35: 55. 


\title{
CÂNCER COLORRETAL: FATORES DE RISCOS, DIAGNÓSTICO E TRATAMENTO
}

\author{
Cleber Queiroz Leite ${ }^{1}$
}

Brian França dos Santos²

1. Centro Universitário São Lucas (UNISL), Porto Velho - RO.

2. Universidade Iguaçu (UNIG), Nova Iguaçu - RJ.

Palavras-chave: Câncer Colorretal, Tratamento, Diagnóstico.

\section{INTRODUÇÃO}

O Câncer Colorretal (CCR) corresponde as neoplasias que acometem a região do intestino grosso (cólon) e/ou reto, sendo o cólon a região mais frequente das neoplasias primárias como adenocarcinomas e adenomas (CAMPOS FG, et al., 2017). O câncer colorretal compreende a terceira neoplasia maligna mais comum e a segunda em mortalidade quando comparada a outras neoplasias (MACIEL DBV, et al., 2019).

Dentre os fatores de risco podemos dividir em hereditários e ambientais. Sendo os hereditários, ocorrência familiar da doença em parentes com idade menor que 50 anos e polipose na região do cólon. Já os ambientais, correlacionam-se ao consumo de álcool, tabagismo, obesidade entre outros (OLIVEIRA MM, et al., 2018).

\section{OBJETIVO}

Revisar a literatura científica acerca do câncer colorretal, buscando esclarecer a importância do reconhecimento dos principais fatores de risco correlacionados a doença, bem como descrever sobre seu diagnóstico e tratamento.

\section{MÉTODO}

Trata-se de uma revisão integrativa nas bases do Google Scholar, com uso dos descritores "Câncer Colorretal", "Tratamento" e "Diagnóstico", obtendo-se como resultado 70 publicações. Utilizou-se os critérios de inclusão: publicações a partir de 2017, idiomas português e inglês. Nos critérios de exclusão estão: artigos que não abordavam a temática e os fora dos parâmetros de inclusão. Assim, foram selecionados os 5 artigos de maior relevância para a produção deste trabalho.

\section{REVISÃO BIBLIOGRÁFICA}

As manifestações clínicas do CCR costumam ser assintomáticas em estágio inicial, com a evolução da doença, os sintomas vão surgindo. Assim, a sintomatologia difere de acordo com o tamanho/localização do tumor (GASHTI SM, et al., 2021). O diagnóstico é conforme a predileção do médico e paciente, sendo associado aos recursos disponíveis. Lembrando sempre a importância da orientação em relação as desvantagens/vantagens dos procedimentos. Entretanto, a colonoscopia comumente é mais utilizada, 
apresentando uma maior eficácia (MELLO MSP, et al., 2020). O tratamento depende da localização, tamanho e saúde geral do paciente, recentemente surgiram modalidades como cirurgias, quimioterapia e radioterapia, que podem ser usadas associadas ou isoladas (GASHTI SM, et al., 2021).

\section{CONSIDERAÇÕES FINAIS}

Enfatiza-se que o reconhecimento dos fatores de risco correlacionados ao câncer colorretal, é de suma importância. Pois através deles podemos orientar os pacientes a manterem medidas preventivas diárias, as quais incluem: praticar exercícios físicos, dieta balanceada, abandono do consumo de tabaco e álcool, e até mesmo o alerta para o rastreio de lesões, tudo com o objetivo de reduzir a mortalidade por essa neoplasia.

\section{REFERÊNCIAS}

1. CAMPOS FG, et al. Incidência de câncer colorretal em pacientes jovens. Revista do Colégio Brasileiro de Cirurgiões, 2017; 44: 208-215.

2. GASHTI, SM et al. Câncer colorretal: principais complicações e a importância do diagnóstico precoce. Revista Eletrônica Acervo Saúde, 2021; 13(4): e6888.

3. MACIEL, DBV, et al. Perfil sociodemográfico de pacientes com estomia definitiva por câncer colorretal: interferência na qualidade de vida. Nursing (São Paulo), 2019; 22(258): 3325-3330.

4. MELLO, MSP, et al. Clinical evaluation and pattern of symptoms in colorectal cancer patients. Arquivos de gastroenterologia, 2020; 57: 131-136.

5. OLIVEIRA, MM, et al. Disparidades na mortalidade de câncer colorretal nos estados brasileiros. Revista Brasileira de Epidemiologia, 2018; 21: e180012. 


\section{EFEITO DA ACUPUNTURA NA REDUÇÃO DA DOR EM MULHERES JOVENS COM DISMENORREIA PRIMARIA: REVISÃO DE LITERATURA}

Sidney Queiroz de Sá Leitão

Amanda Fonseca do Nascimento ${ }^{1}$

Mateus Porfírio Rodrigues ${ }^{1}$

Eudson José Santos do Monte ${ }^{1}$

Jose Carlos Nogueira Nóbrega Júnior ${ }^{1}$

1. Faculdade de Comunicação e Turismo de Olinda (FACOTTUR), Olinda - PE.

Palavras-chave: Acupuntura, Dismenorreia, Medicina tradicional chinesa.

\section{INTRODUÇÃO}

A Dismenorreia Primária (DP) gera dor no baixo ventre ou região lombar, apresenta náuseas, diarreia, cefaleia, dor mamária e inchaço abdominal, podendo perdurar todo período menstrual, quando intenso, capaz de afetar atividades habituais. Há prevalência de até 60 a $80 \%$ entre adolescentes e mulheres durante os anos reprodutivos (da SILVA NSB, et al., 2020).

Dentre as condutas não-farmacológicas está a acupuntura, recurso terapêutico da Medicina Tradicional Chinesa (MTC), com conceitos filosóficos, prevê que qualquer manifestação de doença é um sinal de desequilíbrio de Qi, energia essencial para a manutenção do estado de saúde, Yin e o Yang são forças de equilíbrio do Qi (LEMOS LR e dos SANTOS SG, 2019).

\section{OBJETIVO}

Descrever, com base na literatura científica, de que forma os efeitos da acupuntura são capazes de beneficiar na redução da dor em mulheres jovens com DP, propiciando assim melhor qualidade de vida.

\section{MÉTODO}

Trata-se de uma revisão de integrativa. Para tal, as buscas foram realizadas nas bases de dados: Medline, ScieLo, Pubmed, Acervo e LILACS, de Julho de 2020 a Junho de 2021, procedeu-se à análise de 94 artigos, incluindo 4 artigos dos últimos 5 anos e excluindo os que não atendessem a temática proposta, utilizando os seguintes descritores: Acupuntura, Dismenorreia e Medicina Tradicional Chinesa, agrupados com o uso do operador booleano "AND".

\section{REVISÃO BIBLIOGRÁFICA}


Na MTC, a DP é causada pelo fluxo irregular de Qi e sangue circulando pelos meridianos, observou-se que a acupuntura tem sido utilizada para tratar dor e promover livre circulação de Qi e sangue (WANG H, et al., 2019). Comparando a acupuntura com o medicamento tradicional (ibuprofeno) utilizando a técnica de penetração através de Zhibian (BL54) bexiga, para Shuidao (ST28) estomago, a intensidade da dor foi significativamente reduzida, sendo a acupuntura associada a uma maior taxa de resposta e baixa incidência de eventos adversos (WANGH, et al., 2019). Adquirindo um efeito analgésico imediato mais forte antes e após o tratamento (ZHAO MY, et al., 2017).

\section{CONSIDERAÇÕES FINAIS}

Portanto, os estudos segurem que a acupuntura no tratamento da DP é uma temática bastante pertinente e atual, tem importância para melhoria da qualidade de vida e bem-estar da mulher, podendo regular 0 equilíbrio do organismo, em harmonia, melhora o estado emocional, circulação sanguínea, podendo chegar a reduzir a necessidade de drogas, aumentando a eficácia terapêutica. Ademais, são necessários outros estudos, para ver a eficácia da técnica em outras populações.

\section{REFERÊNCIAS}

1. da SILVA, NSB et al. Impacto da dismenorreia em adolescentes escolares. Revista Eletrônica Acervo Saúde, 2020; 49: e3308.

2. LEMOS LR, dos SANTOS SG. Uso da auriculoterapia na dismenorreia. Brazilian Journal of Health Review, 2019; 2(4): 3402-3407.

3. WANG H, et al. Effect of an Acunpuncture Technique of Penetrating Through Zhibian (BL54) to Shuidao (ST28) with Long Needle for Pain Relief in Patients with Primary Dysmenorrhea: A Randomized Controlled Trial. Pain Research and Management, 2019; 2019: e7978180.

4. ZHAO MY, et al. Influence of De Qi on the immediate analgesic effect of SP6 acupuncture in patients with primary dysmenorrhea and cold and dampness stagnation: a multicentre randomized controlled trial. Acupuncture in Medicine, 2017; 35 (5): 332-338. 


\title{
EFEITOS DA ACUPUNTURA SOBRE A DOR EM MULHERES COM FIBROMIALGIA: UMA REVISÃO DE LITERATURA
}

\author{
Amanda Fonseca do Nascimento ${ }^{1}$ \\ Hellen Beatriz Romão de Souza ${ }^{1}$ \\ Mateus Porfírio Rodrigues ${ }^{1}$ \\ Ingrid Larissa da Silva Laurindo ${ }^{1}$ \\ Jose Carlos Nogueira Nóbrega Júnior ${ }^{1}$
}

1. Faculdade de Comunicação e Turismo de Olinda (Facottur), Olinda - PE.

Palavras-chave: Fibromialgia, Ponto-gatilho, Terapia por acupuntura e medicina tradicional chinesa.

\section{INTRODUÇÃO}

A Fibromialgia (FM) é uma síndrome reumática, idiopática e incurável, caracterizada por um quadro álgico generalizado, crônico, que não provém de lesões e não-inflamatório do sistema musculoesquelético, com duração superior a três meses, associado à sensibilidade exacerbada à palpação em pontos dolorosos preestabelecidos, simetricamente em ambos os hemicorpos, denominados trigger points (da MOTA LML, et al., 2021; FILHO LAM, et al., 2019).

Dentre as condutas não-farmacológicas que podem ser aplicadas nesses indivíduos está a acupuntura, que é um dos recursos terapêuticos na Medicina Tradicional Chinesa (MTC). Trata-se de um recurso que se caracteriza pela inserção de agulhas especiais em pontos específicos, denominados de acupontos (SILVEIRA NC e MARTINS RRC, 2018).

\section{OBJETIVO}

Verificar por meio de um estudo na literatura científica o efeito da acupuntura sobre a dor em mulheres com fibromialgia, com o intuito de tornar conhecida a eficácia da acupuntura nesta síndrome reumática.

\section{MÉTODO}

Trata-se de uma revisão integrativa. As buscas foram realizadas nas bases de dados: Medline, Acervo +, BIREME, Cochrane, LILACS e PEDro, de agosto a outubro de 2021, foram analisados 143 artigos, incluindo 10 ensaios clínicos com participantes acometidos por Fibromialgia, submetidos a um protocolo de Acupuntura Convencional Sistêmica e excluindo aqueles que não atendessem a temática proposta, com os seguintes descritores Fibromialgia, Ponto-gatilho, Terapia por acupuntura e Medicina Tradicional Chinesa.

\section{REVISÃO BIBLIOGRÁFICA}


Fora evidenciado que a Acupuntura se alia no tratamento da FM, pois, além de atuar no alívio agudo da dor, também se mostrou uma técnica com efeitos duradouros, onde a redução do quadro álgico perdurou até 10 semanas após o protocolo utilizado no ensaio clínico (VAZ J, et al., 2018).

Além dos benefícios sobre a dor, atua também na redução da fadiga, na qualidade de sono e de vida dos pacientes com FM (MIST SD e JONES KD, 2018). Outros achados foram que níveis séricos de serotonina mostraram importante aumento e uma redução expressiva da substância $P$ após o tratamento com acupuntura (KARATAY S, et al., 2017).

\section{CONSIDERAÇÕES FINAIS}

Destarte, os estudos sugerem que a Acupuntura é uma grande aliada na redução da dor e melhora dos sintomas de depressão e ansiedade. Proporciona benefícios físicos, sociais e psicológicos. Eficaz tanto na forma aguda quanto crônica, seus efeitos podem durar por até um ano após o término do tratamento, sua utilização deve ser encorajada. Ademais, são necessários outros estudos, protocolos, pontos para ver a eficácia da técnica em outras populações.

\section{REFERÊNCIAS}

1. da MOTA, LML et al. Qualidade de vida, trabalho e apoio familiar de pessoas com fibromialgia. Revista Eletrônica Acervo Científico, 2021; 34: e8601.

2. FILHO, LAM et al. Manifestações de sintomas somáticos em pacientes com Fibromialgia: uma revisão narrativa. Revista Eletrônica Acervo Científico, 2021; 27: e7901

3. KARATAY S, et al. Effects of Acupuncture Treatment on Fibromyalgia Symptoms,Serotonin, and Substance P Levels: A Randomized Sham and Placebo-ControlledClinical Trial. Pain Medicine, 2018; 19(3): 615-628.

4. MIST SD, JONES KD. Randomized Controlled Trial of Acupuncture for Women with Fibromyalgia: Group Acupuncture with Traditional Chinese Medicine Diagnosis BasedPoint Selection. Pain Medicine, 2018; 19(9): 1862- 1871.

5. SILVEIRA NC, MARTINS RCC. Eficácia da acupuntura para o tratamento da fibromialgia:uma revisão sistemática. Revista Psicologia e Saúde em Debate, 2018; 4(1): 85-105.

6. VAZ J, et al. Acupuncture for Fibromyalgia in Primary Care: A Randomised ControlledTrial. Acupuncture in Medicine, 2016; 34(4): 257-266. 
RESUMO SIMPLES: Revisão Integrativa

\title{
SÍNDROME DE LI-FRAUMENI NA POPULAÇÃO BRASILEIRA: UM REVISÃO INTEGRATIVA
}

\author{
Raimundo Azevedo Vilarouca Neto ${ }^{1}$
}

Maria Karollyna do Nascimento Silva Leandro ${ }^{1}$

1. Centro Universitário Doutor Leão Sampaio (UNILEÃO), Juazeiro do Norte - CE.

Palavras-chave: Síndrome de Li-Fraumeni, Alterações genéticas, Doença rara.

\section{INTRODUÇÃO}

A síndrome de Li-Fraumeni (SLF) é uma síndrome autossômica dominante caracterizada por uma mutação no cromossomo 17 (p.R337H - "mutação brasileira"), onde se localiza o gene TP53, o qual codifica a proteína p53 que é supressora tumoral e responsável por regular as alterações de replicação de DNA. Quando a p53 é ativada através da tetramerização proteica, a mesma é induzida a função de supressora tumoral, acarretando na apoptose ou na parada do ciclo celular. Ainda não são bem esclarecido os mecanismos que levam a p53 a determinar o destino da célula (DOYLE MR, et al., 2018; PAIXÃO D, et al., 2018; ZERDOUMI Y, et al., 2017).

\section{OBJETIVO}

Avaliar, por meio da literatura científica, quais os aspectos fisiológicos e patológicos que ocorrem na síndrome de Li- Fraumeni e analisar qual a frequência dessa patologia na população brasileira com a mutação p.R337H.

\section{MÉTODO}

Trata-se de uma pesquisa de revisão integrativa. Incluiu-se os artigos dos anos 2017-2020 que abordaram a temática, excluindo-se os que não atenderam a esses critérios. Foram utilizados os descritores "Li-Fraumeni syndrome", "genetics alteration", "rare disease" e "p.R337H" com o auxílio do operador booleano AND nas bases de dados SciELO e PubMed, totalizando 18.172 trabalhos, finalizando em 5 artigos que abordaram a temática proposta e estavam dentro do recorte temporal.

\section{REVISÃO BIBLIOGRÁFICA}

A grande parte dos cânceres exibem: perda de alelo, deleção ou perda neutra de cópia de heterozigosidade. As alterações no gene TP53 revelou aumento na instabilidade cromossômica (DONEHOWER LA, et al., 2019; ZERDOUMI Y, et al., 2017).

Em crianças, foram evidenciados carcinomas adrenocorticais, osteossarcomas, tumores no sistema nervoso central e sarcoma de tecidos moles, correspondendo entre 5 a $10 \%$ de cânceres pediátricos associados a síndromes hereditárias. Já nos adultos, os carcinomas de mama foram mais evidenciados em 
pacientes do sexo feminino e, em segundo lugar, sarcoma de tecidos moles. É necessária uma ressonância de corpo inteiro para se avaliar melhor a extensão dos tumores (FREBOURG T, et al., 2020).

\section{CONSIDERAÇÕES FINAIS}

Devido à pouca distribuição de trabalhos na temática proposta que, apesar de ser uma síndrome rara, é necessário que haja mais estudos na área em questão a fim de melhorar o critério diagnóstico e esclarecer a população médica e demais profissionais da área da saúde acerca da frequência que esta síndrome se manifesta na população.

\section{REFERÊNCIAS}

1. DONEHOWER LA, et al. Integrated analysis of TP53 gene and pathway alterations in the cancer genome atlas. Cell reports, 2019; 28(5): e5.

2. DOYLE MR, JOHNSTON JM. A novel p. Gly187Arg TP53 variant appears to result in Li-Fraumeni syndrome. Pediatric hematology and oncology, 2018; 35(3): 203-207.

3. FREBOURG T, et al. Guidelines for the Li-Fraumeni and heritable TP53-related cancer syndromes. European Journal of Human Genetics, 2020; 28(10): 1379-1386.

4. PAIXÃO D, et al. Whole-body magnetic resonance imaging of Li-Fraumeni syndrome patients: observations from a two rounds screening of Brazilian patients. Cancer Imaging, 2018; 18(27): 1-8.

5. ZERDOUMI Y, et al. Germline TP53 mutations result into a constitutive defect of p53 DNA binding and transcriptional response to DNA damage. Human molecular genetics, 2017; 26(14): 2591-2602. 
RESUMO SIMPLES: Revisão Integrativa

\title{
POSSIBILIDADES E UTILIZAÇÕES DA TÉCNICA CRISPR-CAS9 NA SAÚDE PÚBLICA
}

\author{
José de Oliveira Alves Júnior ${ }^{1}$ \\ Aline Dayanna Alves de Lima Marcelino' \\ Amanda Barbosa Formiga ${ }^{1}$ \\ Wellington Cipriano Albuquerque ${ }^{1}$
}

1. Universidade Estadual da Paraíba (UEPB), Campina Grande - PB.

Palavras-chave: Crispr-cas9, Engenharia genética, Saúde pública.

\section{INTRODUÇÃO}

No início, os estudos envolvendo o material genético humano tinham por objetivo analisar apenas sua aparência, entretanto, o decorrer do tempo aliado aos avanços dos estudos gênicos corroborou para 0 surgimento da técnica que promete mudar sequências de ácido desoxirribonucleico (DNA) chamada de Clustered Regularly Interspaced Short Palindromic Repeats (crispr-cas9) (BORBOZA CMS, et al., 2020).

A técnica crispr-cas9, na engenharia genética, surgiu como alternativa de baixo custo e eficiente versatilidade, excelência e especificidade nas operações de substituições nas cadeias genéticas (ASTUDILLO A, et al., 2020). Destarte, o crispr-cas9 poderia ter várias utilidades no setor de saúde como barrar e atenuar a incidência de patologias virais (BATISTA FCC e NUNES CP, 2019).

\section{OBJETIVO}

Avaliar a literatura científica disponível sobre o tema buscando revisar e conhecer acerca das possíveis aplicações e a relação da técnica de edição gênica crispr-cas9 voltadas à saúde pública e aos avanços da sociedade na área da saúde.

\section{MÉTODO}

Trata-se de uma revisão integrativa realizada por obras indexadas em Google Acadêmico, Scielo, PubMed e MEDLINE. Os descritores utilizados foram "crispr-cas9 na sociedade" e "crispr-cas9 na saúde". Dos 36 artigos analisados, 21 foram usados sob os critérios de textos claros e coesos nos idiomas português, inglês e espanhol publicados nos últimos 5 anos e, para a pesquisa preliminar, textos que tratavam brevemente a temática de forma rica.

\section{REVISÃO BIBLIOGRÁFICA}

Devido ao seu grau de eficiência na engenharia genética, o crispr-cas9 apresentou-se como possibilidade de atenuar e reduzir índices de câncer através da inibição da ação de genes cancerígenos e tumorigênicas 
(BRESOLIN E, et al., 2021). Ademais, a nova técnica demonstrou-se eficiência na possibilidade em tratar e evitar dislipidemias genéticas como a Diabetes Mellitus do tipo um, utilizando tratamento com células mesenquimais pluripotentes (SILVA MRF, et al., 2020).

A posteriori, outro uso do crispr-cas9 na saúde pública e melhoria na qualidade de vida da população é no tratamento e diagnóstico de enfermos cardiovasculares pelo tratamento em nível molecular de células defeituosas, aprimorando seus decodificadores genéticos (AREND MC, et al., 2017).

\section{CONSIDERAÇÕES FINAIS}

Portanto, a técnica de engenharia genética crispr-cas 9 apresenta grandes possibilidades de uso visto seus custos comparados aos benefícios, possibilitando um grande avanço social na área da saúde e auxiliando no tratamento de vários enfermos, todavia, faz-se essencial que estudos que tangem essa nova técnica continuem de forma consistente para evitar quaisquer complicações em suas possíveis aplicações futuras. Afinal, para a área da saúde, a vitalidade do paciente é muito importante.

\section{REFERÊNCIAS}

1. AREND MC; et al. O Sistema CRISPR/Cas9 e a Possibilidade de Edição Genômica para a Cardiologia. Arquivos Brasileiros de Cardiologia, 2017; 108(1): 81-83.

2. ASTUDILLO A, et al. Uso de CRISPR/Cas9 como herramienta de edición de genomas en hongos filamentosos: una revisión del estado actual y últimas tendências, Revista Genotipia, 2020; 5(5): 45-69.

3. BARBOZA CMS, et al. A TÉCNICA DE CRISPR-Cas9 NA TERAPIA GÊNICA: uma revisão da literatura. Revista Transformar, 2020; 14(1): 562-698.

4. BATISTA FCC, NUNES CP. CRISPR CAS9: ATUAIS APLICAÇÕES NO TRATAMENTO DO HIV. Revista de Medicina de Família e Saúde Mental, 2019; 1(1): 1-6.

5. BRESOLIN E, et al. CRISPR: Edição genômica aplicada à Oncologia / CRISPR: Genomic editing applied to Oncology. Brazilian Journal of Development, 2021; 7(9): 90908-90927.

6. SILVA MRF, et al. CRISPR / Cas 9 as a healing perspective for Diabetes mellitus type 1. Research, Society and Development, 2020; 9(12): e9691210709. 


\title{
OBESIDADE, SOBREPESO E GORDURA CORPORAL: RISCO CARDIOVASCULAR PARA CRIANÇAS E ADOLESCENTES
}

\author{
João Victor Martins Reis ${ }^{1}$ \\ Letícia de Paula Santos ${ }^{1}$ \\ Georgia Luiza Caires Tanajura ${ }^{1}$ \\ Ariele Alves de Oliveira ${ }^{1}$ \\ Mônica Isaura Corrêa ${ }^{1}$
}

1. Centro Universitário de Caratinga (UNEC), Caratinga - MG.

Palavras-chave: Pediatria, Risco cardiovascular, Obesidade.

\section{INTRODUÇÃO}

Na fase infanto-juvenil, a presença de dois ou mais fatores de risco cardiovascular já é o bastante para o indivíduo desenvolver uma doença cardiovascular nos próximos 10 anos e, no caso das crianças, essas doenças podem prevalecer na fase adulta. Ademais, sabe-se que o sobrepeso e a obesidade estão relacionados as principais causas de morte no Brasil, o que torna a obesidade infantil um grave problema de saúde pública. Além disso, também já é conhecido que a obesidade e o sobrepeso são associados a fatores epigenéticos, como a prática de atividade física e a alimentação saudável (SIMÃO MCSA, et al., 2020).

\section{OBJETIVO}

Descrever os principais riscos cardiovasculares para crianças e adolescentes, ressaltando aqueles relacionados ao estilo de vida: gordura corporal, aumento da massa corporal, sobrepeso, obesidade, sedentarismo, dieta rica em açúcares e gorduras, dentre outros.

\section{REVISÃO BIBLIOGRÁFICA}

A obesidade e o índice de gordura corporal estão ligados ao risco cardiovascular porque a obesidade e o sobrepeso podem levar ao aparecimento de doenças como: Diabetes tipo 2, hipertensão arterial e dislipidemia. Tais doenças são consideradas os principais fatores de risco para doença cardiovascular (MCPHEE PG, et al., 2020).

A obesidade infantil leva a uma resistência progressiva à insulina, ao quadro de hiperglicemia e ao surgimento de diabetes tipo 2. Além disso, a dislipidemia causada pela obesidade, caracteriza pelo acúmulo de gorduras na corrente sanguínea, facilitando a formação de placa de gordura na parede das artérias (aterosclerose), com consequente inflamação e enrijecimento das artérias, levando a um quadro de hipertensão arterial (DABELEA D, et al., 2017). 
Já o risco cardiovascular é mediado pelas doenças citadas, que podem culminar com o aumento da Resistência Vascular Periférica (RVP), aumento da viscosidade sanguínea e diminuição do fluxo sanguíneo, levando a uma hipertrofia ventricular esquerda e posteriormente a criança pode desenvolver uma insuficiência cardíaca, podendo alterar tanto as funções sistólicas quanto as funções diastólicas do coração (YANG H, et al., 2017).

\section{CONSIDERAÇÕES FINAIS}

Evidencia-se, então, que a resistência a hábitos de vida saudáveis pelas crianças e adolescentes representa um problema de saúde pública, pois possui como consequência o desenvolvimento de obesidade infantil, que, por sua vez, aumenta o risco cardiovascular, aumentando a possibilidade de a criança desenvolver doenças como a insuficiência cardíaca por hipertrofia ventricular.

\section{REFERÊNCIAS}

1. DABELEA D, et al. Association of Type 1 Diabetes vs Type 2 Diabetes Diagnosed During Childhood and Adolescence With Complications During Teenage Years and Young Adulthood. JAMA, 2017; 317(8): 825835.

2. MCPHEE PG, et al. Childhood Obesity and Cardiovascular Disease Risk: Working Toward Solutions. Canadian Journal of Cardiology, 2020; 36(9): 1352-1361.

3. SIMÃO MCSA, et al. Aumento da obesidade em crianças e adolescentes: risco de complicações cardíacas futuras. Acervo Saúde, 2020; Sup(57): e4070.

4. YANG H, et al. Associations of childhood and adult obesity with left ventricular structure and function. Int $\mathrm{J}$ Obes (Lond), 2017; 41(4): 560-568. 


\title{
A INFLUÊNCIA DA HELICOBACTER PYLORI NAS PATOLOGIAS GÁSTRICAS E EXTRA-GÁSTRICAS
}

\author{
Lanna do Carmo Carvalho ${ }^{1}$
}

Ana Paula Fontana ${ }^{1}$

1. Universidade de Rio Verde (UniRV), Rio Verde - GO.

Palavras-chave: Helicobacter pylori, Patologias gástricas, Infecção.

\section{INTRODUÇÃO}

O ambiente gástrico é constantemente agredido por injúrias endógenas e exógenas, e para isso é composto com um aparato de proteção de origem que garante a integridade estrutural e a homeostase corporal, mesmo com o ambiente desfavorável (CONNOR AO, et al., 2017) Em contraste, quando ocorre um desequilíbrio negativo entre ambos, através do aumento das agressões e redução da proteção simultaneamente, quadro provocado principalmente pelas medicações e pela bactéria Helicobacter pylori, começam as manifestações clínicas de injúrias gástricas e extra gástricas, a qual exigem intervenções habituais, farmacológica e até cirúrgicas (ANSARI AS, 2021).

\section{OBJETIVO}

Discutir e analisar por meio de uma revisão minuciosa de várias literaturas, a respeito da influência do Helicobacter pylori como um potencial causador de patologias gástricas e extra-gástricas sobre o organismo.

\section{MÉTODO}

Trata-se de uma revisão sistemática. A pergunta norteadora foi construída através da estratégia PICD e a busca nas bases de dados renomados do Scielo, PubMed, Biblioteca Virtual em Saúde e Acervo Mais Index Base no período do mês de agosto de 2021 através dos seguintes descritores: Helicobacter pylori, agressão gástrica. Ao total foram achados 8 artigos, elegendo 3 por serem atuais descartando os que não atendiam ao objetivo.

\section{REVISÃO BIBLIOGRÁFICA}

A Helicobacter pylori é a única bactéria apta a permanecer no estômago, devido a liberação de amônia que a encobre e protege de tamanha acidez (CONNOR AO, et al., 2017). A maioria dos pacientes que possuem a bactéria são assintomáticos, no entanto estudou-se algumas cepas virulentas responsáveis por alterações gástricas como mudanças no $\mathrm{pH}$ gastrite, úlceras pépticas, adenocarcinoma gástrico e linfoma MALT e também extra gástricas como púrpura trombocitopênica, anemia ferropriva, déficit de vitamina B12, resistência a insulina, síndrome metabólica e doença hepática não alcoólica, por meio de um crônico processo que resulta em infecção, inflamação e reação imune (QUINTAIROS MQ, et al., 2020). 


\section{CONSIDERAÇÕES FINAIS}

Diante dos estudos apresentados, demonstra-se que o desenvolvimento de patologias gástricas e extra gástricas são altamente relacionadas do contato da $\mathrm{H}$. pylori com o organismo. São necessários estudos mais aprofundados através de maior colaboração da comunidade científica e voluntariado sobre o mecanismo de ação, o fator de peso no desenvolvimento das manifestações e a interação com o hospedeiro e demais acometimentos que a bactéria pode desencadear.

\section{REFERÊNCIAS}

1. ANSARI SA, et al. Association of oral Helicobacter pylori with gastric complications. Life Sciences, 2018; 205: 125-130.

2. CONNOR AO, et al. Population screening and treatment of Helicobacter pylori infection. Nat Rev Gastroenterol Hepatol, 2017; 14: 230-240.

3. QUINTAUROS MQ, et al. Doenças relacionadas à infecção pelo Helicobacter pylori: Revisão Sistemática. Pará Research Medical Journal (PRMJ), 2020; 4: e30. 


\title{
COMPLICAÇÕES DA SÍNDROME HIPERTENSIVA ESPECÍFICA DA GESTAÇÃO
}

\author{
Alaides de Oliveira Souza ${ }^{1}$ \\ Jaqueline Lopes Prates ${ }^{1}$ \\ Rabrine da Silva Matos ${ }^{1}$ \\ Denise Lima Magalhães ${ }^{1}$ \\ Cinoélia Leal de Souza ${ }^{1}$
}

1. Centro Universitário de Guanambi (UNIFG), Guanambi - BA.

Palavras-chave: Gestação, Complicações, Hipertensão Gestacional.

\section{INTRODUÇÃO}

A Síndrome Hipertensiva Específica da Gestação (SHEG) é caracterizada por manifestações clínicas da Hipertensão Arterial Sistêmica (HAS) com níveis pressóricos igual ou superior a 140/90 mmHg após a vigésima semana gestacional, podendo estar associada à proteinúria, denominada de Pré-Eclâmpsia (PE) e além disso, essa enfermidade na atualidade, é a maior responsável por ocasionar óbitos perinatais (SILVA $E C$, et al., 2021). A partir desses apontamentos, destaca-se pelo seu agravamento, uma das complicações procedentes da SHEG, a síndrome de HELLP, no qual é classificada pela hemólise, elevação das enzimas hepáticas e queda de plaquetas (MORAES LSL, et al., 2019).

\section{OBJETIVO}

Realizar uma revisão integrativa da literatura, com vista a levantar um estudo crítico-reflexivo à cerca das complicações das síndromes hipertensivas na gestação e destacar a importância de um tratamento precoce para a prevenção das complicações maternas e fetais.

\section{MÉTODO}

Realizou-se uma revisão integrativa, em setembro de 2021, nas bases Biblioteca Virtual de Saúde (BVS) e Scielo. Os descritores utilizados foram "Gestação", "Complicações" e "Hipertensão Gestacional". Critérios de inclusão: artigos originais publicados nos últimos 5 anos, na língua portuguesa. Os critérios de exclusão foram artigos incompletos e fuga ao tema. Foram identificados 35 artigos no total e após os critérios, selecionaram-se 6 pela sua relevância.

\section{REVISÃO BIBLIOGRÁFICA}

A SHEG, é uma enfermidade que causa um alto índice de morbimortalidade materno e perinatal no Brasil, com elevado percentual de casos e prevalência (ABRAHÃO ACM et, al., 2020). Essas síndromes gestacionais 
podem acarretar em diversas complicações como por exemplo a encefalopatia hipertensiva, colapso cardíaco, hemorragia retiniana e coagulopatias associadas a PE (ARAÚJO IFM, et al., 2017).

Nessa ótica, o tratamento da PE é baseado na prevenção das complicações maternas/fetais, exemplo do deslocamento prematuro da placenta, com agravamento do quadro clinico, resultando na Síndrome de HELLP, logo, o tratamento incide no repouso, decúbito lateral esquerdo, favorecendo retorno venoso e aumento do débito cardíaco (MORAIS CMS, et al., 2021).

\section{CONSIDERAÇÕES FINAIS}

Diante dos estudos apresentados, demonstra-se que a síndrome hipertensiva gestacional é considerada uma importante complicação do ciclo gravídico-puerperal, sendo umas das principais causas de morbimortalidade materna e perinatal, desse modo, entende-se que a melhor forma de prevenção, é a detecção precoce, além disso, que as gestantes possam receber uma assistência de qualidade, de forma individual, promovendo um tratamento que atenda às necessidades das mesmas.

\section{REFERÊNCIAS}

1. ABRAHÃO ACM, et al. Atuação do enfermeiro a pacientes portadoras de síndrome hipertensiva específica da gestação. Revista Científica da Escola Estadual de Saúde Pública de Goiás "Candido Santiago", 2020; 6(1): 51-63.

2. ARAÚJO IFM, et al. Síndromes hipertensivas e fatores de risco associados à gestação. Revista de Enfermagem UFPE on line, 2017; 11(Supl. 10): 4254-62.

3. MORAES LSL, et al. Síndromes hipertensivas na gestação: perfil clínico materno e condição Neonatal ao nascer. Revista Baiana de Saúde Pública, 2019; 43(3): 599-611.

4. MORAIS CMS, et al. Manifestações dos distúrbios hipertensivos da gravidez e complicações associadas à infecção por COVID-19. Revista Eletrônica Acervo Científico, 2021; 26: 1-6.

5. SILVA EC, et al. Atuação do enfermeiro na prevenção das síndromes hipertensivas na gestação no âmbito da atenção básica. Revista Eletrônica Acervo Saúde, 2021; 13(2): 1-7. 


\section{O POTENCIAL INFECCIOSO DO PIERCING}

Lanna do Carmo Carvalho ${ }^{1}$

Ana Paula Fontana ${ }^{1}$

1. Universidade de Rio Verde (UniRV), Rio Verde - GO.

Palavras-chave: Piercing, Infecção, Proteção.

\section{INTRODUÇÃO}

Atualmente, o anseio e a adoção ao uso do piercing aumentou muito, devido ao acessório ser um meio de inclusão em determinados grupos sociais, ser uma forma de expressão e personalidade e tornar o visual mais "moderno" (SANTOS JWM, et al., 2017). O procedimento consiste na perfuração da pele para inserção de uma peça metálica, "....algo simples, frequente e sem complicações..." mas não é inofensivo e em alguns casos pode causar infeções e até internação hospitalar, evidenciando sobre o potencial infecioso do uso de piercing (LIMA LB, et al., 2021).

\section{OBJETIVO}

Analisar, expor, revisar e discutir por meio de uma revisão descritiva e minuciosa de literatura, a respeito da relação entre o uso de piercings e o potencial risco de infectividade.

\section{MÉTODO}

Trata-se de uma revisão sistemática descritiva. A pergunta norteadora foi construída através da estratégia PICD e a busca realizada nas bases de dados do Scielo, PubMed, Biblioteca Virtual em Saúde e Acervo Mais Index Base no período do mês de agosto de 2021 através dos seguintes descritores: Piercing, contaminação, complicação. O recorte temporal foi de 5 anos, foram lidos na integra 18 artigos dos quais apenas 3 artigos atendiam a finalidade proposta.

\section{REVISÃO BIBLIOGRÁFICA}

A perfuração da pele e a inclusão de material estranho é o binômio potencial para expor o organismo a infectividade, como HIV, hepatites B e/ou C, aspiração da peça, traumas locais e hipersensibilidade (GABINA ACS, et al., 2016). Qualquer região do corpo pode ser contaminada e sujeita a complicações sistêmicas, mas são mais vulneráveis as regiões anatômicas preferidas para inserção, como a língua (rica em bactérias e fluxo sanguíneo, facilitando o dano a circulação sistêmica e disseminação de microrganismos aos órgãos adjacentes, resultando em abscesso e hemorragia), a orelha e o nariz compostos por cartilagem e pobre vascularização são alvo de celulite e pericondrite bacteriana (LIMA LB, et al., 2021). 


\section{CONSIDERAÇÕES FINAIS}

Com base na análise dos dados expostos pode-se relatar que são dados preliminares e iniciais para evidenciar algo e ao fazer o uso desse acessório, o indivíduo está praticando injúria contra a própria proteção e se expondo a vários danos. É imprescindível estudos clínicos mais aprofundados sobre o assunto, através de maior interesse da comunidade científica e voluntariado em disseminar mais casos de complicações sistêmicas, a ponto de desestimular a prática por parte da comunidade e evitar complicações.

\section{REFERÊNCIAS}

1. GABINA ACS, et al. A qualidade da água e o desenvolvimento de doenças na cavidade oral. REAS, Revista Eletrônica Acervo Saúde, 2016; Sup. 3: 119-122.

2. LIMA LB, et al. Consequências causadas pelo uso de piercings na cavidade oral. Facit Business and Technology Journal, 2021, 1(26).

3. SANTOS JWDM, et al. Riscos e complicações do uso de piercing oral: uma revisão sistemática. Revista de Saúde e Ciências Biológicas. Journal of Health \& Biological Sciences, 2017; 5(1): 95-103. 


\section{SUSCETIBILIDADE GENÉTICA NA DOENÇA CELÍACA}

Lanna do Carmo Carvalho ${ }^{1}$

Ana Paula Fontana ${ }^{1}$

1. Universidade de Rio Verde (UniRV), Rio Verde - GO.

Palavras-chave: Doença celíaca, Genética, Genes.

\section{INTRODUÇÃO}

A doença celíaca é uma patologia crônica inflamatória que afeta o intestino delgado, resultante da tríade: suscetibilidade genética, reação autoimune e ingesta de glúten, ocasionando inúmeras complicações sistêmicas (VILARINHO FSB, et al., 2019). Os fatores determinantes da suscetibilidade genética para a enteropatia de sensibilidade exagerada ao glúten são encontrados na porção do HLA (Antígeno leucocitário humano) de classe 2, mais especificamente nos genes HLA-DQ (locus genéticos) alelos destes são eficazes no diagnóstico, são menos invasivos e possibilitam o diagnóstico precoce da doença, dado que sua ausência implica na exclusão diagnóstica da doença (VILARINHO FSB, et al., 2019).

\section{OBJETIVO}

Analisar, expor e revisar através da seleção de diversas literaturas científicas, a respeito da potencial suscetibilidade que a genética exerce sobre o desencadeamento da doença celíaca e suas implicações orgânicas.

\section{MÉTODO}

O seguinte estudo é uma revisão sistemática atual, realizada nas plataformas do SciELO, Pubmed, Medline e Acervo Mais Index Base no mês de agosto de 2021. Utilizou-se a estratégia PICO (População, Intervenção, Comparação, Desfecho) para a construção da pergunta norteadora e a associação dos seguintes descritores para a busca: Doença celíaca, antígenos, glúten e fatores genéticos.

\section{REVISÃO BIBLIOGRÁFICA}

Evidenciou-se a relação entre a síndrome e o antígeno de histocompatibilidade da classe 2, a ponto de ser denominada de "locus celíaco", cerca de 95\% dos acometidos apresentam o DQ2 (haplótipo) o restante, $5 \%$, possuem o DQ8 (haplótipo) (BRASIL, 2020). Além de familiares de primeiro grau que possuem a doença ser determinante, ou seja, quanto mais próximos os familiares, maior é a prevalência do antígeno de histocompatibilidade (VILARINHO MDFSB, et al., 2019). Estudos recentes apontam que as moléculas HLA de classe 1 também estão associados a doença celíaca e quando associada a fatores dietéticos, se torna potencial para o quadro clínico (BRASIL, 2021). 


\section{CONSIDERAÇÕES FINAIS}

Pode se analisar que diante do exposto a enteropatia induzida pelo glúten é uma doença autoimune de predisposição genética determinante, logo é essencial o diagnóstico precoce e adaptação dietética para se evitar agravamento. São necessários mais estudos clínicos para se elucidar o fato de alguns portadores dos alelos citados não desenvolverem a doença e também o fato da privação destes ser de caráter eliminatório e a influência dos demais anticorpos.

\section{REFERÊNCIAS}

1. BRASIL. Manual do Ministério de Saúde. Doença celíaca 2020. Disponível em https://www.google.com/url?sa=t\&source=web\&rct=j\&url=https://bvsms.saude.gov.br/doencaceliaca/\%23: :text\%3DDoen\%25C3\%25A7a\%2520cel\%25C3\%25ADaca\%2520\%25C3\%25A9\%2520um a\%2520doen\%25C3\%25A7a,os\%2520nutrientes\%2520dos\%2520alimentos\%252C\%2520vitaminas\&ve $\mathrm{d}=2$ ahUKEwjr05-

CzN7zAhV9LLkGHZHQBwAQFnoECAUQBQ\&usg=AOvVaw3mIXzLApjVdZh8eB1_N9pE. Acessado em 23 de novembro de 2021.

2. CIANFERONE A. Wheat allergy: diagonosis and management. J Asthma Allergy, 2016; 9: 13-25.

3. GRABENHENRICH LB, et al. Anaphylaxis in children and adolescents: The European Anaphylaxis Registry. J Allergy Clin Immunol, 2016; 137(4): 1128-37.

4. VILARINHO FSB, et al. Terapia nutricional na Doença Celíaca: Fatores Associados a Adesão de Crianças e adolescentes. Revista Eletrônica Acervo Saúde, 2019; 7: e1168. 


\title{
RELAÇÃO ENTRE MICROBIOTA INTESTINAL E A CANDIDÍASE DE REPETIÇÃO NAS MULHERES
}

\author{
Juliana Martins Lopes de Souza ${ }^{1}$ \\ Laisejane Silva da Cruz ${ }^{1}$ \\ Matheus Sobral Silveira ${ }^{1}$
}

1. Centro Universitário Estácio da Bahia, Salvador - BA.

Palavras-chave: Microbiota intestinal, Candidíase de repetição, Mulheres.

\section{INTRODUÇÃO}

No trato gastrointestinal são efetuadas funções correlacionadas com a nutrição e o sistema imune, mediante uma barreira imunológica e ação antimicrobiana. Deste modo, a microbiota intestinal possui grande influência na saúde do hospedeiro (PAIXÃO LA e CASTRO FFS, 2016). A disbiose intestinal é caracterizada pelo desequilíbrio entre bactérias benéficas e patogênicas no intestino, ocasionando distúrbios intestinais e extraintestinais, maior produção de toxinas e conseguintes prejuízos ao sistema imunológico e neurológico (VIEIRA GC e CASTRO FFS, 2021). Fungos da Candida são patógenos oportunistas presentes no intestino, sugerindo assim, a hipótese de que a microbiota intestinal tenha relevância na ocorrência da candidíase (PÉREZ JC, 2021).

\section{OBJETIVO}

Revisar na literatura científica sobre a correlação entre a microbiota intestinal e a candidíase de repetição nas mulheres adultas, identificando os fatores de risco, bem como suas formas de prevenção e melhora dos sintomas.

\section{REVISÃO BIBLIOGRÁFICA}

A sintomatologia clássica da candidíase (secreção, prurido e ardor) foi detectada em pacientes cujo perfil habitual apresentado apontou alto consumo de laticínios, uso de anticoncepcional e higiene inadequada, porém insuficientes para a identificação das cepas, fazendo-se necessário análise laboratorial para definição do tratamento (PEREIRA LC, et al., 2021).

Infecções vaginais ocorrem quando há redução de lactobacillus na região vaginal, alterando $\circ \mathrm{pH}$ e propiciando o crescimento de microrganismos patogênicos como a Candida spp. A administração probiótica traz benefícios, sendo provável uma redução da semiologia e prevenção da recorrência. Embora os probióticos não possam ser usados isoladamente como tratamento, eles podem melhorar a qualidade dos medicamentos antifúngicos. Foi afirmado que o Lactobacillus pode modular o sistema imunológico, aderindose à microbiota do intestino delgado e do cólon (VLADAREANU R, et al., 2018). Como consequência, a redução do crescimento de Candida no intestino resultou na diminuição da migração do fungo do reto para a vagina (DAVAR R, et al., 2016). 


\section{CONSIDERAÇÕES FINAIS}

A disbiose ocasiona-se com o uso prolongado de medicamentos, exposição a toxinas ambientais e dieta hiperglicídica, causando debilidade imunológica. É imperioso avaliação individual das pacientes, devido a predisposição a proliferação fúngica. A nutrição através da terapia probiótica como tratamento alternativo favorece a imunidade, tratando a microbiota intestinal e diminuindo a presença do fungo na região vaginal, necessitando-se de estudos para padronização na aplicabilidade clínica.

\section{REFERÊNCIAS}

1. DAVAR R, et al. Comparing the Recurrence of Vulvovaginal Candidiasis in Patients Undergoing Prophylactic Treatment with Probiotic and Placebo During the 6 Months. Probiotics and Antimicrobial Proteins, 2016; 8: 130-133.

2. PAIXÃO LA, CASTRO FFS. A colonização da microbiota intestinal e sua influência na saúde do hospedeiro. Universitas: Ciências da Saúde, 2016; 14(1): 85-96.

3. PEREIRA LC, et al. Vulvovaginal candidiasis and current perspectives: new risk factors and laboratory diagnosis by using MALDI TOF for identifying species in primary infection and recurrence. Eur $\mathrm{J}$ Clin Microbiol Infect Dis, 2021; 40: 1681-1693.

4. PÉREZ JC. Fungi of the human gut microbiota: Roles and significance. International Journal of Medical Microbiology, 2021; 311: e151490.

5. VIEIRA GC, CASTRO FFS. Aspectos fisiopatológicos da disbiose intestinal em estudantes de uma instituição de ensino privada do Distrito Federal. Revista Eletrônica Acervo Saúde, 2021; 13(1): e5249.

6. VLADAREANU R, et al. New evidence on oral L. plantarum P17630 product in women with history of recurrent vulvovaginal candidiasis (RVVC): a randomized double-blind placebo-controlled study. Eur Rev Med Pharmacol Sci, 2018; 22(1): 262-267. 


\title{
PREVALÊNCIA DA AUTOMEDICAÇÃo EM IDOSOS
}

\author{
Ana Carolina Moraes de Oliveira ${ }^{1}$ \\ Larissa Cristina dos Santos Camargos ${ }^{1}$ \\ Nathálya Faria Alves ${ }^{1}$ \\ Renato Canevari Dutra da Silva ${ }^{1}$
}

1. Universidade de Rio Verde (UniRV), Rio Verde - GO.

Palavras-chave: Automedicação, Idosos, Prevalência.

\section{INTRODUÇÃO}

O envelhecimento populacional é um fenômeno multifatorial, decorrente do aumento da expectativa de vida, redução da mortalidade e das taxas de fecundidade, bem como da melhora das condições de saúde (MUNIZ TR, et al., 2021). Atrelado a essa transição demográfica, a frequência e a intensidade do uso de medicamentos aumentam com a idade devido à maior presença de doenças e condições crônicas (FILHO AlL, et al., 2019). Todavia, o uso inadequado presente na disseminada prática da automedicação gera inúmeros eventos adversos, com repercussões significativas para o indivíduo, a sociedade e os sistemas de saúde (MOREIRA TA, et al., 2020).

\section{OBJETIVO}

Abordar a prevalência da automedicação na população idosa, a fim de conhecer os principais pontos que envolvem essa temática, tais como causas, consequências, reflexos nos sistemas de saúde, medicações mais usadas por conta própria e interações medicamentosas.

\section{MÉTODO}

Trata-se de uma pesquisa de revisão sistemática. Realizou-se a busca entre Junho e Julho de 2021 nas bases de dados PubMed, Scielo, LILACS e Acervo+ Index base. Incluiu-se artigos em inglês, português e espanhol, dos últimos 5 anos, excluindo estudos sobre não idosos e receituário médico prescrito. Achou-se 1.257 artigos e 6 foram inclusos ao obedecer adequadamente aos critérios propostos. Utilizou-se como descritores: Automedicação, Idoso, Self Medications e Aged.

\section{REVISÃO BIBLIOGRÁFICA}

Os motivos mais referidos para a automedicação foram experiência anterior com o medicamento e a ideia de que o mesmo é seguro (SANTOS ANM, et al., 2018). Os fármacos mais utilizados foram relaxantes musculares, analgésicos e antipiréticos, além dos anti-inflamatórios e antirreumáticos não esteroidais, tendo manifestações de efeitos adversos, tais como comprometimento do equilíbrio e coordenação, confusão 
mental, déficit cognitivo, sedação e hipotensão ortostática, bem como aumento do risco de fraturas (OLIVEIRA SBV, et al., 2018). Há, ainda, a automedicação de antibióticos, cuja principal consequência é a resistência bacteriana, aumentando os custos médicos e a mortalidade dos pacientes, além de prolongar as internações hospitalares (GONZÁLES JA, et al., 2019).

\section{CONSIDERAÇÕES FINAIS}

Constata-se que a automedicação em idosos pode acarretar prejuízos para a saúde (como interações medicamentosas e quedas) e qualidade de vida desses indivíduos, além de gastos desnecessários, atraso no diagnóstico e na terapêutica adequada. É necessário a disseminação de informações na prática clínica primária, a fim de evitar automedicação e as suas repercussões.

\section{REFERÊNCIAS}

1. FILHO AIL, et al. Subutilização de medicamentos em idosos pelo custo: ELSI-Brasil. Revista de Saúde Pública, 2018; 52(Suplemento 2): 8.

2. GONZÁLEZ JA, et al. Percepções na comunidade sobre o uso de antibióticos sem receita: explorando ideias por trás dessa prática. Pharm Pract, 2019; 17(1): 1394.

3. MOREIRA TA, et al. Uso de medicamentos por adultos na atenção primária: inquérito em serviços de saúde de Minas Gerais, Brasil. Revista Brasileira de Epidemiologia, 2020, e200025.

4. MUNIZ TR, et al. Fatores associados e prevalência de medicamentos prescritos para idosos institucionalizados do extremo norte do Brasil. Revista Eletrônica Acervo Saúde, 2021; 13(5): e7110.

5. OLIVEIRA SBV, et al. 2018. Perfil de medicamentos utilizados por automedicação por idosos atendidos em centro de referência. Einstein (São Paulo), 2018; 16(4).

6. SANTOS ANM, et al. Automedicação de participantes de uma universidade aberta à terceira idade e fatores associados. Revista Brasileira de Geriatria e Gerontologia, 2018; 21(4). 


\section{ALIMENTOS FUNCIONAIS: A CÚRCUMA E O CÂNCER}

Analice Barbosa Santos de Oliveira ${ }^{1}$

1. Centro Universitário FIEO (UNIFIEO), Osasco - SP.

Palavras-chave: Câncer, Curcuma longa L, Curcumina.

\section{INTRODUÇÃO}

Além do uso na cozinha, a cúrcuma (Curcuma longa $L$ ) tem sido utilizada em aplicações terapêuticas devido o seu poder anti-inflamatório, anti-hiperlipidêmico, antimicrobiano, radioprotetor, antiviral, antifúngica, antioxidante, imunomodulador (MOHEBBATI R, 2017).

As decorrências da cúrcuma sobre a saúde são geralmente centradas na curcumina. Constatou-se que a curcumina modula fatores de crescimento, enzimas, fatores de transcrição, quinase, citocinas inflamatórias (GIORDANO A e TOOMONARO G, 2019) e isto significa que ela pode representar um nutriente eficaz para a terapia do câncer e sabe-se que um bom estado nutricional evita doenças (LIMA R, et al., 2021).

\section{OBJETIVO}

Revisar e analisar por meio da literatura científica qual a ação da curcumina, que é uma substância presente na cúrcuma (Curcuma Longa L), em colaboração à terapia contra o câncer.

\section{MÉTODO}

Pesquisa de revisão integrativa realizada no banco de dados Pubmed, com análise de ensaios clínicos randomizados e revisões sistemáticas, referentes aos anos de 2016 a 2021, em língua inglesa, a partir dos descritores: "cancer" e "curcuma". Foram excluídos todos os artigos que não possuíam metodologia clara. Foram encontrados 14 artigos e somente 3 escolhidos.

\section{REVISÃO BIBLIOGRÁFICA}

Realizado ensaio randomizado com indivíduos com câncer de próstata percebeu-se que no de tratamento ativo experimentou um aumento não significativo no Antígeno Prostático Específico (PSA) (VAN DIE MD, et al., 2017). Em revisão sistemática constatou-se que a curcumina reduz a interleucina-1 (resposta imune) e melhora os resultados do câncer (SCHNEIDER A, et al., 2017) e em uma revisão sistemática observou-se que fitoquímicos isolados (sulforafano), extratos fitoterápicos (extrato de romã, cúrcuma, chá verde e broto de brócolis), soja, licopeno e extrato de romã e derivados de soja e licopeno estabilizam, diminuem ou aumentam mais lentamente, os níveis séricos de PSA (VAN DIE MD, et al., 2016).

\section{CONSIDERAÇÕES FINAIS}


Embora estudos tenham evidenciado inúmeras atividades biológicas na curcumina, como as atividades anti-inflamatórias, que são importantes na terapia do câncer, sabe-se que existem atualmente, evidências clínicas limitadas sobre plantas medicinais. Há necessidade de uma investigação mais aprofundada e minuciosa até a confirmação de sua eficácia e segurança.

\section{REFERÊNCIAS}

1. GIORDANO A, TOMMONARO G. Curcumin and Cancer. Nutrients, 2019; 11(10): 2376.

2. LIMAR DCS, et al. Avaliação da influência do estado nutricional na ocorrência de infecção respiratória aguda em menores de dois anos. Revista Eletrônica Acervo Saúde, 2021; 13(4): e6494.

3. MOHEBBATI R, ANAEIGOUDARI A, KHAZDAIR MR. The effects of Curcuma longa and curcumin on reproductive systems. Endocrine Regulations, 2017; 51(4): 220-228.

4. SCHNEIDER A, et al. Comparison of remicade to curcumin for the treatment of Crohn's disease: A systematic review. Complementary Therapies Medicine, 2017; 33: 32-38.

5. VAN DIE MD, et al. Phytotherapeutic interventions in the management of biochemically recurrent prostate cancer: a systematic review of randomised trials. BJU International, 2016; 117(Suppl 4): 17-34.

6. VAN DIE MD, et al. A Placebo-Controlled Double-Blinded Randomized Pilot Study of Combination Phytotherapy in Biochemically Recurrent Prostate Cancer. Prostate, 2017; 77(7): 765-775. 


\section{SAÚDE MENTAL DOS PROFISSIONAIS DE ENFERMAGEM NA PANDEMIA COVID-19}

Kerlison De Souza Silva ${ }^{1}$

Lilian De Oliveira Corrêa ${ }^{1}$

1. Faculdade Estácio de Sá do Amazonas, Manaus - AM.

Palavras-chave: Saúde Mental, Enfermagem, Pandemia.

\section{INTRODUÇÃO}

A saúde mental dos profissionais de Enfermagem na pandemia de COVID-19 tem se tornado um assunto questionado que se intensifica com o tempo. Segundo a Organização Mundial de Saúde (OMS) ainda não há um consenso sobre o que é saúde mental, uma vez que diferentes fatores podem influenciar (OMS, 1946).

A desvalorização e a sobrecarga do corpo de enfermagem é algo de antes da pandemia, e que se intensificou na atual e sabe-se que isso acarreta em transtornos mentais. A saúde mental frente a pandemia dever ser algo levado mais a sério, visto que os seus danos e marcas futuramente podem ser irreparaveis em muitos profissionais (DUARTE MLC, et al., 2021).

\section{OBJETIVO}

Compreender e examinar como os profissionais de enfermagem estão enfrentando a pandemia de COVID19 a partir da perspectiva da saúde mental e interpretar as atuais práticas do corpo de enfermagem.

\section{MÉTODO}

Trata-se de uma revisão integrativa. Para tal, foram realizadas buscas nas bases de dados BVS, BVDH, SciELO e PubMed no período do mês de agosto de 2021, onde foram localizados 90 artigos, procedeu-se à análise de 4 artigos, incluindo artigos dos últimos 2 anos e excluindo aqueles que não atendessem a temática proposta e com mais de 2 anos, utilizando como descritores: Saúde Mental, Enfermagem, Pandemia, COVID19.

\section{REVISÃO BIBLIOGRÁFICA}

O contato direto com os pacientes de COVID-19 e a exposição direta aos pacientes, fez com que os enfermeiros questão na linha de frente sejam mais suscetíveis a sofrer com problemas psicológicos por conta do estresse (BARBOSA DJ, et al., 2020). Nas pandemias, a quantidade de profissionais com saúde mental prejudicada chega a ser maior que o número de pessoas infectadas ou doentes (DUARTE MLC, et al., 2021). A criação de um ambiente virtual para interação social e familiar tem ajudado a diminuir as tensões causadas pela pandemia, aproximando os profissionais de seu círculo sem infligir limites da pandemia (SOUZA JB, et al., 2021). 


\section{CONSIDERAÇÕES FINAIS}

A pandemia trouxe novas questões que se tornaram mais um desafio, necessitando assim uma reinvenção do corpo de enfermagem, sendo o seu trabalho concertado no cuidado humano e na humanização do cuidar, esses e outros fatores acabam desencadeando problemas em sua saúde mental e é comum associar depressão, ansiedade e o impacto que isso causa no bem-estar e as atividades exercidas na pandemia.

\section{REFERÊNCIAS}

1. BARBOSA DJ, et al. Fatores de estresse nos profissionais de enfermagem no combate à pandemia da COVID-19: Síntese de Evidências. Com. Ciências Saúde, 2020; 31 Suppl 1: 31-47.

2. DUARTE MLC, et al. Enfermagem e saúde mental: uma reflexão em meio à pandemia de coronavírus. Rev Gaúcha Enferm., 2021; 42(esp): e20200140.

3. ORGANIZAÇÃO MUNDIAL DE SAUDE (OMS). Constituição da Organização Mundial da Saúde. 1946. Disponível em http://www.direitoshumanos.usp.br/index.php/OMS-Organização-Mundial-daSaúde/constituicao-da-organizacao-mundial-da-saude-omswho. Acessado em: 17 de outubro de 2021. 
RESUMO SIMPLES: Revisão Narrativa

\title{
ATUAÇÃO DA ENFERMAGEM NOS CUIDADOS DE ALTA COMPLEXIDADE E A SÍNDROME DE BURNOUT, UMA REVISÃO NARRATIVA
}

\author{
Thais Pereira da Silva ${ }^{1}$ \\ Ingrid Keylla Marrde ${ }^{1}$ \\ Bruno Mamede Da Silva ${ }^{1}$ \\ Ingridy Melo Sampaio ${ }^{1}$ \\ Jéssica Braga De Carvalo ${ }^{1}$
}

1. Faculdade da Amazônia (UNAMA), Boa Vista - RR.

Palavras-chave: Síndrome de Burnout, Enfermagem, Alta complexidade.

\section{INTRODUÇÃO}

A profissão de enfermagem ao longo dos anos evolui no desenvolvimento dos conhecimentos técnicos científicos, atualmente os profissionais de enfermagem que trabalham em ambiente hospitalar e possuem tendência de experimentar a Síndrome de Burnout (SB). A SB pode ser compreendida a partir de três competências: exaustão emocional, despersonalização e a falta de realização pessoal, sendo que é possível classificar a sintomatologia conforme as manifestações em quatro classesmanifestações físicas, psíquicas e defensivas. Com o advento da pandemia do COVID-19, muitos profissionais podem apresentar sintomas da síndrome e com isso surge a necessidade de estudos sobre a SB e como esta afeta os profissionais que atuam em ambientes de alta complexidade (BASTOS JCS, et al., 2021).

\section{OBJETIVO}

Revisar na literatura científica com o objetivo de identificar como os profissionais de enfermagem são atingidos pela Síndrome de Burnout no contexto da assistência de alta complexidade - Unidade de Terapia Intensiva (UTI) e urgência e emergência.

\section{REVISÃO BIBLIOGRÁFICA}

Conforme os estudos a respeito da SB verificaram se semelhanças nos resultados das pesquisas como faixa etária (20-30) e gênero feminino (RIBEIRO EKA, et al., 2021; ABDO SA, et al., 2016). Segundo os estudos feitos pelos autores a SB predomina-se na faixa etária de 20 a 30 anos, e os profissionais por serem mais jovens apresentam pouco tempo de experiência na área da unidade de terapia intensiva o que acarreta a insegurança pessoal e sobrecarga emocional levando-os a exaustão emocional. Evidenciou-se nos artigos o predomínio da SB no gênero feminino na profissão de enfermagem pelas mulheres sempre estarem presentes a área da saúde e a inter-relação do cuidado formal e informal fora ou dentro do ambiente de trabalho e familiar contendo maior indício de desencadear a Síndrome de Burnout. O local de predomínio da 
Síndrome é em setores de urgência e emergência e UTI por serem locais no qual o profissional está submetido a situações de estresse e ansiedade (RIBEIRO EKA, et al., 2021; ABDO SA, et al., 2016).

\section{CONSIDERAÇÕES FINAIS}

A partir da análise da literatura a respeito do tema, percebe-se que mulheres são mais afetadas, principalmente jovens e atuantes em áreas de alta complexidade, onde há uma alta demanda de cuidados que em longo prazo podem ocasionar em estresse e ansiedade bem como o desenvolvimento da SB. Contudo é necessário um maior número de estudos para determinar também mecânismos de enfrentamento utilizados.

\section{REFERÊNCIAS}

1. ABDO SA, et al. Burnout among physicians and nursing staff working in the emergency hospital of Tanta University, Egypt. East Mediterr Health J, 2016; 21(12): 906-915.

2. BASTOS JCS, et al. Síndrome de Burnout e os estressores relacionados à exaustão emocional em enfermeiros. Revista Eletrônica Acervo Saúde, 2021; 13(2): e5846.

3. RIBEIRO EKA, et al. Influence of burnout syndrome on the quality of life of nursing professionals: quantitative study. Revista Brasileira de Enfermagem, 2021; 74(3): 1-7. 


\section{A IMPORTÂNCIA DO PROGRAMA FARMÁCIA POPULAR DO BRASIL (PFPB)}

Larissa Santos Carneiro Gomes ${ }^{1}$

Ednalda Alves de França Marinho ${ }^{1}$

Antônio Sérgio Alves de Almeida Júnior²

1. Centro Universitário Maurício de Nassau (UNINASSAU), Recife - PE.

2. Instituto Federal do Norte de Minas Gerais (IFNMG), Arinos - MG.

Palavras-chave: Farmácia popular, Programas governamentais, Atenção farmacêutica.

\section{INTRODUÇÃO}

A implementação do Programa Farmácia Popular do Brasil (PFPB) vem trazendo um grande avanço para a população, em relação à acessibilidade a medicamentos e contribuindo na redução de gastos nas famílias (COSTA KS, et al., 2016). O programa contém fármacos para o tratamento de doenças crônicas não transmissíveis, contraceptivos orais e fraldas para incontinência urinária (BRASIL, 2021). O objetivo é também garantir a integralidade do cuidado, entre a unidade de saúde que o paciente é atendido e o local onde adquire os medicamentos. Assim, o farmacêutico deve assegurar que os usuários sejam orientados corretamente e recebam as informações necessárias para o uso racional (ALENCAR TOS, et al., 2018).

\section{OBJETIVO}

Descrever a relevância do PFPB especialmente para a população socioeconômica mais vulnerável no acesso aos medicamentos e acompanhamento farmacoterapêutico, visando o sucesso na terapia medicamentosa e a educação do paciente.

\section{MÉTODO}

Revisão integrativa realizada através das bases Lilacs e Scielo. Os descritores utilizados foram: acesso aos serviços de saúde, programa nacional de saúde e programa nacional de assistência farmacêutica. Para o presente resumo foram selecionados periódicos entre 2016-2021, em inglês e português, sendo 15 artigos selecionados para análise de títulos e 5 escolhidos após leitura. Não foram considerados aqueles antecedentes ao ano de 2016 e com fuga ao objetivo do trabalho.

\section{REVISÃO BIBLIOGRÁFICA}

O PFPB impulsionou o mercado dos genéricos e o acesso aos medicamentos pela população, sendo componente da busca da qualidade dos serviços e consolidação do sistema de saúde (ALENCAR TOS, et al., 2018). Além de beneficiar as farmácias a realizar o acompanhamento farmacoterapêutico, o PFPB elevou o acesso aos medicamentos para hipertensão e diabetes com mais de 3,7 milhões de tratamentos de tal 
forma que conseguiu reduzir a taxa média, ao ano, de internações e óbitos por diabetes mellitus e hipertensão em 27,6\% e 8,0\%, respectivamente (ALMEIDA ATC, et al., 2019; COSTA KS, et al., 2016; GARCIA MM, et al., 2017).

\section{CONSIDERAÇÕES FINAIS}

O PFPB oferece acesso gratuito para a população aos medicamentos, além de acompanhamento farmacoterapêutico e assistência farmacêutica. Logo, o programa é uma ferramenta que contribui para a adesão ao tratamento medicamentoso, pois permite a aquisição de medicamentos para a população que, em virtude das condições socioeconômicas, não conseguiriam. Ademais, a longo prazo, aquela ferramenta promove a redução das taxas de internações hospitalares, além da mortalidade.

\section{REFERÊNCIAS}

1. ALENCAR TOS, et al. Programa Farmácia Popular do Brasil: uma análise política de sua origem, seus desdobramentos e inflexões. Saúde debate, 2018; 42(2): 159-172.BRASIL. Decreto n 5090, de 20 de maio de 2004. 2004. Disponível em: http://www.planalto.gov.br/ccivil_03/_ato20042006/2004/Decreto/D5090.htm Acessado em: 3 de abril de 2021.

2. COSTA KS, et al. Obtenção de medicamentos para hipertensão e diabetes no Programa Farmácia Popular do Brasil: resultados da Pesquisa Nacional de Saúde, 2013. Epidemiol. Serv. Saúde, 2016; 25(1): 33-44.

3. GARCIA MM, et al. Avaliação econômica dos Programas Rede Farmácia de Minas do SUS versus Farmácia Popular do Brasil. Ciênc. saúde coletiva, 2017; 22(1): 221-233. 


\section{CUIDADOS FARMACÊUTICOS AO PACIENTE COM DOENÇAS RENAIS}

Larissa Santos Carneiro Gomes ${ }^{1}$

Stéphanie Beatrice Lopes Martins ${ }^{1}$

Antônio Sérgio Alves de Almeida Júnior²

1. Centro Universitário Maurício de Nassau (UNINASSAU), Recife - PE.

2. Instituto Federal do Norte de Minas Gerais (IFNMG), Arinos - MG.

Palavras-chave: Serviços farmacêuticos, Doença renal, Atenção farmacêutica.

\section{INTRODUÇÃO}

A doença renal corresponde nos últimos tempos um relevante problema de saúde pública no Brasil, sendo definida pela diminuição lenta e progressiva da capacidade da função renal (MIYAHIRA CK, et al., 2016). As principais causas são diabetes, pressão arterial alta ou histórico da doença na família e como consequência cálculos renais, infecção renal ou pielonefrite, cistos renais, tumor ou câncer de rim e perda da função renal (CRUZ MRF, et al., 2016). Em virtude do uso de medicamentos, sobretudo sem prescrição médica, existe a necessidade da análise farmacoterapêutica dos pacientes tornando-se essencial o emprego de cuidados farmacêuticos (PEREIRA THN, 2018).

\section{OBJETIVO}

Analisar e descrever a importância do profissional farmacêutico na prestação de serviços e ou Atenção Farmacêutica (AF) especialmente quanto a orientação farmacoterapêutica, conscientização e manejo de pacientes com doenças renais.

\section{MÉTODO}

Revisão integrativa realizada através das bases BVS e Scielo. Os descritores utilizados através do DeCS foram: doença renal, cuidados farmacêuticos e atenção farmacêutica. Para o processo de síntese do presente resumo foram selecionados periódicos entre 2016-2021, em inglês e português, sendo 15 artigos selecionados para análise de títulos e 5 escolhidos após leitura. Não foram considerados aqueles antecedentes ao ano de 2016 e com fuga ao objetivo do trabalho.

\section{REVISÃO BIBLIOGRÁFICA}

Os pacientes renais diante ao tratamento mostram-se desmotivados por ser uma terapêutica exaustiva e dolorosa. Em virtude da polimedicação e ausência de orientação referente às prescrições médicas, faz-se necessário a análise farmacoterapêutica visando melhor desfecho clínico (PAULA ECA e MENDES SJ, 2019). 
O farmacêutico amplia o foco ao paciente renal voltado à solução das causas farmacoterapêuticas, objetivando a redução da morbimortalidade relacionada aos medicamentos junto à equipe multidisciplinar (GRABE DW e CARDONE KE, 2016). Assim, envolvidos com a equipe multiprofissional abordam diversas questões e insatisfações necessárias à melhoria do regime terapêutico. A sua atuação de preferência preventiva, procura externar melhorias e o bem-estar do paciente (SANTOS KK, et al., 2018).

\section{CONSIDERAÇÕES FINAIS}

A orientação farmacêutica ao paciente com doença renal é de extrema importância na clínica. Aquele profissional, junto a equipe multiprofissional, objetiva a promoção da qualidade de vida do paciente. Neste sentido, o farmacêutico, especificamente, através do seguimento farmacoterapêutico, da reconciliação medicamentosa e da orientação/educação do paciente, contribui grandemente para o aumento da adesão ao tratamento medicamentoso e consequentemente para a melhoria dos resultados clínicos dos pacientes.

\section{REFERÊNCIAS}

1. CRUZ MRF, et al. Descoberta da doença renal crônica e o cotidiano da hemodiálise. Ciência, Cuidado e Saúde, 2016; 15(1): 36-43.

2. GRABE DW, CARDONE KE. Altered pharmacology and pill burden in older adults: A balancing act. In: Misra M. Dialysis in older adults: A Clinical Handbook New York: Springer, 2016; 13(1): 19-32.

3. MIYAHIRA CK, et al. Avaliação da dor torácica, sono e qualidade de vida de pacientes com doença renal crônica. Arquivos de Ciências da Saúde, 2016; 23(4): 61-66.

4. PAULA ECA, MENDES SJ. Farmacoeconomia e farmacoepidemiologia na gestão de recursos em saúde: primeiros resultados de uma revisão integrativa. Journal of Management \& Primary Health Care, 2019; 1: e27s.

5. PEREIRA THN. Acompanhamento farmacoterapêutico em pacientes renais crônicos em hemodiálise. Rev. Especialize On-line IPOG, 2018; 1(16): 1-15.

6. SANTOS KK, et al. Epidemiological profile of chronic renal patients in treatment. Journal Nursing UFPE, 2018; 12(10): 2293-300. 


\title{
A IMPORTÂNCIA DO APOIO DAS ESCOLAS NA PROMOÇÃO DOS PROGRAMAS DE SAÚDE BUCAL: UMA REVISÃO DA LITERATURA
}

\author{
Ingrid Maria Barbosa dos Santos ${ }^{1}$ \\ Rhaina Neusa Pereira da Silva ${ }^{1}$ \\ Dielson Roque da Costa ${ }^{1}$ \\ José Eduardo Queiroz da Silva ${ }^{1}$ \\ Davi Clementino Carneiro²
}

1. UNIESP Centro Universitário, Cabedelo - PB.

2. Universidade Federal da Paraíba (UFPB), João Pessoa - PB.

Palavras-chave: Saúde bucal, Escola, Educação em saúde.

\section{INTRODUÇÃO}

A escola é considerada um local ideal para oferta de programas de saúde, pois é onde as crianças aprendem e adquirem novos hábitos. A literatura destaca que o ensino sobre saúde bucal nas escolas apresenta alto efeito na redução do risco de cárie dentária de alta evolução em crianças nos primeiros 6 anos de vida (CARDOSO AT, et al., 2019).

Por esse motivo a escola tem papel principal na construção e transmissão de conhecimentos, pois é nesse período que as crianças aprendem novos hábitos e estão mais propensas a mudanças que contribuem para melhorar a sua saúde bucal (OLIVEIRA EL, et al., 2018).

\section{OBJETIVO}

Revisar a literatura científica sobre a importância do apoio das escolas na promoção de programas de saúde bucal, com o objetivo de elencar a importância da promoção desses programas de saúde na vida das crianças.

\section{REVISÃO BIBLIOGRÁFICA}

Foi realizada uma experiência com alunos de uma escola pública no Maranhão, com o propósito de identificar os conhecimentos, percepções e práticas voltadas à saúde bucal adquiridos na escola, concluindo que o conhecimento demonstrado pelos alunos é baixo, realçando a necessidade das práticas em saúde bucal nas escolas, os autores alegam que tais práticas permitem à população conhecimento para a manutenção da boa saúde (RODRIGUES CAL, et al., 2020).

Na República de Cabo Verde, África, uma outra experiência foi realizada em uma escola particular de ensino infantil. A escola tem papel fundamental nos programas educativos e preventivos, sendo eficiente na 
formação de uma cultura de prevenção de doenças bucais, atuando como agente transmissor de conhecimentos e informações sobre saúde bucal e dos hábitos necessários para higiene da boca (CARDOSO AT, et al., 2019). Um estudo demonstra o nível de conhecimento sobre saúde bucal dos professores do ensino fundamental da escola pública, concluindo que a maioria dos professores não possui conhecimento específico para realizar um trabalho de educação em saúde bucal com os alunos (OLIVEIRA EL, et al., 2018).

\section{CONSIDERAÇÕES FINAIS}

Embora o tema de saúde bucal seja reconhecido nas escolas como de grande importância, e o apoio da escola exerça papel fundamental na transferência de conhecimentos e hábitos, após a análise da literatura, pode-se perceber que o tema ainda é pouco abordado nas salas de aula das escolas, falta conhecimento específico para a disseminação desse conteúdo de forma adequada e eficiente.

\section{REFERÊNCIAS}

1. CARDOSO ATG, et al. Experiência de educação em saúde bucal em escola de educação infantil na República de Cabo Verde, África. Archive of health investigation, 2019; 8(5).

2. OLIVEIRA EL, et al. A importância do nível de conhecimento dos professores de escola pública do ensino fundamental sobre saúde bucal - revisão de literatura. Revista Campo do Saber, 2018; 4(5).

3. RODRIGUES CAL, et al. Conhecimentos e práticas em saúde bucal na escola: relato de experiências. REAMEC - Rede Amazônica de Educação em Ciências e Matemática, 2020; 8(1): 403-416. 


\title{
TRATAMENTO FISIOTERAPEUTICO EM MULHERES PORTADORAS DE VAGINISMO
}

\author{
Hilana Costa Oliveira ${ }^{1}$ \\ Thais Luna Alencar Araripe ${ }^{1}$ \\ Marlon Agostinho da Silva Porfirio ${ }^{1}$ \\ Rafaela dos Santos Monteiro ${ }^{1}$
}

1. Faculdade Rodolfo Teófilo (FRT), Fortaleza - CE.

Palavras-chave: Vaginismo, Fisioterapia, Terapêutica.

\section{INTRODUÇÃO}

O vaginismo é uma disfunção sexual caracterizada por contrações recorrentes ou persistentes da musculatura da vagina (ANGIN AD, et al., 2020). Alguns fatores que podem predispor o vaginismo estão relacionados com a percepção negativa sobre sexualidade, problemas sexuais com o parceiro masculino, abuso sexual e físico, traumas iatrogênicos, mitos sexuais, conflitos de relacionamento/familiar e doenças psiquiátricas (BATISTA MCS, et al., 2017). No Brasil, 17,8\% das mulheres sofrem com dispareunia, diante dessa incidência a fisioterapia tem um papel importante na prevenção e tratamento do vaginismo (FRARE LEC, et al., 2020).

\section{OBJETIVO}

Identificar a importância do atendimento fisioterapêutico no tratamento da disfunção sexual vaginismo recorrente no cotidiano das mulheres que apresentam um perfil de baixa função sexual e dispareunia referida pelo vaginismo.

\section{MÉTODO}

As buscas foram feitas nas bases de dados PubMed, BVS e SciELO, utilizando os descritores "vaginismo" AND "fisioterapia", "tratamento" AND "vaginismo" onde foram encontrados 71 artigos. Após os critérios de inclusão: artigos em português e inglês relevantes ao objeto de pesquisa, os critérios de exclusão: revisões de literatura, cartas ao editor e artigos pagos. Foram econtrados 13 artigos, porém, 4 selecionados para a referida revisão.

\section{REVISÃO BIBLIOGRÁFICA}

O vaginismo é uma disfunção sexual que consiste em contrações voluntárias recorrentes ou persistentes da musculatura da vagina, ocorrendo o fechamento vaginal contra a penetração (ANGIN AD, et al., 2020). Para as mulheres com vaginismo, o tratamento fisioterapêutico tem se mostrado a melhor opção para alívio da dor. As terapias manuais por meio de massagem no assoalho pélvico auxiliam na diminuição de 
aderências, podendo auxiliar na diminuição das dores e consequentemente uma melhor qualidade de vida para essas mulheres (BATISTA MCS, et al., 2017). Ademais, ativação da musculatura do assoalho pélvico é fundamental para o aumento da vascularização, que contribui na recuperação do vaginismo (BATISTA MCS, et al., 2017).

\section{CONSIDERAÇÕES FINAIS}

As mulheres com vaginismo mostram limitações funcionais sexuais por apresentarem disfunções musculoesqueléticas e/ou neurológicas. Diante do exposto, observa-se que o tratamento fisioterapêutico pode beneficiar a recuperação funcional, melhorar a mobilidade, aliviar a dor e prevenir incapacidades físicas futuras, além da melhor qualidade de vida.

\section{REFERÊNCIAS}

1. ANGIN AD, et al. Effects of predisposing factors on the success and treatment period in vaginismus. Jornal Brasileiro de Reprodução Assistida, 2020; 24(2): 180-188.

2. BATISTA MCS. Fisioterapia como parte da equipe interdisciplinar no tratamento das disfunções sexuais femininas. Revista Diagnóstico \& Tratamento, 2017; 22(2): 83-7.

3. FRARE LEC, et al. Vaginismo em idade reprodutiva. Research, Society and Development, 2020; 9(10): e8579109187.

4. YARAGHI $M$, et al. Comparing the effectiveness of functional electrical stimulation via sexual cognitive/behavioral therapy of pelvic floor muscles versus local injection of botulinum toxin on the sexual functioning of patients with primary vaginismus: a randomized clinical trial. International Urogynecology Journal, 2019; 30: 1821- 1828. 
RESUMO SIMPLES: Revisão Integrativa

\title{
HUMANIZAÇÃO NA ASSISTÊNCIA DA ENFERMAGEM AO PARTO NORMAL: REVISÃO INTEGRATIVA
}

\author{
Juciele Gomes dos Santos ${ }^{1}$ \\ Gleisiane Gaspar Leal de Vasconcelos ${ }^{2}$ \\ Watina Rodrigues Dias ${ }^{3}$ \\ Kelly Silva Gomes ${ }^{4}$ \\ Tatiane Carvalho Mendes 5
}

1. Faculdade das Ciências Agrárias e da Saúde (FAS), Lauro de Freitas - BA.

2. Universidade Estadual do Maranhão (UEMA), Caxias - MA.

3. Faculdade Maurício de Nassau (FMN), Parnaíba - PI.

4. Universidade Estadual do Tocantins (UNITINS), Augustinópolis - TO.

5. Centro Universitário Jorge Amado (UNIJORGE), Salvador - BA.

Palavras-chave: Humanização da assistência, Parto normal, Assistência de enfermagem.

\section{INTRODUÇÃO}

O parto é um evento fisiológico e natural, constituindo experiência única à mulher e sua família, por isso deve ser vivenciado com segurança e dignidade (MOURA JWS, et al., 2020). Entretanto, a atuação da enfermagem humanizada visa proporcionar à mulher durante o parto e pós-parto segurança, conforto, acolhimento, suporte emocional e sempre com uma escuta ativa e comunicação atenciosa (PILLER AA, et al., 2019). Entretanto, os profissionais de Enfermagem devem possuir conhecimento científico, qualificação para desenvolver sua assistência de forma humanizada ao parto normal em sua assistência (ROMÃO RS, et al., 2018).

\section{OBJETIVO}

Identificar as evidências científicas sobre a humanização na assistência da enfermagem, discutir a importância desse conhecimento para os profissionais de enfermagem e avaliar a qualidade na assistência do trabalho de parto normal.

\section{MÉTODO}

Revisão integrativa da literatura de abordagem qualitativa, pesquisado nas bases (MEDLINE, BDENF, LILACS), recorte temporal de 2016-2021. Os descritores utilizados foram: "Humanização da Assistência", "Parto Normal", "Assistência de Enfermagem". Critérios para inclusão: artigos disponíveis na íntegra gratuitamente nos idiomas inglês, espanhol e português. Critérios para exclusão: teses, dissertações e livros. 
Encontrado 132 artigos, ao aplicar os critérios restaram 77. Após leitura dos títulos e resumos, selecionei 8 para compor os resultados.

\section{REVISÃO BIBLIOGRÁFICA}

Identificou-se que o profissional enfermagem é de extrema importância no processo gravídico, puerperal e parto gerando assim autonomia a parturiente, fazendo com que a mesma se sinta confiante, à vontade $\mathrm{e}$ bem acolhida pela equipe, proporcionando a mesma e ao recém-nascido (RN) o primeiro contato pele a pele (ALVES MCT, et al., 2019). Mostrou-se que as práticas humanizadas como, comunicação ativa, orientação no processo de parto/pré-natal e respeito autônomo da mulher são de suma importância para que o parto seja mais confiante, seguro e enriquecedor (ÁLVARES AS, et al., 2017).

\section{CONSIDERAÇÕES FINAIS}

O estudo proporcionou refletir sobre a humanização na assistência da enfermagem ao parto normal. Nesse processo, a enfermagem desempenha papel fundamental para garantia da humanização na assistência, baseadas nas evidências científicas, para que transcorra de forma segura e com qualidade. Ademais, tornamse necessárias projeções de conhecimento científico na área, visando a qualificação na assistência.

\section{REFERÊNCIAS}

1. ALVES T, et al. Contribuição da enfermagem Obstétrica para as Boas práticas no Trabalho de Parto e Parto Normal. Enfermagem em Foco, 2019; 10(4): 54-60.

2. ALVARES A, et al. Práticas humanizadas da enfermeira obstétrica: contribuições no bem-estar materno. Revista Brasileira de Enfermagem, 2018; 71(16): 2620-27.

3. MOURA J, et al. Humanização do Parto na perspectiva da Equipe de Enfermagem de um Centro de parto normal. Enfermagem em Foco, 2020; 11(3): 202-208.

4. PILLER A, et al. Cuidados no processo de parturição sob a ótica dos profissionais de enfermagem. Texto \& Contexto Enfermagem, 2020; 29: 1-16.

5. ROMÃO R, et al. Qualidade da Assistência Obstétrica Relacionada ao Parto Por Via Vaginal. Revista de Enfermagem do Centro Oeste Mineiro, 2018; 8: 1-10. 


\section{BENEFÍCIOS DAS PRÁTICAS INTEGRATIVAS E COMPLEMENTARES NO TRABALHO DE PARTO}

Francisco Lucas Leandro de Sousa ${ }^{1}$

Angelica Ribeiro do Nascimento Oliveira ${ }^{1}$

Danilo da Silva Alves ${ }^{1}$

1. Centro Universitário Maurício de Nassau (UNINASSAU), Fortaleza - CE.

Palavras-chave: Terapias complementares, Trabalho de parto, Parto.

\section{INTRODUÇÃO}

As Práticas Integrativas e Complementares (PIC) compreendem um conjunto de tratamentos onde utilizam-se recursos terapêuticos baseados em conhecimentos tradicionais utilizados há milênios por diversos por diferentes culturas, com o intuito de reduzir o uso de medicamentos durante o trabalho de parto, na tentativa de minimizar as dores do parto (SILVA ADV, et al., 2020). O parto é um evento fisiológico e natural, com o avanço tecnológico às mulheres deixaram de ser protagonistas neste cenário que passou a ser ocupado por intervenções extremamente medicalizadas e parto cirúrgico sem indicação (OLIVEIRA LS, et al., 2020).

\section{OBJETIVO}

Revisar por meio da literatura científica sobre os principais benefícios da PIC durante o trabalho de parto normal, destacando as principais técnicas utilizadas durante o processo de parturição da mulher.

\section{MÉTODO}

Trata-se de uma revisão integrativa realizada através da Biblioteca Virtual em Saúde, veiculados nas bases de dados Lilacs e Scielo. Para inclusão dos artigos considerou-se aqueles que abordassem o tema, disponíveis eletronicamente, na integra, nos idiomas português e inglês publicados entre 2017 e 2021 . Para os critérios de exclusão artigos repetidos nas bases de dados. Foram encontrados incialmente 22 artigos, após análise dos títulos e conteúdos foram selecionados 15 artigos.

\section{REVISÃO BIBLIOGRÁFICA}

Durante o parto o uso da auriculoterapia, hidroterapia, acupressão, aromaterapia, bola suíça, banho de chuveiro e de imersão proporcionam o bem-estar para a mulher, tornando-a dona desse momento. Destacando como benefícios: redução da dor, ansiedade, tempo de trabalho de parto, redução de trauma perineal, proporciona maior dilatação cervical, alivio ao desconforto pélvico, regulação das contrações uterinas, calma e relaxamento e diminuição de estresse (SOUZA VA, et al., 2020). 
Vale salientar que, a recomendação para utilização desses métodos pode variar de acordo com idade gestacional, dilatação, risco obstétrico, números e tipo de gestação. São práticas não invasivas e devem ser encorajadas elos profissionais da saúde (ALVES IGF, et al., 2019).

\section{CONSIDERAÇÕES FINAIS}

Desse modo, destaca-se que as PIC são essenciais durante o trabalho de parto, a fim de proporcionar segurança, conforto e bem-estar para mulher. É essencial que os profissionais de saúde busquem qualificações na área com o intuito de prestar uma assistência adequada e de qualidade durante o trabalho de parto.

\section{REFERÊNCIAS}

1. ALVES IGF, et al. Terapias alternativas e complementares utilizadas por enfermeiras obstetras em um centro de parto normal. Revista Saúde, 2019; 12: 3-4.

2. OLIVEIRA LS, et al. Uso de medidas não farmacológicas para o alívio da dor no trabalho de parto normal. Brazilian Journal of Health Review, 2020; 3: 2850-2869.

3. SILVA ADV, et al. Os benefícios das práticas integrativas e complementares no trabalho de parto. Research, Society and Development, 2020; 9: e614974468-e614974468.

4. SOUZA VA, et al. As práticas integrativas e complementares na atenção à saúde da mulher. Research, Society and Development, 2020; 9: e81985379-e81985379. 


\section{EFEITOS DO CONSUMO DE ALIMENTOS FUNCIONAIS EM IDOSOS}

\section{Débora Helen Gonçalves Silva ${ }^{1}$}

Kássia Héllen Vieira ${ }^{1}$

1. Faculdade de Saúde e Humanidades Ibituruna (FASI), Montes Claros - MG.

Palavras-chave: Dieta saudável, Longevidade, Prevenção de doenças.

\section{INTRODUÇÃO}

Os alimentos funcionais oferecem benefícios à saúde e funções nutricionais básicas, produzindo então efeitos metabólicos e/ou fisiológicos ao nosso corpo. Alimentos fontes de fibras, frutas e vegetais contém em sua composição compostos com propriedades funcionais (COSTA MFN, et al., 2019). Os idosos, devido as alterações funcionais que ocorrem no organismo, apresentam maior predisposição a desenvolver doenças crônicas não transmissíveis como diabetes mellitus, hipertensão arterial e dislipidemias (CAMPOS JO, et al., 2021). Devido a isso, torna-se interessante o consumo desses alimentos para prevenção, controle e tratamento dessas patologias e, consequentemente, promover melhor qualidade e expectativa de vida e saúde.

\section{OBJETIVO}

Revisar por meio da literatura científica os efeitos do consumo de alimentos funcionais em idosos e sua contribuição para a saúde, na prevenção de doenças crônicas não transmissíveis e aumento da expectativa de vida deste público.

\section{MÉTODO}

Trata-se de uma revisão sistemática que foi realizada mediante busca eletrônica de artigos, publicados nas bases de dados SciELO e Google acadêmico, priorizando trabalhos publicados nos últimos cinco anos (2016 a 2021), utilizando os seguintes descritores, de forma isolada ou combinada: "Alimento funcional"; "Consumo de alimentos"; "Educação nutricional", "Idosos", dando prioridade aqueles publicados em inglês e português. Foram encontradas 57 publicações, sendo selecionadas cinco delas, por atenderem a temática proposta.

\section{REVISÃO BIBLIOGRÁFICA}

Os estudos demonstram que a maioria dos idosos não possui o hábito de consumir alimentos funcionais. Alguns fatores podem interferir nesse consumo como boca seca, infecção, edentulismo, dentaduras irregulares e dificuldade de deglutição (PEREIRA BP, et al., 2020). Estudos comprovaram que alimentos funcionais auxiliam no tratamento de doenças crônicas não transmissíveis, principalmente dislipidemias e diabetes (ALKHATIB A, et al., 2017). 
Observou-se também a utilização de fibras alimentares e prebióticos no controle dessas doenças. A implementação desses nutrientes nas refeições diárias dos idosos possui uma grande relevância, pois ao envelhecerem tornam-se mais predispostos a adquirirem certas patologias e os alimentos funcionais apresentam efeito positivo na saúde desses idosos (BARBOSA AAA, et al., 2020).

\section{CONSIDERAÇÕES FINAIS}

Evidenciou-se neste estudo a importância do consumo dos alimentos funcionais pelos idosos e no aumento da sua expectativa de vida, uma vez que, esses alimentos ajudam a evitar ou auxiliam no controle das doenças crônicas não transmissíveis, reduzindo o colesterol e os níveis de glicose no sangue em idosos portadores de diabetes mellitus, por exemplo.

\section{REFERÊNCIAS}

1. ALKHATIB A, et al. Functional foods and lifestyle approaches for diabetes prevention and management. Nutrients, 2017; 9(12): 1310.

2. BARBOZA AAA, et al. Consumo de alimentos funcionais e seus benefícios no diabetes mellitus tipo II: revisão de literatura. Research, Society and Development, 2020; 9(9): e234997058.

3. CAMPOS JO, et al. Estado nutricional e consumo alimentar de idosos participantes dos grupos Hiperdia. Revista Eletrônica Acervo Saúde, 2021; 13(5): e7332.

4. COSTA MFN, et al. Alimentos funcionais: conhecimento e consumo por usuários de restaurante selfservice em capital do nordeste brasileiro. Revista Eletrônica Acervo Saúde, 2019; 11(1): 2369-2379.

5. PEREIRA BP, et al. Consumo alimentar em ultimorbidade entre idosos não institucionalizados de Pelotas, 2014: estudo transversal. Epidemiologia e Serviços de Saúde, 2020; 29(3): e2019050. 


\title{
IMPACTO NA SAÚDE MENTAL DOS (AS) ENFERMEIROS (AS) EM TEMPO DE PANDEMIA DA COVID-19
}

\author{
Juciele Gomes dos Santos ${ }^{1}$ \\ Gleisiane Gaspar Leal de Vasconcelos² \\ Erica Santos da Paixão ${ }^{1}$ \\ Daniela Araújo dos Santos Silva ${ }^{3}$ \\ Tatiane Carvalho Mendes ${ }^{4}$
}

1. Faculdade das Ciências Agrárias e da Saúde (FAS), Lauro de Freitas - BA.

2. Universidade Estadual do Maranhão (UEMA), Caxias - MA.

3. Faculdade Maurício de Nassau (FMN), Campina Grande - PB.

4. Centro Universitário Jorge Amado (UNIJORGE), Salvador - BA.

Palavras-chave: Enfermagem, COVID-19, Saúde Mental.

\section{INTRODUÇÃO}

A COVID-19 é uma doença causada pelo coronavírus, surgida em dezembro de 2019, na cidade de Wuhan, onde foram notificados os primeiros casos de infecção respiratória (ARAÚJO LRA, et al., 2020). Contudo a pandemia causada pela COVID-19, tem afetado a saúde mental dos enfermeiros de forma negativa principalmente os que trabalham na linha de frente assistencial, o que repercute na vida dos mesmo no âmbito psicossocial e do seu bem-estar geral, o que revela a relevância de identificar quais impactos levaram ao sofrimento mental (MIRANDA GBF, et al., 2020).

\section{OBJETIVO}

Identificar por meio de uma revisão da literatura como concebeu a saúde mental dos enfermeiros durante a pandemia de covid-19 e quais impactos levaram ao desenvolvimento do sofrimento mental dos enfermeiros.

\section{MÉTODO}

Revisão integrativa da literatura de abordagem qualitativa, pesquisado nas bases (MEDLINE, BDENF, LILACS), com recorde temporal de 2016-2021. Os descritores utilizados foram "Enfermagem", "COVID-19", "Saúde Mental". Critérios para inclusão: artigos disponíveis na íntegra gratuitamente nos idiomas inglês, espanhol e português. Critérios para exclusão: teses, dissertações e livros. Encontrado 485 artigos, ao aplicar os critérios restaram 29. Por fim, após leitura dos títulos e resumos, selecionou-se 8 para compor os resultados. 


\section{REVISÃO BIBLIOGRÁFICA}

O estudo identificou que o distanciamento dos profissionais de enfermagem com os familiares como medida de prevenção, foi um fator negativo na reestruturação psíquica, o que levou a incerteza na prestação na assistência aos pacientes/clientes (TOESCHER RMA, et al., 2020). Além disso, mostrou-se a prevalência de sintomas associados à depressão como: quadro de ansiedade, tristeza, angústia, medo, insônia, mudanças de apetite, fadiga, alto estresse emocional e danos negativos na qualidade de sua assistência com diminuição da atenção podendo levar ao suicídio (SANTOS RMK, et al., 2020).

\section{CONSIDERAÇÕES FINAIS}

Por fim o estudo possibilitou reflexões acerca dos impactos causados na saúde mental dos enfermeiros(as) durante a pandemia de covid-19 o que torna imprescindível o surgimento de estratégias individuais e organizacionais para que medidas de prevenção e promoção à saúde dos profissionais de enfermagem sejam implementadas de forma efetiva minimizando assim esses impactos mentais.

\section{REFERÊNCIAS}

1. ARAÚJO LRA, et al. O trabalho remoto de enfermeiros docentes em tempos de pandemia. Escola Anna Nery, 2021; 25: 1-9.

2. MIRANDA GBF, et al. Sofrimento psíquico entre os profissionais de enfermagem durante a pandemia da COVID-19: Scoping Review. Escola Anna Nery, 2021; 25: 1-10.

3. SANTOS RMK, et al. Depressão e ansiedade em profissionais de enfermagem durante a pandemia da covid-19. Escola Anna Nery, 2021; 25: 1-15.

4. TOESCHER RMA, et al. Saúde mental de profissionais de enfermagem durante a pandemia de COVID19: recursos de apoio. Escola Anna Nery, 2020; 24: 1-7. 


\section{IMPACTOS DO MOVIMENTO ANTIVACINA E A COBERTURA VACINAL DO SARAMPO NO BRASIL}

Isael de Oliveira Silva ${ }^{1}$

Alex Campos de Aguiar ${ }^{1}$

Natiele Palmeira da Silva ${ }^{1}$

Thaís Ranielle Souza de Oliveira ${ }^{1}$

1. Instituto Euro-Americano de Educação, Ciência e Tecnologia, Centro Universitário Euro-Americano (UNIEURO), Brasília - DF.

Palavras-chave: Imunização, Sarampo, Movimento antivacina.

\section{INTRODUÇÃO}

A imunização é a forma mais segura e eficaz para proteção das pessoas contra uma doença infectocontagiosa, contrariando essa ação, o movimento antivacina ganhou forças nos últimos anos, contribuindo para o ressurgimento de doenças que já estavam controladas (LUIZ AC, et al., 2021).

O sarampo estava controlado no Brasil até o ano de 2016, entretanto, nos últimos anos surtos da doença foram registrados. Processos migratórios e redução da cobertura vacinal contribuiu para volta da doença (MEDEIROS EAS, 2020). O sarampo é uma doença grave com alta transmissibilidade, uma pessoa transmite para dezoito vírus de RNA do gênero Morbillivirus, família Paramyxoviridae (ALMEIDA HS, et al., 2021).

\section{OBJETIVO}

Analisar, através de uma revisão de literatura, o possível impacto do movimento antivacina em relação a sua influência sobre a redução da taxa de cobertura vacinal do sarampo no Brasil.

\section{MÉTODO}

Trata-se de uma revisão de literatura integrativa, utilizando os descritores: Movimento antivacina, Sarampo e Imunização. Com a pesquisa, foi encontrado 76 resultados referente ao tema no ano de 2021. O corte temporal para o estudo foi de setembro de 2019 a agosto de 2021, realizada no Google Acadêmico. Critérios de inclusão: Idiomas português e inglês e artigos completos disponíveis sobre o tema, a busca final resultou em 5 artigos.

\section{REVISÃO BIBLIOGRÁFICA}

A análise do movimento antivacina no Brasil por meio de estudos científicos, mostra a consequência desse movimento sobre a redução da cobertura vacinal principalmente do sarampo, contribuindo para a reincidência da doença (BELTRÃO RPL, et al., 2020). Com a proliferação das Fake News no país o número de pessoas 
imunizadas tem regredido por causa da desinformação sobre os benefícios da vacinação em massa (MASSARANI L, et al., 2021).

O controle do sarampo no Brasil e o movimento antivacinação estão relacionados a um certo nicho da população por desacreditarem que as vacinas não são beneficas e deixam de vacinar seus filhos podendo ocasionar um novo resurgimento (BELTRÃO RP, et al., 2020).

\section{CONSIDERAÇÕES FINAIS}

Com o aumento da influência do movimento antivacina com a disseminação de notícias falsas, ocorre a redução da cobertura vacinal do Sarampo. As mídias sociais e a polarização política têm contribuido para o negligenciamento da vacina. A vacina contra o sarampo já está no Programa Nacional de Imuização (PNI) há décadas, sendo considerada segura e eficaz, assim, não devemos acreditar nas falsas notícias.

\section{REFERÊNCIAS}

1. ALMEIDA HS, et al. A reemergência do sarampo no Brasil associada à influência dos movimentos sociais de pós verdade, fake news e antivacinas no mundo: revisão integrativa. Revista Eletrônica Acervo Saúde, $2021 ; 13(3)$ : e6226.

2. BRELTRÃO RP, et al. Perigo do movimento antivacina: análise epidemio-literária do movimento antivacina no Brasil. Revista Eletrônica Acervo Saúde, 2020; 12(6): e3088.

3. LUIZ AC, et al. Movimento Antivacina: a propagação de uma distopia que ameaça a saúde da população brasileira. Brazilian journal of health Review, 2021; 4(1): 430-441.

4. MASSARANI L, et al. Narrativas sobre a vacinação em tempos de fake news: uma análise de conteúdo em redes sociais. SciELO - Brasil, 2021; 30(2): e200317.

5. MEDEIROS EA. Entendendo o ressurgimento e o controle do sarampo no Brasil. Acta Paul Enferm. 2020; 33: e-EDT20200001. 
RESUMO SIMPLES: Revisão Integrativa

\title{
INTER-RELAÇÃO ENTRE PERIODONTITE E DIABETES MELLITUS: UMA REVISÃO INTEGRATIVA
}

\author{
Dielson Roque da Costa 1 \\ José Eduardo Queiroz Da Silva ${ }^{1}$ \\ Rhaina Neusa Pereira Da Silva ${ }^{1}$ \\ Ingrid Maria Barbosa Dos Santos ${ }^{1}$ \\ Davi Clementino Carneiro 2
}

1. Centro Universitário UNIESP, Cabedelo - PB.

2. Universidade Federal da Paraíba (UFPB), João Pessoa - PB.

Palavras-chave: Diabetes, Periodontia, Odontologia.

\section{INTRODUÇÃO}

A periodontite pode ser denominada como uma doença inflamatória de origem crônica e ligada a múltiplos fatores, sejam estes primários, como o biofilme, ou secundários, que podem modificar tanto a resposta do hospedeiro quanto o modo como os tecidos são atingidos, causando uma destruição dos tecidos de suporte dentários. Já a diabetes mellitus é uma doença que atinge o metabolismo dos carboidratos e produz situações de hiperglicemia, definida como um aumento no número de moléculas de glicose no sangue por falta da ação da insulina (TONETTI MS, et al., 2018). Existindo uma relação entre pacientes diabéticos e o acometimento de periodontite, havendo divergência entre os achados.

\section{OBJETIVO}

Correlacionar as características intrínsecas ligadas tanto à diabetes mellitus, quanto à periodontite, suas influências entre si de maneira bidirecional e demais considerações encontradas na literatura disposta acerca do tema em questão.

\section{MÉTODO}

Foi desenvolvida uma pesquisa para compor a revisão integrativa nas bases de dados Scielo, BvSalud e Acervo+ Index base, entre 2016 a 2021. Foram utilizados os descritores diabetes, periodontia e odontologia com leitura completa de artigos em português, inglês e espanhol, sendo incluídas na revisão publicações relacionadas à periodontia e diabetes correlacionando todo o modo de ação e tratamento das mesmas. Alcançando o intuito da revisão integrativa.

\section{REVISÃO BIBLIOGRÁFICA}


A diabetes é classificada como fator etiológico secundário sistêmico para a periodontite, pois a mesma exacerba a resposta do periodonto do hospedeiro, frente ao biofilme dental, mediante as alterações provocadas no organismo do portador de diabetes, assim como a periodontite promove uma inflamação que não permite que os receptores de insulina de captar a glicose, perdurando a mesma no sangue (CARVALHO WC, et al., 2021).

Assim, muitos autores divergem da forma de tratamento adequada, mas o que se sabe é que o tratamento convencional da periodontia possibilita uma melhora no quadro de hiperglicemia, outros autores não são favoráveis a essa ideia (PIECHA MCR, et al., 2020).

\section{CONSIDERAÇÕES FINAIS}

A diabetes e a doença periodontal tem uma relação bidirecional, para isso é de total importância intervir com o tratamento, pois estudos revelam que ao tratar uma delas melhora significativamente a outra. São necessárias efetivas condutas terapêuticas frente ao indivíduo e uma anamnese detalhada, para isso é essencial que sejam ampliados os estudos com o intuito de propagar conhecimento acerca desse tema tão relevante e que repercute na saúde populacional.

\section{REFERÊNCIAS}

1. CARVALHO WC, et al. Assistência odontológica a pacientes com doença periodontal e diabetes mellitus: revisão bibliográfica. Brazilian Journal Developement, 2021; 7: 67074-67087.

2. PIECHA MCR, et al. Relação bidirecional entre doença periodontal e o diabetes mellitus - revisão de literatura. Revista Eletrônica Acervo Saúde, 2020; 48: e3263.

3. TONETTI MS, et al. Staging and grading of periodontitis: Framework and proposal of a new classification and case definition. Journal Periodontal, 2018; 89(1): 159-172. 


\title{
TRATAMENTO PARA A CEFALEIA PÓS-PUNÇÃO DURAL: UMA REVISÃO SISTEMÁTICA
}

\author{
Priscila Nunes Martins de Almeida ${ }^{1}$ \\ Beatriz Regis da Cunha \\ Rodolfo Ragnolli Perez ${ }^{3}$
}

1. Universidade de Rio Verde (UNIRV), Rio Verde - GO.

2. Universidade de Brasília (UNB), Brasília - DF.

3. Hospital Rede D'Or São Luiz, Brasília - DF.

Palavras-chave: Cefaleia Pós-Punção Dural, Tratamento, Anestesiologia.

\section{INTRODUÇÃO}

A Cefaleia Pós-Punção Dural (CPPD) é uma complicação importante da anestesia neuroaxial e frequentemente observada em mulheres que tiveram parto cesáreo (COSTA AC, et al., 2019; VILEFORT LA, et al., 2021). A dor é descrita como intensa, perturbadora, sua localização costuma ser fronto-occipital e a condição é geralmente aceita como autolimitante (RUSSEL R, et al., 2021).

Os principais fatores de risco identificados são sexo feminino, gestação, trabalho de parto, histórico de cefaleias, idades entre 18 e 50 anos, baixo peso e desidratação (KAMM K e FORDERREUTHER S, 2021). Não há evidências que apoiam medidas profiláticas como hidratação intensa e incentivo ao repouso no leito (HALLER G, et. al., 2018).

\section{OBJETIVO}

Revisar e analisar, por meio de uma revisão bibliográfica, quais são os principais tratamentos estudados para o manejo da Cefaleia Pós-Punção Dural, bem como as principais recomendações descritas na literatura médica.

\section{MÉTODO}

Trata-se de um estudo de revisão sistemática de literatura sobre o tratamento da cefaleia pósraquianestesia. Para a pesquisa foram realizadas buscas nos bancos de dados Pubmed, LILACS e Scielo. Os artigos publicados entre 2016 e 2021 foram selecionados utilizando as palavras-chaves "cefaleia", "raquianestesia" e "tratamento" nas línguas inglesa e portuguesa. Foram encontrados um total de 45 artigos, sendo que 22 foram analisados.

\section{REVISÃO BIBLIOGRÁFICA}


A maioria dos estudos recomenda, como primeira escolha do tratamento, hidratação vigorosa, cafeína oral, analgésicos, hidrocortisona venosa e repouso no leito (KAMM K e FORDERREUTHER S, 2021). Observou-se que os bloqueios do gânglio esfenopalatino e dos nervos occipitais maiores são alternativas minimamente invasivas e eficazes para a redução da dor (BERGER AA, et al., 2021).

Há evidências de que o tratamento padrão-ouro é o tampão sanguíneo peridural, com o alívio completo dos sintomas de 80-98\% na cefaleia moderada a grave (HALLER G, et al., 2018). Por ser uma técnica invasiva e sujeita a riscos, deverá ser postergada após falha do manejo inicial conservador (BERGER AA, et al., 2021).

\section{CONSIDERAÇÕES FINAIS}

Diante dos resultados apresentados, o tratamento com o tampão sanguíneo peridural é o que tem maior evidência para CPPD, portanto, deve ser incentivado e realizado precocemente se os sintomas forem graves. São necessários mais estudos clínicos de grande porte para elucidar melhor o manejo e o tratamento da CCPD.

\section{REFERÊNCIAS}

1. BERGER AA, et al. Caudal epidural blood patch for the treatment of persistent post-dural puncture headache following intrathecal pump placement in a patient with lumbar instrumentation. Anaesthesiology intensive therapy, 2021; 53(1): 187-189.

2. COSTA AC, et al. A ten-year retrospective study of post-dural puncture headache in 32,655 obstetric patients. Canadian journal of anaesthesia, 2019; 66(12): 1464-1471.

3. HALLER G, et al. Risk factors for post-dural puncture headache following injury of the dural membrane: a root-cause analysis and nested case-control study. International journal of obstetric anesthesia, 2018; 36: 17-27.

4. KAMM K, FÖRDERREUTHER S. Post-dural puncture headache. Schmerz, 2021; 35(2): 139-149.

5. RUSSEL R, et al. Treatment of obstetric post-dural puncture headache. Part 2: epidural blood patch. International journal of obstetric anesthesia, 2019; 38: 104-118.

6. VILEFORT LA, et al. Principais complicações pós-operatórias: revisão narrativa. Revista Eletrônica Acervo Científico, 2021; 36: 1-7. 
RESUMO SIMPLES: Revisão Integrativa

\title{
IMPORTÂNCIA DOS CUIDADOS PALIATIVOS ODONTOLÓGICOS EM PACIENTES TERMINAIS: UMA REVISÃO INTEGRATIVA
}

\author{
Dielson Roque da Costa ${ }^{1}$ \\ José Eduardo Queiroz Da Silva ${ }^{1}$ \\ Rhaina Neusa Pereira Da Silva ${ }^{1}$ \\ Ingrid Maria Barbosa Dos Santos ${ }^{1}$ \\ Davi Clementino Carneiro²
}

1. Centro Universitário UNIESP, Cabedelo - PB.

2. Universidade Federal da Paraíba (UFPB), João Pessoa - PB.

Palavras-chave: Qualidade de vida, Saúde bucal, Cuidados paliativos.

\section{INTRODUÇÃO}

A odontologia é uma ciência que atua em diversos contextos, com intuito de restabelecer o bem-estar e promover cuidados integrais aos pacientes. Observa-se o cirurgião-dentista atuando nos cuidados paliativos dando uma melhor qualidade de vida em pacientes com diagnóstico terminal onde o estado terminal desses pacientes é comprovadamente beneficiado pela atuação do cirurgião-dentista para minimizar o sofrimento, precoce ao aparecimento de novos problemas ligado ao ambiente bucal (MACEDO MP, et al., 2020).

A atuação do cirurgião-dentista nos cuidados paliativos prioriza eliminar possíveis focos infecciosos e dores recorrentes de questões bucais, com um bom planejamento e mantendo contato com a família dando suporte e acompanhamento familiar (MIRANDA AF, 2016).

\section{OBJETIVO}

Descrever a importância da atuação do cirurgião-dentista nos cuidados paliativos em pacientes terminais e mostrar os benefícios trazidos com essa intervenção de maneira significativa na saúde e qualidade de vida e do apoio psicossocial.

\section{MÉTODO}

Foi desenvolvida uma pesquisa para compor a revisão integrativa nas bases de dados Google Acadêmico, BvSalud e Acervo+ Index Base, entre 2016 a 2021 usando os descritores: qualidade de vida, saúde bucal e cuidados paliativos, sendo excluídos resumos e artigos não relacionados, sendo encontrados um total de 20 artigos e dentre eles apenas 4 foram utilizados, com intuito de promover resultados nas buscas, satisfazendo o propósito da revisão integrativa. 


\section{REVISÃO BIBLIOGRÁFICA}

Os cuidados paliativos logo de início se tornam cruciais durante todo o processo que o paciente precisa de um diagnóstico da determinada enfermidade, exame físico, higiene bucal bem aplicada, profilaxia e orientações durante todo o processo, promovendo assim uma qualidade melhor no processo saúde-doença com todo o apoio da equipe multiprofissional (de OLIVEIRA ML, et al., 2021).

A atuação do cirurgião-dentista no âmbito hospitalar, se faz necessária para que assim o paciente seja integralizado como um todo. Sem que haja a progressão de doenças que afetam o ambiente bucal, o que vai de acordo com os princípios de cuidados paliativos (de OLIVEIRA CS, et al., 2019).

\section{CONSIDERAÇÕES FINAIS}

Os cuidados paliativos são de grande importância no apoio do paciente e da família, promovendo uma melhor qualidade de vida no estado em que o mesmo se encontra, a fim de remover toda sensação dolorosa e emocional do mesmo. Para isso é necessário que sejam sempre buscadas maior efetivação e atualizações das técnicas na área de odontologia hospitalar dando esse suporte, principalmente, nos leitos de unidade de terapia intensiva.

\section{REFERÊNCIAS}

1. de OLIVEIRA CS, et al. Odontologia e cuidados paliativos. Estudo de caso. Revis. Logeviver 2019 1:4, 4654.

2. de OLIVEIRA ML, et al. A importância da assistência aos pacientes em cuidados paliativos na atenção primária. Revista Eletrônica Acervo Científico, 2021; 21: e6665.

3. MACEDO MP, et al. Aspectos do atendimento odontológico a pacientes internados em uma clínica médica de um hospital universitário. ABCS Health Sciences. 2020; 45: e1198.

4. MIRANDA AF. Oral Health and Care at Intensive Care Units. Journal of Nursing and Care. 2016; 5(6): 1-6. 


\title{
REFLEXOS DA PANDEMIA NO DESENVOLVIMENTO DAS CRIANÇAS AUTISTAS, UMA REVISÃO INTEGRATIVA
}

\author{
Mariana Cordeiro Dias ${ }^{1}$ \\ Lanna Isa Estanislau de Alcântara Oliveira ${ }^{1}$ \\ Giovanna dos Santos Flora ${ }^{1}$ \\ Philippe Mercante Guerra ${ }^{2}$
}

1. Centro Universitário Faculdade de Ciências Gerenciais de Manhuaçu (UNIFACIG), Manhuaçu - MG.

2. Faculdade de Medicina do Vale do Aço (UNIVAÇO), Ipatinga - MG.

Palavras-chave: Autismo, Pandemia, Desenvolvimento infantil.

\section{INTRODUÇÃO}

Com sua resposta imune deficitária, as crianças com Transtorno do Espectro do Autismo (TEA) têm uma vulnerabilidade maior pelas complicações da COVID-19 (ALHUZIMI T, 2021). O isolamento social proposto como medida preventiva diante da pandemia COVID-19 ocasionou a readaptação do sistema educacional, afetando, em geral, negativamente o progresso das crianças com TEA. A rede de apoio oferecida por esse sistema, composta por professores, assistentes sociais e profissionais de saúde foi assumida de forma integral pelos pais. Sabe-se que os indivíduos autistas são mais vulneráveis a essa condição pela dificuldade de avaliar as situações, adaptar a novas rotinas e receber tratamento médico pelo telessaúde (LATZER IT, et al., 2021).

\section{OBJETIVO}

Analisar por meio de uma revisão da literatura o tema os reflexos da pandemia no TEA com a finalidade de elucidar e compreender os impactos da pandemia sobre o desenvolvimento das crianças com TEA.

\section{MÉTODO}

Trata-se de uma revisão integrativa em que foram realizadas buscas nas bases de dados Scielo, Pubmed, Medline e Google Acadêmico, durante setembro 2021. Procedeu com análise de quarenta artigos publicados, usando como descritores: autism e pandemic. Os critérios de exclusão foram artigos que não possuíam ano de publicação em 2021 e que fugiam da temática principal. Os critérios de inclusão foram a abordagem da temática e publicação sendo em 2021.

\section{REVISÃO BIBLIOGRÁFICA}


Na paralisação, responsáveis pelas crianças com TEA relataram aumento de comportamentos repetitivos, observando retrocesso no desenvolvimento. A falta de espaço desafiou a agitação psicomotora. $\mathrm{Na}$ alimentação houve seletividade, restrição, compulsão e padrões alimentares peculiares. Ocorreu dificuldade em adormecer, despertares e pesadelos noturnos. Apesar de reuniões virtuais, houve pior interação e comunicação, e o prolongamento do isolamento agravou as dificuldades. Com a telemedicina, pais relataram melhora no cotidiano e superação da falta de estrutura, houve relatos de melhor domínio físico, linguístico e social (SIVARAMAN M, et al., 2021; WHITE SW, et al., 2021; BAWEJA R, et al., 2021; LATZER IT, et al., 2021).

\section{CONSIDERAÇÕES FINAIS}

Portanto, com as limitações e dificuldades encontradas, observou-se a necessidade de um sistema de apoio aos pais para lidarem com as adversidades, desamparo e sentimento de impotência. É preciso criar um conjunto de habilidades para atender as necessidades das crianças com TEA e manter o desenvolvimento, a socialização e modificar o sentimento de frustração dos pais, para que ambos superem o isolamento e dificuldades encontradas durante a pandemia.

\section{REFERÊNCIAS}

1. ALHUZIMI T. Stress and emotional wellbeing of parents due to change in routine for children with Autism Spectrum Disorder (ASD) at home during COVID-19 pandemic in Saudi Arabia. Research in Developmental Disabilities, 2021; 108: 103822.

2. BAWEJA R, et al. COVID-19 pandemic and impact on patients with autism spectrum disorder. Journal of Autism and Developmental Disorders, 2021; 1-10.

3. LATZER IT, LEITNER Y, KARNIELI OM. Core experiences of parents of children with autism during the COVID-19 pandemic lockdown. Autism, 2021; 25(4): 1047-1059.

4. SIVARAMAN M, VIRUES JO, ROEYERS $\mathrm{H}$. Telehealth mask wearing training for children with autism during the COVID-19 pandemic. Journal of Applied Behavior Analysis, 2021; 54(1): 70-86.

5. WHITE, SW et al. It took a pandemic: Perspectives on impact, stress, and telehealth from caregivers of people with autism. Research in developmental disabilities, 2021; 113: 103938. 


\title{
DESCONEXÃO DO TRABALHO NA ÁREA DE ENFERMAGEM E SUAS IMPLICAÇÕES PSICOLÓGICAS
}

\author{
Carlos Lopatiuk ${ }^{1}$ \\ João Irineu de Resende Miranda ${ }^{1}$ \\ Carla Emanuele Lopatiuk²
}

1. Universidade Estadual de Ponta Grossa (UEPG), Ponta Grossa - PR.

2. Centro Universitário de Jaguariúna (UNIFAJ), Jaguariúna - SP.

Palavras-chave: Desconexão, Covid-19, Enfermagem.

\section{INTRODUÇÃO}

A demanda de profissionais da saúde devido á Covid-19 apresenta agravantes quando o profissional tem seus direitos trabalhistas infringidos. Há relatos de esgotamento mental devido a plantões exaustivos (GALAIO LM, et al., 2021). A presente revisão narrativa discorre sobre o direito da desconexão (direito ao não trabalho) na área de enfermagem. Os profissionais da área de saúde tiveram suas horas de jornada triplicadas para auxiliar no combate ao vírus. A desconexão é um direito que assegura a saúde psicológica e física (PRADO AD, et al., 2020). O trabalhador da área de saúde está sofrendo sobrecarga de trabalho e consequentemente danos de ordem mental e física (LUDOVINO LA, et al., 2020).

\section{OBJETIVO}

Conceitualizar as leis trabalhistas relacionadas à desconexão, elencando riscos psicológicos desta nãodesconexão. Os objetivos específicos são: Apresentar os riscos psicológicos dos trabalhadores que não desconectam; verificar as leis que protegem o direito do profissional de desconectar.

\section{REVISÃO BIBLIOGRÁFICA}

A profissão de enfermeiro tem suas especificidades que fogem da Constituição de 88 . A jornada de escala de trabalho padrão dos enfermeiros é de 12 horas de trabalho tendo 36 horas de descanso. Durante a pandemia, os sistemas de saúde em todo o mundo ficaram sobrecarregados (PRADO AD, et al., 2020).

Os profissionais da saúde, principalmente aqueles que trabalham em ambiente hospitalar, são as pessoas mais vulneráveis aos transtornos de estresse, pois lidam diariamente com a dor, o sofrimento e a morte alheia (LUDOVINO LA, et al., 2020). A não desconexão do empregado gera stress, e com o tempo, este trabalhador não se desvincula do emprego ao longo do dia e deixa de cuidar da própria saúde (SILVA TL e VIANA RCL, 2020).

O direito de se desconectar do trabalho preserva o bem-estar de vida e a saúde mental. $\mathrm{O}$ artigo $6^{\circ}$ da Constituição Federal aborda o direito ao lazer. Este direito é tanto de quem trabalha quanto de quem não 
trabalha, pois alguns não conseguem trabalho à medida que outros estão trabalhando exaustivamente (RUFINO RCP, 2016).

\section{CONSIDERAÇÕES FINAIS}

Neste momento cabe ressaltar que há diversos fatores para que os profissionais de saúde se encontrem fragilizados como as altas cargas de trabalho, a impossibilidade de desconexão, fatores externos ao trabalho como transito e insônia, etc. A não-desconexão afeta diretamente a vida destes profissionais tão importantes que devem cuidar de si mesmos correndo risco de falharem na sua missão de cuidado diário dos pacientes.

\section{REFERÊNCIAS}

1. GALAIO LM, et al. The COVID-19 Impact in hospital healthcare workers: development of an occupational health risk management program. Port J Public Health, 2021; 38: supl.1.

2. LUDOVINO LA, et al. Estresse ocupacional: fatores de risco para os profissionais da medicina e da enfermagem. Revista Eletrônica Acervo Saúde, 2021; 13(11): e9046.

3. PRADO AD, et al. A saúde mental dos profissionais de saúde frente à pandemia do COVID-19: uma revisão integrativa. Revista Eletrônica Acervo Saúde, 2020; 46: e4128.

4. RUFINO RCP. O axioma entre a exigência de trabalho excessivo versus o direito ao lazer do trabalhador: análise sob a ótica da responsabilização do empregado. III Encontro de internacionalização do Conpedi Madrid, 2016; 1(6).

5. SILVA TL, VIANA RCL. Do direito a desconexão digital do trabalhador. Revista Científica Univiçosa, 2020; 12(1). 


\section{A ATUAÇÃO DA EQUIPE DE ENFERMAGEM EM CUIDADOS PALIATIVOS NA UTI NEONATAL E PEDIÁTRICA}

Itamara Queiroz dos Santos ${ }^{1}$

Luciana Dourado Pimenta Almeida ${ }^{1}$

Sonidalva Alves Novaes ${ }^{1}$

1. Hospital Universitário Professor Edgar Santos (HUPES/UFBA), Salvador - BA.

Palavras-chave: Cuidados Paliativos, Enfermagem, Pediatria.

\section{INTRODUÇÃO}

Os Cuidados Paliativos (CP) caracterizam-se pelo amparo integral ao binômio paciente-família, nos aspectos físicos, biopsicossociais e espirituais, como intuito de amenizar o sofrimento no momento de terminalidade, em que a medicina curativa não possibilita outro prognóstico. Os CP compreendem que a morte é um processo natural que não se deve acelerar e nem postergar, e sim promover qualidade de vida, aliviar os sintomas, com uma visão humanizada e integradada as especificidades de cada paciente e família (VERRI RE, et al., 2019). Os profissionais de enfermagem que atuam na Unidade Terapia Intensiva (UTI) Neonatal e Pediátrica enfrentam grandes desafios ao assistir pacientes em $\mathrm{CP}$, âmbito que exige perfil profissional, qualificação, conhecimento e equilíbrio emocional.

\section{OBJETIVO}

Compreender por meio de uma revisão de literatura a atuação da equipe de Enfermagem em CP, acerca da assistência integral ao paciente neonatal/pediátrico e família, considerando a ausência de possibilidades terapêuticas de cura, englobando o processo de terminalidade e morte.

\section{MÉTODO}

Trata-se de um estudo descritivo do tipo revisão sistemática de literatura, cujo levantamento bibliográfico foi realizado nas bases de dados Scielo, LILACS e BVS- Brasil utilizando os descritores: Cuidados Paliativos; Unidade de Terapia Intensiva Pediátrica; Enfermagem; Pediatria, através do conector boleano and. Foram encontrados 85 artigos na íntegra, dos quais foram selecionados nove artigos publicados no período de 2017 a 2020 no idioma português que versavam sobre a temática.

\section{REVISÃO BIBLIOGRÁFICA}

A partir do que foi pesquisado sobre os $\mathrm{CP}$, evidenciou-se que as principais atribuições da enfermagem foram: manejo da dor, ofertar a qualidade de vida, medidas de conforto e cuidado com a família. A promoção 
dos cuidados pela equipe de enfermagem deve ser embasada na sistematização da assistência (LOUZADA MASB, et al., 2020).

Em outro estudo foi identificado que os profissionais de enfermagem apresentam dificuldades para lidar com o processo de finitude. Existe também a falta de diálogo com a equipe médica, assim como a falta de espaço para compartilhar as angústias vivenciadas, aspectos estes que impactam diretamente na filosofia da promoção dos CP (SILVA IN, et al., 2017).

\section{CONSIDERAÇÕES FINAIS}

Diante dos estudos apresentados, percebe-se que a equipe de enfermagem tem enorme potencial para implementação de uma assistência sistematizada e de qualidade. Para tanto, é imprescindível a capacitação profissional a partir da revisão da grade curricular dos cursos técnicos e da graduação, apoio de gestores na regulamentação institucional para elaborações de protocolos que respaldem a assistência prestada e investimento em educação continuada para treinamentos regulares.

\section{REFERÊNCIAS}

1. LOUZADA MASB, et al. Atuação do enfermeiro durante o processo de terminalidade da vida infantil. Revista Enfermagem Brasil, 2020; 19(2): 176-183.

2. SILVA IN, et al. Conhecendo as práticas de cuidado da equipe de enfermagem em relação ao cuidado na situação de vida do recém-nascido. Revista da Escola Ana Nery, 2017; 21(4): 1-8.

3. VERRI RE, et al. Profissionais de Enfermagem: Compreensão sobre cuidados paliativos pediátricos. Revista de Enfermagem UFPE, 2019; 1(13): 126-136. 


\title{
MEDIDAS NÃO FARMACOLÓGICAS PARA O CONTROLE E MANEJO DA DOR EM RECÉM-NASCIDOS INTERNADOS NA UTI NEONATAL: REVISÃO INTEGRATIVA
}

\author{
Kadja de Fatima Pinheiro Freitas da Silva ${ }^{1}$ \\ Patrícia Cavalcante Castro do Nascimento 2 \\ Marina Ferreira de Lima $^{3}$ \\ Daniele Silva Simões Cavalcanti ${ }^{4}$ \\ Thayanne de Azevedo Falção ${ }^{5}$
}

1. Instituto Aggeu Magalhães - Fundação Oswaldo Cruz (IAM-FIOCRUZ), Recife - PE.

2. Centro Universitário Internacional (UNINTER), Recife - PE.

3. Hospital das Clínicas da Universidade de Pernambuco (HC-UFPE/EBSERH), Recife - PE.

4. Faculdade de Ciências Humanas de Olinda (FACHO), Olinda - PE.

5. Universidade Federal Rural de Pernambuco (UFRPE), Recife - PE.

Palavras-chave: Recém-Nascido, Manejo da dor, Unidades de Terapia Intensiva Neonatal.

\section{INTRODUÇÃO}

A Unidade de Terapia Intensiva Neonatal (UTIN) constitui um importante recurso para a sobrevivência dos Recém-Nascidos (RN). Entretanto, é um ambiente muito exaustivo ao RN por provocarem diversos estímulos que podem causar dor (CARDOSO MVLML e MELO GM, 2017).

Por muitos anos a dor no RN foi negligenciada, porém estudos recentes destacam que a dor neste público é mais intensa que crianças e adultos. Experiências dolorosas repetidas e não tratadas podem resultar em prejuízos ao neurodesenvolvimento e ao comportamento. Portanto é de suma importância que os profissionais de saúde conheçam e utilizem as técnicas não farmacológicas para o controle e manejo da dor nos RN (GASPARDO CM, et al., 2018).

\section{OBJETIVO}

Revisar a literatura científica disponível tendo o objetivo de identificar quais as medidas não farmacológicas utilizadas para o controle e manejo da dor em RN internados na UTIN, além de destacar a sua importância e aplicabilidade.

\section{MÉTODO}

Trata-se de uma revisão integrativa com artigos indexados entre 2017-2021 nas bases de dados LILACS, SCIELO, BIREME. Os descritores utilizados: "Recém-Nascido", "Manejo da dor" e "Unidades de Terapia Intensiva Neonatal". Os critérios de inclusão: texto completo em português/ inglês, indexados nas bases de 
dados mencionadas e excluídos os demais artigos. Foram analisados 55 artigos, porém apenas 5 atendiam aos objetivos da pesquisa.

\section{REVISÃO BIBLIOGRÁFICA}

A melhor estratégia para o controle da dor neonatal é evitar intervenções, porém inúmeros procedimentos, muitas vezes dolorosos, são necessários para a recuperação do RN (MACIEL HIA, et al., 2019). As medidas não farmacológicas podem ser utilizadas para o controle e manejo da dor neonatal como: sucção não nutritiva, solução glicosada, método canguru, musicoterapia, aleitamento materno, contenção (MORAIS APS, et al., 2017).

Protocolos internacionais subsidiam a eficácia dessas estratégias e destacam a potencialização das técnicas quando combinadas (LAGO P, et al., 2017). Além disso, os profissionais de saúde podem utilizar escalas para identificar e avaliar a dor neonatal para aplicar intervenções para minimizar a dor (SOUZA VO, et al., 2021).

\section{CONSIDERAÇÕES FINAIS}

Portanto, as medidas não farmacológicas para o controle e manejo da dor no RN constituem ferramentas de grande relevância para a prestação de uma assistência à saúde eficaz e humanizada. Faz-se necessário a sensibilização e capacitação de todos os profissionais de saúde que atuem nas UTIN para minimizar os danos causados aos $\mathrm{RN}$ durante seu período de internação.

\section{REFERÊNCIAS}

1. CARDOSO MVLML, MELO GM. Medidas não farmacológicas em recém-nascidos pré-termo submetidos à punção arterial. Revista Brasileira de Enfermagem, 2017; 70(2): 335-43.

2. GASPARDO CM, et al. Effects of neonatal pain and temperament on attention problems in toddlers born preterm. Journal of Pediatric Psychology, 2018; 43(3): 342-51.

3. LAGO P, et al. Systematic review of nonpharmacological analgesic interventions for common needle related procedure in newborn infants and development of evidence based clinical guidelines. Acta Pediatrica, 2017; 106(6): 864-70.

4. MACIEL HIA, et al. Medidas farmacológicas e não farmacológicas de controle e tratamento da dor em recém- nascidos. Revista Brasileira de Terapia Intensiva, 2019; 31(1): 21-26.

5. MORAIS APS, et al. Medidas não farmacológicas no manejo da dor em recém-nascido: cuidado de enfermagem. Revista Rene, 2017; 17(3): 435-442.

6. SOUSA VO, et al. Inplantação da escala para avaliação da dor em uma Unidade de Terapia Intensiva Neonatal (UTIN) Pública. Revista Eletrônica Acervo Saúde, 2021; 13(8): 1-8. 


\title{
IMPACTO DA PANDEMIA DA COVID-19 NOS ATENDIMENTOS ODONTOLÓGICOS NO SISTEMA DE SAÚDE PÚBLICA: UMA REVISÃO INTEGRATIVA
}

\author{
Rhaina Neusa Pereira da Silva ${ }^{1}$ \\ Davi Clementino Carneiro² \\ Dielson Roque da Costa ${ }^{1}$ \\ Ingrid Maria Barbosa dos Santos ${ }^{1}$ \\ José Eduardo Queiroz da Silva ${ }^{1}$
}

1. Centro Universitário UNIESP, Cabedelo - PB.

2. Universidade Federal da Paraíba (UFPB), João Pessoa - PB.

Palavras-chave: Atendimento odontológico, Saúde bucal, COVID-19.

\section{INTRODUÇÃO}

No Brasil, a pandemia da COVID-19 tem acarretado dificuldade tanto do ponto de vista econômico, político, como principalmente no sistema de saúde. Em contexto como esse, as mudanças no cenário do país durante a pandemia de SARS-COV-2 não atingem somente os profissionais que ofertam a assistência à saúde direta relacionada a esse agravo, porém os demais profissionais de saúde e a população que utiliza esse serviço. No âmbito odontológico não diferiu, visto que a saúde bucal integra a saúde geral do indivíduo, o alto risco às infecções ocasionaram uma diminuição significativa nos atendimentos odontológicos no sistema público de saúde (LUCENA EDH, et al., 2020).

\section{OBJETIVO}

Pesquisar na literatura científica a respeito do tema impacto da pandemia do SARS-COV-2 nos atendimentos odontológicos na saúde pública a fim de contribuir com o acervo literário, ampliando conhecimento acerca da maior temática atualmente: COVID-19 e suas consequências.

\section{MÉTODO}

Trata-se de uma pesquisa de revisão integrativa. Para isso, foram realizadas buscas nas bases de dados Scielo, BVS, Medline, no período do mês de setembro de 2021, derivando-se à análise de 6 artigos e utilizando 3 para o resultado final, pois respeitava às normas éticas. Foram incluídos artigos dos últimos 5 anos e excluindo aqueles que não contribuíssem com a temática proposta, utilizando descritores como: Saúde bucal, pandemia, crise financeira.

\section{REVISÃO BIBLIOGRÁFICA}


Em uma revisão sistemática, uma grande redução no oferecimento de atendimento odontológico em muitas das categorias durante a pandemia. As consultas e procedimentos odontológicos de urgência em serviços de atenção básica e especializada diminuíram 42,5\% e 44,1\% entre 2020 e 2019, respectivamente. Os procedimentos de não urgência diminuíram 92,3\% (CUNHA AR, et al., 2021).

Devido à falta de padrão, a assistência odontológica foi interrompida completamente ou diminuiu significativamente em vários países. Além de aumentar o sofrimento das populações afetadas, isso também aumentará a carga sobre setor emergencial de hospitais que já lutam contra a pandemia. Essa falta de diretrizes pode aumentar a disseminação da COVID-19 (ALHARBI A, et al., 2020).

\section{CONSIDERAÇÕES FINAIS}

Deve-se realizar estudos futuros avaliando os impactos da pandemia na carga de doenças bucais, visto que os atendimentos diminuíram drasticamente. Além disso, a disciplina do cirurgião-dentista perante aos princípios de biossegurança já era rigorosa. Devido às consequências inesperadas trazidas pelo vírus, os procedimentos que visam prevenir os riscos de agentes ofensivos devem ser considerados o braço direito do cirurgião-dentista, tendo como finalidade a segurança e bem-estar próprio e do paciente.

\section{REFERÊNCIAS}

1. ALHARBI A, et al. Guidelines for dental care provision during the COVID-19 pandemic. Saudi Dental Journal, 2020; 6(2). 1-6.

2. CUNHA AR, et al. The impact of the COVID-19 pandemic on the provision of dental procedures performed by the Brazilian Unified Health System: a syndemic perspective. Rev Bras Epidemiol, 2021; 24: e210028.

3. LUCENA EDG, et al. Acesso em saúde bucal na atenção básica antes e após o início da pandemia de COVID-19 no Brasil. Pesquisa Brasileira em Odontopediatria e Clínica Integrada, 2020; 11(4): 1-11. 


\title{
INFLUÊNCIA DA SAÚDE BUCAL NA PERFORMANCE DOS ATLETAS
}

\author{
Rhaina Neusa Pereira da Silva ${ }^{1}$ \\ Davi Clementino Carneiro² \\ Dielson Roque da Costa ${ }^{1}$ \\ Ingrid Maria Barbosa dos Santos ${ }^{1}$ \\ José Eduardo Queiroz da Silva ${ }^{1}$
}

1. Centro Universitário UNIESP, Cabedelo - PB.

2. Universidade Federal da Paraíba (UFPB), João Pessoa - PB.

Palavras-chave: Saúde bucal, Esporte, Desempenho.

\section{INTRODUÇÃO}

A odontologia ainda é vista como uma profissão em que se trabalha a quatro paredes, estando muitas vezes excluída de debates sobre a saúde no meio esportivo. Sabe-se que saúde bucal integra uma parte fundamental da saúde geral e sistêmica do nosso corpo, dessa maneira, estando relacionada também ao rendimento físico dos atletas. Portanto, torna-se de extrema necessidade a implementação do conhecimento acerca da importância da manutenção da saúde bucal dos atletas e como o cirurgião dentista pode contribuir para a melhor performance esportista, tanto na prevenção e tratamento bucal, como na reparação de tecidos musculares e desordens das Articulações Temporomandibulares (ATM) (AZEVEDO L, et al., 2019).

\section{OBJETIVO}

Apresentar achados da literatura científica sobre o tema Odontologia no esporte de modo a contribuir com o acervo literário, ampliando conhecimento e ajudando na qualidade de vida e bem-estar do indivíduo dentro e fora de campo.

\section{MÉTODO}

Trata-se de uma pesquisa de revisão integrativa. Para isso, foram realizadas buscas nas bases de dados Scielo, BVS, Medline, no período do mês de agosto à setembro de 2021, derivando-se analisar 5 artigos, mas utilizando apenas para o resultado final, pois respeitava às normas éticas, incluindo artigos dos últimos 5 anos e excluindo aqueles que não contribuíssem com a temática proposta, utilizando descritores como: Saúde bucal, esporte, odontologia esportiva.

\section{REVISÃO BIBLIOGRÁFICA}


Em estudo de meta-análise constatou-se que para maioria dos parâmetros avaliados os resultados eram semelhantes entre os atletas profissionais e amadores. Mas, no "uso do fio dental" e "trauma facial/dental", observou-se diferenças significativas entre os grupos. Os profissionais estão mais propensos a traumatismos faciais/dentais, assim, a presença do cirurgião-dentista na equipe melhora as condições gerais de saúde bucal dos atletas (SOUZA JJ, et al., 2020).

Em outro estudo, evidencia-se que os atletas entrevistados não têm conhecimento sobre a importância da saúde bucal no esporte, mas concordam que os cirurgiões-dentistas contribuem para melhoria da saúde bucal e consequentemente do rendimento esportivo (ALVES DCB, et al., 2017).

\section{CONSIDERAÇÕES FINAIS}

O campo da Odontologia Esportiva é bastante amplo, englobando a saúde bucal como parte de todo um sistema. Os cuidados bucais devem fazer parte da vida do atleta, buscando assim melhores desempenhos. Por isso, se faz necessária a discussão e estudos acerca dessa temática de modo a disseminar a área odontológica, para que assim o cirurgião-dentista possa garantir bem-estar e melhores performances para os atletas.

\section{REFERÊNCIAS}

1. ALVES DCB, et al. Odontologia no esporte: conhecimento e hábitos de atleta do futebol e basquetebol sobre saúde bucal. Revista Brasileira de Medicina do Esporte, 2017; 5(3): 1-5.

2. AZEVEDO L, et al. Oral health behaviors, dental injuries and mouthguard awareness among a sample of Portuguese athletes: a cross sectional study. J Oral Res 2019; 8(4): 1-8.

3. SOUZA JJ, et al. Evaluation of the oral health conditions of volleyball athletes. Revista Brasileira de Medicina do Esporte, 2020; 4(2): 1-4. 


\title{
USO DE CURATIVOS HIDROCOLÓIDES NA PREVENÇÃO DE LESÃO POR PRESSÃO DECORRENTES DO USO DE EQUIPAMENTOS DE PROTEÇÃO INDIVIDUAL POR PROFISSIONAIS DE SAÚDE
}

\author{
Maria Gabriela Santos Ribeiro ${ }^{1}$ \\ Maria Gabriela da Paz Miranda ${ }^{1}$ \\ Mauro Roberto Biá da Silva ${ }^{1}$
}

1. Universidade Estadual do Piauí (UESPI), Teresina - PI.

Palavras-chave: Lesão por pressão, Prevenção, Curativos hidrocolóides.

\section{INTRODUÇÃO}

A higienização e antissepsia das mãos e o uso de Equipamentos de Proteção Individual (EPIs), como máscaras, óculos, luvas, gorro e aventais por profissionais da saúde, constituem as principais medidas de proteção individual durante a assistência às pessoas com COVID-19 (OMS, 2020; BRASIL, 2020).

O uso prolongado das máscaras, especialmente a N95/PFF2 e óculos de proteção, podem aumentar o risco de lesão por pressão e/ou friç̧ão em face (GALETTO SGS, et al., 2019; DARLENKI R e TSASKOV N, 2020). Diante disso, é fundamental o cuidado para manutenção da integridade da pele do profissional de saúde, uma vez que as lesões podem gerar impacto negativo na assistência (MILLS J, 2020).

\section{OBJETIVO}

Realizar uma revisão de literatura científica atual, a respeito do uso de curativos hidrocolóides na prevenção de lesão por pressão, em decorrência do uso de equipamentos de proteção individual por profissionais de saúde.

\section{MÉTODO}

Realizou-se uma revisão bibliográfica integrativa, em que foram utilizadas as bases de dados LILACS, BDENF e PubMed/MEDLINE, com os descritores "lesão por pressão", "prevenção" e "curativos hidrocolóides". Foram adotados os seguintes critérios de inclusão: artigos em espanhol, português e inglês compreendidos entre 2016 e 2021; e de exclusão: repetição em bases de dados e não adequação à temática. Encontrou-se um total de 14 artigos e selecionou-se 5 .

\section{REVISÃO BIBLIOGRÁFICA}

Diante dos resultados, o hidrocolóide autoadesivo pode ser cortado de acordo com o formato nasal, o uso das bordas curvas do curativo acompanha o contorno da ponte nasal sem reduzir a vedação da máscara. $A$ tira é posicionada abaixo da máscara e pode fornecer alívio da dor e da pressão para um turno inteiro. Por outro lado, o hidrocolóide combinado com o filme de barreira sem álcool à base de terpolímero usado para o 
cuidado da pele facial, reduz a incidência de lesão por pressão facial e melhora o nível de conforto da pele, garantindo isolamento e um efeito protetor (FIELD MH, et al., 2020; ZHANG S, et al., 2021).

\section{CONSIDERAÇÕES FINAIS}

Diante dos estudos apresentados, demonstra-se que o uso dos curativos de hidrocolóide, estão relacionados a eficácia na prevenção de lesão por pressão decorrente do uso prolongado de EPIs, fornecendo proteção e alívio da pressão sem reduzir a eficiência dos EPIs.

\section{REFERÊNCIAS}

1. BRASIL, Agência Nacional de Vigilância Sanitária (Anvisa). Orientações para serviços de saúde: medidas de prevenção e controle que devem ser adotadas durante a assistência aos casos suspeitos ou confirmados de infecção pelo novo coronavírus (SARs-COV-2). Nota técnica GVIMS/GGTES/ANVISA no 04/2020 - 31.03.2020. Disponível em: https://www.gov.br/anvisa/pt$\mathrm{br} /$ centraisdeconteudo/publicacoes/servicosdesaude/notas-tecnicas/nota-tecnica-gvims_ggtes_anvisa04_2020-25-02-para-o-site.pdf. Acesso em: 23 de setembro de 2021.

2. DARLENSKI R, TSANKOV N. Covid-19 pandemic and the skin: What should dermatologists know? Clin Dermatol. journal Clinics in Dermatology, 2020; 38: 785-787.

3. FIELD MH, et al. Tira de curativo hidrocolóide sobre a ponte do nariz para aliviar a dor e a pressão das máscaras faciais filtradas (FFP) durante a pandemia de coronavíris (covid-19). Os anais do Royal College of Surgeons of England, 2020; 102(5): 394-396.

4. GALETTO SGS, et al. Medical Device-Related Pressure Injuries: an integrative literature review. Rev Bras Enferm, 2019; 72(2): 528-36.

5. ORGANIZAÇÃO MUNDIAL DE SAÚDE (OMS). Rational use of personal protective equipment for coronavirus disease 2019 Disponível em: https://apps.who.int/iris/bitstream/handle/10665/331215/WHO2019-nCov-IPCPPE_use-2020.1- eng.pdf. Acessado em: 23 de setembro de 2021.

6. ZHANG S, et al. Effectiveness of using hydrocolloid dressing combined with $3 \mathrm{M}$ Cavilon No-Sting Barrier Film to prevent facial pressure injury on medical staff in a COVID-19 designated hospital in China: a selfcontrolled study. Journal Annals of Palliative Medicine, 2021; 10(1): 3-9. 
RESUMO SIMPLES: Revisão Integrativa

\section{HIDROTERAPIA COMO MÉTODO NÃO FARMACOLÓGICO NO ALÍVIO DA DOR DURANTE O TRABALHO DE PARTO}

Francisco Lucas Leandro de Sousa ${ }^{1}$

Angelica Ribeiro do Nascimento Oliveira ${ }^{1}$

Danilo da Silva Alves ${ }^{1}$

1. Centro Universitário Maurício de Nassau (UNINASSAU), Fortaleza - CE.

Palavras-chave: Hidroterapia, Trabalho de parto, Dor no parto.

\section{INTRODUÇÃO}

O parto representa uma das experiências mais marcantes para a mulher, envolvendo alterações fisiológicas, psicológicas e emocionais. Com o avanço da tecnologia, as mulheres perderam seu lugar de protagonista devido a inclusão de terapias medicamentosas (OLIVEIRA LS, et al., 2020). A hidroterapia configura-se como um método não farmacológico utilizado como terapia alternativa durante as fases do trabalho de parto com o intuito de minimizar as dores, proporcionando relaxamento e redução do estresse durante o processo de parturição. Essas medidas devem ser apresentadas durante às consultas de pré-natal, através de aconselhamento e educação em saúde (DIAS EG, et al., 2018).

\section{OBJETIVO}

Pesquisar na literatura cientifica o uso da hidroterapia como método não farmacológico no alívio da dor durante trabalho de parto normal, ressaltando os benefícios dessa técnica para a saúde da mulher.

\section{MÉTODO}

Trata-se de uma revisão integrativa realizada a partir das bases de dados da Lilacs e Scielo através dos descritores: "hidroterapia", "trabalho de parto" e "dor no parto". Como critérios de inclusão artigos originais que abordassem a temática, disponíveis online, na íntegra, nos idiomas português e inglês, publicados entre 2017 e 2021 e como critérios de exclusão: estudos repetidos nas bases de dados. Totalizando 14 estudos para compor a revisão.

\section{REVISÃO BIBLIOGRÁFICA}

Hidroterapia no parto promove à mulher benefícios, incluindo: aumento da dilatação do colo, otimização do progresso de trabalho de parto, redução da ansiedade, diminuição da pressão arterial, alívio da dor e redução de edemas. Além disso, reduz o uso de intervenções farmacológicas de analgesia favorecendo o protagonismo da mulher durante o parto (FRANÇA GS, et al., 2021). 
Essa técnica mostra-se segura e não invasiva, utilizando somente o uso de estimulação de calor por meio de banhos com água quente à $37^{\circ} \mathrm{C}$, de modo a induzir a vasodilatação periférica e redistribuição do fluxo sanguíneo, conduzindo ao relaxamento das fibras musculares, tornando esse tratamento complementar e alternativo (BRAGA MCS, et al., 2020).

\section{CONSIDERAÇÕES FINAIS}

A hidroterapia, mostrou-se como uma terapia segura, com o intuito de aumentar o conforto e reduzir a apreensão durante às fases do trabalho de parto. Nesse sentido as mulheres durante a assistência pré-natal devem receber orientações em relação aos benefícios dessa prática, tornando as gestantes capazes de fazer escolhas. Essa técnica auxiliará os profissionais, além de contribuir para um parto seguro e sem distorcias.

\section{REFERÊNCIAS}

1. BRAGA MCS, et al. Eficácia das técnicas não farmacológicas de medidas de alivia da dor e sua aplicação no contexto do parto hospitalar. Saúde \& Ciência em Ação, 2020; 6: 16-41.

2. DIAS EG, et al. Eficiência de métodos não farmacológicos para alívio da dor no trabalho de parto normal. Enfermagem em Foco, 2018; 9: 35-39.

3. FRANÇA GS, et al. A utilização de métodos não farmacológicos para o alívio da dor durante o trabalho de parto e parto. Revista Eletrônica Acervo Saúde, 2021; 13: 1-14.

4. OLIVEIRA LS, et al. Uso de medidas não farmacológicas para o alívio da dor no trabalho de parto normal. Brazilian Journal of Health Review, 2020; 3: 2850-2869. 


\title{
A UTILIZAÇÃO DA MICROCORRENTES COMO RECURSO FISIOTERAPÊUTICO NA CICATRIZAÇÃO DE FERIDAS CUTÂNEAS
}

\author{
Paula Thayna Soares Lima ${ }^{1}$ \\ Tereza Cristina dos Reis Ferreira ${ }^{1}$ \\ Eduardo Augusto Silva Monteiro ${ }^{1}$ \\ Rafael Lobato Machado ${ }^{1}$
}

1. Universidade do Estado do Pará (UEPA), Belém - PA.

Palavras-chave: Fisioterapia, Terapia por estimulação elétrica, Cicatrização.

\section{INTRODUÇÃO}

Feridas cutâneas são caracterizadas como a perda da continuidade da pele, causadas por traumas mecânicos, físicos, térmicos ou doenças metabólicas, e podem causar dor, incapacidade ou a morte (BUSANELLO-COSTA M, et al., 2020). Essas feridas passam pelo processo de cicatrização que pode ser dividido em três fases: Inflamatória, proliferativa e de remodelação, que abrangem fenômenos vasculares, hemostáticos, coagulativos, mecanismos celulares, reepitelização, angiogênese, fibroplasia, e por fim a deposição do coagulo de fibrina e sua substituição por tecido de granulação (LIRA HSL, et al., 2020). Dentre as técnicas fisioterapêuticas que auxiliam na cicatrização tecidual, encontra-se a microcorrentes, uma corrente elétrica alternada, de baixa intensidade e subsensorial (ARANTES PB, et al., 2018).

\section{OBJETIVO}

Revisar e analisar por meio da literatura científica sobre a eficácia do uso da microcorrentes, como um dos recursos fisioterapêuticos, para a melhora do processo de cicatrização das feridas cutâneas.

\section{MÉTODO}

Trata-se de uma pesquisa de revisão integrativa. Para tal, utilizou-se as bases eletrônicas: Acervo+ index base, PubMed, Scielo e Lilacs, no período do mês de setembro de 2021. Procedeu-se a análise de 5 artigos após leitura prévia de 27, incluindo artigos dos últimos 5 anos e em português e inglês, e excluindo aqueles que não respondessem a temática proposta, utilizando como descritores: Fisioterapia, Terapia por Estimulação Elétrica, Cicatrização; Physical therapy specialty, Electric Stimulation Therapy, Wound Healing.

\section{REVISÃO BIBLIOGRÁFICA}

Em um ensaio clínico comparou-se a eficácia do tratamento de feridas com pressão negativa e microcorrentes, constatando que a microcorrentes foi mais eficaz na redução da área de superfície da ferida (IBRAHIM ZM, et al., 2019). Em outro, avaliou-se a eficácia da microcorrentes na velocidade de cicatrização 
e sua influência nos sintomas inflamatórios, neste, houve redução dos sintomas inflamatórios, melhora da dor e aceleração do processo cicatricial (HARIKRISHNA KRN, 2018).

Enquanto isso, um estudo experimental observou macroscopicamente o uso da microcorrentes para cicatrização de feridas e evidenciou a estimulação dos fibroblastos, melhora da disposição das fibras colágenas e aumento da síntese proteica, favorecendo assim a cicatrização (CASTRO AS, et al., 2020).

\section{CONSIDERAÇÕES FINAIS}

Diante dos estudos apresentados, demonstra-se que a microcorrentes, recurso fisioterapêutico, atua eficientemente na cicatrização de feridas cutâneas, acelerando o seu processo e reduzindo as sequelas advindas de uma lesão tecidual. Houve limitação de artigos que respondessem ao tema proposto. Por isso, são necessários mais estudos experimentais para elucidar a eficácia da microcorrentes, como recurso fisioterapêutico, nesse processo de cicatrização tecidual.

\section{REFERÊNCIAS}

1. ARANTES PB, et al. Utilização da microcorrentes no processo de cicatrização. Diálogos Interdisciplinares, 2018; 7(3): 215-222.

2. BUSANELLO-COSTA M, et al. Benefícios do Fator de Crescimento Epidérmico (EGF) associado a terapia de fotobiomodulação a LED no reparo tecidual de feridas cutâneas. Research, Society and Development, 2020; 9(10): e9909109369-e9909109369.

3. CASTRO AS, et al. Efeitos da microcorrentes na cicatrização de feridas em ratos diabéticos. Revista CPAQV - Centro de Pesquisas Avançadas em Qualidade de Vida, 2020; 12(2): 2.

4. HARIKRISHNA, KRN. Microcorrentes como terapia adjuvante para acelerar a cicatrização de feridas crônicas e reduzir a dor do paciente. Journal of Wound Care, 2018; 27(5): 296-306.

5. IBRAHIM ZM, et al. Terapia de feridas com pressão negativa versus estimulação elétrica por microcorrentes na cicatrização de feridas em queimaduras. Journal of Wound Care, 2019; 28(4): 214-219.

6. LIRA HSL, et al. Efeitos do uso de Aloe Vera na cicatrização de feridas. Revista Eletrônica Acervo Saúde, 2020; (53): e3571. 


\title{
MANUTENÇÃO DE LENTES DE CONTATO DENTÁRIA - REVISÃO INTEGRATIVA
}

\author{
Ingrid Maria Barbosa dos Santos ${ }^{1}$ \\ Rhaina Neusa Pereira da Silva ${ }^{1}$ \\ Dielson Roque da Costa ${ }^{1}$ \\ José Eduardo Queiroz da Silva ${ }^{1}$ \\ Davi Clementino Carneiro²
}

1. Centro Universitário UNIESP, Cabedelo - PB.

2. Universidade Federal da Paraíba (UFPB), João Pessoa - PB.

Palavras-chave: Estética dentária, Lentes de contato, Odontologia.

\section{INTRODUÇÃO}

A procura por um sorriso perfeito tem levado pacientes aos consultórios odontológicos em busca de soluções que deixem seus dentes mais brancos e esteticamente agradáveis (SILVA KP, et al., 2021). Por esse motivo, as lentes de contato se apresentam como uma solução rápida, prática e de baixo custo para aqueles que querem corrigir o sorriso, causando uma sensação de perfeição nos pacientes (OKIDA RC, et al., 2016).

A popularização destes procedimentos traz discussões sobre a durabilidade dos materiais usados, e as complicações que podem ocorrer após o procedimento, pois de nada adianta uma boa aplicação sem os devidos cuidados e manutenção necessárias (PEIXOTO RVL, et al., 2018).

\section{OBJETIVO}

Analisar através da literatura científica o tema abordado e os tópicos relacionados a respeito da aplicação, manutenção e as complicações causadas pela utilização de lentes de contato, contribuindo para o acervo literário acadêmico e auxiliando no bem-estar da população.

\section{MÉTODO}

Neste trabalho realizou-se uma breve revisão sistemática, foi realizado um levantamento na base de periódicos científicos Google Scholar, no mês de setembro do ano de 2021, foram encontrados 1990 artigos utilizando o descritor: "lente de contato dentária" e foram escolhidos 4 artigos. Utilizou-se os "filtros" oferecido pela plataforma para que mostrasse apenas artigos publicados em português nos últimos 5 anos.

\section{REVISÃO BIBLIOGRÁFICA}


O processo de implante, qualidade e tipologia do material são fatores decisivos para a manutenção das lentes (SILVA KP, et al., 2021). Por se tratar de uma técnica nova, a literatura é carente sobre informações sobre as falhas que resultam em retratamento de lentes de contato (SOUSA JAM, et al., 2021).

Lentes de contato possibilitam um tratamento conservador e estético favoráveis no tratamento para dentes palatinizados (PEIXOTO RVL, 2018). Na procura por alternativas protéticas conservadoras e com eficácia na estética do sorriso, os laminados cerâmicos apresentam resultados clínicos favoráveis sem comprometimento da saúde (OKIDA RC, et al., 2016).

\section{CONSIDERAÇÕES FINAIS}

$\mathrm{Na}$ busca por um sorriso esteticamente perfeito e dentro dos padrões de beleza impostos pela sociedade as lentes se apresentam como solução rápida, prática e conservadora. Entretanto é preciso que hajam alguns cuidados em relação ao processo de aplicação das lentes de contato, com materiais usados e os cuidados pós aplicação para aumentar a longevidade das lentes.

\section{REFERÊNCIAS}

1. OKIDA RC, et al. Lentes de contato: restaurações minimamente invasivas na solução de problemas estéticos. Revista Odontológica de Araçatuba, 2016; 37(1): 53-59.

2. PEIXOTO RVL, et al. Lentes de contato odontológicas - preparo minimamente invasivo: relato de caso. Revista Gestão \& Saúde, 2018; 18(2): 44-54.

3. SILVA KP, et al. Aplicação e manutenção das lentes de contato: uma revisão de literatura. JNT- Facit Business and Technology Journal, 2021;27(1).

4. SOUSA JAM; et al. Retratamento em laminados cerâmicos minimamente invasivos: Uma revisão integrativa da literatura. Research, Society and Development, 2021; 10(4). 


\title{
MUCORMICOSE ORBITAL EM PACIENTES COM COVID-19 GRAVE
}

\author{
Keilla Barbosa de Souza ${ }^{1}$ \\ Ana Beatriz Lima dos Santos ${ }^{1}$ \\ Nathalia dos Santos Melo ${ }^{1}$ \\ Emilly dos Santos de Oliveira ${ }^{1}$ \\ Thaís Ranielle Souza de Oliveira ${ }^{1}$
}

1. Centro Universitário Euro Americano (UNIEURO), Brasília - DF.

Palavras-chave: Mucormicose orbital, COVID-19, Fungo.

\section{INTRODUÇÃO}

A mucormicose é uma infecção oportunista grave causada por fungos, que se manifesta maiormente em imunossuprimidos e comumente encontrada em indivíduos com diabetes descontrolada (GUIMARÃES JA e MOURA FC, 2021). O fungo tem capacidade de desencadear complicações rinocerebrais, pulmonares e cutâneas (HARTNETT KP, et al., 2019).

Os primeiros casos de mucormicose orbital relacionada a COVID-19 foram relatados na Índia, principalmente ao longo da segunda onda pandêmica (PATEL A, et al., 2021). A identificação precoce da infecção fúngica invasiva, principalmente em pacientes com COVID-19, auxilia no tratamento apropriado reduzindo o risco de complicações e óbitos (BRASIL, 2021).

\section{OBJETIVO}

Analisar na literatura científica a relação entre os casos de mucormicose orbital e a pandemia de COVID19, identificando os possíveis fatores que predispõem a essa condição, durante o primeiro semestre de 2021.

\section{MÉTODO}

Trata-se de uma revisão integrativa, realizada na base de dados Ebsco/Medline, em agosto de 2021. Os descritores utilizados foram "mucormicose orbital" e "COVID-19". Foram incluídos no estudo artigos em inglês publicados no primeiro semestre de 2021, e excluídos àqueles que não se adequavam à temática e artigos duplicados. A busca resultou em 32 artigos, após aplicados os critérios de inclusão e exclusão foram selecionados 9 artigos.

\section{REVISÃO BIBLIOGRÁFICA}

Achados na literatura sugerem que a COVID-19 em sua forma mais grave pode propiciar o aparecimento de coinfecções fúngicas, houve o relato de casos de pacientes que desenvolveram mucormicose orbital 
durante o tratamento para COVID-19. A condução do tratamento e doenças de base foram fatores condicionantes para a evolução da doença e para determinar a perda de visão permanente (SARKAR S, et. al., 2021).

Além disso, identificou-se que os pacientes devem ser monitorados quando diagnosticados com COVID19, principalmente quando há em simultâneo diabetes mellitus descontrolada e uso de corticosteróides, pois esses fatores aumentam o risco de desenvolvimento de mucormicose invasiva (BUIL JB, et. al., 2021).

\section{CONSIDERAÇÕES FINAIS}

Verificou-se o aumento de casos de mucormicose orbital associada à COVID-19 em pacientes com diabetes mellitus descontrolada e em uso de corticosteróides. Essa associação demonstra a importância de aprofundar as pesquisas sobre o tema, visando gerar informações que auxiliem no cuidado e prevenção de agravos, sobretudo durante um cenário pandêmico.

\section{REFERÊNCIAS}

1. BRASIL. Agência Nacional de Vigilância Sanitária. Orientações para vigilância, identificação, prevenção e controle de infecções fúngicas invasivas em serviços de saúde no contexto da pandemia da COVID-19. Nota técnica GVIMS/GGTES/ANVISA, de 14 de junho de 2021. Disponível em: https://www.gov.br/anvisa/pt- br/centraisdeconteudo/publicacoes/servicosdesaude/notas-tecnicas/notatecnica-04-2021-infeccoes-fungicas-e- covid19.pdf. Acessado em: 29 de setembro de 2021.

2. BUIL JB, et. al. Case series of four secondary mucormycosis infections in COVID-19 patients, the Netherlands, December 2020 to May 2021. Eurosurveillance, 2021; 26(23): e2100510.

3. GUIMARÃES JA, MOURA FC. Refractory rhino-orbito-cerebral mucormycosis treated with intraconal amphotericin B. Arq Bras Oftalmol, 2021; $1-5$.

4. HARTNETT KP, et al. A guide to investigating suspected outbreaks of mucormycosis in healthcare. Journal of Fungi, 2019; 5(69): 1-25.

5. PATEL A, et. al. Multicenter epidemiologic study of coronavirus disease-associated mucormycosis, India. Emerging Infectious Diseases, 2021; 27(9): 2349-2359.

6. SARKAR S, et. AI. COVID-19 and orbital mucormycosis. Indian J Ophathalmol, 2021; 69(4): 1002-1004. 


\title{
ABORDAGENS E TRATAMENTOS DAS INFECÇÕES ODONTOGÊNICAS SEVERAS: REVISÃO DE LITERATURA
}

\author{
Manoel Gabriel de Melo Pereira da Silva ${ }^{1}$ \\ João Victor do Rêgo Valença ${ }^{1}$ \\ Kalyne Kelly Negromont Gonçalves ${ }^{1}$ \\ Thalles Gabriel Germano de Lima1 \\ Larissa Sousa Rangel ${ }^{1}$
}

1. Centro Universitário Mauricio de Nassau (Uninassau), Recife - PE.

Palavras-chave: Assistência odontológica, Infecções, Emergências.

\section{INTRODUÇÃO}

As infecções odontogênicas continuam sendo uma das maiores preocupações de saúde pública, são provocadas por infecções dentárias, que quando não tratadas, disseminam-se aos espaços faciais profundos (SAVITRI RK, et al., 2017). Infecções maxilofaciais severas são caracterizadas pela disseminação infecciosa pelos tecidos adjacentes e espaços faciais da cabeça, pescoço e tórax, embora a maioria dos quadros de infecções sejam bem controlados com intervenção cirúrgica e antibioticoterapia, algumas infecções mais severas podem ter caráter disseminatório mais profundo, acometendo estruturas nobres, causando o comprometimento de vias aéreas, resultando em septicemia e óbito (FARAH GJ, et al., 2018).

\section{OBJETIVO}

Relatar através de uma revisão de literatura, do tipo narrativa, as características clínicas, sinais e sintomas das infecções de origem odontogênicas severas, além dos principais tratamentos cirúrgico e medicamentoso ofertados aos pacientes.

\section{REVISÃO BIBLIOGRÁFICA}

A sintomatologia do processo infeccioso apresenta-se com tumefações localizadas, assintomáticas ou dolorosas sendo de pouca agressividade ou rápida progressão, sendo um dos fatores importantes na tomada de decisões clínicas, em exigência de um tratamento ambulatorial ou hospitalar (ROCHA AO, et al., 2020).

Entre os diversos sinais e sintomas relacionados as infecções destacam-se o edema, dor no assoalho bucal, febre, disfagia, odinofagia, sialose, trismo, odontalgia e respiração fétida, além de mudanças na fonação, dificuldade respiratória e cianose, sendo esses alguns dos sinais e sintomas mais comuns observados (CAMARGOS FM, et al., 2017).

As formas de tratamento, seja cirúrgica ou medicamentoso, tem como objetivo evitar a disseminação de áreas vizinhas, diminuindo o inoculo bacteriano e evitando complicações pelo desmembramento via sistema 
circulatório, a literatura científica relata algumas classes de medicamentos (penicilina, ampicilina e amoxicilina), que são responsáveis pelo tratamento da fase aguda da infecção, prevenindo as complicações (CHANDRA HJ, et al., 2017).

\section{CONSIDERAÇÕES FINAIS}

A partir dos artigos encontrados na literatura, consideramos, portanto, que atrasos na procura de atendimento, antibioterapia inadequada e condições sistêmicas que favoreçam a disseminação do processo infeccioso, como a falta de conhecimento das estruturas anatômicas, devem ser levadas em considerações, a fim de diagnosticar corretamento o um quadro agudo ou crônico, sendo, no entando, de grande importância analisar e definir os tratamentos mais adequados a cada situação.

\section{REFERÊNCIAS}

1. CAMARGOS FM, et al. infecções odontogenicas complexas e seu perfil epidemiológico. Rev. Cir. traumologia buco-maxilo-fac, 2017; 16: 25-30.

2. CHANDRA HJ, et al. Characterization and antibiotic sensitivity profile of bacteria in orofacial abscesses of odontogenic origin. Journal of maxillofacial and oral surgery, 2017; 16: 445-452.

3. FARAH GJ, et al. Estudo epidemiológico de pacientes portadores de infecções do complexo buco maxilofacial tratados no hospital uniruritano de maringá: RFOUPE, 2018; 23: 280-283.

4. ROCHA AO, et al. odontogenie injection involving surface temporal space: case report. Revista odontológica de Araçatuba, 2020; 41: 09-14.

5. SAVITRI RK, et al. Description of odontogenic infection cases at the Oral Surgery Polyclinic of Hasan Sadikin Hospital Bandung. Journal of Dentistry, 2017; 24: 302-309. 


\title{
EFEITOS DA COVID-19, NA SAÚDE MENTAL DOS PROFISSIONAIS QUE ATUAM NA LINHA DE FRENTE
}

\author{
Nayara Araújo Magalhães ${ }^{1}$ \\ Lyandra Paiva de Aquino²
}

Débora Luiza de Oliveira Rangel Resende ${ }^{3}$

1. Centro Universitário Euro-Americano (UNIEURO), Brasília - DF.

2. Universidade do Distrito Federal (UDF), Brasília - DF.

3. Universidade de Brasília (UNB), Brasília - DF.

Palavras-chave: Saúde ocupacional, Profissional de saúde, COVID-19.

\section{INTRODUÇÃO}

Iniciada a pandemia do vírus SARS-COV-2 em 2020, o sistema de saúde foi surpreendido, consequentemente os profissionais de saúde encontraram-se sobrecarregados (LUCENO-MORENO L, et al., 2020). Essa não é a primeira pandemia, mas declarada a mais impactante, associando diversos prejuízos psicológicos adquiridos a esses profissionais, como aumento de estresse, síndromes e esgotamento emocional/físico (RAUDENSKÁ J, et al., 2020).

A pandemia apresenta desafios sem precedentes para o sistema de saúde. A pressão sobre os profissionais de saúde intensificada, acentuada ao excesso de trabalho, condições degradadas de atendimento devido à emergência sem fim e risco de exposição ao vírus, afeta diretamente a saúde mental dos mesmos (El-HAGE W, et al., 2020).

\section{OBJETIVO}

Reconhecer os impactos que a pandemia do COVID-19 trouxe aos profissionais que atuam de forma direta com os pacientes infectados, observando o impacto que a pandemia pode vir a ter acarretado no estado psíquico desses profissionais.

\section{REVISÃO BIBLIOGRÁFICA}

Apontamentos sobre o aumento da síndrome de Burnout e diversos distúrbios comportamentais durante o período pandêmico evidenciam sua forte contribuição para a morbidade psiquiátrica entre os profissionais que atuam na linha de frente, impactando negativamente o desempenho no trabalho, na qualidade de atendimento e na satisfação do trabalhador (LIN Y, et al., 2021).

Muitos profissionais de saúde optaram pelo distanciamento social de seus familiares e amigos, a fim de reduzirem o risco de contaminá-los, tendo em vista que o distanciamento tem comprovado níveis de diminuição no contagio do vírus em contrapartida o isolamento priva os profissionais do convivo social 
afetando sua disposição física e mental, precisamente quando eles estão em um momento de maior fragilidade emocional, apresentando angustias seguidas por medo, síndromes de ansiedade e distúrbios mentais pelo estado vulnerável, sobrecarga de trabalho devido o colapso da capacidade assistencial do serviço de saúde, resultando na adversidade que esses profissionais apresentam para realizar medidas de autocuidado, lazer, sono, alimentação adequada e exercícios físicos, já que muitos tiveram que dobrar as jornadas de trabalho (BORGES GM, et al., 2021).

\section{CONSIDERAÇÕES FINAIS}

Como forma de deslindar a problematização e promover possíveis estratégias para reduzir os danos à saúde mental desses profissionais, faz necessário desenvolver por meio de promoção e prevenção, a ação advinda do governo assim como Sistema Único de Saúde (SUS) se tratando do Brasil, trazendo por meio de atendimento psicológico, acompanhamento e observação, propondo gratificações e reconhecimento pelo trabalho árduo realizado, promovendo a resolutividade na atuação conjunta dos profissionais.

\section{REFERÊNCIAS}

1. EL-HAGE W, et al. Health professionals facing the coronavirus disease 2019 (COVID-19) pandemic: What are the mental health risks? Encephale, 2020; 46(3S).

2. LUCEÑO-MORENO L, et al. Sintomas de estresse pós-traumático, ansiedade, depressão, níveis de resiliência e esgotamento em pessoal de saúde espanhol durante a pandemia de COVID-19. Jornal internacional de pesquisa ambiental e saúde pública, 2020; 17,15 5514.

3. RAUDENSKÁ J, et al. Síndrome de burnout ocupacional e estresse pós-traumático entre profissionais de saúde durante a nova pandemia de doença coronavírus 2019 (COVID-19). Melhores práticas e pesquisa. Clinical anaesthesiology, 2020; 34,3: 553-560.

4. LIN YY, et al. A pandemia de COVID-19 está associada a um impacto adverso no Burnout e nos transtornos do humor em profissionais de saúde. Int J Environ Res Saúde Pública. 2021; 18(7): 3654.

5. BORGES GM, et al. O impacto da Síndrome de Burnout entre os profissionais de saúde no contexto da pandemia da Covid-19. Revista Eletrônica Acervo Enfermagem, 2021; 13: e8375. 


\title{
IMPACTO DA ATIVIDADE FÍSICA REGULAR NA EVOLUÇÃO CLÍNICA DA INFECÇÃO POR SARS-CoV-2
}

\author{
Bruno Henrico Bertoni de Mendonça ${ }^{1}$ \\ Anny Caroline dos Santos ${ }^{2}$ \\ Thalita Silva de Oliveira ${ }^{3}$ \\ Derick Mendes Bandeira ${ }^{4}$
}

1. Universidade Federal Rural do Rio de Janeiro (UFRRJ), Seropédica - RJ.

2. Blessing Laboratório, Niterói - RJ.

3. Neurolife Laboratórios, Rio de Janeiro - RJ.

4. Laboratório de Morfologia e Morfogênese Viral (LMMV/IOC-FIOCRUZ), Rio de Janeiro - RJ.

Palavras-chave: Atividade física, SARS-CoV-2, Lockdown.

\section{INTRODUÇÃO}

Em dezembro de 2019, na província de Wuhan (China), foi detectado o primeiro caso de COVID-19: uma doença inflamatória multissistêmica causada pelo novo coronavírus SARS-CoV-2 (PAULA L, et al., 2020). A COVID-19 ocasionou a morte de milhões de pessoas ao redor do mundo, e as vacinas desenvolvidas para o controle da doença ainda não estão disponíveis a todas as pessoas. Por essa razão, muito tem-se discutido sobre medidas complementares de profilaxia da infecção ou de reforço da imunidade, como, por exemplo, a prática regular de atividade física.

\section{OBJETIVO}

Realizar uma revisão de literatura científica acerca do impacto da atividade física regular na evolução clínica da infecção por SARS-CoV-2 e os reflexos da pandemia no nível de sedentarismo da população.

\section{REVISÃO BIBLIOGRÁFICA}

Diversos estudos têm mostrado o quanto a pandemia tem diminuído a frequência de realização de atividades físicas, principalmente por conta de medidas de isolamento social (ou ainda mais drásticas, como o lockdown) necessárias ao controle da dispersão do vírus no período pré-vacina (MARTíNEZ-DE-QUEL Ó, et al., 2021; MCCARTHY H, et al., 2021).

Essas ações levaram muitas pessoas a quadros de insônia, depressão e ansiedade. No entanto, indivíduos que, mesmo em meio a este contexto restritivo, mantiveram suas práticas regulares de exercício, apresentaram esses sintomas com menos frequência e intensidade (CHI X, et al., 2021). 
Além disso, já foi constatado que a mortalidade por COVID-19 é maior em indivíduos sedentários (CHO $\mathrm{DH}$, et al., 2021) e que a prática regular de atividade física pode ser crucial para a sobrevivência, especialmente de indivíduos que possuam comorbidades, como doenças cardíacas crônicas (VAN BAKEL BMA, et al., 2021).

\section{CONSIDERAÇÕES FINAIS}

Manter uma rotina de atividade física sem desrespeitar as medidas de prevenção contra a COVID-19 não somente é possível como é algo necessário para possibilitar que o organismo tenha condições de controlar a infecção ou mesmo de responder às vacinas.

\section{REFERÊNCIAS}

1. $\mathrm{CHI} \mathrm{X,} \mathrm{et} \mathrm{al.} \mathrm{Mental} \mathrm{health} \mathrm{problems} \mathrm{among} \mathrm{Chinese} \mathrm{adolescents} \mathrm{during} \mathrm{the} \mathrm{COVID-19:} \mathrm{The} \mathrm{importance}$ of nutrition and physical activity. International Journal of Clinical and Health Psychology, 2021; 21(3): 100218.

2. $\mathrm{CHO} \mathrm{DH}$, et al. Physical Activity and the Risk of COVID-19 Infection and Mortality: A Nationwide PopulationBased Case-Control Study. Journal of Clinical Medicine, 2021; 10(7).

3. MARTÍNEZ-DE-QUEL Ó, et al. Physical activity, dietary habits and sleep quality before and during COVID19 lockdown: A longitudinal study. Appetite, 2021; 158: 105019.

4. MCCARTHY H, et al. Physical Activity Behavior Before, During, and After COVID-19 Restrictions: Longitudinal Smartphone-Tracking Study of Adults in the United Kingdom. Journal of Medical Internet Research, 2021; 23(2): 23701.

5. PAULA L, et al. Potenciais tratamentos no manejo do covid-19. Revista Eletrônica Acervo Saúde, 2020; 12(9): e3963.

6. VAN BAKEL BMA, et al. Impact of COVID-19 lockdown on physical activity and sedentary behaviour in Dutch cardiovascular disease patients. Netherlands Heart Journal, 2021; 29(5): 273-279. 


\title{
ANSIEDADE E ESTRESSE NA EQUIPE DE ENFERMAGEM DIANTE AO ENFRENTAMENTO DA COVID- 19: UMA REVISÃO INTEGRATIVA DA LITERATURA
}

\author{
Michelle Augusta Soares Oliveira ${ }^{1}$ \\ Talita de Cassia Raminelli da Silva ${ }^{1}$ \\ Andréia Guedes Oliva Fernandes ${ }^{1}$
}

1. Centro Universitário Euro Americano (UNIEURO) Brasília - DF.

Palavras-chave: COVID-19, Equipe de enfermagem, Ansiedade.

\section{INTRODUÇÃO}

A COVID-19 é uma doença infecciosa transmitida através de gotículas de saliva ou secreções contaminadas e ocasiona manifestações clínicas leves ou graves (OMS, 2021). Reconhece-se que os casos graves de COVID-19 levam a busca pelos serviços de saúde, e dentre os profissionais de saúde estão os profissionais de enfermagem que encontram-se na linha de frente no enfrentamento da pandemia provocada pela COVID-19. Evidências apontam que por distintos fatores estes trabalhadores estão vulneráveis à ocorrência de problemas de saúde mental, como a ansiedade e o estresse (PRADO AD, et al., 2020; TEIXEIRA CFS, et al., 2020).

\section{OBJETIVO}

Identificar na literatura quais os estressores associados à ocorrência de prejuízos na saúde mental no âmbito do trabalho da equipe de enfermagem durante o enfrentamento da pandemia do coronavírus (COVID19).

\section{MÉTODO}

Revisão integrativa realizada nas bases de dados: National Library of Medicine (PubMed); Scientific Electronic Library Online (SciELO) e Biblioteca Virtual em Saúde (BVS) em 2021. Foram incluídos trabalhos em inglês e português publicados na íntegra entre 2020 e 2021. Após buscas, encontrou-se 103 artigos sendo selecionados após aplicação dos critérios de inclusão 7 trabalhos. Como descritores utilizou-se: "COVID-19"; "Ansiedade"; "Estresse Ocupacional", "Equipe de Enfermagem" e os operadores booleanos "AND" e "OR".

\section{REVISÃO BIBLIOGRÁFICA}

Dentre os fatores identificados na literatura que levam ao estresse e a ansiedade nos profissionais de enfermagem estão: a longa jornada de trabalho; o uso e a ausência dos Equipamentos de Proteção Individual (EPI); a insegurança; a tristeza diante da perda de pacientes, familiares e colegas de trabalho; o sentimento de incapacidade diante das situações vivenciadas no enfrentamento da pandemia; o cansaço; a angústia; o 
medo de adquirir a doença; a estrutura precária dos hospitais e o dimensionamento insuficiente de profissionais que provoca a sobrecarga de trabalho dos mesmos (LUZ EMF, et al., 2020; TOESCHER AMR, et al., 2020).

\section{CONSIDERAÇÕES FINAIS}

Observou-se que mesmo com os diagnósticos de ansiedade e estresse, os profissionais de enfermagem têm destaque por sua importância no combate à pandemia da COVID-19. Ressalta-se a importância de medidas de prevenção e controle de agravos à saúde psíquica desses profissionais, visto que pode melhorar de forma significativa o trabalho e o desempenho de atividades da equipe de enfermagem.

\section{REFERÊNCIAS}

1. LUZ EMF, et al. Repercussões da covid-19 na saúde mental dos trabalhadores de enfermagem. Revista de enfermagem do Centro-Oeste Mineiro, 2020; 10: e3824.

2. ORGANIZAÇÃO MUNDIAL DE SAÚDE (OMS). Folha informativa COVID-19. Brasil, 12 fev 2021. Disponível em: https://www.paho.org/pt/covid19\#sintomas. Acessado em: 16 mar 2021.

3. PRADO AD, et al. A saúde mental dos profissionais de saúde frente à pandemia do COVID-19: uma revisão integrativa. Revista Eletrônica Acervo Saúde, 2020; Esp.46: e4128.

4. TEIXEIRA CFS, et al. A saúde dos profissionais de saúde no enfrentamento da pandemia de Covid-19. Ciência e Saúde Coletiva. Rio de Janeiro, 2020; 25(9).

5. TOESCHER AMR, et al. Saúde mental de profissionais de enfermagem durante a pandemia de COVID19: recursos de apoio. Escola Anna Nery. Rio de Janeiro, 2020; 24. 


\title{
UTILIZAÇÃO DO LAVADO PERITONEAL DIAGNÓSTICO NO TRAUMA ABDOMINAL FECHADO EM SERVIÇOS DE SAÚDE SEM RECURSOS AVANÇADOS DE IMAGEM
}

\author{
Suéllen Nogueira Jardim 1 \\ Vitor Landim de Oliveira ${ }^{1}$ \\ Giovanna dos Santos Flora ${ }^{1}$
}

Alessandra Patricia Soares da Costa Rafael ${ }^{2}$

1. Centro Universitário UNIFAA, Valença - RJ.

2. Centro Universitário UNIFACIG, Manhuaçu - MG.

Palavras-chave: Trauma abdominal fechado, Lavado peritoneal diagnóstico, Recursos de imagem.

\section{INTRODUÇÃO}

A identificação de lesões no Trauma Abdominal Fechado (TAF) vem se tornando cada vez mais rápida e menos invasiva com a implementação de tecnologias diagnósticas, como a Tomografia Computadorizada (TC) e a Avaliação Focalizada com Sonografia para Trauma (FAST) (OLIVEIRA L, et al., 2018). Contudo, diante da precária infraestrutura e recursos reduzidos em grande parte dos serviços de saúde no Brasil, práticas diagnósticas da década de 60, como o Lavado Peritoneal Diagnóstico (LPD), são alternativas plausíveis e eficazes para não retardar a instituição do tratamento, visto que as lesões intra-abdominais podem ser extensas e com alto índice de morbidade e mortalidade (SCHELLENBERG M, et al., 2021).

\section{OBJETIVO}

Analisar a eficácia do Lavado Peritoneal Diagnóstico como método alternativo preciso na identificação de lesões hemorrágicas intraperitoneais em serviços de saúde que não dispõem de ferramentas diagnósticas de imagem mais modernas.

\section{MÉTODO}

O presente estudo trata-se de uma revisão sistemática realizada a partir da consulta das bases de dados Scielo, Europe PubMed Central e EBSCO, a partir dos seguintes descritores: trauma abdominal fechado, lavado peritoneal diagnóstico, TC e FAST. Dos 11 artigos encontrados, selecionou-se 3, publicados entre os anos 2018-2021. Os critérios de exclusão foram artigos não baseados no tema proposto e anteriores ao ano de 2018.

\section{REVISÃO BIBLIOGRÁFICA}


Em um estudo que verificou a utilização do LPD em traumas atualmente, os resultados evidenciaram baixas taxas de falha e complicações na identificação de hemorragia intraperitoneal. Além disso, afirmou que no estudo o LPD foi conclusivo quando positivo, sem falsos positivos (SCHELLENBERG M, et al., 2021).

Outro estudo observacional que avaliou o valor preditivo positivo da TC e do LPD em traumas abdominais concluiu que a TC deve ser o método preferencial na avaliação inicial de pacientes estáveis com TAF (GHAFFAR A, et al., 2019). Porém, os achados cirúrgicos durante o tratamento das lesões foram semelhantes, justificando o uso do LPD em locais que não possuem o serviço de tomografia.

\section{CONSIDERAÇÕES FINAIS}

Diante do estudo apresentado, nota-se que, apesar da maior especificidade da TC e da FAST na identificação de lesões no TAF, o LPD é uma alternativa precisa e de fácil realização devido técnica simples, que utiliza materiais de maior disponibilidade nos serviços de saúde no Brasil. Além disso, muitos hospitais não possuem o equipamento ou equipe com treinamento necessário para realização de tomografia ou ultrassom durante uma emergência.

\section{REFERÊNCIAS}

1. GHAFFAR A, et al. Comparison of computed tomography with diagnostic peritoneal lavage for diagnosis of solid organ damage in patients with blunt abdominal trauma. Professional Medical Journal, 2019; 26(6): 876-880.

2. OLIVEIRA L, et al. Basic ultrasound training assessment in the initial abdominal trauma screening. Rev. Col. Bras. Cir., 2018; 45(01): e1556.

3. SCHELLENBERG M, et al. Contemporary utility of diagnostic peritoneal aspiration in trauma. Journal of Trauma and Acute Care Surgery, 2021; 91(5): 814-819. 
RESUMO SIMPLES: Revisão Integrativa

\title{
CANDIDA AURIS E SEU MECANISMO DE RESISTÊNCIA: UM RISCO PARA A SOCIEDADE
}

\author{
Ewerthon José da Silva Martins ${ }^{1}$ \\ Larissa Santos Carneiro Gomes ${ }^{1}$ \\ Rosilma de Oliveira Araujo Melo ${ }^{1}$
}

1. Centro Universitário Maurício de Nassau (UNINASSAU), Recife - PE.

Palavras-chave: Candida auris, Virulência, Resistência.

\section{INTRODUÇÃO}

Primeiramente identificada após a coleta e realização do isolamento da secreção do canal auditivo de um paciente, em 2009, no Japão, novos casos vêm surgindo de cepas de Candida Auris e espalhando-se rapidamente por todo o mundo. Este trata-se de um fungo emergente e multirresistente a drogas (RHODES J e FISHER MC, 2019).

Por sua alta capacidade de resistir e ser facilmente transmitida, a Candida Auris tem se tornado um problema mundial, sendo associada a uma crescente onda de infecções nosocomiais. Assim, vários casos graves já foram identificados nos cinco continentes, a saber: Ásia, Américas, África, Europa e Oceania (MORENO MV, et al., 2019).

\section{OBJETIVO}

Descrever os principais fatores de virulência bem como de resistência da Candida Auris como um risco para a sociedade associado à multirresistência e a sua alta capacidade de mortalidade e morbidade.

\section{MÉTODO}

Revisão integrativa realizada nos bancos de dados PubMed e SciELO. Os descritores utilizados através do DeCS foram: Candida auris, resistência e virulência. Para o processo de síntese do presente resumo foram selecionados periódicos entre 2016-2021, em inglês, espanhol e português, sendo 15 artigos selecionados para análise de títulos e 5 escolhidos após a leitura. Não foram considerados aqueles antecedentes ao ano de 2016 e com fuga ao objetivo do trabalho.

\section{REVISÃO BIBLIOGRÁFICA}

A Candida Auris expressa vários fatores de virulência devido à capacidade de aderência e formação de biofilmes (RHODES J e FISHER MC, 2019). As expansões de transportadores e lipases dentro da Candida Auris são um provável mecanismo de virulência compartilhado com outras espécies de Candida Albicans (SPIVAK ES e HANSON KE, 2017). 
Um fator preocupante para a saúde pública, além da taxa de mortalidade (30\%-70\%), é a multirresistência da Candida Auris, embora não esteja totalmente elucidada, essa espécie apresenta alta resistência ao fluconazol, por exemplo (MACHADO GS, et al., 2021). Assim, uma maior proporção de cópias de genes relacionada à bombas de efluxo poderiam explicar o fato da multirresistência e resistência a antifúngicos (TAPIA C e BATARCE C, 2019).

\section{CONSIDERAÇÕES FINAIS}

As infecções por Candida Auris continuam a ser relatadas no mundo. Considerada uma nova ameaça global, esse patógeno emergente está associado com alta taxa de morbimortalidade. Com isso, novos testes de antimicrobianos e a identificação correta dessa espécie são cruciais não apenas para a implementação de medidas preventivas, mas também para a detecção dos casos de disseminação rápida.

\section{REFERÊNCIAS}

1. MACHADO GS, DALMOLIN TV, BRANDÃO F. Candida auris - fungo emergente que ameaça a saúde global. Brazilian Journal of Development, 2021; 7(1): 9673-9681.

2. MORENO MV et al. Primer aislamiento de Candida auris en Chile. Rev Chilena Infectol, 2019; 36 (6): 767 773.

3. RHODES J, FISHER MC. Global epidemiology of emerging Candida auris. Current Opinion in Microbiology, 2019; 52: 84-89.

4. SPIVAK ES, HANSON KE. Candida auris: an Emerging Fungal Pathogen. Journal of Clinical Microbiology, 2018; 56(2): 1-10.

5. TAPIA C, BATARCE C. Candida auris multi-resistente en infecciones nosocomiales. Rev Chilena Infectol, 2017; 34 (2): 192. 


\title{
PRINCIPAIS SEQUELAS PÓS-COVID-19: UMA REVISÃO DE LITERATURA
}

\author{
Milena Cristina da Silva Leite ${ }^{1}$ \\ Sheila Chaene Dias Vitor ${ }^{1}$ \\ Thaís Azevedo Cota de Almeida ${ }^{1}$ \\ Fabíola de Araújo Resende Carvalho ${ }^{1}$
}

1. Centro Universitário UNA, Bom Despacho - MG.

Palavras-chave: Sequelas, COVID-19, Recuperados do coronavírus.

\section{INTRODUÇÃO}

O mundo vivenciou a primeira pandemia viral do século XXI quando um novo vírus (SARS-CoV-2) pertencente à família Coronaviridae, deixou de infectar animais e passou a ter o ser humano como hospedeiro (de SOUZA LC, et al., 2021). É um vírus RNA, e apresenta quatro gêneros principais de caráter zoonótico, altamente patogênicos e capazes de causar afecções respiratórias, hepáticas e neurológicas (GOUVEA A, et al., 2021). O quadro clínico pode ser caracterizado em três condições: pacientes assintomáticos, aqueles com doença respiratória aguda ou com pneumonia em diferentes estágios de gravidade. Os pacientes acometidos pelo novo coronavírus apresenta diversas sequelas, ainda desconhecidas. (NOGUEIRA TL, et al., 2021).

\section{OBJETIVO}

Investigar as principais sequelas decorrentes da COVID-19 e avaliar a intensidade dos seus impactos na vida das pessoas acometidas pela doença, tendo em vista que o estado de saúde vai muito além da condição física do paciente.

\section{MÉTODO}

Foi realizada uma revisão sistemática através de uma busca nas bases de dados Scielo, PubMed, e Acervo+ Index Base, utilizando os seguintes descritores: COVID-19, Vírus da COVID-19, SARS-CoV-2. Sintetizou-se os resultados dos 6 artigos, por meio da leitura dos mesmos, tendo por principal guia a seguinte pergunta norteadora: Quais são as principais sequelas decorrentes da COVID-19 e quais impactos elas promovem na vida dos pacientes acometidos? Por meio desta indagação, investigou-se os dados contidos nos estudos.

\section{REVISÃO BIBLIOGRÁFICA}

Pacientes recuperados do COVID-19, estão suscetíveis a contraírem sequela neurológica simples relacionadas às disfunções olfativas e gustativas, cefaleia, fadiga, tontura e sintomas depressivos. Já pacientes que sofreram complicações secundárias (internados em Unidade de Terapia Intensiva (UTI), podem 
comprometer o condicionamento físico e respiratório, perda muscular, distúrbios cognitivos e neuropsiquiátricos (NOGUEIRA TL, et al., 2021).

Em casos graves, o déficit neurológico é o mais relatado, juntamente com o Acidente Vascular Isquêmico (AVI), convulsões e encefalite. Há persistência de sintomas relacionados com a comunicação, alterações na voz e deglutição em doentes recuperados. Pacientes com comorbidades, tais como obesidade infantil, há maior propensão as sequelas graves (COSTA LR, et al., 2020; VALVERDE R, et al., 2021).

\section{CONSIDERAÇÕES FINAIS}

Pode-se considerar que a maioria das sequelas pós covid possuem tratamento, porém muitas das sequelas ainda são desconhecidas pelos profissionais da saúde, visto que se trata de um vírus mutante e novo para a comunidade científica. A prática de exercícios físicos pode ser um ótimo meio de recuperação para os pacientes que obtiveram sequelas pós covid se realizada por um profissional.

\section{REFERÊNCIAS}

1. COSTA LR, et al. Obesidade infantil e quarentena: crianças obesas possuem maior risco para a COVID19?. Residência Pediátrica, 2020; 10(2).

2. de SOUZA LC, et al. SARS-CoV, MERS-CoV e SARS-CoV-2: uma revisão narrativa dos principais Coronavírus do século. Brazilian Journal of Health Review, 2021; 4(1): 1419-1439.

3. GOUVEA ALV, et al. Síndrome pós-covid-19: principais afecções e impactos na Sociedade em foco. Colóquio Estadual de Pesquisa Multidisciplinar. 2021

4. NOGUEIRA TL, et al. Pós covid-19: as sequelas deixadas pelo Sars-Cov-2 e o impacto na vida das pessoas acometidas. Arquivos de Saúde, 2021; 2(3): 457-471.

5. VALVERDE R, et al. Panorama da relação epidemiológica entre obesidade infantil associada ao Covid-19. Revista Artigos.com, 2021; 27: e7123. 


\title{
DIFERENÇA DE CARGA VIRAL DA COVID-19 ENTRE FLUIDOS SALIVARES E NASOFARÍNGEOS: REVISÃO NARRATIVA
}

\author{
Ana Júlia Alencar Holanda ${ }^{1}$ \\ Elivania Maria Aderita Melo da Silva ${ }^{1}$ \\ Maria Fernanda Muniz Araújo ${ }^{1}$
}

1. Universidade Maurício de Nassau (Uninassau), Olinda - PE.

Palavras-chave: Saliva, COVID-19, Nasofaringe.

\section{INTRODUÇÃO}

A COVID-19 causada pelo vírus SARS-CoV-2 caracteriza-se como infecção respiratória aguda com potencialidade elevada e alto poder de transmissão (BRASIL, 2021). Seus sintomas mais comuns consistem em febre, tosse seca e cansaço, podendo se estender também para perda de olfato e paladar, conjuntivite, congestão nasal, etc. (OPAS, 2021). Pode ser detectada através da coleta de amostras contendo secreções e fluidos para análise e diagnósticos, sendo um dos principais exames o RT-PCR, visto que identifica o material genético do vírus através da recolha de secreção orofaríngea, nasal ou escarro, além de testes sorológicos que avaliam a presença de anticorpos no sangue (BRASIL, 2020).

\section{OBJETIVO}

Revisar a literatura científica com o objetivo de comparar a diferença de cargas virais da COVID-19 detectadas entre amostras de fluidos nasofaríngeos e salivares a fim de estabelecer protocolos de coleta de amostras mais eficazes e menos invasivos.

\section{REVISÃO BIBLIOGRÁFICA}

Em um estudo utilizando o método de Fisher, dez amostras nasofaríngeas e orofaríngeas apresentaram maior sensibilidade de 90 e 100\% com área de curva 0,950 e 1,000, seguidamente, e detecção de casos verdadeiramente positivos para COVID-19 quando comparadas à saliva que detectou apenas três com sensibilidade de 30\% (LOSADA CG, et al., 2021).

Outro estudo realizado com a coleta de salivas e swabs nasofaríngeos demonstrou que a saliva apresentou maior sensibilidade, porém uma carga viral inferior quando comparada aos materiais nasofaríngeos relacionados aos dias iniciais dos sintomas (JUSTO AF, et al., 2021).

Por fim, um outro estudo também realizado para comparar a amostra salivar com a nasofaríngea através do teste da reação em cadeia da polimerase da transcriptase reversa (RT-PCR) demonstrou que a saliva oferta a mesma possibilidade e sensibilidade de detecção do vírus da região nasofaríngea com vantagem pela facilidade da coleta (FERNÁNDEZ FP, et al., 2020). 


\section{CONSIDERAÇÕES FINAIS}

Torna-se evidente, portanto, que ainda não existe um consenso sobre a carga viral do COVID-19 entre amostras nasofaríngeas e salivares. Dessa forma, há a necessidade de continuidade de estudos com a saliva a fim de compreender sua eficácia visto que sua coleta não é incômoda nem invasiva e diminuindo a exposição do profissional de saúde ao vírus.

\section{REFERÊNCIAS}

1. FERNÁNDEZ FP, et al. Comparación de la Muestra Salival y de Nasofaringe en la Detección de SARSCoV-2 mediante RT-PCR. International journal of odontostomatology, 2020; 14: 4.

2. JUSTO AF, et al. Comparison of viral load between saliva and nasopharyngeal swabs for SARS-CoV2: the role of days of symptoms onset on diagnosis. Memórias do Instituto Oswaldo Cruz [online], 2021; 116: e210018.

3. LOSADA CG, et al. Comparison between nasopharyngeal swabs and saliva as reliable specimens for the diagnosis of SARS-CoV-2. Revista Habanera de Ciencias Médicas, 2021; 20(3): e3745. 


\title{
EXPANSÃO DA CHIKUNGUNYA: NOVAS ESPÉCIES DE CULICÍDEOS INFECTADOS NO BRASIL
}

\author{
Hilia Duane Alves Cardoso ${ }^{1}$ \\ Luanny Emanuelly Araújo Gomes ${ }^{1}$ \\ Bárbara do Nascimento Pereira ${ }^{1}$ \\ Temistocles Italo de Santana ${ }^{1}$
}

1. Faculdade Maurício de Nassau (UNINASSAU), Petrolina - PE.

Palavras-chave: Chikungunya, Arbovírus, Culicidae.

\section{INTRODUÇÃO}

O Chikungunya (CHIKV) é um vírus de RNA de fita única e senso positivo e é pertencente ao gênero Alphaviridae (VU DM, et al., 2017). Assim como o vírus da Dengue (DENV), Zika (ZIKV) e Febre amarela (YFV), o vírus da Chikungunya representa um grande desafio a saúde pública do Brasil, e isso ocorre devido à diversidade de espécies de Culicidae (artrópodes transmissores como o Aedes aegypti) que habitam os diferentes biomas brasileiros causando epidemias e altas taxas de casos fatais. A doença causada pelo CHIKV é caracterizada por quadros de febre associados a dor articular, erupções cutâneas e outros sintomas. Tal infecção pode se apresentar na forma aguda, subaguda e crônica (XIMENES M, et al., 2020; DAVID M, et al, 2017).

\section{OBJETIVO}

Revisar, por meio de uma análise da literatura, a expansão do vírus CHIKV através de transmissão horizontal e vertical a partir de outras espécies de insetos do mesmo gênero que foram infectados.

\section{REVISÃO BIBLIOGRÁFICA}

Em um dos artigos pesquisados, os autores fizeram a captura de mosquitos em um parque brasileiro que abriga uma valiosa fauna e flora com mais de 350 espécies nativas de plantas herbáceas e arbóreas. Dentre os achados, foi constatado que 5 espécies de mosquitos da família Culicidae foram capturados continham o vírus da Chikungunya, sendo eles fêmeas de: Wyeomyia bourrouli, Aedes albopictus, Aedes fluviatilis e Aedes aegypti e machos de Aedes albopictus. Os mosquitos foram coletados em 8 locais diferentes no mesmo parque, onde houve relatos de pessoas infectadas.

A transmissão horizontal do CHIKV é uma das formas pelas quais o vírus permanece na natureza, entretanto, a partir desse estudo nota-se que também deve haver uma expansão vertical, tendo em vista que, a priori, apenas Aedes aegypti ou Aedes albopictus fêmeas transmitiam o vírus. Os achados reforçam a hipótese de que a expansão global dos arbovírus está associada a outras espécies de mosquitos nas áreas de transmissão, principalmente do CHIKV (XIMENES M, et al., 2020). Felizmente, atualmente existem 
inúmeros estudos promissores que possuem como objetivo identificar possíveis alvos terapêuticos e medidas de prevenção contra essa doença que tanto preocupa as autoridades mundiais (ROBIN B, 2021).

\section{CONSIDERAÇÕES FINAIS}

Noventa por cento dos arbovírus conhecidos por causar doenças em humanos são transmitidos por mosquitos, e sabendo que o quadro articular crônico produzido pela infeção causada pelo vírus da chikungunya interfere na qualidade de vida do indivíduo, causando impactos econômicos significativos, fazse necessária a consideração e reavaliação de políticas ambientais e saúde pública, bem como o aumento de estudos sobre o vírus e relação vírus-mosquito.

\section{REFERÊNCIAS}

1. DAVID M, et al. Chikungunya Virus, Chikungunya Virus, Clinics in Laboratory Medicine, 2017; 37: 371-382.

2. ROBIN B. Selected mosquito-borne illnesses-Chikungunya, Disease-a-Month, 2018; 64: 222-234.

3. XIMENES M, et al. Arbovirus expansion: New species of culicids infected by the Chikungunya virus in an urban park of Brazil. Acta Tropica, 2020; 209. 
RESUMO SIMPLES: Revisão Narrativa

\title{
O PAPEL DO ENFERMEIRO NA EDUCAÇÃO EM SAÚDE SOBRE INFECÇÕES SEXUALMENTE TRANSMISSÍVEIS
}

\author{
Graciele da Silva Carvalho ${ }^{1}$ \\ Victor Guilherme Pereira da Silva Marques ${ }^{1}$ \\ Victor Almeida Brito ${ }^{2}$ \\ Bruno Abilio da Silva Machado ${ }^{1}$
}

1. Centro Universitário do Piauí (UNIFAPI), Teresina - PI.

2. Universidade Brasil (UNIVBRASIL), Teresina - PI.

Palavras-chave: Cuidados de enfermagem, Educação em saúde, Infecções sexualmente transmissíveis.

\section{INTRODUÇÃO}

As Infecções Sexualmente Transmissíveis (IST) são determinadas por mais de 30 agentes etiológicos, a principal forma de transmissão é por relações sexuais, via sanguínea, transmissão vertical, parto e amamentação, essas infecções estão entre os agentes infecciosos mais comuns no mundo e são consideradas um problema de saúde pública (FERREIRA IT, et al., 2018).

Diante disso, acredita-se que a educação em saúde é considerada uma estratégia para diminuir a falta de informação e a ocorrência destas infecções nos pacientes atendidos na atenção básica, por meio de ações como: rodas de conversas, palestras e materiais informativos (CORTEZ EA e SILVA LM, 2017).

\section{OBJETIVO}

Realizar um levantamento bibliográfico sobre as intervenções educativas a serem realizadas pela equipe de enfermagem na estratégia saúde da família sobre IST de acordo com os protocolos estabelecidos pelo ministério da saúde.

\section{REVISÃO BIBLIOGRÁFICA}

O enfermeiro, através de suas habilidades, consegue desenvolver atividades educativas em saúde a partir de seus conhecimentos científicos adquiridos visando uma contribuição efetiva para a proteção da saúde da comunidade adscrita na atenção básica (MATOS JC, et al., 2016). É importante o papel dos profissionais de enfermagem na criação de espaços de discussão sobre sexualidade com as pessoas, aplicando metodologias participativas, capazes de promover reflexão e autonomia para o autocuidado (LEITE AC, et al., 2020).

Neste sentido o profissional no papel de educador em saúde permite que a comunidade possa reconhecer, compreender e interferir em seu desenvolvimento saúde-doença (BATISTA MHJ, et al., 2021). Repara-se então que o enfermeiro possui um papel importante desde a descoberta das IST até a condução final do 
tratamento, com atendimento humanizado, esclarecendo dúvidas, respeitando e preservando a privacidade dos pacientes, buscando a melhor forma para que eles se sintam seguros (SILVA JN, et al., 2018).

\section{CONSIDERAÇÕES FINAIS}

Os profissionais de enfermagem são fundamentais no processo educativo em saúde da comunidade que é atendida na atenção básica, responsáveis por planejar, orientar, tratar e executar atividades para a diminuição de casos. A assistência que o enfermeiro proporciona aos pacientes é de grande importância para fins de previnir e tratar as infecções sexualmente transmissíveis.

\section{REFERÊNCIAS}

1. BATISTA MHJ, et al. Atenção do enfermeiro na educação sexual na adolescência no contexto escolar. Brazilian Journal of Development, 2021; 7(1): 4819-4832.

2. CORTEZ EA, SILVA LM. Pesquisa-ação: promovendo educação em saúde com adolescentes sobre infecção sexualmente transmissível. Revista de Enfermagem UFPE, 2017; 11(9): 3642-3649.

3. FERREIRA IT, et al. Avaliação da qualidade da consulta de enfermagem em infecções sexualmente transmissíveis. Enfermagem Foco, 2018; 9(3): 42-47.

4. LEITE AC, et al. Atribuições do enfermeiro na educação sexual de mulheres adolescentes e a importância do planejamento familiar. Brazilian Journal of Development, 2020; 6(10): 79494-79515.

5. MATOS JC, et at. Atuação da escola na educação sexual de adolescentes: uma revisão integrativa. Revista Eletrônica Gestão e Saúde, 2016; 7(2): 773-792.

6. SILVA JN, et al. Impactos do diagnóstico da infecção sexualmente transmissível na vida da mulher. Enfermagem em Foco, 2018 9(2): 42-47. 


\title{
RASTREAMENTO MAMOGRÁFICO COMO ESTRATÉGIA DA ATENÇÃO PRIMÁRIA NA REDUÇÃO DA MORTALIDADE
}

\author{
Larissa Duarte Costa Gomes ${ }^{1}$ \\ Luísa Lima de Souza e Silva ${ }^{1}$ \\ Thaís Vilela de Pinho Andrade ${ }^{2}$
}

1. Fundação Universidade de Itaúna (UIT), Itaúna - MG.

2. Faculdade de Medicina de Barbacena (FAME), Barbacena - MG.

Palavras-chave: Atenção primária à saúde, Neoplasias da mama, Mamografia.

\section{INTRODUÇÃO}

O câncer de mama é uma doença crônica de alta prevalência entre as mulheres, aproximadamente $8 \% \mathrm{e}$ que representa a causa de morte mais frequente por neoplasia na população feminina brasileira (AZEVEDO A, et al., 2019). A detecção e o tratamento precoce dessa patologia estão relacionados a sua magnitude, sendo um problema de saúde pública no país. Isto ressalta a importância do seu rastreamento, através da mamografia, na atenção básica, como estratégia dirigida às mulheres assintomáticas que visa detectar precocemente tumores ainda em fase pré-clínica, minimizando, assim, a mortalidade (INCA, 2020).

\section{OBJETIVO}

Analisar por meio de uma revisão literária a relevância da mamografia na atenção primária como método de rastreamento na população feminina, para detecção precoce do câncer de mama na redução da mortalidade.

\section{MÉTODO}

Foi realizada uma revisão sistemática nas bases de dados Scientific Electronic Library Online, Biblioteca Virtual em Saúde e PubMed, utilizando os descritores: atenção primária à saúde, neoplasias da mama e mamografia. Foram encontrados 37 resultados, porém após os critérios de exclusão que eliminavam todos os trabalhos com mais de 5 anos, e que não estivessem em línguas inglesa e portuguesa restaram 5 artigos para coleta de dados.

\section{REVISÃO BIBLIOGRÁFICA}

O rastreamento do câncer de mama no Brasil é baseado na realização da mamografia, bienalmente, em mulheres assintomáticas, entre 50 e 69 anos. Há indicativos de que esse exame é capaz de detectar $68 \%$ dos tumores ainda iniciais, menores que $2 \mathrm{~cm}$ (WELCH HG, et al., 2016). A sensibilidade desse rastreamento para lesões benignas alcança $91 \%$, e a especificidade, $63 \%$. Em relação às lesões malignas, esses dados 
são de 57\% e 100\% respectivamente (MAULAZ CA, et al., 2018). Estudos apontam que a mamografia, juntamente aos avanços terapêuticos, é responsável pela redução da mortalidade dessa neoplasia em $30 \%$ (RAMOS ACV, et al., 2018).

\section{CONSIDERAÇÕES FINAIS}

A mamografia, por possuir elevado potencial para detectar precocemente pequenos tumores assintomáticos, promove maior número de opções terapêuticas e aumenta a chance de tratamento conservador para o câncer de mama, minimizando, assim, a necessidade de quimioterapia. Dessa maneira, tem-se como efeito a diminuição do índice de mortalidade, justificando sua realização como importante conduta da atenção básica, cabendo aos médicos dominar essa técnica.

\section{REFERÊNCIAS}

1. AZEVEDO A, et al. O conhecimento de mulheres acerca do rastreamento do câncer de mama e suas implicações. Revista de Medicina, 2019; 98(3): 187-193.

2. INSTITUTO NACIONAL DE CÂNCER JOSÉ ALENCAR GOMES DA SILVA (INCA). Atlas da mortalidade. Rio de Janeiro. $2021 . \quad$ Disponível em: https://www.inca.gov.br/bvscontrolecancer/publicacoes/Atlas\%20de\%20Mortalidade_informativo.pdf. Acessado em: 16 de novembro de 2021.

3. MAULAZ CA, et al. Estudo Comparativo do Desempenho de Imagens por Ressonância Magnética, Mamografia e Ecografiana Avaliação de Lesões Mamárias Benignas e Malignas. Revista Brasileira de Física Médica, 2018; 12(2): 23-29.

4. RAMOS ACV, et al. Estratégia Saúde da Família, saúde suplementar e desigualdade no acesso à mamografia no Brasil. Revista Panam Salud Publica, 2018; 42: 1-9.

5. WELCH HG, et al. Breast-Cancer Tumor Size, Overdiagnosis, and Mammography Screening Effectiveness. New England Journal of Medicine, 2016; 375(15): 1438-1447. 


\title{
A RELAÇÃO ENTRE A FISIOPATOLOGIA DA HEMORRAGIA SUBARACNÓIDEA NÃO TRAUMÁTICA E SEU QUADRO CLÍNICO
}

\author{
Dulcinete Valéria de Albuquerque Ferreira ${ }^{1}$ \\ Nathália Gomes de Lima Beserra ${ }^{1}$ \\ Roberta Simões Guerra ${ }^{1}$ \\ Pedro Henrique Xavier da Cunha ${ }^{1}$
}

1. Faculdade Integrada Tiradentes (FITS), Jaboatão dos Guararapes - PE.

Palavras-chave: Hemorragia subaracnóidea aneurismática, Fisiopatologia, Sinais e sintomas.

\section{INTRODUÇÃO}

A hemorragia subaracnóidea (HSA) não traumática é uma situação clínica que se caracteriza pelo rompimento de um vaso intracraniano. Estima-se que no ano de 2030 os óbitos que são relacionados com doenças cerebrovasculares terão um aumento de 12,1\% aproximadamente pelo índice de morte mundial, segundo a Organização mundial de saúde (GODEGUEZ TS e WATERS C, 2019).

Quando se tem a ruptura de uma artéria tem-se uma coleção de sangue no espaço subaracnóide. Essa anormalidade pode ser devido a várias causas, inclusive um aneurisma cerebral em que corresponde a $80 \%$ das causas. Os aneurismas do tipo sacular têm uma prevalência maior no Polígono de Willis (ALCÂNTARA IHA, et al., 2019).

\section{OBJETIVO}

Pesquisar e analisar a literatura existente acerca da relação da fisiopatologia com o quadro clínico na hemorragia subaracnóide não traumática, com ênfase em descrever como se dá a apresentação clínica da doença.

\section{MÉTODO}

Trata-se de uma revisão integrativa, com questão de pesquisa: "Qual a fisiopatologia da hemorragia subaracnóidea no contexto da sua apresentação clínica? " Critérios de Inclusão: artigos a partir do ano de 2019, em inglês, português e espanhol, nas bases de dados Biblioteca Virtual de Saúde (BVS) e Acervo+. Descritores: Hemorragia Subaracnóidea Aneurismática; Fisiopatologia; Sinais e Sintomas, na BVS encontrouse com critérios 48 e a Acervo+ 29 (artigo e classificação por relevância).

\section{REVISÃO BIBLIOGRÁFICA}


Aneurismas Cerebrais são dilatações anormais nas bifurcações de um vaso arterial. O local mais acometido no encéfalo é o Polígono de Willis e seus principais ramos, quando estes sofrem uma ruptura por um estresse hemodinâmico, se manifestam em importantes sintomatologias (JUNIOR ATS, et al., 2019).

A Cefaleia Holocraniana é a mais frequente, em que mesmo ao uso de analgesia não cessa. Outros sintomas clínicos associados são vômitos, perda da consciência, déficit motor, rigidez de nuca e fotofobia (JUNIOR ATS, et al., 2019; ALCÂNTARA IHA, et al., 2019). O nível de comprometimento neurológico pode ser descrito na escala de coma de Glasgow e Escala de Hunt-Hess (JUNIOR ATS, et al., 2019).

\section{CONSIDERAÇÕES FINAIS}

O paciente com HSA não traumática tem vários aspectos na sintomatologia, por isso é necessário avaliar a localização do vaso acometido para se ter menos repercussões clínicas. É primordial também, se ter um conhecimento de como ocorrem os sintomas característicos e aplicar escalas para estratificar o nível de evolução do paciente e estabelecer um prognóstico adequado ao paciente.

\section{REFERÊNCIAS}

1. ALCÂNTARA IHA, et al. Abordagem de aneurismas intracranianos em um hospital do baixo Amazonas. Revista Eletrônica Acervo Saúde, 2019; Sup.36: e1623.

2. JUNIOR ATS, et al. Estudo Retrospectivo: Prevalência de aneurismas cerebrais por topografia vascular no hospital evangélico goiano. Revista Brasileira de Neurologia e Psiquiatria, 2019; 8(3): e209-223.

3. GODEGUEZ TS, WATERS C. Perfil epidemiológico e assistência de enfermagem a pacientes com aneurisma cerebral: uma pesquisa bibliográfica. Brazilian Journal of health Review, 2019; 2(2): 2049-2077. 


\title{
POTENCIALIDADE DO USO DA FOLHA DA ESTÉVIA NO DESENVOLVIMENTO DE PRODUTOS PARA CONTROLE DE DOENÇAS CRÔNICAS NÃO TRANSMISSÍVEIS: UMA REVISÃO
}

\author{
Lílian Pereira e Silva ${ }^{1}$ \\ Keila Cristiane Batista Bezerra ${ }^{1}$
}

Liejy Agnes dos Santos Raposo Landim ${ }^{1}$

1. Centro Universitário Santo Agostinho (UNIFSA), Teresina - PI.

Palavras-chave: Estévia, Antioxidante, Doença crônica.

\section{INTRODUÇÃO}

As folhas de estévia apresenta crescimento exponencial de utilização para o desenvolvimento de produtos alimentícios que podem favorecer a saúde, na prevenção e tratamento de doenças crônicas não transmissíveis (DCNT). Agrega valor nutricional e funcional capazes de intervir dieteticamente como substituto do açúcar, visando ampliação de novos produtos e garantindo funcionalidade (KHIRAOUI A, et al., 2017), contra a crescente prevalência das doenças crônicas cujo os fatores estão associados à hábitos alimentares inadequados do consumo excessivo de alimentos ultraprocessados com alto teor de gorduras saturadas, açucarados, e pobre nutricionamente (RIBEIRO DDOSS, et al., 2018).

\section{OBJETIVO}

Realizar uma revisão integrativa bibliográfica, para avaliar a potencialidade do uso da folha estévia no desenvolvimento de produtos no controle de doenças crônicas não transmissíveis.

\section{MÉTODO}

Trata-se de uma revisão da literatura integrativa. A busca dos artigos foi realizada nas bases de dados: Scielo, PUBMED e Google Acadêmico, foram cadastrados nos Descritores em Ciência da Saúde (DeCS). "Estévia", "Antioxidante", "Doença crônica". Os critérios de inclusão foram artigos originais, nos idiomas português e inglês; publicados entre os anos de 2017 a 2021. Os critérios de exclusão foram publicações de artigos não relacionados ao tema.

\section{REVISÃO BIBLIOGRÁFICA}

As folhas da estévia obtiveram utilização no desenvolvimento de produtos murffi, adoçante, como também potencial ação na redução glicemia, redução do esvaziamento gástrico, e o aumento da saciedade (GAO J, et al., 2019). Além disso, foi possível verificar sua ação agindo significativamente na doença renal crônica associado à hipertensão e o diabetes, apresentando diminuição da sintomatologia (RIZWAN F, et al., 2018). Em relação a variedade de produtos alimentícios, podem ser desenvolvidos a partir da sua inclusão somando- 
se boa aceitabilidade, e qualidade sensorial se sobressaindo aos produtos já existentes no mercado e seus respectivos benefícios (ALI AM, et al.,2021).

\section{CONSIDERAÇÕES FINAIS}

Com base nos estudos apresentados, pode-se observar que as folhas de estévia podem ser incorporadas na alimentação para desenvolvimento de produtos, mostrando-se ser uma importante opção como substituto do açúcar garantido funcionalidades na atenuação diversas doenças crônicas, mantendo suas ações já citadas, como também propriedades físico-químicas e ópticas adequadas, alto grau de estabilidade, baixo valor calórico, fonte proteica de fibras e minerais.

\section{REFERÊNCIAS}

1. ALI AM, et al., Producing and Quality Attributes of Low Calories Dark Chocolate Using Different Intense sweeteners and Wheat Fiber Isolate. American Journal of Food Science and Technology, 2021; 1:1-7.

2. GAO J, et al., The Potential of Modulating the Reducing Sugar Released (and the Potential Glycemic Response) of Muffins Using a Combination of a Stevia Sweetener and Cocoa Powder. †Foods, 2019; 8: (644).

3. KHIRAOUI A, et al., Nutritional and biochemical properties of natural sweeteners of six cultivars of Stevia rebaudiana Bertoni leaves grown in Morocco. JMES, 2017; 8: 1015-1022.

4. RIBEIRO DDOSS, et al., Avaliação nutricional e prevalência de doenças crônicas não transmissíveis em um grupo de terceira idade de um centro comunitário de Salvador-BA como elemento de gestão em saúde. Revista UNILUS Ensino e Pesquisa, 2018; 15(38).

5. RIZWAN F, et al., Preliminary analysis of the effect of Stevia (Stevia rebaudiana) in patients with chronic kidney disease (stage I to stage III). Contemp Clin Trials Commun, 2018; 21: 17-25. 
RESUMO SIMPLES: Revisão Integrativa

\title{
O REFLEXO DAS MÍDIAS SOCIAIS NOS TRANSTORNOS DE IMAGEM CORPORAL EM MULHERES
}

\author{
Noeme Agostinho Rocha ${ }^{1}$ \\ Ana Beatriz Ribeiro Queiroz ${ }^{2}$ \\ Dandara Lima Santos ${ }^{2}$ \\ Anna Beatriz Conceição de Souza ${ }^{2}$ \\ Mayla Karla de Souza Monteiro ${ }^{3}$
}

1. Universidade da Amazônia (UNAMA), Ananindeua - PA.

2. Universidade Federal do Pará (UFPA), Belém - PA.

3. Universidade da Amazônia (UNAMA), Belém - PA.

Palavras-chave: Autoimagem, Mídias sociais, Mulheres.

\section{INTRODUÇÃO}

A imagem corporal trata-se da percepção de como o indivíduo se enxerga sobre os aspectos físico e mental. No entanto, apesar de ser uma representação individual, sua construção pode ser influenciada por variados fatores externos, com destaque para a mídia (LIRA AG, et al., 2017). Nesse contexto, aponta-se a mídia social como importante disseminador de padrões corporais que se distanciam da realidade corporal da maioria da população, em especial mulheres. Dessa forma, a não adequação ao padrão de beleza propagado pelas redes sociais pode gerar insatisfações referentes à imagem corporal nas mulheres, resultando em maior suscetibilidade a transtornos de autoimagem (MCCOMB SE, et al., 2021).

\section{OBJETIVO}

Avaliar através da revisão literária o reflexo das mídias sociais com o seu predomínio no público feminino e como isso tem sido fator primordial para o desenvolvimento dos transtornos de autoimagem.

\section{MÉTODO}

Trata-se de uma pesquisa de revisão integrativa. Para isso, foi realizada uma busca nas bases de dados Scielo, BvS e Pubmed no período do mês de setembro. Procedeu-se a análise de 4 artigos publicados nos últimos 5 anos no idioma português e inglês, excluindo aqueles que não atendessem a temática proposta. Os descritores utilizados foram: mulheres, mídias sociais, redes sociais, imagem corporal e autoimagem.

\section{REVISÃO BIBLIOGRÁFICA}

A internalização de um padrão corporal provoca uma busca incessante pelo alcance de uma imagem aceitável pela sociedade, isso é reforçado por comentários e julgamentos de pessoas do próprio círculo social, 
favorecendo a insatisfação corporal, sobretudo nas mulheres, podendo agravar-se a distúrbios de imagem (HOGUE JV e MILLS JS, 2019).

Ademais, a mídia fortalece padrões de beleza, além de reforçar a ideia de que o emagrecimento é um objetivo e uma necessidade em comum a todas as mulheres (ECKLER P, et al., 2016). Nesse sentido, a comparação feita com imagens irrealistas afeta a autoestima, prejudica a saúde mental e estimula comportamentos desordenados com a alimentação (MCCOMB SE, et al., 2021).

\section{CONSIDERAÇÕES FINAIS}

Portanto, a auto idealização de um corpo visto nas mídias de comunicação, acaba aumentando as insatisfações corpóreas das mulheres; o predomínio da utilização de mídias sociais que estimula a propagação de imagens irreais, acarreta transtorno de autoimagem, para assim tentar satisfazer esses padrões visto nas redes sociais.

\section{REFERÊNCIAS}

1. ECKLER $P$, et al. Facebook use and negative body image among U.S. college women. Women \& Health, 2016; 57: 249-267.

2. HOGUE JV, MILLS JS. The effects of active social media engagement with peers on body image in young women. American Psychological Association, 2019; 28: 1-5.

3. LIRA AG, et al. Uso de redes sociais, influência da mídia e insatisfação com a imagem corporal de adolescentes brasileiras. Jornal Brasileiro de Psiquiatria, 2017; 66(3).

4. MCCOMB SE, et al. The effects of self-disclaimer Instagram captions on young women's mood and body image: The moderating effect of participants' own photo manipulation practices. Elsevier, 2021; 38: 251261. 


\title{
AVALIAÇÃO DOS EFEITOS DA APLICAÇÃO DO LASER DE BAIXA FREQUÊNCIA EM PACIENTES PORTADORES DE PÉ DIABÉTICO
}

\author{
Maria Eugênia Dias Cruz 1 \\ Ana Carolina Campos Barbosa Soares² \\ Geraldo Darci Ribeiro Soares ${ }^{2}$ \\ Joanilva Ribeiro Lopes $^{3}$
}

1. Faculdades Unidas do Norte de Minas (FUNORTE), Montes Claros - MG.

2. Centro Universitário FIPMoc (UNIFIPMoc), Montes Claros - MG.

3. Universidade Estadual de Montes Claros (UNIMONTES), Montes Claros - MG.

Palavras-chave: Laser, Úlcera, Diabetes.

\section{INTRODUÇÃO}

O Diabetes Mellitus (DM) é uma patologia em que há defeito na produção de insulina pelo pâncreas e na sua absorção pelos tecidos, caracterizando-se tipo 1 e 2 respectivamente. Essa doença afeta cerca de 50 milhões de pessoas no mundo, das quais $90 \%$ possui DM tipo 2 . Suas complicações são diversas, sendo a mais comum, o pé diabético, uma úlcera crônica que implica significativamente numa pior qualidade de vida do seu portador, acarretando perda funcional por consequentes amputações e invalidez (GÓIS JPSG e CHAVES ASC, 2020; IDF, 2021). Assim, medidas inovadoras têm sido propostas no tratamento do pé diabético, como a terapia com laser de baixa frequência.

\section{OBJETIVO}

Reunir dados na literatura pregressa acerca do papel do laser de baixa frequência no manejo do paciente portador de pé diabético, evidenciando seus principais efeitos e o seu impacto na qualidade de vida.

\section{REVISÃO BIBLIOGRÁFICA}

Estudo realizado com a aplicação do laser de baixa frequência em área perilesional resultou em aumento da concentração de hemoglobina total e ampliação da microcirculação sanguínea periférica, com consequente aumento da temperatura tecidual. Tal aumento evidenciado após a aplicação do laser é responsável por estimular a liberação de fatores de crescimento na circulação, provável justificativa para a diminuição da dor neuropática queixada pela maioria dos pacientes portadores de pé diabético (SALVI M, et al., 2017).

Além da analgesia, outro estudo documentou resultados satisfatórios da terapia com laser de baixa frequência associada ao óleo de Calêndula, quando comparado ao tratamento tradicional com assepsia, tal 
modalidade surtiu efeitos anti-inflamatórios e cicatrizantes, com diminuição significativa das lesões e impedindo a evolução destas, minimizando amputações (CARVALHO AFM, et al., 2016).

Outro ponto observado foi a possibilidade de correção do endotélio vascular lesionado devido aos efeitos adversos da hiperglicemia quando submetido ao laser no comprimento de onda de 830 nanômetros, além da redução da concentração do fator de necrose tumoral alfa (TNF-alfa) no tecido acometido após a aplicação (GÓRALCZYK K, et al., 2016).

\section{CONSIDERAÇÕES FINAIS}

O uso isolado da terapia com laser de baixa frequência evidenciou, nos pacientes portadores de pé diabético, efeito analgésico e cicatrizante, aumento da concentração da hemoglobina total e da volemia, redução na concentração do TNF-alfa e consequente correção do endotélio vascular lesionado. A cicatrização também foi benéfica e otimizada na associação do laser ao óleo de Calêndula. Todavia, novos estudos são necessários para constante atualização e descoberta de novos efeitos.

\section{REFERÊNCIAS}

1. CARVALHO AFM, et al. Terapia a laser de baixa intensidade e Calendula officinalis no reparo de úlcera em pé diabético. Revista da Escola de Enfermagem da USP, 2016; 50(4): 628-634.

2. GOIS JPSG, CHAVES ASC. Pé diabético: avaliação dos fatores de risco relacionados a amputações maiores e menores. Revista Eletrônica Acervo Saúde, 2020; 12(1): e1484.

3. GÓRALCZYK K, et al. Low-level laser irradiation effect on endothelial cells under conditions of hyperglycemia. Lasers Med Sci, 2016; 31: 825-831.

4. INTERNATIONAL DIABETES FEDERATION (IDF). The Diabetic Foot. 2021. Disponível em: https://www.idf.org/our- activities/care-prevention/diabetic-foot.html. Acessado em: 28 de setembro de 2021.

5. SALVI M, et al. Effect of low-level light therapy on diabetic foot ulcers: a near-infrared spectroscopy study. Journal of biomedics optic, 2017; 22(3). 
RESUMO SIMPLES: Revisão Integrativa

\title{
O USO DA ACUPUNTURA NA DIMINUIÇÃO DA DOR EM IDOSOS COM ARTRITE REUMATOIDE: REVISÃO INTEGRATIVA
}

\author{
Bruno Morais Kos ${ }^{1}$ \\ Ketry Williene Ribeiro da Silva² \\ Sanara Carvalho $\mathrm{Abade}^{3}$ \\ Cintia Carolina Silva Gonçalves ${ }^{3}$
}

1. Centro Universitário Santo Agostinho (UNIFSA), Teresina - PI.

2. Universidade Federal da Bahia (UFBA), Salvador - BA.

3. Universidade Salvador (UNIFACS), Salvador - BA.

Palavras-chave: Terapias complementares, Paciente, Artrite reumatoide.

\section{INTRODUÇÃO}

As Práticas Integrativas e Complementares (PICS) são meios de tratamentos com base em medicinas tradicionais, destinadas a melhora dos sintomas de paciente com doenças crônicas (MARQUES PP, et al., 2020). Dentre as PICS que podem ser utilizadas, a acupuntura é realizada por meio da inserção de agulhas em pontos específicos do corpo, com intuito de equilibrar energias, prevenir disfunções, doenças no corpo e na mente (RAMOS A, et al., 2018). A sua aplicação clínica pode ser feita em casos de dores e processos inflamatórios, em geral manifestações clínicas encontrada na artrite reumatoide (RANI M, et al., 2020).

\section{OBJETIVO}

Revisar a literatura científica acerca de evidências sobre a aplicação da acupuntura como prática integrativa norteadora para o tratamento destinado à diminuição da dor que acomete o paciente idoso portador de artrite reumatoide.

\section{MÉTODO}

Trata-se de uma revisão integrativa da literatura realizada nas bases de dados Lilacs, Science Direct e na biblioteca eletrônica SciELO, utilizando os seguintes descritores: idoso AND terapias complementares AND artrite reumatoide. Os critérios de inclusão foram estudos primários, livres e publicados nos últimos 5 anos, sendo excluídos estudos incompletos, revisões de literatura e não relacionado ao tema. Foram encontrados 534 estudos, sendo selecionados apenas 7 artigos legíveis para análise.

\section{REVISÃO BIBLIOGRÁFICA}


Em um estudo de campo, evidenciou que a acupuntura promoveu relaxamento, diminuindo a rigidez das articulações e produzindo ganhos para a função articular e motora (MOHABBAT AB, et al., 2019). Em outro estudo, verificou-se que dos 23.815 participantes, 22,2\% usavam acupuntura, prevalecendo ao sexo feminino. Houve maior proporção de idosos com artrite reumatoide, fazendo uso desta PIC como forma de atenuar sintomas que refletem no seu bem-estar (MARQUES PP, et al., 2020). Em outro estudo de campo, verificouse que a acupuntura foi utilizada como terapia adjuvante em combinação com o tratamento farmacológico vigente, auxiliando na redução da dor (RANI M, et al., 2020).

\section{CONSIDERAÇÕES FINAIS}

Diante dos estudos apresentados, demonstra-se que o uso da acupuntura destinada à redução da dor é significante, visto que melhora o bem-estar, qualidade de vida e mobilidade das articulações. São necessários mais estudos clínicos para elucidar a ação benéfica da acupuntura em conjunto com tratamentos farmacológicos para artrite reumatoide.

\section{REFERÊNCIAS}

1. MARQUES PP, et al. Uso de Práticas Integrativas e Complementares por idosos: Pesquisa Nacional de Saúde 2013. Saúde em Debate, 2020; 44: 845-856.

2. MOHABBAT AB, et al. Use of complementary and integrative therapies by fibromyalgia patients: a 14-year follow-up study. Mayo Clinic Proceedings: Innovations, Quality \& Outcomes, 2019; 3(4): 418-428.

3. RAMOS A, et al. Acupuntura para o tratamento da artrite reumatóide. Medwave, 2018; 18(06): e7273.

4. RANI M, et al. Acupressure as an Adjunct to Pharmacological Treatment for Depression, Anxiety, and Stress in Patients with Knee Osteoarthritis. Journal of acupuncture and meridian studies, 2020; 13(4): 129135. 


\title{
ASSISTÊNCIA E CUIDADOS DE ENFERMAGEM AO RECÉM-NASCIDO PREMATURO E A SUA FAMÍLIA
}

\author{
Angelica Ribeiro do Nascimento Oliveira ${ }^{1}$ \\ Thiemmy de Souza Almeida Guedes ${ }^{2}$ \\ Francisco Lucas Leandro de Sousa ${ }^{3}$ \\ Victória de Souza Nery ${ }^{4}$ \\ Caroline Taiane Santos da Silva ${ }^{5}$
}

1. Centro Universitário Maurício de Nassau (UNINASSAU), Teresina - PI.

2. Faculdade Venda Nova do Imigrante (FAVENI), Campina Grande - PB.

3. Faculdade São Franciscco da Paraíba (FASP), Cajazeiras - PB.

4. Centro Universitário Maurício de Nassau (UNINASSAU), Fortaleza - CE.

5. Escola Bahiana de Medicina e Saúde Pública (EBMSP), Salvador - BA.

Palavras-chave: Enfermagem, Assistência, Prematuridade.

\section{INTRODUÇÃO}

A prematuridade no Brasil tem uma taxa elevada, o país está entre os dez com maior taxa de nascidos vivos prematuros. A prematuridade e um fator de risco para mortalidade neonatal com um percentual de $75 \%$, e uma das estratégias para diminuir esses índices é a assistência e os cuidados ao recém-nascido e a sua família durante e após um parto prematuro inevitável (da SILVA KM, 2019).

Os cuidados com a mãe durante o pré-natal são fundamentais para o combate aos nascimentos precoces, pois através dessa assistência o profissional fará a identificação dos riscos gestacionais para o nascimento prematuro, o tratamento das intercorrências e um acompanhamento complexo (OLIVEIRA LL, 2016).

\section{OBJETIVO}

Descrever através da revisão literária de estudos científicos os cuidados, e a assistência prestada pelos profissionais da equipe de enfermagem com o recém-nascido prematuro e sua família diante da prematuridade.

\section{MÉTODO}

Revisão integrativa, selecionando artigos publicados nas bases de dados LILACS, PUBMED e MEDLINE, utilizando os descritores: Enfermagem, Assistência e Prematuridade. Com isso, foram selecionados 3 artigos por se enquadrarem nos propósitos dessa revisão. Critérios de Inclusão: artigos que abordassem a temática 
em português e inglês, publicados nos últimos 5 anos; e de exclusão: literatura cinzenta e artigos que não abordassem a temática.

\section{REVISÃO BIBLIOGRÁFICA}

Os profissionais de enfermagem agem avaliando constantemente o bebê através do padrão respiratório, padrão alimentar, atuam no controle de peso até chegar ao peso adequado, verificam risco de aspiração ao sugar, hidratação adequada, no controle da temperatura corporal, analisam riscos de infecções, integridade da pele do bebê, ajudam a fortalecer o vínculo do binômio mãe-filho, além de estabelecer estratégias que visem a manutenção da vida do recém-nascido no meio familiar (da SILVA KM, 2019).

A enfermagem tem como aliado nesses cuidados ao recém-nascido o método Canguru que contribui na prestação dos cuidados e assistência direcionada aos recém-nascidos e famíliares, permitindo que todos sejam acolhidos (STELMAK AP, et al., 2017).

\section{CONSIDERAÇÕES FINAIS}

Diante do exposto, fica evidenciado a importância da equipe de enfermagem nos cuidados do prematuro e orientações para a família. Fica claro ainda, a importância de implementação de programas educacionais para capacitação da equipe dos profissionais para que possam identificar os riscos de prematuridade e intervindo com tratamento adequado ou encaminhando para áreas de cuidados complexos caso necessário.

\section{REFERÊNCIAS}

1. da SILVA KM. Assistência de enfermagem ao RN prematuro e a família: uma revisão da literatura. Itinerarius Reflectionis, 2019; 15(3): 01-20.

2. OLIVEIRA LL. Fatores maternos e neonatais relacionados à prematuridade. Revista da Escola de Enfermagem da USP, 2016; 50(3): 382- 389.

3. STELMAK AP, et al. O valor atribuído pelos profissionais de enfermagem aos cuidados preconizados pelo método canguru. Revista de enfermagem UFPE on line, 2017; 3376-3385. 


\title{
AS ESTRATÉGIAS DE HUMANIZAÇÃO DA ASSISTÊNCIA AO PARTO UTILIZADAS POR ENFERMEIROS
}

\author{
Angelica Ribeiro do Nascimento Oliveira ${ }^{1}$ \\ Thiemmy de Souza Almeida Guedes ${ }^{2}$ \\ Francisco Lucas Leandro de Sousa ${ }^{3}$ \\ Victória de Souza Nery ${ }^{4}$ \\ Caroline Taiane Santos da Silva ${ }^{5}$
}

1. Centro Universitário Maurício de Nassau (UNINASSAU), Teresina - PI.

2. Faculdade Venda Nova do Imigrante (FAVENI), Campina Grande - PB.

3. Faculdade São Francisco da Paraíba (FASP), Cajazeiras - PB.

4. Centro Universitário Maurício de Nassau (UNINASSAU), Fortaleza - CE.

5. Escola Bahiana de Medicina e Saúde Pública (EBMSP), Salvador - BA.

Palavras-chave: Parto humanizado, Assistência de enfermagem, Cuidados de enfermagem.

\section{INTRODUÇÃO}

O Ministério da Saúde vem implementando políticas públicas de saúde que consistem em melhorias no processo de humanização durante o parto, com esse intuito foi instituída a rede cegonha no âmbito do Sistema Unico de Saúde-SUS e atenção primaria, na qual programam todos os cuidados e direitos das mulheres desde o pré-natal, parto ao puerpério (FURLAN CB e VIEIRA HWD, 2019). As boas práticas de humanização têm início durante as consultas de pré-natal através do acolhimento, orientações e atividades educativas desenvolvidas com a mulher pelos profissionais de enfermagem (JORGE HMF, et al., 2020).

\section{OBJETIVO}

Identificar através da revisão literária de estudos científicos, as estratégias de humanização da assistência ao parto utilizadas pelos profissionais da equipe de enfermagem para tornar o parto mais leve e seguro.

\section{MÉTODO}

Revisão integrativa, selecionando artigos publicados nas bases de dados LILACS, PUBMED e MEDLINE, utilizando os descritores: Parto humanizado, assistência de enfermagem e cuidados de enfermagem. Com isso, foram selecionados 3 artigos por se enquadrarem nos propósitos dessa revisão. Critérios de Inclusão: artigos que abordassem a temática em português e inglês, publicados nos últimos 5 anos; e de exclusão: literatura cinzenta e artigos que não abordassem a temática. 


\section{REVISÃO BIBLIOGRÁFICA}

Os profissionais de enfermagem devem promover o autoconhecimento da mulher para que ela venha a conhecer seus próprios limites e respeita-los, além de dar apoio e atenção através de diálogo e acolhimento para enfrentar situações de medo durante o parto, passando segurança e conforto (ALMEIDA RSS, et al., 2020).

São essenciais as técnicas não farmacológicas utilizadas nesse processo de humanização, passam segurança e conforto para parturiente, as mais utilizadas são musicoterapia, massagem, técnicas de relaxamento, exercícios respiratórios, e escolha da posição dando autonomia à mulher (HANUM SP, et al., 2017). Cita-se ainda, cavalinho, penumbra, o acompanhante e posições de cócoras para o desenvolvimento seguro e humanizado do parto (VIANA RR, et al., 2019).

\section{CONSIDERAÇÕES FINAIS}

Diante do exposto, pôde-se perceber que o trabalho de parto normal vai além das técnicas e exige preparo e conhecimento por parte da equipe para desempenhar uma assistência de forma holística e humanizada. Devendo entender as necessidades de cada mulher dando apoio e utilizando técnicas que tornem esse momento de parto tão aguardado especial dando autonomia a mulher e tendo empatia, algo que se faz fundamental no processo de humanização.

\section{REFERÊNCIAS}

1. ALMEIDA RSS, et al. Vivências de puérperas frente à atuação da equipe de enfermagem durante o trabalho de parto. Revista de Pesquisa Cuidade é Fundamental Care Online, 2020; 12: 345-349.

2. FURLAN CB, VIEIRA HWD. Parto humanizado de uma residente em enfermagem obstétrica: um relato de experiência. REVISA, 2019; 8(4): 518-24.

3. HANUM SP, et al. Estratégias não farmacológicas para o alivio da dor no trabalho de parto: efetividade sob a ótica da parturiente. Revista de enfermagem UFPE online, 2017; 11(Supl. 8): 3303-9.

4. JORGE HMF, et al. Humanized care in high-risk prenatal care: nurses' perceptions. Revista da Rede de enfermagem Nordeste, 2020; 21: e44521.

5. VIANA RR, et al. Assistência de enfermagem ao parto humanizado: vivência de extensionistas. Saúde em redes, 2019; 5(3). 


\title{
A ABORDAGEM DE PACIENTES COM TRANSTORNO OBSESSIVO-COMPULSIVO (TOC): UMA REVISÃO NARRATIVA
}

\author{
Arthur de Morais e Silva ${ }^{1}$ \\ Felipe Nilson Santiago Galiza ${ }^{1}$ \\ Mariana Beatriz Pontes Rangel de Carvalho ${ }^{1}$ \\ Jullyane Beatriz Gomes de Lima ${ }^{1}$ \\ Djane Muniz de Morais²
}

1. Faculdade Integrada Tiradentes (FITS), Jaboatão dos Guararapes - PE.

2. Universidade Federal de Pernambuco (UFPE), Recife - PE.

Palavras-chave: Obsessão, Compulsão, Terapia cognitivo-comportamental.

\section{INTRODUÇÃO}

O Transtorno Obsessivo-Compulsivo (TOC) é uma desordem mental que tem como base a compulsão e/ou a obsessão de caráter recorrente em que há prejuízo nas atividades de vida diárias do paciente. As obsessões são pensamentos persistentes, sendo intrusivos e não desejados, causando sofrimento ao paciente. Normalmente para neutralizar a obsessão os pacientes usam a compulsão, definida por atos práticos ou mentais repetitivos com o objetivo de diminuir o desconforto do pensamento. Dessa forma, notase que se forma um ciclo vicioso mental e/ou prático que atrapalha a vida do paciente em suas atividades de vida diárias, devendo ser tratada o mais precocemente possível (PETERSEN ML, 2019).

\section{OBJETIVO}

Analisar a abordagem de pacientes com TOC no âmbito farmacológico e psicoterápico, revisando a literatura e abordando as melhores condutas terapêuticas na remissão do transtorno e retomada da independência do paciente sem o prejuízo nas atividades de vida diárias.

\section{REVISÃO BIBLIOGRÁFICA}

Em um estudo que analisa o uso da Terapia Cognitivo-Comportamental (TCC) associada à Exposição e Prevenção de Resposta (EPR) notou-se que os pacientes têm uma resposta muito boa, normalmente igual ou levemente superior ao uso dos antidepressivos Inibidores Seletivos de Recaptação da Serotonina (ISRS) (PETERSEN ML, 2019).

Em outro estudo sobre o tratamento com a terapia psicanalítica, vê-se que esta trata a base do TOC, que pelas teorias psicanalíticas, vem da infância (CUNHA AO e FIAMENGHI GA, 2021). Um estudo científico sobre a terapêutica farmacológica, usando principalmente os antidepressivos inibidores seletivos de recaptação da serotonina (ISRS), mostrou que o tratamento isolado com fármacos não é tão efetivo, tendo 
remissão dos sintomas em metade dos casos estudados em um experimento, e, assim, deve ser combinado a psicoterapia (BARBOSA JC, et al., 2017).

Pesquisas recentes mostram, de maneira clara, que a terapêutica mais importante é a psicoterapia, sendo a escolha de sua corrente devendo ser individualizada de acordo com o caso do paciente, analisando, se é possível discutir e tratar questões mais antigas, ou se o paciente necessita de uma atuação mais rápida (PETERSEN ML, 2019).

\section{CONSIDERAÇÕES FINAIS}

Com os estudos até então existentes, o TOC pode ser tratado com psicoterapia, devendo ser a primeira escolha, podendo-se combiná-la com fármacos como os ISRS, a depender do caso de cada paciente e de sua evolução. Entretanto, devem-se realizar estudos sobre o desenvolvimento de novos fármacos que possam ser aplicados na terapêutica, já que a psicoterapia depende muito do profissional e interesse do paciente, gerando resultados inesperados para cada paciente.

\section{REFERÊNCIAS}

1. BARBOSA JC, et al. Tratamento Psicofarmacológico do Transtorno Obsessivo-compulsivo. Revista Eletrônica de Trabalhos Acadêmicos, 2017; 2(4): 1-13.

2. CUNHA AO, FIAMENGHI GA. Transtorno obsessivo-compulsivo: uma compreensão psicanalítica. Psicologia: Abordagens Teóricas e Empíricas, 2021; 1(3): 59-70.

3. PETERSEN ML. A terapia cognitivo-comportamental no tratamento das compulsões mentais. Revista Brasileira de Terapia Cognitiva, 2019; 15(2): 92-9. 


\title{
USO DA FITOTERAPIA NA ATENÇÃO BÁSICA: PAPEL DO PROFISSIONAL DE SAÚDE
}

\author{
Ana Carolina Lopes Cerqueira ${ }^{1}$ \\ João Guilherme Sabino da Silva ${ }^{1}$ \\ João Marcos da Silva Costa ${ }^{1}$ \\ Lethícia Maria de Souza Aguiar ${ }^{1}$ \\ Thaís Santos Bezerra ${ }^{1}$
}

1. Universidade Federal de Pernambuco (UFPE), Recife - PE.

Palavras-chave: Fitoterápicos, Plantas medicinais, Conhecimento.

\section{INTRODUÇÃO}

O uso das plantas medicinais ocorre desde o início da história do Brasil com a conhecida medicina popular, e foi a partir delas que surgiram os fitoterápicos, medicamentos que passam pela Agência Nacional de Vigilância Sanitária (ANVISA) para se tornarem disponíveis (COSTA JW, et al., 2018). A fitoterapia é muito importante no Brasil, principalmente na atenção básica, fazendo necessária uma atenção maior devido à falta de conhecimento e limitações, como as desigualdades sociais, que dificultam o acesso aos remédios e tratamentos médicos (COSTA JW, et al., 2018). Dessa forma, cabe ao profissional de saúde ter conhecimento sobre a fitoterapia para poder orientar a população (MATTOS G, et al., 2018).

\section{OBJETIVO}

Revisar a literatura científica para compreender melhor acerca da importância da fitoterapia na promoção à saúde na atenção básica, e os seus impactos, com ênfase no papel do profissional de saúde.

\section{REVISÃO BIBLIOGRÁFICA}

Em um estudo observacional seccional feito na Atenção Primária da cidade de Blumenau, Santa Catarina, observou-se que a maioria dos entrevistados prefere o uso de remédios caseiros, utilizando as plantas medicinais como tratamento. Além disso, as características sociodemográficas das pessoas que faziam parte da amostra eram similares ao encontrado em outros locais de atenção primária no país, com predominância de pessoas adultas, do sexo feminino e com situação de vulnerabilidade social (ZENI ALB, et al., 2018).

Já em outro estudo, realizaram uma revisão integrativa da literatura sobre a aplicabilidade da fitoterapia na atenção básica e mostraram que os profissionais da saúde precisam ter conhecimento científico sobre o assunto, já que, cada vez mais as pessoas estão usando plantas medicinais e os fitoterápicos como forma de tratamento, assim, é necessário um profissional capacitado para orientar a população sobre o uso correto desses produtos. Porém, além da falta de conhecimento dos profissionais, existem outros desafios para a 
utilização da fitoterapia na atenção básica, como a falta de recursos, de incentivo à fitoterapia no ambiente acadêmico, entre outros (SOUZA LTS, et al., 2021).

\section{CONSIDERAÇÕES FINAIS}

Conforme a análise dos artigos, os fitoterápicos e plantas medicinais são uma das principais formas de tratamento na atenção básica. A atuação dos profissionais de saúde é de suma importância na orientação dos pacientes, uma vez que há ausência do conhecimento científico principalmente da população carente, que apenas usufrui o saber popular. Dessa forma, é necessário o incentivo ao conhecimento desses produtos por parte dos profissionais da saúde.

\section{REFERÊNCIAS}

1. COSTA JW, et al. A fitoterapia no contexto da Atenção Básica. Revista Extensão \& Sociedade, 2018; 8 : 19-32.

2. MATTOS G, et al. Plantas medicinais e fitoterápicos na Atenção Primária em Saúde: percepção dos profissionais. Ciência \& Saúde Coletiva [online], 2018; 23(11): 3735-3744.

3. SOUZA LTS, et al. Desafios enfrentados por enfermeiros na aplicabilidade da fitoterapia na atenção primária: uma revisão integrativa. Revista Brasileira de Revisão de Saúde, 2021; 4(3): 11885-11899.

4. ZENI ALB, et al. Utilização de plantas medicinais como remédio caseiro na Atenção Primária em Blumenau, Santa Catarina, Brasil. Ciência \& Saúde Coletiva [online], 2017; 22: 2703-2712. 


\title{
APLICAÇÃO DA DIETA CETOGÊNICA NO TRATAMENTO DE CRIANÇAS COM EPILEPSIA: UMA REVISÃO DA LITERATURA
}

\author{
Mayara Matos Nascimento ${ }^{1}$ \\ Joelma Cunha Pereira ${ }^{1}$ \\ Liejy Agnes dos Santos Raposo Landim ${ }^{1}$ \\ Daniela Fortes Neves Ibiapina ${ }^{1}$
}

1. Centro Universitário Santo Agostinho (UNIFSA), Teresina - PI.

Palavras-chave: Epilepsia Infantil, Dieta cetogênica, Crises epilépticas.

\section{INTRODUÇÃO}

A epilepsia corresponde a uma alteração decorrente do funcionamento neuronal anormal (COSTA LLO, et al., 2020). A criança com epilepsia está mais propensa a ter dificuldades no rendimento acadêmico, baixa autoestima, problemas de saúde mental (RONCONI MC, 2019). O cuidado é um ponto essencial que não pode ser desprezado (FONSECA GS, et al., 2017).

A dieta cetogenica (DC) é uma das mais estudadas na gestão da epilepsia, a mesma é composta por alto teor de gordura, vários estudos avaliaram os efeitos potenciais da dieta e suplementos dietéticos como tratamento adjunto nos vários distúrbios neurológicos, na epilepsia (SESSA W e FERRAZ RRN, 2019).

\section{OBJETIVO}

Revisar a literatura científica, com o principal propósito de comprovar os benefícios encontrados na aplicabilidade da dieta cetogênica como tratamento benéfico da epilepsia em crianças com difícil controle de crises.

\section{MÉTODO}

Trata-se de uma revisão da literatura integrativa. A busca dos artigos foi realizada nas bases de dados, PubMED e Google Acadêmico, utilizando descritores em português "Epilepsia Infantil", "Dieta cetogênica", "Epilepsia" cadastrados nos Descritores em Ciência da Saúde (DeCS). Os critérios de inclusão foram artigos originais, nos idiomas português e inglês; publicados entre os anos de 2017 a 2021. Os critérios de exclusão foram publicações de artigos não relacionados ao tema.

\section{REVISÃO BIBLIOGRÁFICA}

Em certo estudo avaliaram a eficácia e tolerabilidade da DC durante os primeiros 4 meses em pacientes com epilepsia refratária de 1-18 anos, constatando que muitos pacientes do grupo DC tiveram reduções 
associadas em seus escores de gravidade de epilepsia, enquanto a pontuação total dos efeitos colaterais não aumentou. Os efeitos colaterais mais comumente relatados são sintomas gastrointestinais (LAMBRECHTS, DAJE et al., 2017).

Já em um estudo prospectivo, a DC aplicada por 12 meses em 389 crianças com epilepsia exibiu efeitos positivos no desenvolvimento e no comportamento, conforme relatado pelos pais. Também houve algumas complicações observadas durante o tempo de aplicação da DC (GUZEL O, et al., 2019).

\section{CONSIDERAÇÕES FINAIS}

Com base nos aspectos apresentados no presente estudo, pode-se observar que a dieta cetogênica pode ser uma importante opção terapêutica para pacientes com epilepsia, principalmente em crianças e adolescentes, mostrando efeitos positivos no desenvolvimento e no comportamento. Contudo, protocolos de pesquisas que discutam este tema ainda são essenciais para esclarecer o mecanismo de ação da DC para obter aplicações mais seguras da mesma.

\section{REFERÊNCIAS}

1. COSTA LLO, et al. Atualização em epilepsia: revisão de literatura. Revista de Medicina, 2020; 99(2): 170 181.

2. FONSECA GS, et al. Epidemiological aspectso frefractory epilepsyina pediatrics hospital. Journal of Nursing UFPE online, 2016; 10(3): 1466-73.

3. GUZEL O, et al. Efficacy and tolerability of olive oil-based ketogenic diet in children with drug-resistant epilepsy: A single center experience from Turkey. European journal of paediatric neurology: EJPN: official journal of the European Paediatric Neurology Society, 2019; 23(1): 143-151.

4. LAMBRECHTS DAJE, et al. A randomized controlled trial of the ketogenic diet in refractory childhood epilepsy. Acta Neurologica Scandinavica, 2017; 135(2): 231-239.

5. RONCONI MC. Epilepsia: el contexto escolar y los aspectos neuropsicológicos. In: CARABALLO, R. Epilepsia en la escuela. Buenos Aires: Journal, 2019: 67-75.

6. SESSA W, FERRAZ RRN. Dieta low carb como estratégia de manejo na remissão do diabetes mellitus insulinorresistente: síntese de evidências. International Journal of Health Management Review; 2019: 5(1). 


\title{
ANSIEDADE NA GRAVIDEZ: PREVALÊNCIA E FATORES ASSOCIADOS: REVISÃO INTEGRATIVA
}

\author{
Juciele Gomes dos Santos ${ }^{1}$ \\ Angelica Ribeiro do Nascimento Oliveira ${ }^{2}$ \\ Caroline Taiane Santos da Silva ${ }^{3}$
}

1. Faculdade das Ciências Agrárias e da Saúde (FAS), Lauro de Freitas - BA.

2. Centro Universitário Maurício de Nassau (UNINASSAU), Teresina - PI.

3. Child Behavior Institute of Miami (CBI), Flórida - Estados Unidos.

Palavras-chave: Ansiedade, Gravidez, Fatores Associados.

\section{INTRODUÇÃO}

A gravidez é um processo em que ocorrem alterações fisiológicas, psíquicas e hormonais, onde faz presente o aumento do risco de sofrimento emocional e de morbidade psiquiátrica (de JESUS SILVA MM, et al., 2016). Entretanto, algumas mulheres podem vivenciar a gravidez como uma fonte de alegria e benção e auto realização, porém quando não desejada ou planejada podem vivenciar, neste momento, alterações em sua saúde mental, como o desenvolvimento de ansiedade (MONTIGNY F, et al., 2020). É de suma importância que o profissional de enfermagem faça uma boa assistência à mulher nesse momento que está vivenciando, enfatizando seu conhecimento científico para atuar nessa assistência (ROCHA PC, et al., 2016).

\section{OBJETIVO}

Identificar através da literatura as evidências científicas sobre prevalência e os fatores associados à ansiedade na gravidez, bem como os aspectos que contribuem para o desenvolvimento de transtornos mentais e afins.

\section{MÉTODO}

Revisão integrativa da literatura sendo realizado no período de setembro de 2021, por meio de consulta nas bases dos dados: BDENF, LILACS, MEDLINE, utilizando os descritores "Ansiedade", "Gravidez" e "Fatores Associados". Foram incluídos artigos disponíveis na íntegra gratuitamente, publicados em português, inglês, espanhol, com recorte temporal entre 2016-2021, foram excluídas publicações repetidas e estudos que não respondessem ao objetivo de pesquisa. Por fim, elegeu-se 5 artigos para compor a revisão.

\section{REVISÃO BIBLIOGRÁFICA}

Os aspectos associados à prevalência de ansiedade na gravidez na adolescência ressaltam-se fatores como desemprego, baixa escolaridade, conflitos familiares, falta de parceiro, violência física (MONTIGNY F, 
et al., 2020). Além disso, ausência de momentos de lazer prejudicados pela rotina pós-parto desmotivam muitas mulheres, fazendo com que sintam-se presas, além do uso de drogas ilícitas que contribuem para o desenvolvimento de transtornos mentais (ROCHA PC, et al., 2016). Nessa perspectiva, quando há uma gravidez não desejada pela mulher pode contribuir para uma desordem mental, responsável por acarretar 0 desenvolvimento da ansiedade (SEPÚLVEDA B, 2021).

\section{CONSIDERAÇÕES FINAIS}

Ao final desse estudo, pode-se perceber que os fatores comuns associados à ansiedade na gravidez estão relacionados a baixa autoestima, desemprego, história de problemas psiquiátricos, violência doméstica, baixo nível de escolaridade. Por fim, a gravidez na adolescência a maioria das ocorrências não é planejada e a jovem não ter parceiro causa atitude negativa frente a gravidez causando conflitos familiares e ansiedade.

\section{REFERÊNCIAS}

1. BONILLA-SEPÚLVEDA, ÓA. Estrés, ansiedad y factores asociados en mujeres adolescentes embarazadas y no embarazadas en Medellín (Colombia). Medicina UPB, 2021; 40: 2-9.

2. MONTIGNY F, et al. Protective and risk factors for women's mental health after a spontaneous abortion. Rev. Latino-Am. Enfermagem, 2021; 28: 1-11.

3. de JESUS SILVA MM, et al. Depresión in pregnancy. Prevalence and associated factors. Investigación y educación en enfermería, 2016; 34: 342-350.

4. ROCHA PC, et al. Prevalência e fatores associados ao uso de drogas ilícitas em gestantes da coorte BRISA. Cadernos de Saúde Pública, 2016; 32: 1-13. 
BOAS PRÁTICAS NA ASSISTÊNCIA DE ENFERMAGEM AOS RECÉM-NASCIDOS SAUDÁVEIS: REVISÃO INTEGRATIVA

Juciele Gomes dos Santos ${ }^{1}$

Angelica Ribeiro do Nascimento Oliveira ${ }^{2}$

Caroline Taiane Santos da Silva ${ }^{3}$

1. Faculdade das Ciências Agrárias e da Saúde (FAS), Lauro de Freitas - BA.

2. Centro Universitário Maurício de Nassau (UNINASSAU), Teresina - PI.

3. Child Behavior Institute of Miami (CBI), Flórida - Estados Unidos.

Palavras-chave: Recém-Nascido, Assistência de Enfermagem, Boas Práticas.

\section{INTRODUÇÃO}

As boas práticas na assistência ao recém-nascido tornam-se essenciais e indispensáveis para uma assistência humanizada e segura, garantindo bem-estar para o binômio mãe-filho (SILVA LF, et al., 2021). O profissional de enfermagem exerce um papel fundamental nesse processo que inicia-se na abordagem dos aspectos psicossociais e das atividades educativas e preventivas apropriados, logo no pré-natal com a mãe garantindo uma gestação saudável e um parto seguro, logo as práticas durante a assistência ao parto e nascimento devem estar de acordo com evidências científicas proporcionando um nascimento humano e seguro para a mãe e a criança (SILVA EA, et al., 2021).

\section{OBJETIVO}

Identificar através da literatura científica as boas práticas na assistência de enfermagem aos recémnascidos saudáveis para promoção da saúde do bebê nas maternidades e centros obstétricos, tendo ainda como objetivo disseminar conhecimento sobre essas práticas.

\section{MÉTODO}

Revisão integrativa da literatura, realizada no período de setembro de 2021, nas bases dos dados: BDENF, LILACS e CUMED, através da BVS, utilizando os descritores "Recém-Nascido", "Assistência de Enfermagem" e "Boas Práticas" como conectivo o operador booleano AND. Foram incluídos artigos publicados em português e inglês, entre 2016 e 2021 e excluídos: estudos repetidos nas bases de dados. Encontrado 203 artigos, ao aplicar os critérios restaram 30. Por fim, após a leitura dos títulos e resumos, selecionou-se para compor os resultados.

\section{REVISÃO BIBLIOGRÁFICA}


O contato pele a pele com a mãe logo no primeiro momento de vida é uma boa prática para fortalecer o vínculo mãe-filho passando segurança ao bebê, esse contato deve ser priorizado ainda na sala de parto o que contribui para a formação do apego, trazendo ainda vários benefícios como: adaptação do bebê à vida extrauterina, controla a temperatura através da pele com pele, promove estímulo sensorial adequado, promove o aleitamento materno precoce (SILVA LF, et al., 2021). Tendo ainda a realização do teste de Apgar, monitorando o recém-nascido e incentivando a amamentação e a hidratação da mãe durante todo processo de parto (INAGAKI ADM, et al., 2019).

\section{CONSIDERAÇÕES FINAIS}

Diante do exposto, é extremamente importante a realização de práticas humanizadas durante o cuidado ao recém-nascido, práticas essas que garantem bem-estar não apenas ao mesmo, mas a toda família, como o contato pele a pele, o aleitamento materno na primeira hora pós-parto e a realização dos testes adequados para promoção a saúde do mesmo.

\section{REFERÊNCIAS}

1. INAGAKI ADM, et al. Retrato das práticas obstétricas em uma maternidade pública. Cogitare Enfermagem, 2019; 24: 1-13.

2. SILVA EA, et al. Conhecimento de puérperas sobre boas práticas em centro de parto. Rev. enferm. UFPE on line, $2021 ; 14: 1-14$.

3. SILVA LF, et al. Adesão às boas práticas obstétricas: construção da assistência qualificada em maternidades- escolas. Revista Baiana de Enfermagem, 2021; 35: 1-9. 


\title{
A INCIDÊNCIA DE INTERNAÇÕES EM DECORRÊNCIA DE QUEDAS EM IDOSOS BRASILEIROS
}

\author{
Francisco Walisson de Araujo ${ }^{1}$ \\ Michele Santos da Silva ${ }^{1}$ \\ Antonia Juliana de Souza Sá ${ }^{1}$
}

Francisco José Oliveira Vasconcelos Carvalho ${ }^{1}$

1. Faculdade leducare (FIED/UNINTA), Tianguá - CE.

Palavras-chave: Internação, Idoso, Quedas.

\section{INTRODUÇÃO}

O processo de envelhecimento da população brasileira determina uma importante mudança na morbimortalidade e aumenta o risco ao desenvolvimento de alterações funcionais e comorbidades (ABREU DROM, et al., 2018). As quedas correspondem a um grave problema de saúde pública e estão entre os danos que mais causam prejuízos aos idosos. Durante essa fase, alterações como a diminuição da flexibilidade e mobilidade de membros inferiores, diminuição da força e alterações proprioceptivas, deixa-os mais vulneráveis a sofrerem estes incidentes. Tal situação coloca a população idosa sujeita a adversidades e concomitantemente gera intercorrências que necessitam de cuidados em unidade hospitalar (CONFORTIN SC, et al., 2020).

\section{OBJETIVO}

Revisar e analisar por meio da literatura científica os estudos epidemiológicos que apresentam um quantitativo acerca dos casos de internações hospitalares em decorrência dos casos de quedas em idosos brasileiros.

\section{MÉTODO}

Trata-se de uma revisão integrativa, baseada na consulta à PubMed, LILACS, CINAHL, BDENF e Acervo+ Index base, dos últimos cinco anos. Os descritores foram: hospitalização, acidentes, quedas e idoso. A busca resultou em 411 artigos, e após análise, 04 foram incluídos. Os inclusos foram aqueles que abordassem a epidemiologia de quedas em idosos de mesmo nível no Brasil. Contrariamente, os estudos em duplicatas, do tipo revisão e meta-análise foram exclusos.

\section{REVISÃO BIBLIOGRÁFICA}

Em estudo realizado acerca das internações por quedas em idosos no Brasil, verificou que durante o período de 1996 a 2012, ocorreram 941.923 hospitalizações, havendo uma maior incidência entre mulheres (ABREU DROM, et al., 2018). Uma pesquisa semelhante averiguou que entre os anos de 2006 a 2014 a 
quantidade de internações pelo mesmo motivo foi de 703.791, com uma taxa maior entre idosos de 60 a 69 anos (CONFORTIN SC, et al., 2020). Outros estudos também analisaram esse quantitativo de internações por quedas. Nestes, evidenciaram-se altos índices de hospitalizações nessa população, havendo uma tendência de crescimento desses valores (STOLT LROG, et al., 2020; SILVEIRA FJ, et al., 2020).

\section{CONSIDERAÇÕES FINAIS}

Esse estudo apresentou limitações devido ao número limitado de artigos utilizados e por se tratar de um estudo de revisão que apresenta dados epidemiológicos de pesquisas anteriores. Nesse sentido, novos estudos devem ser realizados para análise desse quantitativo de incidentes relacionados às quedas na população idosa, para que estratégias de prevenção e educação sejam aplicadas à comunidade em geral.

\section{REFERÊNCIAS}

1. ABREU DROM, et al. Internação e mortalidade por quedas em idosos no Brasil: análise de tendência. Ciência \& saúde coletiva, 2018; 23(04): 1131-1141.

2. CONFORTIN SC, et al. Internação por queda em idosos residentes em Florianópolis, em Santa Catarina e no Brasil: tendência temporal 2006-2014. Cadernos Saúde Coletiva, 2020; 28(2): 251-259.

3. SILVEIRA FJ, et al. Internações e custos hospitalares por quedas em idosos brasileiros. Scientia Medica, 2020; 30(1): e36751.

4. STOLT LROG, et al. Internação hospitalar, mortalidade e letalidade crescentes por quedas em idosos no Brasil. Revista de Saúde Pública, 2020; 54(76): 01-12. 


\title{
INIQUIDADES SOCIAIS DE GÊNERO DURANTE A PANDEMIA DA COVID-19 NO BRASIL
}

\author{
Patricia Cavalcante Castro do Nascimento ${ }^{1}$ \\ Aridan Maria Pereira de Holanda² \\ Kadja de Fatima Pinheiro Freitas da Silva ${ }^{3}$ \\ Daniele Silva Simões Cavalcanti ${ }^{4}$ \\ Marina Ferreira de Lima ${ }^{5}$
}

1. Universidade Federal de Pernambuco (UFPE), Recife - PE.

2. Faculdade Internacional de Ciências Sociales (FICS), Assunção - Paraguai.

3. Aggeu Magalhães/Fundação Oswaldo Cruz (IAM/Fiocruz), Recife - PE.

4. Faculdade de Ciências Humanas de Olinda (FACHO), Olinda - PE.

5. Hospital das Clínicas de Pernambuco (HC/UFPE), Recife - PE.

Palavras-chave: Gênero e saúde, Covid-19, Violência doméstica.

\section{INTRODUÇÃO}

A pandemia da Covid-19 transformou-se em uma crise sanitária se espalhando rapidamente no Brasil. Sem vacina e tratamentos específicos foi necessário valer-se de medidas não farmacológicas como isolamento e distanciamento social e quarentena de sintomáticos respiratórios (CARDOSO T, et al., 2021). Porém essas medidas trouxeram consigo um profundo impacto na vida das pessoas, escancarando cada vez mais as desigualdades de gênero existentes no país. Com a chegada do vírus houve uma priorização das medidas biomédicas o que contribuiu para negligenciar ainda mais os determinantes estruturais de saúde no país (REIS AP, et al., 2020).

\section{OBJETIVO}

Identificar na literatura as iniquidades de gênero no Brasil, sua correlação com as desigualdades sociais, possível aumento durante a Pandemia da Covid-19 e qual impacto trouxe para saúde das mulheres.

\section{MÉTODO}

Revisão Integrativa da Literatura com levantamento bibliográfico nas bases de dados, Scielo, Medline e Lilacs, no mês de setembro de 2021. Critérios de inclusão: estudos selecionados nos idiomas português e inglês, encontrados 200 artigos dos quais foram selecionados quatro que se encaixavam aos objetivos do estudo. Critérios de exclusão: textos que não respondessem a temática pretendida. Palavras-chave: Gênero e Saúde, Covid-19, violência doméstica. 


\section{REVISÃO BIBLIOGRÁFICA}

Com a descontinuidade dos serviços de saúde, houve um impacto na saúde reprodutiva feminina, um maior risco de morte durante o ciclo gravídico puerperal, aumento no número de abortos e evidências que o SARS-CoV-2 pode influir nos desfechos gestacionais (REIS AP, et al., 2020). A violência doméstica triplicou durante a pandemia, causada pelo seu parceiro íntimo, reflexo do isolamento social, ficando essas mulheres no espaço onde ocorre mais esse tipo de fenômeno (BARBOSA JPS, et al., 2021). Com a violação dos direitos trabalhistas as mulheres ficaram mais sujeitas a demissão e corte de salários, as atividades domésticas dobraram e os cuidados com parentes doentes aumentaram (GHIRALDELLI R, 2021).

\section{CONSIDERAÇÕES FINAIS}

As desigualdades de gênero foram escancaradas com a covid-19, o modelo biomédico que impera no país foi o modelo de escolha para o enfrentamento durante a pandemia, trazendo maiores iniqüidades estruturais, ficando a atenção básica cada vez mais esquecida e com isso potencializando os problemas de saúde da população, os reflexos são cruéis e afetam diretamente as mulheres.

\section{REFERÊNCIAS}

1. BARBOSA JPM, et al. Interseccionalidade e violência contra as mulheres em tempos de pandemia de Covid-19: Diálogos e possibilidade. Saúde Social, 2021; 30(2): e200367.

2. CARDOSO TF. A desigualdade de gênero na pandemia do novo coranavírus (SARS-COV-2/COVID-19) e seus reflexos no pós-pandemia. Revista Eletrônica Ordem dos Advogados do Rio de Janeiro, 2021; 2.

3. GHIRALDELLI R. Trabalho, reformas ultraliberais, desigualdades e pandemia no Brasil: os sentidos da crise. Trabalho, Educação e Saúde, 2021; 19: e00326158.

4. REIS AP, et al. Desigualdades de gênero e raça na pandemia de covi-19: implicações para o controle no Brasil. Saúde e Debate, 2020; 44: 324-340. 
RESUMO SIMPLES: Revisão Integrativa

\title{
BOAS PRÁTICAS NA ADMINISTRAÇÃO DE MEDICAMENTOS ENDOVENOSOS
}

\author{
Eliana Luz Lopes ${ }^{1}$ \\ Ana Luísa Mendes Ribeiro² \\ Angelica Ribeiro do Nascimento Oliveira ${ }^{3}$ \\ Rafaela de Jesus Portugal ${ }^{4}$ \\ Caroline Taiane Santos da Silva ${ }^{5}$
}

1. Universidade Federal do Oeste da Bahia (UFOB), Barreiras - BA.

2. Universidade Federal do Piauí (UFPI), Teresina - PI.

3. Universidade Salvador (UNIFACS), Salvador - BA.

4. Centro Universitário Maurício de Nassau (UNINASSAU), Teresina - PI.

5. Child Behavior Institute of Miami, Flórida - Estados Unidos.

Palavras-chave: Cuidados de enfermagem, Infusões endovenosas, Segurança do paciente.

\section{INTRODUÇÃO}

Conforme o Instituto Para Práticas Seguras no uso de Medicamentos (ISMP) os erros de medicação estão entre a causalidade de morte de aproximadamente 8.000 pessoas em um período anual, cujo índice numérico é relativamente preocupante (ROCHA DMA, et al., 2020). Assim, as boas práticas referentes à segurança compreendem um conjunto de valores e também competências que se vinculam diretamente na gestão da saúde em prol de resultados satisfatórios (MENDES JR, et al., 2018). Entender o processo é fundamental para intervir com as devidas ações quando necessárias, com foco central no bem-estar do paciente.

\section{OBJETIVO}

Identificar na literatura as boas práticas na administração de medicamentos endovenosos e entender que o mecanismo de articulação coerente e coeso está associado com a adesão à terapia farmacológica eficaz.

\section{MÉTODO}

Trata-se de uma revisão integrativa realizada através de buscas nas bases de dados da Scielo, Pubmed, Medline, Lilacs, utilizando como descritores: Cuidados de Enfermagem; Infusões Endovenosas; Segurança do Paciente, combinados pelo operador booleano "and". Como critérios de inclusão artigos que abordassem a temática disponíveis na íntegra em português e inglês publicados entre 2016 e 2021 e de exclusão artigos repetidos nas bases, totalizando assim, 5artigos para compor a revisão. 


\section{REVISÃO BIBLIOGRÁFICA}

A literatura aponta que o principal mecanismo para boas práticas é higienização das mãos, sendo dividida em cinco momentos, porém o mais importante é o momento "após tocar em superfícies e objetos próximo ao paciente" pois é o que possui menor taxa de adesão, apesar de que a desinfecção desses locais é essencial para redução de patógenos (FERREIRA GS, et al., 2021).

Outra prática importante é seguir os protocolos institucionais, ressaltando a importância de realizar a técnica correta (dos SANTOS EVANGELISTA AC, et al., 2021). A efetividade ou fracasso dessa técnica depende do conhecimento e cuidados prévios e posteriores à aplicação EV (GONZÁLEZ JL e BARBONA LO, 2020).

\section{CONSIDERAÇÕES FINAIS}

Diante do exposto, esse estudo possibilitou compreender a importância do controle e manejo diante a administração de medicamentos endovenosos, e como o profissional da saúde pode contribuir diretamente, por meio de técnicas e habilidades eficazes para evitar a contaminação e agravamento do problema. Concomitantemente, surge a necessidade de ampliar os profissionais em questão no intuito da adesão farmacológica com segurança e eficácia.

\section{REFERÊNCIAS}

1. dos SANTOS EVANGELISTA AC et al. "Prevenção de flebites: conhecimento dos profissionais de enfermagem/Phlebitis prevention: knowledge of nursing professionals/Prevención de la flebitis: conocimiento de profesionales de enfermeira." Journal Health NPEPS" 6.1 (2021).

2. FERREIRA GS, et al. Boas práticas na administração de medicamentos endovenosos. Enferm. Foco, 2021; 12(1): 100-104.

3. GONZÁLEZ JL; BARBARONA LO. Terapia intravenosa períférica: Cuidados de enfermería. Med. Infant, 2020; 56-60.

4. MENDES JR, et al. Tipos e frequência de erros no preparo e na administração de medicamentos endovenosos. Einstein (São Paulo), 2018; 16.

5. ROCHA DMA, et al. Administração de medocamento endovenoso em pacientes de hospital de doenças infectocontagiosas: Atuação da enfermagem. Enfermagem em foco, 2020; 11. 


\title{
OS EFEITOS DO USO DA PÍLULA ANTICONCEPCIONAL NA SAÚDE DA MULHER
}

\author{
Gabrielly Fávaro Costa Amorim 1 \\ Lanna do Carmo Carvalho ${ }^{1}$ \\ Mirelli da Silva Vasconcelos ${ }^{1}$ \\ Juliana Hertel Cardoso de Vasconcelos ${ }^{1}$ \\ Lara Cândida de Sousa Machado ${ }^{1}$
}

1. Universidade de Rio Verde (UNIRV), Rio Verde - GO.

Palavras-chave: Contraceptivos orais, Saúde da mulher, Contraceptivos hormonais.

\section{INTRODUÇÃO}

A pílula anticoncepcional é um dos métodos contraceptivos mais utilizados pelas mulheres. Eles liberam hormônios sintéticos de progesterona e estrogênio, alguns sendo somente de progestogênio. (MORAIS LX, et al. 2019). Esses hormônios atuam na hipófise inibindo a secreção de GnRH (Hormônio Liberador de Gonadotrofina), FSH (Hormônio Folículo Estimulante) e do LH (Hormônio Luteinizante). Já a pílula do dia seguinte possui doses elevadas de progestogênio, podendo agir no período antes da ovulação, atuando no muco e na mobilidade do espermatozoide (MORAIS LX, et al., 2019). Debates foram centrados nos riscos de doenças fatais, como acidentes cardiovasculares. Logo, preocupações com efeitos colaterais impulsionaram pesquisas para seu aprimoramento (DIAS TM, et al. 2018).

\section{OBJETIVO}

Avaliar os efeitos do uso da pílula anticoncepcional na saúde da mulher, por meio da investigação de seus benefícios e malefícios, e comparação de diferentes posologias com objetivo de melhorar a anticoncepção pela adoção das opções avaliadas como mais seguras.

\section{MÉTODO}

O presente estudo é uma revisão integrativa. A busca das produções foi realizada na Scientific Eletronic Library Online (SciELO). Palavras-chave: contraceptivos, contraceptivos orais, anticoncepcional e contraceptivos hormonais. Critérios de inclusão: artigos publicados entre janeiro de 2016 e maio de 2020, no idioma português que abordassem os efeitos colaterais do uso de contraceptivos hormonais. Foram encontrados 54 artigos, excluídos 50 artigos e selecionados 4 artigos que atendiam a finalidade do estudo e não estavam duplicados.

\section{REVISÃO BIBLIOGRÁFICA}


Foi verificado que o contraceptivo oral combinado é o fator de risco mais frequente em pacientes pediátricas com trombose venosa profunda e acidente vascular cerebral pelo fato de os estrogênios aumentarem fatores pró coagulantes (LIMA ACS, et al., 2017; SEQUEIRA AI, et al., 2016).

Mulheres sob uso anticoncepcional oral possuem melhor complacência e volumes pulmonares podendo ser usada em tratamento de desordens respiratórias (RIZZETTI DA, et al., 2017). Há menor aumento da massa óssea em adolescentes que utilizam anticoncepcionais orais devido às diminuições na produção de estrogênio endógeno e consolidação das epífises (RIZZO AC, et al., 2019).

\section{CONSIDERAÇÕES FINAIS}

O uso de anticoncepcional oral combinado é um fator de risco para a TVP, sobretudo os de terceira geração. Os de baixa e muito baixa dosagem de etinilestradiol causam menor aumento de massa óssea. A progesterona, estrógeno e seus similares sintéticos podem ser utilizados como potentes estimuladores respiratórios, necessitando de mais estudos. Evidenciou-se a relação do uso de ACOs e AVC que é potencializado quando associado a fatores de risco.

\section{REFERÊNCIAS}

1. DIAS TM, et al. "Estará nas pílulas anticoncepcionais a solução?” Debate na mídia entre 1960-1970. Rev. Estud. Fem, 2018; 26(3).

2. MORAIS LX, et al. Tromboembolismo venoso relacionado ao uso frequente de anticoncepcionais orais combinados. Revista Fasem Ciências, 2019; 8(1): 85-109.

3. LIMA ACS, et al. Influence of hormonal contraceptives and the occurrence of stroke: integrative review. Revista Brasileira de Enfermagem [online], 2017; 70(3).

4. RIZZETTI DA, et al. Impact of continuous positive airway pressure on the pulmonary changes promoted by immersion in water. J. bras. pneumol. 2017, 43(6): 409-415.

5. RIZZO AC, et al. One-year adolescent bone mineral density and bone formation marker changes through the use or lack of use of combined hormonal contraceptives. Jornal de Pediatria [online], 2019; 95(5): 56774.

6. SEQUEIRA Al, et al. Trombose venosa profunda em idade pediátrica: estudo retrospetivo de 10 anos. Nascer e Crescer, 2017; 25(3): 147-153. 


\title{
LESÃO RENAL AGUDA EM PACIENTES COM COVID-19
}

\author{
Gabrielly Fávaro Costa Amorim ${ }^{1}$ \\ Lanna do Carmo Carvalho ${ }^{1}$ \\ Wallyson Maciel Oliveira ${ }^{1}$ \\ Gabriel José e Silva ${ }^{1}$ \\ Lara Cândida de Sousa Machado ${ }^{1}$
}

1. Universidade de Rio Verde (UNIRV), Rio Verde - GO.

Palavras-chave: Doença renal, Infecção por coronavírus, Lesão renal aguda.

\section{INTRODUÇÃO}

O SARS-CoV-2 é um vírus constituído de glicoproteínas transmembrana Spike (S) que apresentam duas subunidades S1 e S2. A S1 media a ligação com a enzima conversora de angiotensina 2 (ECA) (MARTINEZROJAS MA, et al., 2020). A ECA2 é amplamente distribuída no corpo humano, particularmente pneumócitos tipo 2. Depois da infecção pulmonar o vírus pide passar pelo sangue até os rins, se acumulando e causando danos para as células renais (CHENG Y, et al., 2020). Nesse sentido, há a necessidade de avaliar a prevalência de doença renal na admissão e desenvolvimento de lesão renal aguda (LRA) e sua relação com a mortalidade durante a hospitalização de pacientes com COVID-19 (CHENG Y, et al., 2020).

\section{OBJETIVO}

Verificar se os casos de lesão renal aguda em pacientes com infecção por coronavírus podem indicar maiores riscos de mortalidade e um pior prognóstico garantindo triagem correta e tratamento adequado.

\section{MÉTODO}

O seguinte trabalho se trata de uma revisão integrativa, fundamentada em artigos de referência como o Acervo Mais Index Base, SciELO, MEDLINE, Google Acadêmico e Ministério da Saúde. Foram critérios de seleção estudos publicados nos últimos 2 anos nos idiomas inglês e português no período de agosto de 2021 excluindo -se aqueles que não atendiam a finalidade do trabalho.

\section{REVISÃO BIBLIOGRÁFICA}

A etiologia da LRA associada à (COVID-19) é multifatorial, pode ser causada por depleção de volume, falência de múltiplos órgãos, infecção viral que leva diretamente a lesão tubular renal, processos vasculares trombóticos, glomerulonefrite ou rabdomiólise. Pode estar associado à proteinúria, hematúria (MARTINEZROJAS MA, et al., 2020). 
A maioria dos pacientes é afro-americano o que influencia nos resultados pela maior prevalência de hipertensão e diabetes nesse grupo (MARTINEZ-ROJAS MA, et al., 2020). A incidência de LRA é maior em casos graves e não sobreviventes. Prova disso é a grande incidência em pacientes na UTI (SULEYMAN G, et al., 2020) pelo fato destes possuírem maior desidratação hipernatremica (CHRIST-CRAIN M, et al., 2020).

\section{CONSIDERAÇÕES FINAIS}

Há uma alta prevalência de análises anormais de urina e disfunção renal em pacientes com COVID-19 por diversas causas. A maioria dos pacientes é afro-americano e os pacientes na UTI. Estes estão mais propensos a ter desidratação por hipernatremia que contribui para o desenvolvimento de LRA. Isso é uma das explicações para a maior incidência de LRA em casos graves e em casos não sobreviventes.

\section{REFERÊNCIAS}

1. CHENG $Y$, et al. O comprometimento renal está associado à morte intra-hospitalar de pacientes com COVID-19. MedRxiv, 2020; 02: 18.

2. CHRIST-CRAIN M, et al. Endocrinologia no tempo de COVID-19: controle do diabetes insípido e hiponatremia. European Journal of Endocrinology, 2020; 183: 1.

3. MARTINEZ-ROJAS MA, et al. O rim é um alvo do SARS-CoV-2? American Journal of Phisiology, 2020; 17: 1454-1462.

4. SULEYMAN G, et al. Características clínicas e morbidades associadas à doença coronavirus 2019 em uma série de pacientes na região metropolitana de Detroit. JAMA Netw Open, 2020; 3(6). 


\title{
DESENVOLVIMENTO MOTOR DE CRIANÇAS COM A SÍNDROME CONGÊNITA DO ZIKA VÍRUS: UMA REVISÃO SISTEMÁTICA
}

\author{
Sabrina de Melo Oliveira ${ }^{1}$ \\ Vanessa Ferreira de Lima ${ }^{1}$ \\ Maria Eduarda Pinto Cavalcanti ${ }^{1}$ \\ Adalberto Rodrigues Pinto Junior ${ }^{1}$ \\ Bárbara Bernardo Figueirêdo²
}

1. Centro Universitário Tiradentes (UNIT), Recife - PE.

2. Universidade Federal de Pernambuco (UFPE), Recife - PE.

Palavras-chave: Síndrome congênita de Zika, Destreza motora, Criança.

\section{INTRODUÇÃO}

A Síndrome Congênita do Zika Vírus (SCZV) é classificada como uma doença rara que gera acometimentos múltiplos e características especificas (INSTITUTO DE PESQUISA ECONÔMICA APLICADA, 2018). Esta síndrome pode desencadear uma série de alterações encefálicas, como: microcefalia, calcificações intracranianas, malformação do desenvolvimento cortical, ventriculomegalia, epilepsia, cicatriz macular e diminuição do tecido cerebral (INSTITUTO DE PESQUISA ECONÔMICA APLICADA, 2018; OLIVEIRA MC, et al., 2021).

As manifestações clínicas podem impactar negativamente no desenvolvimento neuropsicomotor, gerando limitações motoras e atrasos múltiplos, afetando assim as aquisições de marcos motores da criança, levando a prejuízos nas habilidades funcionais (OLIVEIRA MC, et al., 2021; MARQUES FJP, et al., 2019; FRANÇA TLB, 2018).

\section{OBJETIVO}

Descrever as evidências cientificas, através de uma revisão sistemática, sobre o desenvolvimento motor de crianças com a Síndrome Congênita do Zika Vírus, a fim de evidenciar uma maior atenção a saúde da criança.

\section{MÉTODO}

Trata-se de uma revisão sistemática realizada através de buscas nas bases de dados, PubMed, Scielo, Portal Regional da BVS, Portal Periódicos da Capes e Cochrane Library. Foram encontrados 74 artigos científicos. Após a aplicação dos critérios de exclusão, restaram 63 estudos para a análise, destes, 5 foram incluídos nesta revisão. Os descritores utilizados foram: Motor Skills, Zika vírus, child, Congenital Zika Syndrome. 


\section{REVISÃO BIBLIOGRÁFICA}

Em um estudo observacional transversal que buscou avaliar a função motora bruta e fatores associados em crianças com SCZV, verificou-se o grave comprometimento motor, onde $81 \%$ das crianças foram classificadas no nível V da escala Gross Motor Function Classification System (GMFCS) (MELO A, et al., 2019). Em outro estudo que objetivou avaliar o desenvolvimento motor grosso de crianças com SCZV nos primeiros 2 anos de vida, verificou que aos 24 meses de idade, a maioria das crianças apresentou habilidades motoras grossas equivalentes à de crianças típicas com 4 meses ou menos (VENTURA PA, et al., 2020).

\section{CONSIDERAÇÕES FINAIS}

De acordo com os estudos revisados, demonstra-se o grave comprometimento motor dessas crianças. A avaliação motora de crianças com a SCZV é um desafio para os fisioterapeutas pediátricos brasileiros, os estudos revisados buscaram seguir as diretrizes preconizadas pelo Ministério da Saúde, mas ainda não existe um protocolo padrão-ouro validado para a avaliação motora dessa população. São necessários mais estudos sobre a avaliação do desenvolvimento motor das crianças com SCZV.

\section{REFERÊNCIAS}

1. FRANÇA TLB, et al. Growth and Development of Children with Microcephaly Associated with Congenital Zika Virus Syndrome in Brazil. International Journal of Environmental Research and Public Health, 2018; 15(9): 1990.

2. INSTITUTO DE PESQUISA ECONÔMICA APLICADA (IPEA). Epidemia do vírus Zika e microcefalia no Brasil: emergência, evolução e enfrentamento. 2018.2 Disponível em: https://www.ipea.gov.br/portal/images/stories/PDFs/TDs/td_2368.pdf. Acessado em: 10 de abril de 2021;

3. MARQUES FJP, et al. Children Born with Congenital Zika Syndrome Display Atypical Gross Motor Development and a Higher Risk for Cerebral Palsy. Journal Child Neurology, 2019; 34(2): 81-85.

4. MELO A, et al. Motor function in children with congenital Zika syndrome. Dev Med Child Neurol., 2020; 62: 221-16.

5. OLIVEIRA MC, et al. Habilidades funcionais da criança com Síndrome Congênita pelo Zika Vírus e sobrecarga da mãe. Revista Neurociências, 2021; 29: 1-23.

6. VENTURA PA, et al. Early Gross Motor Development Among Brazilian Children with Microcephaly Born Right After Zika Virus Infection Outbreak. J Dev Behav Pediatr., 2020; 41(2): 134-140. 


\section{CARACTERÍSTICAS DE CRIANÇAS E ADOLESCENTES INTERNADOS EM UNIDADE DE TERAPIA INTENSIVA ACOMETIDOS PELA A COVID-19}

Andresa Ferreira Lucena ${ }^{1}$

Sabrina de Melo Oliveira ${ }^{1}$

Breno Azevedo da Silva ${ }^{1}$

Bárbara Bernardo Figueirêdo²

1. Centro Universitário Tiradentes (UNIT), Recife - PE.

2. Universidade Federal de Pernambuco (UFPE), Recife - PE.

Palavras-chave: COVID-19, Unidade de terapia intensiva, pediatria.

\section{INTRODUÇÃO}

O vírus da COVID-19 causou infecções em diversas pessoas que o contraíram, ocasionando mortes por todo o mundo devido ao desenvolvimento da Síndrome Respiratória Aguda Grave (SRAG) (DONG E, 2020; GÖTZINGER F, 2020). O primeiro caso de acometimento pela COVID-19 em crianças foi relatado em janeiro de 2020, na cidade de Shenzen, na China. Essa patologia parece ser menos comum em crianças do que em adultos (DONG E, 2020). No Brasil, até 28 de agosto de 2021, entre os 1.056 .031 dos casos confirmados de hospitalizações por covid-19, 16.246 eram de crianças e adolescentes com idade $\leq 19$ anos o que representa $1,53 \%$ das hospitalizações (BRASIL, 2021).

\section{OBJETIVO}

Analisar e reunir as evidências científicas acerca das características encontradas em crianças e adolescentes acometidos com o vírus da COVID-19 e que necessitaram ser internados em Unidades de Terapia Intensiva (UTI).

\section{MÉTODO}

Trata-se de uma revisão integrativa da literatura, realizada através de buscas nas bases de dados SciELO, PubMed, Cochrane Library e Portal Regional da BVS. Foram encontrados 174 artigos científicos. Após a aplicação dos critérios de exclusão, restaram 170 estudos para a análise, destes, 4 foram incluídos nesta revisão. Os descritores utilizados foram: COVID-19, Pandemic, COVID-19, Severe Acute Respiratory Syndrome, SARS-CoV-2, Child, Adolescent, Intensive Care Units, Mechanical Ventilation, adult.

\section{REVISÃO BIBLIOGRÁFICA}


Em um estudo multicêntrico de coorte retrospectivo, que objetivou descrever as características clínicas e a dinâmica da doença dos casos pediátricos de Covid-19, verificou que dentre os 25 pacientes admitidos na UTI, 88\% apresentaram comorbidades, 36\% necessitaram de Ventilação Mecânica Invasiva (VMI) e 16\% morreram nas UTI (ALFRAIJ A, et al., 2021).

Em outro estudo que objetivou capturar rapidamente dados importantes sobre a Covid-19 em crianças na Europa, verificou que dentre os 48 que foram internados nas UTI, 25 necessitaram de VMI e apresentaram sintomas como: pirexia, infecção no trato respiratório, desconfortos gastrointestinais e cefaleia (GÖTZINGER F, et al., 2020).

\section{CONSIDERAÇÕES FINAIS}

Diante dos estudos analisados, a maioria dos pacientes pediátricos que necessitaram de internação na UTI apresentavam comorbidades pré-existentes. Os sintomas mais comuns relatados foram: pirexia, cefaleia, êmese, infecção no trato respiratório superior e inferior. São necessários estudos com amostras maiores, que demonstrem as características da população pediátrica acometida pela Covid-19 e que necessitou de internação em UTI.

\section{REFERÊNCIAS}

1. ALFRAIJ A, et al. Characteristics and outcomes of coronavirus disease 2019 (COVID-19) in critically ill pediatric patients admitted to the intensive care unit: A multicenter retrospective cohort study. Journal of Infection and Public Health. 2021; 14(2): 193-200.

2. BRASIL. Ministério da Saúde. Doença pelo Novo Coronavírus - COVID-19. Boletim Epidemiológico Especial. 2021. Disponível em: https://www.gov.br/saude/pt-br/assuntos/boletins-epidemiologicos. Acessado em: 15 de setembro de 2021.

3. DONG Y, et al. Epidemiological Characteristics of 2143 Pediatric Patients With 2019 Coronavirus Disease in China. Pediatrics, 2020; 145(6): e20200702.

4. GARCÍA-SALIDO A. et al. Children in Critical Care Due to Severe Acute Respiratory Syndrome Coronavirus 2 Infection: Experience in a Spanish Hospital. Pediatric Critical Care Medicine, 2020; 21(8): 576-580.

5. GÖTZINGER F, et al. COVID-19 in children and adolescents in Europe: a multinational, multicentre cohort study. TheLancet Child \& Adolescent Health, 2020; 4(9): 653-661. 


\title{
A RELEVÂNCIA DO ATENDIMENTO ESTOMATOLÓGICO PARA O DIAGNÓSTICO DE DESORDENS COM POTENCIAL DE TRANSFORMAÇÃO MALIGNA
}

\author{
Karen Oliveira Silva ${ }^{1}$ \\ Mirela Carolaine Cunha da $\mathrm{Cruz}^{2}$ \\ Ivam Vicente da Silva ${ }^{2}$ \\ Evelyne Pedroza de Andrade ${ }^{1}$
}

1. Centro Universitário Tiradentes (UNIT), Recife - PE.

2. Universidade Federal de Pernambuco (UFPE), Recife - PE.

Palavras-chave: Estomatologia, Lesões com potencial maligno, Carcinoma.

\section{INTRODUÇÃO}

As desordens com potencial de transformação maligna que acometem a cavidade oral ainda possuem uma etiologia desconhecida e, normalmente, tendem a ser assintomáticas e com manifestações clínicas marcantes, tais quais: placa branca não removível a raspagem, atrofia da borda do vermelhão do lábio inferior e áreas de crosta (ARAÚJO ACS, et al., 2019).

O exame clínico, realizado pelo cirurgião dentista, em associação com a biópsia e o exame histopatológico, consiste em um método eficaz para diagnosticar as desordens com potencial de malignidade, o que facilita em um melhor plano de tratamento e, se feito precocemente, em um prognóstico favorável da doença para o paciente (CASOTTI E, et al., 2016).

\section{OBJETIVO}

Revisar a literatura científica sobre o papel fundamental dos atendimentos estomatológicos, no diagnóstico, tratamento e acompanhamento das desordens com potencial de transformação maligna que acometem a cavidade oral, viabilizando o correto manejo dessas patologias.

\section{REVISÃO BIBLIOGRÁFICA}

Em um estudo de prevalência, 131 de 2.706 pacientes tiveram o diagnóstico de lesões orais com potencial de transformação maligna, sendo a queilite actínica a mais recorrente com 50,4\% dos casos, em seguida a leucoplasia com 45,2\% (RODRIGUES K, et al., 2018). Outro estudo realizado na zona rural do município de Governador Mangabeira com 223 trabalhadores rurais, com idade entre 18 e 91 anos, em que 214 (96,0\%) desses indivíduos alegaram trabalhar expostos ao sol e $71(31,8 \%)$ apresentou lesões orais de queilite actínica (TEIXEIRA A, et al., 2019).

Ao analisar os artigos percebe-se que, no último século, houve um aumento considerável na incidência de lesões com potencial de malignidade, pelo aumento de influências externas prejudiciais à saúde bucal, como 
o uso excessivo do cigarro e do álcool, além de uma maior exposição solar sem fatores de proteção. 0 diagnóstico precoce por parte do estomatologista é de extrema importância para prevenir que a lesão progrida para um carcinoma que, por vezes, é diagnosticado tardiamente e a chance de sobrevida do paciente diminui em até 50\% (IPARRAGUIRRE MF, et al., 2020).

\section{CONSIDERAÇÕES FINAIS}

A partir dos dados encontrados na literatura, as doenças com potencial de transformação maligna devem ser consideras um problema de saúde pública e fomentada a conscientização do paciente sobre a importância de procurar um cirurgião dentista, em especial o estomatologista, a qualquer alteração bucal aparente, para que o diagnóstico precoce seja realizado e, consequentemente, diminuir as chances da lesão evoluir para um carcinoma.

\section{REFERÊNCIAS}

1. ARAÚJO ACS, et al. Ocorrência sincrônica de Carcinoma Espinocelular Bucal Microinvasor e Adenocarcinoma Pulmonar: relato de caso. Revista Eletrônica Acervo Saúde, 2019; 11(12): 1-9.

2. CASOTTI E, et al. Organização dos serviços públicos de saúde bucal para diagnóstico precoce de desordens com potencial de malignização do estado do Rio de Janeiro, Brasil. Ciência \& Saúde Coletiva, 2016; 21: 1573-1582.

3. IPARRAGUIRRE MF, et al. Desordenes orales potencialmente malignos-Lo que el odontólogo debe conocer. Revista Estomatológica Herediana, 2020; 30: 216-223.

4. RODRIGUES KS, et al. Desordens orais potencialmente malignas: um estudo de prevalência. Revista Cirurgia e Traumatologia Buco-Maxilo-Facial, 2018; 18: 6-15.

5. TEIXEIRA ACOC, et al. Presença de queilite actínica em trabalhadores da zona rural de Governador Mangabeira atendidos nas unidades básicas de saúde. Revista Textura, 2019; 13: 176-189. 


\title{
AÇÃO DAS PROTEÍNAS SALIVARES NO DESENVOLVIMENTO DO BIOFILME DE CANDIDA ALBICANS EM PESSOAS COM DOENÇA DE PARKINSON
}

\author{
Ivam Vicente da Silva ${ }^{1}$ \\ Kezia Maria Dias Silva ${ }^{1}$ \\ Karen Oliveira Silva ${ }^{2}$ \\ Gabryelle Maria da Silva Lira ${ }^{1}$ \\ Carla Cabral dos Santos Accioly Lins ${ }^{1}$
}

1. Universidade Federal de Pernambuco (UFPE), Recife - PE.

2. Centro Universitário Tiradentes (UNIT), Recife - PE.

Palavras-chave: Doença de Parkinson, Saúde bucal, Odontologia.

\section{INTRODUÇÃO}

O biofilme pode ser compreendido como comunidades biológicas embebidas em matrizes poliméricas de polissacarídeos com elevado grau de organização. Nessas comunidades há fungos capazes de sintetizar o biofilme, um deles é a Candida albicans. Este, por sua vez, apresenta elevada afinidade pela matriz do biofilme o que acarreta sua adesão aos tecidos do hospedeiro (CACHOEIRA VS, et al., 2018).

A formação dessa película na superfície do dente acontece cotidianamente e sofre efeitos diretos dos métodos de limpeza empregados pelo paciente (ROCHA EF, et al., 2019). Dessa forma, é de grande valia destacar que a higienização oral de pessoas com Parkinson costuma ser deficiente devido aos tremores ou a rigidez muscular (FROTA BMD, et al.,2016).

\section{OBJETIVO}

Revisar a literatura científica e realizar uma descrição narrativa sobre a atividade das proteínas salivares na promoção do biofilme de Candida albicans em pessoas diagnosticadas com a Doença de Parkinson (DP).

\section{REVISÃO BIBLIOGRÁFICA}

A literatura descreve que alterações na cavidade bucal, como variações do conteúdo protéico salivar, podem modular proporcionalmente a virulência de biofilmes (FROTA BMD, et al., 2016). A histatina 5, estaterina, lactoferrina e mucina são proteínas salivares que apresentam propriedades antifúngicas. Apesar de suas propriedades antimicrobianas, estão sujeitas a alterações que podem afetar seu funcionamento. A DP ocasiona limitações físicas que dificultam a remoção adequada do biofilme. Dessa maneira, a má higienização oral permite uma proliferação demasiada de microorganismos que, por consequência, proporciona condições adequadas à síntese do biofilme pela levedura da Candida albicans (FERREIRA BBM, et al., 2017). 
As condições precárias de saúde bucal de pessoas com DP são capazes de evoluir para infecções fúngicas bucais que, se não receberem o tratamento correto, podem causar halitose, xerostomia, eritema e placas brancas removidas à raspagem com caráter recidivante. Além dessas possibilidades sintomatológicas, também é possível que o epitélio oral sofra ulcerações aftosas que exponham o tecido conjuntivo adjacente causando dor e desconforto durante a alimentação (CACHOEIRA VS, et al., 2018; FROTA BMD, et al., 2016).

\section{CONSIDERAÇÕES FINAIS}

Portanto, é possível perceber e reiterar a necessidade de pessoas com a Doença de Parkison serem acompanhadas frequentemente por uma equipe multiprofissional especialista em tratar pessoas com necessidades especiais, na qual tenha um Cirurgião-dentista que servirá para orientar, auxiliar e prevenir agravos nas condições de saúde bucal.

\section{REFERÊNCIAS}

1. CACHOEIRA VS, et al. Desenvolvimento e aplicação de métodos para formação de biofilme de Candida albicans em reembasadores temporários. Archives of health investigation, 2018; 7(6): e3874.

2. FROTA BMD, et al. Avaliação das condições orais em pacientes com doenças neurodegenerativas atendidos em centros geriátricos. RGO-Revista Gaúcha de Odontologia, 2016; 64(1): 17-23.

3. FERREIRA BBM, et al. A Intervenção Odontológica e a Visão da Equipe Multidisciplinar em Pacientes Portadores de Parkinson do Hospital Dia Geriátrico de Anápolis. Scientific Investigation in Dentistry, 2017; 22(1): 76-81.

4. ROCHA EF, et al. Envelhecimento Humano e Desenvolvimento da Doença Periodontal. Revista Eletrônica Acervo Saúde, 2019; 19(26): e775. 


\title{
O EFEITO DA TERAPIA CIRÚRGICA POR MEIO DA IMPLANTOPLASTIA NA RESOLUÇÃO DA DOENÇA PERI- IMPLANTAR: REVISÃO INTEGRATIVA
}

\author{
Thalles Yurgen Balduino ${ }^{1}$ \\ Lucas Menezes dos Anjos ${ }^{1}$ \\ Aurélio de Oliveira Rocha ${ }^{1}$
}

1. Universidade Federal de Santa Catarina (UFSC), Florianópolis - SC.

Palavras-chave: Implantoplastia, Biofilme, Peri-implantite.

\section{INTRODUÇÃO}

A peri-implantite é uma condição patológica de origem bacteriana que afeta tecidos em torno dos implantes dentários, podendo ocasionar a perda óssea marginal (AIRES CCG, et al., 2020). Estudos demostram que abordagens clínicas no tratamento da peri-implantite, como a intervenção não-cirúrgica, não tem fornecido bons resultados (BIANCHINI MA, et al., 2019; LASSERRE JF, et al., 2020).

Para contornar este fato, a intervenção cirúrgica, por meio da implantoplastia, que é a modificação da superfície do implante, através da remoção das roscas expostas e descontaminação antibacteriana da superfície do implante, tem sido proposta como uma alternativa mais eficaz, devido a possibilidade de acesso ao local da infecção (BIANCHINI MA, et al., 2020).

\section{OBJETIVO}

Revisar a literatura existente em relação ao feito da terapia cirurgica por meio da implantoplastia no tratamento da peri-implantite, permitindo assim avaliar se esta abordagem pode ajudar a recuperar a saúde dos tecidos moles peri-implantes.

\section{MÉTODO}

O estudo constituiu de uma revisão integrativa da literatura. As fontes de dados destinados a leitura e análise foram selecionadas através do Pubmed, no período do mês de setembro. Procedeu-se à análise de 45 artigos dos últimos 5 anos, dos quais somente 4 foram selecionados, sendo excluindos aqueles que não atendessem a temática proposta, utilizando como descritores: "Implantoplasty AND Surgical Treatment OR Resective Therapy AND Peri-implant Disease OR Peri-implantitis".

\section{REVISÃO BIBLIOGRÁFICA}

A implantoplastia em um estudo com acompanhamento de 3 anos, demonstrou uma diminuição na profundidade de sondagem de $4,75 \pm 4 \mathrm{~mm}$ e uma redução no índice de sangramento a sondagem em $71 \%$ (BIANCHINI MA, et al., 2020). Em um estudo retrospectivo de 32 implantes, a resolução da doença foi de 
83\% (nível do paciente), com ausência de perda óssea adicional em $87 \%$ dos implantes tratados e ausência de $89,3 \%$ de sangramento a sondagem (BIANCHINI MA, et al., 2019). Somando-se aos achados, uma revisão sistemática com meta-análise, verificou que a taxa de sucesso pós implantoplastia de $97,5 \%$ aos 6 meses e 94,7\% aos 24 meses (LIMA RPE, et al., 2021).

\section{CONSIDERAÇÕES FINAIS}

A implantoplastia tem sido considerada uma alternativa encorajadora para tratar a peri-implantite e prevenir a perda óssea marginal. Todos os cinco estudos demonstraram que a implantoplastia contribuiu para uma melhora significativa da condição peri-implantar, reduzindo a profundidade de sondagem, sangramento, supuração à sondagem e perda óssea marginal, além do que, não relataram nenhuma dor ou fratura dos implantes.

\section{REFERÊNCIAS}

1. AIRES CCG, et al. Etiologia e tratamento das doenças peri-implantares. Revista Eletrônica Acervo Saúde, 2020; 12(11): 4931-4931.

2. BIANCHINI MA, et al. Implantoplasty enhancing peri-implant bone stability over a 3-year follow-up: a case series. Int J Periodontics Restorative Dent, 2020; 40(1): e1-e8.

3. BIANCHINI MA, et al. Two to six-year disease resolution and marginal bone stability rates of a modified resective- implantoplasty therapy in 32 peri-implantitis cases. Clinical implant dentistry and related research, 2019; 21(4): 758-765.

4. LASSERRE JF, et al. Implantoplasty Versus Glycine Air Abrasion for the Surgical Treatment of Periimplantitis: A Randomized Clinical Trial. International Journal of Oral \& Maxillofacial Implants, 2020; 35(1).

5. LIMA RPE, et al. Is implantoplasty efficacious at treating peri-implantitis? a systematic review and metaanalysis. Journal of Oral and Maxillofacial Surgery, 2021; 79(11):2270-2279. 
RESUMO SIMPLES: Revisão Integrativa

\title{
A ENFERMAGEM EM CASOS RAROS DE CÂNCER DE MAMA MASCULINO: UMA REVISÃO INTEGRATIVA DA LITERATURA
}

\author{
Matheus de Sousa ${ }^{1}$ \\ Hernandes Flanklin Carvalho Oliveira ${ }^{1}$ \\ Suzana Honória de Sousa²
}

1. Universidade Estadual do Piauí (UESPI), Floriano - PI.

2. Universidade Estadual do Piauí (UESPI), São Francisco de Assis do Piauí - PI.

Palavras-chave: Câncer de mama, Saúde do homem, Enfermagem.

\section{INTRODUÇÃO}

O câncer é conhecido e definido como uma doença crônica que tem o crescimento caótico das células. Existem vários tipos de cânceres malignos e, um dos mais comuns é a neoplasia de mama, que habitualmente tem sua incidência aumentada a cada ano, assim como, sua frequência em diversos países. É uma doença bastante prevalente e tem sido focado em diversos estudos, e em comparação ao número de casos de cânceres de mamas em mulheres e homens, o ultimo representa números bem inferiores de todos os cânceres mamários (AMARAL DED, et al., 2017).

\section{OBJETIVO}

Analisar com base no introdutório e visando uma maior captação de conhecimento acerca da temática, o presente estudo objetiva discorrer sobre a enfermagem em casos raros de câncer de mama masculino.

\section{MÉTODO}

Revisão integrativa, pelas bases de dados LILACS, MEDLINE e BDENF, com descritores "Câncer de Mama", "Saúde do Homem" e "Enfermagem" integrados pelo operador "AND". Dos 2.269 resultados, após a aplicação dos filtros: publicação entre os anos de 2017 e 2021, disponíveis gratuitamente e nos idiomas português ou espanhol, foram obtidos 62 artigos; foram excluídos os estudos secundários, os duplicados e os que não faziam parte da temática, restando 03 artigos.

\section{REVISÃO BIBLIOGRÁFICA}

A nação Brasileira segue em propensão mundial quanto ao crescimento do número de óbitos por carcinoma de mama masculino. Em relação as circunstâncias dos homens ao adoecer, tratar e sobreviver, constatou-se que os homens apresentaram sinais característicos da patologia e procuraram os serviços de saúde em estado avançado. Os homens apresentam resistência à adesão ao tratamento e enfrentamento da patologia devido à carência de conhecimento do. Contudo, existem brechas nas políticas de atenção voltadas 
a esse gênero, as quais não conseguem atingir importe eficaz, principalmente nas áreas carentes onde ocorre repulsão no acesso às informações e aos serviços de saúde (SILVA JFC, et al., 2020; RAMOS SS, et al., 2017).

\section{CONSIDERAÇÕES FINAIS}

O profissional de enfermagem como agente de promoção de saúde e prevenção de doenças é de extrema importância, a fim de promover através de educação em saúde, a ampliação do conhecimento sobre população sobre a doença, fornecendo assim, conhecimento a esse público.

\section{REFERÊNCIAS}

1. AMARAL DED, et al. Câncer de mama masculino: o contexto do sobrevivente. Revista de enfermagem UFPE on line., Recife, 2017; 11(5):1783-90.

2. SILVA JFC, et al. Mortalidade por câncer de mama masculino nas regiões brasileiras e nos Estados do Nordeste. Revista Saúde (Sta. Maria). 2020; 46(2).

3. RAMOS SS, et al. Conhecimentos, mitos e implicações para o cuidado de enfermagem no câncer de mama masculino. Revista Enfermagem Atual. 2017; 83. 


\title{
O USO DA QUITOSANA NO TRATAMENTO DA PERIODONTITE: UMA REVISÃO INTEGRATIVA DA LITERATURA
}

\author{
Thalles Yurgen Balduino ${ }^{1}$ \\ Lucas Menezes dos Anjos ${ }^{1}$ \\ Aurélio de Oliveira Rocha ${ }^{1}$
}

1. Universidade Federal de Santa Catarina (UFSC), Florianópolis - SC.

Palavras-chave: Quitosana, Biofilme, Administração periodontal de medicamentos.

\section{INTRODUÇÃO}

A periodontite é uma doença inflamatória crônica multifatorial mediada pelo hospedeiro e associada com biofilme, caracterizada pela destruição progressiva do periodonto de sustentação (ROCHA EF, et al., 2019). Tendo em vista a dificuldade de controle dos micro-organismos da cavidade oral, materiais mais eficientes na prevenção de patologias orais vêm sendo estudados (THANGAVELU A, et al., 2021). Nesse universo, a quitosana, um biopolímero, resultado da dessatilização da quitina, oriunda do exoesqueleto de crustáceos, apresenta-se como uma nova possibilidade, no tratamento da periodontite, devido as suas comprovadas propriedades anti-inflamatórias e cicatrizantes (SAH AK, et al., 2019).

\section{OBJETIVO}

Revisar e analisar, por meio da literatura existente, a aplicação da quitosana como material biológico no tratamento da periodontite, avaliando suas propriedades, a fim de, enteder este biopolímero, como um interessante biomaterial coadjuvante no tratamento da periodontite.

\section{MÉTODO}

O estudo constitui de uma revisão integrativa da literatura. As fontes de dados destinados a leitura e análise do trabalho foram selecionadas através das bases de dados: Scielo, Pubmed e Medline, no mês de setembro de 2021. Procedeu-se à análise de 5 artigos dos últimos 5 anos, sendo excluídos aqueles que não atendessem a temática proposta. Foram utilizados os descritores: "Chitosan AND Biopolymer OR Biomaterial AND Periodontal Disease OR Periodontitis".

\section{REVISÃO BIBLIOGRÁFICA}

Avanços científicos e tecnológicos na área de biomateriais passaram a ser vistos como uma alternativa na engenharia biomédica, no desenvolvimento, de moléculas biocompatíveis para uso clínico na odontologia (THANGAVELU A, et al., 2021). A quitosana apresenta características importantes como a biocompatibilidade; biodegradabilidade; bioadesivdade e bioatividade (ÖZDOĞAN Al, et al., 2018). 
Além de possuir ação anti-inflamatória; antimicrobiana; hidrofílica; hemostática e atóxica, atuando na regeneração tecidual e potencializando o processo de diferenciação osteogênica (ASHRI LY, et al., 2020). Entre as várias abordagens prospectivas, os sistemas de entrega baseados em quitosana, apresenta-se como uma importante biomolécula, com uma iminente capacidade de ação no que se refere ao tratamento de patologias periodontais em um futuro próximo. (SAH AK, et al., 2019).

\section{CONSIDERAÇÕES FINAIS}

Como persectivas futuras, é provável que o foco permaneça no uso da quitosana como um importante biomaterial, empregado in situ ou sendo administrado como veículo, como por exemplo na forma de gel ou chips. Além disso, pode ser usado na composição de arcabouços, que visam a entrega in situ de forma lenta de fármacos no tratamento da periodontite, devido suas características de ação preventiva e curativa no processo de saúde-doença.

\section{REFERÊNCIAS}

1. ASHRI LY, et al. Optimization and evaluation of chitosan buccal films containing tenoxicam for treating chronic periodontitis: In vitro and in vivo studies. Journal of Drug Delivery Science and Technology, 2020; (57): 101720.

2. ROCHA EF, et al. Evandro Franco, et al. Envelhecimento humano e desenvolvimento da doença periodontal. Revista Eletrônica Acervo Saúde, 2019; (26): e775.

3. ÖZDOĞAN AI, et al. In vivo evaluation of chitosan based local delivery systems for atorvastatin in treatment of periodontitis. International journal of pharmaceutics, 2018; 550 (1-2): 470-476.

4. SAH AK, et al. Potential of chitosan-based carrier for periodontal drug delivery. Colloids and Surfaces B: Biointerfaces, 2019; (178): 185-198.

5. THANGAVELU A, et al. An overview of chitosan and its role in periodontics. Journal of Pharmacy And Bioallied Sciences, 2021; 13(5): 15. 


\title{
AGENTES OXIGENANTES EM ANTISSÉPTICOS ORAIS COMO ALTERNATIVA NO TRATAMENTO DA MUCOSITE E PERI-IMPLANTITE
}

\author{
Thalles Yurgen Balduino ${ }^{1}$ \\ Lucas Menezes dos Anjos ${ }^{1}$ \\ Aurélio de Oliveira Rocha ${ }^{1}$
}

1. Universidade Federal de Santa Catarina (UFSC), Florianópolis - SC.

Palavras-chave: Oxigênio, Antisséptico, Doenças peri-implantares.

\section{INTRODUÇÃO}

As doenças peri-implantares são caracterizadas por alterações inflamatórias na mucosa ao redor de implantes, classificadas como mucosite e peri-implante, mas, somente a peri-implantite é responsável pela perda óssea de suporte (SCHWARZ F, et al., 2018). Na atualidade, vários estudos propõem diferentes tratamentos peri-implantares, como abordagens cirúrgicas e não cirúrgicas, no entanto, nenhum deles foi eleito um na como referência no tratamento da mucosite e peri-implantite (BIANCHINI MA, et al., 2019). Nesse contexto agentes oxigenantes anti- placas têm surgido como uma alternativa inteligente, em comparação aos agentes antimicrobianos de amplo espectro, pois não erradicam a microbiota oral e mantém o equilíbrio da saúde bucal (VASTHAVI C, et al., 2020).

\section{OBJETIVO}

Revisar a literatura científica com o objetivo de compreender melhor a respeito dos efeitos de agentes oxigenantes em antissépticos orais, como método alternativo na gestão do tratamento das doenças periimplantares.

\section{REVISÃO BIBLIOGRÁFICA}

$\mathrm{Na}$ atualidade, existe uma diversidade de antissépticos bucais disponíveis, contendo vários acingredientes ativos, e o papel da equipe odontológica é aconselhar o seu uso de forma adequada (MOSTAJO MF, et al., 2017). Antissépticos como a clorexidina, não é isenta de efeitos secundários, como manchamento extrínseco do esmlate dental e alteração das papilas gustativas (BOTELHO MPJ, et al., 2017). Esse fato remete à busca de alternativas para a utilização da clorexidina, a fim de que se obtenham resultados sem efeitos colaterais (CAMPOS FRANÇA E, et al., 2021).

O uso de agentes oxigenantes, que apresentam o oxigênio, em sua composição, oferece muitos benefícios no tratamento das doenças peri-implantares, dentre eles, efeito antimicrobiano, imprescindível na manutenção de cepas sensíveis ao efeito do oxigênio, usadas por fagócitos, na atividade bacteriana, levando a uma redução na colonização de baterias anaeróbias e gram negativas, associadas a infecções como a mucosite e a peri-implantite, além de sua eficácia no processo de cicatrização, promovendo a angiogênese e 
revascularização, além de sua atividade essencial para manutenção tecidual; aumentando o metabolismo celular e produção de energia (MOSTAJO MF, et al., 2017).

\section{CONSIDERAÇÕES FINAIS}

Os agentes oxigenantes, estão disponíveis na sua grande maioria a população geral, e seus os efeitos no tratamento de doenças periodontais e peri-implantares parecem ser promissores, devido as mudanças no comportamento do biofilme. Entretanto, dados existentes na literatura, por meio de evidências científicas para o seu uso estão subnotificadas, havendo a necessidade de maiores estudos em condições controladas testando esses compostos.

\section{REFERÊNCIAS}

1. BIANCHINI M A, et al. Two to six-year disease resolution and marginal bone stability rates of a modified resective- implantoplasty therapy in 32 peri-implantitis cases. Clinical implant dentistry and related research, 2019; 21(4): 758- 765.

2. BOTELHO MPJ, et al. Avaliação in vitro da atividade antimicrobiana de extrato alcoólico de própolis comparado à solução de clorexidina 0,12\%. Journal of Health Sciences, 2017; 19(2): 95-97.

3. CAMPOS FRANÇA E, et al. Efeito de um sistema de liberação controlada de clorexidina para o controle de placa e gengivite. Revista Eletrônica Acervo Saúde, 2021; 13(5): e7329.

4. MOSTAJO MF, et al. Effect of mouthwashes on the composition and metabolic activity of oral biofilms grown in vitro. Clinical oral investigations, 2017; 21(4): 1221-1230.

5. SCHWARZ F, et al. Peri-implantitis. Journal of clinical periodontology, 2018; (45): s246-s266.

6. VASTHAVI C, et al. Evaluation of ozone as an adjunct to scaling and root planing in the treatment of chronic periodontitis: A randomized clinico-microbial study. Journal of Indian Society of Periodontology, 2020; (241): 42. 
RESUMO SIMPLES: Revisão Narrativa

\section{MANEJO ODONTOLÓGICO EM PACIENTES SOB USO DE ANTICOAGULANTES SUBMETIDOS A EXODONTIA - REVISÃO NARRATIVA}

Lucas Menezes dos Anjos ${ }^{1}$

Aurélio de Oliveira Rocha ${ }^{1}$

Rafaela de Menezes dos Anjos Santos ${ }^{1}$

Thalles Yurgen Balduino²

Thaine Oliveira Lima ${ }^{1}$

1. Universidade Federal de Santa Catarina (UFSC), Florianópolis - SC.

2. Universidade Federal de Sergipe (UFS), Aracaju - SE.

Palavras-chave: Cirurgia oral, Aspirina, Odontologia.

\section{INTRODUÇÃO}

As intercorrências associadas a exodontias podem estar associadas a variações anatômicas, falta de experiência na execução da técnica cirúrgica pelo operador, complicações associadas a condições sistémicas ou uso crônico de algumas medicações (MAHMOOD H, et al., 2020). A realização de exodontia em pacientes que fazem uso de anticoagulante plaquetário pode aumentar o risco de hemorragia no traz ou pós-operatório, assim como sua suspensão previa ao procedimento cirúrgico pode levar ao risco de complicações tromboembólicas (de ARAUJO HVS, et al., 2021). Diante disso, é necessário conhecer as consequências sistêmicas e locais da suspensão ou não dos anticoagulantes na cirurgia oral menor (CALISKAN M, et al., 2017).

\section{OBJETIVO}

Revisar os achados na literatura sobre a conduta necessária diante de pacientes que fazem uso de anticoagulante que necessitam ser submetidos a exodontia, assim como a necessidade ou não de suspender a terapêutica anticoagulante previamente ao procedimento cirúrgico.

\section{REVISÃO BIBLIOGRÁFICA}

Estudos indicam que a suspensão de anticoagulantes previamente a exodontia não mostram redução significativa do sangramento quando comparados aos pacientes que não foi a suspenção da medicação (MANOR Y, et al., 2021). Quando é recomendado ao paciente a interrupção do uso de anticoagulante, deve ser levado em consideração os riscos de complicações tromboembólicas, sendo necessário parecer medico prévio a conduta adotada (de ARAÚJO HVS, et al., 2021).

O risco associado a suspensão dos anticoagulantes plaquetário traz mais risco a vida do paciente do que uma possível hemorragia no transoperatório (MOHMOOD H, et al., 2020). Nenhum relato de aumento no 
sangramento foi percebido nos pacientes que fazem uso desse tipo de mediação, e complicações como invalidez permanente ou morte, podem estar associados a episódios tromboembólicos quando se opta pela suspensão medicamentosa (MOHMOOD H, et al., 2020).

Medidas de hemostasia local como suturas me massa, utilização de soro fisiológico gelado, compressa com gaze por cinco minutos e coagulantes plaquetários diretamente no osso alveolar, devem ser usadas para diminuir o risco de sangramento, assim como conter possíveis hemorragias (CALISKAN M, et al., 2017).

\section{CONSIDERAÇÕES FINAIS}

Diante do risco de hemorragia em exodontias nos pacientes que fazem uso de anticoagulantes, a suspensão ou não da medicação deve ser baseada em uma anamnese detalhada e em conjunto com o médico do mesmo. A literatura necessita de mais estudos para validar protocolos de atendimentos para esses pacientes, sendo necessários tanto estudos clínicos como revisões dos dados já existentes.

\section{REFERÊNCIAS}

1. CALISKAN M, et al. Is it necessary to alter anticoagulation therapy for tooth extraction in patients taking direct oral anticoagulants? Med Oral Patol Oral Cir Bucal, 2017; 6: 767-73.

2. de ARAÚJO HVS, et al. Qualidade de vida de pacientes em tratamento com anticoagulante oral. Revista Eletrônica Acervo Saúde, 2021; 13(3): 6626-6626.

3. MAHMOOD H, et al. Antiplatelet drugs: a review of pharmacology and the perioperative management of patients in oral and maxillofacial surgery. Ann R Coll Surg Engl, 2020; 102(1): 9-13.

4. MANOR $Y$, et al. A retrospective analysis of dental implantation under anticoagulant treatment. Clin Oral Investig, 2021; 25(3): 1001-1009. 
RESUMO SIMPLES: Revisão Narrativa

\section{ANESTESIA CONTROLADA ELETRONICAMENTE EM ODONTOLOGIA - REVISÃO NARRATIVA}

Lucas Menezes dos Anjos ${ }^{1}$

Aurélio de Oliveira Rocha ${ }^{1}$

Rafaela de Menezes dos Anjos Santos ${ }^{1}$

Thalles Yurgen Balduino²

Thaine Oliveira Lima ${ }^{3}$

1. Universidade Federal de Santa Catarina (UFSC), Florianópolis - SC.

2. Universidade Federal de Sergipe (UFS), Aracaju - SE.

3. Universidade Tiradentes (Unit), Aracaju - SE.

Palavras-chave: Ansiedade, Anestesia odontológica, Dor.

\section{INTRODUÇÃO}

A anestesia odontológica pode estar associada a aumento da ansiedade e medo no paciente, podendo atuar como uma barreira para o tratamento odontológico (DO NASCIMENTO COELHO SK, et al., 2021). A ansiedade e medo podem se originar de experiências de dor durante tratamentos anteriores (GARRETBERNARDIN A, et al., 2017). Como o objetivo de diminuir o desconforto associado a anestesia convencional, foi desenvolvido o sistema de anestesia controlada eletronicamente, o qual deposita pequenas gotas de anestésico nos tecidos diminuindo o desconforto da penetração da agulha, como também reduz a compressão dos feixes nervosos da região reduzindo, assim, a dor durante a execução da técnica (SILVA BS, et al., 2020).

\section{OBJETIVO}

Revisar os achados na literatura sobre a anestesia controlada eletronicamente como alternativa para diminuição da dor associada a execução da técnica anestésica local em comparação a anestesia convencional por meio da seringa carpule.

\section{REVISÃO BIBLIOGRÁFICA}

A anestesia local é o método mais comum para controle da dor durante procedimentos odontológicos, sendo realizada de forma convencional por meio do tubete anestésico e agulha acoplados a seringa carpule (DO NASCIMENTO COELHO SK, et al., 2021). Apesar da técnica anestésica ser utilizada para evitar ou diminuir a dor relacionada aos procedimentos odontológicos, a admiração da solução anestésica nos tecidos bucais está associada a aumento da ansiedade e medo pelo paciente, pois esse procedimento pode levar a desconforto ou dor (GARRET-BERNARDIN A, et al., 2017). 
Como alternativa para a execução de anestesia convencional utilizando a seringa carpule, foi desenvolvida a anestesia controlada eletronicamente, a qual propõe diminuição da dor associada a punção da agulha e analgesia satisfatória das terminações nervosas (SILVA BS, et al., 2020). Para tal, o software programa a deposição de pequenas gotas de solução anestésica ao longo do trajeto da agulha, assim com deposição lenta do sal anestésico nas terminações nervosa, resultando em diminuição da compressão dos feixes nervosos regionais, culminando em menor dor, sendo considerada uma técnica eficaz e segura (SILVA BS, et al., 2020).

\section{CONSIDERAÇÕES FINAIS}

O desconforto associado a realização da técnica anestésica convencional com utilização da seringa carpule pode levar a aumento da ansiedade ou medo no paciente odontológico. A utilização da anestesia controlada eletronicamente permite a execução da anestesia local de forma satisfatória e com diminuição significativa do desconforto ou dor associado a anestesia. A literatura carece de estudos clínicos conclusivos para sedimentação da eficácia dessa técnica.

\section{REFERÊNCIAS}

1. do NASCIMENTO COELHO SK, et al. A utilização dos anestésicos locais em odontologia: revisão de literatura. Revista Eletrônica Acervo Saúde, 2021; 13(1): 5402-5402.

2. GARRET-BERNARDIN A, et al. Pain Experience and Behavior Management in Pediatric Dentistry: A Comparison between Traditional Local Anesthesia and the Wand Computerized Delivery System. Pain Research and Management, 2017; 1: 1-6.

3. SILVA BS, et al. Técnicas inovadoras de anestesia local indolor. Revista de Odontologia da Braz Cubas, 2020; 10(1): 1-6. 


\title{
CORONECTOMIA DE TERCEIROS MOLARES: UMA ALTERNATIVA DE TRATAMENTO QUANTO A PROXIMIDADE DO NERVO ALVEOLAR INFERIOR
}

\author{
João Victor Nascimento Oliveira ${ }^{1}$ \\ Ana Clara Fernandes Fabiano ${ }^{1}$ \\ Julia Pereira das Chagas ${ }^{1}$ \\ Maisa França Teixeira ${ }^{1}$
}

1. Faculdade Evangélica de Goianésia (FACEG), Goianésia - GO.

Palavras-chave: Coronectomia, Sepultamento, Extração.

\section{INTRODUÇÃO}

Coronectomia ou Odontectomia parcial intencional é uma técnica cirúrgica utilizada pelos cirurgiõesdentistas, nos casos de terceiros molares próximos ao nervo alveolar inferior (NAI) que tem como indicação, a extração. Esta técnica está relacionada a odontossecção da parte coronária do dente, onde as raízes são deixadas dentro do alvéolo dentário (MASCARENHAS CL, et al., 2020). Essa alternativa também é conhecida pelo termo "sepultamento das raízes", que na década de 70 , acreditava-se que a estrutura radicular preservava a altura do rebordo alveolar, melhorando a adaptação de uma possível prótese dentária convencional (DIAS RIBEIRO E, et al., 2015).

\section{OBJETIVO}

Revisar a literatura científica com o objetivo de compreender o uso da técnica de Coronectomia e a sua eficácia quanto a proximidade do canal mandibular (NAI), para que, assim, seja considerada uma alternativa de tratamento.

\section{REVISÃO BIBLIOGRÁFICA}

No decorrer do estudo dos artigos referentes ao tema, é perceptível que a cirurgia envolvendo os terceiros molares é considerada um procedimento de rotina dentro de um consultório devido a suas complicações, a presença de pericoronarite, cáries, reabsorções dentárias, presença de cistos e tumores, indicando a extração. A parestesia é uma alteração sensorial causada pelo dano do NAI no momento da intervenção cirúrgica, portanto, a Coronectomia é uma alternativa de tratamento controversa à lesão (MASCARENHAS CL, et al., 2020).

A proximidade das raízes de molares com o NAl é considerada outra complicação no momento de sua remoção, para isso, o cirurgião-dentista planeja e realiza exames imaginológicos a fim de diagnosticar e promover detalhes da região referida (KIM H, et al., 2017). A tomografia computadorizada é um desses exames, conseguindo através dele, no entanto, uma imagem tridimensional que avalia o local em três cortes (sagital, coronal e axial). Por outro lado, a radiografia panorâmica é a mais utilizada na remoção de terceiros 
molares, sendo capaz, portanto, notar escurecimentos da região retromolar, ápice bífido, desvios e curvaturas do canal mandibular (MASCARENHAS CL, et al., 2020).

\section{CONSIDERAÇÕES FINAIS}

Diante deste estudo, foi possível determinar que a técnica da Coronectomia é bastante relatada e praticada, não obstante, existem dúvidas e receios quanto a sua utilização. Destarte, é viável e considerada uma alternativa de tratamento muito eficaz para reduzir significativamente os danos do NAI, sendo ela bem indicada a casos específicos e com o intuito de prevenção do nervo.

\section{REFERÊNCIAS}

1. DIAS-RIBEIRO E, et al. Coronectomia em terceiro molar inferior: relato de casos. Revista de Cirurgia e Traumatologia Bucomaxilofacial, 2015; 2(15): 49-54.

2. KIM H, et al. Intentional partial odontectomy: a long-term follow-up study. Maxillofac Plast Reconstr Surg., 2017; 39(29): 1-5.

3. MASCARENHAS C. L, et al. Coronectomia em terceiro molar inferior: uma alternativa cirúrgica. Brazilian Journal of Health Review, 2020; 3(3): 5562-5575. 
RESUMO SIMPLES: Revisão Narrativa

\section{DIFICULDADE NO DIAGNÓSTICO E TRATAMENTO DA DOR FACIAL ATÍPICA: REVISÃO NARRATIVA}

Lucas Menezes dos Anjos ${ }^{1}$

Aurélio de Oliveira Rocha ${ }^{1}$

Rafaela de Menezes dos Anjos Santos ${ }^{1}$

Thalles Yurgen Balduino²

Thaine Oliveira Lima ${ }^{3}$

1. Universidade Federal de Santa Catarina (UFSC), Florianópolis - SC.

2. Universidade Federal de Sergipe (UFS), Aracaju - SE.

3. Universidade Tiradentes (Unit), Aracaju - SE.

Palavras-chave: Dor facial, Neuralgia trigeminal, Odontologia.

\section{INTRODUÇÃO}

A dor fácil atípica é uma condição psicossomática que leva o paciente e sentir dor sem que haja uma causa visível (CHRISTOFOLLETI LM, et al., 2018). O diagnóstico é feito por eliminação, já que na grande maioria das vezes não há achados clínicos ou imaginológicos que indique uma causa especificar para sua ocorrência (JUNIOR VAC, et al., 2021). Tendo em vista a dificuldade de se conseguir fechar o diagnóstico de forma precisa, seu tratamento também apresenta empasses, o que leva o paciente a procurar vários tipos de profissionais a fim de esclarecer e buscar um tratamento efetivo, sendo essencial nesses casos um tratamento multidisciplinar (GOMES RNS, et al., 2018).

\section{OBJETIVO}

Revisar e analisar, por meio da literatura científica, os possíveis fatores causadores da dor facial atípica, esclarecer as medidas necessárias para seu diagnóstico por meio do correto exame clínico e radiográfico, bem como descrever as condutas frente a essa condição.

\section{REVISÃO BIBLIOGRÁFICA}

A dor facial atípica é uma dor facial persistente que não apresenta características de neuralgias cranianas classificadas e não está associada com uma causa orgânica demonstrável (JUNIOR VAC, et al., 2021). Acomete geralmente mulheres que estão no período pós-menopausa, apresentando-se como uma dor continua, sem eventos aparentes para sua causa, piora ou melhora (CHRISTOFOLLETI LM, et al., 2018).

No exame clinico ou imaginológico não há achados locais que indiquem seu surgimento ou causa, sendo muitas vezes realizados procedimentos como exodontia ou tratamento endodôntico as unidades dentais associadas ao local do desconforto de forma equivocada, situação que pode exacerbar os sintomas (GOMES 
RNS, et al., 2018). O diagnóstico é feito por exclusão por meio de anamnese detalhada, estando distúrbios psicológicos como estresse, depressão ou ansiedade associada a maioria dos casos. (CHRISTOFOLLETI LM, et al., 2018).

Os exames imaginologicos são essenciais para investigação de possíveis massas tumorais que possam estar comprimindo nervos e desencadeando a dor (GOMES RNS, et al., 2018). A conduta mais indicada é o acompanhamento psicológico e utilização de antidepressivos como benzodiazepínicos (GOMES RNS, et al., 2018).

\section{CONSIDERAÇÕES FINAIS}

Condições bucais com baixa prevalência ou de difícil diagnóstico, podem levar o cirurgião-dentista a propor condutas equivocadas e que exacerbem seus sintomas. Nesse contexto, pacientes que apresentam dor fácil atípica, precisam ser tratados por profissionais com conhecimento dessa patologia, sendo o tratamento multiprofissional indicado. Devido ao baixo número de evidencias sobre seu diagnóstico e tratamento, estudos clínicos devem ser conduzidos a fim de elencar a melhor conduta frente essa comorbidade.

\section{REFERÊNCIAS}

1. CHRISTOFOLLETI LM, et al. Personalidade, enfrentamento e dor facial atípica. Relato de casos. Brazilian Journal of Pain, 2018; 1(1): 77-79.

2. GOMES RNS, et al. Efeitos da fotobioestimulação no tratamento da neuralgia pós-herpética: relato de caso. Revista Brasileira de Geriatria e Gerontologia, 2018; 21(1): 102-107.

3. JUNIOR VAC, et al. Avaliação da dor em crianças com câncer: revisão narrativa de literatura. Revista Eletrônica Acervo Saúde, 2021; 13(3): 6544-6544. 
RESUMO SIMPLES: Revisão Integrativa

\title{
A IMPORTÂNCIA DO ISOLAMENTO ABSOLUTO PARA A ODONTOLOGIA RESTAURADORA
}

\author{
Maria de Nazaré Oliveira Rocha ${ }^{1}$ \\ Aurélio de Oliveira Rocha ${ }^{2}$ \\ Lucas Menezes dos Anjos ${ }^{3}$ \\ Thaine Oliveira Lima ${ }^{2}$
}

Rafaela de Menezes dos Anjos Santos ${ }^{4}$

1. Faculdade Maurício de Nassau (UNINASSAU), Aracaju - SE.

2. Universidade Federal de Santa Catarina (UFSC), Florianópolis - SC.

3. Universidade de São Paulo (USP), Bauru - SP.

4. Universidade Federal de Sergipe (UFS), Aracaju - SE.

Palavras-chave: Isolamento absoluto, Restauração dental, Odontologia.

\section{INTRODUÇÃO}

$O$ isolamento absoluto é um recurso ultilizado quando se quer controlar a umidade bucal para a realização de restaurações dentais, bem como a contaminação pelo fluxo salivar do material restaurador, tendo em vista que essa contaminação pode culminar na falha do processo de restauração, como também por meio deste pode-se evitar a deglutição e a aspiração acidental de objetos e resíduos, logo, o isolamento absoluto tornase de grande importância na prática clínica odontológica (BENEVIDES AAA, et al., 2019). Sua indicação compreende a remoção de cárie, em qualquer procedimento adesivo, e em pacientes especiais reduzindo 0 risco de deglutição (CAVIGLIA NA, et al., 2020).

\section{OBJETIVO}

Analisar a efetividade do isolamento absoluto para evitar a contaminação pelo fluxo salivar durante atendimento e discutir a cerca dessa técnica, sobre suas principais indicações e vantagens na prática clínica odontológica.

\section{MÉTODO}

Foi realizada uma revisão integrativa da literatura através de uma busca completa por estudos publicados nos últimos cinco anos na base de dados Google Scholar, utilizando os descritores "Isolamento absoluto, restauração dental e odontologia". Dos estudos encontrados foram selecionados os três de maior relevância científica segundo a base pesquisada, onde, após a leitura do título e resumo os mesmos se enquadravam na temática pesquisada. 


\section{REVISÃO BIBLIOGRÁFICA}

O isolamento absoluto é caracterizado pela proteção da unidade dental em relação a cavidade bucal para realização de procedimentos restauradores e endodônticos (CAVIGLIA NA, et al., 2020; de OLIVEIRA ROCHA A, et al., 2021). Esse isolamento é realizado com a colocação do lençol de borracha e arco específico ao redor da unidade dental.

Essa técnica tem se mostrado eficaz no aumento do sucesso e longevidade das restaurações por não haver contato com a umidade no momento restaurador, observou-se também uma redução significativa em relação aos riscos de contaminação e a deglutição de objetos e líquidos indesejados, proporcionando assim maior segurança ao cirurgião-dentista e aos pacientes (BENEVIDES AAA, et al., 2019).

\section{CONSIDERAÇÕES FINAIS}

Segundo o que foi observado na literatura, o isolamento absoluto é um grande aliado dos cirurgiõesdentistas, pois por meio dele é possível proporcionar maior segurança tanto ao dentista quanto ao paciente. Observou-se também uma maior durabilidade nas restaurações devido maior segurança na técnica, trazendo múltiplos benefícios para a odontologia restauradora. Ademais, a literatura necessita de revisões sistemáticas para validar a utilização de isolamento absoluto na dentistica restauradora.

\section{REFERÊNCIAS}

1. BENEVIDES AAA, et al. A influência do isolamento absoluto no sucesso de restaurações diretas e tratamento endodôntico: uma revisão de literatura. Revista Odontológica de Araçatuba, 2019; 35-40.

2. CAVIGLIA NA, et al. Determinação da umidade relativa do campo operatório com isolamento absoluto, modificado e relativo-estudo piloto. Revista Odontológica do Brasil Central, 2020; 29(88).

3. de OLIVEIRA ROCHA A, et al. Intervenção estética anterior por meio de facetas diretas em resina composta: relato de caso. Revista Eletrônica Acervo Saúde, 2021; 13(3): 6439-e6439. 
RESUMO SIMPLES: Revisão Integrativa

\section{CONSEQUÊNCIAS DA PERDA PRECOCE DE MOLARES DECÍDUOS EM ODONTOPEDIATRIA}

Aurélio de Oliveira Rocha ${ }^{1}$

Lucas Menezes dos Anjos ${ }^{1}$

Thaine Oliveira Lima ${ }^{2}$

Thalles Yurgen Balduino ${ }^{3}$

Maria de Nazaré Oliveira Rocha ${ }^{4}$

1. Universidade Federal de Santa Catarina (UFSC), Florianópolis - SC.

2. Universidade de São Paulo (USP), Bauru - SP.

3. Universidade Federal de Santa Catarina (UFSC), Florianópolis - SC.

4. Faculdade Maurício de Nassau (UNINASSAU), Aracaju - SE.

Palavras-chave: Perda precoce, Odontopediatria, Molar.

\section{INTRODUÇÃO}

A perda precoce de molares decíduos está vínculada principalmente a cárie dental e atingem com maior frequência crianças na faixa etária de 1 a 3 anos (NOBREGA ML, et al., 2018). De acordo com a literatura essa perda acomete entre 15,1 a $54,62 \%$ das crianças, principalmente na região mandibular (dos SANTOS MOREIRA AK, et al., 2020). A dentição decídua desempenha um importante papel para o desenvolvimento das funções mastigatória e fonética. Dessa forma, essa perda precoce pode afetar diretamente a função, desenvolvimento e qualidade de vida dessas crianças (ARMENIO R, et al., 2018).

\section{OBJETIVO}

Analisar e discutir sobre as consequências funcionais, estéticas e oclusais vinculadas com a perda precoce de molares decíduos no desenvolvimento e qualidade de vida de crianças, bem como abordar sua etiologia e manejo.

\section{MÉTODO}

O presente estudo configura uma revisão integrativa da literatura realizada através de uma busca completa na base de dados Google Scholar, datada dos últimos cinco anos, utilizando os descritores "Perda precoce, Molar e Odontopediatria". Dentre os estudos encontrados e após leitura do título e resumo foram selecionados os três de maior relevância de acordo com a base científica.

\section{REVISÃO BIBLIOGRÁFICA}


A perda precoce, ocorre quando a exodontia da unidade é realizada pelo menos, um ano antes da esfoliação normal ou após a confirmação com o auxílio de ragiografias que o permanente ainda não apresenta formação coronária completa, ou seja, abaixo do estágio 6 de Nolla e o processo de formação radicular já iniciada (NOBREGA ML, et al., 2018).

Com a perda precoce, ocorrem alterações indesejadas, extrusão do dente antagonista e diminuição ou fechamento do espaço original devido migração dos dentes adjacentes. Tal situação leva a necessidade da instalação de um dispositivo chamado mantenedor de espaço, o qual auxilia para que a oclusão tenha um melhor desenvolvimento (SILVA AJ, et al., 2019).

\section{CONSIDERAÇÕES FINAIS}

De acordo com os estudos analisados, a perda precoce de molares decíduos está vinculada principalmente com a cárie dental e gera um impacto significante na oclusão e qualidade de vida de crianças, o manejo dessa condição pode ser realizado com a instalação de um mantenedor de espaço que favorece para amenizar os efeitos causados por essa condição. Porém, mais ensaios clínicos randomizados sobre essa temática são necessários na literatura.

\section{REFERÊNCIAS}

1. ARMENIO R, et al. Uso de mantenedor de espaço fixo não funcional em dentição decídua - relato de caso. Ação Odonto, 2018; 2.

2. dos SANTOS MOREIRA AK, et al. A Importância da Instalação de Mantenedor de Espaço Fixo Não Funcional em Odontopediatria-Revisão de Literatura. Brazilian Journal of Development, 2020; 6(12).

3. NOBREGA ML, et al. Implicações da perda precoce em odontopediatria. Revista Pró-UniverSUS. 2018; 09(1): 61-67.

4. SILVA AJ, et al. Perda de primeiros molares permanentes em crianças e adolescentes atendidos na Clínica-Escola de Odontologia-UFPE. Revista Eletrônica Acervo Saúde, 2019; 11(17). 


\section{BENEFÍCIOS DA CASTANHA DO BRASIL COMO FONTE DE SELÊNIO NA ALIMENTAÇÃO DE IDOSOS}

Amanda Morais de Farias ${ }^{1}$

1. Polo DNA Pós-Graduação, Campina Grande - PB.

Palavras-chave: Nutrição, Saúde, Senescência.

\section{INTRODUÇÃO}

O período de envelhecimento demarca diversas alterações nos indivíduos, podendo provocar mudanças que afetam desde o contexto físico, biológico e bioquímico (NOGUEIRA B, et al., 2020). Frente a isto, tornase possível observar a importância de fontes alimentares naturais que determinem ao organismo inúmeras funções benéficas. Nesse contexto, destaca-se a frequente e adequada ingestão da castanha do Brasil, alimento no qual possui em sua composição uma grande quantidade de selênio, sendo esse composto considerado como um mineral necessário ao metabolismo humano, pois desempenha papéis na prevenção de doenças (CARDOSO B, et al., 2017).

\section{OBJETIVO}

Revisar e descrever por meio da literatura científica sobre a importância do consumo da castanha do Brasil como fonte de selênio na alimentação de idosos e seus benefícios para esse público.

\section{MÉTODO}

O estudo baseia-se sobre o método de revisão sistemática. No entanto, foram efetuadas buscas em bases eletrônicas de tamanha confiabilidade, tais como: Acervo+ Index base, Scielo, Science, Google acadêmico, Revistas entre outras. Esse processo se remeteu a uma coleta de dados mediante os últimos 5 anos, sendo feita uma análise de 4 artigos consideráveis relevantes para com a temática.

\section{REVISÃO BIBLIOGRÁFICA}

Sobre analise, a utilização da castanha do Brasil na rotina alimentar da população brasileira é de total importância devido ao seu alto teor de selênio e a suas características nutricionais (MOREDA J, et al., 2016). Associando-se seu consumo em idosos, verificou-se que sua ingesta classifica funcionalidade no metabolismo em geral, podendo garantir alta capacidade antioxidante e anti-inflamatória. Dessa forma, fatores interligados as funções cerebrais são ativadas, melhorando critérios de cognição e concentração. Em contrapartida, défices nutricionais de selênio podem acarretar alterações no que tange o sistema cerebral, propiciando facilitar o acometimento da Doença de Alzheimer em idosos de diferentes idades (DEMIRCI K, et al., 2017). 


\section{CONSIDERAÇÕES FINAIS}

O consumo adequado de fontes alimentares ricas em selênio, em especial da castanha do Brasil devido a sua alta biodisponibilidade pode remeter aos idosos uma ótima qualidade de vida e um adequado processo de senescência. Para isso, sua inclusão na alimentação se faz indispensável, principalmente quando sugerido em quantidades necessárias para o correto suprimento absortivo no organismo.

\section{REFERÊNCIAS}

1. CARDOSO BR, et al. Castanha do Brasil: Composição nutricional, benefícios para a saúde e aspectos de segurança. Revista Food Research International, 2017; 3(100): e 25-30.

2. DEMIRCI K, et al. O selênio atenua a apoptose, a inflamação e o estresse oxidativo no sangue e no cérebro de ratos idosos com demência induzida por escopolamina. Revista Doença cerebral metabólica, 2017; 2(32): 321-329.

3. MOREDA PJ, et al. Avaliação da biodisponibilidade de metais essenciais e tóxicos em nozes e sementes comestíveis. Revista Química alimentar, 2016; 1(205): e 146-331.

4. NOGUEIRA BSL, et al. O consumo de selênio e sua relação com a manutenção da função cognitiva: uma revisão sistemática sobre humanos e animais. Revista Neurociências, 2020; 1(28): 1-31. 


\section{FATORES ASSOCIADOS AO REGANHO DE PESO APÓS O OPERATÓRIO DE CIRURGIA BARIÁTRICA}

Amanda Morais de Farias ${ }^{1}$

1. Polo DNA Pós-Graduação, Campina Grande - PB.

Palavras-chave: Estado nutricional, Alimentação, Emagrecimento.

\section{INTRODUÇÃO}

Nas últimas décadas, a perda de peso tornou-se uma das maiores dificuldades encontradas, sendo recorrente do exacerbado consumo diário de alimentos industrializados por grande parte da população (MORA AC e ROCHA R, 2021). Frente a esse cenário, indivíduos estão cada vez mais suscetíveis a ocasionarem uma das consequências a saúde pública mundial, sendo esta definida como a obesidade, doença composta pelo elevado acumulo de gordura corporal (RASPANTE L, et al., 2020). Nesse sentido, a cirurgia bariátrica tem sido um método crescente no tratamento da obesidade, podendo ser eficaz ou não, estando a depender de como o indivíduo irá determinar seus hábitos ao decorrer dos anos (LEE Y, et al., 2019).

\section{OBJETIVO}

Revisar por meio de revisão narrativa de literatura sobre o reganho de peso no pós-operatório de cirurgia bariátrica, bem como descrever alguns dos fatores alimentares associados a essa ocorrência.

\section{REVISÃO BIBLIOGRÁFICA}

Sob realização de analise na literatura, destaca-se sobre a bariátrica que apesar da grande porcentagem cirúrgica ser positiva, esse procedimento não possibilita total certeza de que o indivíduo não acarrete novamente o aumento de peso e volte ao seu peso inicial, uma vez que diversas são as características que o predispõe ao reganho de peso. Diante desse preceito, estimativas descrevem que 5 a $60 \%$ de pessoas submetidas ao processo cirúrgico bariátrico efetuam pela segunda vez o método, classificando-se essa razão pela baixa eficácia nos resultados do peso desejado (BARDAL A, et al., 2016).

Entretanto, observa-se que fatores como alimentação inadequada, consumo alimentar em quantidades não estimadas, baixa frequência de exercícios físicos e falta de analise hormonal classificam-se como influentes marcadores do reganho de peso ponderal. Sendo assim, a forma como o indivíduo irá proceder suas mudanças de estilo de vida se relaciona diretamente no resultado final da cirurgia, alegando-se que $o$ período de emagrecimento integra não só a redução estomacal, mas, bem como, todas as escolhas a curto e longo prazo realizadas pelo indivíduo (RASPANTE L, et al., 2020).

\section{CONSIDERAÇÕES FINAIS}


Desse modo, torna-se perceptível observar que para solucionar a obesidade não basta apenas métodos rápidos e cirúrgicos, abrange-se que é preciso principalmente que o paciente entenda a importância de seguir uma adequada qualidade de vida. Para isso, buscar o acompanhamento multiprofissional é indispensável para a facilitação da adaptação de todas as mudanças acarretadas em seu estilo de vida.

\section{REFERÊNCIAS}

1. BARDAL AG, et al. Fatores de risco para recidiva de peso no pós-operatório tardio de cirurgia bariátrica. Scientia médica, 2016; 4(26): 24224.

2. LEE $Y$, et al. Valor diagnóstico dos níveis de proteína $C$ reativa em complicações infecciosas pósoperatórias de cirurgia bariátrica: uma revisão sistemática e meta-análise. Cirurgia de obesidade, 2019; 7(29): 2022-2029.

3. MORO AL, ROCHA REP. Alterações comportamentais após cirurgia bariátrica: Uma revisão sistemática de literatura. Pesquisa, Sociedade e Desenvolvimento, 2021; 6(10): e453.

4. RASPANTE LBP, et al. Revisão e ensaio pictórico sobre complicações da cirurgia bariátrica. Revista da Associação Médica Brasileira, 2020; 2(66): 1289-1295. 


\title{
CÂNCER DE CÓLON: TRATAMENTOS E NOVAS PERSPECTIVAS
}

\author{
Daniel Higor da Silva Barros ${ }^{1}$ \\ Priscila Katleen Rodrigues de Oliveira ${ }^{2}$ \\ Ana Julia Souza Malheiro ${ }^{3}$ \\ Débora Monteiro Paredes ${ }^{1}$ \\ Rubia Brasil da Silva Menezes ${ }^{3}$
}

1. Universidade Católica de Brasília (UCB), Taguatinga - DF.

2. Universidade de Brasília (UnB), Brasília - DF.

3. Centro Universitário de Brasília (UniCEUB), Brasília - DF.

Palavras-chave: Câncer de cólon, Tratamento, Novos tratamentos.

\section{INTRODUÇÃO}

O câncer colorretal (CCR) é o segundo câncer mais letal e o terceiro tipo mais prevalente no mundo (SUNG $\mathrm{H}$, et al., 2021). Os principais fatores de risco são: sexo masculino, aumento da idade, hereditariedade, fatores ambientais e hábitos alimentares (PAULA L, et al., 2020). Pacientes com doenças inflamatórias intestinais e histórico de adenomas devem ser mantidos em vigilância. A mortalidade tende a cair, graças a novos métodos de rastreio e tratamento. A abordagem no tratamento do CCR envolve a eliminação cirúrgica do tumor e das metástases. Em estágios iniciais é possível tratamento local, com ressecção endoscópica (DEKKER E, et al., 2019).

\section{OBJETIVO}

Mostrar as evidências encontradas nas publicações científicas, no período de 2015 a 2021, sobre as características do Câncer Colorretal (CCR) e as modalidades de tratamento para essa patologia.

\section{REVISÃO BIBLIOGRÁFICA}

Em lesões de CCR não tratáveis cirurgicamente, o tratamento baseia-se na redução do tamanho do tumor com a radioterapia e a quimioterapia. $O$ tratamento quimioterápico atual inclui a terapia com agente único fluoropirimidina e terapias combinadas, que envolvem Oxallplatina, Irotecano e Capecitabina. A quimioterapia proporciona um aumento de sobrevida, porém possui limitações como toxicidade sistêmica, resposta insatisfatória, resistência adquirida e baixa seletividade tumoral. Existem novas terapias alvo promissoras, principalmente os anticorpos monoclonais Cetuximab e Bevacizumab (XIE Y, et al., 2020), que atuam em alvos intracelulares ou na superfície celular de células cancerosas causando inibição de proliferação celular, diferenciação ou migração (MARMOL I, et al., 2017). 
Regorafenib (inibidor da tirosina quinase) e Lonsurf $\circledast$ trifluridina + cloridrato de tipiracila (um antimetabólito), são os novos medicamentos aprovados para pacientes com câncer de cólon metastático refratário (DEKKER E, et al., 2019). Terapias alternativas têm sido investigadas com o objetivo de aumentar a eficácia do tratamento, reduzir os efeitos colaterais assim como diminuir o risco do surgimento de tumores secundários. (MARMOL I, et al., 2017).

\section{CONSIDERAÇÕES FINAIS}

Há uma ampla incidência de CCR e suas taxas de morbimortalidade impactam a vida de pacientes e a saúde pública. Apesar de grandes avanços nos tratamentos modernos, boa parte do sucesso depende de diagnóstico precoce. Portanto, são também importantes iniciativas que possam fazer um rastreio adequado à população. Terapias alternativas, principalmente drogas anti-inflamatórias, probióticos e medicamentos compostos por ouro, têm sido investigadas.

\section{REFERÊNCIAS}

1. DEKKER E, et al. Colorectal Cancer. Lancet 2019. 394: 1467-1480.

2. PAULA L, et al. Microbiota intestinal e câncer colorretal: uma revisão bibliográfica. Revista Eletrônica Acervo Mais. 2020; 12(11): 1-11.

3. MARMOL I, et al. Colorectal Carcinoma: a general overview and future perspectives in colorectal câncer. International Journal of Molecular Sciences. 2017; 187(18): 1-39.

4. SUNG H, et al. Global Cancer Statistics 2020: GLOBOCANB Estimates of Incidence and Mortality Worldwide for 36 Cancers in 185 Countries. ACS Journals. 2021; 71(3): 209-249.

5. XIE Y, et al. Comprehensive review of target therapy for colorectal câncer. Signal Transduction and Targeted Therapy. 2020; 5(22): 1-30. 
RESUMO SIMPLES: Revisão Integrativa

\title{
CONDUTAS DE ENFERMAGEM NOS CUIDADOS AO PACIENTE COM O PÉ DIABÉTICO
}

\author{
Thiemmy de Souza Almeida Guedes ${ }^{1}$ \\ Vanessa Nascimento Alvino² \\ Arianny Luiza Barros de Santana ${ }^{3}$ \\ Daiane de Matos Silva ${ }^{4}$ \\ Felippo de Oliveira Maximum 5
}

1. Faculdade Venda Nova do Imigrante (FAVENI), Venda Nova do Imigrante - ES.

2. Faculdade de Medicina Estácio de Juazeiro do Norte (FMJ), Juazeiro do Norte - CE.

3. Centro Universitário de Ciências e Tecnologia do Maranhão (UniFacema), Caxias - MA.

4. Universidade Nove de Julho (UNINOVE), São Paulo - SP.

5. Universidade Federal de Alfenas (UNIFAL), Minas Gerais - MG.

Palavras-chave: Diabetes Mellitus, Pé diabético, Cuidados de Enfermagem.

\section{INTRODUÇÃO}

A Diabetes Mellitus (DM) é considerada uma doença crônica, caracterizada pela junção heterogênea de distúrbios metabólicos advindos de distorções na secreção ou ação da insulina. Dentre os principais desafios apresentados por portadores de DM, estão as complicações evidenciadas por lesões nos pés que são caracterizadas com presença de infecção, ulceração ou destruição de tecido profundo. Ademais, considerada um dos mais incidentes problemas de saúde pública, a DM tem um alto índice de morbimortalidade, tendo como seus principais fatores de riscos, relacionados às lesões no pé, a neuropatia, devido a fatores externos como rachaduras, calos, cortes por perfuro cortantes e falta de prevenção (GUEST JF, et al., 2017).

\section{OBJETIVO}

Identificar na literatura científica quais são as condutas da equipe de enfermagem, frente aos cuidados oferecidos ao paciente diagnosticado com o pé diabético, que vise reforçar a importância da capacitação e atualização dos profissionais de enfermagem nessa área de atuação.

\section{MÉTODO}

Revisão integrativa, elaborada em setembro de 2021, realizada a partir dos trabalhos científicos disponíveis na Biblioteca Virtual de Saúde (BVS). Para a busca, utilizou-se os seguintes descritores (DECS): "Cuidados de Enfermagem", "Tratamento" e "Pé Diabético" empregando o operador booleano "AND". Como critérios de inclusão, encontram-se artigos em inglês e português, publicados nos últimos 5 anos. Com isso, encontrou-se 215 estudos dos quais 3 foram selecionados para compor essa pesquisa. 


\section{REVISÃO BIBLIOGRÁFICA}

De acordo com os artigos selecionados, observa-se que a enfermagem tem um papel essencial, não só no diagnóstico da doença, mas também em auxiliar os pacientes nas formas de prevenção e tratamento desse problema, através de ações que busquem o cuidado preventivo, a identificação e a classificação de risco do quadro patológico. É importante uma abordagem educativa dos profissionais de enfermagem junto com os pacientes que apresentam Diabetes Mellitus, ao qual possa ser repassado orientações sobre o autocuidado, incentivando o severo controle do nível glicêmico para que se possa evitar possíveis amputações (GUEST JF, et al., 2017; LOBMANN R, et al., 2019; PAGGIARO AO, et al., 2018).

\section{CONSIDERAÇÕES FINAIS}

Diante do exposto, evidencia-se a necessidade de atendimento interdisciplinar em pacientes portadores de DM para a identificação do risco do pé diabético e as posteriores intervenções para o tratamento. Dessa maneira, é preciso intervir sobre o ambiente e os hábitos de vida do paciente. Salienta-se que ao prestar o cuidado, fica evidente a importância dos enfermeiros nesse cenário, desde a função de cuidar à melhoria no prognóstico.

\section{REFERÊNCIAS}

1. GUEST JF, et al. Cost-effectiveness of using adjunctive porcine small intestine submucosa tri-layer matrix compared with standard care in managing diabetic foot ulcers in the US. Journal of Wound Care, 2017; 26.

2. LOBMANN R, et al. Custo-efetividade de TLC-sacarose octassulfato versus curativos de controle no tratamento de úlceras de pé diabético. Journal of Wound Care, 2019; 28.

3. PAGGIARO AO, et al. Efeitos biológicos da membrana amniótica em feridas de pé diabético: uma revisão sistemática. Journal of Wound Care, 2018; 27. 


\title{
SUPLEMENTAÇÃO DE VITAMINA D NO TRATAMENTO DE MULHERES COM LÚPUS: REVISÃO SISTEMÁTICA
}

\author{
Fernanda Ferraz de Toledo ${ }^{1}$
}

Danielle Cristina Zimmermann Franco ${ }^{1}$

1. Universidade Presidente Antônio Carlos (UNIPAC), Juiz de Fora - MG.

Palavras-chave: Vitamina D, Lúpus Eritematoso Sistêmico, Mulheres.

\section{INTRODUÇÃO}

A vitamina $D(1,25$-di-hidroxivitamina $D)(V D)$, também considerada como um hormônio, possui função central na absorção de cálcio e metabolismo ósseo (SANTOS TAB, et al., 2021). Com o avanço do entendimento sobre VD, outros efeitos de grande relevância têm sido investigados, como a modulação do sistema imune pelas respostas inata e adaptativa. Suas funções imunológicas surgiram devido a presença de receptores para VD nas células apresentadoras de antígenos, linfócitos $B$ e $T$, sendo assim, potencialmente capaz de promover atividade imunorregulatória (DUPUIS ML, et al., 2021). Portanto, procura-se estabelecer sua utilidade no tratamento de doenças autoimunes, tal como no Lúpus Eritematoso Sistêmico (LES).

\section{OBJETIVO}

Analisar, por meio de uma revisão da literatura, a eficácia e a segurança da suplementação com vitamina D como parte da estratégia terapêutica aplicada a mulheres com lúpus eritematoso sistêmico.

\section{MÉTODO}

Revisão sistemática da literatura elaborada a partir da pesquisa realizada nas bases de dados MedlLine, Biblioteca Cochrane e Biblioteca Virtual em saúde, em outubro de 2021. As palavras-chaves utilizadas foram: vitamina $D$, lúpus eritematosos sistêmicos e mulheres. Foram incluídos estudos originais observacionais, publicados nos últimos 5 anos, nos idiomas inglês, português e espanhol. Foram excluídos estudos realizados com pacientes masculinos.

\section{REVISÃO BIBLIOGRÁFICA}

Foi relatada eficácia e segurança da VD no tratamento de mulheres com LES, promovendo ligeira diminuição na atividade da doença, redução nos níveis da fração C3 e estabilização nos níveis de anticorpos anti-dsDNA (MARINHO A, et al., 2016). Dois estudos relataram segurança, sem alterações no metabolismo ósseo e na produção do paratormônio, porém sem eficácia no curso da LES (ANDREOLI L, et al., 2015; SALMAN-MONTE TC, et al., 2016). Foi relatado, contudo, que pacientes com insuficiência de VD relataram maior fadiga (SALMAN-MONTE TC, et al., 2016). Por fim, um dos estudos não avaliou a segurança e não constatou eficácia da suplementação (GARCIA-CARRASCO M, et al., 2016). 


\section{CONSIDERAÇÕES FINAIS}

A maioria dos estudos selecionados demonstrou que a suplementação com vitamina $D$ é bem tolerada. Todavia, apenas um evidenciou seu potencial no tratamento de mulheres com LES, ainda que outros desdobramentos, como a fadiga, tenham sido minimizados. Diante disso, mais estudos devem ser realizados com diferentes doses e tempos de seguimento para esclarecer todos os benefícios da suplementação desse hormônio em mulheres com LES.

\section{REFERÊNCIAS}

1. ANDREOLI L, et al. A 24-month prospective study on the efficacy and safety of two different monthly regimens of vitamin $D$ supplementation in pre-menopausal women with systemic lupus erythematosus. Lupus, 2015; 24: 499-506.

2. DUPUIS ML, et al. The role of vitamin $D$ in autoimmune diseases: could sex make the difference? Biology Of Se Differences, 2021; 12(1): 12.

3. GARCIA-CARRASCO M, et al. Insuficiencia y deficiencia de vitamina $D$ en pacientes mexicanas con lupus eritematoso sistémico: prevalencia y relación con actividad de la enfermedad. Reumatología Clinica, 2017; 13(2): 97-101.

4. MARINHO A, et al. Vitamin D supplementation effects on FoxP3 expression in T cells and FoxP3+/IL-17A ratio and clinical course in systemic lupus erythematosus patients: a study in a Portuguese cohort. Immunologic Research, 2016; 65: 197-206.

5. SALMAN-MONTE TC, et al. Prevalence and predictors of vitamin D insufficiency in supplemented and nonsupplemented women with systemic lupus erythematosus in the Mediterranean region. Rheumatology International, 2016; 36: 975-85.

6. SANTOS TAB, et al. Análise da correlação entre os níveis séricos da Vitamina $D$ e os níveis de OPG/RANKL intraósseo. Rev. Eletrônica Acervo Saúde, 2021; 13(2): 1-9. 
RESUMO SIMPLES: Revisão Integrativa

\title{
BENEFÍCIOS DO USO DA AROMATERAPIA NO TRABALHO DE PARTO
}

\author{
Amélia Carina Messias da Costa ${ }^{1}$ \\ Augusto Cezar Antunes de Araújo Filho ${ }^{1}$ \\ Jhussara Silva Alves ${ }^{1}$ \\ Raiane Araujo Brito ${ }^{1}$
}

Livia Caroline Carvalho Lima ${ }^{1}$

1. Universidade Estadual do Piauí (UESPI), Floriano - PI.

Palavras-chave: Aromaterapia, Atenção integral à saúde da mulher, Trabalho de parto.

\section{INTRODUÇÃO}

Métodos terapêuticos alternativos são usados mundialmente, sendo inseridos no âmbito das maternidades brasileiras desde a década de 1990. A aromaterapia é uma das práticas incluídas no contexto das Práticas Integrativas e Complementares, e baseia-se no uso terapêutico das propriedades de óleos essenciais de diferentes formas e vias do organismo (SILVA MA, et al., 2019).

O parto está associado à sensação de dor, devido as contrações que levam a dilatação do colo uterino para possibilitar o nascimento. Porém, essa dor pertence a própria natureza feminina, e, o uso da aromaterapia durante esse processo se torna um aliado no manejo das sensações dolorosas e psicológicas, atendendo às diretrizes do parto humanizado (PIMENTEL MM, et al., 2021).

\section{OBJETIVO}

Revisar e analisar, por meio da literatura científica, quais os benefícios do uso da aromaterapia no trabalho de parto, a partir da perspectiva da aromaterapia como método não farmacológico para alívio da dor.

\section{MÉTODO}

Pesquisa de revisão integrativa da literatura, realizada na Biblioteca Virtual em Saúde, no mês de outubro de 2021, utilizando os descritores: "aromaterapia", "dores de parto" e "enfermagem obstétrica", combinados pelo operador "AND", direcionando para 10 resultados. Foram incluídos artigos completos, em português, publicados entre 2017 e 2021. Excluiu-se artigos em inglês e que não contemplavam a temática. Após aplicação dos critérios, restaram três artigos para compor a amostra deste estudo.

\section{REVISÃO BIBLIOGRÁFICA}

Um estudo aponta a aromaterapia como método complementar não farmacológico que utiliza óleos essenciais de características específicas, com resultados expressivos na redução do tempo das fases do 
parto (PIMENTEL MM, et al., 2021). Outro estudo verificou que ao serem aspiradas, as essências impulsionam receptores sensíveis específicos no cérebro, tendo resultados benefícos no controle da dor e da ansiedade (ARAÚJO AS, et al., 2018). Um outro estudo, que analisou a utilização da aromaterapia durante o trabalho de parto, apontou que maior parte das parturientes prefere a inalação e tem como resultado, significativa melhora da dor, e redução da ansiedade e medo (SILVA MA, et al., 2019).

\section{CONSIDERAÇÕES FINAIS}

A técnica da aromaterapia revela-se importante como método para alívio da dor e outros desconfortos durante o trabalho de parto, sendo considerada um método de baixo custo, simples execução e com reações adversas quase nulas para mãe e bebê. Ressalta-se a importância de os profissionais de saúde terem conhecimento acerca dessa e outras Práticas Integrativas e Complementares, bem como incentivar sua adoção, a fim de melhorar a qualidade da assistência prestada.

\section{REFERÊNCIAS}

1. ARAÚJO AS, et al. Métodos não farmacológicos no parto domiciliar. Revista de Enfermagem UFPE on line, 2018; 12(4): 1091-1096.

2. PEREIRA AC, et al. Métodos não farmacológicos para alívio da dor durante o trabalho de parto: revisão sistemática. Revista Eletrônica Acervo Saúde, 2020; 12(10): e4448.

3. PIMENTEL MM, et al. Non-invasive technologies for pain relief in parturition. Revista Online de Pesquisa Cuidado é Fundamental, 2021; 13: 671-7.

4. SILVA MA, et al. Aromaterapia para alívio da dor durante o trabalho de parto. Revista de Enfermagem UFPE on line, 2019; 13(2): 455-463. 


\title{
O IMPACTO DO EXERCÍCIO FÍSICO NA SÍNDROME METABÓLICA: UMA REVISÃO DA LITERATURA
}

\author{
Luísa Akl Urankar ${ }^{1}$ \\ Ana Carolina Vargas Pontes ${ }^{1}$ \\ Thatiana Simão de Oliveira ${ }^{1}$ \\ Danielle Cristina Zimmermann Franco ${ }^{1}$
}

1. Universidade Presidente Antônio Carlos (UNIPAC), Juiz de Fora - MG.

Palavras-chave: Síndrome metabólica, Exercício físico, Risco cardiovascular.

\section{INTRODUÇÃO}

A síndrome metabólica (SM) é diagnosticada a partir da associação de três ou mais fatores: obesidade abdominal, triglicérides e glicemia de jejum elevados, pressão arterial elevada e colesterol HDL em baixos níveis (MARQUES JGPG, et al., 2018). A SM pode acarretar doenças cardiovasculares, com o auxílio das dislipidemias, que contribuem para isso pois elevam a possibilidade de aterosclerose. Assim, a prática de atividade física regular é proposta de tratamento e prevenção da SM e doenças cardiovasculares pois promove diminuição da pressão arterial, redução de peso associado à evolução do perfil lipídico, redução da glicemia e recuperação da sensibilidade à insulina (SANTOS FAA et al., 2020; ALBARELLO RA, et al., 2017).

\section{OBJETIVO}

Revisar a literatura científica relacionando a prevalência de síndrome metabólica e a sua relação com a prática regular de exercícios físicos, relacionando com a predisposição para o desenvolvimento de enfermidades.

\section{REVISÃO BIBLIOGRÁFICA}

Em um artigo original publicado em 2017, homens e mulheres, entre 38 e 66 anos, portadores de síndrome metabólica, foram submetidos a um protocolo de treinamento resistido, demonstrando que tal intervenção ocasionou o aumento dos níveis de lipoproteína de alta densidade (HDL) e a diminuição da concentração de ureia e da circunferência abdominal, fatores associados a um risco cardiovascular atenuado (ALBARELLO RA, et al., 2017). Outro estudo, com base na participação de 1388 coreanos acima de 65 anos, mostrou que os níveis de HDL são mais elevados nas pessoas que praticam atividade física (AN KY, 2020).

Ademais, um estudo de base populacional, no qual foram analisados 818 adultos do sexo feminino e masculino, com 20 anos ou mais, demonstrou que indivíduos que deixaram de ser ativos ou que permaneceram fisicamente inativos apresentaram, respectivamente, $108 \%$ e $124 \%$ maior probabilidade de desenvolvimento de síndrome metabólica (SANTOS FAA, et al., 2020). Ao analisar os artigos, infere-se que a prática de exercício físico reflete em fatores de menor risco cardiovascular e, consequentemente, é responsável por diminuir a predisposição à síndrome metabólica. 


\section{CONSIDERAÇÕES FINAIS}

Diante dos dados encontrados na literatura sobre o tema, indivíduos sedentários têm maior predisposição para o quadro de síndrome metabólica. Além disso, a prática de atividades físicas mostrou-se relevante para a redução do risco cardiovascular em pacientes portadores desse distúrbio, através do aumento dos níveis de HDL, da redução da circunferência abdominal e da queda da concentração de ureia.

\section{REFERÊNCIAS}

1. ALBARELLO RA, et al. Efeitos do treinamento resistido sobre o perfil lipídico de indivíduos com síndrome metabólica. Revista Andaluza de Medicina del Deporte, 2017; 10(3): 142-146.

2. AN KY. Comparison between walking and moderate-to-vigorous physical activity: associations with metabolic syndrome components in Korean older adults. Epidemiology and Health, 2020; 42: e2020066.

3. MARQUES JGPG, et al. Exercício aeróbico como ferramenta não farmacológica na prevenção e/ou tratamento de pacientes com síndrome metabólica. Revista Ciência e Saúde, 2018; 3(1): 22-31.

4. SANTOS FAA, et al. Nível de atividade física de lazer e sua associação com a prevalência de síndrome metabólica em adultos: estudo de base populacional. Revista Brasileira de Epidemiologia, 2020; 23 : e200070. 


\section{ANEMIA NO PACIENTE ONCOLÓGICO: UMA REVISÃO SOBRE ESSA ENTIDADE CLÍNICA}

Maíra Reis Pimenta de Queiroz ${ }^{1}$

Danielle Cristina Zimmermann Franco ${ }^{1}$

1. Centro Universitário Presidente Antonio Carlos (UNIPAC), Juiz de Fora - MG.

Palavras-chave: Anemia, Câncer, Comorbidade.

\section{INTRODUÇÃO}

A anemia é uma doença hematológica em que a concentração de hemoglobina e/ou o número de glóbulos vermelhos e, consequentemente, a quantidade de oxigênio distribuída por eles, são menores do que o normal e insuficientes para atender às necessidades fisiológicas de um indivíduo (CELKAN TT, 2020). Estima-se que um terço da população mundial (32,9\%) se apresenta com algum grau de anemia. Apesar de ser uma doença muitas vezes negligenciada, seus efeitos sobre a saúde humana são significativos (CHAPARRO CM e SUCHDEV PS, 2019). Se os efeitos deletérios da anemia são perceptíveis na população em geral, quando se considera o paciente oncológico, o problema é ainda maior.

\section{OBJETIVO}

Revisar sobre as causas da anemia no paciente oncológico, os principais tipos de tumores relacionados à anemia, além de como os tratamentos antitumorais podem ser relacionados ao surgimento dessa comorbidade.

\section{REVISÃO BIBLIOGRÁFICA}

A patogênese da anemia induzida por câncer pode ser complexa, de difícil identificação e multifatorial. Pode ser relacionado ao tumor, ao estado do paciente ou ao regime antineoplásico. Pode surgir como uma consequência da inflamação crônica associada à doença neoplásica (MADEDDU C, et al., 2018). A perda de sangue pode ocorrer especialmente em tumores gastrointestinais, geniturinários e ginecológicos (GASTHI SM, et al., 2021).

O tratamento (radioterapia e quimioterapia) pode ser imunossupressor, inibindo a eritropoiese; algumas drogas usadas nesse contexto causam um grau mais grave de anemia do que outros. Analisando estudos epidemiológicos confirma-se uma incidência relativamente alta de anemia de grau leve a moderado em pacientes com tumores em tratamento com agentes isolados ou em regimes quimioterápicos combinados (KIFLE E, et al., 2019).

$\mathrm{Na}$ anemia associada à inflamação crônica, observa-se mecanismos subjacentes responsáveis pelo quadro pouco claros. Acredita-se que haja ativação de citocinas como Interferon- $\gamma$, Interleucina-1 e Fator de Necrose Tecidual, substâncias que podem suprimir a produção de eritropoietina endógena, prejudicar a utilização do ferro e reduzir a proliferação do precursor eritroide (SWEGA K e WIDIANA CR, 2019). 


\section{CONSIDERAÇÕES FINAIS}

Diante da fundamentação apresentada e considerando que a anemia pode prejudicar o estado de saúde e recuperação do paciente oncológico, é fundamental ter conhecimento acerca de todas as circunstâncias que levam o paciente ao quadro anêmico para propor o tratamento mais adequado. De igual modo, é crucial o conhecimento de como diferentes tipos de tumores e tratamentos podem causar anemia nesses indivíduos.

\section{REFERÊNCIAS}

1. CELKAN TT. What does a hemogram say to us?. Turk Pediatri Ars., 2020; 55(2): 103-116.

2. CHAPARRO CM, SUCHDEV PS. Anemia epidemiology, pathophysiology, and etiology in low- and middleincome countries. Ann N Y Acad Sci., 2019; 1450(1): 15-31.

3. KIFLE E, et al. Prevalence of Anemia and Associated Factors among Newly Diagnosed Patients with Solid Malignancy at Tikur Anbessa Specialized Hospital, Radiotherapy Center, Addis Ababa, Ethiopia. Adv Hematol., 2019; 2019: 8279789.

4. MADEDDU C, et al. Pathogenesis and Treatment Options of Cancer Related Anemia: Perspective for a Targeted Mechanism-Based Approach. Front Physiol., 2018; 9:1294.

5. GASTHI SM, et al. Câncer colorretal: principais complicações e a importância do diagnóstico precoce. Revista Eletrônica Acervo Saúde, 2021; 13(4): 1-8.

6. SWEGA K e WIDIANA CR. Predicting hepcidin level using inflammation markers and iron indicators in patients with anemia of chronic disease. Hematol, Tranf, Cell Ther., 2019; 41(4): 342-348. 
RESUMO SIMPLES: Revisão Integrativa

\title{
O CONHECIMENTO E A ASSISTÊNCIA DE ENFERMAGEM FRENTE AO SERVIÇO DE HEMOTERAPIA: UMA REVISÃO INTEGRATIVA
}

\author{
Beatriz Caroline Leão Lima ${ }^{1}$ \\ Andressa Dâmaras Freitas Feitosa ${ }^{1}$ \\ Daniela dos Santos Mangueira de Almeida ${ }^{1}$ \\ Maria Clara Rodrigues de Abreu ${ }^{1}$ \\ Mauro Roberto Biá da Silva ${ }^{1}$
}

1. Universidade Estadual do Piauí (UESPI), Teresina - PI.

Palavras-chave: Enfermagem, Transfusão sanguínea, Assistência de enfermagem.

\section{INTRODUÇÃO}

A hemoterapia é um recurso terapêutico que envolve a obtenção e administração de sangue e seus componentes, utilizada como tratamento para inúmeras doenças e para o suporte de procedimentos como transplantes e quimioterapias. A hemoterapia tem impacto fundamental no paciente e representa um tratamento de grande importância no âmbito da saúde, desse modo, faz-se necessário que a equipe de enfermagem esteja capacitada e os profissionais estejam aptos para dar uma assistência segura e eficiente ao paciente submetido à hemoterapia, possuindo preparo para atuar na redução dos riscos ao paciente e para agir diante das possíveis reações adversas do procedimento por meio dos cuidados de enfermagem (AMARAL JHS, et al., 2016).

\section{OBJETIVO}

Revisar e analisar por meio da literatura científica atual o conhecimento, a assistência e os desafios da equipe de enfermagem frente aos serviços de hemoterapia e os seus respectivos cuidados.

\section{MÉTODO}

Trata-se de uma revisão integrativa da literatura, com busca na Biblioteca Virtual em Saúde do Ministério da Saúde - BVS, tendo como bases de dados: MEDLINE, LILACS e SciELO. Os critérios de inclusão para esse estudo foram: artigos originais condizentes com a temática, em português e inglês, publicados nos últimos cinco anos (2016 a 2021). Como critério de exclusão adotou-se artigos de revisão e que fugiram ao tema.

\section{REVISÃO BIBLIOGRÁFICA}


A atuação da enfermagem em hemoterapia é regulamentada pela Resolução COFEN № 0511/2016, determinam-se atribuições ao profissional desde que este possua competência técnica para exercer tal função (COFEN, 2016). A assistência de enfermagem requer conhecimento acerca das especificidades da área e a constante atualização teórica e prática do serviço visando uma assistência qualificada (FRANTZ SRS, et al., 2020).

Entretanto, evidenciou-se o despreparo em parte da enfermagem devido à falta de capacitação, treinamento ou experiência, o que pode interferir no sucesso do procedimento, pois não está isento de riscos e pode haver o comprometimento da qualidade dos componentes, assim como, pode causar reações adversas ao paciente (CARNEIRO VSM, et al., 2017).

\section{CONSIDERAÇÕES FINAIS}

Entende-se que há necessidade da qualificação de enfermeiros para a área, pois a equipe de enfermagem tem papel fundamental na qualidade do serviço prestado e na atuação diante das complicações. A capacitação é imprescindível, modalidades como a educação permanente e a educação continuada são de suma importância para que o profissional atue de forma plena, objetivando a melhoria na prática transfusional e o bom estado de saúde do paciente.

\section{REFERÊNCIAS}

1. AMARAL JHS, et al. Hemoterapia: um desafio no cotidiano da equipe de enfermagem. Revista de Enfermagem UFPE Online, 2016; 10(Supl. 6): 4820-7.

2. CARNEIRO VSM, et al. Hemoterapia e reações transfusionais imediatas: atuação e conhecimento de uma equipe de enfermagem. Revista Mineira de Enfermagem, 2017; 21: e-1031.

3. COFEN. C. F. Resolução COFEN no 0511/2016. Normatiza a atuação do enfermeiro em Hemoterapia, p. 16-18, 2016. Disponível em: http://www.cofen.gov.br/resolucao-cofen-no05112016_39095.html. Acessado em: 07 de outubro de 2021.

4. FRANTZ SRS, et al. Nursing work and competence in hemotherapy services: an ergological approach. Revista Brasileira de Enfermagem, 2020; 73(3): e20180775.

5. FRANTZ SRS, VARGAS MAO. Renormalização do trabalho do enfermeiro em hemoterapia: entre o prescrito e o real. Texto \& Contexto Enfermagem, 2021; 30: e-20190060. 
RESUMO SIMPLES: Revisão Integrativa

\title{
ADMISSÃO DE PACIENTE AO CENTRO CIRÚRGICO EM TEMPOS DE PANDEMIA
}

\author{
Regina Celly da Silva ${ }^{1}$ \\ Giselda Bezerra Correia Neves ${ }^{1}$ \\ José Luís Silva Dos Santos ${ }^{1}$ \\ Vitória Cristina Clementino dos Santos ${ }^{1}$
}

1. Centro Universitário Brasileiro (UNIBRA), Recife - PE.

Palavras-chave: Pandemia, Bloco cirúrgico, Admissão.

\section{INTRODUÇÃO}

A preocupação com a segurança do paciente sempre foi primordial para realização de cirurgia com excelência e segurança (LOPES TMR, et al., 2019). As ações que estabelecem a admissão do paciente ao bloco cirúrgico compreendem desde a atenção durante o agendamento e marcação do procedimento, direcionamento do cliente a sala mais adequada para devida cirurgia, desinfecção de sala e desparamentação dos profissionais envolvidos. Sabendo dos riscos as instituições de saúde, investiram em melhorar na qualidade assistencial, ações do gerenciamento de risco têm como objetivo a segurança dos pacientes, através de identificação dos riscos agindo na sua prevenção e controle (SANTOS DMN, et al., 2021).

\section{OBJETIVO}

Compreender de forma abrangente sobre novas normativas de segurança, através de uma revisão de literatura, acerca dos métodos desenvolvidos para admissão de pacientes suspeitos, confirmados e eletivos em bloco cirúrgico em períodos pandêmicos.

\section{MÉTODO}

Trata-se de uma pesquisa de revisão integrativa para esse fim, sucederam buscas nas bases de dados SCIELO, Acervo + Index Base, Pubmed, no período do mês de outubro, resultou de uma análise de 4 artigos, contendo artigos dos últimos 5 anos e como critério de exclusão aqueles que não atendem a temática solicitada, empregando como descritores: Pandemia, centro cirúrgico, admissão do paciente.

\section{REVISÃO BIBLIOGRÁFICA}

Os protocolos vigentes sobre cirurgias mudaram com o advento da pandemia; testagem de swabs nasal ou PCR-RT devem ser realizados com antecedência; O check list cirúrgico que se trata de uma certificação objetiva sobre o procedimento agora agrega mais segurança (MAGALHAES CM, et al., 2021). Manter salas exclusivas para atendimento de portadores de Covid e os manter próximos a porta, usar de filtro descartável durante cirurgia. As salas precisam estar com sinalização, em caso de admissão de pacientes suspeitos a 
equipe deve se paramentar e realizar processos de desinfecção após cada procedimento ocorrido. As mãos que são veículos de contaminação, contam com esquema de higienização mais rigoroso (CUNHA AG, et al., 2020).

\section{CONSIDERAÇÕES FINAIS}

À atual situação que o mundo vem enfrentando devido a infecção do vírus de alta patogenicidade o SARS Cov 2, tornou indispensável as atualizações com novos protocolos de segurança na admissão de pacientes em centro cirúrgico. Descrevendo medidas preventivas, uso adequando de EPIs conforme procedimento realizado, higienização e descarte de matérias após término de procedimentos. Baseando-se através de recomendações do Ministério da saúde em contingência com a Anvisa.

\section{REFERÊNCIAS}

1. CUNHA AG. Como preparar o centro cirurgico para pacientes com covid-19. Revista do Colégio Brasileiro de Cirurgiões, 2020: 47: e20202575.

2. LOPES TMR, et al. Atuação do enfermeiro na segurança do paciente no centro cirúrgico: uma revisão integrativa da literatura. Revista Eletrônica Acervo Enfermagem, 2019; (26): e769.

3. MAGALHAES CM, et al. Adesão ao checklist cirúrgico para a segurança do paciente: percepção da equipe de enfermagem. Revista Eletronica Acervo Enfermagem, 2021; 13(7): e8184.

4. SANTOS DMN, et al. Desafios do enfermeiro do centro cirúrgico frente a pandemia da covid 19 e transição de uma sala cirúrgica em unidade de terapia intensiva. Revista Eletrônica Acervo Enfermagem, 2021; 13(6): e7760. 


\title{
QUALIDADE DE VIDA DE PORTADORES DE ESCLEROSE MÚLTIPLA E FATORES ASSOCIADOS: UMA REVISÃO INTEGRATIVA
}

\author{
Beatriz Caroline Leão Lima ${ }^{1}$ \\ Andressa Dâmaras Freitas Feitosa ${ }^{1}$ \\ Daniela dos Santos Mangueira de Almeida ${ }^{1}$ \\ Maria Clara Rodrigues de Abreu ${ }^{1}$ \\ Mauro Roberto Biá da Silva ${ }^{1}$
}

1. Universidade Estadual do Piauí (UESPI), Teresina - PI.

Palavras-chave: Esclerose múltipla, Qualidade de vida, Impacto da doença na qualidade de vida.

\section{INTRODUÇÃO}

A esclerose múltipla (EM) é uma doença crônica desmielinizante do sistema nervoso central, apresenta evolução progressiva e afeta diversas funcionalidades do corpo humano, desse modo, a esclerose múltipla resulta em diversas manifestações clínicas ao longo dos anos e provoca a perda de autonomia do indivíduo portador (ROSA RC, et al., 2021).

A perda do papel social e outros diversos fatores advindos da EM, como os sintomas da doença, o grau de acometimento e os transtornos psicológicos, podem impactar negativamente no bem-estar mental do indivíduo e modificar a sua percepção acerca da sua posição na sociedade, em consequência, interfere na qualidade de vida desses indivíduos (SILVA MCN e CAVALCANTI DBA, 2019).

\section{OBJETIVO}

Pesquisar e revisar sobre o impacto na qualidade de vida de portadores de esclerose múltipla e analisar os fatores que podem ter relação direta com os efeitos da doença no bem-estar psicológico do portador de EM.

\section{MÉTODO}

Trata-se de uma revisão integrativa da literatura, foram realizadas buscas na Biblioteca Virtual em Saúde do Ministério da Saúde - BVS, tendo como bases de dados: MEDLINE, LILACS e SciELO. Os critérios de inclusão para esse estudo foram: artigos originais condizentes com a temática, em português, inglês e espanhol, publicados nos últimos cinco anos (2016 a 2021). Como critério de exclusão adotou-se artigos de revisão e que fugiram ao tema.

\section{REVISÃO BIBLIOGRÁFICA}


A esclerose múltipla é uma doença de trajetória irregular e apresenta progressão e sintomas que distinguem-se dentre os portadores, como a fadiga e a deambulação limitada, podem estar presentes ou não na condição particular de cada indivíduo (KASSIE SA, et al., 2021). Tais sinais clínicos impactam negativamente na funcionalidade física e, devido à perda de autonomia, a EM repercute diretamente nos aspectos mentais e apresenta incidência significativa em transtornos como a depressão e a ansiedade (SILVA MCN e CAVALCANTI DBA, 2019). No manejo do enfrentamento da EM considera-se importante atuar na percepção da qualidade de vida desde o diagnóstico, objetivando o bem-estar físico e mental (VÁZQUEZGÓMEZ LA, et al., 2021).

\section{CONSIDERAÇÕES FINAIS}

Diante das pesquisas, foi evidenciado que as manifestações físicas e psicológicas decorrentes da esclerose múltipla são decisivas e de grande impacto no bem-estar mental e emocional do indivíduo. Reconhece-se a necessidade de uma abordagem multidimensional prévia e contínua ao paciente portador de EM, com atenção para o apoio psicológico e psiquiátrico, visto que pode ser significativo para uma melhora na qualidade de vida desses indivíduos.

\section{REFERÊNCIAS}

1. KASSIE SA, et al. Biopsychosocial implications of living with multiple sclerosis: a qualitative study using interpretative phenomenological analysis. BMJ Open, 2021; 11: e049041.

2. ROSA RC, et al. Correlação entre a qualidade de vida e a capacidade funcional em pacientes com esclerose múltipla. Saúde e Pesquisa, 2021; 14(2): 271-277 - e: ISSN 2176-9206.

3. SILVA MCN, CAVALCANTI DBA. Avaliação da qualidade de vida em portadores de esclerose múltipla: impacto da fadiga, ansiedade e depressão. Fisioterapia e Pesquisa, 2019; 26(4): 339-345.

4. VÁZQUEZ-GÓMEZ LA, et al. Estrategia para el seguimiento multidisciplinario a pacientes con esclerosis múltiple. Edumecentro, 2021; 13(3): 42-63; ISSN 2077-2874. 


\title{
REALIZAÇÃO DO TESTE RÁPIDO ORAL DE DETECÇÃO DO HIV NA ODONTOLOGIA
}

\author{
Kátia Ferreira dos Santos ${ }^{1}$
}

Lúcia Yasuko Izumi Nichiata²

1. Coordenadoria de Controle de Doenças da Secretaria de Estado de Saúde de São Paulo (CCD-SESSP), São Paulo - SP.

2. Universidade de São Paulo (USP), São Paulo - SP.

Palavras-chave: HIV, Diagnóstico precoce, Kit de reagentes para diagnóstico.

\section{INTRODUÇÃO}

O Programa das Nações Unidas sobre HIV/aids estimou que pessoas vivendo com HIV/aids chegou a 3,5 milhões e 8,6 milhões de mortes/ano ocorreram em países de baixa renda, pela negligência aos acessos de saúde, de 2015 a 2020. Intervenções de prevenção e estratégias socioculturais podem ser eficazes para erradicar o HIV (GOVENDER RD, et al., 2021). Cirurgiões-dentistas (CD), podem contribuir com monitoramento da infecção, pela aplicação do teste rápido oral (TRO) e diminuir o percentual de pessoas que não conhecem seu estado sorológico (SANTELLA AJ, et al., 2016). O TRO utiliza biomarcadores salivares que corroboram para prevenção do HIV/aids (GAO B, et al., 2021, NETO JMAS, et al., 2020).

\section{OBJETIVO}

Revisar a literatura científica para identificar artigos que tratem da atuação dos CD em relação ao TRO e verificar a aceitação de implantação dos testes em consultórios e clínicas odontológicas que permitam a identificação da sorologia dos portadores de HIV.

\section{MÉTODO}

Revisão integrativa nas bases PubMed, Cochrane, Lilacs e Scopus, no período de outubro de 2018 a agosto de 2019, com critérios de inclusão: artigos em inglês, online, gratuitos e os repetidos foram excluídos. 89 artigos foram encontrados e 11 selecionados para análise. Somente cinco relataram ação clínica direta do $C D$ e os demais relataram pesquisas sobre TRO e atuação do CD na contribuição da identificação de pessoas infectadas com HIV.

\section{REVISÃO BIBLIOGRÁFICA}

Foi identificado um caso-controle realizado por $C D$, em duas clínicas odontológicas que mostrou o diagnóstico de doenças bucais baseadas nos sintomas iniciais da aids, como candidíase, herpes zoster, herpes simplex, infecção fúngica, úlcera oral recorrente e procederam com o tratamento odontológico, após a aplicação do TRO (SHIFU L, et al., 2017). Em outro estudo transversal examinou-se a aceitabilidade do 
TRO, em ambiente odontológico e verificou- se que os CD podem colaborar com a difusão dos testes de HIV, por meio de treinamentos que aprimorem seus conhecimentos e o acolhimento em HIV que permitam a utilização dos testes, inclusive com possibilidade de reembolso para sua implementação (BRADLEY ELP, et al., 2018).

\section{CONSIDERAÇÕES FINAIS}

Diante dos estudos apresentados, verificou-se que o CD pode atuar diretamente na implementação do TRO em consultórios odontológicos, pois contribui de forma direta e significativa para a saúde pública com diagnóstico precoce, tratamento, longevidade e melhora na qualidade de vida das pessoas que vivem com infecções por HIV, pois atua na diminuição das taxas de comorbidades para aids.

\section{REFERÊNCIAS}

1. BRADLEY ELP, et al. Acceptability of oral rapid HIV testing at dental clinics in communities with high HIV prevalence in South Florida. PLoS One, 2018; 27; 13(4): e0196323.

2. GAO B, et al. HIV testing behaviors and willingness to receive oral rapid HIV testing among dental patients in Xi'an, China. PLoS One, 2021; 25; 16(3): e0248585.

3. GOVENDER RD, et al. Global epidemiology of HIV/AIDS: a resurgence in North America and Europe. Journal of Epidemiology and Global Health. 2021; 11(3): 296-301.

4. SANTELLA AJ, et al. The potential role of dentists in HIV screening. British Dental Journal, 2016; 11; 220(5): 229-233.

5. SHIFU L, et al. A comparison of effectiveness between oral rapid testing and routine serum-based testing for HIV in an outpatient dental clinic in Yuxi Prefecture, China: a case-control study. BMJ Open, 2017; 7(6): e014601.

6. NETO JMAS, et al. A saliva como sendo um meio de diagnósticos: uma revisão de literatura. Revista Eletrônica Acervo Saúde, 2020; (41): e2506. 
RESUMO SIMPLES: Revisão Integrativa

\section{O PAPEL DO ENFERMEIRO NOS CUIDADOS PALIATIVOS EM ONCOLOGIA PEDIÁTRICA: UMA REVISÃO INTEGRATIVA}

Maria Clara Rodrigues de Abreu ${ }^{1}$

Andressa Dâmaras Freitas Feitosa ${ }^{1}$

Beatriz Caroline Leão Lima ${ }^{1}$

Daniela dos Santos Mangueira de Almeida ${ }^{1}$

Mauro Roberto Biá da Silva ${ }^{1}$

1. Universidade Estadual do Piauí (UESPI), Teresina - PI.

Palavras-chave: Cuidados paliativos, Oncologia, Enfermagem.

\section{INTRODUÇÃO}

O câncer infanto-juvenil é uma doença crônica que configura-se como um problema de saúde pública no Brasil, pois apresenta elevado índice de mortalidade na faixa etária de 1 a 19 anos. Ele é caracterizado por um crescimento desordenado das células que consequentemente perdem suas capacidades de desenvolvimento (BRASIL, 2020.

Assim, diante do adoecimento por câncer, crianças e adolescentes são retiradas de sua vida social para uma situação na qual a expectativa de futuro é duvidosa. Nesse cenário, é fundamental as intervenções da equipe de saúde, e os cuidados paliativos (CP) se apresentam como uma possibilidade de melhoria na qualidade de vida dos pacientes e seus familiares (SOUSA ADRS, et al., 2019).

\section{OBJETIVO}

Revisar e analisar por meio da literatura científica o papel do enfermeiro nos cuidados paliativos em oncologia pediátrica e assim mapear a sua importância sob a ótica do cuidar em enfermagem.

\section{MÉTODO}

Trata-se de uma revisão integrativa da literatura, com busca na Biblioteca Virtual em Saúde (BVS), tendo como bases de dados: Lilacs, Scielo e BDENF no período do mês de outubro, procedeu-se à análise de 4 artigos, incluindo artigos em português e inglês, publicados nos últimos cinco anos e excluindo artigos não condizentes com a temática e revisões de literatura, utilizando como descritores: Cuidados Paliativos, oncologia, enfermagem.

\section{REVISÃO BIBLIOGRÁFICA}


No contexto da oncologia e cuidados paliativos, o enfermeiro tem o papel de ajudar o paciente e sua família a viver os últimos momentos de forma mais humanitária, com respeito aos seus valores e crenças, preservando sua dignidade humana (SILVEIRA NR, et al., 2016). Contudo, para que esse cuidado seja de forma integral, com técnicas adequadas, o enfermeiro deve ter uma formação generalista, crítica e humanista desde a sua graduação. Acresce que, em pacientes pediátricos é necessário um diferencial no cuidado, logo os recursos lúdicos e brincadeiras que envolvam a distração podem atenuar o difícil processo de hospitalização e facilitar sua integração com outras crianças (GUIMARÃES TM, et al., 2017).

\section{CONSIDERAÇÕES FINAIS}

Reitera-se que os cuidados paliativos são de suma importância na assistência aos pacientes oncológicos. E para melhorar a qualidade de vida em Oncologia Pediátrica, urge a necessidade de capacitação e desenvolvimento por parte da equipe e avanços durante a graduação.

\section{REFERÊNCIAS}

1. BRASIL. MINISTÉRIO DA SAÚDE. Instituto Nacional do Câncer. José Alencar Gomes da Silva (Brasil). ABC do Câncer: Abordagens básicas para o controle do câncer. INCA. 2020. Disponível em: https://www.inca.gov.br/publicacoes/livros/abc-do-cancer-abordagens-basicas-para-o-controle-do-cancer. Acesso em: 13 de outubro de 2021.

2. GUIMARÃES TM, et al. Cuidado paliativo em oncologia pediátrica na formação do enfermeiro. Revista Gaúcha de Enfermagem, 2017; 38(1): e65409.

3. SOUSA ADRS, et al. Instrumento Assistencial de Enfermagem em cuidados paliativos para centro de terapia intensiva pediátrica oncológica. Revista Enfermagem em Foco, 2019: 28-34.

4. SILVEIRA NR, et al. Cuidado paliativo e enfermeiros de terapia intensiva: sentimentos que ficam. Revista Brasileira de Enfermagem, 2016; 69(6): 1074-1081. 


\title{
AS IMPLICAÇÕES DA LIDERANÇA DE ENFERMAGEM EM TEMPOS DE COVID-19
}

\author{
Renato Barbosa Japiassu ${ }^{1}$ \\ Márcia Mello Costa De Liberal ${ }^{1}$ \\ Chennyfer Dobbins Abi Rached ${ }^{2}$
}

1. Universidade Federal de São Paulo (UNIFESP), São Paulo - SP.

2. Universidade de São Paulo (USP), São Paulo - SP.

Palavras-chave: Liderança, Enfermagem, COVID-19.

\section{INTRODUÇÃO}

A enfermagem é uma profissão que possui grande quantidade de líderes, tendo destaque no fortalecimento da prática interprofissional colaborativa e do trabalho em equipe, sendo a forma de comunicação com os outros membros da equipe de saúde essencial, que promoverá harmonia, uma melhor tomada de decisão e impacto na qualidade do cuidado direcionado aos pacientes. As competências de atuação em equipe, como uma boa comunicação, cordialidade, respeito, confiança, conhecimento mútuo, poder, centralização das ações no paciente, características das tarefas e ambiente foram práticas utilizadas durante a pandemia de COVID-19 (ANDERS RL, et al., 2021; BELARMINO AC, et al., 2020; PAULA LMM, et al., 2020).

\section{OBJETIVO}

Realizar uma revisão de literatura sobre a importância da liderança de enfermagem durante a pandemia do Coronavírus 2 da Síndrome Respiratória Aguda Grave (SARS-CoV-2) e a necessidade de ter um olhar acolhedor para os seus liderados.

\section{REVISÃO BIBLIOGRÁFICA}

A COVID-19 possui uma grande demanda por líderes de enfermagem que possam estar junto com sua equipe. Deve haver uma mútua confiança entre os enfermeiros da linha de frente e os líderes de enfermagem. É necessária uma comunicação frequente e contínua, assegurando a existência de vias de mão-dupla estruturadas e regulares, como a junção de turnos, para que a equipe possa ter consciência da ação do empregador e um auxiliar o outro nas atualizações relacionadas à COVID-19, salvaguardando a equipe para que eles sejam devidamente instruídos, com informações sobre os Equipamentos de Proteção Individual e entendendo como minimizar a exposição ao vírus. O líder de enfermagem necessita promover intervalos para descanso da equipe durante o plantão, devido ao alto nível de estresse tanto para os pacientes quanto para a equipe, como também para ouvir e apoiar a equipe. Ser esse elo de manutenção de cuidado com a equipe de enfermagem não deve ser subestimado (ANDERS RL, et al., 2021; VENTURA-SILVA JMA, et al., 2020; MONTE LM, et al., 2020). 


\section{CONSIDERAÇÕES FINAIS}

A reestruturação de toda a assistência de saúde mostrou-se desafiadora, tendo necessidade da interconexão entre gestão do cuidado e liderança em toda a área da saúde. A reorganização dos recursos humanos, como insumos e novas tecnologias, a necessidade de utilização de indicadores epidemiológicos e fluxogramas, ações educativas e de assistência aos profissionais da linha de frente, intersubjetividade no atendimento aos pacientes e familiares, indicando princípios interdisciplinares no enfrentamento do COVID19.

\section{REFERÊNCIAS}

1. ANDERS RL, et al. Liderança em enfermagem para o Século XXI. Revista Latino-Americana de Enfermagem, 2021; 29: e:3472.

2. BELARMINO AC, et al. Práticas colaborativas em equipe de saúde diante da pandemia de COVID-19. Revista Brasileira de Enfermagem, 2020; 73(Suppl 6): e20200470.

3. MONTE LM, et al. Complicações atípicas do e características clínico-epidemiológicas do COVID-19: uma revisão integrativa. Revista Eletrônica Acervo Saúde, 2020; 46(46): e3699.

4. PAULA LMM, et al. Potenciais tratamentos nomanejo do COVID-19. Revista Eletrônica Acervo Saúde, 2020; 12(9): e3963.

5. VENTURA-SILVA JMA, et al. Planejamento organizacional no contexto de pandemia por COVID-19: implicações para a gestão de enfermagem. Journal Health NPEPS, 2020; 5(1): e4626. 


\title{
TRANSTORNO DE ANSIEDADE GENERALIZADA COMO FATOR DESENCADEANTE DE AUTOMEDICAÇÃO NO CONTEXTO DA PANDEMIA DE COVID-19
}

\author{
Nayara de Oliveira Santos ${ }^{1}$
}

Ligia Maria Oliveira de Souza ${ }^{1}$

Marta Lopes ${ }^{1}$

Mauricio Luis Aguilar Linares ${ }^{1}$

Seidel Guerra López ${ }^{1}$

1. Universidad Politécnica y Artística del Paraguay (UPAP), Ciudad del Este, Alto Paraná - Paraguai.

Palavras-chave: Automedicação, Ansiedade, COVID-19.

\section{INTRODUÇÃO}

O Transtorno de Ansiedade Generalizada (TAG) é um distúrbio mental caracterizado por preocupação excessiva, inquietação mental e sintomas físicos associados: insônia, sensação de aperto no peito, falta de ar, taquicardia, tensão, dor muscular, cefaleia, fadiga mental, reações exacerbadas em situações adversas, medo, boca seca, náusea, palpitações, sentimento de tragédia iminente e tremores (LOPES AB, et al., 2021).

O tratamento inclui: terapia cognitivo-comportamental, outras terapias biológicas e tratamento farmacológico com inibidores seletivos da recaptação da serotonina e benzodiazepínicos. Estudos apontam aumento significativo de TAG na pandemia de COVID-19, resultante do isolamento social imposto e luto familiar, com incremento da automedicação e abandono das consultas ambulatoriais (FÁVERO V e DAMIAN PB, 2021).

\section{OBJETIVO}

Realizar uma revisão narrativa de literatura acerca do transtorno de ansiedade generalizada como fator desencadeante da automedicação, destacando o aumento do uso de medicamentos no contexto da pandemia de COVID-19.

\section{REVISÃO BIBLIOGRÁFICA}

A ansiedade em algumas situações é considerada normal como forma de alerta em situações de perigo e reflexiva no âmbito estrutural em longo prazo. No entanto, quando esse sentimento se torna um distúrbio psiquiátrico e afeta o bem-estar do indivíduo é considerado patológico. O TAG na pandemia de COVID-19 pode ser causado por diversos fatores como o estresse, adversidade infantil, traumas, fatores congênitos de enfermidades psíquicas em parentes de primeiro grau, comorbidades, abuso infantil, luto, entre outros (FIGUEIRA DCM, et al., 2021). 
Esses aspectos podem ser subdiagnosticados pelo indivíduo, devido à ampla sintomatologia do TAG, influenciando a automedicação, por ser um meio de escapismo e de fácil acesso, dando assim a falsa impressão de alívio e camuflando a verdadeira causa do transtorno. Por esses aspectos é de extrema importância à atuação clínica do profissional de saúde na atenção primaria com atendimento competente e especializado, promovendo prescrição medica responsável e diagnóstico assertivo (SOUSA FV e TREVISAN $M, 2021)$.

\section{CONSIDERAÇÕES FINAIS}

Diante dos estudos apresentados, demonstra-se que o consumo irracional de medicamentos além de ser uma prática bastante comum entre os brasileiros, seu uso aumentou significativamente na pandemia de COVID-19. Desse modo, é evidente que novos estudos devem ser realizados pós-pandemia para elucidar as principais consequências dessa prática no âmbito da Saúde Mental e traçar novas políticas.

\section{REFERÊNCIAS}

1. FÁVERO V, DAMIAN PB. Levantamento bibliométrico da prevalência da ansiedade e depressão por meio do Covid-19. Revista Artigos.Com, 2021; 31: e8811.

2. FIGUEIRA DCM, et al. Covid-19 e os impactos na saúde mental: uma revisão narrativa. Revista Eletrônica Acervo Saúde, 2021; 13(9): e7656.

3. LOPES AB, et al. Transtorno de ansiedade generalizada: uma revisão narrativa. Revista Eletrônica Acervo Científico, 2021; 35: e8773.

4. SOUSA FV, TREVISAN M. Relação farmacêutico-paciente a partir do olhar clínico, Revista Artigos.Com, 2021; 29: e7632. 
RESUMO SIMPLES: Revisão Narrativa

\section{DISFUNÇÃO TEMPOROMANDIBULAR E IMPACTO NA QUALIDADE DE VIDA: UMA REVISÃO NARRATIVA}

Marcos Antônio Lima dos Santos ${ }^{1}$

Lucas Alves da Mota Santana²

Aline Piruna Martins dos Santos ${ }^{1}$

Francisco Barbara Abreu Barros ${ }^{1}$

Marcelo de Gusmão Paraiso Cavalcanti ${ }^{1}$

1. Universidade de São Paulo (USP), São Paulo - SP.

2. Universidade Federal de Sergipe (UFS), Aracaju - SE.

Palavras-chave: Qualidade de vida, Disfunção Temporomandibular, Mastigação.

\section{INTRODUÇÃO}

As Disfunções Temporomandibulares (DTM) foram identificadas como as principais causas de dor não dental na região orofacial. A sintomatologia dolorosa normalmente localiza-se nos músculos da mastigação, área pré-auricular e nas articulações temporomandibulares. A etiologia das DTM's é complexa e multifatorial. Um dos fatores que pode influenciar na mastigação, é o aumento do nível de estresse emocional. O estresse afeta o corpo através da ativação do eixo Hipotalâmico-Pituitário-Adrenal (HPA) que, por intermédio de vias neurais complexas, aumenta a atividade dos eferentes gamas, provocando a contração das fibras intrafusais através da sensibilização dos fusos musculares. Em decorrência desse mecanismo, há um aumento na tonicidade dos músculos (KLATKIEWICZ T, et al., 2018).

\section{OBJETIVO}

Investigar e discorrer sobre as DTMs no âmbito odontológico, narrando sua etiopatologia e discursando sobre o seu impacto na qualidade de vida dos pacientes que possuem esta patologia e formas de tratamento.

\section{REVISÃO BIBLIOGRÁFICA}

As DTMs costumam afetar mais mulheres do que os homens. O tratamento precoce e multidisciplinar deve ser realizado para evitar a sobreposição de eventos dolorosos que podem resultar na cronificação da dor. Entre as limitações craniofaciais que acometem os pacientes, está a limitação de abertura de boca e a perda do suporte oclusal (MATSUBARA R, et al., 2018).

Quando os pacientes costumam apresentar os primeiros sinais e sintomas da DTM, os mesmos devem ser submetidos ao exame de imagem de Ressonância Magnética Inicial (RMI), caso seja possível, para que o melhor plano de tratamento seja escolhido. Outra forma de investigação muito utilizada no diagnóstico das 
desordens temporomandibulares é a ultrassonografia, que precisa de uma padronização do método aplicado, bem como de novas pesquisas para que se confirme a sua eficácia (NGUYEN MS, et al., 2018).

É importante que os cirurgiões-dentistas notem que o tratamento pode se tornar a causa dos sintomas da DTM, já que os pacientes não têm conhecimento sobre a patologia. Por esta razão, a triagem correta, deve ser parte importante da prática odontológica (ABOUELHUDA AM, et al., 2017).

\section{CONSIDERAÇÕES FINAIS}

A dor apresentada pelo paciente costuma ser crônica, recorrente, de alta intensidade e baixa incapacidade, afetando a qualidade de vida, principalmente para mastigar alimentos duros. Dentre as fisiopatologias, a dor de cabeça e a enxaqueca costumam ser mais prevalentes, o que contribui para que o paciente com DTMs apresentem uma condição psicossocial afetada.

\section{REFERÊNCIAS}

1. ABOUELHUDA AM, et al. Association between headache and temporomandibular disorder. Journal of the Korean Association of Oral and Maxillofacial Surgeons, 2017; 43(6): 363.

2. KLATKIEWICZ T, et al. Ultrasonography in the Diagnosis of Temporomandibular Disorders: A MetaAnalysis. Medical Science Monitor, 2018; 24: 812-7.

3. MATSUBARA R, et al. Assessment of MRI findings and clinical symptoms in patients with temporomandibular joint disorders. British Institute of Radiology, 2018; 47(4): 20170412.

4. NGUYEN MS, et al. Temporomandibular Disorder Signs, Occlusal Support, and Craniofacial Structure Changes Among the Elderly Vietnamese. Journal of Maxillofacial and Oral Surgery, 2017; 17(3): 362-371. 


\title{
PROTOTIPAGEM NA RADIOLOGIA ODONTOLÓGICA E O SISTEMA CAD/CAM: UMA REVISÃO NARRATIVA
}

\author{
Marcos Antônio Lima dos Santos ${ }^{1}$ \\ Lucas Alves da Mota Santana² \\ Aline Piruna Martins dos Santos ${ }^{1}$ \\ Francisco Barbara Abreu Barros ${ }^{1}$ \\ Marcelo de Gusmão Paraiso Cavalcanti ${ }^{1}$
}

1. Universidade de São Paulo (USP), São Paulo - SP.

2. Universidade Federal de Sergipe (UFS), Aracaju - PE.

Palavras-chave: Impressão tridimensional, Tecnologia odontológica, Planejamento.

\section{INTRODUÇÃO}

O termo CAD/CAM é um acrônimo das palavras "Computer Aided Design" (Desenho guiado por computador) e "Computer Aided Manufacturing" (Fabricação guiada por computador). Esta tecnologia tem sido implementada e incorporada na área odontológica, promovendo uma automatização e padronização do processo de fabricações de próteses, assim como redução dos custos de realizaç ão dos procedimentos. Entre as vantagens destes sistemas destacam-se a melhor reprodutibilidade, precisão de dimensão, diminuição do tempo de confecção e a possibilidade de utilização de novos sistemas cerâmicos, considerados mais resistentes (FILGUEIRAS A, et al., 2018).

\section{OBJETIVO}

Dissertar sobre o uso da prototipagem no âmbito odontológico, descrevendo a importância da radiologia odontológica no planejamento da confecção de biomodelos, apresentando suas especificidades e softwares necessários para sua realização.

\section{REVISÃO BIBLIOGRÁFICA}

A aquisição das imagens de tomografia computadorizada, para confecção de biomodelos do complexo estomatognático deve seguir um protocolo específico, envolvendo determinados aspectos considerados importantes, como o posicionamento do paciente no scanner, mantendo-o imóvel para evitar errosdelimitando a região anatômica a ser englobada no exame. Sendo assim, o plano e a espessura da forma retiradas das imagens podem ser salvas em arquivos e posteriormente, fresadas (DUTRA DN, et al., 2017).

A aquisição de imagens a partir da tomografia computadorizada fornece uma sequência de secções de diversos planos da região de interesse em um formato específico. Para realizar a manipulação dessas imagens, no intuito de criar modelos volumétricos a partir delas, são necessários softwares biomédicos 
específicos. Estes programas possuem a capacidade de processar as imagens no formato DICOM, bidimensionais, e modificá-las em um modelo tridimensional a ser utilizado pela máquina de prototipagem para confeccionar estes protótipos (LIMA LC, et al., 2021).

\section{CONSIDERAÇÕES FINAIS}

Com a necessidade da reprodução fidedigna de estruturas anatômicas para a construção de biomodelos, torna-se essencial o correto planejamento por via de exames especializados como a tomografia computadorizada, exame essencial para confecção destes exemplares, facilitando assim a vida do profissional, além de trazer conforto e estética ao paciente.

\section{REFERÊNCIAS}

1. DUTRA DN, et al. Aplicabilidade da prototipagem rápida na odontologia - uma revisão de literatura. Revista de Ciências Médicas e Biológicas, 2017; 16: 89.

2. FILGUEIRAS A, et al. Aplicabilidade clínica dos avanços da tecnologia CAD-CAM em Odontologia. HU Revista, 2018; 44(1): 29-34.

3. LIMA LC, et. al. Prototipagem rápida confeccionada pela técnica da impressão tridimensional na cirurgia e implantodontia. Research, Society and Development, 2021; 10: e405101220633. 


\title{
PANORAMA DE ATUAÇÃO DE ENFERMEIROS FRENTE A TERAPIA NUTRICIONAL POR VIA ENTERAL E PARENTERAL NAS DOENÇAS INFLAMATÓRIAS DO TRATO GASTROINTESTINAL
}

\author{
Vitória Cristina Clementino dos Santos ${ }^{1}$ \\ Giselda Bezerra Correia Neves ${ }^{1}$ \\ Géssica Daiane da Silva ${ }^{1}$ \\ Luana Vanessa Teixeira Gomes ${ }^{1}$ \\ Regina Celly da Silva ${ }^{1}$
}

1. Centro Universitário Brasileiro, (UNIBRA), Recife - PE.

Palavras-chave: Enfermagem, Terapias nutricionais, Nutrição enteral e parenteral.

\section{INTRODUÇÃO}

A terapia nutricional (TN) é caracterizada como procedimento terapêutico que possibilita ao paciente, em especial, àqueles acometidos por doenças inflamatórias do trato gastrointestinal (DII) a manutenção ou recuperação do estado nutricional, por meio, da nutrição enteral ou parenteral: A Terapia nutricional (TN), envolve de forma direta a equipe de enfermagem que precisa er embasamento cientifico sobre a passagem da sonda, tipos de dietas e formas de administração, e principalmente aptidão durante o monitoramento para avaliar continuamente a efetividade do procedimento, a prevenção das infecções e agravos a saúde do paciente que possa culminar em óbitos (POSSO PNV, et al., 2020).

\section{OBJETIVO}

Descrever as formas existentes de terapia nutricional por via enteral e parenteral, bem como a atuação das equipes de enfermagem para prevenção de infecções e agravos à saúde dos pacientes.

\section{MÉTODO}

Trata-se de uma pesquisa de revisão integrativa, portanto, sucederam buscas em bases de dados cientificas SCIELO, Acervo+ Index Bases, Pubmed, no periodo do mês de outubro, proveio de uma ánalise de artigos, contendo artigos dos últimos anos e como critério de exclusão aqueles que não atendem a tématica proposta, empregado como descritores: Nutrição parentera, enfermagem, infecção.

\section{REVISÃO BIBLIOGRÁFICA}

A desordem do estado nutricional, pode acarretar desnutrição durante período de internação hospitalar proveniente da evolução de doenças. A enfermagem adjunta com equipe de nutrição traça formas de combater seus prejuízos (MACHADO M, et al., 2020). Para obter manutenção do peso ajustando as 
necessidades nutricionais quando encontrasse inadequada requer indicação de sondagem enteral suprindo aporte de substâncias. Por sua vez na impossibilidade desta via por agravos recomenda-se nutrição parenteral administrado de forma sistêmica (SOUSA JCSDS, et al., 2018). É importante reconhecer e tratar as possíveis complicações e seus risco por ambas formas de terapia nutricional desde mau posicionamento da sonda até infecções no cateter de infusão (SILVEIRA CG, et al., 2020).

\section{CONSIDERAÇÕES FINAIS}

Em síntese mediante os achados dispostos nesta pesquisa, que a terapia nutricional pode propiciar ao paciente estado nutricional satisfatório e que a atuação conjunta da equipe de enfermagem durante todo o processo reduz a incidência de infecções e agravos à saúde do paciente, o tempo de internação hospitalar e, por fim, a mortalidade.

\section{REFERÊNCIAS}

1. MACHADO M, et al. Avaliação do estado nutricional de pacientes adultos internados em uma fundação hospitalar da cidade de cascavel- PR. Revista FAG JOURNAL OF HEALTH, 2020; 2(1): 67-73.

2. POSSO PNV, et al. Indicadores de qualidade em terapia nutricional enteral em uma unidade de terapia intensiva no interior de Rondônia. Revista Eletrônica Acervo Saúde, 2020; (47), e2709.

3. SILVEIRA GC, ROMEIRO FG, As dificuldades e riscos durante a introdução e posicionamento da sonda nasoentérica. Revista Nursing, 2020; 23 (266): 4360-4373.

4. SOUSA JCSDS, et al. Avaliação do estado nutricional de pacientes hospitalizados: Uso de métodos convencionais e não convencionais. Portal de publicações eletrônicas da UERJ, 2018; 13(1): 195-208. 


\title{
RECOMENDAÇÕES PARA A ASSISTÊNCIA À PUÉRPERA NO CONTEXTO DA PANDEMIA DE COVID- 19: UMA REVISÃO INTEGRATIVA
}

\author{
Maria Clara Rodrigues de Abreu ${ }^{1}$ \\ Andressa Dâmaras Freitas Feitosa ${ }^{1}$ \\ Beatriz Caroline Leão Lima ${ }^{1}$ \\ Daniela dos Santos Mangueira de Almeida ${ }^{1}$ \\ Mauro Roberto Biá da Silva ${ }^{1}$
}

1. Universidade Estadual do Piauí (UESPI), Teresina - PI.

Palavras-chave: Assistência perinatal, Infecções por coronavírus, Neonatologia.

\section{INTRODUÇÃO}

Com a rápida propagação do novo Coronavírus, SARS-COV-2, agente etiológico da Covid-19, pelo mundo inteiro, diversos grupos viram-se vulnerabilizados, dentre eles, as gestantes (ESTRELA FM, et al., 2020). É sabido que a gravidez acarreta diversas mudanças fisiológicas com possíveis riscos de morbimortalidade, dessa forma o Ministério da Saúde incluiu as gestantes em qualquer idade gestacional e mulheres no período puerperal ou aquelas que passam por abortamento ou óbito fetal como grupo de risco. Com relação aos sintomas, podem aparecer dispneia, fadiga, tosse, sintomas gastrointestinais, congestão nasal, e outras complicações mais graves como a síndrome respiratória aguda grave (BRASIL, 2021).

\section{OBJETIVO}

Analisar por meio da literatura científica qual as recomendações para a assistência a puérpera no contexto da pandemia de Covid-19 e assim mapear os principais achados com relação aos cuidados.

\section{MÉTODO}

Trata-se de uma revisão integrativa da literatura, com busca na Biblioteca Virtual em Saúde (BVS), tendo como bases de dados: Lilacs, Scielo e BDENF no período do mês de outubro, procedeu-se à análise de 4 artigos, incluindo artigos em português e inglês, publicados nos últimos cinco anos e excluindo artigos não condizentes com a temática, utilizando como descritores: Assistência perinatal, infecções por coronavírus, neonatologia.

\section{REVISÃO BIBLIOGRÁFICA}

Portanto, com relação às recomendações para a assistência à puérpera, verificou-se que o profissional de saúde deve seguir rigorosamente as medidas de precaução padrão e gotículas, com paramentação e 
higienização adequadas. Além disso, deve-se orientar as mães sobre a higienização adequada das mãos antes e após o contato com a criança, além do uso de máscara cirúrgica durante a amamentação e outros cuidados (BRASIL, 2020). Com relação a amamentação, recomenda-se manter em casos de suspeita ou confirmação da infecção materna, desde que a mãe tenha o desejo de amamentar e esteja em condições clínicas favoráveis (RONDELLI G, et al., 2020).

\section{CONSIDERAÇÕES FINAIS}

Diante os estudos apresentados, demonstra-se que as gestantes enquadram-se como um grupo mais propenso a complicações da Covid-19. Contudo, se torna imprescindível que a puérpera adote medidas de segurança, como o uso de máscaras cirúrgicas e higienização das mãos antes e após as mamadas.

\section{REFERÊNCIAS}

1. BRASIL. Ministério da Saúde. Secretaria de Atenção Especializada à Saúde. Departamento de Atenção Hospitalar, Domiciliar e de Urgência. Protocolo de manejo clínico da Covid-19 na Atenção Especializada [recurso eletrônico]. 2021.2 Disponível em: https://bvsms.saude.gov.br/bvs/publicacoes/manejo_clinico_covid-_ 19_atencao_especializada.pdf. Acesso em: 11 de outubro de 2021.

2. BRASIL. Ministério da Saúde. Protocolo de manejo clínico do coronavírus (Covid-19) na atenção primária à saúde. Secretaria de Atenção Primária à Saúde (SAPS), Brasília; 2020. Disponível em: https://portalarquivos2.saude.gov.br/images/pdf/2020/marco/24/20200323-ProtocoloManejo-ver05.pdf. Acesso em: 10 de outubro de 2021.

3. ESTRELA FM, et al. Gestantes no contexto da pandemia da Covid-19: reflexões e desafios. Physis: Revista de Saúde Coletiva, 2020; 30(2): e300215.

4. RONDELLI G, et al. Assistência às gestantes e recém-nascidos no contexto da infecção Covid-19: Uma revisão sistemática. Desafios - Revista Interdisciplinar da Universidade Federal do Tocantins, 2020; 7(Especial-3): 48-74. 
RESUMO SIMPLES: Revisão Integrativa

\title{
AÇÕES DE SAÚDE PARA PREVENIR A OCORRÊNCIA DA GRAVIDEZ NA ADOLESCÊNCIA
}

\author{
Erica Hortência Santana da Cruz ${ }^{1}$ \\ Kaline Silva Meneses ${ }^{1}$ \\ Simone Santos Souza ${ }^{1}$
}

1. Centro Universitário Dom Pedro II (UNIDOM), Salvador - BA.

Palavras-chave: Gravidez na adolescência, Sexualidade, Política de saúde.

\section{INTRODUÇÃO}

A adolescência sendo um período de constantes modificações, deixam os adolescentes vulneráveis a várias influências externas que podem afetar o início da vida sexual de forma precoce e como consequência uma gravidez indesejada (CÂNDIDO TCR, et al., 2019). A gravidez na adolescência representa um problema social e de saúde pública que pode trazer problemas não só para a mãe e o bebê, mas também econômicos e interferindo nos estudos, por isso o enfermeiro tem grande importância não só no cuidado, mas na prevenção da gravidez na adolescência por meio de estratégias que eduque os jovens de maneira ativa sobre prevenção (RIBEIRO VCS, et al., 2016).

\section{OBJETIVO}

Analisar e enumerar por meio de uma revisão da literatura integrativa as ações de saúde para evitar a gravidez na adolescência no período de 2016 a 2021 no contexto brasileiro.

\section{MÉTODO}

Essa revisão integrativa foi feita nas bases de dados SCIELO, BDENF, MEDLINE, LILACS, durante o mês de setembro, incluindo artigos dos últimos 5 anos e excluindo aqueles que não se encaixassem no tema proposto, utilizando como descritores: ações de enfermagem e gravidez na adolescência. Foram encontrados 17 artigos e após análise e leitura foram utilizados 3 artigos neste trabalho.

\section{REVISÃO BIBLIOGRÁFICA}

Um estudo em Minas Gerais mostrou a importância de o enfermeiro dar atenção básica, instruir sobre prevenção da gravidez por meio de distribuição de panfletos, cartilhas, contraceptivos, realizar palestras, orientação individual, dinâmicas abordando o uso de contraceptivos, planejamento familiar e riscos da gravidez precoce (RIBEIRO VCS, et al., 2016).

Pode ser feita a abordagem na escola sobre temas como uso de métodos contraceptivos e consequências da gravidez não planejada como evasão escolar, conflitos familiares e dificuldade em conseguir um emprego 
(BALDOINO LS, et al., 2018). Outro estudo mostrou a recorrência da gravidez durante a adolescência, sendo necessário a criação de políticas públicas para mitigar essa realidade (CÂNDIDO TCR, et al., 2019).

\section{CONSIDERAÇÕES FINAIS}

Diante dos estudos apresentados, demonstra-se a promoção da saúde do adolescente, é função da atenção primária implementar o acompanhamento e desenvolvimento, no qual inclua a abordagem à saúde reprodutiva de maneira integral e permanente, envolvendo educação em saúde, atividades em grupo e atendimento individual. No entanto, observa-se que as ações são pontuais, prevalecendo apenas a distribuição de métodos contraceptivos, não estabelecendo condutas assistenciais que venham a minimizar essa problemática.

\section{REFERÊNCIAS}

1. BALDOINO LS, et al. Educação em saúde para adolescentes no contexto escolar: um relato de experiência. Revista de Enfermagem UFPE On Line, 2018; 12(4): 1161-1167.

2. CÂNDIDO, TCR, et al. O uso de bebida alcoólica entre gestantes adolescentes. Revista Eletrônica de Saúde Mental Álcool Drogas, 2019; 15(4): 1-8.

3. RIBEIRO VCS, et al. Papel do enfermeiro da estratégia de saúde da família na prevenção da gravidez na adolescência. Revista de Enfermagem do Centro Oeste Mineiro, 2016; 1(6): 1957-1975. 


\title{
FALTA DE ORIENTAÇÃO NO MANUSEIO DOS INSUMOS DE INSULINOTERAPIA
}

\author{
Cyntia Costa Guimarães ${ }^{1}$ \\ Thais Francielle de Souza ${ }^{2}$ \\ Ana Cecília Andrade Cavalcante ${ }^{1}$
}

1. Universidade Nilton Lins (UNINILTONLINS), Manaus - AM.

2. Centro Universitário Sagrado Coração (UNISAGRADO), Bauru - SP.

Palavras-chave: Resíduos, Diabetes Mellitus, Insulina.

\section{INTRODUÇÃO}

A Diabetes Mellitus (DM) é uma doença crônica, classificando-se como um problema de saúde pública por ser um dos principais fatores de risco cardiovascular e cerebrovascular, com alta predominância em idosos e no mundo (BARROS AE e SOUZA EN, 2018). Os tipos mais frequentes de diabetes são o tipo 2 que causa defeitos na ação e secreção da insulina e o tipo 1 que ocorre a destruição das células $b$ do pâncreas responsáveis pela produção de insulina, aumentando o número de pessoas acometidas devido a elevada prevalência de obesidade e sedentarismo, crescimento e envelhecimento populacional impactando na qualidade de vida da população (SILVA ENSF, et al. 2016).

\section{OBJETIVO}

Descrever a importância da orientação feita pelo enfermeiro da atenção primária em saúde para os insulinodependentes no manejo de insumos gerados no domicílio, visto que a distribuição gratuita dos insumos é garantida por Lei pela Unidade Básica de Saúde.

\section{REVISÃO BIBLIOGRÁFICA}

Visto que no tratamento da DM muitas vezes é exigida frequente monitorização de glicemia e múltiplas aplicações diárias de insulinas, para que evite alterações e complicações locais decorrentes da aplicação (BARROS AE e SOUZA EN, 2018), é necessário que além do enfermeiro orientar sobre o manejo na hora da auto aplicação, também pontue sobre o armazenamento, transporte e principalmente no descarte adequado de agulhas, lancetas e fitas reagentes, não reutilização e não compartilhamento objetos perfuro-cortantes. $O$ manejo seguro e adequado é importante pois há presença de material biológico com capacidade de causar infecção e objetos perfuro cortantes potencialmente contaminados. (ARAÚJO MFM, et al., 2009).

\section{CONSIDERAÇÕES FINAIS}

Quando o paciente não recebe orientação correta para manejo do descarte de insumos, pode gerar lesões nesse processo como lipodistrofia insulínica e abscessos no paciente, contaminação do ambiente e colocar 
em risco a saúde dos coletores de lixo sendo necessário o enfermeiro orientar e desenvolver atividades e práticas educativas dentro de uma Estratégia de Saúde da Família para estimulação da continuidade do tratamento e autocuidado.

\section{REFERÊNCIAS}

1. ARAÚJO MFM, et al. Reutilização de agulhas e seringas descartáveis por um grupo de diabéticos. Ciência, Cuidado e Saúde, 2009; 8(1): 93-100.

2. BARROS AE, SOUZA EN. Autoaplicação de insulina: atitudes de um grupo de diabéticos. Revista Enfermagem UFPE on line, 2018; 5(3): 593-603.

3. SILVA ENSF, et al. Descarte de seringas e agulhas por pacientes com diabetes mellitus. Revista Enfermagem Contemporânea, 2016; 2(1): 82-102. 


\title{
ASSISTÊNCIA DE ENFERMAGEM NA MANUTENÇÃO DO POTENCIAL DOADOR DE ÓRGÃOS EM MORTE ENCEFÁLICA: UMA REVISÃO INTEGRATIVA
}

\author{
Andressa Dâmaras Freitas Feitosa ${ }^{1}$ \\ Beatriz Caroline Leão Lima ${ }^{1}$ \\ Daniela dos Santos Mangueira de Almeida ${ }^{1}$ \\ Maria Clara Rodrigues de Abreu ${ }^{1}$ \\ Mauro Roberto Biá da Silva ${ }^{1}$
}

1. Universidade Estadual do Piauí (UESPI), Teresina - PI.

Palavras-chave: Assistência de enfermagem, Doador de órgãos, Morte encefálica.

\section{INTRODUÇÃO}

A Morte Encefálica (ME) é conceituada como a parada total e irreversível das funções do córtex e tronco cerebral, de causa conhecida e constatada de modo indiscutível, regulamentada através da Resolução 1.480/97 pelo Conselho Federal de Medicina no Brasil (ALVES NCC, et al., 2018). Os cuidados prestados ao paciente com ME, envolvem uma atividade com processos complexos implementados pela equipe multiprofissional que atua em Unidade de Terapia Intensiva (UTI). Dentre essa atuação, destaca-se o papel do enfermeiro, responsável no manejo da alterações fisiopatológicas inerentes e monitoração hemodinâmica, associado à efetivação da doação de órgãos (FARIAS IP, et al., 2017).

\section{OBJETIVO}

Revisar e analisar por meio da literatura científica a atuação do profissional enfermeiro frente a manutenção fisiológica de um potencial doador de órgãos para contribuição com aumento da quantidade e qualidade de órgãos para transplantes.

\section{MÉTODO}

Trata-se de uma revisão integrativa da literatura, com busca na BVS, com auxílio dos bancos de dados: MEDLINE, LILACS e BDENF. Foram encontrados 118 artigos e 21 destes selecionados com critérios de inclusão: artigos em português, inglês e espanhol, publicados nos últimos cinco anos, disponíveis na íntegra e gratuitos; critérios de exclusão: artigos não condizentes com a temática e revisões de literatura.

\section{REVISÃO BIBLIOGRÁFICA}

A ME pode ocasionar complicações ao organismo, gerando instabilidade hemodinâmica, no qual, tais repercussões podem inviabilizar a doação de órgãos (ALVES NCC, et al., 2018). Ressalta-se que diante das 
hipóteses, o enfermeiro utiliza de seus conhecimentos e práticas para prestar um cuidado de qualidade mantendo a estabilidade do paciente, investindo toda responsabilidade para conservação das condições hemodinâmicas favoráveis ao processo (MAGALHÃES ALP, et al., 2018).

As principais condutas descritas são: manutenção da temperatura corporal, monitoração do estado hemodinâmico e nutricional do paciente, controle de diurese e glicemia, observação de distúrbios hidroeletrolíticos, carecimento de transfusões e demais recomendações (MAGALHÃES ALP, et al., 2019).

\section{CONSIDERAÇÕES FINAIS}

Diante dos estudos apresentados, demonstrou-se a compreensão da importância do cuidado ao paciente em ME como potencial doador, sendo esse um processo complexo e tendo em vista que o enfermeiro deve estar estreitamente capacitado na identificação de quaisquer alterações fisiológicas para que possa intervir com medidas terapêuticas adequadas, mantendo o doador estável para o processo de doação dos órgãos.

\section{REFERÊNCIAS}

1. ALVES NCC, et al. Manejo dos pacientes em morte encefálica. Revista de Enfermagem UFPE on line, 2018; 12(4): 953-961.

2. FARIAS IP, et al. Construção de protocolo assistencial de enfermagem para o potencial doador de órgãos em morte encefálica. Revista de Enfermagem UFPE on line, 2017; 11(9): 3492-3496.

3. MAGALHÃES ALP, et al. Gerência do cuidado de enfermagem ao paciente em morte encefálica. Revista de Enfermagem UFPE on line, 2019; 13(4): 1124-1132.

4. MAGALHAES ALP, et al. Significados do cuidado de enfermagem ao paciente em morte encefálica potencial doador. Revista Gaúcha de Enfermagem, 2018; 39: e2017-0274. 
RESUMO SIMPLES: Revisão Integrativa

TRANSMISSÃO, PREVENÇÃO E CONTROLE DA HANSENÍASE: UMA REVISÃO INTEGRATIVA

\author{
Andressa Dâmaras Freitas Feitosa ${ }^{1}$ \\ Beatriz Caroline Leão Lima ${ }^{1}$ \\ Daniela dos Santos Mangueira de Almeida ${ }^{1}$ \\ Maria Clara Rodrigues de Abreu ${ }^{1}$ \\ Mauro Roberto Biá da Silva ${ }^{1}$
}

1. Universidade Estadual do Piauí (UESPI), Teresina - PI.

Palavras-chave: Hanseníase, Transmissão, Prevenção.

\title{
INTRODUÇÃO
}

A Hanseníase consiste em uma patologia infectocontagiosa que afeta principalmente a pele e os nervos periféricos, sendo ocasionada pela bactéria chamada Mycobacterium leprae, na qual pode evoluir de forma mais grave no indivíduo gerando incapacidades físicas. A mesma representa ainda um importante problema de saúde pública no mundo e no Brasil, em que a respeito de prevalência, o país ocupa o segundo lugar atrás da Índia e o primeiro lugar de casos na América Latina (MENDONÇA MA, et al., 2019). Portanto, é de extrema valia a implementação de estratégias que proporcionem a cessação da transmissão da doença para acelerar o controle da mesma (SOUZA EA, et al., 2019).

\section{OBJETIVO}

Revisar e analisar por meio da literatura científica quanto a Hanseníase, com ênfase em descrever particularidades das formas de transmissão, tal como evidenciar as medidas preventivas relacionadas a patologia, para seu devido controle.

\section{MÉTODO}

Trata-se de uma revisão integrativa da literatura, com busca na BVS, com auxílio dos bancos de dados: MEDLINE, LILACS e BDENF. Foram encontrados 331 artigos e 34 destes selecionados com critérios de inclusão: artigos em português, inglês e espanhol, publicados nos últimos cinco anos, disponíveis na íntegra e gratuitos; critérios de exclusão: artigos não condizentes com a temática e revisões de literatura.

\section{REVISÃO BIBLIOGRÁFICA}

A hanseníase é transmitida por meio do contato prolongado e próximo entre indivíduos com maior probabilidade de adoecer, com predisposição genética e pacientes multibacilares não tratados, através da inalação dos bacilos eliminados pelas vias aéreas superiores de contato direto. $O$ diagnóstico, triagem dos 
contatos e o tratamento precoce segundo os estudos analisados, são a melhor forma de prevenção e controle da doença (ANCHIETA JJS, et al., 2019). Na complementação, outro estudo mostrou como vigilância, o exame de contatos, a regularidade terapêutica, procedimentos reabilitacionais, e a quimioprofilaxia em dose única de rifampicina aos contatos de casos conhecidos (CORTELA DCB, et al., 2020).

\section{CONSIDERAÇÕES FINAIS}

Em virtude dos fatos mencionados, o presente estudo reforça a afirmativa de que a Hanseníase ainda constitui um problema de saúde pública, com particularidades importantes de sua transmissão, mas que apresenta medidas de prevenção e controle que devem ser partidas principalmente das ações públicas aos usuários.

\section{REFERÊNCIAS}

1. ANCHIETA JJS, et al. Análise da tendência dos indicadores da hanseníase em estado brasileiro hiperendêmico, 2001-2015. Revista de Saúde Pública, 2019; 53: 61.

2. CORTELA DCB, et al. Aceitabilidade da quimioprofilaxia em área endêmica para a hanseníase: projeto PEP-Hans Brasil. Cadernos de Saúde Pública, 2020; 36(3): e00068719.

3. MENDONÇA MA, et al. Perfil epidemiológico dos contatos intradomiciliares de casos de hanseníase em capital hiperendêmica no Brasil. Revista de Pesquisa Cuidado é Fundamental Online, 2019; 11(4): 873879.

4. SOUZA EA, et al. Desempenho da vigilância de contatos de casos de hanseníase: uma análise espaçotemporal no Estado da Bahia, Região Nordeste do Brasil. Cadernos de Saúde Pública, 2019; 35(9): e00209518. 


\title{
TREINAMENTO DE FORÇA E QUALIDADE DO SONO EM IDOSOS: UMA REVISÃO NARRATIVA
}

\author{
Márcio Bruning ${ }^{1}$ \\ Leonardo Pestillo de Oliveira ${ }^{1}$
}

1. Universidade Cesumar (UNICESUMAR), Maringá - PR.

Palavras-chave: Idosos, Qualidade do sono, Treinamento de força.

\section{INTRODUÇÃO}

O sono é um importante componente que pode impactar a qualidade de vida de idosos. Distúrbios do sono têm sido associados com declínios cognitivos, depressão, incapacidade funcional para realização de atividades da vida diária e risco de quedas (MIN Y e SLATTUM PW, 2018; BIDDLE DJ, et al., 2017).

Dentre as formas não farmacológicas de prevenção e tratamento dos problemas relacionados ao sono, a prática de atividades físicas tem sido recomendada. Porém, muitos estudos têm relacionado a prática do treinamento aeróbio, e poucos tem investigado a eficácia da modalidade de treinamento de força (TF) na melhora da qualidade do sono de idosos (DOLEZAL BA, et al., 2017).

\section{OBJETIVO}

Revisar a literatura científica nos últimos cinco anos, no intuito de verificar se a prática do treinamento de força pode proporcionar uma melhora na qualidade do sono em indivíduos idosos ( $\geq 60$ anos).

\section{REVISÃO BIBLIOGRÁFICA}

Em um estudo clínico randomizado que objetivou avaliar a efetividade de 8 semanas do TF com cargas progressivas, na qualidade de sono de idosos, melhores resultados foram encontrados para o grupo TF: diminuição média de 1.3 pontos (quanto menor, mais qualidade do sono) na escala do questionário PSQI (Pittsburgh Sleep Quality Index), com diferença significativa quando comparado aos grupos caminhada e grupo controle (BAKER BS, et al., 2021).

Outro estudo clínico testou 12 semanas do TF com cargas moderadas (65-70\% de 1 Repetição Máxima) na qualidade de sono de idosos residentes em uma instituição na China. Resultados mostraram uma melhora da eficiência, fragmentação do sono e saúde cognitiva dos indivíduos (LI Z, et al., 2021).

Em idosos com sarcopenia, o TF também pode ser uma boa estratégia de treinamento. Em um estudo conduzido durante 12 semanas com 28 idosos, melhoras na qualidade (-1,6 pontos no PSQI) e eficiência do sono foram significativamente melhores do que o grupo controle após a intervenção (SOUZA H, et al., 2020).

\section{CONSIDERAÇÕES FINAIS}


A partir dos dados existentes na literatura sobre o tema, a prática do TF pode ser uma modalidade que melhora a qualidade do sono de idosos. No entanto, mais estudos clínicos que avaliem o sono de forma objetiva, com instrumentos como a polissonografia, são necessários.

\section{REFERÊNCIAS}

1. BAKER BS, et al. Efficacy of an 8-week resistance training program in older adults: A randomized controlled trial. Journal of Aging and Physical Activity, 2021; 29(1): 121-129.

2. BIDDLE DJ, et al. Associations of objective and subjective sleep disturbance with cognitive function in older men with comorbid depression and insomnia. Sleep Health, 2017; 3(3): 178-183.

3. DOLEZAL BA, et al. Interrelationship between sleep and exercise: A Systematic Review. Advances in Preventive Medicine, 2017; 2017: 1-14.

4. LI Z, et al. The effect of resistance training on sleep in Chinese older adults: A randomized controlled trial. Geriatric Nursing, 2021; 42(1): 289-294.

5. MIN Y, SLATTUM PW. Poor sleep and risk of falls in community-dwelling older adults: A Systematic Review. Journal of Applied Gerontology, 2018; 37(9): 1059-1084.

6. SOUZA H, et al. Physical exercise improves sleep and muscle function in sarcopenic patients: a randomized controlled trial. Sleep, 2020; 43(1): 413-414. 


\title{
A SOLIDÃO EM IDOSOS NO CONTEXTO DA PANDEMIA DE COVID-19: UMA REVISÃO INTEGRATIVA
}

\author{
Lynara Silva de Oliveira ${ }^{1}$
}

1. Universidade Federal do Piauí (UFPI), Teresina - PI.

Palavras-chave: Idosos, Solidão, COVID-19.

\section{INTRODUÇÃO}

Com a pandemia do novo coronavírus, iniciada em dezembro de 2019, foi descoberto que os idosos faziam parte do grupo de risco, tanto por sua idade, como pelas comorbidades preexistentes, chegando a quase $70 \%$ das mortes no Brasil causadas pelo vírus. (ALCANTARA SFS, et al., 2021). Em consequência, o isolamento social favoreceu o aumento da solidão, principalmente em idosos que experienciavam a interrupção de suas relações sociais, que aos poucos foram substituídas por chamadas de vídeo, para evitar o contato e a possível propagação do vírus (HEIDINGER T e RICHTER L, 2020).

\section{OBJETIVO}

Analisar na literatura científica existente, os artigos pertinentes sobre o aumento da solidão em idosos durante o contexto da pandemia do COVID-19 e as principais intervenções para a diminuição desse sentimento.

\section{MÉTODO}

Refere-se a uma pesquisa de revisão integrativa realizada nos bancos de dados SciELO e PubMed. Os descritores utilizados foram idosos; solidão; COVID-19 e seus correspondentes em inglês. Os critérios de inclusão envolveram artigos completos, publicados nos anos de 2020 e 2021, nos idiomas português e inglês, descartando- se os estudos não vinculados ao tema e duplicações. Foram encontrados 415 artigos e selecionados 04 por sua relevância.

\section{REVISÃO BIBLIOGRÁFICA}

Com o avanço da pandemia, a solidão e o isolamento social foram prevalentes ao redor do mundo, sendo descritos como uma epidemia de comportamento. Assim, observou-se que a solidão pode ser intimamente ligada a repercussões físicas e mentais (HWANG TJ, et al., 2020).

Para a diminuição desses fatores, recomenda-se o incentivo e a quebra da barreira dos idosos quanto ao uso da tecnologia para aproximação virtual entre os familiares e amigos, respeito à privacidade do idoso quando usá-la, adoção de telepsicologia para apoio mental, assim como oferecer ajuda para a conexão com outras pessoas que estejam vivendo essa mesma experiência (GORENKO JA, et al., 2020). 


\section{CONSIDERAÇÕES FINAIS}

Diante dos artigos apresentados, foi possível observar a importância da tecnologia nesse contexto de isolamento social e sua influência positiva na melhora da solidão vivenciada por esses idosos durante a pandemia. Dessa forma, foi avaliado que quanto maior a interação social proporcionada, mesmo que virtual, menor será o sentimento de solidão, sendo necessária a busca de constantes estudos para a diminuição desses fatores negativos decorrentes do isolamento.

\section{REFERÊNCIAS}

1. ALCANTARA SFS, et al. Reflexões acerca da saúde do idoso na pandemia do covid-19: revisão integrativa. Revista Artigos.Com, 2021; 26(1): e574.

2. GORENKO JA, et al. Social Isolation and Psychological Distress Among Older Adults Related to COVID19: A Narrative Review of Remotely-Delivered Interventions and Recommendations. Journal of Applied Gerontology. 2021; 40(1): 3-13.

3. HEIDINGER T, RICHTER L. The Effect of COVID-19 on Loneliness in the Elderly. An Empirical Comparison of Pre- and Peri-Pandemic Loneliness in Community-Dwelling Elderly. Frontiers in Psychology, 2020; 11 (1), 1-5.

4. HWANG TJ, et al. Loneliness and social isolation during the COVID-19 pandemic. International Psychogeriatrics, 2020; 32(10), 1217-1220. 
RESUMO SIMPLES: Revisão Integrativa

\section{CEFALEIA EM SALVAS: MECANISMOS NEURAIS E FISIOPATOGÊNICOS}

Diego Bezerra Soares ${ }^{1}$

Isabela Reis Manzoli ${ }^{1}$

Mariana Kely Diniz Gomes de Lima ${ }^{1}$

1. Centro Universitário da Faculdade de Ciências Biomédicas de Cacoal (Unifacimed), Cacoal - RO.

Palavras-chave: Cefaleia em Salvas, Fisiopatologia, Mecanismos neurais.

\section{INTRODUÇÃO}

Sabe-se que a Cefaleia em Salvas (CES), também chamada de dor de cabeça suicida é uma doença caracterizada pelo surgimento de uma algia intensa com episódios recorrentes e excruciantes na região periorbitária de distribuição orbitotemporal (OLIVEIRA RMM, et al., 2017), geralmente apresenta-se de forma unilateral, podendo estar associada a um período de curta duração que varia de 15 a 180 minutos (JURNO ME, et al., 2018).

Ademais, a CES tem uma origem idiopática e possui como fatores desencadeantes da crise o tabagismo bem como etilismo (BURISH M, et al., 2018). Além disso, os principais sintomas autonômicos ipsilaterais associados são: ptose, rubor facial, lacrimejamento, rinorreia e congestão nasal (CASTRO NA, et al., 2016).

\section{OBJETIVO}

Destacar os mecanismos fisiopatológicos da CES a partir do entendimento da neuromodulação da dor, esclarecendo os papéis das interações genéticas e conexões neurais. Sob esse viés, foi levantado o seguinte questionamento: "Quais os mecanismos Neurais e fisiopatogênicos envolvidos na CES?".

\section{MÉTODO}

Realizou-se uma revisão bibliográfica, integrativa com pesquisa em bases de dados do PubMed, ScienceDirect, SciELO e Medline, a partir dos descritores "cefaleias em salvas", "Fisiopatologia" e "Mecanismos Neurais" decorrentes do período de 2016 a 2021. Foram incluídos trabalhos de relato de caso, revisão de literatura, artigos na integra, na língua portuguesa, inglesa e espanhola. Excluiu-se os artigos que estavam fora do período selecionado e não estavam disponíveis na integra.

\section{REVISÃO BIBLIOGRÁFICA}

A partir desse estudo, observa-se que a CES pode ser desencadeada pela neuromodulação das conexões neurais do hipotálamo que atua como centro regulatório da dor ao liberar substâncias químicas que podem estimular o sistema trigeminovascular, causando uma hiperatividade neuronal e vasodilatação das artérias 
resultando na pressão dos tecidos adjacentes a região orbital, gerando assim a cefaleia em salvas e os sintomas autônomos cranianos ipsilaterais (MAY A, et al., 2018).

Nessa perspectiva, alguns estudos evidenciam uma relação intrínseca entre a cefaleia em salvas e a hereditariedade devido a um mecanismo de polimorfismos de genes que aumentam a suscetibilidade gênica e a expressão fenotípica da cefaleia em salvas nos indivíduos, sendo um importante fator de risco (MONTEIRO JMP, et al., 2019).

\section{CONSIDERAÇÕES FINAIS}

Por meio dessa análise, nota-se que a CES um viés multifatorial, a partir da neuromodulação das conexões hipotalâmicas com o sistema trigeminovascular e o polimorfismo genômico que influencia na predisposição ao aparecimento da CES. Outrossim, torna-se fundamental entender os mecanismos fisiopatológicos envolvidos no processo de surgimento da cefaleia em salvas visando compreender o seu funcionamento e suas implicações na qualidade de vida da população.

\section{REFERÊNCIAS}

1. BURISH M, et al. "Cluster headache and other trigeminal autonomic cephalalgias." Continuum: Lifelong Learning in Neurology, 2018; 24(4): 1137-1156.

2. CASTRO NA, et al. Qual a efetividade clínica da oxigenioterapia para o tratamento agudo das cefaleias em salvas? Revista de Medicina e Saúde de Brasília, 2016; 5(2): 313-21.

3. JURNO ME, et al. Estudo epidemiológico da prevalência da cefaleia em salvas em uma cidade de médio porte do Brasil. Arquivos de Neuro-Psiquiatria, 2018; 7: 467-472.

4. MAY A, et al. Cluster headache. Nature Reviews Disease Primers, 2018; 1: 1-17.

5. MONTEIRO JMP. Cefaleia em Salvas: O Advento de Novas Terapêuticas. Gazeta Médica, 2019; 6(4): 251-55.

6. OLIVEIRA RMM, et al. DIAGNÓSTICO E TRATAMENTO DE CEFALEIA EM SALVAS. Revista Eletrônica Acervo Saúde, 2017; 14: 774-775. 


\title{
TREINAMENTO DOS MÚSCULOS DO ASSOALHO PÉLVICO COMO TRATAMENTO DA INCONTINÊNCIA URINÁRIA EM MULHERES
}

\author{
Márcio Bruning ${ }^{1}$ \\ Giovana Mioto de Moura ${ }^{1}$ \\ Leonardo Pestillo de Oliveira ${ }^{1}$
}

1. Universidade Cesumar (UNICESUMAR), Maringá - PR.

Palavras-chave: Exercício, Incontinência urinária, Músculos do assoalho pélvico.

\section{INTRODUÇÃO}

A incontinência urinária (IU) é caracterizada como a perda involuntária de urina e pode acarretar problemas como a depressão e piora na qualidade de vida (PEREIRA PB, et al., 2019). 50\% das mulheres no mundo podem apresentar IU em alguma fase da vida. Envelhecimento, obesidade e incapacidade física são alguns dos fatores de risco (HU JS e PIERRE EF, 2019).

Dentre as abordagens terapêuticas no tratamento da IU o treinamento dos músculos do assoalho pélvico (TMAP) tem sido utilizado. Os exercícios consistem em contrações dinâmicas e isométricas de músculos da parte inferior da pélvis que são importantes no mecanismo de abertura e fechamento da uretra (WOODLEY SJ, et al., 2017).

\section{OBJETIVO}

Revisar a literatura científica nos últimos cinco anos, no intuito de verificar se o treinamento dos músculos do assoalho pélvico, melhora a incontinência urinária em mulheres de diferentes faixas etárias.

\section{REVISÃO BIBLIOGRÁFICA}

Em um estudo clinico que objetivou verificar a efetividade do TMAP na melhora da IU de mulheres de 20 a 50 anos por 12 semanas, dois grupos (intervenção, $n=36$ e controle, $n=37$ ) foram formados. Contrações de 3 a 10 segundos foram realizadas de forma progressiva no decorrer das semanas, na posição supina. Melhoras de $47,2 \%$ e $41,7 \%$ foram observadas na frequência e quantidade de vazamento urinário, respectivamente, para o grupo intervenção, com diferenças significativas quando comparado ao grupo controle (BELUSHI ZI, et al., 2020).

Outro estudo de intervenção com mulheres idosas de 60 a 75 anos, comparou o TMAP associado a educação sobre a saúde da bexiga (grupo 1, n=298), com um grupo que apenas recebeu a educação, sem a realização do treinamento físico (grupo $2, n=274$ ). A cada 4 semanas num total de 24 , os indivíduos preencheram um recordatório de 3 dias relatando o número de episódios de vazamento urinário. Observouse uma diferença média de -6,64 episódios a favor do grupo 1 no final da intervenção (WAGG A, et al., 2019). 


\section{CONSIDERAÇÕES FINAIS}

A partir de dados existentes na literatura sobre o tema, o TMAP pode melhorar a IU em mulheres de diferentes faixas etárias. No entanto, mais estudos com avaliações urodinâmicas que permitem avaliar variáveis como a sensibilidade da bexiga e respostas eletromiográficas dos músculos pélvicos, são necessários.

\section{REFERÊNCIAS}

1. BELUSHI ZI, et al. Effects of home-based pelvic floor muscle training on decreasing symptoms of stress urinary incontinence and improving the quality of life of urban adult Omani women: A randomized controlled single-blind study. Neurourology and Urodynamics, 2020; 39(5): 1557-1566.

2. HU JS, PIERRE EF. Urinary incontinence in women: Evaluation and management. American Family Physician, 2019; 100(6): 339-348.

3. PEREIRA PB, et al. Incontinência urinária feminina: uma revisão bibliográfica. Revista Eletrônica Acervo Saúde, 2019; 11(14): e1343.

4. WAGG A, et al. Exercise intervention in the management of urinary incontinence in older women in villages in Bangladesh: a cluster randomised trial. The Lancet Global Health, 2019; 7(7): e923-e931.

5. WOODLEY SJ, et al. Pelvic floor muscle training for preventing and treating urinary and faecal incontinence in antenatal and postnatal women. Cochrane Database of Systematic Reviews, 2017; 12(3): cd007471. 
RESUMO SIMPLES: Revisão Integrativa

\title{
UTILIZAÇÃO DO PLASMA RICO EM PLAQUETAS (PRP) PARA O TRATAMENTO DE LESÕES MUSCULOESQUELÉTICAS
}

\author{
Juliana Renata da Silva Ferreira ${ }^{1}$ \\ Jennyfer Martins de Carvalho ${ }^{1}$
}

1. Universidade Federal de Pernambuco (UFPE), Recife - PE.

Palavras-chave: Plasma Rico em Plaquetas, Regeneração, Lesões musculoesqueléticas.

\section{INTRODUÇÃO}

O Plasma Rico em Plaquetas (PRP) é obtido através do processamento laboratorial do sangue. O sangue é coletado do paciente e posteriormente processado através das centrífugas, obtendo-se a concentração de células vermelhas, brancas, plaquetas e plasma. Com isso, o PRP é uma concentração autóloga de plaquetas em um pequeno volume de plasma. Esta fração dispõe de significativa concentração de fatores de crescimento derivados de plaquetas e leucócitos, onde pode contribuir para a angiogênese e regeneração tecidual. Assim sendo, a utilização clínica do PRP, norteia-se na sua habilidade de otimizar o processo de regeneração celular, em lesões com impedimentos de reparo natural, como as lesões musculoesqueléticas (NESELLO PFT, et al., 2020).

\section{OBJETIVO}

Apresentar, através de uma revisão de literatura, o desempenho clínico e as indicações referentes ao tratamento restaurador com PRP em lesões musculoesqueléticas, referente aos critérios que definem ou não a necessidade do procedimento.

\section{MÉTODO}

Trata-se de uma Revisão Integrativa da Literatura com busca nas bases de dados, Scielo, Medline e PubMed, sob as palavras-chave como: Plasma Rico em Plaquetas, Platelet-rich Plasma, Platelets, Regeneração, Therapy, Lesões Musculoesqueléticas. Critérios de inclusão: estudos com texto na íntegra, publicados nos idiomas português e inglês, publicados nos últimos cinco anos. Foram encontrados 12 artigos dos quais houveram 9 exclusões por não se enquadrarem no objetivo, totalizando 3 produções revisadas.

\section{REVISÃO BIBLIOGRÁFICA}

A maioria dos estudos revisados evidencia a longevidade do tratamento restaurador, pelo fato das plaquetas serem as primeiras células existentes na lesão e agem no andamento da hemostasia, liberando fatores de crescimento, principalmente são PDGF, TGF-B e IGF, que são importantes na reparação óssea. Posto isso, o tratamento com PRP seria um tipo de escolha para terapia, sendo recomendado, para lesões 
musculoesqueléticas, especialmente, em jovens atletas que precisam de retorno imediato às suas atividades (GRASSI A, et al., 2018).

O PRP possui propriedades osteogênica, osteocondutiva e osteoindutiva, tendo como principal vantagem o aumento da velocidade da reparação óssea, reduzindo o tempo necessário para a osseointegração (CONTRERAS-MUÑOZ P, et al., 2017).

\section{CONSIDERAÇÕES FINAIS}

Diante dos estudos apresentados, demonstra-se que muitos autores avaliaram os benefícios do tratamento com PRP para lesões musculoesqueléticas, contudo, as evidências atualmente são insuficientes para apoiar o uso rotineiro dessa intervenção na prática clínica, sendo indispensável o acompanhamento médico e fisioterapêutico.

\section{REFERÊNCIAS}

1. CONTRERAS-MUÑOZ $P$, et al. Postinjury Exercise and Platelet-Rich Plasma Therapies Improve Skeletal Muscle Healing in Rats But Are Not Synergistic When Combined. The American journal of sports medicine, 2017; 45(9): 2131-2141.

2. GRASSI A, et al. Is Platelet-Rich Plasma (PRP) Effective in the Treatment of Acute Muscle Injuries? A Systematic Review and Meta-Analysis. Sports medicine (Auckland, N.Z.), 2018; 48(4): 971-989.

3. NESELLO PFT, et al. Level of Evidence and Industry Sponsorship Associated with Favorable Outcomes in Publications on Platelet-Rich-Plasma Therapy in Musculoskeletal Disorders. Revista brasileira de ortopedia, 2020; 55(3): 263-268. 


\title{
O POTENCIAL TERAPÊUTICO DO CANABIDIOL NO TRATAMENTO DE CRIANÇAS COM TRANSTORNO DO ESPECTRO AUTISTA
}

\author{
Junior de Jesus Guimaraes ${ }^{1}$ \\ Jean David Alves da Silva ${ }^{1}$ \\ Sara Figueiredo da Silva e Silva ${ }^{1}$ \\ Juliana Alves Ferreira ${ }^{1}$ \\ Leisiane Karolaine Santos ${ }^{2}$
}

1. Universidade Tiradentes (UNIT), Aracaju - SE.

2. Centro Universitário Estácio de Sergipe, Aracaju - SE.

Palavras-chave: Canabidiol, Transtorno do Espectro Autista, Adesão à medicação.

\section{INTRODUÇÃO}

O transtorno do espectro autista (TEA) é um transtorno que acomete neurodesenvolvimento, comumente identificado ainda na infância, demonstrando dificuldades de comunicação, expressão, interação social e comportamental (FERNANDES A, et al., 2021). Contudo, o canabidiol (CBD) - que não tem efeitos psicoativos é uma substância presente na Cannabis sativa considerado livre de efeitos psicotrópicos, redutor da ansiedade e contribuindo para a uma melhor concentração, reduz os efeitos do tetrahidrocanabinol ( $\triangle 9-\mathrm{THC})$, é responsável pela maioria dos efeitos psicoativos, sendo considerado eficaz como medicamento e tratamentos terapêuticos (TZADOK M, et al., 2016).

\section{OBJETIVO}

Evidenciar o potencial terapêutico do fármaco canabidiol no tratamento de crianças com transtorno do espectro autista; Analisar como o uso do Canabidiol pode trazer benefícios para o tratamento de transtornos psiquiátricos.

\section{REVISÃO BIBLIOGRÁFICA}

Um estudo com 188 pacientes com TEA concluiu que após seis meses os pacientes em uso do óleo do CBD contendo $30 \%$ de CBD e $1,5 \%$ de $\triangle 9 \mathrm{THC}$, em que $30 \%$ dos pacientes relataram melhora significativa e $75 \%$ apresentaram melhora em sintomas de inquietação, ataque de raiva, problemas para dormir entre outros (SCHLEIDER L, et al., 2019).

Crianças com TEA não possui homeostase nas células do sistema endocanabinóide, o uso do óleo do CBD irá atuar sistema da criança, ocasionando a homeostase, adequando a produção de serotonina e os níveis de atividade neuronais com ação ansiolítica, antipsicótica, proteção dos neurônios, anti-inflamatória, 
antiepiléptica e nos distúrbios do sono, relatando também que o CBN não gera qualquer alucinação na criança (OLIVEIRA AD e POTTKER CA, 2019).

No estudo, retrata que o uso do composto canabidiol é de caráter satisfatório no tratamento do TEA, principalmente nas questões de relação e interação social, e o uso apresentou resultados na diminuição da autolesão, ansiedade, hiperatividade e dificuldade para dormir, apresentando os mesmos resultados de drogas convencionais (SOUZA BC, et al., 2020).

\section{CONSIDERAÇÕES FINAIS}

De acordo com as pesquisas, os fármacos à base de canabidiol, poderão ser uma relevante opção terapêutica a se pensar no tratamento de transtornos e sintomas psiquiátricos em um futuro próximo, com a sua eficácia no tratamento do TEA semelhante a medicamentos de uso habitual.

\section{REFERÊNCIAS}

1. FERNANDES A, et al. esafios cotidianos e possibilidades de cuidado com crianças e adolescentes com Transtorno do Espectro Autista (TEA) frente à COVID-19. Cadernos Brasileiros de Terapia Ocupacional, 2021; 29: e2121.

2. OLIVEIRA AD, POTTKER CA. Considerações sobre o canabidiol no processo psicoterapêutico de crianças com transtorno do espectro autista. Revista Uningá Review, 2019; 34(4): 24-37.

3. SCHLEIDER L, et al. Real-life Experience of Medical Cannabis Treatment in Autism: Analysis of Safety and Efficacy. Scientific Reports, 2019; 9(10): 1038/s41598-018-37570-y.

4. SOUZA BC, et al. Efetividade do uso do Canabidiolno tratamentos de comorbidades relacionadas ao transtorno do espectro autista. Brazilian Journal of Development, 2020; 6(10): 74803-74806.

5. TZADOK M, et al. CBD-enriched medical cannabis for intractable pediatric epilepsy the current Israeli experience. Seizure: European Journal of Epilepsy, 2016; 35: 41-44. 


\title{
O PROTAGONISMO DO ENFERMEIRO NO AMBIENTE ESCOLAR: A EDUCAÇÃO PODE SALVAR VIDAS
}

\author{
Junior de Jesus Guimaraes ${ }^{1}$ \\ Jean David Alves da Silva ${ }^{1}$ \\ Sara Figueiredo da Silva e Silva ${ }^{1}$ \\ Juliana Alves Ferreira ${ }^{1}$ \\ Leisiane Karolaine Santos ${ }^{2}$
}

1. Universidade Tiradentes (UNIT), Aracaju - SE.

2. Centro Universitário Estácio de Sergipe, Aracaju - SE.

Palavras-chave: Primeiros Socorros, Acidentes, Escola.

\section{INTRODUÇÃO}

Os acidentes na infância retratam um sério problema para o sistema de saúde no mundo, sendo responsáveis por um grande número de atendimento nas urgências hospitalares. Acidente é compreendido como o acontecimento não intencional e evitável gerador de danos físicos e/ou emocionais no âmbito doméstico ou nos outros ambientes sociais (MOURA TV, et al., 2018). Para a atuação do enfermeiro no ambiente escolar, é necessário um amplo conhecimento teórico e científico pelo profissional, atuando na coordenação e no incentivo das práticas que envolvem a promoção, prevenção e tratamento em situações de saúde/doença (BRASIL, 2019).

\section{OBJETIVO}

Estabelecer benefícios para a população alvo, orientando na conduta de primeiros socorros. Objetivo Específico: Avaliar o grau do entendimento em primeiros socorros das crianças, pais e professores, após uma intervenção educativa.

\section{REVISÃO BIBLIOGRÁFICA}

Atinando que o ambiente escolar é responsável pela formação do cidadão, existe a grande necessidade de trabalhar temáticas voltadas à saúde humana como forma de prevenção com ênfase em situações de acidentes sejam por queda, engasgo, intoxicação na escola, possibilitando a formação de adultos com conhecimentos sobre suporte básico a vida (LIMA LL, et al., 2016; GRIMALDI M, et al., 2020).

O manejo por partes dos alunos, professores e funcionários devido à deficiência de conhecimentos sobre a conduta correta frente às situações de emergências, uma intervenção educativa voltada para a discussão de primeiros socorros, frente às intercorrências de emergências, abordando conceitos, possíveis causas e modos de intervenção de primeiros socorros com simulações, isso contribuirá para a construção do saber e 
da aprendizagem para execução de uma conduta direcionada e efetiva durante um acidente (SILVA LG, et al., 2017).

Contudo, observou que o público alvo, não sabia intervir de forma precoce e eficaz em determinadas situações, como por exemplo, em uma parada cardiorrespiratória, pois os relatos revelaram carência de fundamentos básicos de primeiros socorros (LEITE HS, et al., 2018).

\section{CONSIDERAÇÕES FINAIS}

A conduta de qualidade durante um acidente é de extrema importância principalmente no primeiro minuto da situação ocorrida, podendo evoluir a fatalidade da vítima durante a assistência, caso não tenham o direcionamento básico para uma conduta adequada. Nos ambientes escolares os estudantes atuam de forma eficiente como multiplicadores de conhecimento, o que revela a importância da capacitação destes.

\section{REFERÊNCIAS}

1. GRIMALDI M, et al. A escola como espaço para aprendizado sobre primeiros socorros. Rev. Enferm. UFSM - REUFSM Santa Maria, RS, 2020; 10(e20): 1-15.

2. LEITE HS, et al. Primeiros Socorros na Escola: conhecimentos da equipe que compõe a gestão educacional. Temas em Saúde, 2018: 290-312.

3. LIMA LL, et al. Brigada Estudantil de Prevenção de Acidentes e Primeiros Socorros em Palmas (TO). Revista Brasileira de Educação Médica, 2016; 40(2).

4. MOURA TV, et al. Práticas educativas em primeiros socorros: relato de experiência extensionista. Revista Ciência em Extensão, 2018; 14(2): 180-187.

5. BRASIL. Ordem dos Enfermeiros. Regulamento do exercício profissional do enfermeiro. Decreto-Lei $\mathrm{n}$. $\circ$ 161/96, de 4 de Setembro. 2019.2 Disponível em: https://www.ordemenfermeiros.pt/arquivo/AEnfermagem/Documents/REPE.pdf. Acessado em: 12 de Outubro de 2021.

6. SILVA LG, et al., 2017. Primeiros socorros e prevenção de acidentes no ambiente escolar: intervenção em unidade de ensino. Enferm. Foco, 2017; 8(3): 25-29. 


\title{
FATORES DESENCADEANTES DA SÍNDROME DE BURNOUT EM MÉDICOS RESIDENTES: CUIDAR DE QUEM CUIDA
}

\author{
Gabrielly Fávaro Costa Amorim 1 \\ Lanna do Carmo Carvalho ${ }^{1}$ \\ Laís Celi Mendes Rezende ${ }^{1}$ \\ Marihá Taís Thombetta ${ }^{1}$ \\ Lara Cândida de Sousa Machado ${ }^{1}$
}

1. Universidade de Rio Verde (UNIRV), Rio Verde - GO.

Palavras-chave: Residência médica, Burnout, Profissionais da saúde.

\section{INTRODUÇÃO}

A Síndrome de Burnout ou Síndrome do Esgotamento Profissional um transtorno de adaptação a estressores crônicos. Os sintomas são uma combinação de exaustão emocional, baixa autoestima, depressão e falta de sensibilidade. Logo, profissionais da saúde como médicos residentes, os quais estão expostos à altas cargas de responsabilidade, competitividade e auto exigências, fazem parte do principal grupo acometido por essa síndrome (SILVEIRA FF e BORGES LO, 2021).

A Síndrome de Burnout é causada por 3 fatores inter-relacionados: exaustão emocional, despersonalização e diminuição da realização profissional. As principais consequências são a perda de empatia e compaixão, perca da qualidade de vida e o desenvolvimento de ideação suicida (DEGGERONE I, et al., 2021).

\section{OBJETIVO}

Relatar os fatores desencadeantes da Síndrome de Burnout em médicos residentes por meio de uma revisão integrativa e propor possíveis soluções para essa problemática que prejudica tanto os profissionais como seus pacientes e familiares.

\section{MÉTODO}

O seguinte estudo se trata de uma revisão integrativa, fundamentada em artigos renomados do SciELO, Ministério da Saúde e Google Acadêmico no período de agosto de 2021, utilizando como descritores: Burnout, Esgotamento Profissional e Profissionais de Saúde. Foram selecionados estudos sobre médicos residentes publicados nos últimos 5 anos excluindo -se os demais que não atendiam a finalidade proposta.

\section{REVISÃO BIBLIOGRÁFICA}


Há uma maior prevalência de Burnout em residentes de certas especialidades médicas em relação a outras. Além disso, residentes de países asiáticos possuem maior prevalência de Burnout em relação aos residentes de outros países. Outros fatores como idade e sexo também estão relacionados (LOW ZX, et al., 2019).

A Síndrome de Burnout está relacionada com mais erros de prescrição e baixa qualidade do atendimento médico em geral. (LOW ZX, et al., 2019). Entre os fatores de risco destacam-se: trabalhar em unidade de urgência, sexo feminino, especialidades cirúrgicas. As possíveis explicações são a sobrecarga de trabalho a e falta de confiança sobre o próprio conhecimento médico (DEGGERONE I, et al., 2021).

\section{CONSIDERAÇÕES FINAIS}

A prevalência de Síndrome de Burnout em médicos residentes é elevada em espacialidades cirúrgicas e ambientes de urgência e emergência. A falta de qualidade de vida e a indução de erros médicos são as principais consequências que podem evoluir com a piora no atendimento dos pacientes. Desde a faculdade de medicina, para a prevenção do Burnout, é necessário investir no aprendizado de técnicas de redução do estresse, como o mindfullness.

\section{REFERÊNCIAS}

1. DEGGERONE I, et al. Síndrome de Burnout em Estudantes de Medicina. Caderno ESP, 2015; 15: 77-86.

2. LOW ZX, et al. Prevalência de Burnout em residentes médicos e cirúrgicos: uma meta-análise. Int. J. Environ. Res. Public Health, 2019; 16(9): 1479.

3. SILVEIRA FF, BORGES OL. Prevalência da Síndrome de Burnout entre Médicos Residentes. Psicologia: Ciência e Profissão, 2021; 41: e221076. 
RESUMO SIMPLES: Revisão Integrativa

\title{
ASSISTÊNCIA DE ENFERMAGEM NO PRÉ-NATAL DE ALTO RISCO: UMA REVISÃO INTEGRATIVA
}

\author{
Daniela dos Santos Mangueira de Almeida ${ }^{1}$ \\ Andressa Dâmaras Freitas Feitosa ${ }^{1}$ \\ Beatriz Caroline Leão Lima ${ }^{1}$ \\ Maria Clara Rodrigues de Abreu ${ }^{1}$ \\ Mauro Roberto Biá da Silva ${ }^{1}$
}

1. Universidade Estadual do Piauí (UESPI), Teresina - PI.

Palavras-chave: Assistência de enfermagem, Cuidado pré-natal, Gravidez de alto risco.

\section{INTRODUÇÃO}

A gestação é um evento fisiológico que é representada por modificações biológicas e modificações psicossociais na gestante e que normalmente tendem a evoluir de maneira saudável, contudo, por alguns fatores determinadas essas gestações podem evoluir para gestações de alto risco, devido patologias que podem ameaçar a vida da parturiente ou do feto (ERRICO LSP, et al., 2018). Neste âmbito o profissional de Enfermagem, com a sua destreza, qualificação e conhecimento atua com as consultas de Enfermagem no pré-natal de alto risco promovendo melhorias no prognóstico dessa gestante (TELES PA, et al., 2019).

\section{OBJETIVO}

Revisar e analisar por meio da literatura científica quanto a qualidade da assistência prestada através do profissional enfermeiro no atendimento à gestante durante as consultas no pré-natal de alto risco.

\section{MÉTODO}

Trata-se de uma revisão integrativa de literatura com busca na Biblioteca Virtual de Saúde (BVS), nas bases de dados SCIELO, LILACS e BDENF. Encontrados 144 artigos e destes 4 foram selecionados segundo critérios de inclusão: artigos publicados nos últimos cinco anos, gratuitos e nas modalidades português, inglês e espanhol; critérios de exclusão: artigos não condizentes com a temática e revisões de literatura.

\section{REVISÃO BIBLIOGRÁFICA}

A atuação do enfermeiro no pré-natal de alto risco apresenta-se de suma importância para a prevenção de morbidades durante o período gravídico, que podem atingir mãe e filho, através de ações de promoção e prevenção da saúde, além da atuação em educação em saúde e orientações que o profissional dará a essa gestante referente ao momento do parto e amamentação, mostrando a sua competência e habilidade na assistência (JUNIOR ARF, et al., 2018). E a qualidade dessa assistência está intimamente ligada à dedicação 
e responsabilidade do profissional que presta os cuidados, principalmente o enfermeiro, que presta seus cuidados focado no bem-estar integral de seus pacientes (MEDEIROS AL, et al., 2016).

\section{CONSIDERAÇÕES FINAIS}

Os estudos evidenciam o profissional de enfermagem como parte essencial que integra a equipe que prestará assistência à gestante de alto risco durante seu pré-natal, a consulta de enfermagem e seus cuidados baseados em uma visão integral das suas necessidades permitem uma melhor compreensão do seu estado de saúde visando assim a prevenção e resolução de problemas e proporcionando segurança e acolhimento.

\section{REFERÊNCIAS}

1. ERRICO LSP, et al. The work of nurses in high-risk prenatal care from the perspective of basic human needs. Revista Brasileira de Enfermagem, 2018; 71(3): 1257-1264.

2. JUNIOR ARF, et al. O enfermeiro no pré-natal de alto risco: papel profissional. Revista Baiana de Saúde Pública, 2018; 41(3): 650-667.

3. MEDEIROS AL, et al. Avaliando diagnósticos e intervenções de enfermagem no trabalho de parto e na gestação de risco. Revista Gaúcha de Enfermagem, 2016; 37(3): e55316.

4. TELES PA, et al. Diagnósticos de Enfermagem mais prevalentes em gestantes de alto risco. Revista Oficial do Conselho Federal de Enfermagem, 2019; 10(3): 119-125. 


\title{
TRATAMENTO NUTRICIONAL DO DIABETES MELLITUS NA ATENÇÃO PRIMÁRIA
}

\author{
Ane Karolyne Araújo Silva ${ }^{1}$ \\ Yanka Kevnny Sousa Ferreira ${ }^{1}$ \\ Kelly Anne Valentim de Araújo ${ }^{1}$
}

1. Centro Universitário de Patos (UNIFIP), Patos - PB.

Palavras-chave: Diabetes Mellitus, Atenção primária a saúde, Nutrição.

\section{INTRODUÇÃO}

A Diabetes Mellitus (DM) é uma doença crônica não transmissível (DCNT) que cresce gradativamente. Suas causas e fatores de risco são: antecedentes familiares, sobrepeso, sedentarismo, dentre outros (BERCKER BR, et al., 2017); A (DM) acarreta sintomas como: perda de peso, poliúria, polidipsia e aumento da glicemia (RAMOS KA e PRUDÊNCIO FA, 2020).

O tratamento da DM abrange alterações no estilo de vida, bem como terapia farmacológica (GAMA CAB, et al., 2017). Na atenção primária o paciente com (DM) tem o seu primeiro acesso ao atendimento na Estratégia de Saúde da família (ESF), a mesma auxilia significativamente na melhoria da qualidade de vida dos usuários com (DM) (GIBICOSKI FS, et al., 2020).

\section{OBJETIVO}

Revisar, descrever e elucidar os principais achados na literatura, no que diz respeito aos tratamentos nutricionais do Diabetes Mellitus na Atenção primária, bem como, avaliar o nível dos tratamentos da (DM).

\section{MÉTODO}

A pesquisa foi realizada a partir de uma revisão sistemática, fundamentada na análise de artigos das bases de dados, SciELO, Google Acadêmico e Acervo +. Utilizando os descritores: Diabetes Mellitus e Atenção Primária a Saúde. Utilizando como recorte temporal 2016 a 2021, nos idiomas Português e Inglês. Excluíramse artigos que não se adequavam a pesquisa e artigos fora da delimitação dos anos. A revisão foi precedida por 4 artigos.

\section{REVISÃO BIBLIOGRÁFICA}

A nutrição é essencial para o tratamento da (DM). Estudos apontam que a alimentação específica utilizada pelos pacientes com (DM) encontram-se em um nível indesejado, sendo desafiadora para o tratamento da doença. É necessário que os indivíduos acometidos tomem consciência que aderir a alimentação específica, trará inúmeros benefícios, como: estabilização da glicemia, saciedade, dentre outros (GIBICOSKI FS, et al., 2020). 
$\mathrm{Na}$ atenção primária a saúde, identificou-se que controlar a alimentação foi a mudança mais difícil de ser alcançada pelos usuários com (DM). Uma das estratégias utilizadas pelos profissionais nesse caso foi a negociação quanto a redução da quantidade e ingestão regular de alimentos considerados contraindicados (BERCKER BR, et al., 2017).

\section{CONSIDERAÇÕES FINAIS}

Diante do exposto, faz-se necessário o enfoque da equipe multiprofissional em saúde, no incentivo a práticas educativas a conscientização dos portadores de Diabetes Mellitus quanto, a importância da melhoria do estado nutricional e de hábitos alimentares, bem como, de estilo de vida, visando uma melhor qualidade de vida.

\section{REFERÊNCIAS}

1. BERCKE BR, et.al. CUIDADO A PARTIR DA ATENÇÃO PRIMÁRIA: estado nutricional do portador de diabetes mellitus. Revista da Universidade Vale do Rio Verde, 2017; 15(1): 229-239.

2. GAMA CAP, et.al. Diabetes Mellitus e atenção primária: percepção dos profissionais sobre os problemas relacionados ao cuidado oferecido às pessoas com diabetes. Pepsic: periódicos eletrônicos em psicologia, 2017; 12(3): 1-16.

3. GIBICOSKI FS, et.al. Adesão de atividades de autocuidado de usuários com diabetes atendidos na atenção primária. Research, Society And Development, 2020; 9(5):1-16

4. RAMOS KA, PRUDÊCIO FA. Conhecimento de pacientes sobre diabetes mellitus tipo 2. Revista artigos.com, 2020; 18: 1-13. 


\title{
ATUAÇÃO DA ENFERMAGEM NA PREVENÇÃO DE LESÃO POR PRESSÃO EM TERAPIA INTENSIVA
}

\author{
Cristhallay Silva Cavalcante ${ }^{1}$
}

1. Estácio de Sá do Amazonas (UESA) Manaus - AM.

Palavras-chave: Lesão por pressão, Cuidados de enfermagem, Unidades de terapia intensiva.

\section{INTRODUÇÃO}

A lesão por pressão ocorre devido a compressão das proeminências ósseas, tendo como fatores causais: idade, morbidade, estado nutricional, hidratação, mobilidade, nível de consciência, pressão, cisalhamento, fricção e umidade, em terapia intensiva possuem mais probabilidade de desenvolver lesão, devido a delimitação física, perda da percepção dos sentidos relacionados ao uso de anestésicos, reduzindo o nível de consciência e consequentemente a sensação cutânea, ressaltando a importância da atuação da equipe de enfermagem realizando ações preventivas, para assegurar a integridade da pele (ALMEIDA F, et al., 2019). A escala de braden avalia os fatores relacionados ao desenvolvimento de lesão, estratificando o risco (MACHADO LCLR, et al., 2019).

\section{OBJETIVO}

Relatar quais as medidas realizadas pela equipe de enfermagem na prevenção da lesão por pressão em terapia intensiva e suas implicações na sistematização da assistência de enfermagem e segurança do paciente.

\section{MÉTODO}

Trata-se de uma pesquisa de revisão integrativa. A busca foi feita na base de dados da Acervo + Index base no período de abril de 2019 a março de 2021, procedeu-se à análise de 20 artigos, incluindo artigos dos últimos 3 anos em portugês e excluindo aqueles que não atendessem a temática, utilizando os descritores: lesão por pressão, cuidados de enfermagem e unidades de terapia intensiva.

\section{REVISÃO BIBLIOGRÁFICA}

As ações utilizadas para prevenção consistiram em: mudança de decúbito de duas em duas horas, uso de colchão pneumático ou piramidal, suporte nutricional adequado, proteção das proeminências ósseas com coxins, minimizar exposição da pele a umidade, hidratar a pele, exame físico diário da pele, realização de massagem de conforto, monitorar e documentar intervenções e resultados obtidos, utilização de escalas de avaliação do grau de risco (PEREIRA E, et al., 2020). Estas ações foram referidas como cuidados preventivos para lesão por pressão assegurando a segurança do paciente e sistematização da assistência de enfermagem (PANERAI GS, et al., 2021). 


\section{CONSIDERAÇÕES FINAIS}

De acordo com os resultados obtidos na pesquisa, verificou-se a relevância da atuação do enfermeiro atuando junto a sua equipe com o intuito de assegurar a integridade da pele do paciente de forma profilática através de instrumentos que subsidiem os cuidados de enfermagem de forma sistematizada e eficaz. Os artigos levantados demonstram que as medidas profiláticas são efetivas, assegurando a segurança do paciente com vistas à sistematização da assistência de enfermagem.

\section{REFERÊNCIAS}

1. ALMEIDA F, et al. Assistência de enfermagem na prevenção da lesão por pressão: uma revisão integrativa. Revista Eletrônica Acervo Saúde, 2019; (30), e1440.

2. MACHADO LCLR, et al. Fatores de risco e prevenção de lesão por pressão: aplicabilidade da Escala de Braden. Revista Eletrônica Acervo Saúde, 2019; (21), e635.

3. PEREIRA E, NOGUEIRA MS. Atuação do enfermeiro na prevenção da lesão por pressão em pacientes acamados: revisão de literatura. Revista Eletrônica Acervo Saúde, 2020; (49), e3332.

4. PANERAI GSS, et al. Conhecimento de enfermeiros de um pronto atendimento sobre lesão por pressão: potencialidades e fragilidades vivenciadas. Revista Eletrônica Acervo Saúde, 2021; 13(5), e7241. 


\title{
INFECÇÃO POR MICROORGANISMO MULTIRRESISTENTE EM RECÉM-NASCIDOS NA UNIDADE DE CUIDADOS INTERMEDIÁRIOS NEONATAIS
}

\author{
Eliana Luz Lopes ${ }^{1}$ \\ Ana Luísa Mendes Ribeiro² \\ Angelica Ribeiro do Nascimento Oliveira ${ }^{3}$ \\ Rafaela de Jesus Portugal ${ }^{4}$ \\ Caroline Taiane Santos da Silva ${ }^{5}$
}

1. Universidade Federal do Oeste da Bahia (UFOB), Barreiras - BA.

2. Universidade Federal do Piauí (UFPI), Teresina - PI.

3. Universidade Salvador (UNIFACS), Salvador - BA.

4. Centro Universitário Maurício de Nassau (UNINASSAU), Teresina - PI.

5. Child Behavior Institute of Miammi, Flórida - Estados Unidos.

Palavras-chave: Segurança do paciente, Serviços de saúde infantil, Recém-nascido.

\section{INTRODUÇÃO}

Infecções Relacionadas à Assistência à Saúde (IRAS) estão interligadas com o contexto de infecções adquiridasdurante o processo de cuidado em hospitais, ambulatórios e clínicas. Segundo a Organização Mundial da Saúde (OMS), as IRAS correspondem a um problema de saúde pública, sendo necessárias respostas efetivas e imediatas para seu controle (BARROS FS, et al., 2019).

As bactérias são organismos que podem desempenhar ações patológicas em relação ao seu hospedeiro, ao mesmo tempo que desenvolvem uma complexidade de mecanismos no quetange a resistência aos antimicrobianos (de SOUZA PNHEIRO LF, et al., 2021). No âmbito dos cuidados neonatais em recémnascidos a problemática em questão é bastante presente, sendo motivo de estudo para muitos pesquisadores.

\section{OBJETIVO}

Identificar na literatura científica evidências relacionadas à infecção por microrganismos em recémnascidos diante os cuidados intermediários neonatais, tendo como base a compreensão característica do ambiente bem como os principais microrganismos envolvidos.

\section{MÉTODO}

Trata-se de uma revisão integrativa realizada através de buscas nas bases de dados da Scielo, Pubmed e Medline, como descritores: "Segurança do paciente", "Serviços de saúde infantil" e "Recém-nascido", utilizando o operador booleano and. Como critérios de inclusão artigos que abordassem a temática 
disponíveis online na íntegra em português e inglês publicados entre 2016 e 2021 e de exclusão artigos repetidos nas bases. Totalizando 4 artigos para compor a revisão.

\section{REVISÃO BIBLIOGRÁFICA}

Por intermédio de uma análise mais rebuscada, verificou-se por meio de um estudo que na sociedade brasileira, que $60 \%$ das mortes referente às crianças no primeiro ano de vida ocorrem no período neonatal, e as sinapses são a principal causa. Ademais, a Unidade de Terapia Intensiva Neonatal (UTIN) é um local insalubre, que permite agregar a presença de microrganismos patogênicos multirresistentes aos multimicrobianos (PAULA AO, et al., 2017).

Um outro estudo realizado com o objetivo de descrever infecção por microorganismo resistente em recémnascidos, verificou-se que resistência à enterobactérias foi de 100\% para o Cefepime e Ceftazidima, e diante as bactérias gram-negativas o percentual se coincidem (de LIMA FHA, et al., 2020).

\section{CONSIDERAÇÕES FINAIS}

O presente trabalho possibilitou compreender a importância do monitoramento correto em prol do bemestar dos pacientes, associado com a necessidade da formulação de protocolos interligados entre hospital e gestores para o controle da infecção juntamente com a fiscalização dos serviços. Intervir e fiscalizar são ações conjuntas para compreender o processo patológico, tendo em vista resultados satisfatórios.

\section{REFERÊNCIAS}

1. BARROS FE, et al. Controle de infecções a pacientes em precaução de contato. Journal of Nursing UFPE/Revista de Enfermagem UFPE, 2019; 13(4).

2. de LIMA FHA, et al. Multiresistant microorganism infection in newborns at an intermediate neonatal care unit and intensive care unit of reference: cross-sectional study. Bioscience Journal, 2020; 36(6).

3. de SOUZA PINHEIRO, et al. Fatores de risco e mortalidade em pacientes criticamente enfermos com infecções por microrganismos multirresistentes. Revista Eletrônica Acervo Saúde, 2021; 13(4): e7319.

4. PAULA AO, et al. Infecções relacionadas à assistência em saúde em unidades de terapia intensiva neonatal: uma revisão integrativa. Enfermería Global, 2017; 16(1): 508-536. 
RESUMO SIMPLES: Revisão Integrativa

\title{
ATUAÇÃO DA EQUIPE DE ENFERMAGEM NO PROCESSO DE ENVELHECIMENTO SAUDÁVEL: REVISÃO DE LITERATURA
}

\author{
Raiane Araujo Brito ${ }^{1}$ \\ Jhussara Silva Alves ${ }^{1}$ \\ Amélia Carina Messias da Costa ${ }^{1}$ \\ Hernandes Flanklin Carvalho Oliveira ${ }^{1}$ \\ Augusto Cezar Antunes de Araujo Filho'
}

1. Universidade Estadual do Piauí (UESPI), Floriano - PI.

Palavras-chave: Saúde do idoso, Envelhecimento saudável, Cuidados de enfermagem.

\section{INTRODUÇÃO}

A população idosa vem aumentando significativamente, essa realidade está atrelada à redução de fecundidade e aumento da expectativa de vida. $12 \%$ da população mundial é composta por idosos, a estimativa é que até 2050 esse quantitativo possa duplicar e triplicar em 2100. Esse aumento da perspectiva de vida permite a essa população planejar o futuro, diferente das gerações anteriores, em conformidade com um elemento primordial: a saúde. Nesse sentido, as políticas públicas contribuem positivamente no envelhecimento, é essencial o desenvolvimento de atividades e programas sociais voltadas para este grupo, com a finalidade de promover um envelhecimento bem-sucedido, ativo e saudável (VEAS RP e OLIVEIRA M, 2018).

\section{OBJETIVO}

Identificar e avaliar, por meio da literatura científica, estudos que discorrem sobre a atuação da equipe de enfermagem e a perspectiva de idosos no processo de envelhecimento ativo e saudável.

\section{MÉTODO}

Trata-se de uma revisão integrativa da literatura, realizada em agosto de 2021, na Biblioteca Virtual em Saúde. Foram utilizados descritores associados ao operador "AND": "saúde do idoso", "envelhecimento saudável" e "cuidados de enfermagem", os quais direcionaram para seis artigos. Os critérios de inclusão foram: artigos em português e publicado entre 2017 e 2021. Foram excluídas as teses e monografias. Após filtragem obteve- se uma amostra final de três artigos.

\section{REVISÃO BIBLIOGRÁFICA}


A adoção de comportamentos e hábitos auxilia diretamente no controle das Doenças Crônicas Não Transmissíveis (DCNT), a qual corresponde às principais causas de mortalidades desse grupo, assim, os profissionais devem estimular a autorresponsabilidade do idoso na adoção de um estilo de vida saudável (TAVARES RE, et al., 2017).

Outro fator importante é estabelecer vínculo entre a equipe de enfermagem e o idoso, sendo o envolvimento dos seus familiares fundamental para que o processo de cuidar seja compartilhado e efetivo. A equipe de enfermagem deve desenvolver uma assistência com reconhecimento do ambiente econômico e social do idoso e que os incentivem a manter atitudes independentes (ARAUJO ET e SOUZA NB, 2019).

\section{CONSIDERAÇÕES FINAIS}

A equipe de enfermagem deve ofertar um cuidado integral, respeitando as características individuais e socioeconômicas de cada idoso. Dessa forma, a equipe deve estar capacitada e atualizada sobre as ações de promoção da qualidade de vida, bem como estimular a adotar condutas e encoraja-los com cautela.

\section{REFERÊNCIAS}

1. ARAUJO ET, SOUZA NB. Assistência de enfermagem no processo de envelhecimento. Revista Científica Online, 2019; 11(1): 1980-6957.

2. TAVARES RE, et al. Envelhecimento saudável na perspectiva de idosos: uma revisão integrativa. Revista Brasileira de Geriatria e Gerontologia, 2017; 20(6): 889-900.

3. VERAS RP, OLIVEIRA M. Envelhecer no Brasil: a construção de um modelo de cuidado. Revista Ciênc Saúde Colet, 2018; 23(6): 1-8. 


\title{
DIREITOS SEXUAIS E REPRODUTIVOS PARA MULHERES COM TRANSTORNOS MENTAIS: REVISÃO INTEGRATIVA DA LITERATURA
}

\author{
Luciana Batista ${ }^{1}$ \\ Margarita Antonia Villar Luis ${ }^{1}$ \\ Carla Aparecida Arena Ventura ${ }^{1}$
}

1. Universidade De São Paulo (USP), Ribeirão Preto - SP.

Palavras-chave: Direito da mulher, Saúde sexual e reprodutiva, Saúde mental.

\section{INTRODUÇÃO}

A Declaração dos Direitos Humanos, rompendo barreiras geográficas, padronizou internacionalmente os direitos humanos fundamentais, objetivando a proteção dos bens jurídicos e da dignidade da pessoa, nela incluso as com deficiência (AMBROSIO RBA, et al, 2019). Todavia a sexualidade de mulheres com transtornos mentais permaneceu estigmatizada, mantendo-se o conceito de assexuada, com seus desejos ignorados e taxados como agravamento da patologia (DETOMINI VC e RASERA EF, 2018).

A questão de gênero, em relação a saúde mental, é um poderoso determinante social, que historicamente passou- se desapercebida pelos principais estudiosos, porém deve ser analisado de forma a produzir ações específicas nas questões de direitos sexuais e reprodutivos (MARCOLINO ABL, et al., 2019).

\section{OBJETIVO}

Revisar de forma integrativa os direitos em saúde sexual e reprodutiva para mulheres com de transtornos mentais, com a finalidade de elucidar e proporcionar subsídios para determinar a qualidade das ações desenvolvidas no campo da saúde mental.

\section{MÉTODO}

Revisão integrativa da literatura nas bases de dados LILACS, BDENF, BVS (Biblioteca Virtual de Saúde), CINAHL, PUBMED e SCOPUS realizada em maio de 2021 utilizando os descritores mulher, saúde mental, direito e saúde sexual e reprodutiva. Sendo os critérios de inclusão idiomas em português, inglês e espanhol dos últimos 05 anos, e de exclusão: geriátrica e hospitalização. Foram encontradas 1.243 referências, após avaliação, 06 artigos foram considerados para esse estudo.

\section{REVISÃO BIBLIOGRÁFICA}

Um estudo apresentou a imposição para anticoncepção de profissionais da saúde e familiares de mulheres com transtornos mentais e deficiências, não respeitando sua autonomia e desejos bem como violando seus direitos humanos, sexuais e reprodutivos (KONG C, 2019). Em outro estudo, profissionais apontaram que a 
identificação dos direitos sexuais tem sido aceita, porém se mantêm estigmatizada (WICKSTRÖM M, et al., 2020).

Em um estudo de intervenção, foi constatado que além dos pais não pensarem que seus filhos não têm necessidades sexuais, também estão preocupados com a "transmissão" da deficiência para as próximas gerações, o que consideram problemas para a sociedade (CHOU YC, et al., 2019).

\section{CONSIDERAÇÕES FINAIS}

Diante dos estudos apresentados, demonstra-se que os direitos sexuais e reprodutivos para mulheres com de transtornos mentais estão expressos em legislações nacionais e internacionais fundamentadas em suas crenças, conceitos e valores. Entretanto, mantem-se estigmatizada desfavorecendo o gozo dos direitos, assim como a contracepção forçada ou desinformada continua a ser exercida como proteção. São necessários mais estudos sobre a temática para elucidar e direcionar ações assertivas para essa população.

\section{REFERÊNCIAS}

1. AMBROSIO RBA, et al. Sexualidade do Adolescente com deficiência: Ancoragens na literatura. Revista Eletrônica Acervo Saúde, 2019; 11(3): 1-11, e277.

2. CHOU YC, et al. 'Transformed rights' sexual health programme evaluation for the parents and service workers of adults with an intellectual disability. Journal of Intellectual Disability Research, 2019; 63(9): $1125-1136$.

3. DETOMINI VC, RASERA EF. Sexualidade e saúde mental: construindo sentidos com pessoas usuárias de um caps. Estudos de Psicologia, 2018; 23(3): 306-316.

4. MARCOLINO ABL, et al. Sexualidade e deficiência intelectual: revisão integrativa da literatura. Brazilian Journal of Health Review, 2019; 2(4): 2677-2694.

5. KONG C. Constructing female sexual and reproductive agency in mental capacity law. International Journal Of Law And Psychiatry, 2019, 66: 101488.

6. WICKSTRÖM M, et al. How can sexual and reproductive health and rights be enhanced for young people with intellectual disability? focus group interviews with staff in Sweden. Reproduct Health, 2020; 17(1):110. 
RESUMO SIMPLES: Revisão Integrativa

\title{
MANEJO DA ENFERMAGEM NA LESÃO POR PRESSÃO DE PACIENTES IDOSOS EM CUIDADOS PALIATIVOS: REVISÃO INTEGRATIVA
}

\author{
Raiane Araujo Brito ${ }^{1}$ \\ Jhussara Silva Alves ${ }^{1}$ \\ Amélia Carina Messias da Costa ${ }^{1}$ \\ Hernandes Flanklin Carvalho Oliveira ${ }^{1}$ \\ Augusto Cezar Antunes de Araujo Filho ${ }^{1}$
}

1. Universidade Estadual do Piauí (UESPI), Floriano - PI.

Palavras-chave: Cuidados paliativos na terminalidade da vida, Lesão por pressão, Cuidado de enfermagem.

\section{INTRODUÇÃO}

Idosos geralmente apresentam uma série de alterações principalmente na pele, inicia-se um processo de despedida de suas funções orgânicas progressiva com várias manifestações clínicas, ocasionando a Lesão Por Pressão (LPP). Essas lesões são prevalentes em idosos hospitalizados que se encontram na terminalidade da vida, resultantes de lesão do tecido adjacente ou da pele causada por pressão, fricção ou cisalhamento, que pode na maioria das vezes ser evitadas. Para isso, a equipe de enfermagem deve agregar conhecimentos sobre como prevenir e tratar, e quando possível, curar ou minimizar complicações para promover o conforto do paciente (VERAS R, 2020).

\section{OBJETIVO}

Revisar e analisar por meio da literatura científica estudos que discorrem sobre à atuação da equipe de enfermagem na lesão por pressão de pacientes idosos em cuidados paliativos que se encontram hospitalizados.

\section{MÉTODO}

Trata-se de uma revisão integrativa da literatura. A busca foi realizada na Biblioteca Virtual de Saúde, no mês de julho de 2021. Foram utilizados os descritores: "cuidados paliativos na terminalidade da vida", "lesão por pressão" e "cuidados de enfermagem". Critérios de inclusão foram: artigos completos em português entre os anos de 2019 e 2020. Foram excluídos os repetidos e que não contemplassem a temática. Após filtragem, resultou-se em três artigos.

\section{REVISÃO BIBLIOGRÁFICA}


Idosos apresentam alto risco para o desenvolvimento prejudicado da integridade da pele, o avanço da idade proporciona a diminuição da elasticidade e do turgor da pele. O ambiente de maior surgimento de LPP é o hospitalar durante o período de internação, idosos com comorbidades estão mais predispostos (SILVA CC, et al., 2021).

Nesse contexto, o cuidado paliativista é fundamental, pois diminui o sofrimento do idoso e seus familiares, fornecendo apoio e respondendo as necessidades básicas de saúde emocional, física, social e espiritual. Assim, a enfermagem deve focar não só na doença, mas também no alívio da dor e desconforto, promovendo um excelente suporte ao paciente (BONFIM AP, et al., 2019).

\section{CONSIDERAÇÕES FINAIS}

O enfermeiro tem um papel muito importante tanto nos cuidados paliativos como na prevenção de LPP, deve traçar métodos para uma assistência humanizada embasada na qualidade de vida, influenciando positivamente no curso da lesão, proporcionando uma morte digna a esse paciente.

\section{REFERÊNCIAS}

1. BONFIM AP, et al. Atuação do enfermeiro na assistência ao paciente idoso portador de úlcera venosa. Revista Eletrônica Acervo Saúde, 2019; 22: e682.

2. SILVA CC, et al. A assistência de enfermagem e as lesões por pressão em idosos: uma revisão. Brazilian Journal of development, 2021; 7: 1-14.

3. VERAS R. O modelo assistencial contemporâneo e inovador para os idosos. Revista Brasileira de Geriatria e Gerontologia, 2020; 23(1): e200061. 
RESUMO SIMPLES: Revisão Integrativa

\title{
QUALIDADE E SEGURANÇA NO USO DA INSULINOTERAPIA PELA POPULAÇÃO IDOSA
}

\author{
Ana Luísa Mendes Ribeiro ${ }^{1}$ \\ Angelica Ribeiro do Nascimento Oliveira ${ }^{2}$ \\ Eliana Luz Lopes ${ }^{3}$ \\ Rafaela de Jesus Portugal ${ }^{4}$ \\ Caroline Taiane Santos da Silva ${ }^{5}$
}

1. Universidade Federal do Piauí (UFPI), Teresina - PI.

2. Centro Universitário Maurício de Nassau (UNINASSAU), Teresina - PI.

3. Universidade Salvador (UNIFACS), Salvador - BA.

4. Universidade Federal do Oeste da Bahia (UFOB), Barreiras - BA.

5. Child Behavior Institute of Miami (CBI of Miami), Flórida - Estados Unidos.

Palavras-chave: Idoso, Diabetes Mellitus, Insulina.

\section{INTRODUÇÃO}

A insulinoterapia corresponde a técnica que é utilizada na aplicação intramuscular de insulina exógena diária com o objetivo de regular os níveis glicêmicos, sendo prescrita nos pacientes submissos ao Diabetes Mellitus Tipo 1 (DMT1) ou com Diabetes Mellitus Tipo 2 (DMT2) (BERTONHI LG e DIAS JCR, 2018).

A título de exemplo, a população geriátrica é mais suscetível às complicações micro e macrovasculares, isso é verificado por conta da funcionalidade fisiológica reduzida, o que promove o desequilíbrio diante a homeostase do organismo. Assim dentre as alternativas plausíveis para controle metabólico encontra-se a insulinoterapia (VIANNA MS, et al., 2017).

\section{OBJETIVO}

Identificar na literatura a qualidade e segurança no uso da insulinoterapia pela população idosa portadora de Diabetes Mellitus, tendo em vista que está é uma terapia farmacológica com resultados satisfatórios.

\section{MÉTODO}

Trata-se de uma revisão integrativa realizada através de buscas nas bases de dados da Scielo, Pubmed, Medline, utilizando como descritores: Idoso; Diabetes Mellitus; Insulina, combinados entre si utilizando o operador booleano "and". Como critérios de inclusão artigos que abordassem a temática disponíveis online na íntegra em português e inglês publicados entre 2016 e 2021 e de exclusão artigos repetidos nas bases de dados. Totalizando 4 artigos para compor a revisão. 


\section{REVISÃO BIBLIOGRÁFICA}

Em um estudo realizado em abrangência de atenção primária à saúde corte intitulado "Saúde do idoso" e a participação da Estratégia Saúde da Família (ESF), verificou-se que a reutilização de agulhas e seringas foi relatada em mais da metade da população geriátrica, o que corresponde $55 \%$ dos registros e apenas $10 \%$ dos materiais perfurantes são alojados e destinados corretamente para as Unidades Básicas de Saúde (UBS) (KROLOW MR, et al., 2021).

Ademais, infere-se a importância da equipe multiprofissional para obter resultados satisfatórios e coesos. O profissional da enfermagem pode compactuar positivamente com uma orientação precisa, que vista a segurança e qualidade da terapia (da CUNHA RKP, et al., 2021).

\section{CONSIDERAÇÕES FINAIS}

O presente trabalho permitiu compreender a necessidade existente referente ao acompanhamento mais eficaz e corriqueiro da população idosa, a educação em saúde corresponde uma ação válida em ambientes domiciliares ou hospitalares, em prol da adesão à terapia. Compreende-se a necessidade da equipe multiprofissional, por meio da realização do acompanhamento diário com esses pacientes. Sabe-se que uma orientação com qualidade altera positivamente o cenário de tratamento.

\section{REFERÊNCIAS}

1. BERTONHI LG, DIAS JCR. Diabetes mellitus tipo 2: aspectos clínicos, tratamento e conduta dietoterápica. Revista Ciências Nutricionais Online, 2018; 2(2): 1-10.

2. da CUNHA RKP et al. The contribution of the nursing consultation facing the psychosocial factors related to the adherence to insulin therapy treatment. Research, Society and Development, 2021; 10(7): e24410716485.

3. KROLOW MR, et al. Qualidade e segurança no uso da insulinoterapia pela população idosa. Revista de Enfermagem da UFSM, 2021; 11(e38): 1-19.

4. VIANNA MS, et al. Competência para o autocuidado na administração de insulina por idosos septuagenários ou mais de idade. Revista Latino-Americana de Enfermagem, 2017; 25: e2943. 


\title{
CARDIOMIOPATIA HIPERTRÓFICA E RISCO PARA ATLETAS
}

\author{
Thaís Vieira da Silva ${ }^{1}$ \\ Larissa da Costa Boy ${ }^{1}$ \\ Mônica Isaura Corrêa ${ }^{1}$
}

1. Centro Universitário de Caratinga (UNEC), Caratinga - MG.

Palavras-chave: Cardiomiopatia Hipertrófica, Morte súbita, Atletas.

\section{INTRODUÇÃO}

A cardiomiopatia hipertrófica é uma doença genética caracterizada por hipertrofia não-dilatada do ventrículo, mais frequente no Ventrículo Esquerdo (VE), na ausência de patologias que levem a essa alteração. Hipertrofia assimétrica septal interventricular desproporcional às outras localidades do VE e obstrução dinâmica na via de saída desse mesmo ventrículo são achados característicos da doença, obtidos através do ecocardiograma. É a doença cardíaca de origem genética mais comum, podendo ser assintomática ou apresentar manifestações como insuficiência cardíaca refratária, arritmias ventriculares, até morte súbita. Sua significância no meio atlético está relacionada à importância do diagnóstico precoce, pois pacientes portadores possuem maior risco de morte súbita caso pratiquem exercícios (BAZAN SGZ, et al., 2020).

\section{OBJETIVO}

Descrever os principais riscos cardiovasculares para atletas que possuem cardiomiopatia hipertrófica, ressaltando a importância do diagnóstico precoce nessa classe de pacientes para evitar futuramente maiores problemas cardíacos e até mesmo a morte súbita.

\section{REVISÃO BIBLIOGRÁFICA}

A cardiomiopatia hipertrófica á a causa mais frequente de morte súbita em atletas com idade inferior a 35 anos. Dentre os jovens com idade entre 14 e 35 anos, um quinto tem maior espessura da parede do ventrículo esquerdo, sendo que a maioria fica abaixo de $12 \mathrm{~mm}$. Porém, uma pequena proporção de atletas, apresentam uma espessura ventricular esquerda de 13-16 mm, que se sobrepõe com cardiomiopatia hipertrófica morfologicamente leve (MALHOTRA A e SHARMA S, 2017).

A participação em esportes, principalmente quando de alta intensidade, pode, teoricamente, levar a taquicardia ventricular, fibrilação ventricular, acidose metabólica, desidratação, isquemia microvascular, entre outros sinais e sintomas nos indivíduos portadores de cardiomiopatia hipertrófica. Dessa forma, a participação em esportes de alta intensidade pode ser considerada um fator de risco independente, mesmo não havendo marcadores de risco convencionais intrínsecos à doença (SHAH M, 2017). 
O diagnóstico da cardiomiopatia hipertrófica em atletas pode ser difícil, visto que a hipertrofia patológica do ventrículo esquerdo também pode imitar a hipertrofia ventricular esquerda fisiológica (HVE) em resposta ao exercício (MALHOTRA A e SHARMA S, 2017).

\section{CONSIDERAÇÕES FINAIS}

A realização de exercícios físicos proporciona benefícios importantes para a saúde cardiovascular, pois pode prevenir e reduzir a progressão de doenças. A prática de exercícios causa adaptações no sistema cardiovascular, essas alterações cardíacas podem aumentar o risco de morte súbita em atletas cardiomiopatas. Por isso é de suma importância, como forma de prevenção, incluir avaliações físicas e exames médicos mais completos, além de avaliações em pré-participações de atividades esportivas.

\section{REFERÊNCIAS}

1. BAZAN SGZ, et al. Cardiomiopatia Hipertrófica - Revisão. Arquivos Brasileiros de Cardiologia, 2020; 115(5): 927-935.

2. MALHOTRA A, SHARMA S. Hypertrophic Cardiomyopathy in Athletes. European Cardiology Review, 2017; 12: 80-82.

3. SHAH M. Hypertrophic cardiomyopathy. Cardiology in the Young, 2017; 27: 25-30. 
RESUMO SIMPLES: Revisão Integrativa

\title{
NEAR MISS NA ATENÇÃO PRIMÁRIA À SAÚDE E A SEGURANÇA DO PACIENTE
}

\author{
Ana Luísa Mendes Ribeiro ${ }^{1}$ \\ Angelica Ribeiro do Nascimento Oliveira ${ }^{2}$ \\ Eliana Luz Lopes ${ }^{3}$ \\ Rafaela de Jesus Portugal ${ }^{4}$ \\ Caroline Taiane Santos da Silva ${ }^{5}$
}

1. Universidade Federal do Piauí (UFPI), Teresina - PI.

2. Centro Universitário Maurício de Nassau (UNINASSAU), Teresina - PI.

3. Universidade Salvador (UNIFACS), Salvador - BA.

4. Universidade Federal do Oeste da Bahia (UFOB), Barreiras - BA.

5. Child Behavior Institute of Miami (CBI of Miami), Flórida - Estados Unidos.

Palavras-chave: Segurança do paciente, Atenção primária à saúde, Near miss.

\section{INTRODUÇÃO}

O Near miss deve ser notificado por se tratar de um evento que atingiu ou não o paciente, ou seja, causou ou não dano ao paciente, nesse contexto torna-se importante notificar para proporcionar um ambiente de aprendizado e seguro de atendimento, tornando-se necessário compartilhar essas informações importantes para o desenvolvimento da segurança do paciente (OMS, 2016). As notificações por acidentes/incidentes são uma prática comum no meio hospitalar, em especial eventos que possam comprometer a segurança dos pacientes, sendo obrigatórias essas notificações para que as organizações de saúde possam conhecer os riscos que envolvem este nível de cuidado (AMARO MAC e BOHOMOL E, 2020).

\section{OBJETIVO}

Identificar através da literatura científica as evidências dos incidentes near miss em serviços de atenção primária a saúde, bem como os tipos de acidentes e erros mais notificados nesses serviços.

\section{MÉTODO}

Trata-se de uma revisão integrativa realizada através de buscas nas bases de dados LILACS E BDENF, utilizando como descritores: Quase acidente, Saúde; Segurança do paciente; Atenção primária à saúde, combinados pelo operador booleano "and". Como critérios de inclusão artigos que abordassem a temática disponíveis online na íntegra publicados entre 2016 e 2021 e de exclusão artigos repetidos nas bases de dados. Totalizando 2 artigos para compor a revisão. 


\section{REVISÃO BIBLIOGRÁFICA}

Os dados sobre a ocorrência de eventos adversos relacionados aos cuidados de saúde não sugerem que os profissionais intencionam causar os danos e sim que não priorizam a segurança do paciente (ALVES MFT, et al., 2019). Em relação ao near miss, sobre a conduta dos profissionais da Atenção Primária à Saúde (APS) são destacados os erros de medicamentos, seguidos dos erros com documentação e erros de administração clínica, que estão ligados aos erros na prescrição, em relação a prescrição incompleta, existem riscos graves no momento da administração ou dispensação do medicamento, além dos transtornos em cima dos usuários (AMARO MAC e BOHOMOL E, 2020).

\section{CONSIDERAÇÕES FINAIS}

Diante do exposto, fica evidente a importância da notificação do near miss para garantir segurança no atendimento e fornecer informações às organizações de saúde sobre o atendimento que está sendo prestado nas instituições e unidades básicas de saúde evitando que nossos casos possam acontecer ou até mesmo agravar-se os erros.

\section{REFERÊNCIAS}

1. ALVES MFT, et al. Motivos para a não notificação de incidentes de segurança do paciente por profissionais da saúde: revisão integrativa. Ciências \& Saúde Coletiva, 2019; 24(8): 2895-2908.

2. AMARO MAC, BOHOMOL E. Notificação de eventos near miss na atenção primária à saúde. Enfermagem em Foco, 2020; 11(5).

3. ORGANIZAÇÃO MUNDIAL DE SAÚDE (OMS). Minimal information model for patient safety incident reporting and learning systems: user guide. Geneva: OMS; 2016. Disponível em: https://apps.who.int/iris/handle/10665/255642. Acessado em: 10 de out. de 2021. 


\title{
PREDITORES DE VIA AÉREA DIFÍCIL (VAD)
}

\author{
Roberta Simões Guerra1 \\ Nathália Gomes de Lima Beserra1 \\ Dulcinete Valéria de Albuquerque Ferreira1 \\ Pedro Henrique Xavier da Cunha1
}

1. Faculdade Tiradentes (FITS), Jaboatão dos Guararapes - PE.

Palavras-chave: Manuseio das vias aéreas, Intubação, Emergências.

\section{INTRODUÇÃO}

Por definição, uma Via Aérea Difícil (VAD) é aquela em que um profissional experiente na hora da intubação tenha alguma dificuldade para executá-la. Ocorre em média, em 10\% dos pacientes, podendo ocorrer em índices maiores nas situações não eletivas, de emergência (DEXHEIMER FL, et al., 2016).

Estas dificuldades se dão por singularidades da anatomia das vias aéreas de determinados pacientes e em situações específicas (DEXHEIMER FL, et al., 2016). Logo, é importante saber identificar durante o manejo das vias aéreas os preditores de dificuldade, objetivando manter o profissional alerta acerca da possibilidade de outros meios de intervenção, visando diminuir os riscos ao paciente (LILOT M, et al., 2019).

\section{OBJETIVO}

Pesquisar e analisar a literatura existente acerca da via aérea difícil (VAD), com ênfase em descrever os seus preditores bem como, a importância da sua identificação prévia no manejo da via aérea.

\section{MÉTODO}

Trata-se de uma revisão integrativa, com pesquisa a partir das bases de dados Scielo e Acervo+ de artigos entre 2016 e 2020. Os critérios de inclusão: artigos em inglês, português e espanhol, publicados nos últimos 5 anos. Na Scielo encontrou-se, com critérios, 8 artigos e sem os critérios, 27 e na Acervo+, 33 sem critérios e 3 com a classificação por relevância. Descritores: Manuseio das Vias Aéreas, Intubação, Emergências.

\section{REVISÃO BIBLIOGRÁFICA}

Em relação a pesquisa dos preditores de $\mathrm{VAD}$, inicialmente é importante pesquisar antecedentes pessoais de intubação difícil (SANTOS RD, et al., 2020). Posteriormente, analisar situações como: gestação, síndrome de apneia obstrutiva, trauma ou queimaduras em face ou pescoço, obesidade, pescoço curto e com dificuldade de mobilização, desdentado, dentes superiores compridos, prognatismo, retrognatismo e distância tireomentoniana pequena (ANDRADE RGAC, et al., 2017). 
Alguns índices são utilizados para avaliar a VAD, escalas de Mallampati e Cormack Lehane. Ambas escalas estabelecem escores que qualificam ítens: visibilidade de estruturas como palato mole, úvula, pilares amigdalianos, epiglote, sendo o menor escore associado a maior chance de sucesso na intubação (ANDRADE RGAC, et al., 2017).

\section{CONSIDERAÇÕES FINAIS}

Diante da relevância do tema via aérea difícil, faz-se essencial o reconhecimento dos seus preditores, visando alertar o profissional para possível realização de diferentes procedimentos ao manejar uma via aérea, e assim minimizar complicações ao paciente. São necessários mais estudos clínicos sobre o tema, oferecendo mais conhecimento para os profissionais e assim, reduzir índices de falha na intubação.

\section{REFERÊNCIAS}

1. ANDRADE RGAC, et al. Dificuldade na laringoscopia e na intubação orotraqueal: estudo observacional. Revista Brasileira de Anestesiologia, 2017; 68(2): e168-173.

2. DEXHEIMER FL, et al. Uso de guia introdutor (bougie) caseiro para intubação em situação de emergência em pacientes com via aérea difícil: uma série de casos. Revista Brasileira de Anestesiologia, 2016; 66(2): e204-207.

3. LILOT M, et al. Simulação de manejo de via aérea difícil para residentes: estudo comparativo prospectivo. Revista Brasileira de Anestesiologia, 2019; 69(4): e358-368.

4. SANTOS RD, et al. Via aérea difícil em paciente com bócio multinodular volumoso da tireoide. Revista Eletrônica Acervo Saúde, 2020; Sup(45): e2789. 


\title{
DORES E LESÕES MUSCULOESQUELÉTICAS EM ATLETAS RELACIONADAS A PRÁTICA DE E- SPORTS: UMA REVISÃO NARRATIVA DA LITERATURA
}

\author{
Arthur Henrique Silva da Fonseca ${ }^{1}$ \\ José Railson de Souza Oliveira ${ }^{1}$ \\ Victoria Carolina Pereira Nunes ${ }^{1}$ \\ Raquel de Souza Mota ${ }^{1}$ \\ Tereza Cristina dos Reis Ferreira ${ }^{1}$
}

1. Universidade do Estado do Pará (UEPA), Belém - PA.

Palavras-chave: Fisioterapia, Transtorno de adição à internet, Traumatismos em atletas.

\section{INTRODUÇÃO}

Os E-sports, ou esportes eletrônicos, representam uma modalidade de competição profissional ou recreativa disputada em plataformas eletrônicas, caracterizado como esporte pelo Comitê Olímpico Internacional. Na última década, os E-sports apresentaram rápido crescimento e atualmente possuem alcance similar a esportes competitivos tradicionais (PEREIRA AM, et al., 2019).

Apesar do carente movimento corporal, os esportes eletrônicos demandam movimentos dinâmicos e repetitivos que costumam associarem-se a postura inadequada. Estima-se que atletas de alta performance treinem até 15 horas diariamente, realizando até 400 movimentos de controle fino por minuto. Diante disso, espera-se que a realização dessa prática esteja associada à ocorrência de dores e lesões musculoesqueléticas nesses atletas (GEOGHEGAN L e WORMALD JCR, 2019).

\section{OBJETIVO}

Revisar a literatura científica, condizente com a temática supracitada, para verificar a ocorrência de dores e lesões musculoesqueléticas, as quais sejam resultantes da prática de E-sports em atletas dessa modalidade esportiva.

\section{REVISÃO BIBLIOGRÁFICA}

Foram encontrados quatro estudos; dentre a literatura analisada, os dois principais riscos de dores e lesões musculoesqueléticas na prática dos E-sports referem-se à realização repetitiva de movimentos motores finos, repercutindo nos membros superiores, e a postura inadequada, repercutindo principalmente nas costas e pescoço. Um estudo que analisou a manifestação de lesões na mão e punho, descreve que os sintomas predominantes devido ao esforço repetitivo correspondem a: dormência, fraqueza, dor e comprometimento funcional (GEOGHEGAN L e WORMALD JCR, 2019). 
Outros dois estudos que buscaram revisar e analisar a implicação dos esportes eletrônicos nas disfunções musculoesqueléticas exibiram resultados semelhantes na sua busca. Entre os resultados, destaca-se que nos membros superiores, a fraqueza do manguito rotador, nos ombros, e dores, hipertrofia dos tendões flexores e edemas no nervo mediano, nos punhos, são as repercussões mais presentes; já no pescoço e costas, verificou-se que dores e tensão muscular são os sintomas mais significativos e estão relacionados também ao estresse da articulação cervicotorácica e dos discos intervertebrais (ZWIBEL H, et al., 2019; EMARA AK, et al., 2020).

\section{CONSIDERAÇÕES FINAIS}

Diante dos estudos apresentados, a prática de E-sports parece estar significativamente relacionada com a manifestação de sintomas relacionados com dores e lesões musculoesqueléticas em atletas dessa modalidade. Entretanto, independente do crescimento massivo da atividade, a literatura acerca do tema ainda é bastante escassa e faz-se necessário que mais estudos sejam conduzidos para investigar os impactos diretos dos esportes eletrônicos com as disfunções musculoesqueléticas.

\section{REFERÊNCIAS}

1. EMARA AK, et al. Gamer's health guide: Optimizing performance, recognizing hazards, and promoting wellness in e- sports. Current Sports Medicine Reports, 2020; 19(12): 537-545.

2. GEOGHEGAN L, WORMALD JCR. Sport-related hand injury: a new perspective of e-sports. Journal of Hand Surgery Europe Volume, 2019; 44(2): 219-220.

3. PEREIRA AM, et al. Virtual sports deserve real sports medical attention. BMJ Open Sport \& Exercise Medicine, 2019; 1-5(1): e000606.

4. ZWIBEL H, et al. An osteopathic physician's approach to the e-sports athlete. Journal of the American Osteopathic Association, 2019; 119(11): 756-762. 


\title{
MANIFESTAÇÕES ORAIS E COVID-19: REVISÃO DE LITERATURA
}

\author{
Daiany Araújo da Silva ${ }^{1}$ \\ Jainy Estefany Martins ${ }^{1}$ \\ Fernando Silva Miranda ${ }^{1}$ \\ Tarciana Santos Silva ${ }^{1}$ \\ Regina Coeli Cançado Peixoto Pires ${ }^{1}$
}

1. Universidade de Itaúna (UIT), Itaúna - MG.

Palavras-chave: COVID-19, Coronavirus, Manifestações orais.

\section{INTRODUÇÃO}

A COVID-19, se tornou uma pandemia em pouco espaço de tempo e apresenta grave ameaça para a saúde global. Durante os 2 primeiros meses do surto, se espalhou rapidamente por toda a China e causou vários graus da doença. (GUAN WJ, et al., 2020). As condições bucais de pacientes com COVID-19 foram analisadas em vários estudos. Diante disso, observou-se que diversas manifestações orais foram encontradas. Percebeu-se então a importância da participação do cirurgião-dentista na equipe multiprofissional das unidades de terapia intensiva para o diagnóstico correto dessas lesões e para a melhora do quadro de saúde bucal em pacientes críticos, mesmo quando não acometidos pelo coronavírus (SANTOS JA, et al., 2020).

\section{OBJETIVO}

Realizar uma revisão de literatura sobre as manifestações orais que podem estar associadas à COVID-19 e foram relatadas por profissionais de saúde envolvidos com os pacientes infectados ou sob suspeita da doença.

\section{REVISÃO BIBLIOGRÁFICA}

As manifestações orais mais comumente encontradas foram: herpes simples recorrente, candidíase, língua geográfica, disgeusia, petéquias, úlceras, infecção por HSV-1, úlceras parecidas com sapinhos, aftas, áreas esbranquiçadas, angina bolhosa hemorrágica, distúrbio vascular, estomatites inespecíficas, bolhas, hipossalivação, xerostomia, ageusia, hipogeusia, lesões vesículo bolhosas/maculares, parotidite, erosão, vesícula, pústula, língua fissurada ou despapilada, mácula, pápula, placa, pigmentação, halitose, crosta hemorrágica, necrose, inchaço, eritema, sangramento espontâneo, gengivite necrosante, lesões semelhantes a eritema multiforme, alterações de glândula salivar, gengivite descamativa, papilite lingual transitória, glossite com indentações laterais, mucosite e sensação de queimação. 
Em relação à localização, as manifestações orais foram encontradas em: língua, lábio, mucosa labial, palato, gengiva, mucosa bucal, orofaringe, tonsila e glândulas salivares (SANTOS JA, et al., 2020; CORCHUELO J e ULLOA FC, 2020; TAPIA ROC, et al., 2020). O tratamento com Phtalox ® se mostrou eficaz com rápida recuperação de úlceras bucais, em média 2,37 dias (ORCINA BF e SANTOS PSS, 2021).

\section{CONSIDERAÇÕES FINAIS}

É evidente a importância da anamnese e do exame intraoral para diagnosticar as manifestações orais nos pacientes sob suspeita ou confirmados com a COVID-19, pois pode assegurar um suporte adequado ao paciente acometido. Mais estudos são necessários para comprovar a associação direta entre a COVID-19 e as manifestações orais relatadas.

\section{REFERÊNCIAS}

1. CORCHUELO J, ULLOA FC. Oral manifestations in a patient with a history of asymptomatic COVID-19: Case report. Int $\mathrm{J}$ Infect Dis, 2020; 100: 154-7.

2. GUAN WJ, et al. Clinical Characteristics of Coronavirus Disease 2019 in China. N Engl J Med, 2020; 382(18): 1708-1720.

3. ORCINA BF, SANTOS PSS. Oral manifestation COVID-19 and the rapid resolution of symptoms postPhtalox treatment: a case series. Int. J. Odontostomat, 2021; 15(1): 67-70.

4. SANTOS JA, et al. Oral mucosal lesions in a COVID-19 patient: new signs or secondary manifestations?. Int J Infect Dis, 2020; 97: 326-8.

5. TAPIA ROC, et al. Oral mucosal lesions in patients with SARS-CoV-2 infection. Report of four cases. Are they a true sign of COVID-19 disease?. Spec Care Dentist, 2020; 40(6): 555-60. 
RESUMO SIMPLES: Revisão Narrativa

MANIFESTAÇÕES OROFACIAIS DECORRENTES DA COVID-19: UMA REVISÃO LITERÁRIA

\author{
Júlia Pereira das Chagas ${ }^{1}$ \\ João Victor Nascimento Oliveira ${ }^{1}$ \\ Ana Clara Fernandes Fabiano ${ }^{1}$ \\ Mariana Matos de Souza ${ }^{2}$ \\ Maísa França Teixeira ${ }^{1}$
}

1. Faculdade Evangélica de Goianésia (FACEG), Goianésia - GO.

2. Universidade Veiga de Almeida (UVA), Rio de Janeiro - RJ.

Palavras-chave: SARS-CoV-2, Manifestações bucais, COVID-19.

\title{
INTRODUÇÃO
}

A COVID-19 é uma infecção causada pela doença do novo coronavírus da Síndrome Respiratória Aguda Grave 2 (SARS-CoV-2), infecção que rapidamente se expandiu resultando em um alerta de pandemia global (L. LI et al., 2020). Teve seu início no final de 2019 e sua transmissão é por contato direto com gotículas salivares. A relevância desse tema para a Odontologia se dá devido ao aparecimento de manifestações orofaciais em pacientes que foram acometidos pela COVID-19, levando-se a teoria de que a infecção viral seja responsável por essas alterações bucais (BEHZAD S, et al., 2020).

\section{OBJETIVO}

Revisar a literatura científica artigos disponíveis, com o intuito de compreender o aparecimento de manifestações bucais em pacientes acometidos pelo vírus da COVID-19, e consequentemente identificar as lesões mais prevalentes na cavidade oral.

\section{REVISÃO BIBLIOGRÁFICA}

No decorrer da análise dos artigos referentes ao tema, é possível compreender que os receptores da enzima conversora de angiotensina-2 (ECA2) se tornou o receptor funcional da SARS-CoV-2, representando uma via de entrada mais susceptível a propagação nos sítios anatômicos orais, visto que o vírus tem a capacidade de alterar a microbiota oral, na qual pode-se explicar a variabilidade das manifestações na cavidade bucal (CARDOSO TF, et al., 2020).

As principais manifestações analisadas na literatura foram: lesões aftosas, disgeusia, úlceras, lesões de placa branca, gengivite, xerostomia. No entanto, não há de fato uma conclusão a respeito da relação direta da infecção com as alterações descritas, visto que se deve levar em consideração fatores como comprometimento sistêmico do paciente e possivelmente reações adversas aos fármacos utilizados durante o tratamento (SANABRIA EAP, et al., 2020). Entretanto, a conduta clínica minuciosa do cirurgião dentista é 
algo essencial nesse momento pandêmico; realizar uma anamnese e exame físico detalhado é de suma importância no diagnóstico e tratamento de manifestações que possam emergir em decorrência da infecção viral.

\section{CONSIDERAÇÕES FINAIS}

Em virtude do que foi mencionado, nota-se que há uma interligação no aparecimento das manifestações bucais com a infecção da COVID-19. Porém, ainda se torna primordial mais estudos para entender se são alterações secundárias ao tratamento ou se estão diretamente correferidas ao coronavírus. Contudo, considerando a incidência das lesões, denota-se a importância da presença do cirurgião dentista na equipe multiprofissional durante e após o tratamento do paciente com COVID-19.

\section{REFERÊNCIAS}

1. BEHZAD S, et al. "Extrapulmonary manifestations of COVID-19: Radiologic and clinical overview." Clinical imaging, 2020; 66: 35-41.

2. CARDOSO TF, et al. COVID-19 e a Cavidade Bucal: interações, manifestações clínicas e prevenção. Ulakes Journal of Medicine; 2020; 1: 98-105.

3. LI L, et al. COVID-19 patients' clinical characteristics, discharge rate, and fatality rate of meta-analysis. Journal of medical virology, 2020; 92: 577-583.

4. SANABRIA EAP, et al. Manifestaciones orales y maxilofaciales asociadas a la COVID-19. Revisión de la literatura. Acta Odontológica Colombiana, 2020; 10: 60-80. 


\title{
POLUIÇÃO LUMINOSA: UMA REVISÃO SISTEMÁTICA SOBRE OS IMPACTOS DO AUMENTO DA EXPOSIÇÃO Á LUZ ARTIFICIAL NA SAÚDE HUMANA
}

\author{
Bianca Thiengo Guimarães ${ }^{1}$ \\ José Flávio Giardini Pimenta ${ }^{1}$ \\ Leonardo Victor Lima Dutra Almeida ${ }^{1}$ \\ Lorran Nunes Santana ${ }^{1}$ \\ Marli do Carmo Cupertino ${ }^{1,2}$
}

1. Faculdade Dinâmica do Vale do Piranga (FADIP), Ponte Nova - MG.

2. Universidade Federal de Viçosa (UFV), Viçosa - MG.

Palavras-chave: Poluição luminosa, Saúde pública, Meio ambiente e saúde.

\section{INTRODUÇÃO}

A poluição luminosa pode ser definida como o uso inadequado ou excessivo de luz artificial, desencadeando ofuscamento devido ao brilho excessivo e/ou transgressão de luz devido a luz difusa cair onde não é necessária (FALCHI F, et al., 2016) A poluição luminosa está entre as perturbações ambientais mais crônicas da Terra e tem aumentado nas últimas décadas, devido ao crescente uso de dispositivos eletrônicos ligados ao processo de urbanização e a revolução tecnológica (HOHN C, et al., 2021). Um estudo de 2017 sugere que, em todo o mundo, a poluição luminosa tem aumentado cerca de $2,2 \%$ ao ano, interferindo em vários sistemas humanos (KYBA CCM, et al., 2017).

\section{OBJETIVO}

Analisar as evidências científicas sobre o efeito da exposição excessiva a luz artificial na saúde humana, com enfoque nas principais alterações no organismo humano e os principais tipos de luzes poluentes.

\section{MÉTODO}

Realizou-se uma revisão sistemática seguindo as diretrizes PRISMA, buscando por estudos nas bases PubMed/ Medline, Acervo+ Index base, e Web of Science, com a utilização dos descritores "light (title) AND health" e a palavra-chave "light pollution". Foram incluídos artigos originais publicados nos últimos cinco anos, nos idiomas português e inglês. Foram excluídos artigos de revisão publicados anteriormente a 2016 ou com texto completo indisponível. Vinte artigos foram incluídos na pesquisa.

\section{REVISÃO BIBLIOGRÁFICA}


As exposições mais frequentes são feitas a partir de luzes de dispositivos eletrônicos e artificial a noite (SCHAMACHE MMP, et al., 2021). As características físicas e psicossociais mais abordadas envolveram distúrbios do sono, obesidade, ritmo circadiano, produção de cortisol e melatonina, distúrbios de sistema nervoso central e humor (SHEN J e TOWER J, 2019).

Porém alguns estudos abordaram aspectos relacionados a espermatogênese, aterosclerose, termorregulação, estruturas oculares e doenças cardiovasculares ( $\mathrm{HOHN} \mathrm{C}$, et al., 2021). Evitar a luz ambiente durante o sono, uso de lentes âmbar, filtro azul e cortinas são algumas alternativas para diminuir os efeitos adversos devido a exposição prolongada a luz artificial (XIAO Q, et al., 2020).

\section{CONSIDERAÇÕES FINAIS}

O excesso de exposição a luz artificial está relacionado a efeitos negativos na saúde humana, principalmente relacionados a distúrbios do sono e humor, sendo a luz de dispositivos eletrônicos e a artificial noturna as principais fontes de poluição. Novas pesquisas são necessárias, a fim de estabelecer os tipos de exposição e o tempo de exposição para determinar efeitos indesejáveis e ao mesmo tempo as alternativas para a prevenção de doenças.

\section{REFERÊNCIAS}

1. FALCHI F, et al. The new world atlas of artificial night sky brightness. Science Advances, 2016; 2(6): e1600377.

2. HOHN C, et al. Preliminary Results: The Impact of Smartphone Use and Short-Wavelength Light during the Evening on Circadian Rhythm, Sleep and Alertness. Clocks \& Sleep, 2021; 3(1): 66-86.

3. KYBA CCM, et al. Artificially lit surface of Earth at night increasing in radiance and extent. Science Advances, 2017; 3(11): e1701528.

4. SCHAMACHE MMP. Problemas oculares relacionados ao uso de telas em pacientes pediátricos. Revista Eletrônica Acervo Saúde, 2021; 13(9): e8864.

5. SHEN J, TOWER J. Effects of light on aging and longevity. Ageing Research Reviews, 2019; 53: 100913.

6. XIAO Q, et al. Cross-sectional association between outdoor artificial light at night and sleep duration in middle-to-older aged adults: The NIH-AARP Diet and Health Study. Environmental Research, 2020; 180: 108823. 


\section{ANOMALIAS DENTÁRIAS DE TAMANHO}

Letícia Pontes Nascimento ${ }^{1}$

Híttalo Carlos Rodrigues de Almeida²

Larissa Soderini Ferracciù ${ }^{3}$

Marcela Macedo de Freitas Oliveira ${ }^{3}$

Mirela Caroline Cunha da Cruz ${ }^{4}$

1. Centro Universitário Maurício de Nassau (UNINASSAU), Recife - PE.

2. Universidade de Pernambuco (UPE), Recife - PE.

3. Associação Caruaruense de Ensino Superior (ASCES), Caruaru - PE.

4. Universidade Federal de Pernambuco (UFPE), Recife - PE.

Palavras-chave: Odontologia, Anatomia, Anormalidades dentárias.

\section{INTRODUÇÃO}

As anomalias dentárias advêm de desvios dos processos normativos de crescimento, desenvolvimento ou de diferenciamento da célula, sendo sua etiologia complexa e multifatorial, pois podem possuir origem hereditária, congênita ou adquirida. Assim, as mesmas podem afetar o elemento dentário em sua forma, tamanho, posição, constituição número elou função dos dentes. As manifestações dessas são corriqueiras, sendo de fácil diagnóstico, além de possuir um prognóstico favorável, entretanto torna-se necessária a atuação do cirurgião-dentista para realizar-se o diagnóstico correto e tratamento minimamente invasivo dessas alterações, a fim de devolver ao paciente a funcionalidade, além da estética dentária (ANDRADE CES, et al., 2017).

\section{OBJETIVO}

Realizar uma revisão integrativa da literatura acerca das anormalidades anatômicas relacionadas ao tamanho dentário, assim esta revisão visa resumir de forma concisa e eficaz as questões que circundam o tema proposto.

\section{MÉTODO}

Trata-se de um estudo descritivo, de abordagem qualitativa, do tipo revisão integrativa da literatura. Foram utilizadas as bases BVS, Acervo, LILACS e Scielo para elaboração desta revisão. Usou-se os descritores "Odontologia", "Anatomia" e "Anormalidade Dentárias", sendo escolhidos quatro artigos, tendo como critério de inclusão: artigos em português e inglês, publicados entre 2016 e 2021, foram excluídos os artigos que não supriram os critérios citados anteriormente. 


\section{REVISÃO BIBLIOGRÁFICA}

A alteração no tamanho dentário manifesta-se como: Macrodontia ou Microdontia (REIS JC, et al., 2020). A macrodontia caracteriza-se pela presença de dentes maiores que o padrão, associando-se a distúrbios sistêmicos, pode apresentar dificuldade na erupção e suscetibilidade à cárie, além do aumento de volume. A microdontia caracteriza-se pela redução do volume do dente, esses possuem coroas clínicas curtas (MARTINS NETO RS, et al., 2019).

Essa anomalia ocorre no estágio de morfodiferenciação do desenvolvimento dos dentes e afeta um único ou múltiplos dentes, e o tratamento de ambas prioriza devolver a funcionalidade do elemento e a estética (MAGALHÃES GP, et al., 2019). Sendo relevante realizar a investigação radiográfica, pois essa pode favorecer o diagnóstico precoce dos casos (WANDERLEY AEC, et al., 2019).

\section{CONSIDERAÇÕES FINAIS}

A alteração dentária de tamanho pode se manifestar como macrodontia ou microdontia, sendo essas opostas em suas características principais, visto que enquanto a macrodontia proporciona alterações estéticas e funcionais vinculadas ao aumento do elemento dentário desproporcional, enquanto a manifestação da microdontia é caracterizada pela redução do volume dentário. Seu tratamento deve priorizar proporcionar ao paciente uma harmonia funcional dos elementos dentários e quando possível devolver a estética orofacial.

\section{REFERÊNCIAS}

1. ANDRADE CES, et al. As principais alterações dentárias de desenvolvimento. Rev. Salusvita (Online), 2017; 5(30).

2. MAGALHÃES GP, et al. Diagnóstico de anomalias dentárias em radiografias panorâmicas. Revista Odontológica do Brasil Central, 2019; 28(87).

3. MARTINS NETO RS, et al. Prevalência de anomalias dentárias em radiografias panorâmicas. Arch. Health Invest, 2019; 6(5).

4. REIS JC, et al. Prevalência das anomalias dentárias e alterações ósseas em radiografias panorâmicas de crianças. RGO-Revista Gaúcha de Odontologia, 2020; 68.

5. WANDERLEY AEC, et al. Odontoma composto como fator de impactação dentária: Relato de caso. Revista Eletrônica Acervo Saúde, 2019; (34): e1794. 
RESUMO SIMPLES: Revisão Integrativa

\title{
FATORES QUE VIABILIZAM O SURGIMENTO DE DIABULIMIA E SUAS CONSEQUÊNCIAS NO CORPO DA POPULAÇÃO COM DIABETES TIPO 1
}

\author{
Anna Beatriz Conceição de Souza ${ }^{1}$ \\ Ana Beatriz Ribeiro Queiroz ${ }^{1}$ \\ Dandara Lima Santos ${ }^{1}$ \\ Noeme Agostinho Rocha ${ }^{2}$ \\ Mayla Karla de Souza Monteiro²
}

1. Universidade Federal do Pará (UFPA), Belém - PA.

2. Universidade da Amazônia (UNAMA), Belém - PA.

Palavras-chave: Diabulimia, Diabetes Mellitus tipo 1, Cetoacidose diabética.

\section{INTRODUÇÃO}

A diabulimia, é um termo associado ao diabetes mellitus tipo 1 e a bulimia nervosa para um Transtorno Alimentar não especificado, a qual se tem a restrição da aplicação de insulina, com a dose desse hormônio reduzida tem-se a quebra de gordura e o excesso de glicose eliminada na urina (KARASTOGIANNIDOU C, et al., 2021), com a finalidade perda de peso ou prevenir o ganho, na forma de purgação, que vem em conjunto com a atividade física em excesso, restrição alimentar e a utilização de métodos laxativos, acarretando a ingestão excessiva alimentar (YAHYA AS, et al., 2020).

\section{OBJETIVO}

Definir quais os fatores que propiciam o surgimento do transtorno alimentar de diabulimia e as consequências no organismo dos indivíduos portadores de diabetes tipo 1 acometidos com essa desordem comportamental.

\section{MÉTODO}

Revisão integrativa da literatura, de abordagem qualitativa. Tiveram como critérios de adesão artigos publicados nas bases de dados PubMed e Biblioteca Virtual em Saúde (BvS); a qual foram datados nos anos entre 2020 e 2021; nos idiomas português, espanhol e inglês. Foram excluídas monografias, devido às normas da revista e pesquisas acadêmicas a qual abordavam Diabetes Mellitus tipo 2, e não correlacionavam transtornos alimentares com Diabetes Mellitus tipo1.

\section{REVISÃO BIBLIOGRÁFICA}


Fatores como o monitoramento alimentar e o manejo da diabetes para controle da glicemia, além dos sentimentos negativos são um dos principais entraves que influenciam na autoimagem e a saúde mental do indivíduo (COLEMAN SE e CASWELL N, 2020; HERNÁNDEZ RJ e LEDÓN LL, 2020). Ademais, a insatisfação corporal acoplada com a saúde psicológica do paciente, acarreta supressão ou omissão de insulina, ou seja, a diabulimia (YAHYA AS, et al., 2020), porém a sua diminuição resulta em alterações metabólicas, pois os tecidos como não conseguem utilizar a glicose presentes na corrente sanguínea, metabolizam gorduras e com essa quebra, tem-se o aumento de quadros de cetoacidose diabética, nocivos ao organismo (RIBEIRO LB, et al., 2021).

\section{CONSIDERAÇÕES FINAIS}

Portanto, os fatores a qual são acometidos a população com diabetes no manejo e controle da doença, influencia tanto a saúde mental quanto o modo como eles se veem, acarretando quebras de gordura devido a diabulia, a qual os produtos são maléficos ao corpo do indivíduo.

\section{REFERÊNCIAS}

1. COLEMAN SE, CASWELL N. Diabetes and eating disorders: an exploration of "Diabulimia". BMC Psychology, 2020; 8(1): e32967730

2. HERNÁNDEZ RJ, LEDÓN LL. Hacia un definición y consenso del término "diabulimia." Revista cubana de endocrinologia, 2020; 31(1): e156.

3. KARASTOGIANNIDOU C, et al. The Diabetes Eating Problem Survey-Revised (DEPS-R) in a Greek Adult Population with Type 1 Diabetes Mellitus: Model Comparison Supporting a Single Factor Structure. Nutrients, 2021; 13(7): e2375.

4. RIBEIRO LB, et al. A relação entre a mulher com diabetes e o seu corpo: o risco da diabulimia. Escola Anna Nery, 2021; 25(4): e20200270.

5. YAHYA AS, et al. Early Diagnosis and Management of Bulimia Nervosa in Type 1 Diabetes. The Primary Care Companion For CNS Disorders, 2020; 22(6): e33351292. 


\title{
ASPECTOS DIETÉTICOS ASSOCIADOS AO CÂNCER GÁSTRICO: REVISÃO BIBLIOGRÁFICA NARRATIVA
}

\author{
Clara Mariana Leme de Andrade ${ }^{1}$ \\ Suênia Marcele Vitor de Lima ${ }^{1}$ \\ Lívia Maria Gomes de Melo ${ }^{1}$ \\ Sarah Mendes Fabrício ${ }^{1}$
}

1. Universidade Federal de Pernambuco (UFPE), Recife - PE.

Palavras-chave: Câncer, Nutrição, Estômago.

\section{INTRODUÇÃO}

Câncer gástrico (CG) é uma das neoplasias mais comuns mundialmente, sendo mais predominante em homens e pessoas de idade mais avançada (LEITE FRL, et al., 2021). Além de ter sintomas comuns, levando o paciente a suspeitar de outras patologias com sintomatologia semelhante, atrasando o diagnóstico correto (SANTOS GRAC, et al., 2020), é uma doença de etiologia multifatorial, podendo ser desencadeada por fatores genético, bem como fatores ambientais, tais como: etilismo, fumo, infecção bacteriana (Helicobacter pylori), sedentarismo, exposição crônica a toxinas e maus hábitos alimentares (consumo excessivo de Sódio e glicose) (RAMOS MFKP, et al., 2019).

\section{OBJETIVO}

Avaliar através da revisão bibliográfica narrativa a influência dos variados padrões alimentares como fator preventivo ou desencadeador do CG, explorando as relações de causa e efeito que a dieta da população pode ter contribuído para a incidência dessa patologia.

\section{REVISÃO BIBLIOGRÁFICA}

Com ação preventiva ao CG, temos os seguintes componentes alimentares: Vitamina C, presente em frutas cítricas, previne por inibir formação de Nitrosaminas e age contra radicais livres oxidativos, que são mutagênicos; Alimentos antioxidantes, como frutas e vegetais, protegem o epitélio gástrico e atenuam a agressão da H. pylori; Flavonóides, encontrados em frutas, legumes e vinho, modulam o metabolismo de carcinogênicos inibindo a proliferação celular; Flavona, presente em frutas e hortaliças, inibem processos celulares relacionados à carcinogênese.

Em contrapartida, com ações carcinogênicas, temos: Grande ingestão de carboidratos e lipídios, pois a longo prazo leva a um quadro de obesidade, e o excesso de gordura estimula a proliferação celular através de uma super regulação do fator de crescimento semelhante à insulina-1, além da gordura produzir citocinas pró inflamatórias que levam à inflamação crônica; Alto consumo de carne vermelha, por ter alto teor de aminas heterocíclicas, e compostos $\mathrm{N}$-nitrosos, que são substâncias capazes de iniciar a carcinogênese por interagir 
com o DNA; Excesso de sal, pois danifica a mucosa, facilitando a ação de carcinogênicos (LEITE FRL, et al., 2021; SANTOS GRAC, et al., 2020).

\section{CONSIDERAÇÕES FINAIS}

O câncer gástrico ainda é uma patologia com predominância de diagnóstico em período avançado, tornando o tratamento e o pós-cirúrgico situações ainda mais delicadas, pois o paciente estará com o tecido gástrico mais lesionado. É importante conscientizar que obesidade e hipertensão não são as únicas consequências de uma alimentação desequilibrada. Para melhor prognóstico dessa doença com alta mortalidade, é ideal buscar ajuda nos primeiros sintomas.

\section{REFERÊNCIAS}

1. LEITE FRL, et al. Os fatores de risco e seus mecanismos na gênese do câncer gástrico. Revista Eletrônica Acervo Saúde, 2021; 13(2): e5627.

2. RAMOS MFKP, et al. Câncer gástrico em adultos jovens: um grupo de pior prognóstico?. Revista do Colégio Brasileiro de Cirurgiões, 2019; 46(4): e20192256.

3. SANTOS GRAC, et al. A situação do câncer gástrico em Salvador, no Brasil e no mundo. Revista Eletrônica Acervo Saúde, 2020; 53: e3629. 


\title{
ALEITAMENTO MATERNO E PRÁTICAS DE INTRODUÇÃO AO GLÚTEN COMO FATORES RELACIONADOS À INCIDÊNCIA DE DOENÇA CELÍACA
}

\author{
Dafne Cristine Lima de Oliveira ${ }^{1}$ \\ Laisy Nazaré Araújo da Cunha ${ }^{1}$ \\ Vânia Maria Barboza da Silva ${ }^{1}$
}

1. Universidade Federal do Pará (UFPA), Belém - PA.

Palavras-chave: Aleitamento materno, Doença celíaca, Glúten.

\section{INTRODUÇÃO}

Classificada como autoimune, a Doença Celíaca (DC) desenvolve-se a partir do consumo de glúten por pessoas com genética suscetível (BENÍTEZ-PÁEZ A, et al., 2020). Sua incidência expandiu nas últimas décadas, aumentando o interesse na identificação de fatores de risco, a fim de possibilitar a prevenção (MEIJER C, et al., 2018).

Ademais, estudos comprovam a importância da amamentação e introdução alimentar adequada nos primeiros anos de vida, pois refletem significativamente na saúde dos indivíduos futuramente, sendo capaz de interferir no surgimento de diversas doenças (MOZETIC RM, et al., 2016). Assim, este estudo trará as perspectivas atuais para a prevenção da DC.

\section{OBJETIVO}

Elucidar, com base na literatura científica, se as práticas alimentares, desde o aleitamento materno até a introdução ao glúten, são associadas às chances de o indivíduo desenvolver a Doença Celíaca posteriormente.

\section{REVISÃO BIBLIOGRÁFICA}

Estudos iniciais concluíram haver uma "janela de oportunidade" (4 a 6 meses) para introdução ao glúten a fim de diminuir os riscos para a doença. Entretanto, estudos prospectivos posteriores mostraram que nem a duração da amamentação nem o momento de introdução ao glúten influenciam (MEIJER C, et al., 2018). Em contrapartida, estudos observacionais retrospectivos continuam evidenciando que crianças amamentadas no período de introdução ao glúten possuem menor risco de serem afetadas pela DC (MARTíN-MASOT R, et al., 2020; BENÍTEZ-PÁEZ A, et al., 2020).

Encontrou-se ainda que a introdução ao glúten em quantidades consideráveis a partir dos 4 meses de idade pode reduzir a prevalência de DC, podendo ser uma importante estratégia preventiva (LOGAN K, et al., 2020; POPP A e MÄKI M, 2019). É importante salientar que as diferentes composições de leite materno podem explicar parcialmente a disparidade de resultados entre os estudos (BENÍTEZ-PÁEZ A, et al., 2020). 
E ainda que ela exista, a Sociedade Europeia de Gastrenterologia Pediátrica, Hepatologia e Nutrição recomenda a introdução de baixas doses de glúten nos primeiros meses de vida (LOGAN K, et al., 2020).

\section{CONSIDERAÇÕES FINAIS}

Dessa forma, os dados conflitantes demonstram a necessidade de se realizar outros estudos, com ferramentas epidemiológicas mais precisas, a fim de chegar a resultados acurados acerca da prevenção da DC por meio da amamentação e/ou da introdução adequada ao glúten. Fazendo com que, assim, os indivíduos geneticamente predispostos apresentem menor risco de desenvolver a doença, e tenham uma melhor qualidade de vida.

\section{REFERÊNCIAS}

1. BENÍTEZ-PÁEZ A, et al. Breast-Milk Microbiota Linked to Celiac Disease Development in Children: A Pilot Study From the PreventCD Cohort. Front Microbiol, 2020; 11(1335): 1-12.

2. LOGAN K, et al. Gluten Introduction and Celiac Disease in the EAT Study: A Prespecified Analysis of the EAT Randomized Clinical Trial. JAMA Pediatr, 2020; 174(11): 1041-1047.

3. MARTÍN-MASOT R, et al. The Role of Early Programming and Early Nutrition on the Development and Progression of Celiac Disease: A Review. Nutrients, 2020; 12(3427): 1-18.

4. MEIJER C, et al. Celiac Disease Prevention. Front Pediatr, 2018; 6(368): 1-13.

5. MOZETIC RM, et al. A importância da nutrição nos primeiros mil dias. Revista Eletrônica Acervo Saúde, 2016; 8(2): 876-884.

6. POPP A, MÄKI M. Changing Pattern of Childhood Celiac Disease Epidemiology: Contributing Factors. Front Pediatr, 2019; 7(357): 1-16. 


\title{
OS EFEITOS DO USO DE ALIMENTOS ULTRAPROCESSADOS COMO ESTRATÉGIA DE RECOMPENSA ALIMENTAR NO COMPORTAMENTO ALIMENTAR INFANTIL
}

\author{
Ana Beatriz Ribeiro Queiroz ${ }^{1}$ \\ Anna Beatriz Conceição de Souza ${ }^{1}$ \\ Dandara Lima Santos ${ }^{2}$ \\ Noeme Agostinho Rocha ${ }^{1}$ \\ Mayla Karla de Souza Monteiro ${ }^{3}$
}

1. Universidade Federal do Pará (UFPA), Belém - PA.

2. Universidade da Amazônia (UNAMA), Ananindeua - PA.

3. Universidade da Amazônia (UNAMA), Belém - PA.

Palavras-chave: Recompensa, Comportamento alimentar, Crianças.

\section{INTRODUÇÃO}

A recompensa alimentar é uma estratégia que consiste no uso de determinados alimentos como recompensa para estimular a aceitação e ingestão de alimentos saudáveis por crianças, prática muito utilizada por diversas famílias. Entretanto, esse método baseia-se principalmente no oferecimento de alimentos não saudáveis como recompensa para alcançar esse objetivo, em especial o uso de ultraprocessados (BROILO MC, et al., 2017).

Tendo em vista o papel dos pais como principais promotores da alimentação das crianças e destacando a infância como um período de construção de hábitos alimentares, a utilização de alimentos ultraprocessados por meio dessa estratégia pode ter impactos negativos na formação do comportamento alimentar infantil (YEE AZH, et al., 2017).

\section{OBJETIVO}

Revisar a literatura científica com o objetivo de analisar e identificar os efeitos que a recompensa alimentar baseada no uso de alimentos ultraprocessados têm na formação do comportamento alimentar infantil.

\section{MÉTODO}

Trata-se de uma revisão integrativa. Foi realizada uma busca eletrônica nas bases de dados Scielo e PubMed, delimitando-se a estudos publicados entre 2017 e 2021, nos idiomas inglês e português, excluindo aqueles que não se relacionassem com a temática e estivessem fora do recorte temporal. Os descritores utilizados foram: crianças, alimentos e recompensa. Ao fim, foram selecionados 4 estudos para análise. 


\section{REVISÃO BIBLIOGRÁFICA}

Verificou-se que o uso de alimentos não saudáveis como recompensa, sobretudo ultraprocessados, está associado a formação de hábitos alimentares inadequados em crianças, pois contribui para que se crie uma predileção ao alimento usado como recompensa, desenvolvendo preferência ao consumo de ultraprocessados desde cedo pelo público infantil, apresentando-se como fator de risco para 0 desenvolvimento de sobrepeso e obesidade (SANTOS KF, et al., 2021; YEE AZH, et al., 2017).

Além disso, a associação da comida ultraprocessada como um prêmio pode fomentar a representação do alimento como regulador emocional, resultando em maior suscetibilidade ao comer emocional e aumentar a procura por esses alimentos no futuro (MAŁACHOWSKA A e JEŻEWSKA-ZYCHOWICZ M, 2021).

\section{CONSIDERAÇÕES FINAIS}

Portanto, o uso de alimentos ultraprocessados como recompensa tem resultados contrários ao esperado pelas famílias, pois ao invés de ser mecanismo de incentivo ao consumo alimentar adequado, a recompensa alimentar pode ter impactos prejudiciais na formação do comportamento alimentar infantil, resultando em maior propensão ao comer emocional e obesidade. Sendo assim, torna-se importante o desenvolvimento de mais estudos direcionados a compreender os efeitos dessa estratégia.

\section{REFERÊNCIAS}

1. BROILO MC, et al. "What can I do when he/she doesn't want to eat?": Maternal strategies for ensure children's food consumption in early childhood. Appetite, 2017; 116: 575-583.

2. MAŁACHOWSKA A, JEZZEWSKA-ZYCHOWICZ M. Does Examining the Childhood Food Experiences Help to Better Understand Food Choices in Adulthood?. Nutrients, 2021; 13(3): 983.

3. SANTOS KF, et al. Práticas parentais e comportamento alimentar da criança. Texto \& Contexto Enfermagem, 2021; 30: e20200026.

4. YEE AZH, et al. The influence of parental practices on child promotive and preventive food consumption behaviors: a systematic review and meta-analysis. International Journal of Behavioral Nutrition and Physical Activity, 2017; 14(1): 47. 


\title{
BENEFÍCIOS DA VITAMINA D NO SISTEMA IMUNOLOGICO DE PESSOAS COM COVID-19: UMA REVISÃO DA LITERATURA
}

\author{
Joelma Cunha Pereira ${ }^{1}$ \\ Mayara Matos Nascimentos ${ }^{1}$ \\ Liejy Agnes dos Santos Raposo Landim ${ }^{1}$
}

1. Centro Universitário Santo Agostinho (UNIFSA), Teresina - PI.

Palavras-chave: Vitamina D, Imunidade, Infecção por coronavírus.

\section{INTRODUÇÃO}

A atual pandemia causada pelo COVID-19 está associada a uma síndrome respiratória aguda causada pelo Novo Coronavírus (SARS-CoV-2), (BRASIL, 2020). O SARS-CoV-2 detém genoma de RNA de fita simples de sentido positivo pertencente ao gênero Betacoronavírus, possui elevada transmissibilidade e sintomas como febre, mal-estar, tosse seca, e até mesmo pneumonia, levando a morte (CHAN JF, et al., 2020). O recurso terapêutico dá se através de vacinas licenciadas pelos órgãos reguladores (RAWATT K, et al., 2021). Outra alternativa de tratamento preventivo e/ou adjuvante é o uso da vitamina $D$, pois a mesma se faz útil na redução do risco associado às mortes por COVID-19 (MOOZHIPURATH RK, et al., 2020).

\section{OBJETIVO}

Revisar a literatura científica, a fim de demonstrar a importância da vitamina $D$ na prevenção do sistema imunológico, e na contribuição nos possíveis mecanismos de ação em relação à infecção por COVID-19.

\section{MÉTODO}

Trata-se de uma revisão da literatura integrativa. A busca dos artigos foi realizada nas bases de dados, PubMED e Google Acadêmico, utilizado descritores em português "Vitamina D", "sistema imunológico" cadastrados nos Descritores em Ciência da Saúde (DeCS). Os critérios de inclusão foram artigos originais, nos idiomas português e inglês; publicados entre os anos de 2020 a 2021. Os critérios de exclusão foram publicações de artigos não relacionados ao tema.

\section{REVISÃO BIBLIOGRÁFICA}

Existem vias nas quais a vitamina D (VD) reduz possíveis infecções virais e microbianas, e como resultado também a diminuição da mortalidade, a mesma utiliza três mecanismos: barreira física, imunidade celular natural e adaptativa (ALI N, 2020). Visto que, em certo estudo 50 pacientes submetidos à suplementação da VD, somente 1 precisou de internação em UTI (2\%). Já $n=26$ pacientes não sujeitados a VD, 13 necessitaram 
de UTI (50\%), ( $\mathrm{p}<0.001)$. O grupo tratado com VD se mostrou benéfico quanto à mortalidade, não havendo registro de óbitos, já o outro grupo evidenciou 2 óbitos (CASTILLO ME, et al., 2020).

\section{CONSIDERAÇÕES FINAIS}

Foi possível observar que as células do sistema imunológico são capazes de sintetizar e responder à VD, podendo ser útil no tratamento preventivo e adjuvante do COVID-19. Portanto, são necessários estudos mais aprofundados sobre o coronavírus e a suplementação de VD, bem como a atuação dessa vitamina frente às novas cepas do COVID-19.

\section{REFERÊNCIAS}

1. ALI N, Papel da vitamina $D$ na prevenção da infecção, progressão e gravidade da COVID-19, Jornal de infecção e saúde pública, 2020; 13(10): 1373-1380.

2. BRASIL. Ministério da Saúde. Secretaria de Atenção Primária à Saúde. Protocolo de Manejo Clínico do Coronavírus (COVID-19) na Atenção Primária à Saúde, 2020; 9(1): 35-40.

3. CASTILLO ME, et al. Efeito do tratamento com calcifediol e melhor terapia disponível versus melhor terapia disponível na admissão à unidade de terapia intensiva e mortalidade entre pacientes hospitalizados por COVID-19: Um estudo clínico piloto randomizado. O Jornal de bioquímica de esteroides e biologia molecular, 2020; 203: e105751.

4. CHAN JF, et al. Caracterização genômica do novo coronavírus patogênico humano de 2019 isolado de um paciente com pneumonia atípica após visitar Wuhan. Emerg Microbes Infect., 2020; 9(1): 221-236.

5. MOOZHIPURATH RK, et al. Evidência do papel protetor da radiação ultravioleta $B$ (UVB) na redução de mortes por covid-19. Sci Rep., 2020; 10(1): 17705.

6. RAWAT K, et al. Covid-19 vacina: uma atualização recente no gasoduto vacinas, suas estratégias de design e desenvolvimento. Eur J Pharmacol., 2021; 5(892): 173751. 
RESUMO SIMPLES: Revisão Integrativa

\title{
MANIFESTAÇÕES ORAIS, DIAGNÓSTICO E TRATAMENTO PARA HANSENÍASE
}

\author{
Gabryel Fernandes da Silva ${ }^{1}$ \\ Maria Alice da Silva Souza ${ }^{1}$ \\ Carolina Pereira da Silva ${ }^{1}$ \\ Shamara Pinto Ferreira da Cruz ${ }^{1}$ \\ Isaque Ferreira Soares ${ }^{2}$
}

1. Universidade de Pernambuco (UPE), Recife - PE.

2. Centro Universitário Facol (UniFacol), Vitória de Santo Antão - PE.

Palavras-chave: Hanseníase, Diagnóstico, Saúde bucal.

\section{INTRODUÇÃO}

A Hanseníase é uma doença infecciosa, crônica e endêmica que apresenta uma diversidade de sintomas clínicos neurológicos e dermatológicos (FILGUEIRA AA, et al., 2020; LOPES FC, et al., 2021). Além das modificações sistêmicas, manifestações orais podem surgir e tornam-se ainda mais agravantes diante da falta de acesso aos serviços públicos odontológicos e a falta de conhecimento apresentada por grande parte dos acometidos, desse modo, a hanseníase apresenta-se como um importante problema de saúde pública, pois trata-se de uma doença com alto potencial incapacitante e por muitos negligenciada (ALMEIDA ZM, et al., 2017; LOPES FC, et al., 2021; SANTOS AR e IGNOTTI E, 2020).

\section{OBJETIVO}

Analisar por meio de uma revisão integrativa as principais manifestações orais, estratégias diagnósticas e tratamentos para pacientes acometidos pela hanseníase como um importante fator para a redução da disseminação do bacilo de Hansen na sociedade.

\section{MÉTODO}

O estudo baseou-se em uma revisão integrativa da literatura na qual foi realizada a seleção dos descritores: Hanseníase, Diagnóstico e Saúde Bucal a partir da plataforma Descritores em Ciências da Saúde (DeCS) com subsequente cruzamento nas bases de dados, Medline, Lilacs e Scielo entre o período de 2016 a 2021, levando-se a exclusão de artigos que não atendiam a temática proposta o que resultou na seleção final de 4 artigos.

\section{REVISÃO BIBLIOGRÁFICA}


O mau estado da cavidade oral representa um importante fator de risco para a transmissão da doença, além disso, é comum a presença de cárie e sangramento gengival que ocorrem em decorrência das limitações motoras (ALMEIDA ZM, et al., 2021). Embora já existam diversas formas de diagnóstico como detecção através de exames de mucosa oral por meio de métodos laboratoriais incluindo exames anatomopatológicos, Reação em Cadeia da Polimerase (PCR) e tratamento com a Poliquimioterapia (PQT) a escolaridade deficiente e o atraso no diagnóstico são alguns dos fatores que levam a evasão do tratamento e a persistência do preconceito na sociedade (ALMEIDA ZM, et al., 2017; LOPES FC, et al., 2021).

\section{CONSIDERAÇÕES FINAIS}

Além de um bom manejo e orientação quanto a necessidade de manutenção de um tratamento contínuo contra a doença, destaca-se a importância na adoção de um plano de tratamento odontológico adequado com relação a saúde bucal dos pacientes, uma vez que as lesões na mucosa oral podem ser uma importante fonte para transmissão do bacilo.

\section{REFERÊNCIAS}

1. ALMEIDA ZM, et al. Oral health conditions in leprosy cases in hyperendemic area of the Brazilian Amazon. Revista do Instituto de Medicina Tropical de São Paulo, 2017; 59: e50.

2. FILGUEIRA AA, et al. Relação da saúde bucal com reações hansênicas em município hiperendêmico para hanseníase. Cadernos Saúde Coletiva, 2020; 28(1): 44-55.

3. LOPES FC, et al. Hanseníase no contexto da Estratégia Saúde da Família em cenário endêmico do Maranhão: prevalência e fatores associados. Ciência \& Saúde Coletiva, 2021; 26(5):1805-1816.

4. SANTOS AR, IGNOTTI E. Prevenção de incapacidade física por hanseníase no Brasil: análise histórica. Ciência \& Saúde Coletiva, 2020; 25(10): 3731-3744. 


\title{
PAPEL DO ZINCO NA IMUNIDADE DO ORGANISMO EM TEMPOS DE COVID-19: UMA REVISÃO DA LITERATURA
}

\author{
Joelma Cunha Pereira ${ }^{1}$
}

Mayara Matos Nascimento ${ }^{1}$

Liejy Agnes dos Santos Raposa Landim ${ }^{1}$

1. Centro Universitário Santo Agostinho (UNIFSA), Teresina - PI.

Palavras-chave: Micronutrientes, Zinco, Imunidade.

\section{INTRODUÇÃO}

O COVID-19 trata-se de uma infecção viral causada pelo Coronavírus 2 da Síndrome Respiratória Aguda Grave. A doença surgiu em Wuhan, China, em dezembro de 2019, se espalhando-se e tornando-se em uma pandemia mundial (KIMBALL A, et al., 2020). Certos micronutrientes têm sido estudados afim de minimizar os efeitos da COVID-19, com destaque para o zinco, um mineral que exerce função antiviral, e é importante para a ação de mais de 300 enzimas, além de participar de processos celulares de sinalização, proliferação, diferenciação e viabilidade celular. O zinco é adotado principalmente na modulação da função imunológica, assim como, na resposta imune inata e adaptativa (SANNA A, et al., 2018).

\section{OBJETIVO}

Revisar a literatura cientifica, a fim de descrever o papel fisiológico do zinco e o possível benefício do uso de suplementação para a melhora da imunidade na prevenção e tratamento da Covid-19.

\section{MÉTODO}

Realizou-se uma revisão integrativa, em que, a busca foi executada nas bases de dados PubMed, Google Acadêmico, Scielo, no período do mês de outubro. A análise resultou-se de 4 artigos, incluindo artigos dos últimos 5 anos e excluindo os que não atendessem a temática planejada, usando como descritores: Micronutrientes, zinco, imunidade; infecção por coronavírus.

\section{REVISÃO BIBLIOGRÁFICA}

O zinco é considerado como o potencial tratamento de suporte na terapia da infecção por COVID-19 devido ao seu efeito imunomodulador, bem como ao efeito antiviral direto (ZHANG L, \& LIU Y, 2020). O consumo de até $50 \mathrm{mg}$ de zinco diariamente pode permitir função protetora contra vírus, como o novo coronavírus e a influenza, devido sua participação na modulação imunológica e na resposta à infecção viral (GASMI A, et al., 2020). Quanto à Covid-19, observou-se em um estudo de quatro casos que houve a melhora dos sintomas da doença, e os participantes aumentaram as doses de zinco à medida da progressão dos sintomas (FINZI E, 2020). 


\section{CONSIDERAÇÕES FINAIS}

O zinco contém mecanismos de inibição da replicação viral, ação imunomoduladora e anti-inflamatória. Além disso, a suplementação desse mineral em pacientes com COVID-19 diminui os sintomas causados pelo virus, e o mesmo sendo alvo de ensaios clínicos que ainda estão em desenvolvimento.

\section{REFERÊNCIAS}

1. FINZI E. Tratamento de SARS-CoV-2 com sais de zinco orais em altas doses: um relatório sobre quatro pacientes. International Journal of Infectious Diseases, 2020; 99: 307-309.

2. GASMI A, et al. Status do zinco e autoimunidade: uma revisão sistemática e meta-análise. Clinical Immunology, 2020; 215: e108409.

3. KIMBALL A, et al. Infecções assintomáticas e pré-sintomáticas por SARS-CoV-2 em residentes de uma unidade de enfermagem especializada em cuidados prolongados - King County, Washington, março de 2020. MMWR. Relatório semanal de morbidade e mortalidade, 69(13): 377-381.

4. SANNA A, et al. Status do zinco e autoimunidade: uma revisão sistemática e meta-análise. Nutrients. 2018; 10(1):68

5. ZHANG L e LIU Y. Intervenções potenciais para novos coronavírus na China: uma revisão sistemática. Journal of medical virology, 2020; 92(5): 479-490. 
RESUMO SIMPLES: Revisão Integrativa

\title{
ASSISTÊNCIA E MANEJO ODONTOLÓGICO PARA PACIENTES COM SÍNDROME DE DOWN
}

\author{
Maria Alice da Silva Souza ${ }^{1}$ \\ Melissa Noêmia Barbosa da Silva ${ }^{1}$ \\ Julia Soledade Vieira de Mello ${ }^{1}$ \\ Carolina Pereira da Silva ${ }^{1}$ \\ Isaque Ferreira Soares ${ }^{2}$
}

1. Universidade de Pernambuco (UPE), Recife - PE.

2. Centro Universitário Facol (UNIFACOL), Vitória de Santo Antão - PE.

Palavras-chave: Assistência odontológica para pessoas com deficiência, Síndrome de Down, Saúde bucal.

\section{INTRODUÇÃO}

A Síndrome de Down (SD) é uma alteração genética trissomial que afeta o par cromossômico 21 e que resulta em diversas condições físicas, mentais e comportamentais (PINI DM, et al., 2016). Além dessas características neuropsíquicas e sistêmicas, os pacientes com SD apresentam particulares alterações orofaciais como atraso no desenvolvimento craniofacial, erupção dentária tardia, grande acúmulo de placa bacteriana, controle deficiente de lábios e língua além de apresentar um risco aumentado para os quadros de respiração bucal e má oclusão (PEINADO NR, et al., 2018). Dessa forma, destaca-se que o manejo odontológico adequado é uma importante estratégia para a promoção da saúde bucal desses pacientes (JENSEN KM, et al., 2021).

\section{OBJETIVO}

Analisar por meio de uma revisão integrativa da literatura a importância do manejo odontológico adequado para pacientes com Síndrome de Down na prática odontológica como uma ferramenta estratégica para o cuidado e a promoção da saúde integral desses pacientes.

\section{MÉTODO}

Realizou-se uma revisão integrativa a partir do cruzamento dos descritores: Assistência Odontológica para Pessoas com Deficiência, Síndrome de Down e Saúde bucal, nas bases de dados BVS, Scielo e busca livre na Acervo+ Index base no período de 2016 a outubro de 2021, excluindo-se do resumo os artigos que não atendiam a temática proposta, o que possibilitou a seleção final de 5 artigos.

\section{REVISÃO BIBLIOGRÁFICA}


Pacientes com SD apresentam diversas alterações bucais, principalmente devido aos maus hábitos alimentares, menor fluxo salivar e desenvolvimento motor, o que exige uma atenção quanto à saúde bucal desses indivíduos (VARGAS-RAMÍREZ J, et al., 2021; ARAÚJO DGS, et al., 2019). Para pacientes na primeira infância, recomenda-se a realização de consultas odontológicas antes da erupção dentária, o que permite identificar comportamentos habituais como sucção não nutritiva e posicionamento lingual, ademais, para o manejo dos pacientes, recomenda se a realização dos procedimentos com o menor tempo de cadeira possível, profilaxia antibiótica para pacientes cardiopatas, além de promover a estabilização de cabeça e tronco para evitar a realização de movimentos bruscos (BRASIL, 2019).

\section{CONSIDERAÇÕES FINAIS}

É fundamental que mais condutas sejam introduzidas no cuidado para pessoa com deficiência, sobretudo, no momento da prática odontológica, uma vez que o manejo individualizado pelo cirurgião-dentista para os portadores da síndrome de Down permite realizar consultas com menores intercorrências e minimiza potenciais complicações orais e sistêmicas, além de contribuir para a promoção de uma melhor qualidade de vida para esses pacientes.

\section{REFERÊNCIAS}

1. ARAÚJO, DGS et al. Aspectos nutricionais de portadores de Síndrome de Down: Uma revisão bibliográfica. Revista Eletrônica Acervo Saúde, 2019; 21: e562

2. BRASIL. Manual do Ministério da Saúde. 2019. Disponível em: https://bvsms.saude.gov.br/bvs/publicacoes/guia_atencao_saude_bucal_pessoa_deficiencia.pdf.

Acessado em: 15 de outubro de 2021.

3. JENSEN, KM. et al. Authors' Response to 'Importance of Oral Health for Adolescents and Adults With Down Syndrome". American Journal of Preventive Medicine, 2021; 61(4): 213.

4. PEINADO NR, et al. A study of the dental treatment needs of special patients: Cerebral paralysis and Down syndrome. European journal of paediatric dentistry, 2018; 19(3): 233-238.

5. PINI DM, et al. Avaliação da saúde bucal em pessoas com necessidades especiais. Einstein (São Paulo), 2016; 14(4): 501-507.

6. VARGAS-RAMÍREZ J, et al. Estrategias lúdicas para mejorar la higiene bucal en una población con síndrome de Down. Hacia la Promoción de la Salud, 2021; 26(2): 23-37. 


\title{
ATENDIMENTO ODONTOLÓGICO PARA PACIENTES AUTISTAS: UMA JORNADA ADAPTATIVA
}

\author{
Alana Beatriz Ferreira Lucena ${ }^{1}$ \\ Mariana de Moraes Corrêa Perez ${ }^{1}$
}

1. Universidade Federal de Pernambuco (UFPE), Recife - PE.

Palavras-chave: Autismo, Saúde bucal, Manejo clínico.

\section{INTRODUÇÃO}

O autismo é uma condição bastante complexa, no qual diversos segmentos da vida do indivíduo são afetados, como o convívio social, a cognição, linguagem e até o desenvolvimento motor. Tal dificuldades pode variar a depender do grau do autismo que compreende o nível de comprometimento de uma determinada pessoa (SANT'ANNA LFC, et al., 2017). O Transtorno do Espectro Autista (TEA) tem um caráter heterogêneo, uma vez que sua etiologia é multifatorial (MARQUES VG, et al., 2021).

As principais características do paciente com TEA são dificuldades no convívio social, comunicação e uma série limitada de comportamentos e interesses (SILVA MJL, et al., 2019). É importante que o atendimento odontológico para pacientes autistas seja colocado em evidência, para que assim a comunidade profissional de cirurgiões dentistas possa construir o interesse pelo estudo dos métodos adaptativos de atendimento em consultório para esses pacientes que precisam de um manejo personalizado e, assim, oferecer um atendimento de qualidade (SANTANA LM, et al., 2020).

\section{OBJETIVO}

Apresentar métodos adaptativos para atendimento odontológico de crianças com autismo a partir de uma revisão de literatura voltada para o autismo e a odontologia, visando a popularização da temática entre os profissionais da área.

\section{REVISÃO BIBLIOGRÁFICA}

Entre os métodos mais aceitos pelos pacientes autistas na facilitação do atendimento odontológico, em primeiro plano, destacou-se a familiarização com o ambiente desde pequeno, de preferência, nos mesmos dias, horários e pelo mesmo profissional da área (SANTANA LM, et al., 2020).

Métodos de abordagem específicos para pessoas com TEA como TEACH, ABA, PECS e MV também têm sido colocados cada vez mais em prática na clínica odontológica, acrescentando efetivamente na comunicação profissional com paciente e no, consequentemente, na fluidez do tratamento. A orientação dos pais por parte dos cirurgiões dentistas também é um promotor de saúde bucal e também método efetivo para evitar procedimentos mais demorados no consultório odontológico (SANTANA LM, et al., 2020). A técnica dizer-mostrar-fazer também obtém resultados positivos no manejo do paciente autista, uma vez que eles possuem facilidade de compreender cronogramas (SANTANA LM, et al., 2020). 


\section{CONSIDERAÇÕES FINAIS}

Ao decorrer da análise dos registros literários, é responsabilidade do cirurgião dentista dispor, não apenas dos métodos convencionais de atendimento odontológico, mas também das formas alternativas adaptadas para pacientes com TEA. Assim, fatores que possam atrapalhar o desenvolvimento do paciente na clínica odontológica devem ser evitados, como estímulos sensoriais que causem estresses e avaliação demorada.

\section{REFERÊNCIAS}

1. MARQUES VG, et al. Transtorno do espectro autista: o impacto na dinâmica familiar e as habilidades no cuidado. Revista Eletrônica Acervo Saúde, 2021; 13(10): e 9036.

2. SANT'ANNA LFC, et al. Atenção à saúde bucal do paciente autista. Revista pró-universus. 2017; 08(1): 67-74.

3. SANTANA LM, et al. Pacientes autistas: manobras e técnicas para condicionamento no atendimento odontológico. Revista extensão e sociedade, 2020; 21(8): 155-165.

4. SILVA MJL, et al. Pacientes com transtorno do espectro autista: conduta clínica na odontologia. Revista Uningá, 2019; 56(55): 122-129. 
RESUMO SIMPLES: Revisão Integrativa

\title{
A NECESSIDADE DO ACOMPANHAMENTO ODONTOLÓGICO PARA PACIENTES ONCOLÓGICOS
}

\author{
Camyla Éllen da Silva Oliveira ${ }^{1}$ \\ Ítalo Vinícius Ferreira da Silva ${ }^{1}$ \\ Beatriz Pinheiro Cavalcante Melo ${ }^{1}$ \\ Catarina Melo de Andrade Lima ${ }^{1}$ \\ Mariana de Moraes Corrêa Perez ${ }^{1}$
}

1. Universidade Federal de Pernambuco (UFPE), Recife - PE.

Palavras-chave: Odontologia, Cuidados paliativos, Oncologia.

\section{INTRODUÇÃO}

O Câncer é um nome genérico para uma condição multifatorial de saúde global, caracterizado por mais de 100 doenças. Formado por células agressivas, forma tumores ou neoplasias malignas que invadem tecidos e órgãos, se espalhando, em casos mais severos, por todo o corpo (SOUTO KLC, et al., 2019). O câncer tem baixo poder de cura quando avançado e dentro do trabalho em equipe que trata o paciente acometido, o dentista tem papel crucial na devolução da autoestima, alívio da dor, identificação precoce de manifestações orais, sanando dores físicas e psicológicas, aumentando positivamente a qualidade de vida de pacientes oncológicos (CALMON MV, et al., 2019).

\section{OBJETIVO}

Analisar e destacar na literatura científica a necessidade do acompanhamento odontológico a pacientes em tratamento cancerígeno e situações ou alterações que acometam suas cavidades orais, para a manutenção da saúde e da autoconfiança.

\section{MÉTODO}

Trata-se de uma revisão integrativa de literatura. Para sua construção, foi realizada uma busca nas bases de dados SciELO e Biblioteca Virtual de Saúde (BVS), com os descritores "odontologia", "câncer" e "autopercepção", utilizando um lapso temporal de 2016-2021, nos idiomas inglês, português e espanhol. Com isso, foram encontrados 11 artigos, dos quais foram utilizados 4 que agregavam com a discussão.

\section{REVISÃO BIBLIOGRÁFICA}

A odontologia, nos cuidados paliativos, atua como o estudo e tratamento de pacientes com a doença em progressão ou avançada. O surgimento de manifestações orais em pacientes com câncer em estágio terminal é constante, devido ao agravamento das condições sistêmicas corporais (SOUTO KLC, et al., 2019). A 
quimioterapia afeta os tecidos, causando diversos efeitos colaterais. As reações causadas por esta são as mais comprometedoras, pois afetam a alimentação e comunicação (CALMON MV, et al., 2019). Por isso, o atendimento odontológico durante esse processo se torna imperioso, já que esses pacientes apresentam alta prevalência de cárie, doenças periodontais, patologias da mucosa bucal e necessidade de próteses (KAMRAM A, et al., 2018).

\section{CONSIDERAÇÕES FINAIS}

Diante dos pontos analisados, conclui-se que a odontologia, além de sanar condições sistêmicas em pessoas que realizam tratamento quimioterápico pela alta exposição, decorrente da baixa na imunidade, também devolve autoestima a estes, de forma a restaurar sua confiança e bem-estar.

\section{REFERÊNCIAS}

1. CALMON MV, et al. Impact of oral health problems on the quality of life of women with breast cancer. RGO - Revista Gaúcha de Odontologia, 2019; 67(1): 1-10.

2. KAMRAN A, et al. Self-perceived preparedness of final year dental students in a developing country-A multi institution study. European Journal of Dental Education, 2018; 22(4), 745-750.

3. MACÊDO TS, et al. Hospital and oncological dental care: a series of cases. RGO - Revista Gaúcha de Odontologia, 2019; 67(1), 1-7.

4. SOUTO KCL, et al. Dental care to the oncological patient in terminality. RGO - Revista Gaúcha de Odontologia, 2019; 67(1): 1-5. 
RESUMO SIMPLES: Revisão Integrativa

\title{
O REFLEXO DA OBESIDADE EM PACIENTES COM COVID-19: UMA REVISÃO DA LITERATURA
}

\author{
Mayara Matos Nascimento ${ }^{1}$ \\ Joelma Cunha Pereira ${ }^{1}$
}

Liejy Agnes dos Santos Raposo Landim ${ }^{1}$

1. Centro Universitário Santo Agostinho (UNIFSA) Teresina - PI.

Palavras-chave: Obesidade, Mortalidade, Infecção por coronavírus.

\section{INTRODUÇÃO}

Na China, no final de 2019, a descoberta do surto da Síndrome Respiratória Aguda Grave do Coronavírus 2 (SARS-CoV-2) foi o responsável pelo decreto de uma pandemia, em março de 2020, realizado pela Organização Mundial da Saúde (DANTAS KLS, et al., 2021; COSTA IBSS, et al., 2020). A pandemia COVID19 espalhou-se, afetando milhares de pessoas e matando muitas delas (ZHOU F, et al., 2020).

O excesso de peso está relacionado a várias comorbidades (diabetes mellitus tipo 2, doenças cardiovasculares, insuficiência cardíaca, hipertensão e apneia obstrutiva do sono) a obesidade tem sido associada ao aumento das taxas de hospitalização, da gravidade e de mortalidade pela COVID-19 (SIMONNET A, et al., 2020).

\section{OBJETIVO}

Revisar a literatura científica, a fim de evidenciar a obesidade como fator agravante que pode ocasionar em infectados por COVID-19, assim como, o maior risco de internações em UTI e de mortalidade.

\section{MÉTODO}

Trata-se de uma revisão integrativa, realizada no mês de outubro de 2021. Foram excluídos artigos que não se encaixavam a pesquisa, aderindo-se aos critérios de inclusão 4 artigos publicados nos últimos 5 anos. A busca foi realizada nas bases de dados eletrônicas: Google Acadêmico, Scielo, PubMED, utilizando os seguintes descritores: obesidade, mortalidade, infecção por coronavírus, todos selecionados de acordo com os Descritores em Ciências da Saúde (DeCS).

\section{REVISÃO BIBLIOGRÁFICA}

Um estudo de coorte realizado com 20.133 pacientes internados com COVID-19 demonstrou que em relação à mortalidade dos pacientes, a obesidade estava presente. $26 \%$ foram a óbito, e $34 \%$ continuaram a receber cuidados até o momento da coleta dos dados. A prevalência de obesidade foi de $11 \%$ (DOCHERTY $A B$, et al., 2020). 
Em uma avaliação de 103 pacientes adultos admitidos com COVID-19, a obesidade apresentou-se em 47,5\% dos pacientes hospitalizados, 56,8\% necessitaram de internação em UTI e 65,5\% necessitaram de VMI. Durante os primeiros 10 dias de internação, 44 dos 103 pacientes foram admitidos na UTI e 29 deles necessitaram de VMI (KALLIGEROS M, et al., 2020).

\section{CONSIDERAÇÕES FINAIS}

A obesidade foi encontrada na maioria dos pacientes com COVID-19 e está fortemente ligado à gravidade dos sintomas, se enquadrando nos casos mais graves e de piores respostas ao tratamento clínico, maior quantidade de pacientes em UTI e mortalidade. A obesidade merece atenção, principalmente diante da COVID-19 para que haja um controle considerável tanto de outras comorbidades associadas, como ao índice de mortalidade causada pelo vírus.

\section{REFERÊNCIAS}

1. COSTA IBSS, et al. O Coração e a COVID-19: O que o Cardiologista Precisa Saber. Arquivos Brasileiros de Cardiologia, 2020; 114(5): 805-816.

2. DOCHERTY AB, et al. Features of 20133 UK patients in hospital with covid-19 using the ISARIC WHO Clinical Characterisation Protocol: prospective observational cohort study. BMJ Journals, 2020; 369: 0112.

3. DANTAS KLS, et al. SARS-CoV-2: a view on its origin, transmission, genetic characteristics and pathogenicity. Revista Eletrônica Acervo Saúde, 2021; 13(6): 7567.

4. KALLIGEROS M, et al. Associação de Obesidade com Gravidade da Doença entre Pacientes com Doença por Coronavírus 2019. Obesidade (Silver Spring Md.), 2020; 28(7): 12001204.

5. SIMONNET A, et al. High prevalence of obesity in severe acute respiratory syndrome coronavirus-2 (SARSCoV-2) requiring invasive mechanical ventilation. Obesity, 2020; 28(7): 1195-1199.

6. ZHOU F, et al. Curso clínico e fatores de risco para mortalidade de pacientes adultos internados com COVID-19 em Wuhan, China: um estudo de coorte retrospectivo. Lancet, 2020; 395(10229): 1054-62. 
RESUMO SIMPLES: Revisão Integrativa

A RELEVÂNCIA DA ODONTOLOGIA NA AMAMENTAÇÃO DE RECÉM-NASCIDOS

Camyla Éllen da Silva Oliveira ${ }^{1}$

Fernanda Maria da Cunha Silva ${ }^{1}$

Rute Oliveira dos Santos ${ }^{2}$

Eduardo Fernandes José Oliveira Ferreira ${ }^{1}$

Mariana de Moraes Corrêa Perez ${ }^{1}$

1. Universidade Federal de Pernambuco (UFPE), Recife - PE.

2. Universidade Maurício de Nassau (UNINASSAU), Recife - PE.

Palavras-chave: Cirurgião-dentista, Neonatos, Aleitamento.

\section{INTRODUÇÃO}

A amamentação, além de ser um acontecimento que institui um elo entre mãe e filho (ZINI CARBONNE $\mathrm{CNH}$, et al., 2021), é importante para o desenvolvimento do sistema imunológico do neonato, do sistema digestório e das suas estruturas da face. Assim, se for interrompida, pode causar danos potenciais à saúde deste, além da não alimentação correta da criança e fissuras e lacerações no seio da mãe (TRICHES TC, et al., 2018). Por isso, deve ser acompanhada por um odontopediatra, para que, se necessário, procedimentos que melhorem a qualidade da amamentação sejam feitos e o noenato se alimente corretamente (BROCKVELD LSM e VENANCIO SI, 2020).

\section{OBJETIVO}

Analisar a importância do acompanhamento odontológico à neonatos desde o nascimento para a identificação de alterações que atrapalhem a amamentação e demonstrar a atuação do cirurgião-dentista na solução desses empecilhos.

\section{MÉTODO}

Trata-se de uma revisão integrativa de literatura. Para sua realização, foi realizada uma busca nas bases de dados SciELO e PubMed, com os descritores "amamentação", "odontologia" e "recém-nascidos", utilizando um lapso temporal de 2016 a 2021. A partir desses dados, foram encontrados 16 artigos, utilizando 5 que agregaram à discussão e que respondiam à pergunta norteadora "Qual a importância do profissional da Odontologia no combate ao desmame precoce?".

\section{REVISÃO BIBLIOGRÁFICA}


A amamentação promove manutenção da saúde de neonatos, além de ser um dos grandes aliados na redução da mortalidade infantil. Sua falta representa prejuízos na digestão e maior exposição do lactente à agentes infecciosos (ZINI CARBONNE CNH, et al., 2021). Isso pode ser causado por alterações congênitas, como a anquiloglossia, pois essas crianças têm maior dificuldade na pega correta, ocasionando o uso de mamadeiras, confusão de bico e no desmame precoce (SIQUEIRA B, et al., 2020). Se presentes dores no momento da amamentação e alterações na língua do recém-nascido, devem ser solucionadas e acompanhadas pelo cirurgião-dentista com procedimentos como a frenectomia em casos mais graves (TRICHES TC, et al., 2018).

\section{CONSIDERAÇÕES FINAIS}

Diante dos fatos apresentados, mostra-se que ao apresentar alguma anomalia congênita na cavidade bucal, o neonato não consegue efetivar o aleitamento e que é de suma importância o atendimento desse recém-nascido por um o cirurgião dentista especializado, para que este examine e sane qualquer alteração e o neonato possa se alimentar corretamente.

\section{REFERÊNCIAS}

1. BROCKVELD LSM e VENANCIO SI. Avanços e desafios na formação do cirurgião-dentista para sua inserção nas práticas de promoção da saúde. Physis: Revista de Saúde Coletiva, 2020, 30(3): 1-18.

2. SIQUEIRA B, et al. Oral health of neonates: mothers' perception of lingual frenotomy performed in a university hospital. Revista Gaúcha de Odontologia, 2020, 68(1): 1-7.

3. TRICHES TC, et al. Natal and neonatal teeth: two clinical cases report. Revista Gaúcha de Odontologia, 2018, 66(1): 101-105.

4. ZINI CARBONNE, et al. La importancia de la lactancia materna en odontologia. Revista del Ateneo Argentino de Odontología, 2021, 64(1), 83-90. 
RESUMO SIMPLES: Revisão Integrativa

\title{
A OBESIDADE COMO DESFECHO DO DISTANCIAMENTO SOCIAL NA PANDEMIA DO SARS-COV-2
}

\author{
Mariana Lisboa de Jesus ${ }^{1}$ \\ Ana Carolina Rioga da Silva ${ }^{1}$ \\ Juliana Tomé Pereira ${ }^{1}$
}

1. Centro Universitário de Belo Horizonte (UNIBH), Belo Horizonte - MG.

Palavras-chave: Obesidade, Isolamento, Covid.

\section{INTRODUÇÃO}

A obesidade é uma doença crônica causada por fatores genéticos, consumo elevado de alimentos industrializados e gordurosos associados ao sedentarismo e fatores psicológicos, como estresse e depressão. Sendo determinada pelo excesso de gordura corporal identificada por meio do índice de massa corporal (IMC) maior que $30 \mathrm{~kg} / \mathrm{m}^{2}$ (BRASIL, 2021).

O distanciamento social e a abertura restrita dos serviços essenciais à saúde como um dos métodos de prevenção da transmissão viral provocaram modificações no cotidiano e no estilo de vida de muitos indivíduos, consequentemente desencadeou diversos impactos nos hábitos alimentares e na prática de atividades físicas, resultando no aumento da prevalência de cidadãos obesos em diversas regiões do mundo (HEINBERG LJ e STEFFEN K, 2021).

\section{OBJETIVO}

Identificar e analisar por meio da revisão de literatura os impactos do confinamento social decorrente da pandemia da COVID-19 na mudança dos hábitos alimentares e na prática esportiva, com ênfase na obesidade.

\section{MÉTODO}

Trata-se de uma revisão integrativa realizada em outubro de 2021, com buscas nas bases de dados eletrônicas Biblioteca Virtual em Saúde, Scielo, Pubmed, Acervo + e Medline. Utilizou os descritores: obesidade, isolamento e covid associados ao operador booleano AND. Como critérios de inclusão adotou-se artigos publicados nos últimos 5 anos, texto completo em inglês ou português, sendo utilizadas 5 literaturas.

\section{REVISÃO BIBLIOGRÁFICA}

A Organização Mundial da Saúde, deferiu que 500 milhões de indivíduos são obesos no mundo, sendo $20 \%$ somente no Brasil, mas esses dados estão em progressão (BRASIL, 2021). Uma revisão narrativa realizada nos Estados Unidos da América revelou que durante a pandemia houve um aumento do consumo em $43,5 \%$ de alimentos processados, e crescimento de peso de $33,4 \%$ dos cidadãos durante este período, 
potencializando a obesidade (HEINBERG LJ e STEFFEN K, 2021). O confinamento, a perda de rotina e a adaptação aos novos hábitos resultaram no aumento do consumo de alimentos industrializados, na compulsão alimentar e no comportamento sedentário, que intensificou a prevalência desta doença (ZEIGLER Z, 2021).

\section{CONSIDERAÇÕES FINAIS}

Diante das literaturas analisadas, demonstra-se que o distanciamento social decorrente da pandemia do SARS CoV-2 desencadeou alterações nos estilos de vida de grande parte da população. Acredita-se na importância desta temática, pois trata-se de um problema de saúde pública, que necessita da atenção e do cuidado da equipe multidisciplinar para fornecer medidas de promoção e prevenção do excesso de gordura corporal e das complicações decorrentes da obesidade.

\section{REFERÊNCIAS}

1. BRASIL. Associação Brasileira para o Estudo da Obesidade e da Síndrome Metabólica (ABRESO). Diretrizes Brasileiras de Obesidade. 2016. Disponível em: https://abeso.org.br/wpcontent/uploads/2019/12/Diretrizes-Download-Diretrizes-Brasileiras-de-Obesidade-2016.pdf. Acessado em: 15 de outubro de 2021.

2. HEINBERG LJ, STEFFEN K. Social Isolation and Loneliness during the COVID-19 Pandemic : Impact on Weight. Curr Obes Rep, 2021; 10: 365-370.

3. PEARL RL, SCHULTE EM. Weight Bias Durint the COVID-19 Pandemic. Current Obesity Reports, 2021; 10(2): 181-190.

4. ZEIGLER Z. COVID-19 Self-quarantine and Weight Gain Risk Factors in Adults. Current Obesity Reportes, 2021; 10(3): 423-433.

5. SILVA J. Obesidade e COVID-19: Quais as evidências?. Revista Artigos. Com, 2020; 21: e5346. 


\title{
ASSISTÊNCIA DE ENFERMAGEM A PACIENTES COM COMPORTAMENTO SUICIDA: UMA REVISÃO INTEGRATIVA
}

\author{
Daniela dos Santos Mangueira de Almeida ${ }^{1}$ \\ Andressa Dâmaras Freitas Feitosa ${ }^{1}$ \\ Beatriz Caroline Leão Lima ${ }^{1}$ \\ Maria Clara Rodrigues de Abreu ${ }^{1}$ \\ Mauro Roberto Biá da Silva ${ }^{1}$
}

1. Universidade Estadual do Piauí (UESPI), Teresina - PI.

Palavras-chave: Assistência de enfermagem, Ideação suicida, Suicídio.

\section{INTRODUÇÃO}

O suicídio é um grave problema de saúde pública, a cada ano, no mundo, mais pessoas colocam fim a sua vida. No Brasil a mortalidade advinda do suicídio vem crescendo, principalmente em jovens do sexo masculino de 15 a 29 anos, tornando-se a terceira maior causa de morte nessa faixa etária (SANTOS RS, et al., 2017).

Nesse contexto a ideação suicida pode ocasionar futuras tentativas de suicídio e requer atenção clínica (AMARAL AP, et al., 2020). Nessa perspectiva o enfermeiro desempenha um papel que ajuda na identificação de indícios de ideação suicida, prevenção do comportamento suicida e reabilitação do paciente (PESSOA DMS, et al., 2020).

\section{OBJETIVO}

Revisar e analisar por meio da literatura científica quanto ao comportamento suicida, enfatizando as ações realizadas através da assistência prestada pelo profissional enfermeiro ao atendimento do paciente com esse comportamento.

\section{MÉTODO}

Trata-se de uma revisão integrativa de literatura com busca na Biblioteca Virtual de Saúde (BVS), nas bases de dados SCIELO, LILACS e BDENF. Encontrados 53 artigos e destes 3 foram selecionados segundo critérios de inclusão: artigos publicados nos últimos cinco anos, gratuitos e nas modalidades português, inglês e espanhol; critérios de exclusão: artigos não condizentes com a temática, revisões de literatura e textos incompletos.

\section{REVISÃO BIBLIOGRÁFICA}


O enfermeiro presta assistência em diversos níveis da saúde, como a atenção primária à saúde, onde desempenha um importante papel na prevenção do comportamento suicida através da sua proximidade com a comunidade, possibilitando a identificação de fatores de risco (PESSOA DMS, et al., 2020). Em Centros de Atenção psicossocial o profissional realiza ações como Projetos Terapêuticos Singulares e visitas domiciliares, presando pela humanização e visando que o paciente retome a sua vida. Nos serviços de emergência ocorre o primeiro contato com o paciente com tentativa de suicídio e realização de cuidados. Nos hospitais psiquiátricos há a prestação de cuidados com foco na reabilitação do paciente (SANTOS RS, et al., 2017).

\section{CONSIDERAÇÕES FINAIS}

O suicídio é uma realidade, diante dos estudos foi evidenciado o amplo campo de atuação do enfermeiro quanto aos cuidados aos pacientes com comportamentos suicidas e como ocorre esses cuidados em cada um dos níveis. Diante disso percebe-se como são essenciais os cuidados prestados na prevenção do suicídio e reabilitação dos pacientes com tentativas de suicídio, cuidados que exigem sensibilidade e competências que o enfermeiro possui.

\section{REFERÊNCIAS}

1. AMARAL, AP, et al. Depresión e ideación suicida en la adolescencia: implementación y evaluación de un programa de intervención. Enfermería global, 2020; 19(59): 1-35.

2. PESSOA, DMS, et al. Assistência de Enfermagem na Atenção Primária à Saúde de adolescentes com ideações suicidas. REME - Revista Mineira de Enfermagem, 2020; 24: e-1290.

3. SANTOS, RS, et al. A atuação do enfermeiro com a pessoa em situação de suicídio: análise reflexiva. Revista de enfermagem UFPE on line, 2017; 11(2): 742-748. 
RESUMO SIMPLES: Revisão Integrativa

\title{
CUIDADOS DE ENFERMAGEM AO PACIENTE COM DERIVAÇÃO VENTRICULAR EXTERNA
}

\author{
Jéssica Luciana dos Santos Pereira ${ }^{1}$ \\ Simone Daria Assunção Vasconcelos Galdino²
}

1. Faculdade Cosmopolita, Belém - PA.

2. Universidade do Estado do Pará (UEPA), Belém - PA.

Palavras-chave: Enfermagem, Hidrocefalia, Neurocirurgia.

\section{INTRODUÇÃO}

A hidrocefalia é uma patologia multifatorial que ocorre predominantemente na infância, é definida pelo aumento da quantidade de líquido cefalorraquidiano (LRC) na caixa craniana e nas cavidades ventriculares, causando a dilatação dos ventrículos (CESTARI VRF, et al., 2013). A hidrocefalia provoca o aumento anormal da cabeça, abaulamento, tensão das fontanelas, distensão das veias do couro cabeludo, estiramento da pele, êmeses, crises convulsivas e desenvolvimento neuropsicomotor retardado. $O$ uso de drenagens através das válvulas unidirecionais, denominada Derivação Ventricular (DV), implica-se na remoção do excesso de LCR (SILVA NEC, et al., 2019).

\section{OBJETIVO}

Verificar e analisar as evidências científicas acerca da importância do cuidado da enfermagem à criança submetida a cirurgia neurológica: derivação para hidrocefalia, observadas na literatura durante o período de 2011 a 2021.

\section{MÉTODO}

Trata-se de uma Revisão Integrativa da Literatura, realizou-se a busca de artigos nas bases de dados: BVS, LILACS, SCIELO, BDENF e Base Científica Acervo Saúde, correspondentes ao período de 2011 a 2021, em português, inglês e espanhol. Inicialmente obteve-se 16 artigos, após a análise criteriosa, foram excluídos estudos repetidos, indisponível na íntegra e que não correspondiam à temática proposta. Resultando assim, em 05 artigos para o presente estudo.

\section{REVISÃO BIBLIOGRÁFICA}

Observou-se a carência de dados na literatura sobre cuidados de enfermagem à criança com derivação ventricular. O enfermeiro acompanha o paciente no pré e pós-operatório, as tarefas vão além da realização de procedimento, abrange avaliação diária através do registro detalhado e participação dos pais no tratamento até o momento de alta hospitalar (SAKAMOTO VTM, et al., 2021; ALCANTARA MCM, et al., 2011b). 
O cuidado direcionado de enfermagem ao paciente neurocirúrgico, torna-se necessária, a sistematização da assistência, permite organizar o cuidado conforme a necessidade de cada paciente. $O$ tratamento cirúrgico pode desencadear problemas como: aparecimento de úlceras por pressão, bexiga neurogênica, risco de infecção e dor aguda, além disso, as principais complicações decorrentes das derivações ventriculares são: mecânicas, funcionais e infecciosas, podendo levar a óbito (ALCANTARA MCM, et al., 2011a).

\section{CONSIDERAÇÕES FINAIS}

O cuidado ao paciente com hidrocefalia requer conhecimento, domínio técnico e científico sobre a função neurológica para detecção precoce da doença. A educação em saúde é essencial para a continuidade do tratamento, bem como o investimento em novas pesquisas sobre o tema, com intuito de contribuir para a assistência humanizada, voltada às necessidades da criança com hidrocefalia.

\section{REFERÊNCIAS}

1. ALCANTARA MCM, et al. Problemas de enfermagem em crianças com hidrocefalia e mielomeningocele. Revista de Enfermagem UFPE online, 2011a; 5(6): 1483-491.

2. ALCANTARA MCM, et al. Características clínicas de crianças em uso de derivações ventriculares para tratamento da hidrocefalia. Revista Rene, 2011b; 12(4): 776-82.

3. CESTARI VRF, et al. Assistência de enfermagem à criança com hidrocefalia: revisão Integrativa. Revista de Enfermagem UFPE online, 2013; 7(esp): 1490-6.

4. SILVA NEC, et al. Práticas assistenciais de enfermagem ao recém-nascido com hidrocefalia. Revista de Enfermagem UFPE online, 2019; 13(5): 1394-404.

5. SAKAMOTO VTM, et al. Nursing assistance in patient care with external ventricular drain: a scoping review. Revista Brasileira de Enfermagem, 2021; 74(2): e20190796. 


\title{
TEORIA TRANSCULTURAL DE LEININGER ASSOCIADA AO CUIDADO DE ENFERMAGEM: UMA REVISÃO INTEGRATIVA DA LITERATURA
}

\author{
Jéssica Luciana dos Santos Pereira \\ Simone Daria Assunção Vasconcelos Galdino
}

1. Faculdade Cosmopolita, Belém - PA.

2. Universidade do Estado do Pará (UEPA), Belém - PA.

Palavras-chave: Cuidado de enfermagem, Cultura, Enfermagem transcultural.

\section{INTRODUÇÃO}

Madeleine Leninger correlacionou os cuidados da enfermagem à antropologia. Com isto, desenvolveu a Teoria Transcultural do Cuidado (TCC), conceituando assim, o cuidado universal ao ser humano, com objetivo de compreender e interpretar as experiências de vida das pessoas, relacionada a saúde, cuidado e bem-estar humano (SILVA ER, et al., 2020).

A enfermagem possui um amplo papel no cuidar, dentre estes, requer identificar e proteger todas as práticas, valores que promovam o bem-estar e a preservação da saúde. Portanto, se a crença ou prática exercida pelo paciente é benéfica, ou se não faz mal à vida, a mesma deve ser preservada e incentivada (OJEDA M, et al., 2020).

\section{OBJETIVO}

Realizar uma revisão por meio da literatura científica, sobre a importância do cuidado transcultural na assistência e no processo de cuidar da enfermagem, baseado na teoria Transcultural de Madeleine Leininger.

\section{MÉTODO}

Trata-se de uma revisão integrativa da literatura, com objetivo de reunir conhecimentos sobre a temática: Transculturação vinculado ao processo de cuidar da enfermagem. Realizou-se a busca de artigos nas bases de dados da Biblioteca Virtual de Saúde (BVS), utilizando os seguintes descritores: cuidado de enfermagem, cultura e enfermagem transcultural. Também, foi realizada a busca de artigos na Revista Eletrônica Acervo Saúde, sobre teoria transcultural de Leininger, com recorte temporal dos últimos 5 anos. Procedeu à análise de 22 artigos, após a implementação dos critérios de exclusão somente 05 foram selecionados.

\section{REVISÃO BIBLIOGRÁFICA}

O cuidado humano é universal, podendo ser experimentado de diferentes formas e em variadas culturas. Conhece-las é essencial para o desenvolvimento da assistência de enfermagem de maneira satisfatória e holística (BUDÓ MDL, 2020). A inserção da TCC, contribui na condução da assistência de enfermagem, 
permite um cuidado diferenciado baseado em fundamentos científicos, acarretando uma assistência mais concreta e reflexiva com as crenças e valores dos seres humanos (SILVA ER, et al., 2020).

Para que o desenvolvimento da atenção à saúde ocorra de modo eficaz, o profissional precisa além de uma comunicação efetiva, paciência para ouvir, ter empatia, vontade de aprender e compreender, impactando positivamente no processo saúde-doença (SOARES JL, et al., 2020).

\section{CONSIDERAÇÕES FINAIS}

A enfermagem atua diretamente com o paciente, seja na prevenção ou com indivíduo doente. O cuidado da enfermagem associado ao respeito e valorização da cultura do paciente é imprescindível para o bom atendimento e consequentemente a melhoria da saúde do paciente. Do mesmo modo, Madeleine Leininger busca através de sua teoria, orientar o profissional de como proceder no atendimento às necessidades do paciente sem que as individualidades culturais sejam ignoradas.

\section{REFERÊNCIAS}

1. BUDÓ MLD, et al. Cuidado e cultura: uma interface na produção do conhecimento de enfermagem. J. res.: fundam. care. online, 2016; 8(1): 3691-3704.

2. MARTINS LA, et al. Prática do aleitamento materno em comunidades quilombolas à luz da teoria transcultural. Revista Brasileira de Enfermagem, 2020; 73(4): e2019019.

3. OJEDA M, et al. Ethnonursing: cuidados culturais em uma comunidade mapuche em puerto aguirre, aysén, chile. Texto \& Contexto-Enfermagem, 2020; 29(spe): e20190262.

4. SILVA ER, et al. Transculturalidade na enfermagem baseada na teoria de Madeleine Leininger. Revista Eletrônica Acervo Saúde, 2020; 13(2): e5561.

5. SOARES JL, et al. Teoria transcultural na assistência de enfermagem às mulheres com infecções. Revista Brasileira de Enfermagem, 2020; 73 (supl4): e20190586. 
RESUMO SIMPLES: Revisão Integrativa

\title{
A INTERRUPÇÃO PRECOCE DO ALEITAMENTO MATERNO ASSOCIADA A MAIOR INCIDÊNCIA DE OBESIDADE INFANTIL
}

\author{
Dandara Lima Santos ${ }^{1}$ \\ Ana Beatriz Ribeiro Queiroz ${ }^{1}$ \\ Anna Beatriz Conceição de Souza ${ }^{1}$ \\ Noeme Agostinho Rocha ${ }^{2}$ \\ Mayla Karla de Souza Monteiro²
}

1. Universidade Federal do Pará (UFPA), Belém - PA.

2. Universidade da Amazônia (UNAMA), Belém - PA.

Palavras-chave: Criança, Sobrepeso, Aleitamento materno.

\section{INTRODUÇÃO}

O Aleitamento Materno (AM) promove inúmeros benefícios que se estendem até a vida adulta e influenciam na qualidade de vida do indivíduo, permitindo um crescimento saudável adequado e atendendo suas necessidades nutricionais (CIAMPO LAD e CIAMPO IRLD, 2018). Entretanto, crianças que tiveram interrupção precoce do processo de amamentação estão mais propensas a desenvolverem doenças crônicas como a obesidade, ademais o consumo de outros alimentos também irá prejudicar a absorção de nutrientes essenciais fornecidos no leite materno, além dos anticorpos fornecidos que envolvem o sistema imunológico (ROSA LCD, et al., 2019).

\section{OBJETIVO}

Revisar nos dados fornecidos pela literatura científica a relação e os efeitos entre a interrupção precoce do aleitamento materno com o aumento e a incidência de casos de obesidade infantil.

\section{MÉTODO}

Trata-se de uma revisão integrativa. Foi realizada uma busca eletrônica nas bases de dados Scielo e Pubmed, delimitando-se a estudos publicados entre 2019 e 2020, nos idiomas português e inglês, excluindo aqueles que não se relacionassem com a temática e estivessem fora do recorte temporal. Os descritores utilizados foram: aleitamento materno, obesidade e sobrepeso. Ao fim, foram selecionados 4 estudos para análise.

\section{REVISÃO BIBLIOGRÁFICA}


Os estudos evidenciaram que crianças não amamentadas ou com interrupção precoce possuem maiores chances de desenvolverem graus de obesidade infantil (WAGNER KJP, et al., 2021). Nesse sentido, essa incidência pode estar relacionada ao aumento do consumo de alimentos industrializados após o desmame, como a introdução de leites e alimentos com alta densidade energética, assim a introdução da fórmula infantil por possuir menor conteúdo de energia metabolizável, proporciona menor ingestão de energia e maior ingestão proteica que nos casos além da necessidade do lactente pode levar ao aumento do peso (TRABULSI JC, et al., 2020).

\section{CONSIDERAÇÕES FINAIS}

Dessa forma, observa-se a importância do aleitamento exclusivo até os 6 meses e a introdução alimentar posteriormente, haja vista que o leite materno oferece diversos nutrientes importantes para o desenvolvimento e crescimento da criança, assim como atua na prevenção de diversas doenças crônicas.

\section{REFERÊNCIAS}

1. CIAMPO LAD, CIAMPO IRLD. Breastfeeding and the Benefits of Lactation for Women's Health. Revista Brasileira de Ginecologia e Obstetrícia [online], 2018; 40: 354-359.

2. ROSA LCD, et al. Relationship between overweight at 6 years of age and socioeconomic conditions at birth, breastfeeding, initial feeding practices and birth weight. Revista de Nutrição [online], 2019; 32: e190033.

3. TRABULSI JC, et al. Impact of early rapid weight gain on odds for overweight at one year differs between breastfed and formula-fed infants. Pediatr Obesidade, 2020; 10: e12688.

4. WAGNER KJP, et al. Association between breastfeeding and overweight/obesity in schoolchildren aged 714 years. Rev Paul Pediatr, 2021;39: e2020076. 


\section{DISTÚRBIO DO SONO EM PROFISSIONAIS DA SAÚDE EM TEMPOS DE PANDEMIA: UMA REVISÃO INTEGRATIVA DA LITERATURA}

Thallita Caroline Cassiano Gouvêa ${ }^{1}$

Ana Paula Fontana ${ }^{1}$

Laís Celi Mendes Rezende ${ }^{1}$

1. Universidade de Rio Verde, Rio Verde - GO.

Palavras-chave: COVID-19, corpo clínico hospitalar, Insônia.

\section{INTRODUÇÃO}

A qualidade do sono afeta as cognições, emoções e desempenho. É durante o ato de dormir que o organismo exerce as principais funções restauradoras do corpo, como por exemplo, o reparo de tecidos, o crescimento dos músculos e também a síntese de proteínas. (BRITO-MARQUES JMAM, et al., 2021). Os deficits de humor e desempenho, além de vários problemas da saúde são diretamente associados a privação do sono. Quando se analisa os profissionais da área saúde e o contexto da pandemia da COVID-19, percebe uma alta incidência de privação do sono associada a longas horas de trabalho e a uma rotina estressante (PAPPA S, et al., 2020).

\section{OBJETIVO}

Apresentar qual profissional da saúde apresenta maior incidência de distúrbios do sono dentre os trabalhadores da área da saúde e os principais fatores relacionados, no período da pandemia do COVID-19.

\section{MÉTODO}

Trata-se de uma revisão integrativa da literatura nas bases de dados PubMed, SciELO, Cochrane Brasil e Science de 2019-2021. Na busca inicial foram identificados 27 artigos, em inglês, com o os descritores: " health scholars, "healthcare workers" AND "COVID 19". Após a leitura na integra dos 27 artigos, apenas 6 foram incluídos na amostra final, de acordo com a relevância e objetivos do estudo apresentado.

\section{REVISÃO BIBLIOGRÁFICA}

Os resultados apresentam alta prevalência de distúrbios do sono em profissionais da saúde. Em geral, os brasileiros tiveram sua qualidade de vida afetada pela pandemia. Já quando analisados os tipos de profissionais de saúde, os médicos foram os mais acometidos, visto que $70 \%$ dos avaliados apresentavam comprometimento no sono (MIRANDA FBG, et al., 2021).

Entre os fatores que podem estar relacionados a essa perturbação do sono estão o ambiente de isolamento, ansiedade, depressão associada, altas cargas horárias de trabalho, com elevado estresse e com 
estilo de vida pouco saudável que levam altos riscos de eventos cardiovasculares, devido a perturbação crônica e estressores ocupacionais (MOTA I, et al., 2021).

\section{CONSIDERAÇÕES FINAIS}

O impacto na qualidade do sono da população em geral foi perceptível, porém entre os profissionais de saúde, os médicos apresentaram uma incidência maior. O ambiente hospitalar tornou-se extremamente difícil, pacientes gravemente enfermos, aumentando a sobrecarga nos profissionais de saúde. Esse momento é marcado por isolamento, principalmente por estar em contato direto com o vírus, muitos tiveram que estar em moradias diferentes do restante da família, causando solidão.

\section{REFERÊNCIAS}

1. BREWER B, et al. An exploration of clinical, behavioral, and community factors associated with sleep duration and efficiency among middle-aged Black/African American smokers. Slepp Health, 2021; 7: 397407.

2. BRITO-MARQUES JMAM, et al. Impact of COVID-19 pandemic on the sleep quality of medical professionals in Brazil. Revista Arquivos de Neuropsiquiatria, 2021.

3. MIRANDA FBG, et al. Sofrimento psíquico entre os profissionais de enfermagem durante a pandemia da COVID 19: Scoping Review. Escola Anna Nery - Revista de Enfermagem, 2021.

4. MOTA IA, et al. Impact of COVID-19 on eating habits, physical activity and sleep in Brazilian healthcare professionals. Revista Cientifica em Ciência da Saúde. Brasil, 2021.

5. PABLO G. Impact of coronavirus syndromes on physical and mental health of health care workers: Systematic review and meta-analysis. Journal of Affective Disorders, 2020; 48-57.

6. PAPPA S, et al. Prevalence of depression, anxiety, and insomnia among healthcare workers during the COVID-19 pandemic: A systematic review and meta-analysis. Journal Brain, Behavior, and Immunity, 2020; 88: $901-907$. 


\title{
O PROTAGONISMO DO ENFERMEIRO NA ASSISTÊNCIA AO PRÉ-NATAL
}

\author{
Jean David Alves da Silva ${ }^{1}$ \\ Junior de Jesus Guimarães ${ }^{1}$ \\ Sara Figueiredo da Silva e Silva ${ }^{1}$ \\ Juliana Alves Ferreira ${ }^{1}$ \\ Leisiane Karolaine Santos ${ }^{1}$
}

1. Universidade Tiradentes (UNIT), Aracaju - SE.

Palavras-chave: Gestante, Pré-natal, Enfermeiro.

\section{INTRODUÇÃO}

A gestação é a fase da mulher em que ocorrem diversas modificações fisiológicas, psicológicas e alterações emocionais devido ao desenvolvimento de uma nova vida (SANTOS MR, et al., 2021). O acompanhamento desta gestante, desde as primeiras semanas de gestação, é primordial. No decorrer do período gestacional, a mulher deve ser introduzida em atividades educacionais com o intuito de ajuda-la nessa fase da sua vida, tais como grupos de gestantes. Contudo, a mesma não deve negligenciar as consultas prénatais, pois elas são vitais para o acompanhamento e evolução da gestação de forma segura (OLIVEIRA EC, et al., 2016). Nesse contexto, o enfermeiro tem um papel vital tanto na adesão de gestantes como na periodicidade e funcionalidade das consultas.

\section{OBJETIVO}

Destacar a importância da realização do acompanhamento da gestante nas consultas de pré-natal bem como compreender a fundamental importância da atuação do enfermeiro nesse processo garantindo o desenvolvimento gestacional saudável.

\section{REVISÃO BIBLIOGRÁFICA}

No pré-natal, a gestante é acolhida por uma equipe multiprofissional que realiza ações para que a mesma esteja preparada para vivenciar essa nova fase de sua vida. Nesse ponto, o profissional de enfermagem desempenha uma função fundamental uma vez que o mesmo, orienta, examina, prescreve e traça cuidados durante cada consulta (BRITO GA, et al., 2018).

O cuidado no pré-natal capacitado se relaciona diretamente com a diminuição de casos negativos durante e após a gestação, dentre eles pode-se citar a prematuridade, além de reduzir os riscos de complicações durante a gestação, como é o caso da diabetes gestacional, eclampsia e, principalmente, a morte materna (MARQUES BL, et al., 2021). 
Segundo dados, países desenvolvidos têm taxa de mortalidade materna de 12 óbitos maternos, por cada 100 mil nascidos vivos, enquanto países em desenvolvimento possuem 239 óbitos maternos, por cada 100 mil nascidos vivos. Vale ressaltar que considera-se razoável até 20 óbitos maternos, por 100 mil nascidos vivos (MARTINS AC e SILVA LS, 2017). Nesse sentido, a atuação profissional do enfermeiro é de grande relevância uma vez que o mesmo desempenha papeis fundamentais durante as consultas.

\section{CONSIDERAÇÕES FINAIS}

A realização do pré-natal é de suma importância tanto para o crescimento e desenvolvimento saudável da criança quanto para a saúde e bem-estar da mãe em todas as fases da gestação. Nesse contexto, o enfermeiro tem grande importância tanto na captação dessas gestantes como no desenvolvimento gestacional saudável através das consultas periódicas com vistas a examinar e orientar a gestante.

\section{REFERÊNCIAS}

1. BRITO GA, et al. Ações do enfermeiro no pré-natal e a importância atribuída pelas gestantes. Revista SUSTINERE. 2018, 6(1): 52-62.

2. MARQUES BL, et al. Orientações às gestantes no pré-natal: a importância do cuidado compartilhado na atenção primária em saúde. Escola Anna Nery, 2021; 25(1): e20200098.

3. SANTOS MR, et al. Protagonismo do enfermeiro na consulta do pré-natal de baixo risco: reflexões da educação em saúde. Revista científica saúde e tecnologia, 2021 1(2): e 1216.

4. OLIVEIRA EC, et al. A importância do acompanhamento pré-natal realizado por enfermeiros. Revista Científica FacMais, 2016; 7(3): 2238-8427.

5. MARTINS AC e SILVA LS. Perfil epidemiológico de mortalidade materna. Revista Brasileira de Enfermagem. 2018;71(1): 725-731. 


\title{
MANIFESTAÇÕES ORAIS DECORRENTES DA SÍNDROME DE SJÖGREN
}

\author{
Marcela Macedo de Freitas Oliveira ${ }^{1}$ \\ Larissa Soderini Ferracciù ${ }^{1}$ \\ Letícia Pontes Nascimento ${ }^{2}$ \\ Mirela Carolaine Cunha da Cruz ${ }^{3}$ \\ Mariana de Moraes Corrêa Perez ${ }^{2}$
}

1. Associação Caruaruense de Ensino Superior (ASCES UNITA), Caruaru - PE.

2. Universidade Federal de Pernambuco (UFPE), Recife - PE.

3. Centro Universitário Maurício de Nassau, Recife - PE.

Palavras-chave: Manifestações bucais, Síndrome de Sjögren, Odontologia.

\section{INTRODUÇÃO}

A síndrome de Sjögren (SS) é uma desordem imunológica de caráter inflamatório crônico e sistêmico relativamente comum que prevalece, sobretudo, em mulheres entre a quarta e sexta década da vida (SERRANO J, et al., 2018; GARLAPATI K, et al., 2019). Apesar de ainda ter etiologia desconhecida, sabe-se que pode estar ligada a fatores genéticos, hormonais, neurológicos e nutricionais, afetando, principalmente, as partes funcional e estrutural de glândulas exócrinas. Frequentemente são afetadas as glândulas salivares e lacrimais, porém também podem ser acometidas as glândulas humidificadoras da vagina, respiratórias, cutâneas e gastro-intestinais. Sintomas clínicos comumente observados são: queratoconjuntivite seca, xerostomia, inchaço e dor nas glândulas salivares e/ou parótidas (WANDERLEY AEC, et al., 2019).

\section{OBJETIVO}

Revisar e analisar, através da literatura científica, as principais manifestações bucais em decorrência da SS, apresentando os principais sintomas relatados pelos pacientes e as alterações clinicamente observadas pelos profissionais cirurgiões-dentistas.

\section{MÉTODO}

Revisão integrativa de literatura na qual foram realizadas buscas nas bases de dados: BVS, MEDLINE, PubMed e Acervo+ Index Base no período do mês de outubro. Utilizou-se os descritores "Manifestações Bucais", "Síndrome de Sjögren" e "Odontologia", selecionando-se 04 artigos que tinham como critérios de inclusão: idiomas inglês ou português, estudos completos e dos últimos 03 anos e sendo excluídos aqueles que não possuíam relevância com a temática. 


\section{REVISÃO BIBLIOGRÁFICA}

A saliva exerce um importante papel para a manutenção da saúde bucal, portanto, a xerostomia, (principal repercussão oral da SS) aumenta o risco para o desenvolvimento de diversos problemas orais. As alterações das glândulas salivares, além diminuir o fluxo da saliva, também modifica sua composição, que se torna mais espessa e esbranquiçada (WANDERLEY AEC, et al., 2019).

Problemas de fala e deglutição são relatados pelos pacientes, bem como alteração de paladar e sensação de queimação bucal. Clinicamente, são observadas alterações na língua, ulceração inespecífica recorrente e a associação entre SS e lesões orais de etiologia autoimune, como líquen plano e pênfigo vulgar (SERRANO J, et al., 2018, AL HAMAD A, et al., 2019).

\section{CONSIDERAÇÕES FINAIS}

A SS, em muitos casos, afeta a saúde bucal e psicossocial dos portadores. A prevalência de manifestações orais varia de cárie até diversos tipos de lesões em mucosa, assim como alterações de fala e deglutição que podem interferir na vida social do paciente. Desse modo, o cirurgião-dentista deve conhecer tais repercussões orais a fim de realizar os devidos protocolos odontológicos com o objetivo de prevenir, diagnosticar e tratar seus pacientes.

\section{REFERÊNCIAS}

1. AL HAMAD A, et al. Interventions for dry mouth and hyposalivation in Sjögren's syndrome: A systematic review and metaanalysis. Oral diseases, 2019; 25(4): 1027-1047.

2. GARLAPATI K, et al. Meta-analysis on pharmacological therapies in the management of xerostomia in patients with Sjogren's syndrome. Immunopharmacology and immunotoxicology, 2019; 41(2): 312-318.

3. SERRANO J, et al. Oral lesions in Sjögren's syndrome: A systematic review. Medicina oral, patologia oral y cirugia bucal, 2018; 23(4): e391.

4. WANDERLEY AEC, et al. Síndrome de Sjögren Secundária diagnosticada por cirurgião-dentista: relato de caso. Revista Eletrônica Acervo Saúde, 2019; 20: e496. 
RESUMO SIMPLES: Revisão Narrativa

\title{
ATUALIZAÇÃO DA NR 32 MEDIANTE O CENÁRIO PANDÊMICO DE COVID-19 NO CONTEXTO DA HIGIENIZAÇÃO DAS MÃOS
}

\author{
Marciele de Lima Silva ${ }^{1}$ \\ Alberlene Baracho Sales ${ }^{2}$ \\ Maura Rahianny Cardoso Araújo² \\ Karem Cristinny Fontes Pascoal ${ }^{3}$ \\ Ângela Amorim de Araújo²
}

1. Centro Universitário UNIESP, João Pessoa - PB.

2. Universidade Federal da Paraíba (UFPB), João Pessoa - PB.

3. Centro Universitário de João Pessoa (UNIPÊ), João Pessoa - PB.

Palavras-chave: NR 32, Covid-19, Saúde do trabalhador.

\section{INTRODUÇÃO}

O contexto pandêmico trouxe novas observações quanto a saúde do trabalhador, principalmente ao profissional em saúde. O fato risco biológico derivado do contato direto com vírus da COVID-19 modificou a rotina dos ambientes de saúde afirmando uma necessidade de revisão do uso dos equipamentos de proteção (EPIs) e cuidados individuais e coletivos. A lavagem das mãos é considerada uma prática corriqueira nos ambientes de saúde que passou a ser implementada com maior frequência e rigor devido ao risco de disseminação por covid-19, associado ao processo de paramentação e desparamentacão como um dos processos executados em diversas áreas do ambiente hospitalar (MATTE DL, et al., 2020).

\section{OBJETIVO}

Analisar as modificações realizadas nas orientações da NR 32, aplicadas na Nota Técnica № 04/2020, mediante o contexto pandêmico de Covid-19, com ênfase na técnica e prática de lavagem das mãos.

\section{REVISÃO BIBLIOGRÁFICA}

Essa síntese realizada em setembro de 2021, busca realizar uma análise partindo da interpretação documental achados nas bases de dados institucionais da ANVISA, a Nota Técnica № 04/2020, e Ministério do Trabalho, a NR 32. A NR 32 (2005) consiste em uma normativa referente a saúde e segurança do trabalhador em serviços de saúde. Encontramos no item 32.2 as considerações sobre riscos biológicos, que afirma a necessidade de disposição ao lavatório de uso exclusivo para higienização das mãos, contando com materiais como água corrente, sabonete líquido, toalha descartável e lixeira sem contato manual (BRASIL, 2008). 
Verifica-se que o procedimento é indispensável mesmo com o uso das luvas. A Nota Técnica № 04/2020 (2021) apresenta em algoritmo os 5 momentos de higienização das mãos, visando a segurança do paciente acometido por covid-19 e do profissional de saúde, enfatizando a higienização imediata. Inclui ainda a preparação alcoólica a 70\% (ANVISA, 2020).

\section{CONSIDERAÇÕES FINAIS}

Este estudo corrobora o conhecimento sobre a relevância da lavagem das mãos para a segurança do profissional de saúde e do paciente. Realiza também apontamentos sobre as modificações encontradas na Nota Técnica $\mathrm{N}^{\circ}$ 04/2020, que descreve o procedimento e enfatiza a prática como um importante meio de prevenção de doenças, principalmente da COVID-19.

\section{REFERÊNCIAS}

1. BRASIL. Normas Regulamentadoras. NR 32-Segurança e saúde no trabalho em serviços de saúde. Brasília: Ministério do Trabalho e Emprego, 2008. Disponível em: < https://www.gov.br/trabalho-eprevidencia/pt-br/composicao/orgaos-especificos/secretaria-de-trabalho/inspecao/seguranca-e-saude-notrabalho/ctpp-nrs/norma-regulamentadora-no-32-nr-32> Acessado em: 12 de setembro de 2021.

2. ANVISA. Agência Nacional de Vigilância Sanitária. Orientações para serviços de saúde: medidas de prevenção e controle que devem ser adotadas durante a assistência aos casos suspeitos ou confirmados de infecção pelo novo coronavírus (SARS-CoV-2) [Internet]. Nota Técnica GVIMS/GGTES/ANVISA no 04/2020: Brasília, DF. Disponível em: < https://www.gov.br/anvisa/ptbr/centraisdeconteudo/publicacoes/servicosdesaude/notas-tecnicas/nota-tecnica-gvims_ggtes_anvisa04_2020-25-02-para-o-site.pdf> Acessado em: 12 de setembro de 2021.

3. MATTE DL, et al. Recomendações sobre o uso de equipamentos de proteção individual (EPIs) no ambiente hospitalar e prevenção de transmissão cruzada na COVID-19. ASSOBRAFIR Ciência, 2020; 11(Suplemento 1): 47-64. 
RESUMO SIMPLES: Revisão Integrativa

\title{
O USO DAS TÉCNICAS DE JATEAMENTO E MICRO-OXIDAÇÃO PARA PROMOÇÃO DE UMA MELHOR OSSEOINTEGRAÇÃO EM IMPLANTES DE TITÂNIO
}

\author{
Leonardo Moraes de Oliveira Júnior ${ }^{1}$ \\ Maria Alice da Silva Souza ${ }^{1}$ \\ Luiz Gustavo de Sousa Duda Júnior ${ }^{1}$ \\ Robinson Felipe Santana da Silva ${ }^{1}$ \\ Juliana Silva do Nascimento ${ }^{1}$
}

1. Universidade de Pernambuco (UPE), Recife - PE.

Palavras-chave: Osseointegração, Implantação dentária, Titânio.

\section{INTRODUÇÃO}

A implantodontia permite a reabilitação oral para pacientes que apresenta a ausência de elementos dentários, atualmente os implantes à base de titânio são os mais utilizados, pois permitem maior biocompatibilidade, alta resistência à corrosão e melhor osseointegração (BLANCO LÓPEZ P, et al., 2018; ALGHAMDI HS e JANSEN JA, 2020).

Apesar das suas vantagens, os implantes de titânio apresentam capacidade biológica diminuída com o passar do tempo (CIGERIM L e KAPLAN V, 2020). O jateamento com areia de granulação e ataque ácido (SLA) e micro-oxidação por arco (MAO) são técnicas que têm sido bastante utilizadas, pois melhoram a capacidade osseointegrativa da região implantar (HE W, et al., 2019).

\section{OBJETIVO}

Analisar a importância da associação do Jateamento com areia de granulação e ataque ácido e a microoxidação por arco para a promoção de melhor osseointegração em pacientes com implantes dentários de titânio.

\section{MÉTODO}

Realizou-se uma revisão integrativa nas bases de dados: Índice Bibliográfico em Ciências da Saúde (IBECS), Literatura Latino-Americana e do Caribe em Ciências da Saúde (LILACS) e Medline, utilizando-se dos descritores: Osseointegração, Implantação Dentária e Titânio, no período de 2016 a outubro de 2021, utilizando-se como idiomas base: português, inglês e espanhol, excluindo-se artigos que não atendiam a temática proposta, o que resultou na seleção final de 4 artigos.

\section{REVISÃO BIBLIOGRÁFICA}


Estudos indicam a ineficácia da implantação em superfícies lisas, o que vem resultando na busca de superfícies texturizadas para melhor adaptação implantar e melhor osseointegração, as técnicas que promovem o aumento das rugosidades em superfícies implantares favorecem uma maior resistência à tensão, compressão e estresse (BLANCO LÓPEZ P, et al., 2018).

Segundo a literatura a técnica SLA quando associada a MAO tem apresentado melhores resultados do que o uso da técnica SLA aplicada isoladamente e apresenta como principais vantagens uma melhor adesão, proliferação e diferenciação osteogênica além de promover uma melhor cicatrização do tecido em volta do implante (HE W, et al., 2019).

\section{CONSIDERAÇÕES FINAIS}

As técnicas SLA e MAO tem se apresentado como importantes estratégias para que o cirurgião-dentista, sobretudo o implantodontista, realize a implantação dentária com menores riscos e maior osseointegração, uma vez que essas ferramentas aumentam a rugosidade do implante e contribuem para uma maior diferenciação osteogênica em implantes de titânio. Dessa forma, indica-se a importância para que mais estudos sejam feitos nessa área visando aprimorar essas técnicas.

\section{REFERÊNCIAS}

1. ALGHAMDI HS, JANSEN, JA. The development and future of dental implants. Dental materials journal, 2020; 39(2): 167-172.

2. BLANCO LÓPEZ $P$, et al. La oseointegración de implantes de titanio con diferentes superficies rugosas. Avances en odontoestomatología, 2018; 34(3): 141-149.

3. CIGERIM L, KAPLAN V. The Effect of Age of Titanium Dental Implants on Implant Survival and Marginal Bone Resorption: A 5-Year Retrospective Follow-Up Study. Journal of Oral Implantology, 2020; 46(5): 475479.

4. HE W, et al. Enhancing osseointegration of titanium implants through large-grit sandblasting combined with micro-arc oxidation surface modification. Journal of Materials Science: Materials in Medicine, 2019; 30(6): 73. 


\section{O USO DA INTELIGENCIA ARTIFICIAL NA ODONTOLOGIA}

Isabella Monteiro de Moraes ${ }^{1}$ Plínio Alves Vieira ${ }^{1}$

Amanda Benevenuto Bezerra²

Fernanda Carla Pantoja Quaresma ${ }^{1}$

Erick Nelo Pedreira ${ }^{1}$

1. Universidade Federal do Pará (UFPA), Belém - PA.

2. Centro Universitário FIBRA (FIBRA), Belém - PA.

Palavras-chave: Inteligência artificial, Informática odontológica, Odontologia.

\section{INTRODUÇÃO}

Desde o advento da ciência, busca-se entender o cérebro humano, mas, mesmo na atualidade, construir um modelo que o imite exatamente continua sendo um desafio (TANDON D E RAJAWAT J, 2020). Em 1950, o termo "Inteligência Artificial" (IA) foi descrito, se referindo a capacidade de construir maquinas que realizassem tarefas que eram feitas pelo homem (SCHWENDICKE F, et al., 2020). Na odontologia a IA é usada especialmente para tornar os diagnósticos mais precisos e eficientes, fornecendo para os pacientes um melhor tratamento, já que com esse artificio o cirurgião dentista pode ter um guia na tomada de decisões e ter uma melhor conduta clínica (KHANAGAR SB, ET AL., 2021).

\section{OBJETIVO}

Revisar a literatura científica com o objetivo de compreender melhor a respeito do uso da Inteligência Artificial na Odontologia e os benefícios que ela pode trazer para o atendimento odontológico.

\section{REVISÃO BIBLIOGRÁFICA}

A IA passou a estar presente na odontologia com o advento da computação de dados e o fornecimento de grande quantidade de dados de pacientes (TANDON D E RAJAWAT J, 2020). Programas de software automatizados, em que são usados sistemas baseados em IA, tornam o diagnóstico e o gerenciamento de dados mais rápidos na Odontologia, sendo utilizados para dar suporte as decisões clinicas dos profissionais, melhorando o diagnóstico, planejamento de tratamento e ajudando a prever o prognóstico dos pacientes. Além disso, a Inteligência Artificial ajuda, através dos sistemas automatizados a poupar tempo e aumentar a eficiência dos profissionais (KHANAGAR SB, et al., 2021).

A aplicabilidade da inteligência artificial na odontologia é vasta (AHMED N, et al., 2021), porém, as inteligências artificiais ainda não são, em muitos casos, empregadas na pratica clínica de rotina (SCHWENDICKE F, et al., 2020). Dentre as limitações do uso dessa tecnologia na Odontologia estão 
complexidade de alguns sistemas ou mecanismos, os custos e equipamento necessários para cada configuração e exigência de treinamento para cada modelo de IA (AHMED N, et al., 2021).

\section{CONSIDERAÇÕES FINAIS}

A Inteligência Artificial apresenta várias aplicabilidades na Odontologia, ajudando o cirurgião dentista na tomada de decisões, melhorando o planejamento do tratamento e determinando o prognostico do paciente, além de poupar tempo e melhorar a eficácia dos profissionais. Porém, apesar dos benefícios dessa tecnologia, ela ainda enfrenta desafios, sendo necessárias mais pesquisas na área da saúde para que a Inteligência Artificial possa ser amplamente implementada na rotina clínica odontológica.

\section{REFERÊNCIAS}

1. AHMED N, et al. Técnicas de Inteligência Artificial: Análise, Aplicação e Resultado em Odontologia - Uma Revisão Sistemática. BioMed Research International, 2021; 2021: 9751564.

2. KHANAGAR SB, et al. Developments, application, and performance of artificial intelligence in dentistry - A systematic review. Journal of Dental Sciences, 2021; 16(1): 508-522.

3. SCHWENDICKE F, et al. Artificial Intelligence in Dentistry: Chances and Challenges. Journal of Dental Research, 2020; 99(7): 769- 774.

4. TANDON D, et al. Present and future of artificial intelligence in dentistry. Jornal de Biologia Oral e Pesquisa Craniofacial, 2020; 10(4): 391- 396. 


\title{
IMPLICAÇÕES DO TABAGISMO NA DOENÇA PERIODONTAL
}

\author{
Júlia Maria Costa Baltazar ${ }^{1}$ \\ Marina Aparecida Duarte ${ }^{1}$ \\ Vitor Gabriel Martins Silva ${ }^{1}$ \\ Luiz Paulo Carvalho Rocha ${ }^{1}$
}

1. Centro Universitário Una Bom Despacho (Una), Bom Despacho - MG.

Palavras-chave: Doença periodontal, Periodontia, Tabaco.

\section{INTRODUÇÃO}

A doença periodontal se caracteriza pela inflamação de tecidos periodontais em resposta ao estímulo bacteriano periodontopatogênico. O biofilme bacteriano consiste no acúmulo, e organização, de microrganismos da microbiota bucal, e é o fator determinante para o surgimento da patologia. A doença é classificada como gengivite quando a infecção se restringe ao periodonto de proteção e como periodontite quando se estende para o periodonto de sustentação. A manifestação das doenças periodontais associa-se à uma gama de fatores de risco. Entretanto, seu surgimento, progressão e severidade podem estar relacionados às modificações fisiológicas desencadeadas pelo consumo de tabaco (MENESES TCS, et al., 2019; ROCHA EF, et al., 2019).

\section{OBJETIVO}

Realizar uma revisão na literatura científica a respeito da relação entre a doença periodontal e as substâncias presentes no tabaco, destacando as principais implicações para progressão e agravo dessa patologia.

\section{REVISÃO BIBLIOGRÁFICA}

O tabaco é constituído por várias substâncias químicas que provocam efeitos deletérios à saúde humana. A nicotina e o monóxido de carbono podem alterar a resposta imune, enfraquecendo-a frente aos periodontopatógenos. Isso pode resultar em maior perda de inserção periodontal e reabsorção óssea alveolar em pacientes acometidos pela periodontite (MENESES TCS, et al., 2019).

As alterações ósseas são provocadas pela diminuição proliferativa de osteoblastos, limitação da atividade dos fibroblastos e da síntese de colágeno. O consumo crônico e prolongado do tabaco provoca um efeito vasoconstritor, atenuando o fluxo sanguíneo, que modifica e aumenta a prevalência da microbiota patogênica. Devido à redução da angiogênese e fluxo sanguíneo, há supressão do sangramento gengival, contudo, há a destruição tecidual (MENESES TCS, et al., 2019; ROCHA EF, et al., 2019). 
Estudos demonstram a relação dose-dependente entre a extensão e gravidade da doença periodontal e o consumo de tabaco. Tabagistas apresentam menor capacidade de reparação de células periodontais, o que reduz a capacidade de formação de novos tecidos e prejudica a efetividade e previsibilidade do tratamento (CHAFFEE BW, et al., 2021; FESER G, et al., 2019).

\section{CONSIDERAÇÕES FINAIS}

Com base nas informações apresentadas, constata-se a influência das substâncias que compõe o tabaco, principalmente a nicotina e o monóxido de carbono, e seu efeito dose-dependente nas alterações microbiológicas, ósseas e teciduais que se associam à doença periodontal. Desse modo, compete ao cirurgião-dentista orientar seus pacientes sobre os efeitos deletérios do tabagismo para a saúde periodontal.

\section{REFERÊNCIAS}

1. CHAFFEE BW, et al. Oral and periodontal implications of tobacco and nicotine products. Periodontology 2000, 2021; 87: 241-253.

2. FESER G, et al. Severity of periodontal disease in smokers. Revista Científica do CRO-RJ (Rio de Janeiro Dental Journal), 2019; 4(1): 34-40.

3. MENESES TCS, et al. Análise da Doença Periodontal em pacientes Fumantes abrangendo os Efeitos Deletérios do Cigarro na perda de Inserção Clínica: Revisão de Literatura. Revista Multidisciplinar e de Psicologia, 2019; 13(48): 29-40.

4. ROCHA EF, et al. O cigarro, o narguilé e a doença periodontal. Revista Eletrônica Acervo Saúde, 2019; 28: e784. 


\section{BACTÉRIAS DO GÊNERO BIFIDOBACTERIUM SP.: UMA POSSÍVEL CORRELAÇÃO BENÉFICA NA ATENUAÇÃO DE HEPATITE AUTOIMUNE}

Paulo Henrique Silva ${ }^{1}$

Thaysa Durval de Souza ${ }^{1}$

Janaina da Silva Ferreira ${ }^{1}$

Ana Lúcia Figueiredo Porto ${ }^{1}$

Maria Taciana Cavalcanti Vieira Soares ${ }^{1}$

1. Universidade Federal Rural de Pernambuco (UFRPE), Recife - PE.

Palavras-chave: Bactéria, Bifidobacterium, Hepatite autoimune.

\section{INTRODUÇÃO}

Hepatite autoimune (HA), doença crônica caracterizada, principalmente, por infiltrações de células do sistema imunológico no tecido hepático, tende, se não tratada, levar à morte de indivíduos acometidos (SUCHER E, et al., 2019). Na literatura científica, a utilização de bactérias benéficas, colonizadoras ou não do intestino, como forma de auxiliar, seja no tratamento e/ou prevenção de diversas doenças, já é cada vez mais descrito e comprovado (KESIKA P, et al., 2021; MOLSKA M e REGULA J, 2019). Como por exemplo, foram observadas melhorias em distúrbio metabólicos, promovendo, também, modificações do sistema imune, através de modulação da microbiota intestinal (WANG B, et al., 2021).

\section{OBJETIVO}

Analisar as possíveis relações direta e/ou indireta entre bactérias do gênero Bifidobacterium sp. e a doença Hepatite autoimune em seres humanos e em camundongos acometidos, através de literatura científica presente em plataformas digitais.

\section{MÉTODO}

Trata-se de uma revisão integrativa. Para busca de artigos científicos, foi utilizado a plataforma digital PubMed, utilizando os seguintes descritores em inglês: Bacteria, Bifidobacterium e autoimmune hepatitis. Ao total, 10 artigos foram postos para análise, porém, apenas 6 artigos foram incluídos nesta revisão. Foram excluídas monografias, resumos, trabalhos não relacionados ao tema, artigos publicados antes de 2017, etc.

\section{REVISÃO BIBLIOGRÁFICA}

Ao analisar parâmetros microbiológicos em seres humanos acometidos com HA, percebeu-se uma diminuição nos níveis de bactérias do gênero Bifidobacterium sp., demonstrando assim, uma possível 
correlação inversamente proporcional, podendo estar relacionado à modulação da microbiota intestinal (LIWINSKI T, et al., 2020).

Outrossim, a administração por gavagem de bactérias da espécie Bifidobacterium animalis em camundongos com HA, demonstrou ser eficiente no melhoramento da doença, observando-se uma diminuição de infiltração de células inflamatórias no tecido hepático, bem como lesões. Além disso, aumentou concentrações de ácido butírico e diminuiu citocinas pró-inflamatórias como, por exemplo, IL-6 (ZHANG H, et al., 2020).

\section{CONSIDERAÇÕES FINAIS}

Diante dos resultados expostos nesta revisão, pode-se observa que pacientes acometidos com Hepatite autoimune, tendem a apresentar diminuição de bactérias do gênero Bifidobacterium, porém, como observado em estudos utilizando camundongos, a administração destas bactérias em indivíduos com esse quadro, apresentou-se com bons resultados. Sendo assim, a utilização biotecnológica dessas bactérias pode ser mais uma opção na mitigação da problemática.

\section{REFERÊNCIAS}

1. KESIKA P, et al. Role of gut-brain axis, gut microbial composition, and probiotic intervention in Alzheimer's disease. Life sciences, 2021; 264: 118627.

2. LIWINSKI T, et al. A disease-specific decline of the relative abundance of Bifidobacterium in patients with autoimmune hepatitis. Alimentary pharmacology \& therapeutics, 2020; 51(12): 1417-1428.

3. MOLSKA M, REGULA J. Potential Mechanisms of Probiotics Action in the Prevention and Treatment of Colorectal Cancer. Nutrients, 2019; 11(10): 2453.

4. SUCHER E, et al. Autoimmune Hepatitis-Immunologically Triggered Liver Pathogenesis-Diagnostic and Therapeutic Strategies. Journal of immunology research, 2019; 2019: 9437043.

5. WANG B, et al. Bifidobacterium adolescentis Isolated from Different Hosts Modifies the Intestinal Microbiota and Displays Differential Metabolic and Immunomodulatory Properties in Mice Fed a High-Fat Diet. Nutrients, 2021; 13(3): 1017.

6. ZHANG H, et al. Bifidobacterium animalis ssp. Lactis 420 Mitigates Autoimmune Hepatitis Through Regulating Intestinal Barrier and Liver Immune Cells. Frontiers in immunology, 2020; 11: 569104. 


\section{CUIDADOS PALIATIVOS EM ONCOLOGIA PEDIÁTRICA}

Thayz Gadelha de Paula Moreira ${ }^{1}$

Bárbara Wirtzbiki ${ }^{1}$

José Vieira da Silva Neto ${ }^{1}$

1. Unidade de Ensino Superior do Sul do Maranhão (UNISULMA), Imperatriz - MA.

Palavras-chave: Cuidados paliativos, Oncologia pediátrica, Crianças e adolescentes.

\section{INTRODUÇÃO}

A Organização Mundial da Saúde (OMS) define Cuidados Paliativos (CP) como uma abordagem que direciona a atenção e cuidado tantos aos pacientes, quanto aos familiares, abrangendo não somente questões físicas, mas também espirituais e psicossociais (OMS, 2020). Deste modo, não se recomenda associar cuidados paliativos apenas com a terminalidade (SOARES ES, et al., 2021).

O câncer infantil é caracterizado pela presença de neoplasias em crianças e adolescentes, de 0 a 19 anos, apresentando crescimento rápido e invasivo. Neste público, é mais comum a manifestação de leucemias, linfomas e cânceres do sistema nervoso central e neuroblastomas (OMS, 2021).

\section{OBJETIVO}

Discorrer sobre a importância dos cuidados paliativos em oncologia pediátrica, visto que há necessidade de favorecer maior conforto e uma melhor qualidade de vida a crianças e adolescentes com câncer.

\section{REVISÃO BIBLIOGRÁFICA}

Seguido do diagnóstico oncológico deve-se iniciar o processo de CP para prevenir, e aliviar o sofrimento tanto da doença quanto do tratamento promovendo uma melhor qualidade de vida. Na oncologia pediátrica, são necessários 3 níveis de intervenção - físico, psicossocial e espiritual, de modo que abranja tanto o paciente quanto sua família (PACHECO CL e GOLDIM JR, 2019).

A equipe profissional que atua nos $\mathrm{CP}$, necessita respeitar as individualidades dos pacientes e familiares, sendo de suma importância essa assistência desde as fases iniciais - como nas investigações da doença até o diagnóstico, tratamento e alta ou processo de luto. De modo que quanto maior a integração entre a tríade - equipe, paciente, família - melhor será o vínculo e os cuidados prestados (GUEDES AKC, et al., 2019).

Dentre os princípios necessários para os $\mathrm{CP}$, estão o alívio da dor e dos sintomas enfrentados, não visando gerar uma ideia de adiamento ou aproximação da morte e sim, oferecendo suporte necessário para que a criança viva da forma mais ativa possível durante o processo (OLIVEIRA TCB, et al., 2017). 


\section{CONSIDERAÇÕES FINAIS}

Concernente ao exposto nota-se a importância dos cuidados paliativos na oncologia pediátrica, oferecendo suporte tanto a criança quanto a família, envolvendo a todos na paliação. Mostrou-se necessário também o empenho da equipe em suprir todas as necessidades aparentes e proporcionar uma melhor qualidade de vida ao decorrer do processo de adoecimento.

\section{REFERÊNCIAS}

1. GUEDES AKC, et al. Cuidados paliativos em oncologia pediátrica: perspectivas de profissionais de saúde. Revista da Sociedade Brasileira de Psicologia Hospitalar. 2019. 1: 128-148.

2. OLIVEIRA TCB, et al. Equipe multiprofissional de cuidados paliativos em oncologia pediátrica: Uma revisão sistemática. Revista Multidisciplinar e de Psicologia. 2017. 1: 492 - 530.

3. ORGANIZAÇÃO MUNDIAL DE SAÚDE (OMS). Cuidado paliativos. 2020.Disponível em: https://www.who.int/news-room/fact-sheets/detail/palliative-care. Acessado em: 15 de outubro de 2020.

4. ORGANIZAÇÃO MUNDIAL DE SAÚDE (OMS). Iniciativa global da OMS para o câncer infantil: Implementação na América Latina e no Caribe. 2021. Disponível em: https://iris.paho.org/handle/10665.2/54416. Acesso em: 15 de outubro de 2020.

5. PACHECO CL, GOLDIM JR. Percepções da equipe interdisciplinar sobre cuidados paliativos em oncologia pediátrica. Revista Bioética. 2019. 1:67 - 75.

6. SOARES ES, et al. Desenvolvimento de tecnologia educativa para mães de crianças internadas em paliação não oncológica. Revista Eletrônica Acervo em Saúde, 2021;1:1 -10. 


\section{ALEITAMENTO MATERNO DURANTE A PANDEMIA POR COVID-19 (SARS-COV-2): REVISÃO NARRATIVA}

Bárbara Wirtzbiki ${ }^{1}$

Thayz Gadelha de Paula Moreira ${ }^{1}$

José Vieira da Silva Neto ${ }^{1}$

1. Unidade de Ensino Superior do Sul do Maranhão (UNISULMA), Imperatriz - MA.

Palavras-chave: Aleitamento materno, Leite materno, Pandemia.

\section{INTRODUÇÃO}

O ato da amamentação vai além de prover nutrientes para o Filho. Amamentar envolve proximidade entre mãe e bebê, é a melhor estratégia de vínculo entre os dois, gerando afeto, proteção e consequente impacto no seu estado nutricional (da SILVA JN, 2020). No cenário pandêmico atual (COVID-19), as inúmeras vantagens do leite materno e sua superioridade sobre qualquer outro tipo de leite, destaca sua capacidade imunomoduladora, desejável em qualquer situação (TACLA MTGM, et al., 2020). No entanto, o vírus não foi encontrado no leite materno, mas os dados são limitados e que a transmissão de gotículas para o recémnascido, ocorre no contato próximo durante a alimentação (FERNANDES E, et al., 2020).

\section{OBJETIVO}

Verificar através de uma revisão narrativa da literatura os benefícios do aleitamento materno para o bebê e os cuidados que devem ser tomados durante o período da pandemia do COVID-19.

\section{REVISÃO BIBLIOGRÁFICA}

O alimento ideal para os lactentes é o leite materno. O aleitamento é um dos pilares essenciais para a promoção da saúde dos bebês, resultando em vantagens para o binômio mãe - bebê. Esta deve ser estimulada pelos profissionais de saúde, assim como a doação de leite (da SILVA JN, 2020).

O leite materno é considerado o melhor alimento para o bebê devido suas propriedades nutricionais, que se mostram importantes para que o lactente cresça e se desenvolva da forma correta em seus primeiros meses de vida. Também é necessário para a prevenção de doenças e agravos, devido a sua concentração de anticorpos (GALVÃO DM e SILVA E, 2020).

Os fatores considerados, para o aleitamento, são as condições clínicas da mãe e do bebê, se a infecção da mãe é suspeita ou confirmada e o resultado do teste COVID-19 da criança for positivo, a separação não é necessária. Para minimizar o contato direto, o bebê é alimentado por um cuidador saudável com leite materno expresso do seio da lactante, até sua recuperação, visando manter a amamentação (FERNANDES E, et al., 2020). 


\section{CONSIDERAÇÕES FINAIS}

Os estudos colaboram para o aprendizado e comportamento deste vírus, sendo importante que continuem para que haja uma melhor orientação às puérperas, não onerando prejuízos nutricionais aos lactentes, considerando o não abandono do aleitamento com leite materno, sendo este essencial para a nutrição e proteção contra vírus comuns na infância, bem como contra o vírus SARS-CoV2.

\section{REFERÊNCIAS}

1. da SILVA JN. Aleitamento materno: motivos e consequências do desmame precoce em crianças. Revista Artigos.Com, 2020; 20: e4756.

2. FERNANDES E, et al. Amamentação X COVID-19. Revista Extensão \& Sociedade, 2020; 12(1).

3. GALVÃO DM, SILVA E. Amamentação e COVID-19: contributos para práticas seguras. Millenium, 2020; 2: $161-168$.

4. TACLA MTGM, et al. Reflexões sobre o aleitamento materno em tempos de pandemia por COVID-19. Revista da Sociedade Brasileira de Enfermagem Pediátrica, 2020; 20(esp): 60-76. 


\title{
OS BENEFÍCIOS DAS PRÁTICAS INTEGRATIVAS E COMPLEMENTARES NO PERÍODO GESTACIONAL: REVISÃO INTEGRATIVA
}

\author{
Lucas Manoel Oliveira Costa ${ }^{1}$
}

Gaubeline Teixeira Feitosa²

1. Instituto de Ensino Superior Múltiplo (IESM), Timon - MA.

2. Universidade Federal do Piauí (UFPI), Teresina - PI.

Palavras-chave: Terapias alternativas e complementares, Saúde da mulher, Gravidez.

\section{INTRODUÇÃO}

As Práticas Integrativas e Complementares (PICS) são medidas que estimulam os mecanismos naturais de prevenção, na qual promovem a recuperação da saúde utilizando recursos naturais, e se abstendo da alopatia (MENDES SD, et al., 2019). Durante a gestação ocorrem diversas mudanças físicas, psíquicas e sociais significativas, em que é comum o uso de tratamento farmacológico, inviabilizando a independência do autocuidado e catalisando o modelo biomédico (FERNANDES KS, et al., 2021). Assim, o uso das PICS se faz necessário para enaltecer a humanização na gestação e minimizar técnicas invasivas (ROBLEJO ESS, et al., 2021).

\section{OBJETIVO}

Revisar e identificar, por meio da literatura científica disponível nas bases de dados, os benefícios relacionados à adesão de um novo aspecto gestacional por meio das práticas integrativas e complementares.

\section{MÉTODO}

Trata-se de uma revisão integrativa da literatura, realizada por meio da estratégia PICO. Desta forma, a busca ocorreu nas bases de dados LILACS e SCIELO, usando os descritores: Terapias complementares; Gravidez e Análise de Intenção de Tratamento, perfazendo um total 460 artigos. Após aplicar os critérios de inclusão: recorte temporal de 2016 a 2021 e estudos originais, excluindo-se os que não atendem estes critérios, obteve-se um total de 06 artigos.

\section{REVISÃO BIBLIOGRÁFICA}

Sabe-se que as PICS estão em avanço constante, tornando-se, muitas vezes, a primeira escolha em tratamento. Salienta-se ainda que o vínculo materno-fetal é estimulado pelo uso destas práticas (SILVA HL, et al., 2020). Em outro estudo nota-se que há uma tendência progressiva entre as mulheres a se sentirem mais confiantes durante o processo parturitivo, ao usar uma terapia alternativa no período gestacional, e demonstram mais coragem frente à dor do parto (LARA SRG, et al., 2020). Outro aspecto positivo, é que tais 
terapias não requerem altos investimentos em recursos, sendo de fácil uso, facilitando a assistência, além de atender as necessidades da gestante (CAVALCANTI ACV, et al., 2019).

\section{CONSIDERAÇÕES FINAIS}

Desta forma, percebe-se que a gestação é um processo fisiológico desafiador, na qual é imprescindível o uso de meios que auxiliem a evolução deste ciclo. Assim, as PICS tornam-se mediadoras para possíveis repercussões negativas durante o período gravídico e puerperal, como também atuam na promoção do autocuidado, proporciona a humanização do atendimento profissional e nutre o horizonte em que a gestante é a protagonista deste ciclo de sua vida.

\section{REFERÊNCIAS}

1. CAVALCANTI ACV, et al. Terapias complementares no trabalho de parto: ensaio clínico randomizado. Revista Gaúcha de Enfermagem, 2019; 40(20190026): 01-09.

2. FERNANDES KS, et al. Uso das Práticas Integrativas e Complementares em Saúde pelos profissionais em gestantes com dores lombares: revisão integrativa. The Brazilian Journal of Pain, 2021; 4(2): 161-166.

3. LARA SRG, et al. Vivência de mulheres em trabalho de parto com o uso de essências florais. Revista de Pesquisa: Cuidado é Fundamental Online, 2020; 12(7178): 162-168.

4. MENDES DS, et al. Benefícios das práticas integrativas e complementares no cuidado de enfermagem. Journal Health NPEPS, 2019; 4(1): 302-318.

5. ROBLEJO ESS, et al. Utilização das práticas integrativas e complementares em saúde no pré-natal: revisão integrativa. Journal of Nursing and Health, 2021; 11(1): 01-19.

6. SILVA HL, et al. Efeitos da auriculoterapia na ansiedade de gestantes no pré-natal de baixo risco. Acta Paulista de Enfermagem, 2020; 33(20190016): 01-08. 


\title{
ATENÇÃO FARMACÊUTICA NO MANEJO DA DOR ONCOLÓGICA
}

\author{
Larissa Santos Carneiro Gomes ${ }^{1}$ \\ Raquel Olímpio Vicente da Silva Mendonça ${ }^{1}$ \\ Antônio Sérgio Alves de Almeida Júnior²
}

1. Centro Universitário Maurício de Nassau (UNINASSAU), Recife - PE.

2. Instituto Federal do Norte de Minas Gerais (IFNMG), Arinos - MG.

Palavras-chave: Atenção farmacêutica, Dor oncológica, Farmacoterapia.

\section{INTRODUÇÃO}

A dor oncológica é um problema clínico significativo em todo o mundo, com causas multifatoriais e complexas, podendo variar de acordo com os fatores e processos relacionados ao tumor e ao hospedeiro (CHWISTEK M, 2017). Sua prevalência é alta, sendo um dos aspectos mais temidos do câncer, afetando $55 \%$ dos pacientes em tratamento anticâncer e $66 \%$ dos pacientes com metástase avançada (OMS, 2019).

Entre os elementos essenciais para o manejo do paciente destaca-se o tratamento antineoplásico. Assim, o acompanhamento farmacoterapêutico visa detectar possíveis reações adversas aos medicamentos e garantir a adesão ao tratamento, promovendo a segurança, eficácia e, consequentemente, a melhoria na qualidade de vida (SIERKO E, et al., 2016).

\section{OBJETIVO}

Analisar e descrever a importância da atenção farmacêutica no seguimento farmacoterapêutico para manejo da dor crônica em pacientes com câncer visando a promoção e adesão ao tratamento e, por conseguinte, a melhoria na qualidade de vida do paciente.

\section{MÉTODO}

Revisão sistemática realizada através das bases Medline, PubMed e Scielo. Os DeCS utilizados foram: "phamaceutical services" e "cancer pain". Para o processo de síntese do presente resumo foram selecionados periódicos entre 2016-2021, em inglês e português, sendo 20 artigos selecionados para análise de títulos e 5 escolhidos após leitura. Não foram considerados aqueles antecedentes ao ano de 2016 e com fuga ao objetivo do trabalho.

\section{REVISÃO BIBLIOGRÁFICA}

Os cuidados farmacêuticos visam melhorar o uso de medicamentos para conseguir resultados concretos e eficientes junto a equipe multidisciplinar. $O$ farmacêutico tem grande influência para garantir ao paciente 
compromisso e eficiência do seu tratamento medicamentoso da melhor maneira possível (CALADO DS, et al., 2019).

Na literatura ainda carece de estudos voltados à dor do câncer. Contudo, a atenção farmacêutica é uma estratégia importante para a terapia do paciente oncológico, pois objetiva evitar erros relacionados ao medicamento e contribuir de maneira eficaz no cuidado ao paciente e melhoria da qualidade de vida (MEDEIROS JA, et al., 2019; MILLARD SK e KNEGT NC, 2019).

\section{CONSIDERAÇÕES FINAIS}

A dor oncológica é um fenômeno individual que tem grande influência na qualidade de vida do paciente. A equipe multidisciplinar se envolve, então, para proporcionar alívio da dor ao paciente. $O$ farmacêutico, portanto, pode analisar possíveis reações adversas e interações medicamentosas, intervindo para reduzir esses quadros, pois este profissional além da dispensação, tem a responsabilidade de orientar e acompanhar a terapia medicamentosa, contribuindo significativamente para o êxito do tratamento.

\section{REFERÊNCIAS}

1. ORGANIZAÇÃO MUNDIAL DA SAÚDE (OMS). WHO Guidelines for the pharmacological and radiotherapeutic management of cancer pain in adults and adolescentes. 2019. Disponível em: https://www.who.int/publications-detail-redirect/9789241550390. Acessado em: 27 de Outubro de 2021.

2. CHWISTEK M. Recent advances in understanding and managing cancer pain. F1000Research. 2017; 6(945): 1-10.

3. CALADO DS, et al. O papel da atenção farmacêutica na redução das reações adversas associados ao tratamento de pacientes oncológicos. Revista Brasileira De Educação E Saúde, 2019; 9(3), 94-99.

4. MEDEIROS JA, et al. Atuação do farmacêutico clínico hospitalar em pacientes oncológicos frente ao avanço na legislação brasileira. Revista Brasileira De Educação E Saúde, 2019; 9(3), 56-65.

5. MILLARD SK, DE KNEGT NC. Cancer Pain in People With Intellectual Disabilities: Systematic Review and Survey of Health Care Professionals. Journal of Pain and Symptom Management. 2019; 58(6): 1081 1099.e3. 
RESUMO SIMPLES: Revisão Integrativa

IMPACTO NA SAÚDE BUCAL DE PACIENTES COM SOROPOSITIVIDADE PARA HIV

\author{
Beatriz Pinheiro Cavalcante Melo ${ }^{1}$ \\ Arísia Graziele Galdino dos Santos ${ }^{1}$ \\ Giovanna Gabrielle Torquato e Silva ${ }^{1}$ \\ Mirela Carolaine Cunha da Cruz ${ }^{1}$ \\ Mariana de Moraes Correa Pérez ${ }^{1}$
}

1. Universidade Federal de Pernambuco (UFPE), Recife - PE.

Palavras-chave: HIV, Saúde oral, Qualidade de Vida.

\title{
INTRODUÇÃO
}

O Vírus da Imunodeficiência Humana (HIV) é uma doença sistêmica que acomete o indivíduo e o deixa mais suscetível às lesões bucais (ARAÚJO JF, et al., 2018). A cavidade oral está relacionada à saúde de todo sistema humano, sendo um dos principais pilares que contribui com a qualidade de vida (PARISH CL, et al., 2020). Ademais, em um estudo foi verificado que $67 \%$ dos entrevistados não sabiam quais os possíveis sintomas resultantes do HIV, fato este que reflete na cavidade oral, desde que muitos não estão cientes dos impactos que essa doença pode causar (COSTA FCA, et al., 2020).

\section{OBJETIVO}

Revisar e analisar, por meio de uma revisão de literatura, os impactos ocasionados à saúde oral de pessoas soropositivas e as possíveis alterações na microbiota oral devido a terapia antirretroviral.

\section{MÉTODO}

Trata-se de uma revisão integrativa de literatura, onde foram feitas buscas nas bases de dados Scielo, Pubmed, Acervo+ Index Base e Wiley Online Library, utilizando os seguintes descritores: HIV e Saúde Oral; totalizando 5 artigos científicos os quais tiveram como critério seletivo trabalhos nos idiomas inglês e português e, realizados nos últimos 5 anos.

\section{REVISÃO BIBLIOGRÁFICA}

Em uma revisão de literatura que avaliou, em diferentes partes do mundo, as manifestações orais do HIV, evidenciou que a Candidíase Oral (CO) foi a mais acometida em diferentes países, inclusive, sendo relatada em grupos que faziam terapia antirretroviral, como também, a prevalência de verrugas orais nesses grupos (TAPPUNI AR, 2020). Em outro estudo que objetificou avaliar status da mucosa oral, periodontal e dentição de pacientes com HIV, verificou que a $\mathrm{CO}$ foi a lesão oral mais prevalente afetando mais de $30 \%$ dos 
pacientes, e em seguida, outros tipos de lesões orais, como a gengivite ulcerativa necrosante (CHAUDHARY $P$, et al., 2020).

\section{CONSIDERAÇÕES FINAIS}

Com a revisão realizada, foi possível observar os impactos na saúde bucal de pacientes com HIV, destacando a CO como uma das infecções mais pertinentes, porém, muitas outras lesões acometem a cavidade oral. Considerando esse contexto, pacientes com soropositividade para HIV demandam atenção e cuidado na saúde bucal devido a suscetibilidade a doenças.

\section{REFERÊNCIAS}

1. ARAÚJO JF, et al. Principais manifestações bucais em pacientes pediátricos HIV positivos e o efeito da terapia antirretroviral altamente ativa. Ciência \& Saúde Coletiva, 2018; 23(1): 115-122.

2. CHAUDHARY $P$, et al. Oral health status and treatment needs among HIV/AIDS patients attending antiretroviral therapy center in Western India: a cross-sectional study. Journal of Family Medicine and Primary Care, 2020; 9(7): 3722.

3. COSTA FCA, et al. Perfil informacional de uma população jovem a respeito da AIDS e suas consequências. Revista Eletrônica Acervo Saúde, 2020; (47): e3173.

4. PARISH CL, et al. Oral health-related quality of life and unmet dental needs among women living with HIV. The Journal of the American Dental Association, 2020; 151(7): 527-535.

5. TAPPUNI AR. The global changing pattern of the oral manifestations of HIV. Oral Diseases, 2020; 26: 2227. 


\title{
CONSEQUÊNCIAS DO DÉFICIT DE VITAMINA B12 EM PESSOAS COM ESTILO DE VIDA VEGETARIANO
}

\author{
Junior de Jesus Guimaraes ${ }^{1}$ \\ Jean David Alves da Silva ${ }^{1}$ \\ Sara Figueiredo da Silva e Silva ${ }^{1}$ \\ Juliana Alves Ferreira ${ }^{1}$ \\ Leisiane Karolaine Santos ${ }^{2}$
}

1. Universidade Tiradentes (UNIT), Aracaju - SE.

2. Centro Universitário Estácio de Sergipe, Aracaju - SE.

Palavras-chave: Vitamina B12, Vegetarianismo, Complicações.

\section{INTRODUÇÃO}

Atualmente muitas pessoas estão aderindo às dietas vegetarianas ou veganas e são inúmeros os motivos que influenciam essa decisão. O principal problema dessas dietas é a limitação no consumo de determinados grupos de nutrientes, como é o caso da vitamina B12 encontrada principalmente na carne e derivados (MARTINEZ A, et al., 2019).

A vitamina B12 é uma importante substância que age na manutenção do funcionamento de praticamente todas as regiões do corpo. Apesar da vitamina ser sintetizada pelo próprio organismo sua melhor fonte de absorção está na alimentação de origem animal, tornando-nos dependentes da dieta para a obtenção (GARCIA M, et al., 2019).

\section{OBJETIVO}

Compreender melhor como a deficiência da vitamina B12 afeta os indivíduos que adotam a dieta vegetariana para suas vidas e descrever as manifestações clínicas em casos de deficiência da vitamina B12.

\section{REVISÃO BIBLIOGRÁFICA}

As dietas vegetarianas, apesar de serem considerada saudáveis, apresentam pequenas reservas de determinados micronutrientes, podendo causar déficits nutricionais, um dos principais problemas que pode ser desenvolvido quando adere essa dieta e realiza a restrição de certos alimentos ou grupos de alimentos específicos, consequentemente deixando poucas opções disponíveis para a obtenção de todos os nutrientes essenciais nisso, apresentam maior risco de carência de vitamina B12 (SILVA M, et al., 2019). As frequências de deficiência de B12 entre os vegetarianos são de $62 \%$ em gestantes, $25 \%-86 \%$ em crianças, $21 \%-41 \%$ em adolescentes e 11\% -90\% nos idosos" (ALLENDE A, et al., 2017). 
Diante disso, na deficiência de vitamina B12, as principais complicações encontradas são de ordens hematológicas, neurológicas e cutâneo. Em vista disso, a suplementação de vitamina B12 ou a ingestão de alimentos fortificados, são a melhor maneira de prevenir a deficiência, e estes também se mostram eficazes no tratamento (RíOS AJ e LÓPEZ CR, 2017).

\section{CONSIDERAÇÕES FINAIS}

Com o desenvolvimento do tema em questão, é verídico que existem perigos de aderir uma dieta vegetariana, sem dispor de acompanhamento nutricional adequado pode gerar malefícios para a saúde do indivíduo, sendo que a vitamina B12 é um importante nutriente para a fisiologia do corpo humano, em especial para o sangue e o sistema nervoso.

\section{REFERÊNCIAS}

1. ALLENDE D, et al. Ventajas y desventajas nutricionales de ser vegano o vegetariano. Revista Chilena de Neuropsicologia, 2017; 44: 218-225.

2. GARCIA M, et al. ¿Son las dietas vegetarianas nutricionalmente adecuadas? Una revisión de la evidencia científica. Revista Nutrición Hospitalaria 2019; 36: 950-961.

3. MARTíNEZ A, et al. Estudio exploratorio del vegetarianismo en restauración colectiva. Revista Nutrición Hospitalaria, 2019; 36; e10.20960.

4. RÍOS AJ e LÓPEZ CR. Secuelas neurofuncionales por déficit de cobalamina (vitamina B12) em um adulto joven: Estudio de caso. Revista Chilena de Neuropsicologia, 2017; 12: e10.5839.

5. SILVA M, et al. Vitamina B12 (Cobalamina): Aspectos clínicos de sua deficiência. Revista Referências em Saúde FESGO. 2019; 2: 147-152. 
RESUMO SIMPLES: Revisão Integrativa

\title{
ATUAÇÃO DA EQUIPE DE ENFERMAGEM NO CONTROLE DA SÍFILIS GESTACIONAL NA ATENÇÃO PRIMÁRIA À SAÚDE
}

\author{
Victória de Souza Nery ${ }^{1}$ \\ Angelica Ribeiro do Nascimento Oliveira ${ }^{2}$ \\ Jennifer Martins Pereira ${ }^{2}$ \\ Keith Ranny Pereira Cruz ${ }^{3}$ \\ Milena Nunes Alves de Sousa ${ }^{4}$
}

1. Faculdade São Francisco da Paraíba (FASP), Cajazeiras - PB.

2. Centro Universitário Maurício de Nassau (UNINASSAU), Teresina - PI.

3. Universidade Estadual de Maringá (UEM), Maringá - PR.

4. Centro Universitário de Patos (UNIFIP), Patos - PB.

Palavras-chave: Assistência da enfermagem, Sífilis, Atenção primária à saúde.

\section{INTRODUÇÃO}

As Infecções Sexualmente Transmissíveis vêm se tornando cada vez mais recorrentes nos últimos anos, configurando um verdadeiro problema de saúde pública. Nesse contexto, a sífilis gestacional destaca-se como umas das mais incidentes em todo o globo, chegando à faixa de mais de 900.000 gestantes infectadas no mundo segundo a Organização Mundial de Saúde e mais de 62.599 casos somente no Brasil (ROSA RFN, et al., 2020).

A atuação da equipe de enfermagem é indispensável, tanto na assistência quanto no controle dos casos, atuando na detecção prévia, diagnóstico e tratamento, objetivando um melhor prognóstico e qualidade de vida para essas gestantes (RODRIGUES ARM, et al., 2016).

\section{OBJETIVO}

Identificar, revisar e analisar por meio da literatura científica a atuação da equipe de enfermagem na assistência e a sua atuação no controle da sífilis gestacional na Atenção Primária à Saúde.

\section{MÉTODO}

Trata-se de uma revisão integrativa. Para tal, foram realizadas buscas nas bases de dados LILACS, BDENF, Coleciona SUS, no período do mês de outubro, a partir dos descritores em ciências da saúde assistência da enfermagem, sífilis e atenção primária à saúde. A análise contemplou quatro documentos, incluindo-se artigos originais em português, inglês e espanhol dos últimos cinco anos e excluindo-se os duplicados ou que não atendessem a temática proposta. 


\section{REVISÃO BIBLIOGRÁFICA}

O enfermeiro responsabiliza-se pela detecção precoce da sífilis gestacional mediante administração de testes rápidos, distribuídos nas unidades de saúde as gestantes a cada trimestre, os quais são necessários para o controle da doença a fim de evitar a transmissão vertical (SILVA VBS, et al., 2020).

Em outro estudo notou-se que a equipe de enfermagem ainda realiza o diagnóstico da doença e a notificação compulsória com a finalidade de criar e traçar o plano de tratamento e monitoramento das gestantes (PEREIRA BB, et al., 2020). Também foi constatado que o profissional utiliza como artifício à educação em saúde para diminuir a cadeia de transmissão (RODRIGUES ARM, et al., 2016).

\section{CONSIDERAÇÕES FINAIS}

Diante dos estudos apresentados, fica claro que o enfermeiro desempenha papel primordial nas unidades básicas de saúde ao detectar e realizar precocemente o diagnóstico da doença, oferecendo um melhor tratamento com o propósito de ofertar um pré-natal tranquilo, visto que as mulheres grávidas constituem um grupo sensível pela sua própria fisiologia, fazendo com que a assistência nesse meio se torne essencial.

\section{REFERÊNCIAS}

1. PEREIRA BB, et al. Realização de testes rápidos de sífilis em gestantes por enfermeiros da atenção básica. Revista Enfermagem UFSM, 2020; 10(82): 1-13.

2. ROSA RFN, et al. O manejo da sífilis gestacional no pré-natal. Revista Enfermagem UFPE online, 2020; 14.

3. RODRIGUES ARM, et al. Atuação de enfermeiros no acompanhamento da sífilis na atenção primária. Revista enfermagem UFPE online, 2016; 10(4): 247-55.

4. SILVA VBS, et al. Construção coletiva de um fluxograma para acompanhamento das gestantes com sífilis no município de São José-SC. Cogitare Enfermagem, 2020; 25: e65361. 


\title{
RELAÇÃO ENTRE A PERIODONTITE E O LÚPUS ERITEMATOSO SISTÊMICO (LES)
}

\author{
Arísia Graziele Galdino dos Santos ${ }^{1}$ \\ Beatriz Pinheiro Cavalcante Melo ${ }^{1}$ \\ Giovanna Gabrielle Torquato e Silva ${ }^{1}$ \\ Mirela Carolaine Cunha da Cruz $^{1}$ \\ Mariana de Moraes Corrêa Perez ${ }^{1}$
}

1. Universidade Federal de Pernambuco (UFPE), Recife - PE.

Palavras-chave: Periodontite, Lúpus Eritematoso Sistêmico, Dental care.

\section{INTRODUÇÃO}

A periodontite é uma inflamação crônica agressiva que compromete a cavidade oral afetando, principalmente, os tecidos periodontais, podendo ocasionar a perda do dente (CALDERARO D, et al., 2016). Já o Lúpus Eritematoso Sistêmico (LES) é uma disfunção autoimune que afeta o tecido conjuntivo e, consequentemente, vários órgãos do corpo (CALDERARO D, et al., 2016).

Desse modo, é compreensível validar a interferência mútua dessas enfermidades devido às semelhanças existentes entre elas, de forma que estudos recentes evidenciam a relação da doença periodontal em pacientes com LES (LIMA P, et al., 2018).

\section{OBJETIVO}

Revisar e verificar através de uma busca na literatura científica as relações existentes entre a doença periodontal e o Lúpus, uma vez que a primeira se enquadra como sendo uma patologia infecciosa e, a segunda, uma doença autoimune.

\section{MÉTODO}

Foi realizada uma revisão integrativa, a partir de buscas nas bases de dados Pubmed, Scielo, BVS e Acervo+ Index base, utilizando os seguintes descritores: Periodontite, Lúpus Eritematoso Sistêmico, Dental Care; totalizando 5 artigos científicos, os mesmos tiveram como critério seletivo trabalhos nos idiomas português e inglês e, realizados, nos últimos 5 anos.

\section{REVISÃO BIBLIOGRÁFICA}

Verificou-se através de pesquisas que a resposta do hospedeiro a periodontite é mediada pelos linfócitos T e B, neutrófilos e macrófagos. Essas células são desencadeadas para produzir mediadores inflamatórios, que contribuem com a degradação do tecido e reabsorção óssea. A disfunção imunológica do LES intensifica 
a atividade dos linfócitos $\mathrm{B}$, o que aumenta a síntese de imunoglobulinas e anticorpos, ocasionando a deposição de complexos imunes e posterior dano ao tecido conjuntivo e a diversos órgãos (SETE M, et al., 2016). Além disso, percebeu-se que o polimorfismo no receptor Fcy relaciona-se tanto à periodontite quanto a doenças autoimunes, como o LES (GOFUR N, et al., 2020).

\section{CONSIDERAÇÕES FINAIS}

Assim, os estudos revisados revelaram que pacientes com LES correm mais riscos de possuir um comprometimento da saúde bucal assim sendo maior chance a doenças periodontais. De modo que as mesmas influenciam a progressão de ambas as disfunções. Logo, é necessário serem feitos mais estudos, a fim de se ter um melhor domínio das patogenicidades semelhantes às mesmas, desde que, há uma associação significativa entre periodontite e LES.

\section{REFERÊNCIAS}

1. CALDERARO DC, et al. Há associação entre o lúpus eritematoso sistêmico e a doença periodontal? Revista Brasileira de Reumatologia, 2016; 56(3): 280-284.

2. CORREA JD, et al. Subgingival microbiota dysbiosis in systemic lupus erythematosus: association with periodontal status. Microbiome, 2017; 5(1): 1-13.

3. GOFUR NRP, et al. Periodontal tissue condition on systemic lupus erythematosus patients: a clinical study. Pesquisa Brasileira em Odontopediatria e Clínica Integrada, 2020; 20: e5094.

4. LIMA PS, et al. O Lúpus eritematoso sistêmico e seu processo de adoecimento: uma concepção feminina. Revista Eletrônica Acervo Saúde, 2018; 20(18): e115.

5. SETE MRC, et al. Periodontitis and systemic lupus erythematosus. Revista brasileira de reumatologia, 2016; 56(2): 165-170. 
RESUMO SIMPLES: Revisão Integrativa

\title{
FATORES DE RISCO E FATORES PROTETORES PARA AUTO-ESTIMA NA GESTAÇÃO
}

\author{
Angelica Ribeiro do Nascimento Oliveira ${ }^{1}$ \\ Caroline Taiane Santos da Silva²
}

1. Centro Universitário Mauricio de Nassau (UNINASSAU), Teresina - PI.

2. Escola Bahiana de Medicina e Saúde Pública (EBMSP), Salvador - BA.

Palavras-chave: Autoimagem, Gestante, Gravidez.

\section{INTRODUÇÃO}

A gestação é um processo fisiológico repleto de transformações na vida da mulher que gera muitos sentimentos e alterações corporais, psicológicas, sociais e culturais, mudanças internas e externas (ALVES FLC, 2019). Em sua maioria essas alterações fazem parte do processo natural da gravidez, mas afeta o psicológico da mulher por acreditar que não se encontra no padrão corporal feminino adequado, tais mudanças acabam tendo consequências na imagem corporal da mulher, a identificação precoce desses desconfortos com sua aparência é imprescindível minimizar o possível impacto sobre a saúde do binômio materno-fetal, visando colaborar com a melhoria dos indicadores de saúde (RODRIGUES ARM, et al., 2017).

\section{OBJETIVO}

Conhecer as considerações apresentadas pela literatura sobre a autoestima em mulheres durante 0 período gestacional, identificando o que representam fatores de risco ou proteção para a autoestima na mulher grávida.

\section{MÉTODO}

Trata-se de uma revisão integrativa da literatura, realizada nas bases de dados SCIELO, PUBMED E LILACS, utilizando os descritores "Autoimagem"; "Gestante" e "Gravidez" e o operador booleano "AND". Adotou-se como critérios de inclusão: artigos nos idiomas português e inglês, que estivessem de acordo com a temática abordada. Foram excluídos estudos repetidos. A amostra final foi constituída por três artigos.

\section{REVISÃO BIBLIOGRÁFICA}

As mulheres durante o processo gestacional passam por inúmeras alterações anatômica e fisiológicas, dermatológicas, além de mudanças emocionais onde ela se ver com uma imagem destorcida do que realmente ela e. Todas essas mudanças causam baixa autoestima na gestante decorrentes de estrias, celulites, obesidade, falta de apoio familiar e também do parceiro, baixo poder aquisitivo, não planejamento da gravidez e falta de assistência (DIAS GL, et al., 2021). 
E fatores para melhorar a autoestima pode observar uso de hidrantes, cuidados com a saúde mental, assistência de saúde, pré-natal de qualidade, apoio familiar, situação financeira estável, apoio do parceiro e informações adequadas sobre as mudanças gestacionais (RODRIGUES ARM, et al., 2017).

\section{CONSIDERAÇÕES FINAIS}

Os cuidados com a gestante durante a gestação são essenciais dando suporte, apoio emocional, dialogando e entendendo que esse processo vivido pelas mulheres, são repletos de mudanças que afetam e causam alterações tanto físicas, como mentais e emocionais, pois em sua maioria as mulheres lidam com doenças comuns na gestação e obesidade decorrente da gravidez.

\section{REFERÊNCIAS}

1. ALVES FLC, et al. Group of high-risk pregnant women as a health education strategy. Revista Gaúcha de Enfermagem, 2019.

2. DIAS GL, et al. Aspectos sociais e biológicos da autoestima na gravidez e a assistência de enfermagem: revisão narrativa. Revista Eletrônica Acervo Enfermagem, 2021; 11: e5320.

3. RODRIGUES ARM, et al. High-risk pregnancy: analysis of health determinants. Sanare [Internet]. 2017; 16(1): 23-28. 
RESUMO SIMPLES: Revisão Narrativa

\title{
ATRIBUIÇÕES DA EQUIPE DE ENFERMAGEM NO TRANSPORTE DE PACIENTES NO SERVIÇO AEROMÉDICO
}

\author{
Sara Figueiredo da Silva e Silva ${ }^{1}$ \\ Jean David Alves da Silva ${ }^{1}$ \\ Junior de Jesus Guimarães ${ }^{1}$ \\ Juliana Alves Ferreira ${ }^{1}$ \\ Leisiane Karolaine Santos ${ }^{2}$
}

1. Universidade Tiradentes (UNIT), Aracaju - SE.

2. Centro Universitário Estácio de Sergipe, Aracaju - SE.

Palavras-chave: Cuidados de enfermagem, Enfermagem em emergência, Medicina aeroespacial.

\section{INTRODUÇÃO}

O atendimento aeromédico é complexo e destina-se a busca, localização, resgate e atendimento de pacientes vítimas de acidentes, violências ou complicações clínicas, em locais afastados ou de difícil acesso, nos quais as ambulâncias, por via terrestre, não possam alcançar de forma fácil e rápida, prestando atendimento também em situações de calamidades e desastres (NASCIMENTO KC, et al., 2018).

A prática dos enfermeiros no atendimento pré-hospitalar móvel e inter-hospitalar em aeronaves requer experiência prévia em contextos pré-hospitalares e hospitalares para o desenvolvimento de competências e habilidades específicas (RADUENZ SBP, et al., 2020).

\section{OBJETIVO}

Revisar a literatura cientifica com o objetivo de descrever as atribuições da equipe de enfermagem durante o desempenho do seu trabalho no serviço aeromédico em aeronaves de asas fixas e asas rotativas.

\section{REVISÃO BIBLIOGRÁFICA}

A equipe no transporte aéreo necessita de entendimento sobre a fisiologia de voo e das mudanças que podem sobrevir a condição de saúde do paciente, sendo esse conhecimento o fundamento das habilidades específicas para atuação no ambiente aeroespacial (SCHWEITZER G, et al., 2020). Em um estudo exploratório-descritivo com 50 enfermeiros de serviços aeroespaciais do Brasil, o enfermeiro realiza atividades relacionadas ao planejamento, à organização e à provisão de recursos para uma assistência integral e segura ao paciente (RADUENZ SBP, et al., 2020).

Ainda nesse mesmo estudo a atribuição realizada com maior frequência pelos participantes "enfermeiros" foi a verificação e o teste da funcionalidade de cada aparelho na etapa de pré-voo, com ênfase na importância 
do enfermeiro na previsão e provisão de materiais e equipamentos na gestão de insumos e materiais nos serviços de saúde. Durante o voo, a assistência integral ao paciente destacou-se como principal atividade dos enfermeiros e no pós-voo, destacou-se como principal atividade a reposição de insumos e equipamentos utilizados (RADUENZ SBP, et al., 2020).

\section{CONSIDERAÇÕES FINAIS}

Com base nos achados, é evidente que as atribuições desenvolvidas pela equipe de enfermagem são primordiais no serviço aeromédico. A realização desse tipo de transporte de pacientes por ainda ser recente em nosso país requer treinamento específico e constantes atualizações, visando uma assistência de enfermagem cada vez mais qualificada.

\section{REFERÊNCIAS}

1. NASCIMENTO KC, et al. Idosos atendidos em um serviço aeromédico. Rev. Bras. Geriatr. Gerontol, 2018; 21(1): 82-90.

2. RADUENZ SBP, et al. Atribuições do enfermeiro no ambiente aeroespacial. Rev Bras Enferm. 2020; 73(4): e20180777.

3. SCHWEITZER G, et al. Implementação do protocolo de cuidados de enfermagem no trauma em serviço aeromédico. Rev Bras Enferm. 2020; 73(3): e20180516. 


\title{
COMPLICAÇÕES NEUROLÓGICAS POR SHIGELOSE NA PRIMEIRA INFÂNCIA
}

\author{
Felipe Nilson Santiago Galiza ${ }^{1}$ \\ Jullyane Beatriz Gomes de Lima ${ }^{1}$ \\ Arthur de Morais e Silva ${ }^{1}$ \\ Dijalva Muniz de Morais ${ }^{2}$
}

1. Faculdade Tiradentes (FITS), Jaboatão dos Guararapes - PE.

2. Universidade Federal de Pernambuco (UFPE), Recife - PE.

Palavras-chave: Shigella spp, Primeira infância, Neurológico.

\section{INTRODUÇÃO}

A Shigelose é uma infecção gastrointestinal causada pela bactéria do gênero Shigella spp, sua transmissividade pode ser por contato direto, por alimentos, por água contaminados e por vetores. A Shigella spp é apontada como um problema de saúde pública, principalmente em países em desenvolvimento, com ênfase na faixa etária da primeira infância (DA CUNHA FPL, et al., 2017)

A infecção gastrointestinal aguda pela Shigella spp têm tendência a ter apresentação clínica branda em adultos, mas na primeira infância se pode ter diarreia aguda, que é uma das principais causas de mortalidade infantil no mundo, além de uma possível apresentação extra-intestinal (DA CUNHA FPL, et al., 2017; AFROZE F, et al., 2020).

\section{OBJETIVO}

Produzir uma revisão narrativa sobre as principais complicações neurológicas por Shigelose em crianças da faixa etária da primeira infância, e dando ênfase nos países subdesenvolvidos, ademais abordando alterações de curto e longo prazo.

\section{REVISÃO BIBLIOGRÁFICA}

Nos artigos analisados foi observado que, além da importância na mortalidade na primeira infância por diarreia aguda. Estima-se 188 a 269 milhões de novos casos por ano no mundo, que acabam acarretando entre 164.300 a 212.440 mortes, com maior prevalência em crianças na primeira infância. Apesar disso, o estudo epidemiológico no Brasil ainda não é tão visado (JAYAKRISHNAN MP, et al., 2020).

A Shigelose tem como relevância suas complicações neurológicas, que podem ser de curto prazo, como a encefalopatia tóxica letal ou Síndrome de Ekiri, da qual seus principais sintomas associados são as convulsões prolongadas e alteração sensorial prolongada, que induzem maior probabilidade de morte. Ademais, as consequências neurológicas a longo prazo de uma Shigelose, em crianças de até 6 anos, podem prejudicar o desenvolvimento neuropsicológico, promovendo um aumento no índice de crianças com TDAH 
(Transtorno do déficit de atenção com hiperatividade (JAYAKRISHNAN MP, et al., 2020; MERZON E, et al., 2020).

\section{CONSIDERAÇÕES FINAIS}

A Shigelose tem uma influência importante no desenvolvimento neurológico e na mortalidade infantil. Vale ressaltar que se deve ter uma atenção maior sobre essa doença, a ponto de se melhorar os diagnósticos e a prevenção, reduzindo assim as complicações neurológicas e mortalidade de crianças na primeira infância. Existe hoje uma vacina oral da bactéria viva em desenvolvimento aos moldes da vacina para rotavírus que pode reduzir os casos da doença.

\section{REFERÊNCIAS}

1. AFROZE F, et al. Pathogen-specific risk of seizure in children with moderate-to-severe diarrhoea: Case control study with follow-up. Tropical Medicine and International Health, 2020; 25(8): 1032-1042.

2. DA CUNHA, FPL, et al. Shigella sp: Um Problema de Higiene Alimentar, 2017; 31(264/265): 52-57.

3. JAYAKRISHNAN MP, et al. Factors Associated With Mortality in Toxic Encephalopathy Due to Shigellosis in Children. Indian Pediatrics, 2020; 57(11): 1029-1032.

4. MERZON E, et al. Early Childhood Shigellosis and Attention Deficit Hyperactivity Disorder: A PopulationBased Cohort Study with a Prolonged Follow-up. Journal of Attention Disorders, 2020; 25(13): 1791-1800. 


\title{
VIOLÊNCIAS OBSTÉTRICAS: ANÁLISE DO RECONHECIMENTO E SUA ABORDAGEM
}

\author{
Joyce Silva Casotti Deccache Ribeiro ${ }^{1}$ \\ Ana Cristina da Silva Santos ${ }^{2}$ \\ Géssica Silva Cazagrande ${ }^{3}$
}

1. Universidade Estácio de Sá (UNESA), Niterói - RJ.

2. Faculdade de Ciências Empresariais (FACEMP), Amargosa - BA.

3. Universidade Federal Fluminense (UFF), Niterói - RJ.

Palavras-chave: Violência obstétrica, Parto hospitalar, Saúde da mulher.

\section{INTRODUÇÃO}

$\mathrm{Na}$ atualidade, a ideia do parto seguro é frequentemente associada a medicalização, esse é um pensamento enraizado e que para muitos configura segurança e eliminação de prováveis riscos. Porém, o avanço transformou o processo do parto em um momento apenas científico, em que a prática médica deve ser exercida com o objetivo de se obter êxito no processo (BARRERA DC e MORETTI-PIRES RO, 2021). É justamente essa concepção que afeta a busca por um parto não apenas seguro, mas também humanizado. Assim, mesmo com os avanços e lutas contra a violência obstétrica, ainda é comum a ocorrência de crueldades e injustiças antes, durante e após o parto.

\section{OBJETIVO}

Realizar uma análise integrativa de estudos sobre violência obstétrica, de modo a descrever e discutir os elementos associados e correlacionados às ocorrências, além de investigar a produção científica atual acerca do tema.

\section{MÉTODO}

Trata-se de um estudo de revisão bibliográfica integrativa com busca na base de dados Scielo e Acervo + Index Base, usando os descritores "violência obstétrica", "parto hospitalar", "saúde da mulher" e "episiotomia", foram encontrados 50 artigos e destes selecionados 4 para a revisão. Critérios de inclusão: artigos na íntegra, em português, publicadas entre 2017 e 2021. Foram excluídas publicações cujos títulos ou objetivos não possuíam associação direta com o assunto.

\section{REVISÃO BIBLIOGRÁFICA}

Observa-se a ocorrência de violência obstétrica entre 18,3\% a 44,3\% (HENRIQUES T, 2021). Em São Paulo, a taxa de cesarianas chegou a 58,6\% (CNS, 2019). As violências obstétricas mais comuns são, impor 
a realização de cesariana, ignorar queixas, impedir acompanhamento durante o parto, não aplicar anestesia, realizar Manobra de Kristeller, uso de ocitocina e episiotomia sem consentimento (COELHO JA, et al., 2020; RIBEIRO KG, et al., 2021). O pré-natal inadequado resulta na desinformação, medo de dores e modificações vaginais, que contribuem para cesariana. A naturalização da violência favorece a sua incidência, e dificulta o seu reconhecimento. (COELHO JA, et al., 2020).

\section{CONSIDERAÇÕES FINAIS}

É possível notar que a violência durante o parto ocorre com frequência e reconhecê-la é um passo importante para que possa ser evitada. É através da promoção da saúde e da consulta pré-natal que a gestante deve ser orientada, para ter consentimento dos procedimentos que serão realizados. O parto deve ser realizado com exercício profissional qualificado, respeitando todos os direitos da mulher e priorizando seu bem-estar.

\section{REFERÊNCIAS}

1. BARRERA, DC; MORETTI-PIRES, RO. Da violência obstétrica ao empoderamento de pessoas gestantes no trabalho das doulas. Rev. Estud. Fem. 2021; 29(1).

2. CAVALHEIRO EAM, et al. Violência obstétrica: revisão de literatura. Revista Artigos.Com. 2021: 26.

3. COELHO JA, et al. Violência Obstétrica: A Agressão Silenciosa Nas Salas De Parto. Revista da Graduação em Psicologia da PUC Minas, 2021; 5(9): 719-740.

4. CONSELHO NACIONAL DE SAÚDE (CNS). Recomendação № 038. 2019. Disponível em: http://conselho.saude.gov.br/images/Reco038.pdf?fbclid=IwAR3cTQjbEo8NQ7m6rELCJbqelhtooluKSRk vgEhg0l1EDtwXB2vOhhgPvSU. Acessado em: 05 de outubro de 2021.

5. HENRIQUES T. Violência obstétrica: um desafio para saúde pública no Brasil. Página Grená, 2021: 1-4. 


\section{ADERÊNCIA DOS BUNDLES COMO ESTRATÉGIA DE PREVENÇÃO DE PNEUMONIA ASSOCIADA À VENTILAÇÃO MECÂNICA}

Josilene Nascimento do Lago ${ }^{1}$

Emyly Monteiro Correa ${ }^{1}$

Cosmo de Sousa Costa ${ }^{2}$

Raissa Ribeiro da Silva ${ }^{1}$

Nadja Adriana Ferreira da Silva Zweite ${ }^{3}$

1. Universidade da Amazônia (UNAMA), Belém - PA.

2. Universidade Federal do Pará (UFPA), Altamira - PA.

3. Faculdade Cosmopolita, Belém - PA.

Palavras-chave: Pneumonia associada à ventilação mecânica, Pacotes de Assistência ao Paciente, Unidade de Terapia Intensiva.

\section{INTRODUÇÃO}

A Pneumonia Associada à Ventilação Mecânica (PAVM) é uma infecção pulmonar acometida nos indivíduos internados em Unidade de Terapia Intensiva (UTI), que concentra recursos humanos e técnicos altamente especializados como o uso de Ventilação Mecânica (VM), intubação endotraqueal ou orotraqueal (CAVALCANTE ABL, et al., 2019).

Cerca de $8 \%$ a $28 \%$ dos usuários em suporte à VM desenvolvem PAVM, sendo que o agravamento pode ultrapassar $50 \%$ dos casos, posteriormente no contato com os agentes infecciosos (bactéria, vírus, fungo e outros). Nesse contexto, os bundles são classificados como medidas preventivas baseadas em evidências científicas que contribuem no controle da PAVM na UTI (VIANA AA, et al., 2018).

\section{OBJETIVO}

Identificar os principais estudos sobre os pacotes assistenciais ao paciente crítico e analisar a eficácia dos bundles na prevenção da Pneumonia Associada à Ventilação Mecânica na Unidade de Terapia Intensiva.

\section{MÉTODO}

Optou-se pela Revisão Integrativa da Literatura descritiva/qualitativa. A busca ocorreu com a estratégia PICo na Biblioteca Virtual em Saúde, junto ao cruzamento dos descritores e o operador booleano AND. Foram inclusos estudos originais, completos e publicados entre 2016 a 2020. Foram excluídas revisões, estudo fora do recorte temporal. Para a análise, utilizamos o método de Bardin (2011), focando na seleção, elegibilidade e a inclusão de estudos (CARVALHO BC, 2018). 


\section{REVISÃO BIBLIOGRÁFICA}

Dos 783 estudos rastreados, apenas 20 artigos foram incluídos, apontando os bundles como estratégia de prevenção da PAVM. As medidas mais comuns na constituição das bundles são a elevação da cabeceira a $30^{\circ}$, troca do circuito, interrupção diária da sedação, aspiração subglótica, higiene oral, mudança de decúbito, profilaxia de úlceras, procedimentos endotraqueais e verificação da pressão do cuff (FROTA ML, et al., 2019).

Os resultados encontrados revelaram que houve um número significativo de adesão dos bundles, levando uma diminuição na taxa de incidência da PAVM na UTI. No entanto, constatou a utilização de medidas diferentes, tornou ainda mais difícil determinar as reais medidas eficazes (FORTUNATTI CFP, 2017).

\section{CONSIDERAÇÕES FINAIS}

Verificou-se a carência de publicações relacionadas ao tema, ou seja, não há um quantitativo de evidências científicas que corrobore que o uso de todas as medidas é eficaz. Diante disso, é plausível afirmar necessidade da realização de novos estudos nesta área, para definir uma única abordagem de intervenções que incorporarem os pacotes de assistência ao paciente na UTI, assim, poder afirmar a eficácia dos bundles na prevenção da PAVM.

\section{REFERÊNCIAS}

1. CARVALHO BC. Atuação da Equipe de Enfermagem no Cuidado ao Paciente Grave. Revista Eletrônica Acervo Saúde, 2018; 17: e36.

2. CAVALCANTE ABL. Pneumonia associada à ventilação mecânica: consequências e mortalidade em uma unidade de terapia intensiva. Revista Eletrônica Acervo Saúde, 2020; 44: e2385.

3. FROTA ML, et al. Boas práticas para prevenção de pneumonia associada ao ventilador no pronto-socorro. Revista da Escola de Enfermagem da USP, São Paulo, 2019; 53: e0460.

4. FORTUNATTI CFP. Impacto de dois bundles na infração útil a um cateter central em pacientes críticos. Revista Latino-Americana de Enfermagem, Ribeirão Preto, 2017; 25: e2951.

5. RODRIGUES AN, et al. Impactos e fatores determinantes no bundle de pneumonia associada à ventilação mecânica. Revista Brasileira de Enfermagem, Brasília, 2016; 69(6): 1108-1114.

6. VIANA AA, et al. Resultados clínicos relacionados à incidência de pneumonia associada à ventilação mecânica em adultos- um estudo de coorte. Fisioterapia em movimento, Curitiba, 2018; 31: e003115. 


\section{VARIAÇÕES DA NORMALIDADE DA ATM}

Deivson Henrique dos Santos ${ }^{1}$

Marília de Matos Amorim ${ }^{1}$

1. Unidade de Ensino Superior de Feira de Santana (FAESF/UNEF), Feira de Santana - BA.

Palavras-chave: Anomalias, Articulação temporomandibular, DTM.

\section{INTRODUÇÃO}

A Articulação Temporomandibular (ATM) é uma estrutura bilateral constituída por tecido ósseo e tecidos moles que associados desempenham mecanismos fundamentais na orientação dos movimentos mandibulares e distribuição de forças produzidas continuamente pela mandíbula e demais ossos craniofaciais, tais como abrir a boca, mastigar, deglutir e falar. As Disfunções Temporomandibulares (DTM's) surgem da desarmonia dos constituintes da ATM e do sistema estomatognático, são uma classe de desordens musculoesqueléticas onde variam de crônicas à agudas, até mesmo degenerativas, podendo levar à perda de função e deformidades das estruturas de suporte, sua etiologia está associada à maloclusões, traumas faciais e fatores emocionais (VILAR EGS, et al, 2020; da SILVA CL, et al, 2021).

\section{OBJETIVO}

Revisar a literatura científica sobre a anatomia habitual da Articulação Temporomandibular (ATM) e as possiveis anomalias que podem the acometer, como as Disfunções Temporomandibulares (DTM's) e seus impactos na vida do indivíduo, descrevendo suas principais causas e manifestações.

\section{REVISÃO BIBLIOGRÁFICA}

O posicionamento normal do disco articular da ATM no indivíduo com a boca fechada ocorre quando há alinhamento do ponto médio do contorno superior do côndilo e do limite distal da zona posterior do disco. Variações da normalidade podem ser identificadas quando a proeminência anterior do côndilo está posicionada na altura e região do disco; é considerado deslocamento do disco quando há leve movimentação da porção intermediária para a anterior. Normalmente o disco encontra-se posicionado entre a superfície póstero-superior do côndilo e a superfície convexa do tubérculo temporal, quando a abertura máxima da boca é estimulada.

As patologias musculoesqueléticas podem acometer a ATM, como o posicionamento irregular do disco articular; sinovites; osteoartrites e artrites inflamatórias. A sintomatologia dolorosa à palpação e/ou por estimar o Limiar de Dor à Pressão (LDP), são sinais clínicos importantes, os principais sintomas são: dor na região frontal, fundo dos olhos e têmporas, dificuldade mastigatória, barulho próximo à orelha, tonturas e vertigens, desgaste dental e sensação de travamento da mandíbula (ORTHLIEB JD, 2016; GÜVEN O, 2019; VILAR EGS, et al., 2020; da SILVA CL, et al., 2021). 


\section{CONSIDERAÇÕES FINAIS}

A disfunção da ATM é um distúrbio da articulação e/ou dos músculos responsáveis pelo processo mastigatório que impactam diretamente no bem-estar e saúde do indivíduo. Suas causas mais comumente relatadas são as maloclusão; o edentulismo, principalmente quando há perda dentária precoce; o uso de próteses mal adaptadas; o bruxismo e/ou briquismo. Tais danos devem ser tratados, visando conforto para o paciente e prevenção de problemas oriundo no sistema estomatognático.

\section{REFERÊNCIAS}

1. da SILVA CL, et al. Condromatose sinovial: caso raro em articulação temporomandibular. Revista Eletrônica Acervo Saúde, 2021; 13(2): e6026

2. GÜVEN O. Nearthrosis in true long-standing temporomandibular joint dislocation; a report on pathogenesis and clinical features with review of literature. Journal of Cranio- Maxillofacial Surgery, 2019; 47(6): 945950.

3. ORTHLIEB JD, et al. Articulation temporo-mandibulaire, occlusion et bruxisme. Revue de stomatologie, de chirurgie maxillo-faciale et de chirurgie orale, 2016; 117(4): 207-211

4. VILAR EGS, et al. Indicações cirúrgicas de deslocamento do disco articular da articulação temporomandibular. Brazilian Journal of health Review, 2020; 3(5): 13790-13809. 


\section{ESTUDO DA ATM POR MEIO DA RESSONÂNCIA MAGNÉTICA}

Deivson Henrique dos Santos ${ }^{1}$

Marília de Matos Amorim ${ }^{1}$

1. Unidade de Ensino Superior de Feira de Santana (FAESF/UNEF), Feira de Santana - BA.

Palavras-chave: Anomalias, Articulação temporomandibular, Ressonância magnética.

\section{INTRODUÇÃO}

Constituída por estruturas ósseas e tecido mole, a Articulação Temporomandibular (ATM) é classificada como uma das mais exigidas e mais complexa articulação do corpo humano, é caracterizada como o encaixe da mandíbula com os demais ossos do crânio, além de ser responsável pelos movimentos de abertura e fechamento da boca. Para localizá-la, deve-se posicionar os dedos logo em frente a região de orelhas; abrir e fechar a boca e então sentir movimentos temporomandibulares, de ambos os lados do rosto, o que não é o suficiente no diagnóstico de patologias temporomandibulares, sendo necessário métodos complementares como a Ressonância Magnética (RM) (da SILVA CL, et al., 2021).

\section{OBJETIVO}

Revisar a literatura científica para fornecer embasamento teórico sobre os mecanismos de uso da ressonância magnética em odontologia na avaliação da ATM, verificando o emprego das técnicas de estudo no diagnóstico de anomalias da articulação.

\section{REVISÃO BIBLIOGRÁFICA}

A Ressonância Magnética, é o exame de imagem de primeira escolha no diagnóstico das anomalias em tecido mole da ATM, devido ao potencial de determinar a posição real do disco articular. Sua técnica possui três etapas: alinhamento, onde propriedade de magnetismo de núcleos de determinados átomos seguem paralelos a um campo, determinando por razões físicas o próton - núcleo de hidrogênio empregado na produção de imagens biológicas. O campo magnético orienta tais prótons para direção correta.

Posteriormente, a excitação onde ciente que cada próton possui "vibração" proporcionalmente ao campo magnético que insere-se, o aparelho de RM emite com mesma frequência uma onda eletromagnética, a ressonância surge da energia de onda eletromagnética do aparelho para os átomos de hidrogênio e a detecção da radiofrequência que por fim, detecta a receptividade de da energia dos prótons, e tornam-se instáveis, emitindo ondas eletromagnéticas de igual frequência, é quando o equipamento identifica as ondas, determinando a posição espacial e intensidade da energia, sinal evidenciado pelo "brilho" (JESUS JRB, et al., 2017; GOMES RC, CARNEIRO CC, 2019; ABBEHUSEN C, 2019; da SILVA CL, et al., 2021).

\section{CONSIDERAÇÕES FINAIS}


A ressonância magnética ainda é o único exame capaz de representar com clareza a imagem do disco articular, possibilitando assim, verificar os seus deslocamentos, condição da cortical e da medula, degenerações discais, presença de fluido sinovial, anormalidades em tecidos moles e posições habituais.

\section{REFERÊNCIAS}

1. ABBEHUSEN C. Ressonância Magnética na Avaliação do Desarranjo Articular Interno da Articulação Temporomandibular. Revista Científica HSI, 2019; 3(3): 158-163.

2. da SILVA CL, et al. Condromatose sinovial: caso raro em articulação temporomandibular. Revista Eletrônica Acervo Saúde, 2021; 13(2): e6026.

3. GOMES RC, CARNEIRO CC. Ressonância Magnética: Princípios Basicos na Formação da Imagem com Ênfase na Utilização do Contraste Gadolínio. Revista eletrônica do UNIVAG - Connectionline, 2019; 21.

4. JESUS JRB, et al. O Uso da Ressonância Magnética na Investigação da Epilepsia. Revista Saúde.Com, 2017; 13(4): 986-993. 
RESUMO SIMPLES: Revisão Integrativa

\title{
ATUAÇÃO DA EQUIPE MULTIPROFISSIONAL NO ATENDIMENTO A MULHERES VÍTIMAS DE VIOLÊNCIA NA ATENÇÃO PRIMÁRIA À SAÚDE
}

\author{
Victória de Souza Nery ${ }^{1}$ \\ Angélica Ribeiro do Nascimento Oliveira ${ }^{2}$ \\ Jennifer Martins Pereira ${ }^{3}$ \\ Leandro Luiz da Silva Loures ${ }^{4}$ \\ Kelly Alencar de Souza ${ }^{5}$
}

1. Faculdade São Francisco da Paraíba (FASP), Cajazeiras - PB.

2. Centro Universitário Maurício de Nassau (UNINASSAU), Teresina - PI.

3. Universidade Federal de Juiz de Fora (UFJF), Juiz de Fora - MG.

4. Universidade Estadual de Maringá (UEM), Maringá - PR.

5. Faculdade São Francisco da Paraíba (FASP), Cajazeiras - PB.

Palavras-chave: Violência, Mulheres, Atenção primária a saúde.

\section{INTRODUÇÃO}

A violência contra as mulheres é considerada um fenômeno de escala mundial, sendo sua causa um fator multicausal e atingindo-as independente da sua classe social, religião ou raça, perpetuando-se de diferentes maneiras que vão desde a violência doméstica, física, moral, sexual até a emocional, chegando a evoluir para inúmeros transtornos mentais e episódios traumáticos (SILVA VG, et al., 2020).

Nesse contexto, a equipe multiprofissional de saúde que atua na Atenção Primária possui papel fundamental no acolhimento, abordagem e assistência personalizada de maneira ampla a mulher, reconhecendo e levando em consideração todas as suas particularidades e características a fim de promover seu bem-estar (ARBOIT J, et al., 2020).

\section{OBJETIVO}

Identificar, revisar e analisar por meio da literatura científica a atuação de uma equipe multiprofissional frente a sua assistência no atendimento de mulheres vítimas de violência sexual que são atendidas na rede de atenção primária.

\section{MÉTODO}

Trata-se de uma revisão integrativa. Para tal, foram realizadas busca nas bases de dados LILASC, MEDLINE, BDENF, SCIELO no período do mês de outubro, a partir dos descritores em saúde: violência, mulheres e Atenção Primária a Saúde. A análise contemplou quatro documentos, incluindo-se artigos originais 
em português, inglês e espanhol dos últimos cinco anos e excluindo-se os duplicados ou que não atendessem a temática proposta.

\section{REVISÃO BIBLIOGRÁFICA}

A equipe multiprofissional em saúde é responsável pela prestação dos mais variados serviços a fim de minimizar os danos e agravos físicos, psicológicos, sociais e emocionais que podem surgir dessa violência (GOMES MC, et al., 2017). Observou-se também que as equipes quando juntas objetivam principalmente 0 acolhimento as essas mulheres com o propósito de identificar suas vulnerabilidades e assim entender e atender suas demandas naquele momento (MARTINS LCA, et al., 2016).

Em outro estudo foi ressaltada a importância desses profissionais no reconhecimento de possíveis situações de risco para essas mulheres onde os mesmos trabalharam na construção de práticas do cuidado e projetos terapêuticos (ARBOIT J, et al., 2020).

\section{CONSIDERAÇÕES FINAIS}

Diante dos estudos apresentados, fica claro que a atuação de uma equipe multiprofissional no combate e apoio as mulheres que são vítimas dos mais diversos tipos de violência acaba se tornando essencial a fim de garantir a sua saúde e segurança, prestando cuidados físicos, emocionais e psicológicos, além de ajudar na identificação de possíveis sinais de risco que possam surgirem nesse meio, fazendo com que sua assistência seja primordial.

\section{REFERÊNCIAS}

1. ARBOIT J, et al. Violência contra a mulher na atenção básica a saúde: Potencialidade e limitações à identificação. Atenas Editora, 2020; 52(1): 14-21.

2. SILVA VG, et al. Violência contra as mulheres na prática dos enfermeiros da atenção primária à saúde. Revista Enfermagem, 2020; 24(4).

3. GOMES MC, et al. Violência contra a mulher: compreendendo a atuação interdisciplinar. Revista Enfermagem UFPE on online, 2017; 11(12): 5245-5251.

4. MARTINS LCA, et al. Violência contra a mulher: acolhimento na estratégia saúde da família. Ciências, Cuidado e Saúde, 2016; 15(3): 507-514. 


\section{TRAUMAS DE FACE: REVISÃO DE LITERATURA}

Daiany Araújo da Silva ${ }^{1}$

Jainy Estefany Martins ${ }^{1}$

Ana Júlia Rodrigues da Cruz Faria ${ }^{1}$

Regina Coeli Cançado Peixoto Pires ${ }^{1}$

1. Universidade de Itaúna (UIT), Itaúna - MG.

Palavras-chave: Epidemiologia, Traumatismos faciais, Saúde pública.

\section{INTRODUÇÃO}

O trauma craniofacial é uma lesão onde ocorre a ruptura de tecidos anatômicos da face e são caracterizadas por lesões de partes moles ou duras (SOLLER ICS, et al., 2016). Os estudos que descrevem sobre os traumas faciais são essenciais para a delineação e a avaliação da saúde pública, sobretudo se considerarmos a variedade etiológica das fraturas e a influência de fatores geográficos, econômicos e sociais (MENDES N, et al., 2016). Além disso, estas informações epidemiológicas podem ser empregadas para implantação de protocolos direcionados à execução de programas de prevenção (MOURA MTFL, et al., 2016).

\section{OBJETIVO}

Realizar uma revisão de literatura dos levantamentos epidemiológicos em pacientes vítimas de fraturas faciais em diversas regiões do Brasil no período de 2016 a 2020 analisando seus objetivos, metodologia e resultados.

\section{MÉTODO}

Revisão sistemática de estudos epidemiológicos observacionais realizados e publicados entre 2016 e 2020 no Brasil, em que traumatismo de face foi o evento de interesse. As bases de dados utilizadas foram BIREME, SciELO e Google Acadêmico, empregando-se os descritores: epidemiologia, traumatismos faciais, saúde pública, trauma. Essa pesquisa foi finalizada em agosto de 2020. Foram considerados 6 levantamentos que estavam relacionados aos traumas craniofaciais e artigos completos na íntegra.

\section{REVISÃO BIBLIOGRÁFICA}

Houve maior ocorrência de traumas faciais no sexo masculino que representou $89 \%$ dos estudos (MOURA MTF, et al., 2016). A faixa etária mais acometida foi de 21 a 30 anos em $34 \%$ dos estudos (GARCEZ RHM, et al., 2019). No que se refere à região anatômica, a mandíbula foi o local de maior incidência nos traumatismos faciais em 43\% dos estudos (SILVA NKS, et al., 2019; MENDES N, et al., 2016). A etiologia dos traumas mais frequente foram os acidentes de trânsito em cinco artigos 56\% (MARANO R, et al., 2020). 


\section{CONSIDERAÇÕES FINAIS}

Diante das principais etiologias, para a redução dos acidentes de trânsito é necessária maior fiscalização das leis de trânsito vigentes, maiores campanhas de prevenção para o uso rotineiro de equipamentos de segurança como cintos e capacetes. A necessidade de novos estudos de levantamentos epidemiológicos dos traumas faciais é constante, assim como todas as doenças e agravos, na busca de alternativas para controle e prevenção destes.

\section{REFERÊNCIAS}

1. GARCEZ RHM, et al. Characterization of oral maxilofacial lesions resulting from physical aggression: differencer between gender. Ciência e Saúde Coletiva, 2019; 24(3), 1143-1152.

2. MARANO R, et al. Epidemiological Analysis of 736 Patients who Suffered Facial Trauma in Brazil. International journal of odontostomatology, 2020; 14(2), 257-267.

3. MOURA MTFL, et al. Traumas faciais: uma revisão sistemática da literatura, RFO, 2016; 21(3), 331-337.

4. MENDES $\mathrm{n}$, et al. Perfil epidemiológico dos pacientes portadores de fraturas de face. Ver. Assoc. Paul. Cir. Dent., 2019; 70(3), 323-329.

5. SILVA NKS, et al. Perfil das fraturas faciais em um serviço de emergência no Maranhão. Rev. Cir. Traumatol. Buco-Maxilo-Fac., 2019; 19 (1), 8-13.

6. SOLLER ICS, et al. Epidemiological Profile of $P$ atients With Facial Injuries Treated in Na Emergency Hospital. REME: Revista Mineira de Enfermagem, 2016; 20, 1-8. 
RESUMO SIMPLES: Revisão Integrativa

\title{
IMPACTOS DA SUPLEMENTAÇÃO DE CREATINA PARA A POPULAÇÃO IDOSA
}

\author{
José de Oliveira Alves Júnior ${ }^{1}$ \\ Amanda Barbosa Formiga ${ }^{1}$ \\ Wellington Cipriano Albuquerque ${ }^{1}$ \\ Lindomar de Farias Belém ${ }^{1}$
}

1. Universidade Estadual da Paraíba (UEPB), Campina Grande - PB.

Palavras-chave: Suplementação de creatina, Massa muscular, Idosos.

\section{INTRODUÇÃO}

A creatina é um recurso ergogênico muito utilizado por praticantes de atividades físicas, pois ela potencializa a força e a potência do músculo auxiliando o desenvolvimento da hipertrofia muscular e estabilidade do corpo em atividades intensas (FLORENTIN ÁN, et al., 2020). Por sua vez, a massa muscular é importante para os idosos, pois mantém a estabilidade corporal, entretanto, ela tende a se perder com o passar dos anos corroborando para lesões. Assim, a nutrição para manter o tecido muscular na terceira idade demonstra-se como importante (FERREIRA LF, et al., 2021). Destarte, a creatina pode ser utilizada para conservar a massa magra para o grupo idoso (SILVA KA, et al., 2018).

\section{OBJETIVO}

Avaliar a literatura disponibilizada entre o período de 2016 a 2021 sobre o tema, buscando revisar e conhecer a ação da suplementação da creatina em idosos analisando seus efeitos, para esse grupo, e possíveis aplicações terapêuticas da suplementação dessa substância.

\section{MÉTODO}

Trata-se de uma revisão realizada por obras indexadas nas bases de dados Google Acadêmico, Scielo, PubMed, MEDLINE e a Revista Brasileira de Nutrição Esportiva. Os descritores utilizados foram "suplementação de creatina e "creatina em idosos". Das 50 obras analisados apenas 6 principais foram usados sob os critérios de textos coesos em português, inglês e espanhol publicados nos últimos 5 anos para essa pesquisa preliminar e que abordavam ricamente a temática.

\section{REVISÃO BIBLIOGRÁFICA}

Devido seu uso na nutrição esportiva, em relação aos idosos, a suplementação de creatina se demonstra eficaz no ganho de massa muscular em praticantes de exercícios físicos auxiliando na estabilidade de força e resistência (NASCIMENTO OVD e AMARAL ADS, 2020). Assim, o suplemento apresentou significativo resultado de ganhos de massa magra durante seu consumo, não descartando o essencial e correto 
acompanhamento profissional (MELO ALD, et al., 2016). A posteriori, foi visto que a creatina pode atuar indiretamente como antioxidante, ajudando a impedir reações violentas do oxigênio no corpo, o que seria outro benefício que a terceira idade poderia obter com o correto uso do suplemento (COQUEIRO AY, et al., 2017).

\section{CONSIDERAÇÕES FINAIS}

Portanto, a creatina possui efeitos benéficos para a população idosa auxiliando na sua manutenção e desempenho muscular pelo seu melhor aproveitamento de ATP e conservando a essencial massa magra para esse grupo. Destarte, ela pode atuar, também, indiretamente com efeitos antioxidantes retardando danos ocasionados pelo passar dos anos e, por promover conservação e desenvolvimento da massa muscular até na condição sarcopenia, também pode beneficiar preservando as articulações em longo prazo.

\section{REFERÊNCIAS}

1. COQUEIRO AY, et al. Creatina como antioxidante em estados metabólicos envolvendo estresse oxidativo. Revista Brasileira de Prescrição e Fisiologia do Exercício (RBPFEX), 2017; 11(64): 128-137.

2. FERREIRA LF, et al. Importância da avaliação do estado nutricional de idosos / Importance of the evaluation of the nutritional state of elderly. Brazilian Journal of Health Review, 2020; 3(5): 14712-14720.

3. FLORENTIN ÁN, et al. Uso do suplemento de creatina em praticantes de atividades físicas: uma revisão integrativa. Revista Eletrônica Acervo Saúde, 2021; 13(2): e5890.

4. MELO ALD, et al. Efeito da suplementação de creatina no treinamento neuromuscular e composição corporal em jovens e idosos. Revista Brasileira de Nutriçao Esportiva, 2016; 10(55): 79-86.

5. NASCIMENTO AVD, AMARAL ADS. Efeitos da suplementação de creatina sobre o desempenho humano: uma revisão de literatura. BIUS - Boletim Informativo Unimotrisaúde em Sociogerontologia, 2020; 21(15): $1-20$.

6. SILVA KA, et al. Suplementação de creatina e treinamento de força em idosos: uma revisão sistemática. Caderno de Educação Física e Esporte, 2018; 16(1): 246-257. 
RESUMO SIMPLES: Revisão Integrativa

\title{
PAPEL DO ENFERMEIRO NO ACOLHIMENTO DE ADOLESCENTES COM IDEAÇÕES SUICIDAS
}

\author{
Rafaela Sapucaia Andrade ${ }^{1}$ \\ Jocemar de Oliveira Lima Júnior ${ }^{1}$ \\ Géssica Santos Brito² \\ Josumah Castro Lima Neto ${ }^{1}$ \\ Jaqueline Soares da Silva ${ }^{3}$
}

1. Centro Universitário Brasileiro (UNIBRA), Recife - PE.

2. Centro Universitário Jorge Amado (UNIJORGE), Salvador - BA.

3. Universidade de Pernambuco (UPE), Recife - PE.

Palavras-chave: Assistência de enfermagem, Adolescentes, Suicídio.

\section{INTRODUÇÃO}

$\mathrm{Na}$ adolescência é esperado que os indivíduos adquiram experiências para adapta-los à fase adulta, portanto, os adolescentes se veem diante dos aspectos da sociedade atual, onde há inúmeros componentes estressores, consequentemente essa etapa apresentará conflitos que, frequentemente, vêm acompanhados de riscos para vida, incluindo ideias suicidas (PESSOA DMS, et al., 2020).

O suicídio configura-se como problema de saúde pública, dados revelam que no mundo ocorre aproximadamente 800 mil casos de suicídio a cada ano. Muitas pessoas temem a morte, no entanto, a mesma pode ser considerada como única opção para aqueles que não encontram soluções para suas adversidades (NUNES NR, et al., 2019).

\section{OBJETIVO}

Revisar e analisar, por meio da literatura científica, qual a importância das ações de uma equipe de enfermagem capacitada para acolher e planejar uma assistência a adolescentes com ideações suicidas.

\section{MÉTODO}

Trata-se de revisão bibliográfica, onde, foram realizadas buscas nas bases de dados LILACS, SciELO através da Biblioteca Virtual em Saúde, além de levantamento bibliográfico na base de dados da Acervo+. No periodo do mês de setembro de 2021, procedeu-se à análise de 8 artigos, destes, 6 foram incluidos e 2 excluidos, os criterios de inclusão foram artigos gratuito, na língua portuguesa e exclusão aqueles que não atendessem a temática proposta.

\section{REVISÃO BIBLIOGRÁFICA}


Identificar ideações suicidas é um processo complexo, sendo necessário que a sociedade inteira, atentemse aos sinais (LEITE AC, et al., 2021). Diante da meta-analise, percebemos que a assistência ao paciente com ideações suicidas é um desafio para enfermeiros, pois, muitas vezes não são capacitados para situação, logo, a falta de estratégia negligencia as necessidades dos adolescentes (SANTOS RS, et al., 2017). Entretanto, a enfermagem é encarregada a prestar os primeiros cuidados ao paciente (SILVA LLT, et al., 2020), logo, desempenha um papel importante na prevenção do suicídio, seu atendimento de forma holística, assegurara o planejamento de melhores condutas, visto que, encontram-se mais tempo com pacientes (SOUSA JF, et al., 2019).

\section{CONSIDERAÇÕES FINAIS}

Por meio dos estudos, concluímos que o enfermeiro como integrante da equipe que compõe a Atenção Primaria à Saúde (APS) desempenha um papel importante na prevenção do comportamento suicida, pois, é o profissional que dispõe mais tempo com o paciente, sendo assim, é necessário que sejam capacitados para desenvolver estratégias que possam reduzir as dificuldades em captar adolescentes ao serviço de saúde.

\section{REFERÊNCIAS}

1. LEITE AC, et al. Contribuições da assistência de enfermagem no acolhimento de adolescentes com ideações suicidas. Research, Society and Development, 2021; 10(9): e6510917740.

2. NUNES NR, et al. Acolhimento da equipe de enfermagem frente aos adolescentes com ideações suicidas: uma revisão integrativa de literatura. Revista Científica Multidisciplinar Núcleo do Conhecimento, 2019; 3: 49-66.

3. PESSOA DMS, et al. Assistência de Enfermagem na Atenção Primária à Saúde de adolescentes com ideações suicidas. Revista Mineira de Enfermagem, 2020; 24: e-1290.

5 SANTOS RS, et al. A atuação do enfermeiro com a pessoa em situação de suicídio: análise reflexiva. Revista de Enfermagem UFPE on line, 2017; 11(2): 742-748.

6 SILVA LLT, et al. Profissionais de enfermagem de um serviço de urgência e emergência frente ao suicídio na adolescência. Revista Eletrônica Acervo Saúde, 2020; 12(10): e4042.

7 SOUSA JF, et al. Prevenção ao suicídio na atenção básica: concepção de enfermeiros. Revista Cuidarte, 2019; 10(2): e609. 


\title{
| ESTUDOS DE CASO
}

RESUMO SIMPLES: Estudo de Caso

\section{PROTOCOLOS DO CONVERSOR RADIOELÉTRICO ASSIMÉTRICO (REAC) EM ÍNDICES DE SONOLÊNCIA EXCESSIVA}

\author{
Ester Suane Lima Monteiro ${ }^{1}$ \\ João Douglas Quaresma de Oliveira ${ }^{1}$ \\ Pedro Guilherme Castilho Costa ${ }^{1}$ \\ Analizia Pena da Silva ${ }^{1}$ \\ Ana Rita Pinheiro Barcessat ${ }^{1}$
}

1. Universidade Federal do Amapá (UNIFAP), Macapá - AP.

Palavras-chave: REAC, Neuromodulação, Sonolência.

\section{INTRODUÇÃO}

Distúrbios do sono estão entre os principais problemas de saúde mental, somado aos estressores psicossociais têm forte relação com distúrbios cardiovasculares (TELLES SL e VOOS MC, 2021). A privação de sono, intencional ou não, gera modificações patológicas que evidenciam a sonolência diurna excessiva (OLIVEIRA MCS, et al., 2020).

Outrossim, há forte associação entre má qualidade do sono, sintomas depressivos e estresse (PEREIRA FZ, et al., 2020). Os protocolos de neuromodulação pela Tecnologia do Conversor Radioelétrico Assimétrico (REAC) atenuam a tríade sintomática: ansiedade, estresse e depressão (BARCESSAT ARP, et al., 2020). Portanto, o uso dessa tecnologia pode representar uma possível intervenção terapêutica na perspectiva de melhora da qualidade do sono.

\section{OBJETIVO}

Estudar o caso de uma pessoa com má qualidade do sono e quadro de sonolência diurna após intervenção terapêutica dos protocolos de neuromodulação pela tecnologia REAC, com o protocolo de Otimização Neuro Postural (ONP) e Otimização Neuro Psico Física (ONPF).

\section{ESTUDO DE CASO}

Participante do sexo feminino, de 41 anos, residente no Estado do Amapá. Antes da terapia, apresentava quadros de qualidade do sono prejudicada e grau sonolência diurna. Negou doenças de base no histórico familiar. Relatou usar medicamento hidroxicloroquina e infecção recente por COVID-19. 
A participante foi submetida aos protocolos ONP e ONPF, posteriormente foi avaliada pela Escala De Sonolência De Epworth (ESE-BR), que examina experiências gerais de sonolência excessiva ao longo de um dia inteiro, avaliando as chances de cochilar no período, por meio de uma escala de pontuação que varia de 0 a 24 pontos, sendo os valores acima de 10 indicativos para grau de sonolência diurna excessiva.

Antes da aplicação dos protocolos a participante apresentava escore global de 19 pontos, caracterizando sonolência excessiva diurna grave, ao término do ciclo de ONP e ONPF a participante respondeu novamente ao questionário e apresentou um escore final de 7 pontos, designado como grau de médio de sonolência. Este estudo foi submetido ao Comitê de Ética e aprovado com o CAAE № 08920619.3.0000.0003, sob o parecer № 3.640 .674 .

\section{CONSIDERAÇÕES FINAIS}

Observou-se que o uso dos protocolos de neuromodulação pela tecnologia REAC impacta a qualidade do sono, evidenciado pela redução dos níveis de sonolência excessiva diurna avaliados pela Escala de Sonolência de Epworth, ao observar-se diminuição da propensão em cochilar em determinadas situações ou contextos do cotidiano. Portanto, o uso dessa plataforma tecnológica em saúde, apresenta-se promissora na melhora da qualidade do sono ao reduzir a sonolência excessiva.

\section{REFERÊNCIAS}

1. BARCESSAT ARP, et al. REAC cervicobrachial neuromodulation treatment of depression, anxiety, and stress during the COVID-19 pandemic. Psychology Research and Behavior Management, 2020; 13(2020): 929-927.

2. OLIVEIRA MCS, et al. Qualidade do sono e sonolência excessiva diurna em acadêmicos de medicina. Revista Eletrônica Acervo Saúde, 2021; 12(10): e4011.

3. PEREIRA FZ, et al. Estresse e sono em estudantes de medicina. Brazilian Journal of Health Review, 2020; 3(6): 16858-16870.

4. TELLES SL, VOOS MC. Distúrbios do sono durante a pandemia de COVID-19. Fisioterapia e Pesquisa, $2021 ; 28(2): 124-125$. 


\title{
ABORDAGEM TERAPÊUTICA PARA QUALIDADE DO SONO PELA TECNOLOGIA REAC COM OS PROTOCOLOS DE NEUROMODULAÇÃO
}

\author{
Ester Suane Lima Monteiro ${ }^{1}$ \\ João Douglas Quaresma de Oliveira ${ }^{1}$ \\ Rebeca Góes Gonçalves ${ }^{1}$ \\ Analizia Pena da Silva ${ }^{1}$ \\ Ana Rita Pinheiro Barcessat ${ }^{1}$
}

1. Universidade Federal do Amapá (UNIFAP), Macapá - AP.

Palavras-chave: REAC, Sono, Neuromodulação.

\section{INTRODUÇÃO}

Os distúrbios do sono afetam a sua qualidade e duração, contribuindo para alterações no organismo, com impacto nas funções cognitivas mentais. A insônia traz em associação fadiga e dificuldade de concentração. Assim, o sono não exerce seu papel na regulação do metabolismo (FATTINGER S, et al., 2017). Portanto, indivíduos que sofrem com a má qualidade do sono lidam com consequências que interferem no cotidiano e na saúde (OLIVEIRA MCS, et al., 2020).

O Conversor Radioelétrico Assimétrico (REAC) é uma tecnologia baseada em neuromodulação que otimiza respostas orgânicas, gerando efeitos nos fluxos bioelétricos endógenos, apresentando efeitos importantes nos aspectos funcionais, celulares, teciduais e sistêmicos (BARCESSAT ARP, et al., 2020).

\section{OBJETIVO}

Estudar os efeitos da neuromodulação pela tecnologia REAC na qualidade do sono de uma paciente com apresentação de hábitos usuais de má qualidade do sono comparando dados antes e após terapêutica.

\section{ESTUDO DE CASO}

Paciente do sexo feminino, 43 anos, mora no estado do Amapá, apresenta histórico familiar de Hipertensão Arterial Sistêmica e Diabetes Mellitus usa continuamente Naltrexona em baixas doses (LDN). Relatou demora para dormir e qualidade do sono prejudicada. A participante foi submetida aos protocolos Otimização Neuropostural (ONP) e Otimização Neuropsicofísica (ONPF) com o Conversor Radioelétrico Assimétrico (REAC).

Antes e após as aplicações foram avaliados os hábitos do sono e natureza dos transtornos pelo Índice de Qualidade De Sono De Pittsburgh (PSQI), instrumento desenvolvido por Buysse o qual avalia a qualidade e perturbações do sono no mês precedente, estabelecendo uma pontuação global de 0-21 pontos, quanto maior o escore, pior é a qualidade do sono (BUYSSE DJ, et al., 1989). 
Antes da terapia apresentava escore igual a 6 , indicando qualidade ruim do sono. Ao término dos protocolos foi repetida a avaliação, na qual o escore obtido foi de 1 ponto, classificado como boa qualidade do sono. Este estudo foi submetido ao Comitê de Ética, aprovado com o CAAE № 08920619.3.0000.0003, sob o parecer № 3.640 .674 .

\section{CONSIDERAÇÕES FINAIS}

O estudo de caso apresentado evidenciou que o uso dos protocolos de neuromodulação REAC apresenta resultados satisfatórios no auxílio da otimização do sono. O efeito avaliado pelo questionário PSQI constatou a diminuição dos aspectos negativos dos transtornos do sono e a melhora da qualidade do sono, no qual a diferença entre os escores apresentou uma melhora percentual de $83 \%$.

\section{REFERÊNCIAS}

1. BARCESSAT ARP, et al. REAC Neuromodulation Treatments in Depression, Anxiety and Stress. A Comparative Retrospective Study. Psychology Research and Behavior Management, 2021; 13(2020): 1247-1256.

2. BUYSSE DJ, et al. The Pittsburgh Sleep Quality Index: a new instrument for psychiatric practice and research.

3. Psychiatry research, 1989; 28(2): 193-213.

4. FATTINGER $S$, et al. Deep sleep maintains learning efficiency of the human brain. Nature communications, 2017; 8(15405): 1-13.

5. OLIVEIRA MCS, et al. Qualidade do sono e sonolência excessiva diurna em acadêmicos de medicina. Revista Eletrônica Acervo Saúde, 2020; 12(10): e4011. 


\title{
OTIMIZAÇÃO NEURO POSTURAL E OTIMIZAÇÃO NEUROPSICOFÍSICA REAC NO ÍNDICE DE GRAVIDADE DE INSÔNIA (IGI): ESTUDO DE CASO
}

\author{
João Douglas Quaresma de Oliveira ${ }^{1}$ \\ Ester Suane Lima Monteiro ${ }^{1}$ \\ Lucas dos Santos Nunes ${ }^{1}$ \\ Analizia Pena da Silva ${ }^{1}$ \\ Ana Rita Pinheiro Barcessat ${ }^{1}$
}

1. Universidade Federal do Amapá (UNIFAP), Macapá - AP.

Palavras-chave: Insônia, Dissonias, REAC.

\section{INTRODUÇÃO}

O sono é um processo fisiológico humano de recuperação do organismo, logo, quando prejudicado, pode afetar o funcionamento cognitivo, psicomotor e afetar a qualidade de vida. (FATTINGER S, et al., 2017; OLIVEIRA MCS, et al., 2020). Dessa forma, é importante a utilização de terapias que possam auxiliar a recuperar a qualidade do sono, promovendo melhora do organismo como um todo. A tecnologia do Conversor Rádio Elétrico Assimétrico (REAC) tem apresentado evidências na redução de índices de ansiedade, estresse e depressão (RINALDI A, et al., 2019, PEREIRA JAC, et al., 2018, BARCESSAT ARP, et al., 2020).

\section{OBJETIVO}

Avaliar as implicações dos protocolos de Otimização Neuro Postural (ONP) e Otimização Neuro Psico Física (ONPF) da tecnologia REAC sobre o índice de gravidade da insônia em uma participante, antes e após a terapia.

\section{ESTUDO DE CASO}

A participante E.D.B, do sexo feminino, de 71 anos, residente do estado do Amapá, inicialmente preencheu o Termo de Conhecimento Livre Esclarecido (TCLE) concordando com os termos da pesquisa. Apresenta histórico familiar de Diabetes Mellitus, portadora de Hipertensão Arterial Sistêmica, após transplante de rim direito há 7 anos, usa continuamente imunossupressor, anti-hipertensivo, anti-hiperlipidêmico e betabloqueador.

A Escala de Insônia de Atenas (EIA), possui escore que varia de 0-24 pontos, sendo considerado insônia a partir de 6, e o Índice de Gravidade de Insônia (IGI), que possui 4 graus de resultado, estes instrumentos foram utilizados para verificar transtornos do sono caracterizados por graus de insônia. Os resultados pré ciclos de ONP e ONPF foram de 13 para a EIA e o escore de 18 para IGI, significando presença de insônia clínica moderada. 
Após os protocolos de aplicação dos protocolos de neuromodulação, a participante respondeu novamente aos questionários autoaplicáveis, nos questionários EIA obteve-se o escore de 3, caracterizando ausência de insônia e no questionário IGI, o resultado do escore global foi de 5 pontos, classificando-se em ausência de insônia significativa.

\section{CONSIDERAÇÕES FINAIS}

Obteve-se resultado satisfatório a melhora da qualidade no sono tanto na descrição da participante quanto pelos questionários. Os resultados quantitativos dos questionários foram de 3 na EIA, retirando a participante do grau considerado de insônia e 5 para o questionário IGI, considerado como ausência de insônia significativa. $O$ uso dos protocolos de neuromodulação pela tecnologia REAC se mostrou promissor no transtorno do sono caracterizado.

\section{REFERÊNCIAS}

1. FATTINGER S, et al. Deep sleep maintains learning efficiency of the human brain. Nature communications, 2017; 8(1): 1-14

2. OLIVEIRA MCS, et al. Qualidade do sono e sonolência excessiva diurna em acadêmicos de medicina. Revista Eletrônica Acervo Saúde, 2020; 12(10): e4011

3. PEREIRA JAC, et al. REAC neuromodulation treatments in subjects with severe socioeconomic and cultural hardship in the Brazilian state of Pará: a family observational pilot study. Neuropsychiatric disease and treatment, 2018; 14(2018): 1047

4. RINALDI A, et al. Radio electric asymmetric conveyer neuromodulation in depression, anxiety, and stress. Neuropsychiatric disease and treatment, 2019; 15(2019): 469-480. 


\title{
AUTOPERCEPÇÃO ACERCA DA QUALIDADE DO SONO FRENTE AOS PROTOCOLOS DE NEUROMODULAÇÃO PELA TECNOLOGIA REAC
}

\author{
João Douglas Quaresma de Oliveira ${ }^{1}$
}

Ester Suane Lima Monteiro ${ }^{1}$

Ana Vitória Gonçalves de Oliveira Cruz ${ }^{1}$

Analizia Pena da Silva ${ }^{1}$

Ana Rita Pinheiro Barcessat ${ }^{1}$

1. Universidade Federal do Amapá (UNIFAP), Macapá - AP.

Palavras-chave: Sono, Neuromodulação, Tecnologia biomédica.

\section{INTRODUÇÃO}

O sono é responsável por regular diversos processos fisiológicos humanos e a sua ausência afeta a qualidade de vida, provocando modificações físicas e psicossociais. (LESSA RT, et al., 2020). Um sono adequado quanti e qualitativamente acarreta boa saúde e bem-estar (MANZOLI JPB, et al., 2018). Os protocolos de neuromodulação pela Tecnologia do Conversor Radioelétrico Assimétrico (REAC), propõem-se a atuar na reorganização dos fluxos bioelétricos endógenos, otimizando o funcionamento celular, com redução dos níveis de ansiedade, estresse e depressão (BARCESSAT ARP, et al., 2020). Este estudo foi submetido ao Comitê de Ética, aprovado com CAAE № 08920619.3.0000.0003, sob o parecer № 3.640.674.

\section{OBJETIVO}

Relatar o caso de uma paciente com distúrbios no sono antes e após aplicação da tecnologia REAC com os protocolos de neuromodulação Otimização Neuro Postural (ONP) e Otimização Neuro Psico Física (ONPF).

\section{ESTUDO DE CASO}

Participante do sexo feminino, 35 anos de idade, casada e policial civil, apresenta histórico familiar de Diabetes Mellitus tipo 2 e doenças cardiovasculares, residente no Estado do Amapá. Possui histórico familiar de Hipertensão Arterial Sistêmica e cardiopatias, histórico clínico caracterizado por Transtorno Misto Ansioso e Depressivo, em uso contínuo de antidepressivos e ansiolíticos, cloridrato de imipramina e clonazepam, respectivamente. Relata insônia, sensação de sono não reparador e episódios de soniloquismo, distúrbio benigno caracterizado por falar enquanto dorme, fadiga acentuada, sonolência, baixo limiar de tolerância associado à irritabilidade.

Após assinatura do TCLE, iniciou os protocolos de neuromodulação ONP e ONPF com a tecnologia REAC e foi avaliada antes e após a terapia por uma entrevista semi-estruturada com as seguintes perguntas finais: 
"Como tem sido o seu sono nos últimos 14 dias?" e "Você acha que a terapia REAC influenciou na qualidade do seu sono? O que você percebeu após a terapia?". Após realizados os protocolos, a paciente relatou melhora da qualidade do sono com sensação de sono reparador e diminuição da insônia, sonolência diurna, irritabilidade e ansiedade, evidenciado pela entrevista semi-estruturada.

\section{CONSIDERAÇÕES FINAIS}

Após a aplicação dos protocolos de neuromodulação com a tecnologia REAC, foi relatada redução da insônia, sonolência e irritabilidade, assim como melhora na qualidade do sono. As informações subjetivas prestadas e relatadas pela participante evidenciaram que essa tecnologia representa uma proposta terapêutica inovadora na melhora da qualidade do sono.

\section{REFERÊNCIAS}

1. BARCESSAT ARP, et al. REAC Neuromodulation Treatments in Depression, Anxiety and Stress. A Comparative Retrospective Study. Psychology research and behavior management, 2020; 13: 1247-1256.

2. LESSA RT, et al. A privação do sono e suas implicações na saúde humana: uma revisão sistemática da literatura. Revista Eletrônica Acervo Saúde, 2020; 56: e3846.

3. MANZOLI JPB, et al. Conceptual and operational definitions of the defining characteristics of the nursing diagnosis Disturbed Sleep Pattern. Revista latino-americana de enfermagem, 2018; 26: e3105. 


\title{
| RELATOS DE EXPERIÊNCIA
}

RESUMO SIMPLES: Relato de Experiência

\section{A LIGA ACADÊMICA E O PROTAGONISMO DO ACADÊMICO: UM RELATO DE EXPERIÊNCIA}

\author{
Larissa Nascimento Salustriano ${ }^{1}$ \\ Railda Lima Rodrigues ${ }^{1}$
}

1. Universidade Estadual do Maranhão (UEMA), São Luís - MA.

Palavras-chave: Administração das tecnologias da informação, Estudantes de enfermagem, Sucesso acadêmico.

\section{INTRODUÇÃO}

A Pandemia causada pelo novo Coronavirus promoveu novos desafios, porém essa ocasião possibilitou a utilização de novas metodologias de ensino na educação com o desenvolvimento de novas habilidades e estratégias (MALTA CP, et al., 2021). Partindo desse suposto, as ligas acadêmicas são entidades científicas que objetivam a complementação da formação acadêmica através da tríade universitária, com ações voltadas para o ensino, pesquisa e extensão (CAVALCANTE ASP, et al., 2018). Os discentes que pertencem a essa corporação contribuem significativamente com a ciência através da implantação das suas atividades extracurriculares (SILVA WBH, et al., 2020).

\section{OBJETIVO}

Relatar a importância da Liga Acadêmica de Enfermagem em Saúde da Família (LAESF), da Universidade Estadual do Maranhão (UEMA), na construção do protagonismo do acadêmico através da participação dos universitários na diretoria.

\section{RELATO DE EXPERIÊNCIA}

Relato de experiência, realizado durante a atuação dos discentes de enfermagem na diretoria da LAESF, no período de março a setembro de 2021. Mesmo após a readequação institucional ao ensino remoto, em decorrência da pandemia de Covid-19, as atividades da diretoria foram realizadas através de reuniões quinzenais no Microsoft Teams pautadas na organização de eventos, na escala dos grupos para a criação dos posts informativos disponibilizados no Instagram, Facebook e YouTube e na motivação da produção científica.

A diretoria é composta pelo Presidente; Vice-presidente; Secretário-Geral; Diretor de Vivência Prática; Diretor de Comunicação e Marketing; Diretor de Ensino, Pesquisa e Extensão e Diretor Financeiro. Desse modo, os ligantes além de adquirirem conhecimentos voltados à área Saúde da Família e da Educação em Saúde para a população através da disseminação de informações nas redes sociais da LAESF, protagonizam 
o desenvolvimento de habilidades didáticas de liderança de pessoal, administrativas, tecnológicas e de organização bem como a aquisição de responsabilidades e autonomia na tomada de decisões.

\section{CONSIDERAÇÕES FINAIS}

Através das experiências vivenciadas na gestão da LAESF no modo remoto, foi possível a obtenção de competências e habilidades gerais e específicas, para o desenvolvimento dos discentes na construção de um profissional líder capaz de enfrentar as adversidades do ambiente de trabalho e no desempenho em equipe.

\section{REFERÊNCIAS}

1. CAVALCANTE ASP, et al. As ligas acadêmicas na área da saúde: lacunas do conhecimento na produção científica brasileira. Revista Brasileira de Educação Médica, 2018; 42: 199-206.

2. MALTA CP, et al. Atuação da liga acadêmica de cardiologia durante a pandemia da Covid-19 e as implicações na educação médica: relato de experiência. Revista Eletrônica Acervo Saúde, 2021; 13(1): e5588.

3. SILVA WBH, et al. Reinvenção das ligas acadêmicas em período de pandemia e interrupção das aulas presenciais. Global Academic Nursing, 2020; 1(3): e51. 


\title{
IMPORTÂNCIA DAS ATIVIDADES DE MONITORIA NA DISCIPLINA DE ANATOMIA HUMANA EM MEIO À PANDEMIA
}

\author{
Juliana Silva Ribeiro ${ }^{1}$ \\ Francisco Roberto Napoleão Ibiapina ${ }^{1}$
}

1. Universidade Estadual do Maranhão (UEMA), Bacabal - MA.

Palavras-chave: Anatomia, COVID-19, Tutoria.

\section{INTRODUÇÃO}

A monitoria acadêmica é um instrumento de ensino-aprendizagem que proporciona ao discente-monitor e ao assistido a oportunidade de ampliar conhecimento, sanar dúvidas inerentes à disciplina trabalhada e fortalecer o ensino prático (ANDRADE EGR, et al., 2018). O avanço do vírus SARS-CoV-2 culminou no distanciamento social e paralisação das aulas presenciais, dessa forma, as instituições de ensino superior passaram a adotar o ensino remoto emergencial aliado às tecnologias e metodologias ativas para dar continuidade ao processo de aprendizagem (APPENZELLER S, et al., 2020). Assim, as atividades de monitoria continuaram atuando através de plataformas virtuais, fóruns de discussão e videoconferências de acordo com o projeto pedagógico (LANZA CC, et al., 2021).

\section{OBJETIVO}

Relatar a experiência adquirida por meio de uma monitoria realizada na modalidade de ensino remoto na disciplina de anatomia humana para alunos do primeiro período do curso de bacharel em enfermagem na Universidade Estadual do Maranhão (UEMA).

\section{RELATO DE EXPERIÊNCIA}

A monitoria acadêmica na disciplina de anatomia humana ocorreu no período de dezembro de 2020 a março de 2021 tendo como orientador o docente da disciplina. No plano de trabalho de monitoria desenvolvido em conjunto com orientador, durante uma reunião online, foram determinadas atividades síncronas e assíncronas a serem executadas no decorrer dos meses. Logo no início do período foi criado um grupo no aplicativo WhatsApp com os alunos e repassadas as informações sobre a disciplina, horário e link para as aulas. O WhatsApp foi o principal veículo de contato entre discentes e monitor para quaisquer dúvidas a respeito das aulas, trabalhos e provas.

O primeiro encontro por videoconferência teve como foco a revisão dos assuntos já repassados pelo professor, amostras e estudos de peças anatômicas referentes aos sistemas ósseo, nervoso e cardiovascular em que muitos alunos tiraram suas dúvidas e contribuíram com seus conhecimentos adquiridos. As atividades assíncronas incluíam desenhos do sistema digestivo, reprodutor masculino e feminino. O acompanhamento da execução dessa atividade foi bastante intenso e os assistidos se mostraram interessados e empenhados. 


\section{CONSIDERAÇÕES FINAIS}

As atividades feitas durante a monitoria mostram-se de grande importância para a completa e satisfatória aprendizagem dos discentes na disciplina de anatomia humana, sendo esta, uma matéria base para as seguintes e que é de difícil compreensão. Além disso, a monitoria serve como ponte entre os novos alunos e veteranos. Com isso, entende-se que monitoria contribui não só com a facilitação dos conteúdos mas também com a integração dos discentes

\section{REFERÊNCIAS}

1. ANDRADE EGR, et al. Contribuição da monitoria acadêmica para o processo ensino-aprendizagem na graduação em enfermagem. Revista Brasileira de Enfermagem, 2018; 71(4): e16908.

2. APPENZELLER $S$, et al. Novos tempos, novos desafios: estratégias para equidade de acesso ao ensino remoto emergencial. Revista Brasileira de Educação Médica, 2020; 44(1): e0155.

3. LANZA CC, et al. Atividade de monitoria durante o Regime Letivo Remoto: relato de experiência no curso de medicina. Revista Eletrônica Acervo Saúde, 2021; 13(5): e7163. 


\title{
VIVÊNCIA ACADÊMICA DURANTE A MONITORIA NA DISCIPLINA DE PSICOLOGIA DA SAÚDE: UM RELATO DE EXPERIÊNCIA
}

\author{
Bárbara Lorrany Feitosa Rios Almeida ${ }^{1}$ \\ Railda Lima Rodrigues ${ }^{1}$
}

1. Universidade Estadual do Maranhão (UEMA), Bacabal - MA.

Palavras-chave: Aprendizagem, Conhecimento, Instituições de ensino superior.

\section{INTRODUÇÃO}

A monitoria acadêmica obtém relevância como ferramenta de apoio pedagógico, através do discentemonitor e o assistido, quando adquirem oportunidades de aprofundar seus conhecimentos, fortalecendo habilidades teórico-práticas e esclarecendo dúvidas a respeito de uma área de conhecimento (ANDRADE EGR, et al., 2018).

A psicologia da saúde e seus atributos acrescenta conhecimentos e mostra como saída para os problemas de percepção teórica e intervenção prática, a conexão entre intervenção e níveis de complexidade de atenção em saúde (ALVES R, et al., 2017). Dessa forma, é imprescindível que a instauração dos programas de monitoria nas instituições de ensino superior seja um facilitador no processo de ensino-aprendizagem (de SOUSA MS, et al., 2019).

\section{OBJETIVO}

Relatar a experiência de monitoria da disciplina de Psicologia da saúde, em uma universidade pública, no município do Maranhão, no período de três meses, entre maio e agosto de 2021.

\section{RELATO DE EXPERIÊNCIA}

A monitoria de psicologia da saúde ocorreu via aula remota, sob orientação da professora da disciplina, com encontros semanais. Tratando sobre temas relevantes para a Psicologia da Saúde aplicada a Enfermagem, tais como: A introdução da psicologia na saúde, teorias do desenvolvimento, personalidade e comportamento humano, comunicação profissional na enfermagem e os problemas enfrentados pelos enfermeiros ao tratarem pacientes com risco iminente de morte. Realizaram-se debates e discussões acerca do conteúdo, incluindo a retirada de dúvidas.

Além disso, utilizou-se o WhatsApp para reforçar as orientações aos discentes com dificuldades em apreender as temáticas. Também foi estimulado a criatividade dos alunos, nas elaborações de pôsteres e folders sobre os temas, apresentação de seminários, além da criação de um perfil no Instagram para as postagens e interação com o público. Foi notório a participação dos alunos durante as monitorias, bem como o melhor rendimento na disciplina. 


\section{CONSIDERAÇÕES FINAIS}

Evidencia-se o bom aproveitamento do aluno na disciplina com orientação do professor e mediação do monitor, fazendo com que o discente monitor tenha maior domínio do conteúdo ao ensinar. O programa de monitoria nas universidades, é imprescindível, tornando o aluno mais confiante, com novas habilidades, autonomia e com maior capacidade de lidar com situações adversas, sejam elas na vida acadêmica ou profissional.

\section{REFERÊNCIAS}

1. ALVES R, et al. Atualidades sobre a Psicologia da Saúde e a realidade brasileira. Psicologia, Saúde e Doenças, 2017; 18(2): 545-555.

2. ANDRADE EGR, et al. Contribuição da monitoria acadêmica para o processo ensino-aprendizagem na graduação em enfermagem. Revista Brasileira de Enfermagem. 2018; 71(4): 1690-8.

3. de SOUSA MS, et al. A monitoria acadêmica como instrumento facilitador no processo de ensino e aprendizagem no curso de enfermagem: um relato de experiência. Revista Eletrônica Acervo Científico, 2019; 6: e1662. 
RESUMO SIMPLES: Relato de Experiência

\title{
VIVÊNCIA DE MONITORIA NA DISCIPLINA DE ASSISTÊNCIA DE ENFERMAGEM EM PACIENTES EM ESTADO GRAVE
}

\author{
Cremilson de Paula Silva ${ }^{1}$
}

Milene Dias Ferreira Magri²

1. Universidade Federal de Alfenas (UNIFAL), Alfenas - MG.

2. Instituto Federal de Educação, Ciência e Tecnologia do Sul de Minas Gerais (IFSULDEMINAS), Muzambinho - MG.

Palavras-chave: Educação técnica em enfermagem, Ensino, Unidades de terapia intensiva.

\section{INTRODUÇÃO}

A monitoria trata-se de uma estratégia pedagógica utilizada nas instituições de ensino com o objetivo de potencializar o processo de ensino-aprendizagem (SILVA CC, et al., 2019). Através das práticas de monitoria, os estudantes monitores são capazes de promover a indissociabilidade entre o tripé universitário (ensino, pesquisa e extensão), contribuindo para a ampliação do conhecimento (CHERMONT GG, et al., 2020).

Devido a pandemia de COVID-19, o projeto foi readequado ao ambiente virtual de aprendizagem, sendo esta ação, fundamental para continuidade do semestre letivo e melhor compreendimento dos estudantes acerca das temáticas abordadas no ambiente de aprendizagem (DIAS FSS, et al., 2021).

\section{OBJETIVO}

Relatar a experiência adquirida em monitoria na disciplina de Assistência de Enfermagem em Pacientes em Estado Grave, na modalidade de remota, em um curso Técnico em Enfermagem de uma Instituição Federal do Sul de Minas Gerais

\section{RELATO DE EXPERIÊNCIA}

O presente estudo trata-se de um relato de experiência, elaborado a partir da atuação como monitor na disciplina de Assistência de Enfermagem em Pacientes em Estado Grave em um curso Técnico em Enfermagem durante o primeiro semestre de $2021 \mathrm{em}$ um Instituto Federal do Sul de Minas Gerais, através de ferramentas virtuais de comunicação. Em decorrência da pandemia da COVID-19, as práticas de monitoria foram readequadas ao ambiente virtual de aprendizagem, sendo orientadas pela professora orientadora da disciplina e realizadas através do Google Meet e do WhatsApp.

O monitor foi orientado a realizar encontros síncronos e assíncronos, produzir materiais didáticos (resumos, mapas mentais) e realizar discussões acerca das questões relacionadas à disciplina, com o intuito de estimular o desenvolvimento do senso crítico-reflexivo dos estudantes, assim como o desenvolvimento de competências como habilidades de comunicação, trabalho em equipe e interação dos alunos. Por meio dos encontros realizados pode-se perceber que a prática de monitoria minimizou os impactos decorrentes da 
readaptação dos alunos para o ambiente virtual de aprendizagem, permitindo o aprendizado mútuo entre os docentes, discentes e o estudante monitor.

\section{CONSIDERAÇÕES FINAIS}

Adequar as práticas de monitoria para o ambiente virtual de aprendizagem foi uma experiência desafiadora, todavia, foi uma experiência de muitos aprendizados. Além de promover instrução mútua e coletiva, a monitoria possibilitou o desenvolvimento de competências cruciais para atuação no mercado profissional, nesse sentido, considera-se que foi estratégia fundamental para a formação profissional dos estudantes.

\section{REFERÊNCIAS}

1. CHERMONT GG, et al. Monitores da disciplina Anatomia Humana desenvolvem material didático durante a pandemia da Covid-19. Revista Eletrônica Acervo Saúde, 2021; 13(3): e6600.

2. DIAS FSS, et al. O ensino remoto na pandemia da COVID-19: opinião de estudantes de um curso técnico em enfermagem. Revista Eletrônica Acervo Saúde, 2021; 13(3): e6530.

3. SILVA CC, et al. Monitoria acadêmica em enfermagem em doenças infecciosas e parasitárias: um relato de experiência. Revista Eletrônica Acervo Saúde, 2019; 11(11): e579. 


\section{ALEITAMENTO MATERNO: EXPERIÊNCIA VIRTUAL EDUCATIVA EM SAÚDE}

Cremilson de Paula Silva ${ }^{1}$

Ana Paula Alonso Reis Mairink ${ }^{1}$

1. Instituto Federal de Educação, Ciência e Tecnologia do Sul de Minas Gerais (IFSULDEMINAS), Muzambinho - MG.

Palavras-chave: Aleitamento materno, Educação em saúde, Tecnologias em saúde.

\section{INTRODUÇÃO}

O aleitamento materno é fundamental para o crescimento e desenvolvimento da criança devido aos seus benefícios nutricionais, emocionais, imunológicos e econômico-sociais, além dos benefícios para a mãe (SOUSA FLL, et al., 2021). No contexto interdisciplinar, a comunicação, o trabalho em equipe e a cooperação entre os profissionais, são fundamentais para a maior adesão da família ao aleitamento. (NASCIMENTO AMR, et al., 2019).

Assim, no contexto da pandemia da COVID-19, essa interação profissional-paciente foi limitada pela segurança e preservação da vida, e os meios de comunicação, através das mídias sociais, se tornaram aliados fundamentais para a educação em saúde (LODI JC, et al., 2020).

\section{OBJETIVO}

Relatar a experiência de participação em uma atividade educativa, em ambiente virtual, desenvolvida na disciplina de Assistência de Enfermagem na Integralidade da Saúde da Mulher, de um curso Técnico em Enfermagem, de uma Instituição de Ensino da Rede Federal.

\section{RELATO DE EXPERIÊNCIA}

Foi proposta na disciplina a elaboração do infográfico sobre aleitamento materno, com finalidade de compartilhar informações e apoiar ações de incentivo à amamentação em agosto, mês dedicado mundialmente à intensificação das ações de promoção, proteção e apoio ao aleitamento materno. O material foi desenvolvido de 05/07 à 09/08 de 2021 e, para sua elaboração, a turma se auto dividiu em quatro grupos: grupo 1 (elaborou conteúdo para orientações, após a aula da temática); grupo 2 (digitou conteúdo elaborado pelo grupo 1); grupo 3 (elaborou arte do infográfico no CANVA; grupo 4 (publicou material informativo nas redes sociais do curso).

Os grupos 1, 2 e 3 tiveram três estudantes cada e, o grupo 4, dois. Os grupos se reuniram pelo Google Meet, Whatsapp e ambiente virtual da disciplina, através de encontros síncronos e assíncronos para discussão sobre o tema, esclarecimento de dúvidas e criação do infográfico. Os encontros possibilitaram o desenvolvimento de habilidades como comunicação, uso de tecnologias virtuais, trabalho em equipe, 
aprendizado mútuo e incentivou o desenvolvimento do senso crítico-reflexivo acerca da temática do Aleitamento Materno.

\section{CONSIDERAÇÕES FINAIS}

A construção do material educativo (infográfico), em ambiente remoto, constituiu um desafio, todavia, uma experiência com muitos aprendizados pois proporcionou um espaço fundamental para o desenvolvimento profissional e pessoal dos estudantes, além de fortalecer o nosso compromisso com a universidade, e da universidade com a sociedade.

\section{REFERÊNCIAS}

1. LODI JC, et al. Planejamento e gestão estratégica de um grupo de incentivo ao aleitamento materno em tempos de Covid-19. Revista Internacional de Extensão da Unicamp, 2020; 1(1): 44-52.

2. NASCIMENTO AMR, et al. Atuação do enfermeiro da estratégia de saúde da família no incentivo ao aleitamento materno durante o período pré-natal. Revista Eletrônica Acervo Saúde, 2019; 21: e667.

3. SOUSA LLM, et al. Benefícios do aleitamento materno para a mulher e o recém nascido. Research, Society and Development, 2021; 10(2): e12710211208. 


\title{
EXPERIÊNCIA DE ESTUDANTES NA CAMPANHA DE VACINAÇÃO CONTRA A COVID-19 EM UM MUNICÍPIO DA AMAZÔNIA PARAENSE
}

\author{
Elem Cristina Silva da Costa ${ }^{1}$ \\ Maria Fernanda Santos Araújo ${ }^{1}$ \\ Thamires Renata Sousa e Silva ${ }^{1}$ \\ Linda Inêz Alves da Silva ${ }^{1}$ \\ Adriana Paiva Camargo Saraiva ${ }^{1}$
}

1. Universidade do Estado do Pará (UEPA) - Conceição do Araguaia-PA

Palavras-chave: Vacinação, COVID-19, Enfermagem.

\section{INTRODUÇÃO}

Esforços mundiais de produção e distribuição das vacinas contra a COVID-19 são realizados, entretanto, sua credibilidade com a população não acompanhou sua evolução, a exemplo, a hesitação, medo e excesso de questionamentos no ato da vacinação. O êxito nos esquemas de vacinação relaciona-se com as taxas de produção científica/adesão em massa da população. A produção em tempo reduzido das vacinas, o desconhecimento propagado na mídia popular/social, a polarização dos cenários políticos e as complexidades inerentes aos esforços de vacinação em massa têm potencial para gerar desconfiança a respeito da vacinação contra a COVID-19 (RUTTEN LJF, et al., 2021; CARNEIRO DC, et al., 2021; CASCINI F, et al., 2021).

\section{OBJETIVO}

Relatar a experiência na campanha de vacinação contra a COVID-19, vivenciada por estudantes de graduação em enfermagem de um município da região amazônica no Estado do Pará, destacando a percepção sobre a adesão da população à vacinação.

\section{RELATO DE EXPERIÊNCIA}

A experiência corresponde ao período de maio a julho de 2021, em um município da região sudeste da Amazônia paraense. A participação dos discentes de enfermagem na campanha de vacinação contra a COVID-19 partiu da parceria entre universidade e Secretaria Municipal de Saúde, com supervisão docente e da enfermeira responsável pela sala de vacina. Durante o período de observação, percebeu-se desconfiança em relação à existência do imunobiológico na seringa, sua validade e eficácia, medo do material perfurocortante, ansiedade no momento da aplicação da vacina e receio da dor.

Constatou-se que quanto menor a faixa etária, menor a adesão à vacinação e maior procura por informações sobre confiabilidade e efeitos adversos. Notou- se que as vacinas de determinados laboratórios, 
disponíveis no município no momento, com menor eficácia global, foram um fator contributivo para objeção de esquema vacinal de duas doses, recusa à vacinação na fila de espera ou o não retorno para tomar a segunda dose. A preferência por esquema vacinal de dose única foi notada durante o período observado.

\section{CONSIDERAÇÕES FINAIS}

Insegurança sobre a eficácia da vacina, acesso a informações conflitantes e aspectos psicológicos contribuíram para redução da adesão à vacinação em jovens e idosos, principalmente na segunda dose, devendo ser investigado o motivo. Ações educativas como oferecer informações sobre a vacina e o procedimento da vacinação, estabelecer boa comunicação e proporcionar um ambiente seguro/acolhedor podem ser adotadas para estimular o retorno dos usuários às salas de vacina.

\section{REFERÊNCIAS}

1. CARNEIRO DC, et al.The COVID-19 vaccine development: A pandemic paradigm. Virus research, 2021; 301:198454.

2. CASCINI F, et al. Attitudes, acceptance and hesitancy among the general population worldwide to receive the COVID-19 vaccines and their contributing factors: A systematic review. EClinicalMedicine, 2021; 40: 101113.

3. RUTTEN LJF, et al. Evidence-Based Strategies for Clinical Organizations to Address COVID-19 Vaccine Hesitancy. Mayo Clinic Proceedings, 2021; 96(3): 699-707. 
RESUMO SIMPLES: Relato de Experiência

\section{EDUCAÇÃO EM SAÚDE EM UM HOSPITAL PÚBLICO DE MANAUS}

Cristhallay Silva Cavalcante ${ }^{1}$

1. Estácio de Sá do Amazonas (UESA), Manaus - AM.

Palavras-chave: COVID-19, Enfermagem, Educação continuada.

\section{INTRODUÇÃO}

A COVID-19 é uma patologia viral que causa comprometimento respiratório com elevada taxa de infecção e transmissibilidade. Este vírus causa síndrome respiratória aguda, acarretando elevado índice de internação em unidade de terapia intensiva. Sua transmissão ocorre através do contato de gotículas respiratórias de indivíduos infectados (PRADO AD, et al., 2020).

A educação em saúde é primordial no manejo clínico, na identificação de casos suspeitos, realização de medidas profiláticas e no diagnóstico do vírus (OLIVEIRA LS, et al., 2017). Os principais sintomas são: febre, tosse e dispneia. As principais medidas profiláticas são: higienização das mãos, distanciamento social, uso de máscara e o não compartilhamento de objetos pessoais (GONÇALVES RA, et al., 2018).

\section{OBJETIVO}

Enfatizar as ações de educação em saúde realizadas pelo núcleo de educação continuada, avaliar o conhecimento científico acerca da temática e capacitar os profissionais de saúde no desenvolvimento de uma assistência qualificada.

\section{RELATO DE EXPERIÊNCIA}

A educação em saúde ocorreu em um hospital público em Manaus - AM através do núcleo de educação continuada frente a equipe multiprofissional, contribuindo de forma significativa na assistência a pacientes com COVID-19, norteando as ações adequadas no manejo clínico, como na realização de posição prona, protocolo de intubação e parada cardiorrespiratória, evitando a propagação de aerossóis que podem contaminar a equipe multiprofissional, enfatizando a paramentação adequada na assistência destes pacientes.

A educação continuada realizou treinamento em serviço com 30 profissionais de saúde embasado em protocolos do Ministério da Saúde, direcionando o manejo clínico de pacientes com suspeita ou confirmação do diagnóstico de COVID-19. Todos os 30 profissionais passaram por 3 estações de simulação realísticas.

Na primeira estação deveriam realizar paramentação na ordem correta, na segunda estação o profissional deveria aplicar medidas realizadas em pacientes em parada cardiorrespiratória na COVID-19 e na terceira estação deveriam realizar ações fundamentais para evitar a contaminação da equipe multiprofissional durante a intubação e posicionar o paciente em posição prona adequada. 


\section{CONSIDERAÇÕES FINAIS}

Educação em saúde proporciona a construção do conhecimento científico por meio do processo educacional, contribuindo na qualidade da sistematização da assistência de enfermagem, desenvolvendo a atuação dos profissionais de saúde através do ensino, subsidiando as ações de promoção, proteção e recuperação em saúde. Verificou-se que a capacitação da equipe multiprofissional possibilitou a prática baseada em evidência científica de pacientes com COVID-19. A educação continuada proporcionou autonomia e segurança do paciente.

\section{REFERÊNCIAS}

1. GONÇALVES RA, STANCATO K. Análise da educação continuada de dois hospitais públicos e um privado na região de Campinas-São Paulo. Revista Eletrônica Acervo Saúde, 2018; 7(1): 723-726.

2. OLIVEIRA LS, et al . A educação continuada na percepção dos profissionais de enfermagem da área hospitalar. Revista Eletrônica Acervo Saúde, 2017; 8: S615-S623.

3. PRADO AD, et al. A saúde mental dos profissionais de saúde frente à pandemia do COVID-19: uma revisão integrativa. Revista Eletrônica Acervo Saúde, 2020; 46: e4128. 


\title{
ATUAÇÃO DE ENFERMEIRAS NOS CUIDADOS DE PACIENTES SUSPEITOS E CONFIRMADOS DA COVID-19
}

\author{
Luciene Maria dos Reis ${ }^{1}$ \\ Alda Helena dos Santos Carvalho²
}

1. Faculdade de Ciências e Tecnologia de Unaí (FACTU), Unaí - MG

2. Faculdade Pitágoras Instituto Camilo Filho (ICF), Teresina - PI.

Palavras-chave: Coronavírus, Pandemia, Profissionais de enfermagem.

\section{INTRODUÇÃO}

A COVID-19 é conhecida como uma síndrome respiratória aguda grave provocada pelo novo coronavírus SARS- COV-2, foi registrados os primeiros casos em Wuhan, na China (BRASIL, 2020). Por apresentar alta infectividade se propagou rapidamente mundialmente, em 30 de janeiro de 2020 foi decretado Emergência de Saúde Pública de Importância Internacional pela Organização Mundial de Saúde (HUH S., 2020), assim sendo, os profissionais de saúde, e principalmente, os profissionais de enfermagem mostraram durante a pandemia da COVID-19 um alto risco de contaminação na cadeia epidemiológica dessa doença, devido à exposição ocupacional diariamente, visto que, muitas vezes estão sob condições de trabalho insatisfatórias para prevenção da transmissão (ZHOU M, et al., 2020).

\section{OBJETIVO}

Relatar a experiência de enfermeiras que atuam na linha de frente nos cuidados a pacientes suspeitos e confirmados da COVID-19 em um hospital escola na região metropolitana de Belo Horizonte, Minas Gerais.

\section{RELATO DE EXPERIÊNCIA}

Descreveu-se a experiência vivenciada até os dias atuais, quanto aos fluxos operacionais de serviço que a instituição disponibilizou, modelos estes, que os profissionais seguem desde a classificação de risco até a internação, os pacientes são encaminhados para área reservada para o atendimento sem ter contatos com os demais pacientes que não apresentam sintomas gripais, estes setores são para prestar a assistência isolada destes casos, e contam com uma equipe distinta para o atendimento.

Houve capacitação quanto a utilização de Equipamentos de Proteção Individual (EPI), porém quando ocorreram os primeiros contatos com pacientes suspeitos e/ou confirmados da patologia ainda ocorreram dúvidas e inseguraça, principalmente, devido a forma de se paramentar e desparamentar e como deveriam lidar com situações de maior gravidade.

Por fim, em relação à saúde física e mental dos profissionais de enfermagem durante a pandemia foi possível ver uma pequena parte dos profissional se afastando por motivos emocionais, outra parcela por sintomas gripais e outros que se contaminaram pela própria COVID-19. 


\section{CONSIDERAÇÕES FINAIS}

É necessário que os gestores estejam envolvidos no processo de gestão do cuidado, de mais, é para enfatizar a necessidade de treinamento constante dos profissionais estão na primeira linha de luta contra 0 uso adequado das barreiras de exposição,pois, portanto, ajustes na estrutura dos fluxos operacionais dos serviços.

\section{REFERÊNCIAS}

1. BRASIL. Ministério da Saúde. Portaria $M S / G M ~ n^{\circ}$ 188, de 3 de fevereiro de 2020. Declara Emergência em Saúde Pública de importância Nacional (ESPIN) em decorrência da Infecção Humana pelo novo Coronavírus (2019-nCoV) [Internet]. Diário Oficial da União, Brasília (DF), 2020 fev 4 [citado 2020 mar 4]; Seção Extra:1. Disponivel em :. Acessado em: 15 de maio de 2020.

2. HUH S. How to train the health personnel for protecting themselves from novel coronavirus (COVID-19) infection during their patient or suspected case care. Journal of educational evaluation for health professions, 2020; 17(10).

3. ZHOU M, et al. Knowledge, attitude and practice regarding COVID-19 among health care workers in Henan, China. The Journal of hospital infection, 2020; 105(2). 


\title{
ABORDAGEM EDUCACIONAL PARA PROMOÇÃO DE SAÚDE EM ADOLESCENTES: UM RELATO DE EXPERIÊNCIA
}

\author{
Ana Flávia da Silva Ribeiro ${ }^{1}$ \\ Anderson Lima dos Santos ${ }^{1}$ \\ Andréa Veruska de Souza Almeida ${ }^{1}$ \\ Anna Thereza Ribeiro Pindaíba Moura ${ }^{1}$ \\ Maria Tamires Alves Ferreira ${ }^{1}$
}

1. Faculdade Estácio de Teresina (ESTÁCIO), Teresina - PI.

Palavras-chave: Adolescente, Ações educativas, Problemas educacionais.

\section{INTRODUÇÃO}

O processo de desenvolvimento visto na transição da infância e adolescência é tido como etapa de vivências diversas, sendo considerado um período de descobrimento e amadurecimento pessoais e sociais (LEBOURG EH, et al., 2021). Portanto, é imprescindível a permanência dos jovens nas escolas, uma vez que práticas educativas e atuação das famílias contribuem para transformação biopsicossocial e educação em saúde intervindo nas vulnerabilidades expostas na sociedade. Assim, profissionais da saúde dentro da escola são sujeitos desencadeadores de ações em saúde, no qual abordam temas sobre qualidade de vida dos adolescentes, bem como assuntos atuais e rotineiros como Infecções Sexualmente Transmissíveis (IST), Bullying e drogas (CASTRO ATV, et al., 2020; SILVA JLL, et al., 2020).

\section{OBJETIVO}

Relatar a experiência de uma abordagem educativa realizada por acadêmicos de enfermagem com adolescentes em uma escola de Teresina (PI), sobre problemas educacionais como Infecção Sexualmente Transmissível, Drogas llícitas e Bullying.

\section{RELATO DE EXPERIÊNCIA}

A atividade foi realizada em uma instituição escolar de ensino público por acadêmicos do curso de bacharelado em enfermagem, onde ocorreu em duas fases: I- diagnóstico situacional; II- intervenções educativas a respeito de três temáticas, com dinâmicas variadas de acordo com o tema. Dessa forma, o uso de drogas por adolescentes tem forte incidência e é tido como um grave problema de saúde pública, assim, para explanar as informações necessárias de forma objetiva, realizou-se a dramatização, em que traz a encenação para o contexto real.

Subsequentemente, foi abordado o bullying, tendo em vista que é um problema presente nas escolas. Nesse contexto, desenvolveu-se a dinâmica "teia de aranha" com intuito de mostrá-los, independente das 
diferenças, todos fazemos parte de um todo e somos igualmente importantes. Por fim, para melhor entendimento dos alunos sobre as IST, discorreu-se com a dinâmica que aborda a transmissão dessas infecções, bem como debate sobre as diversas fases de desenvolvimento hormonal e a elaboração de um "caixa secreta" para os adolescentes colocarem suas dúvidas, garantido o anonimato.

\section{CONSIDERAÇÕES FINAIS}

A intervenção educacional proporcionou maior visibilidade na abordagem de temas comumente silenciados por serem considerados tabus. Assim sendo, o objetivo esperado foi alcançado pois a dinâmica oportunizou uma abordagem de forma descontraída e teve uma contribuição significativa com a sensibilização dos alunos, no qual também expuseram suas concepções sobre tais temáticas. Desse modo, observou-se a necessidade de serem otimizadas mais ações educativas de forma permanente no cenário escolar.

\section{REFERÊNCIAS}

1. CASTRO ATV, et al. O papel da atenção primária à saúde no controle de infecções sexualmente transmissíveis em adolescentes. Revista Eletrônica Acervo Saúde, 2020; 12(12): e4908.

2. LEBOURG EH, et al. Juventude e transição para o ensino médio: desafios e projetos de futuro. Revista Brasileira de Estudos Pedagógicos, 2021; 102: 82-98.

3. SILVA JLL, et al. Educação em saúde com adolescentes na escola: relato de experiência. Brazilian Journal of Health Review, 2020; 3(3): 6007-6017. 
RESUMO SIMPLES: Relato de Experiência

\title{
SEGURANÇA DO PACIENTE: PREVENÇÃO DE QUEDAS EM IDOSOS HOSPITALIZADOS
}

\author{
Luciene Maria dos Reis ${ }^{1}$ \\ Alda Helena dos Santos Carvalho²
}

1. Faculdade de Ciências e Tecnologia de Unaí (FACTU), Unaí - MG.

2. Faculdade Pitágoras Instituto Camilo Filho (ICF), Teresina - PI.

Palavras-chave: Idoso, Hospitalização, Prevenção.

\section{INTRODUÇÃO}

O Ministério da Saúde do Brasil, por meio da Portaria ํㅡ 529 de $1^{\circ}$ de abril de 2013, instituiu o Programa Nacional de Segurança do Paciente (PNSP) para o monitoramento e prevenção de danos na assistência em saúde (BRASIL, 2013). Dentre os objetivos desse programa está a prevenção de quedas, que por sua vez, são definidas como os deslocamentos não intencionais do corpo a um nível inferior em relação à posição inicial (ROSA VPP, et al., 2019). Os idosos apresentam um elevado índice para quedas, que estão associados a fatores vinculados tanto ao indivíduo como ao ambiente (SOUZA LHR, et al., 2017).

\section{OBJETIVO}

Relatar a experiência de enfermeiras quanto às medidas de prevenção de quedas em idosos hospitalizados em um setor de clínica médica de um hospital escola da região metropolitana de Belo Horizonte, Minas Gerais.

\section{RELATO DE EXPERIÊNCIA}

Descreveu-se as condutas adotadas pelas enfermeiras para reduzir os riscos de quedas em pacientes idosos, primeiramente, na admissão se aplicava a escala de Morse, após a análise do escore dessa escala que avalia o risco de queda, os idosos que apresentavam risco moderado ou elevado para queda recebiam uma pulseira de cor amarela para sinalizar o risco de queda, dessa forma, alertando a equipe multiprofissional e orientando o próprio idoso.

Além disso, realizava o teste Timed Up \& Go, que consiste na avaliação clínica da mobilidade, além disso, eram sinalizados nos formulários de passagem de plantão e dito verbalmente entre os enfermeiros quanto ao risco de queda do idoso, era reavaliado diariamente durante a corrida de leito do enfermeiro o risco de queda devendo ser evoluído no prontuário do paciente.

Quanto as ações desenvolvidas pela equipe estavam assegurar que as camas permanecessem em posição baixa, com as rodas travadas e as grades elevadas, orientava ao paciente e acompanhante sobre as mudanças medicamentosas que pudessem causar vertigem, além disso, auxiliava pacientes com risco durante deambulação e transferência. 


\section{CONSIDERAÇÕES FINAIS}

O presente estudo contribuiu para entender que a queda é um evento multicausal que necessita de estratégias para que seus índices diminuam, a equipe de enfermagem que assiste este idoso hospitalizado deve intensificar o estabelecimento de ações/estratégias voltadas à prevenção de quedas, a fim de conscientizar os idosos sobre o risco de queda dentro do hospital e estimular a coparticipação em sua segurança.

\section{REFERÊNCIAS}

1. BRASIL. Portaria $n^{\circ} 529$, de $1^{\circ}$ de Abril de 2013. Institui o Programa Nacional de Segurança do Paciente (PNSP). Saúde Legis. 2013. Disponível em: http://bvsms.saude.gov.br/bvs/saudelegis/gm/2013/ prt0529_01_04_2013.html. Acessado em: 10 de setembro de 2020.

2. ROSA VPP, et al. Análise dos fatores de risco para queda em idosos institucionalizados. Revista Brasileira de Geriatria e Gerontologia, 2019; 22(1): e180138.

3. SOUZA LHR, et al. Queda em idosos e fatores de risco associados. Revista Atenção em Saúde, 2017; 15(54): 55-60. 


\title{
A RELEVÂNCIA DOS PROJETOS DE EXTENSÃO PARA ACADÊMICOS DA ÁREA DA SAÚDE: RELATO DE EXPERIÊNCIA
}

\author{
Larissa Siqueira Rodrigues ${ }^{1}$ \\ Patrick Roberto Gomes Abdoral² \\ Carlos Alex de Menezes Carneiro ${ }^{1}$
}

1. Universidade da Amazônia (UNAMA), Belém - PA.

2. Faculdade Cosmopolita, Belém - PA.

Palavras-chave: Aprendizado baseado na experiência, Área da saúde , Estudantes.

\section{INTRODUÇÃO}

Os projetos de extensão na área da saúde são muito importantes para acadêmicos, pois interligam a teoria e prática de alunos universitários com a sociedade, sendo assim, possibilitam uma troca de saberes de ambas as partes (SILVA ALB, et al., 2017). Também propicia atividade de ensino e pesquisa (FIGUEIREDO MO, et al., 2020).

Tendo em vista essa perspectiva de formação de profissionais proativos, é fundamental que o aluno participe de projetos de extensão, para haver essa troca de educação e evolução do conhecimento (SANTOS MCV e MOREIRA JR, 2019). Assim, o projeto em extensão vem proporcionar o aluno a colocar o que aprendeu em prática e aumentar sobre o conhecimento da área fisioterapia.

\section{OBJETIVO}

Descrever experiências obtidas com aprendizagens teóricas-prático e atendimentos fisioterapêuticos no projeto de extensão de uma universidade do norte no ano de 2021, como importante fonte enriquecedora para construção profissional do discente.

\section{RELATO DE EXPERIÊNCIA}

Durante o período do projeto de extensão em neurologia, em 2021, no setor da clínica escola, foram observados pontos positivos sobre a participação do discente, como desenvolvimento crítico- reflexivo, criativo, autoconfiança dos alunos e um despertar clínico e humanizado no atendimento com a comunidade.

O projeto de extensão visa ampliação do conhecimento, saindo da perspectiva sala de aula para ação com a comunidade, tornando mais fluido o aprendizado prático. Ademais, foram realizadas outras pesquisas por meio do projeto de extensão como relato de experiências em congressos, despertar de temáticas para publicações em revistas e livros.

Sendo assim, é perceptível a importância da implementação de atividade universitária desse perfil, afim de estimular o profissional a se qualificar e ensino e aprendizagem de maneira mais abrangente e 
enriquecedora, beneficiando não apenas o próprio aluno, mas a área da saúde, pois conseguimos avançar em pesquisas e aumentar a evidência científica de tratamentos e suas eficácias em sua aplicação no paciente.

\section{CONSIDERAÇÕES FINAIS}

Destaca-se a importância do projeto de extensão na vida acadêmica, como forma de amplificar o ensino e incentivar a pesquisa em saúde, possibilita os discentes um aprendizado prático-teórico, desperta de temáticas a serem estudadas, proporciona amadurecimento profissional, assegurando uma formação proativa e significativa. Ademais, ocorre a troca de conhecimentos entre aluno e comunidade. Também, os editais de residência pontuam projetos de extensão, elevando a importância do mesmo para os alunos.

\section{REFERÊNCIAS}

1. FIGUEIREDO MO, et al. Contribución de las actividades de extensión a la formación en Terapia Ocupacional. Revista Ocupación Humana, 2020; 20(1): 7-26.

2. SANTOS MCV, MOREIRA, JR. Extensão universitária: análise comparativa das políticas de extensão do grupo projeção com as novas diretrizes do MEC Revista Projeção e Docência, 2019; 10(1): 113-129

3. SILVA ALB, et al. Importância da extensão universitária na formação profissional: Projeto Canudos. Revista de enfermagem UFPE On Line, 2019; 13(2): e242189. 
RESUMO SIMPLES: Relato de Experiência

\section{IMPLICAÇÕES NUTRICIONAIS EM ADULTOS JOVENS E IDOSOS TABAGISTAS}

Amanda Morais de Farias ${ }^{1}$

1. Polo DNA Pós-Graduação, Campina Grande - PB.

Palavras-chave: Saúde, Hábitos de vida, Alimentação.

\section{INTRODUÇÃO}

Constitui-se o tabagismo como um dos principais motivos de óbitos acerca de todo o mundo, sendo ele caracterizado como uma pratica de consumo presente desde a antiguidade (GUERRA AA, et al., 2019). Ao passar dos anos, pode-se analisar que o tabagismo desenvolve diversos agravantes na adequada funcionalidade do corpo humano, causando alterações em órgãos como: pulmão, coração, fígado, estômago, rins e outros componentes indispensáveis a vida (BELTRAME DPC, et al., 2018). Nesse sentido, o habito pelo tabaco é predominado por várias condições sociais, dentre elas, ressaltam-se o fácil acesso e o baixo custo (GOMES D, et al., 2020).

\section{OBJETIVO}

Relatar e apresentar mediante de experiência vivenciada em Programa Multidisciplinar de Tratamento ao Tabagismo - PMTT (HUAC/PB), através de participação na equipe de nutrição, quais implicações nutricionais apresentadas em adultos jovens e idosos tabagistas.

\section{RELATO DE EXPERIÊNCIA}

Trata-se de um relato de experiência qualitativo-descritivo desenvolvido sobre participação no programa multidisciplinar de tratamento e combate ao tabagismo do HUAC - PB. O programa integra encontros semanais onde ao decorrer de cada sexta feira um grupo de pacientes é vinculado a participação de palestras, rodas de conversas, atividades físicas, entrega de medicamentos e outros aspectos profissionais que ajudam no cessamento do vício ao tabaco, ao total, cada grupo integra seis encontros.

Desse modo, referente a atuação da equipe interdisciplinar de nutrição, pode-se perceber que ao decorrer dos encontros diversos fatores permaneciam discutidos pelos pacientes como sintomatologia recorrente ao período como fumante. Entre esses, destacavam-se as alterações alimentares e fisiológicas nas quais inevitavelmente propiciavam malefícios nutricionais em grande porcentagem da população elencada.

Para tanto, implicações como compulsões do consumo de alimentos açucarados, ricos em gorduras e industrializados marcavam a rotina diária dos fumantes, o que garantia sobre avaliação complicações nutricionais como aumento de peso e então obesidade, levando tanto os participantes idosos quanto os adultos jovens a ficarem suscetíveis ao risco de doenças crônicas não transmissíveis, como hipertensão e diabetes. 


\section{CONSIDERAÇÕES FINAIS}

Os encontros ocorridos durante a realização do programa constituiu-se como pressupostos essenciais no que tange a promoção da saúde dos tabagistas entre a faixa etária de idosos e/ou adultos jovens. Frente a isto, o compartilhamento como profissional e ouvinte das experiências traçadas pelos participantes sobre 0 vício e suas peculiaridades, possibilitou o aumento da análise de riscos nutricionais e do estado nutricional em que estes indivíduos permaneciam.

\section{REFERÊNCIAS}

1. BELTRAME DPC, et al. Tabagismo em idosos: fatores associados e influência na hipertensão arterial sistêmica. Saúde (Santa Maria), 2018; 44(3): e 31.

2. GOMES, Débora Thais Batista; CARVALHO, Jéssika Silva; PACHÚ, Clésia Oliveira. Comorbidades entre idosos tabagistas. Editora Cientifica Digital, 2020; 1(1) e 219-228.

3. GUERRA AA, et al. Prevalência de Tabagismo em Idosos usuários de Unidades Básicas no Município de Santos/SP. Anais do Encontro Nacional de Pós Graduação, 2018; 1(2): e 304-308. 


\title{
DIFICULDADES E FACILIDADES DOS AGENTES COMUNITÁRIOS DE SAÚDE NA REALIZAÇÃO DAS VISITAS DOMICILIARES
}

\author{
Richard Augusto Thomann Beckert ${ }^{1}$ \\ Jeane Barros de Souza ${ }^{1}$ \\ Evelyn do Rosario ${ }^{1}$ \\ Vanessa Zancanaro ${ }^{1}$ \\ Rafaela Márcia Gadonski ${ }^{1}$
}

1. Universidade Federal da Fronteira Sul (UFFS), Chapecó - SC.

Palavras-chave: Educação continuada, Agentes comunitários de saúde, Atenção primária à saúde.

\section{INTRODUÇÃO}

O Agente Comunitário de Saúde (ACS) integra a equipe da Estratégia Saúde da Família, sendo responsável pelo vínculo que as famílias estabelecem com a Unidade Básica de Saúde (UBS), levando informação à comunidade assistida e corroborando com a acessibilidade e resolubilidade nas ações em saúde (SANTOS SG, et al., 2020; SILVA JMA, et al., 2019). Durante as atividades teórico-práticas de acadêmicos de enfermagem de uma Universidade pública de Santa Catarina, surgiu a oportunidade e necessidade de realizar educação continuada com ACS sobre a Visita Domiciliar (VD), buscando conhecer como desenvolvem o acompanhamento regular das famílias, o que contribui para uma melhor compreensão do processo saúdedoença (SANTANA VC, et al., 2019).

\section{OBJETIVO}

Compartilhar a experiência de acadêmicos do curso de enfermagem, durante as atividades teórico-práticas de um componente curricular da graduação, na realização de educação continuada para os ACS sobre as dificuldades e facilidades da VD.

\section{RELATO DE EXPERIÊNCIA}

Realizou-se educação continuada no auditório de uma escola pública, envolvendo 34 ACS de um município do Oeste catarinense, em setembro de 2021. Assim, solicitou-se para os ACS que escrevessem, numa folha, suas facilidades e dificuldades na realização da VD. Seus escritos foram discutidos em grupo. Ademais, realizou-se a discussão de dois casos clínicos previamente elaborados pelos acadêmicos, instigando o pensamento crítico dos ACS. Assim, construiu-se um ambiente propício para reflexão acerca da VD. Também, foi distribuída, via WhatsApp, uma cartilha de orientação para o desenvolvimento da VD.

Durante a educação continuada, os ACS destacaram como principais facilidades da VD: oportunidade de criar vínculo; conhecimento do território e a capacidade de trabalhar em equipe. Já as dificuldades mais 
recorrentes foram: cães nos lares como barreira para o acesso; endereços e telefones desatualizados; impaciência de usuários com as ACS e a dificuldade de comunicação com imigrantes. Os ACS mantiveramse participativos e a discussão tornou-se intensamente reflexiva e crítica, dando ênfase à necessidade de maior valorização do trabalho desse profissional pela equipe da UBS e comunidade adscrita (SILVA JMA, et al., 2019).

\section{CONSIDERAÇÕES FINAIS}

É notória a importância da atuação profissional do ACS na realização das VD, a fim de manter o vínculo das famílias com a UBS. Portanto, é de suma importância promover, de maneira contínua, espaços de discussões para o aprimoramento das ações destes profissionais e sua devida valorização, com vistas a qualificar as ações da Estratégia Saúde da Família.

\section{REFERÊNCIAS}

1. SANTANA VC, et al. A casa como espaço do cuidado: as práticas em saúde de agentes comunitários de saúde em montes claros (mg). Saúde em Debate, 2019; 43(120): 159-169.

2. SANTOS SG, et al. A importância da Enfermeira na Educação Permanente do Agente Comunitário de Saúde (ACS) na Estratégia Saúde da Família (ESF). Brazilian Journal Of Development, 2020; 6(12): 98517-98533.

3. SILVA JMA, et al. Dificuldades Experienciadas pelos Agentes Comunitários de Saúde na Realização da Educação em Saúde. Revista Enfermagem em Foco, 2019; 10(3). 
1. Universidade Federal do Piauí (UFPI), Teresina - PI.

Palavras-chave: Infecções por coronavírus, Vacinas, Prevenção e controle.

\section{INTRODUÇÃO}

Em 2019, na cidade de Wuhan, na China, teve origem um surto do novo coronavírus que logo se espalhou, caracterizando se como pandemia no início de março de 2020 pela Organização Mundial da Saúde (OMS) (COUTO MT, et al., 2021). Em seguida, iniciaram-se as abordagens de saúde pública com a busca de pacientes positivos, rastreamento de seus contactantes e adoção do distanciamento social (JÚNIOR JRS, et al., 2020). No Brasil, à medida que as vacinas iam sendo autorizadas para uso emergencial, surgiam os grupos de pessoas que questionavam sua eficácia e que refutavam os dados científicos (OLIVEIRA BLCA, et al., 2021).

\section{OBJETIVO}

Relatar a experiência de vacinação da população alvo contra a COVID-19 na área adscrita de uma Unidade Básica de Saúde (UBS), localizada na zona rural em um município do Maranhão, no período de março de 2021 a setembro de 2021.

\section{RELATO DE EXPERIÊNCIA}

A vacinação contra a COVID-19 teve sua campanha iniciada em março de 2021, com a faixa etária de 90 anos ou mais, no município do Maranhão relatado. Foi observado que enquanto as idades iam diminuindo, maior era a resistência contra a vacinação. Os principais questionamentos envolviam a sua eficácia, o risco de contrair outras doenças derivadas do imunizante, o laboratório de fabricação das vacinas ou o país do qual eram importadas suas doses.

Para diminuir essa resistência, a enfermeira e a técnica de enfermagem responsável pela sala de vacina adotaram medidas de educação continuada com os Agentes Comunitários de Saúde (ACS), por meio de palestras e capacitações. Esses profissionais possuem uma maior proximidade com a população e são fortes representantes da equipe na comunidade, podendo auxiliar no fortalecimento desse elo de comunicação e no esclarecimento das dúvidas levantadas. Dessa forma, a população obteve informações seguras e confiáveis, e pôde construir um vínculo de maior confiança com a equipe de vacinação para que a campanha obtivesse êxito.

\section{CONSIDERAÇÕES FINAIS}


A pandemia trouxe um cenário nunca vivenciado por essa geração e colocou a ciência como ponto-chave para a elucidação da doença, assim como desafiou a confiança da população na comunidade científica. É possível observar a importância da equipe de saúde da família nesse papel de combate às informações falsas, e de responsabilidade com a população para que as medidas de prevenção contra o vírus possam ser confiadas e adotadas.

\section{REFERÊNCIAS}

1. COUTO MT, et al. Considerações sobre o impacto da covid-19 na relação indivíduo-sociedade: da hesitação vacinal ao clamor por uma vacina. Revista Saúde e Sociedade, 2021; 30(1): e200451.

2. JÚNIOR JRS, et al. COVID-19 e a promoção da saúde em tempos de pandemia. Revista Eletrônica Acervo Saúde, 2020; 46(1), e3837.

3. OLIVEIRA BLCA, et al. Prevalence and factors associated with covid-19 vaccine hesitancy in Maranhão, Brazil. Revista de Saúde Pública, 2021; 55(12), 1-12. 


\title{
PERCEPÇÃO DA ENFERMAGEM DOS IMPACTOS CAUSADOS AO PACIENTE PEDIÁTRICO E FAMILIARES NA SUSPENSÃO DE VISITAS E TROCA DE ACOMPANHANTES NA PANDEMIA DA COVID-19
}

\author{
Gilcimeire Santa Rosa Costa ${ }^{1}$ \\ Greice Kely Oliveira de Souza ${ }^{1}$ \\ Naiara Costa Salvador Ribeiro da Silva ${ }^{1}$ \\ Cristiani de Souza Barros ${ }^{1}$ \\ Itamara Queiroz dos Santos ${ }^{1}$
}

1. Hospital Universitário Professor Edgar Santos (HUPES), Salvador - BA.

Palavras-chave: Acompanhantes de pacientes, COVID-19, Profissionais de enfermagem pediátrica.

\section{INTRODUÇÃO}

A COVID-19 é considerada uma doença pandêmica, de alta transmissibilidade, sem tratamento eficaz, sendo necessária uma reorganização estrutural nos serviços de saúde (BRASIL, 2021). Durante muito tempo acreditou-se que a presença do acompanhante na Unidade de Terapia Intensiva (UTI), não traria benefícios aos pacientes e sim riscos como infecções, alterações de rotina do ambiente e mais estresse. Estudos comprovaram o bem que um familiar faz para o paciente, trazendo segurança, conforto, estimulando a melhoria, participando do cuidado e uma melhor recuperação. (NUNES MEP e GABARRA LM, 2017; JUNIOR ABF e BATISTA LA, 2020). A suspensão de visitas e da troca de acompanhantes impactou negativamente nos pacientes e seus familiares.

\section{OBJETIVO}

Descrever a percepção da enfermagem sobre os impactos causados a pacientes pediátricos e seus familiares devido a suspensão de visitas e troca de acompanhantes numa Unidade de Terapia Intensiva Pediátrica (UTI ped), durante a pandemia da COVID-19.

\section{RELATO DE EXPERIÊNCIA}

Durante a pandemia de COVID-19 várias medidas foram adotadas visando prevenir a disseminação da doença, como criação de protocolos e mudanças de rotinas nos serviços de saúde. A suspensão de visitas e trocas de acompanhantes causaram impactos na vida de crianças internadas e seus acompanhantes. Por se tratarem de pacientes pediátricos, muitas vezes ainda sem capacidade de entendimento do que está acontecendo, não compreendiam a ausência do pai e/ou mãe.

O familiar que se encontrava presente, mostrava-se cansado fisicamente devido a rotina exaustiva de permanência numa UTI, sem receber visita de familiares, cônjuges, nem realizar troca de acompanhante, já 
que muitos pacientes são de internamento prolongado. Tais situações demonstraram alterações emocionais, impaciência, dificuldade para amamentar e para estabelecer vínculo mãe e filho.

A enfermagem teve o papel de buscar formas de atenuar as dificuldades impostas pela pandemia, seja na escuta, no acolhimento, proporcionando momentos de descanso, hora em que são evitados procedimentos e manipulações do paciente, solicitando o apoio de profissionais da equipe multidisciplinar, psicólogo, serviço social e terapeuta ocupacional para acompanhamento e buscar formas de amenizar o sofrimento.

\section{CONSIDERAÇÕES FINAIS}

A pandemia trouxe novos geradores de estresse, distanciamento, suspensão de atividades, medo, ansiedade e o risco de contaminação pela doença. $O$ familiar tem grande importância no acompanhamento das crianças e a troca de acompanhantes e visitas proporcionam momentos de descanso e tomada de decisões em conjunto. A ruptura disto evidenciou nos pacientes e familiares humor deprimido, menos aceitação dos cuidados e aumento do estresse diário.

\section{REFERÊNCIAS}

1. BRASIL. Ministério da Saúde. Secretaria de Vigilância em Saúde. Boletim Epidemiológico Especial. Doença pelo Coronavírus COVID -19. Semana Epidemiológica 23.2. 2021. Disponível em https://www.gov.br/saude/pt- $\quad$ br/media/pdf/2021/junho/18/boletim_epidemiologico_covid_67.pdf. Acessado em: 30 junho de 2021.

2. NUNES MEP, GABARRA LM. Percepção de familiares sobre visitas a pacientes e regras em Unidade De Terapia Intensiva. Revista Arquivos de Ciências da Saúde, 2017; 24(3): e84.

3. JUNIOR ABF, BATISTA LA. Humanização Hospitalar: A Importância de um acompanhante na Unidade de Tratamento Intensivo. Revista Educação Meio Ambiente e Saúde, 2020; 10(1): 58-74. 


\title{
ATUAÇÃO DA LIGA ACADÊMICA EM SAÚDE DA CRIANÇA DURANTE A PANDEMIA: UM RELATO DE EXPERIÊNCIA
}

\author{
Fernanda Larisse Souza da Silva ${ }^{1}$ \\ Railda Lima Rodrigues ${ }^{1}$ \\ Valbene Gomes Teixeira ${ }^{1}$
}

1. Universidade Estadual do Maranhão (UEMA), Bacabal - MA.

Palavras-chave: Liga acadêmica, Saúde da criança, COVID-19.

\section{INTRODUÇÃO}

As Ligas são entidades universitárias que integram o ensino, pesquisa e extensão, e têm como objetivo articular conhecimentos proporcionando discussões aprofundadas que auxiliam na formação acadêmica e profissional dos envolvidos, viabilizando autonomia e desenvolvendo ações que impactam a sociedade (SANTARATO N, et al., 2021).

A pandemia trouxe um cenário desafiador, sendo fundamental um novo formato de ensino para atender essa realidade. Assim, as atividades foram adaptadas ao ensino remoto (SANTARATO N, et al., 2021). As redes sociais são plataformas com alta acessibilidade para realizar postagens acadêmicas (XAVIER F, et al., 2020). Portanto, essas atividades são relevantes para garantir a continuidade do ensino (SILVA MD, et al., 2021).

\section{OBJETIVO}

Relatar as ações da Liga Acadêmica de Enfermagem em Saúde da família com ênfase na Saúde da Criança promovendo educação e saúde através das redes sociais durante a pandemia da COVID-19.

\section{RELATO DE EXPERIÊNCIA}

A Liga Acadêmica em saúde da Família (LAESF) foi criada e protocolada por iniciativa de graduandos de Enfermagem em novembro de 2019, e institucionalizada no ano de 2020, cujas ações eram realizadas na modalidade presencial seguindo um plano anual de atividades sobre várias temáticas, dentre elas a Saúde da Criança.

Entretanto, devido à Pandemia da COVID-19 as ações foram adaptadas para atender o novo formato de ensino remoto com abordagem e comunicação síncrona e assíncrona. O grupo responsável pela referida temática é composto por dois acadêmicos cujas atividades foram realizadas no período de 2020 a 2021 .

Durante as comunicações síncronas formam realizadas webconferências via plataforma Microsoft Teams sobre saúde ocular e os principais problemas oculares em crianças e live no Instagram da liga sobre a saúde da criança. Na comunicação assíncrona foram produzidos pôsteres sobre vacinas; amamentação; 
desnutrição; diarreia e a importância do soro caseiro; segurança da criança de zero a seis meses; que foram publicados nas redes sociais da LAESF tais como: site, facebook, instagram.

\section{CONSIDERAÇÕES FINAIS}

Sendo assim, a liga acadêmica por meio de seus recursos tecnológicos trouxe atualizações e conteúdos relevantes para promover a manutenção da educação em saúde, proporcionando novos domínios e gerando conteúdos que expandem os saberes dos acadêmicos e da sociedade que acompanha suas divulgações em épocas remotas onde o ensino tornou-se ainda mais incitador, necessitando de novas práticas e ferramentas didáticas para torna-lo mais proveitoso.

\section{REFERÊNCIAS}

1. SANTARATO $\mathrm{N}$, et al. Atuação de uma liga acadêmica de cuidados à saúde da mulher durante o primeiro ano da pandemia da COVID-19. Revista Eletrônica Acervo Saúde, 2021; 13(9): e8768.

2. SILVA MD, et al. Coronavírus: consequências da pandemia no ensino superior. Revista Eletrônica Acervo Saúde, 2021; 13(5): e7120.

3. XAVIER $F$, et al. Análise de redes sociais como estratégia de apoio à vigilância em saúde durante a Covid19. Revista Scielo Brasil - Estudos avançados [online], 2020; 34(99): 261-282. 


\title{
RESSIGNIFICANDO O VALOR DA EQUIPE DE ENFERMAGEM DO AMBULATÓRIO DE UM HOSPITAL DE ALTA COMPLEXIDADE EM TEMPOS DE PANDEMIA
}

\author{
Patricia da Rocha de Sousa ${ }^{1}$ \\ Shirley Pereira de Souza ${ }^{1}$ \\ Joice César de Aguiar Barbosa ${ }^{1}$ \\ Paula Rezende do Amaral Gallino ${ }^{1}$ \\ Janaína Mengal Gomes Fabri ${ }^{1}$
}

1. Instituto Nacional de Traumatologia e Ortopedia (INTO), Rio de Janeiro - RJ.

Palavras-chave: Humanização, Cuidados de enfermagem, Equipe de enfermagem.

\section{INTRODUÇÃO}

O Instituto de Traumatologia e Ortopedia apresentava uma dinâmica de trabalho consolidada desde 2011, porém com o novo cenário imposto pela Pandemia e suspensão das cirurgias eletivas, a Divisão de Enfermagem precisou redimensionar a equipe do instituto. No ambulatório $80 \%$ da equipe de enfermagem foi remanejada para outros setores. Após o retorno total das atividades, uma parte da equipe original foi realocada em outros setores do Instituto definitivamente, sendo necessária uma reestruturação para a nova realidade. A reconfiguração no trabalho trouxe aspectos significativos para o cotidiano da equipe de enfermagem, destacam-se o medo e a ansiedade diante do novo panorama (PORTUGAL JKA, et al., 2020; PRADO AD, et al., 2020).

\section{OBJETIVO}

Relatar a experiência da equipe de enfermagem na reestruturação do ambulatório de um Instituto de alta complexidade de ortopedia no município do Rio de Janeiro, no período de março de 2020 a Julho de 2021.

\section{RELATO DE EXPERIÊNCIA}

Devido à reestruturação setorial, imposta pelo caos Pandêmico, ocasionando a redução das atividades ambulatoriais, $80 \%$ dos profissionais de enfermagem foram realocados na unidade de internação do instituto. Desta forma, estabeleceu-se a necessidade de redesenhar as funções de cada profissional de enfermagem para atender as demandas reduzidas do ambulatório.

Para reduzir a sensação de ansiedade e medo do desconhecido foram realizadas rodas de conversas e dinâmicas com as equipes, abordando os temas: ressignificando o caos e resiliência, e valorização do profissional de enfermagem. A partir das falas das rodas de conversas foram propostas melhorias e reorganização das funções e atribuições, o que gerou implicações positivas para a equipe como a sensação de pertencimento e valorização profissional (GOUVEIA AO, et al., 2020). 
Percebeu-se o aumento da motivação, o engajamento nos protocolos assistenciais e melhoria nos resultados assistenciais. Reitera-se a importância da promoção de estratégias de saúde mental que sejam atenuantes da sensação de desamparo e medo no cotidiano do profissional de saúde. (PORTUGAL JKA, et al., 2020; PRADO AD, et al., 2020).

\section{CONSIDERAÇÕES FINAIS}

As práticas de educação em saúde permeadas pela escuta empática e acolhimento se fazem necessárias diante de um cenário de incertezas. A resiliência e ressignificação do trabalho refletem diretamente no cotidiano do profissional de enfermagem atenuando os fatores estressores e promovendo um ambiente saudável de trabalho. A limitação deste estudo relaciona-se ao formato relato de experiência, novas pesquisas de campo deverão ser realizadas para comprovar os benefícios.

\section{REFERÊNCIAS}

1. GOUVEIA AO, et al. Estresse ocupacional em profissionais de uma Unidade de Pronto-Atendimento (UPA): práticas interventivas de educação em saúde. Revista Eletrônica Acervo Saúde, 2020; 12(10), 4627-36.

2. PORTUGAL JKA, et al. Percepção do impacto emocional da equipe de enfermagem diante da pandemia de COVID 19: relato de experiência. Revista Eletrônica Acervo Saúde, 2020; 46, 3794- 98.

3. PRADO $A D$, et al. A saúde mental dos profissionais de saúde frente à pandemia do COVID-19: uma revisão integrativa. Revista Eletrônica Acervo Saúde, 2020; 46, 4128-26. 
RESUMO SIMPLES: Relato de Experiência

\title{
DESAFIOS DO ENSINO REMOTO NA GRADUAÇÃO DE ENFERMAGEM: UM RELATO DE EXPERIÊNCIA
}

\author{
Valbene Gomes Teixeira ${ }^{1}$ \\ Fernanda Larisse Souza da Silva ${ }^{1}$ \\ Railda Lima Rodrigues ${ }^{1}$
}

1. Universidade Estadual do Maranhão (UEMA), Bacabal - MA.

Palavras-chave: Graduação em enfermagem, Ensino remoto, Tecnologia de informação e comunicação.

\section{INTRODUÇÃO}

A Pandemia da Covid-19 provocou mudanças no ensino. Deste modo, o Ministério da Educação determinou ensino remoto como método emergencial para todas as Universidades. Logo, alunos e professores precisaram usar com as Tecnologias da Informação e Comunicação (TICs), para a realização das aulas e projetos de extensão (SANTARATO N, et al., 2021).

Dentre os desafios, a falta de suporte necessário para adaptar-se ao novo cenário, dificuldades dos professores em manusear novas ferramentas tecnológicas e a resistência dos alunos quanto a modalidade deste ensino (BARBOSA IEB, et al., 2021). Além disso, a instabilidade da internet dificulta acesso e ocasiona desmotivação deles (DIAS JL, et al., 2021).

\section{OBJETIVO}

Relatar a experiência acadêmica sobre os desafios e as dificuldades do ensino remoto na graduação de enfermagem em uma Universidade Pública do Maranhão impostas pelo uso das TICs na promoção de conhecimento em tempos de pandemia.

\section{RELATO DE EXPERIÊNCIA}

Para efetivar o ensino remoto foram incorporadas as plataformas Google Meet, Microsoft Teams e Jitsi Meet nas quais foram realizadas as atividades síncronas e assíncronas. Nas atividades síncronas, professores e alunos reuniram-se simultaneamente compartilhando informações e trocando ideias. Nas assíncronas, a comunicação era indireta e as atividades eram desenvolvidas em prazos determinados pelo professor.

Entretanto, essa modalidade de ensino trouxe vários desafios e inúmeras dificuldades tanto para o aluno quanto para o professor, dentre as quais a instabilidade com a internet por mudanças climáticas, banda larga com baixa qualidade, quedas de energia, dificuldades para lidar com as tecnologias que interferiram na assiduidade e produtividade deles. Dentre outros desafios, foi perceptível a desigualdade no acesso à internet entre os alunos, de maneira que alguns eram mais favorecidos que outros. 
Além disso, outros fatores influenciaram no rendimento do ensino-aprendizagem, entre eles os imprevistos do dia a dia e consequentemente, no ambiente domiciliar ocorriam interferência familiar, trabalhos domésticos, visitas repentinas, barulhos externos provocados por vizinhos ou ruídos de automotores, ocasionando a sobrecarga emocional e cognitiva resultando em estresse pelo uso prolongado das TICs.

\section{CONSIDERAÇÕES FINAIS}

As atividades remotas desenvolvidas durante a pandemia tornaram-se indispensáveis para 0 ensinoaprendizagem e, consequentemente na promoção do conhecimento com o uso das TICs. E, mesmo com a instabilidade da internet e outros fatores, a interação e o uso dessas ferramentas tecnológicas contribuíram significativamente nos processos metodológicos, na construção e no fortalecimento das estratégias de ensino na graduação de enfermagem.

\section{REFERÊNCIAS}

1. BARBOSA IEB, et al. Procedimentos e técnicas de enfermagem realizadas durante a pandemia de COVID19. Revista Eletrônica Acervo Enfermagem, 2021; 9: e6016.

2. DIAS JL, et al. Relato de experiência da Implantação da capacitação sobre imunização do estado do Amazonas por meio do Telessaúde. Revista Eletrônica Acervo Saúde, 2021; 13(3): e6636.

3. SANTARATO $\mathrm{N}$, et al. Atuação de uma liga acadêmica de cuidados à saúde da mulher durante o primeiro ano da pandemia da COVID-19. Revista Eletrônica Acervo Saúde, 2021; 13(9): e8768. 


\title{
BIOSSEGURANÇA DURANTE A PANDEMIA DA COVID-19, A IMPORTÂNCIA DA PARAMENTAÇÃO E DESPARAMENTAÇÃO
}

\author{
Letícia Pontes Nascimento ${ }^{1}$ \\ Híttalo Carlos Rodrigues de Almeida² \\ Maria Eduarda Santos Diniz ${ }^{1}$
}

1. Centro Universitário Maurício de Nassau (UNINASSAU), Recife - PE.

2. Universidade de Pernambuco (UPE), Recife - PE.

Palavras-chave: COVID-19, Odontologia, Equipamento de proteção individual.

\section{INTRODUÇÃO}

A COVID- 19 é disseminada através do contato interpessoal com pessoas infectadas, via gotículas de saliva, espirro, tosse, secreções, além de contato com superfícies contaminadas (OLIVEIRA AC, et al., 2020). Devido a isso, a segurança biológica do profissional de saúde é possibilitada através do uso de equipamentos de proteção individual (EPI), associado a higienização das mãos e dos equipamentos utilizados durante o atendimento (MACHADO WCA, et al., 2020.). Na clínica odontológica há alto índice de disseminação de aerossol, sendo indispensável o uso dos capotes de manga longa impermeável; máscara N95/PFF2; protetor facial; pares de luvas de procedimentos; óculos de proteção, touca descartável e propé (ARAUJO JUNIOR $A G, 2019)$.

\section{OBJETIVO}

Relatar a experiência de estudantes de odontologia na etapa de paramentação e desparamentação dos EPIs, na Clínica Escola Odontológica UNINASSAU - Boa Viagem, Pernambuco; em meio à pandemia da COVID-19.

\section{RELATO DE EXPERIÊNCIA}

Tendo em perspectiva a diminuição da possibilidade de contaminação direta e indireta, na Clínica Escola Odontológica UNINASSAU - Boa Viagem, as etapas de biossegurança denominadas de: paramentação e desparamentação são exigidas. Na sala de paramentação, é a realizada a higiene das mãos, somada a vestimenta sequencial dos seguintes itens, previamente separados: propé, lavagem de rosto e mãos, máscara cirúrgica N95/PFF2, touca descartável, avental N40 ou superior de manga longa, óculos de proteção, protetor facial e luvas de procedimento.

Em seguida, deve-se se direcionar para o ambiente clínico, onde se realiza atendimento odontológico e após a finalização desse, é iniciado o procedimento de desparamentação com a retirada e descarte correto das luvas, uma nova higienização das mãos com álcool 70\%, e remoção sequencial dos itens: avental (evitando tocar na porção externa); protetor facial; bem como da touca descartável, remoção dos óculos de 
proteção; retirada da máscara pelos elásticos laterais; seguida da remoção propé na saída da clínica e descarte desse no local indicado e por fim, lavagem das mãos, sendo indicada a higiene das mãos com álcool $70 \%$ durante as etapas.

\section{CONSIDERAÇÕES FINAIS}

Sob essa perspectiva, tais medidas visam prevenir a contaminação do aluno em atendimento, bem como do paciente. É evidente que a biossegurança é essencial para minimizar a propagação da COVID-19 e demais vírus, no ambiente clínico. Cabe aos estudantes da área da saúde estarem cientes e comprometidos em garantir a biossegurança de si e daqueles envolvidos no fluxo presente da clínica escola.

\section{REFERÊNCIAS}

1. ARAUJO JUNIOR AG, et al. Microbiological analysis of high speed motor aerosol from a clinical school of dentistry. Focus Oral Research, 2019; 2(1): 10.

2. MACHADO WCA, et al. COVID-19 in the paramentation movements of dressing and disposing of nurses: nightingale, the pioneer, was reasoned. Research, Society and Development, 2020; 9(7): 23.

3. OLIVEIRA ACD, et al. O que a pandemia da COVID-19 tem nos ensinado sobre adoção de medidas de precaução?. Texto \& Contexto-Enfermagem, 2020; 29. 
RESUMO SIMPLES: Relato de Experiência

\title{
SETEMBRO AMARELO: A COMUNICAÇÃO EM SAÚDE COMO ESTRATÉGIA PARA VALORIZAÇÃO DA VIDA
}

\author{
Felipe dos Santos Paixão ${ }^{1}$ \\ Rafael Nascimento da Silva ${ }^{1}$ \\ Letícia Santos do Monte ${ }^{1}$ \\ Camila Rodrigues Barbosa Nemer ${ }^{1}$
}

1. Universidade Federal do Amapá (Unifap), Macapá - AP.

Palavras-chave: Saúde mental, Prevenção ao suicídio, Comunicação em saúde.

\section{INTRODUÇÃO}

O suicídio é considerado um grave problema de saúde pública e de múltiplos fatores, sobretudo de difícil abordagem social em decorrência da estigmatização dos sujeitos e familiares envolvidos (RUCKERT MLT, et al., 2019). Nesse contexto, surge o Setembro Amarelo, uma campanha de prevenção ao suicídio, com o objetivo de conscientizar sobre essa temática que se configura como uma das três maiores causas de morte entre jovens de 15 a 29 anos (PENSO MA e SENA DP, 2020). A comunicação relacionada ao suicídio deve ser direcionada à prevenção ao suicídio, contribuindo para a diminuição de estigmas, expondo conhecimentos sobre os recursos e estratégias de apoio (FERREIRA RS, et al., 2021).

\section{OBJETIVO}

Relatar a experiência de acadêmicos de enfermagem durante o planejamento e execução de ações do Setembro Amarelo, com foco nas estratégias de comunicação em saúde em materiais gráficos e redes sociais.

\section{RELATO DE EXPERIÊNCIA}

As ações foram desenvolvidas pela prefeitura de uma capital do norte do Brasil, durante todo o mês de setembro de 2021. Foram realizadas reuniões para definição das estratégias de divulgação e atividades a serem desempenhadas a fim de fortalecer o acesso de atendimento psicológico aos munícipes. As estratégias de comunicação foram voltadas para estimular o entendimento da importância do autocuidado e incentivar a busca pelo atendimento à saúde mental, sendo utilizados materiais impressos e digitais.

Banners e folders com frases de valorização da vida e locais de atendimento psicológico foram espalhados em pontos estratégicos da cidade, permitindo uma reflexão acerca da temática, além de desmistificar estigmas existentes. Todos os materiais físicos continham QR Code que permitiam a população acessar quais os locais onde poderiam buscar ajuda. 
Foi uma estratégia nova, usada pela primeira vez e que teve boa aceitação popular. Os materiais digitais produzidos foram vídeos com profissionais da saúde mental e cards para postagens nas redes sociais. Todos os materiais produzidos tiveram como essência a temática de prevenção à vida e o estímulo à busca por ajuda profissional.

\section{CONSIDERAÇÕES FINAIS}

É imprescindível que durante a execução de ações como a do Setembro Amarelo os métodos de comunicação sejam diversificados, o que permite difundir as informações ao maior número de pessoas possíveis, possibilitando acesso equânime às ações e serviços de saúde.

\section{REFERÊNCIAS}

1. FERREIRA RS, et al. Notícias sobre suicídio veiculadas em jornal brasileiro. Ciência e saúde coletiva, $2021 ; 26(4): 10$.

2. PENSO MA, SENA DPA. A desesperança do jovem e o suicídio como solução. Sociedade e Estado, 2020; 35(1): 61-81.

3. RUCKERT MLT, et al. Suicídio: a importância de novos estudos de posvenção no Brasil. Revista Brasileira de Terapias Cognitivas, 2019; 15(2): 85-91. 
RESUMO SIMPLES: Relato de Experiência

\section{AÇÃO DE ACESSO AOS EXAMES DE MAMOGRAFIA E PCCU À MULHERES DE UM DISTRITO RURAL: UM RELATO DE EXPERIÊNCIA}

Felipe dos Santos Paixão ${ }^{1}$

Rafael Nascimento da Silva ${ }^{1}$

Camila Rodrigues Barbosa Nemer ${ }^{1}$

1. Universidade Federal do Amapá (Unifap), Macapá - AP.

Palavras-chave: Saúde da mulher, Acesso a saúde, Atenção primária.

\section{INTRODUÇÃO}

O acesso à saúde é considerado um dos principais determinantes de qualidade de vida e de dimensão das desigualdades. Nas áreas rurais, o acesso à saúde é menor em relação às áreas urbanas, em consequência da maior vulnerabilidade social dos seus habitantes e das questões geográficas envolvidas (ARRUDA NM, et al., 2018). As iniquidades de acesso ao Sistema Único de Saúde (SUS) enfraquece a garantia de cuidados em saúde às populações rurais. No que diz respeito à saúde da mulher, estudos demonstram que residir em zona rural representa uma marcante barreira para realização de exames preventivos, acentuando as desigualdades (FERNANDES NFS, et al., 2019; GARNELO L, et al., 2018).

\section{OBJETIVO}

Descrever a experiência vivenciada por acadêmicos de enfermagem durante a ação de rastreamento de mulheres moradoras de um distrito rural do norte do Brasil para realização de mamografia e PCCU.

\section{RELATO DE EXPERIÊNCIA}

A ação ocorrida em outubro de 2021, realizada pela prefeitura local em conjunto com acadêmicos de enfermagem, foi dedicada a levar mulheres moradoras de um distrito rural localizado a 51 quilômetros do centro urbano de uma capital do norte do Brasil para realização de exames preventivos. Iniciou-se com a busca de dez mulheres, com idade entre 50 e 69 anos, que aguardavam as equipes na Unidade Básica de Saúde local.

Durante o percurso, as mulheres foram informadas sobre os procedimentos que seriam realizados e suas dúvidas foram sanadas, este momento também serviu para que a equipe de saúde pudesse conhecer as participantes da ação. A equipe foi informada que nenhuma daquelas mulheres havia realizado o exame de mamografia pela rede pública, enquanto 4 delas nunca haviam realizado o exame em suas vidas.

As mulheres foram recepcionadas, apresentadas à equipe de saúde que as atenderia e foram encaminhadas para fazer o exame de mamografia, PCCU, sinais vitais, massoterapia e auriculoterapia. Ao final da atividade as mulheres foram cadastradas para as próximas ações e levadas de volta ao seu distrito de origem. 


\section{CONSIDERAÇÕES FINAIS}

Evidencia-se a importância de aprimorar as políticas públicas de acesso aos serviços de saúde da mulher como mamografia e PCCU, acentuadamente nas comunidades rurais, que possuem diversas questões que dificultam o alcance aos serviços. Vale ressaltar que é responsabilidade do estado promover esse acesso.

\section{REFERÊNCIAS}

1. ARRUDA NM, et al. Desigualdade no acesso à saúde entre as áreas urbanas e rurais do Brasil: uma decomposição de fatores entre 1998 a 2008. Cadernos de Saúde Pública, 2018; 34(6): e00213816.

2. FERNANDES NFS, et al. Acesso ao exame citológico do colo do útero em região de saúde: mulheres invisíveis e corpos vulneráveis. Cadernos de Saúde Pública, 2019; 35(1): e00234618.

3. GARNELO L, et al. Acesso e cobertura da Atenção Primária à Saúde para populações rurais e urbanas na região norte do Brasil. Saúde debate, 2018; 42(1): 81-99. 


\title{
REESTRUTURAÇÃO DE UMA UNIDADE DE INTERNAÇÃO ORTOPÉDICA: RELATO DE EXPERIÊNCIA DA GESTÃO DE ENFERMAGEM NO CONTEXTO DA PANDEMIA
}

\author{
Regina da Cruz Garofalo ${ }^{1}$ \\ Janaína Mengal Gomes Fabri ${ }^{1}$ \\ Rose Mary Costa Rosa Andrade Silva ${ }^{1}$ \\ Viviane da Conceição Carius Comym² \\ Eliane Ramos Pereira ${ }^{2}$
}

1. Instituto Nacional de Traumatologia e Ortopedia Jamil Haddad (INTO), Rio de Janeiro - RJ.

2. Universidade Federal Fluminense (UFF), Niterói - RJ.

Palavras-chave: Infecções por coronavírus, Liderança, Equipe de enfermagem

\section{INTRODUÇÃO}

Em dezembro de 2019, a Organização Mundial de Saúde (OMS) foi notificada sobre casos recorrentes de complicações respiratórias causadas por um vírus até então não identificado em seres humanos (OPAS, 2020). Essa situação logo é declarada como uma pandemia causada pelo novo corona vírus (SARS CoV2) atingindo subitamente a sociedade deixando profissionais e instituições de saúde diante de uma realidade desconhecida e delicada. Exigiu-se uma remodelação nos cuidados aos pacientes internados de maneira a garantir a segurança daqueles que estavam em tratamento e os profissionais de saúde (BITENCOURT JVOV, et al., 2020).

\section{OBJETIVO}

Relatar a experiência da chefia de enfermagem na implementação de uma enfermaria exclusiva para Covid de um instituto ortopédico de alta complexidade localizado no Rio de Janeiro durante o ano de 2020.

\section{RELATO DE EXPERIÊNCIA}

A unidade de internação é composta por 232 leitos separados em 6 postos de enfermagem com 34 leitos e 1 posto com 28 leitos. Com o surgimento dos primeiros casos de covid no instituto foi necessário criar uma área isolada e fechada para a coorte desses pacientes. A escolha do posto passou por questões de ordem estrutural tendo o apoio e a parceria da equipe de engenharia e infraestrutura.

A partir dos direcionamentos da chefia de enfermagem do setor e da Comissão de Controle de Infecção Hospitalar instalaram-se barreiras físicas para o isolamento da área, bloqueio de elevadores, isolamento de escadas e sinalização (BITENCOURT JVOV, et al., 2020). 
Diversas mudanças nos protocolos e rotinas foram necessárias atendendo as mudanças diárias de orientação fornecidas pela ANVISA. A chefia de enfermagem da unidade utilizou a estratégia de direcionar um grupo exclusivo para atuação na área isolada. Desta forma, houve menor número de profissionais expostos e a equipe manteve-se atualizada e bem treinada pelo serviço de educação permanente (GONÇALVES S, et al., 2020; PORTUGAL JKA, et al., 2020).

\section{CONSIDERAÇÕES FINAIS}

A implementação de uma área específica para a coorte na unidade de internação resultou no controle da transmissibilidade e na qualidade da assistência. As ações de capacitação mostraram-se relevantes diante do cenário de crise. Destaca-se o papel do enfermeiro no planejamento e na gestão de recursos humanos e materiais. Esta pesquisa tem como limitação o ponto de vista dos autores, são necessárias mais pesquisas.

\section{REFERÊNCIAS}

1. BITENCOURT JVOV, et al. Protagonismo do enfermeiro na estruturação e gestão de uma unidade específica para covid-19. Texto contexto - enferm, 2020; 29(sp): 2013-224.

2. GONÇALVES S, et al. Programa de educação permanente em saúde e a práxis profissional: possibilidades e desafios. Revista Eletrônica Acervo Saúde, 2020; 12(10): 4084-92.

3. OPAS. Organização Pan-Americana da Saúde. OMS afirma que COVID-19 é agora caracterizada como pandemia. Brasília; 2020. Disponível em: https://www.paho.org/bra/index.php?option=com_content\&view=article\&id=6120:oms-afirma-que-covid19-eagora-caracterizada-comopandemia\&ltemid=812. Acessado em: 10 de outubro de 2021.

4. PORTUGAL JKA, et al. Percepção do impacto emocional da equipe de enfermagem diante da pandemia de COVID-19: relato de experiência. Revista Eletrônica Acervo Saúde, 2020; 46(1): 3794- 99. 


\title{
IMPLEMENTAÇÃO DA ROTINA DE BANHO DE SOL COMO ESTRATÉGIA DE HUMANIZAÇÃO DO CUIDADO DE ENFERMAGEM
}

\author{
Viviane da Conceição Carius Comym ${ }^{1}$ \\ Janaína Mengal Gomes Fabri ${ }^{1}$ \\ Rose Mary Costa Rosa Andrade Silva ${ }^{1}$ \\ Regina da Cruz Garofalo² \\ Eliane Ramos Pereira ${ }^{2}$
}

1. Instituto Nacional de Traumatologia e Ortopedia Jamil Haddad (INTO), Rio de Janeiro - RJ.

2. Universidade Federal Fluminense (UFF), Niterói - RJ.

Palavras-chave: Humanização, Cuidados de enfermagem, Equipe de enfermagem.

\section{INTRODUÇÃO}

O Brasil é pioneiro em saúde pública, contudo precisa melhorar a humanização e a prática centrada no paciente. A implantação da Política Nacional de Humanização trouxe atenção para essa temática (BARBOSA IEB, et al., 2021). A internação prolongada representa um agravante nas complicações da saúde física e mental de pacientes, assim como desgaste na equipe de enfermagem, porém o profissional precisa ver 0 paciente como um ser único e completo (BARBOSA IEB, et al., 2021; SILVA ÁMB, et al., 2021). No Instituto Nacional de Traumatologia e Ortopedia Jamil Haddad (INTO) um grande percentual de pacientes encontrase em tratamento para osteomielite crônica, o que resulta em internação de longa permanência.

\section{OBJETIVO}

Relatar a experiência do banho de sol para pacientes de longa permanência internados em enfermarias de um instituto especializado em traumatologia e ortopedia, no período de julho a setembro de 2021.

\section{RELATO DE EXPERIÊNCIA}

A Rotina de Banho de Sol foi implementada na enfermaria ortopédica de adultos em julho de 2021. Os pacientes elegíveis são os que apresentam internação de longa permanência (acima de 15 dias). $O$ banho de sol acontece na área externa de frente para a Baía de Guanabara, é um momento ímpar de relaxamento e prazer. Duas técnicas de enfermagem acompanham e cantam com os pacientes, leem as Escrituras Sagradas, falam palavras de conforto e esperança.

Os pacientes interagem uns com os outros melhorando a sensação de bem-estar. Para ocorrer integração entre equipe e paciente é preciso valorizar o cuidado além do contexto biológico, estar atento as demandas e necessidades emocionais, sociais e espirituais (SANTOS RS, et al., 2020). No Banho de Sol verificamos 
benefícios para ambos, os pacientes melhoram o humor facilitando o cuidado de enfermagem e propiciando relações interpessoais profícuas.

\section{CONSIDERAÇÕES FINAIS}

Essa experiência deve ser expandida para demais setores com pacientes internados e sua periodicidade deve ser aumentada. Atualmente o projeto viabiliza, para cada paciente, usufruir semanalmente do Banho de Sol. É importante desenvolvimento de estratégias de humanização em ortopedia, muitos pacientes podem ficar com incapacidades transitórias ou permanentes potencializando o risco de distúrbios psíquicos. A limitação do estudo relaciona-se ao curto período de observação para composição deste relato.

\section{REFERÊNCIAS}

1. BARBOSA IEB, et al. Fatores que difundem a assistência de enfermagem humanizada na unidade de terapia intensiva. Revista Eletrônica Acervo Saúde, 2021; 13(4): 7082-88.

2. SANTOS RS, et al. Uma análise acerca da humanização da assistência em unidades de terapia intensiva. Revista Eletrônica Acervo Saúde, 2020; 12(12): 5117-25.

3. SILVA ÁMB, et al. A aplicabilidade da humanização no atendimento aos usuários do sistema único de saúde. Revista Eletrônica Acervo Saúde, 2021; 13(2): 4912-20. 


\title{
IMPLEMENTAÇÃO DA ROTINA DE LANCHE ESPECIAL COMO ESTRATÉGIA DE HUMANIZAÇÃO DO CUIDADO INTERDISCIPLINAR
}

\author{
Viviane da Conceição Carius Comym ${ }^{1}$ \\ Janaína Mengal Gomes Fabri ${ }^{1}$ \\ Rose Mary Costa Rosa Andrade Silva ${ }^{1}$ \\ Neidianna Martins Mendonça² \\ Eliane Ramos Pereira ${ }^{2}$
}

1. Instituto Nacional de Traumatologia e Ortopedia Jamil Haddad (INTO), Rio de Janeiro - RJ.

2. Universidade Federal Fluminense (UFF), Niterói - RJ.

Palavras-chave: Humanização, Cuidados de enfermagem, Equipe de enfermagem.

\section{INTRODUÇÃO}

A internação prolongada representa um agravante nas complicações da saúde física e mental de pacientes, assim como desgaste da equipe de enfermagem. Diante disso, a humanização hospitalar tem papel relevante na ampliação do bem-estar para pacientes e profissionais (BARBOSA IEB, et al., 2021). Prestar assistência segura e humanizada requer mudança de processos de trabalho. É extremamente relevante para recuperação dos pacientes, aumentando a eficácia e adesão ao tratamento, melhorando a satisfação dos pacientes e ajudando a estreitar as relações entre usuário e equipe, quebrando assim paradigmas concernentes às relações verticalizadas entre profissional e usuário (COSTA JVS, et al., 2019; ALMEIDA SL, et al., 2019).

\section{OBJETIVO}

Relatar a experiência da implementação do lanche especial para pacientes de longa permanência internados em enfermarias de um instituto especializado em traumatologia e ortopedia, no período de julho a setembro de 2021.

\section{RELATO DE EXPERIÊNCIA}

A Rotina de Lanche Especial foi implementada na enfermaria ortopédica de adultos em julho de 2021. Os pacientes elegíveis para recebem o lanche são os que apresentam internação igual ou superior a 30 dias. A enfermeira do Núcleo de qualidade e Humanização semanalmente atualiza a listagem de pacientes com esse perfil e encaminha ao Serviço de Nutrição.

O lanche é entregue nas enfermarias adultas todas às sextas-feiras a tarde com um bilhete motivacional. Caso esteja próximo de alguma data festiva, como festa junina, o responsável pela entrega vai caracterizado e com muita alegria entrega o lanche aos pacientes. Os pacientes interagem com o funcionário de forma 
muito positiva. Sentem-se valorizados e importantes para a instituição. Na Pediatria esse lanche é entregue a todas as crianças internadas.

A Instituição tem um grande ganho com esse projeto, promovendo benefícios para a equipe de enfermagem e para os pacientes participantes do projeto. A equipe relata que os pacientes melhoram o humor o que facilita o cuidado de enfermagem além de propiciar relações interpessoais profícuas.

\section{CONSIDERAÇÕES FINAIS}

Essa experiência deve ser expandida para todos os pacientes adultos internados. Dado os benefícios é importante aumentar o alcance desse projeto. É relevante o desenvolvimento de estratégias de humanização na ortopedia, visto que em muitos casos esses pacientes podem ficar com incapacidades transitórias ou permanentes para o trabalho, potencializando o risco de distúrbios psíquicos. Essa experiência é recente e tem como limitação o tempo de realização.

\section{REFERÊNCIAS}

1. ALMEIDA SL, et al. Política de humanização (HumanizaSUS): uma política transversal na saúde. Revista Eletrônica Acervo Saúde, 2019; 30(1): 786- 792.

2. BARBOSA IEB, et al. Fatores que difundem a assistência de enfermagem humanizada na unidade de terapia intensiva. Revista Eletrônica Acervo Saúde, 2021; 13(4): 7082-88.

3. COSTA JVS, et al. Humanização da assistência neonatal na ótica dos profissionais de enfermagem. Rev enferm UFPE on line, 2019; 13: 242642- 53. 


\section{CONTRIBUIÇÃO DO PROGRAMA DE RESIDÊNCIA MULTIPROFISSIONAL NO SERVIÇO PÚBLICO DE SAÚDE ATRAVÉS DA CONSULTORIA ESPECIALIZADA}

Everton Barroso Rios ${ }^{1}$

Sara Antunes Rocha ${ }^{1}$

Patrícia Fernanda Gonçalves Bessa ${ }^{1}$

1. Universidade Estadual de Montes Claros (UNIMONTES), Montes Claros - MG.

Palavras-chave: Residência Multiprofissional, Saúde Pública, Resolutividade.

\section{INTRODUÇÃO}

A saúde pública passa por grandes desafios na ampliação da produção de conhecimentos, no processo de trabalho e na construção das redes de atenção (LIMA CLV e NETO ACS, 2020). Nesse sentido, foram criados em 2005 pela Portaria Interministerial MEC/MS no 2.117, os programas de residência multiprofissionais que visam formar profissionais para que atendam às necessidades da área de atuação garantindo resolutividade e fortalecimento das diretrizes do Sistema Único de Saúde (SUS) (BRASIL, 2005).

Desta maneira, a odontologia tem ganhado destaque através do envolvimento multiprofissional e da formação ampliada, propiciada pelo conhecimento técnico científico aplicado ao processo de trabalho e pelas consultorias especializadas que as residências em saúde proporcionam (CARNEIRO JDB, et al., 2020).

\section{OBJETIVO}

Relatar a experiência da contribuição do Programa de residência no serviço público de saúde de um município em Minas Gerais através de consultorias especializadas no período de março a dezembro de 2021.

\section{RELATO DE EXPERIÊNCIA}

As consultorias especializadas em odontologia, visando formar cirurgiões-dentistas resolutivos e preparados tecnicamente para atuação no serviço público, fazem parte da grade curricular do Programa de Residência Multiprofissional em Saúde da Família sendo executadas na Universidade Estadual de Montes Claros (UNIMONTES) no período de março a dezembro de 2021.

Dispondo de atividades teórico-práticas em prótese dentária e disfunção temporomandibular sob supervisão de um docente especialista na área, foram realizados atendimentos clínicos semanais de pacientes adscritos em Estratégias Saúde da Família do município de Montes Claros, Minas Gerais.

Durante tais consultorias foi possível o diagnóstico, planejamento e execução de casos odontológicos complexos. $O$ acesso às ações e a qualidade do cuidado oferecido a população são princípios do sistema de saúde que refletem as práticas realizadas. Os tratamentos previstos nas consultorias têm sido iniciados, desenvolvidos e concluídos em tempo hábil beneficiando diversos pacientes usuários do SUS. 


\section{CONSIDERAÇÕES FINAIS}

As consultorias especializadas viabilizaram a resolução de problemas de saúde que comumente se tornam demanda reprimida para a atenção secundária nas redes do SUS. Com isso, entende-se que tais programas de pós-graduação que permitem estas possibilidades favorecem o acesso com qualidade a serviços que extrapolam o cuidado primário.

\section{REFERÊNCIAS}

1. BRASIL. Ministério da Saúde e da Educação. Portaria no 2117. 2005. Disponível em: http://portal.mec.gov.br/index.php?option=com_docman\&view=download\&alias=15432-port-inter-n211703nov-2005\&ltemid=30192. Acessado em: 11 de outubro de 2021.

2. CARNEIRO JDB, et al. RESIDÊNCIA MULTIPROFISSIONAL EM SAÚDE DA FAMÍLIA: percepções e sentidos para residentes graduados em odontologia. Revista Baiana de Saúde Pública, 2020; 42(2): 280 294.

3. LIMA CLV, NETO ACS. A alegoria da caverna e o atual panorama da política pública de saúde no modelo da atenção primária à saúde. Revista Eletrônica Acervo Saúde, 2020; Sup(5): e3273. 


\title{
PRIMEIRO CONTATO DO DISCENTE DE ODONTOLOGIA COM O SERVIÇO DE CIRURGIA BUCO- MAXILO FACIAL: RELATO DE EXPERIÊNCIA
}

\author{
Maria Eduarda Santos Diniz ${ }^{1}$ \\ Letícia Pontes Nascimento ${ }^{1}$ \\ Alexandre Freitas de Santana ${ }^{2}$
}

1. Faculdade Maurício de Nassau (Uninassau), Recife - PE.

2. Associação Caruaruense de Ensino Superior (ASCES), Caruaru - PE.

Palavras-chave: Cirurgia e traumatologia buco-maxilo-facial, Odontologia, Discente de odontologia.

\section{INTRODUÇÃO}

A cirurgia e traumatologia buco-maxilo-facial é uma especialidade odontológica com caráter medico que atua em cirurgias orais e maxilofaciais,tem seu âmbito ambulatorial e hospitalar (ALCOFORADO RLG, et al., 2021). No âmbito ambulatorial realizam cirurgias de baixa complexidade enquanto no hospitalar realiza-se atendimentos de urgências de traumas faciais e cirurgias de alta complexidade como ortognáticas, ressecção de grandes tumores e fraturas (RIBOLI R, et al., 2016).

Durante a graduação de odontologia, os discentes podem transitar por diversas áreas de especialização para que eles possam desenvolver embasamento teórico e prático (FONTES FLL, et al., 2019) em cada uma dessas áreas, visando criar afinidade e ajudar na escolha da sua especialidade após sua formação (JESUS JTA, et al., 2016).

\section{OBJETIVO}

Relatar a experiência de uma discente do 6o período de odontologia da Universidade Maurício de Nassau (Uninassau) de maneira descritiva sobre seu primeiro contato com a área de cirurgia e traumatologia bucomaxilo facial de um hospital público de Pernambuco.

\section{RELATO DE EXPERIÊNCIA}

Durante a graduação ter a oportunidade de acompanhar e vivenciar profundamente o cotidiano do cirurgião buco-maxilo-facial dentro de um hospital é extremamente proveitos, poder acompanhar atendimentos de urgência de diversos traumas faciais e dento- alveolares decorrentes de várias etiologias, sendo os mais comuns: agressões físicas, acidentes automobilísticos, quedas de própria altura e traumas faciais decorrente de ferimentos por projétil de arma de fogo (PAF).

Os procedimentos que são muito realizados durante os atendimentos são suturas em cortes faciais, identificação de fraturas maxilares sendo bem comum a fratura do osso mandibular, internamentos para cirurgias eletivas de redução dessas f raturas e também observar a atuação dos cirurgiões no bloco cirúrgico. 
Diferente do habitual odontológico que é trabalhar sempre em ambiente clinico. a cirurgia e traumatologia buco-maxilo-facial (CTBMF) permite que exista o trabalho multiprofissional agregando conhecimentos de todas as áreas atuantes dentro do ambiente hospitalar, é comum que o paciente além de estar em atendimento pelo setor de CTBMF também esteja por outro setor médico como a neurologia ou cirurgia geral.

\section{CONSIDERAÇÕES FINAIS}

Esse contato durante a graduação com a área é uma experiência que contribui com o desenvolvimento de controle emocional visto que é uma área oposta ao dia a dia do atendimento clínico, postura profissional diante do paciente e habilidades praticas com a área cirúrgica.

\section{REFERÊNCIAS}

1. ALCOFORADO RLG, et al. A judicialização de cirurgia bucomaxilofacial e o sistema de assistência à saúde dos servidores públicos de Pernambuco. Revista de Direito Sanitário, 2021; 21: e0002.

2. FONTES FLL, et al. Contribuições da monitoria acadêmica em Centro Cirúrgico para o processo de ensinoaprendizagem: benefícios ao monitor e ao ensino. Revista Eletrônica Acervo Saúde, 2019; 27: e901.

3. JESUS JTA, et al. Primeiro contato do discente com a clínica: relato de experiência. Revista da ABENO, 2016; 16(3): 78-84.

4. RIBOLI R, et al. Papel do cirurgião bucomaxilofacial nas unidades de terapia intensiva. Revista da Faculdade de Odontologia - UPF, 2016; 21(2). 


\title{
GESTÃO DO ENFERMEIRO NA CONSTRUÇÃO DE ROTINAS DE INTERFACE DE UM INSTITUTO ESPECIALIZADO EM TRAUMATOLOGIA E ORTOPEDIA: RELATO DE EXPERIÊNCIA
}

\author{
Shirley Pereira de Souza Rocha ${ }^{1}$ \\ Janaína Mengal Gomes Fabri ${ }^{1}$ \\ Joice César de Aguiar ${ }^{1}$ \\ Patrícia da Rocha de Sousa ${ }^{1}$
}

Paula de Rezende Gallino Alves do Amaral ${ }^{1}$

1. Instituto Nacional de Traumatologia e Ortopedia Jamil Haddad (INTO), Rio de Janeiro - RJ.

Palavras-chave: Gestão de enfermagem, Ambulatório, Processo de enfermagem.

\section{INTRODUÇÃO}

O Instituto Nacional de Traumatologia e Ortopedia (INTO) é uma unidade de alta complexidade especializada em cirurgias ortopédicas. $O$ ambulatório, do referido Instituto recebe pacientes em sua primeira avaliação ortopédica, após ser referenciado pelo sistema de regulação de vagas, e aqueles que estão em pós-operatório ortopédico. O ambulatório é a porta de entrada do INTO e tem interface com várias áreas como o Núcleo de Regulação interna (NIR), admissão, transporte e Trauma Referenciado. Para o atendimento efetivo pautado na integridade da assistência e na continuidade do cuidado é imprescindível uma proposta de atendimento sistematizada (CHELONI G, et al., 2021; GONÇALVES SO, et al., 2020; BRASIL, 1990).

\section{OBJETIVO}

Relatar a experiência do projeto de integração entre serviços de enfermagem que compõem a porta de entrada de um Instituto especializado em ortopedia e traumatologia no Rio de Janeiro no período de julho a setembro de 2021.

\section{RELATO DE EXPERIÊNCIA}

O serviço ambulatorial faz conexões com os setores da admissão e alta hospitalar. Percebeu-se, a partir da atuação das chefias de enfermagem, no período de janeiro a maio de 2021, que estes serviços desconheciam o fluxo do atendimento do paciente na instituição. Desta forma, propôs-se a realização de encontros periódicos para a construção de processos de trabalho entre os serviços.

Foram realizadas 12 reuniões para revisão das rotinas de interface das unidades e discussão dos processos de trabalho bem como as boas práticas de cuidado e acolhimento. As reuniões aconteceram semanalmente, entre julho e agosto de 2021, com a participação das chefias de enfermagem e enfermeiros diaristas. 
Os principais resultados foram o aprimoramento das rotinas de interface, compreensão das funções e da importância de cada setor e melhoria no relacionamento entre os profissionais. Destaca-se a importância da comunicação efetiva e do conhecimento ampliado acerca das peculiaridades de cada serviço, promovendo assim a assistência integral ao paciente e reduzindo os conflitos interpessoais entre os serviços (JESUSH HG, et al., 2019).

\section{CONSIDERAÇÕES FINAIS}

O ambulatório, como porta de entrada, proporciona acesso seguro e qualificado. Neste processo, o enfermeiro é o protagonista na implantação e desenvolvimento das ações. Foram desconstruídas ideias arraigadas, possibilitando o compartilhamento de conhecimentos, aumentando a qualidade dos processos e intensificando o sentimento de pertencimento institucional. Esta pesquisa tem como limitação o ponto de vista dos autores, são necessárias mais pesquisas para avaliar os benefícios do projeto de integração.

\section{REFERÊNCIAS}

1. BRASIL. Lei 8080 , de 19 de setembro de 1990. Dispõe sobre as condições para a promoção, proteção e recuperação da saúde, a organização e o funcionamento dos serviços correspondentes e dá outras providências. Disponível em: http://www.planalto.gov.br/ccivil_03/leis//8080.htm. Acesso em 14 de outubro de 2021.

2. CHELONI G, et al. Construção e validação de instrumento para coleta de dados de enfermagem em ambulatório de quimioterapia. Revista Eletrônica Acervo Saúde, 2021; 13(2): 5676-85.

3. GONÇALVES SO, et al. Programa de educação permanente em saúde e a práxis profissional: possibilidades e desafios. Revista Eletrônica Acervo Saúde, 2020; 12(10): 4084-92.

4. JESUSH HG, et al. O processo de implantação do ambulatório de feridas do centro universitário do estado Pará. Revista Eletrônica Acervo Enfermagem, 2019; 1(1): 2093-99. 


\title{
CAPACITAÇÃO DOS AGENTES COMUNITÁRIOS DE SAÚDE DA ZONA RIBEIRINHA SOBRE PRIMEIROS SOCORROS: RELATO DE EXPERIÊNCIA
}

\author{
Vanessa de Oliveira Gomes ${ }^{1}$ \\ Paula Andreza Viana Lima'. \\ Ana Maria Souza da Costa ${ }^{1}$ \\ Thayza Davila Pereira Rocha ${ }^{1}$ \\ Raynah Leticia Feitosa Torres ${ }^{1}$
}

1. Universidade Federal do Amazonas (UFAM), Coari - AM.

Palavras-chave: Primeiros socorros, Enfermagem, Agentes comunitários de saúde.

\section{INTRODUÇÃO}

As ocorrências de vítimas por obstrução das vias aéreas por corpos estranhos são uns dos tipos de emergências que fazem parte do cotidiano. Evidencia-se que distintos profissionais não estão preparados para intervir em uma situação de engasgo (JONGE AL, et al., 2020). Mediante a isto, os primeiros socorros aliado ao suporte básico de vida, são tidos como uma técnica inicial que é primordial para o salvamento de qualquer vítima de engasgo (AMARAL JBD, et al., 2019). Assim, as capacitações que são promovidas para esses profissionais são uma das estratégias essenciais, para que se possa atender as fragilidades que são apresentados por esses agentes em área (LE WBT e GARDENAL CLC, 2019).

\section{OBJETIVO}

Descrever as vivências dos discentes de enfermagem em uma ação de capacitação sobre primeiros socorros, para os agentes comunitários de saúde que atuam na assistência à saúde aos ribeirinhos do município de Coari, Amazonas.

\section{RELATO DE EXPERIÊNCIA}

Esta ação ocorreu no turno da manhã do dia 28 de junho de 2021, no Telessaúde do município de Coari. Os sujeitos das vivências foram seis discentes de enfermagem do Instituto de Saúde e Biotecnologia (ISB) de Coari-Amazonas. No que tange sobre a preparação da ação, foi realizado uma revisão bibliográfica sobre a temática obstrução das vias aéreas por corpos estranhos, a partir do conhecimento científico os discentes elaboraram um folder ilustrativos, com falas típicas da região, com a finalidade de proporcionar uma linguagem de fácil entendimento.

A ação dividiu-se em dois momentos: o primeiro momento destaca-se o uso do folder ilustrativo e o diálogo entre os acadêmicos e os agentes comunitários de saúde. No segundo momento os acadêmicos promoveram uma simulação realística sobre diferentes casos de vítimas de engasgo, o procedimento de salvação foi 
explicado passo a passo, nesta etapa os agentes comunitários de saúde tiveram a oportunidade de praticar depois de todo conhecimento que foram repassados.

\section{CONSIDERAÇÕES FINAIS}

Face ao exposto, a vivência contribuiu para a formação dos futuros profissionais de enfermagem. O elo intercultural desenvolve no futuro profissional um olhar cultural, onde se respeita os valores e crenças tradicionais desses ribeirinhos. Desse modo, percebeu-se que o objetivo da ação foi alcançado, tendo em vista, que a referida ação para os ACS's visou a prevenção de fatalidades, ao ensinar técnicas e conhecimentos básicos sobre os primeiros socorros.

\section{REFERÊNCIAS}

1. AMARAL JBD, et al. Caracterização dos casos de óbito acidental de crianças por aspiração de corpos estranhos em Minas Gerais. Revista Mineira de Enfermagem, 2019; 23: 1-6.

2. JONGE AL, et al. Conhecimentos de profissionais de educação infantil sobre obstrução de vias aéreas por corpo estranho. Enfermagem em Foco, 2020; 11(6): 192-8.

3. LE WBT, GARDENAL CLC. Capacitação de Agentes Comunitários de Saúde em manobra de desengasgo: multiplicando ações em saúde em Unidade de Saúde da Família. Revista da Faculdade de Ciências Médicas de Sorocaba, 2019; 21(1): 33-38. 


\title{
EDUCAÇÃO EM SAÚDE E ELABORAÇÃO DO PLANO DE PARTO COM GESTANTES EM UMA ESTRATÉGIA SAÚDE DA FAMÍLIA EM BELÉM-PA: RELATO DE EXPERIÊNCIA
}

\author{
Jéssica Luciana dos Santos Pereira ${ }^{1}$ \\ Pamela Farias Santos ${ }^{1}$ \\ Hiasmin Rocha Teles² \\ Juliana Pacheco Leão Costa ${ }^{1}$ \\ Silvia Cristina Santos da Silva ${ }^{3}$
}

1. Faculdade Cosmopolita, Belém - PA.

2. Universidade Federal do Pará (UFPA), Belém - PA.

3. Universidade do Estado do Pará (UEPA), Belém - PA.

Palavras-chave: Educação em saúde, Enfermagem, Parto humanizado.

\section{INTRODUÇÃO}

O desenvolvimento de uma gestação é marcado por profundas mudanças fisiológicas, psicológicas e sociais (TEIXEIRA JA, et al, 2017). A violência neste ciclo acarreta traumas que interferem na saúde reprodutiva e sexual da mulher. O plano de parto é um instrumento educativo, visa garantir o direito da mulher durante o parto (CARVALHO BF, et al., 2021).

A OMS (2018) e o Ministério da Saúde (2017), afirmam a necessidade de mudanças no contexto obstétrico, determina diminuir as intervenções desnecessárias durante o parto, assegurando o nascimento natural e respeitoso. Diante do exposto, a educação em saúde, torna-se indispensável, além do apoio dos gestores locais e atualização dos profissionais voltados à humanização (MELO LAA, et al., 2018).

\section{OBJETIVO}

Relatar a experiência vivenciada na implementação da educação em saúde realizada com um grupo de gestantes cadastradas na estratégia saúde da família (ESF), localizada no município de Belém do Pará.

\section{RELATO DE EXPERIÊNCIA}

A educação em saúde com as gestantes ocorreu na ESF, na cidade de Belém do PA, foi solicitada pela enfermeira da Estratégia Saúde da Família a busca das gestantes através dos agentes comunitários de saúde (ACS), e posteriormente o agendamento para a participação da ação. Comparecem 8 gestantes que realizam acompanhamento de pré-natal pela unidade. 
Realizou-se, uma roda de conversa, para a elucidação sobre plano de parto, elaboração e importância de realizar o pré-natal. Foi apresentado documento impresso contendo ilustrações relacionadas ao tema, seguindo da distribuição de um questionário sobre o que poderiam optar no momento do parto.

Seguindo a realização e elaboração do plano de parto, discussão geral em uma concepção pedagógica de sistematização das experiências, que possibilitou a troca de saberes a partir do diálogo durante a roda de conversa. Durante a explanação, as grávidas interagiram, realizaram perguntas: "o que é enema?", "o que é episiotomia?" E "o que é parto induzido?". As dúvidas foram sanadas, percebendo-se o quão elas estavam interessadas em compartilhar suas opiniões, preocupações e receber orientações.

\section{CONSIDERAÇÕES FINAIS}

As gestantes foram sensibilizadas sobre a relevância da elaboração do plano de parto, para evitar que seus direitos sejam desrespeitados no momento de parir. Com isso, a educação em saúde foi muito valiosa, pois possibilitou a realização de uma assistência de forma integral, humanizada, equânime e universal, oportunizando o conhecimento sobre a importância de elaborar o plano de parto, revelando-se um momento oportuno para educação em saúde.

\section{REFERÊNCIAS}

1. BRASIL. Ministério da Saúde. 2017.2 Disponível em: https://bvsms.saude.gov.br/bvs/publicacoes/diretrizes_nacionais_assistencia_parto_normal.pdf. Acessado em: 17 de junho de 2021.

2. CARVALHO BF, et al. Violência obstétrica: fatos relatados na prática e os impactos na vida da mulher. Revista Eletrônica Acervo Saúde, 2021; 13(8): e8610.

3. MELO LAA, et al. Implantação de um Modelo de plano de parto em uma Maternidade de risco Habitual em Curitiba-PR. Revista de Enfermagem da UFJF, 2018; 4(2): 141-147.

4. Organização Mundial da Saúde (OMS). recommendations: intrapartum care for a positive childbirth experience. 2018. Disponível em: https://www.who.int/reproductivehealth/publications/intrapartum-careguidelines/en/. Acessado em: 20 de junho de 2021.

5. TEIXEIRA JA, et al. Percepção dos profissionais de saúde da atenção básica sobre os grupos de gestantes. Revista Saúde, 2017; 43(1): 94-103. 


\title{
VIVÊNCIA DA COMUNIDADE FEMININA DO MUNICÍPIO DE TUCURUÍ SOBRE ALTERAÇÕES FISIOLÓGICAS NATURAIS: CLIMATÉRIO E MENOPAUSA
}

\author{
Luciana Monteiro Soares ${ }^{1}$ \\ Julyany Rocha Barrozo de Souza ${ }^{1}$ \\ Ronisson Vargens Ribeiro ${ }^{1}$ \\ Jessica Dias Ribeiro ${ }^{1}$
}

1. Faculdade de Teologia, Filosofia e Ciências Humanas Gamaliel (FATEFIG), Tucuruí - PA.

Palavras-chave: Saúde Pública, Climatério, Menopausa.

\section{INTRODUÇÃO}

$\mathrm{Na}$ fase da sexualidade madura a mulher passa por constantes descobertas, mudanças hormonais e psicológicas. Sentimentos que geram medo, insegurança e incompreensão sobre as mudanças ocorridas em seu corpo, com essas alterações orgânicas e não orgânicas (de ALMEIDA MJS, et al., 2018).

Essas alterações sofridas se caracterizam como menopausa. A menopausa é o processo natural e determinante, que ocorre no corpo feminino, resultando em alterações como a perda da capacidade reprodutiva e a cessação da menstruação (TOMÁS CC, et al., 2018; VIEIRA FM, et al., 2018). Alguns momentos da vida da mulher, são historicamente negligenciados, como o climatério, fase de passagem do período reprodutivo, para o não reprodutivo (FERREIRA LUZ MM e PETROLI FRUTUOSO MF, 2021).

\section{OBJETIVO}

Relatar a experiência de um projeto de extensão que teve o intuito de proporcionar conhecimento junto as mulheres da comunidade sobre as alterações do climatério e menopausa, por meio de palestras, rodas de conversa, dinâmicas e trabalho colaborativo.

\section{RELATO DE EXPERIÊNCIA}

O projeto de extensão Flor De Orquídea, foi ministrado para a comunidade nos CRAS de um município no sudeste do Pará uma vez ao mês, tendo como organizadores o autor e coautores do projeto. A cada encontro, contou-se com o auxílio dos coordenadores de cada CRAS. Os primeiros encontros tiveram como temática a apresentação do projeto e seu objetivo para a comunidade, explicação sobre a anatomia e fisiologia do corpo feminino, diferença entre climatério e menopausa, saúde emocional, dinâmicas e roda de conversa, onde notou-se uma interação excelente da comunidade.

No segundo encontro abordou-se o tema autopercepção corporal, sexualidade e violência contra a mulher, além de dinâmicas e exercícios sobre a evolução climatérica. Nesses eventos contou-se com a participação de uma advogada e psicóloga e uma profissional de enfermagem e docente de uma Instituição de Ensino 
Superior (IES), que explanaram sobre direitos, saúde emocional, cuidados e exames precoces para identificação de possíveis doenças relacionadas ao útero. Nesse evento assim como no outro, obteve-se interação com o tema abordado.

\section{CONSIDERAÇÕES FINAIS}

Os eventos realizados durante o decorrer do projeto, mostram-se de grande valia, visto que ilustraram informações ainda desconhecidas e abordadas de forma criativa para as mulheres que participaram de forma ativa no projeto. Com isso, entende-se que projetos como esse, voltados para a comunidade, de cunho educativo, melhoram o vínculo profissional-cliente e possuem potencial para transformar a realidade das comunidades negligenciadas.

\section{REFERÊNCIAS}

1. de ALMEIDA MJS, et al. Terapia cognitivo-comportamental em grupo para a disfunção sexual na pósmenopausa. Jornal Brasileiro de Psiquiatria [online]. 2018; 67(4): 231-238.

2. FERREIRA LUZ, et al. O olhar do profissional da Atenção Primária sobre o cuidado à mulher climatérica. Interface - Comunicação, Saúde, Educação. Botucatu, 2021: 15.

3. TOMAS CC, et al. Representações e consequências percebidas da menopausa e andropausa: resultados preliminares do evisa. Psic., Saúde \& Doenças, Lisboa, 2018; 19(1): 87-93.

4. VIEIRA FM, et al. Prevalência de sobrepeso e obesidade e associação entre as fases do climatério. Revista Eletrônica Acervo Saúde, 2018; 6: S437-S441. 


\section{AGRADECIMENTOS}

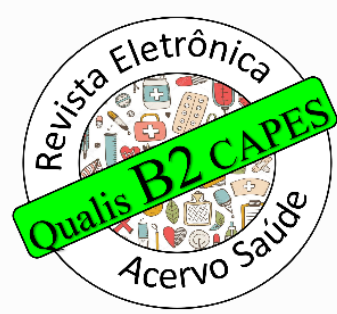

Revista

Eletrônica

Acervo

Saúde

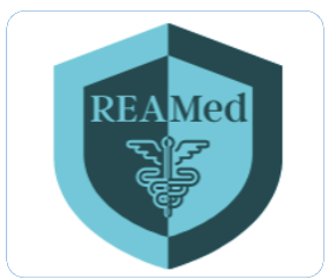

Revista

Eletrônica

Acervo Médico

\section{REAEnf \\ Revista \\ Eletrônica \\ Acervo \\ Enfermagem}

READdonto

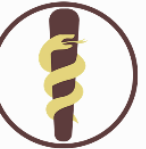

Revista

Eletrônica

Acervo

Odontológico

REAC

Revista

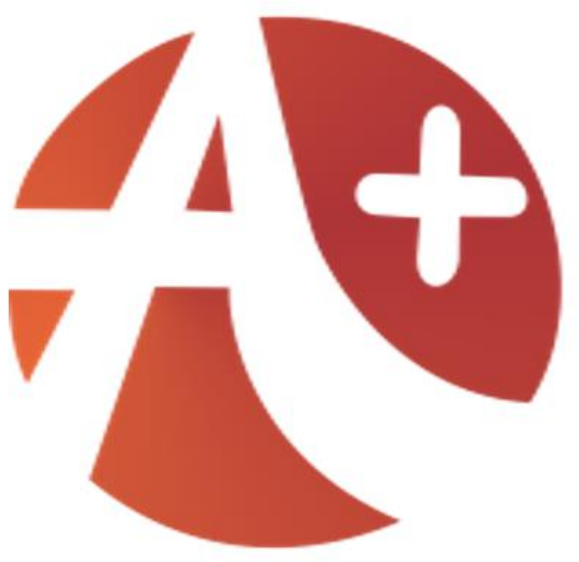

acervo+

Eletrônica

Acervo

CIENTífico

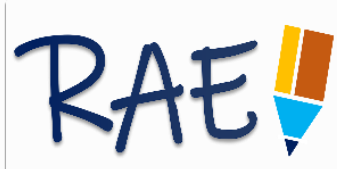

Revista

Acervo

Educacional

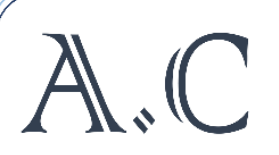

Revista

Artigos.

Com 